\title{
nanomaterials
}

Synthesis and
Applications of

Nanomaterials for

Photocatalysis and

Electrocatalysis

Edited by

Giuseppe Cappelletti and Claudia Letizia Bianchi Printed Edition of the Special Issue Published in Nanomaterials 


\section{Synthesis and Applications of Nanomaterials for Photocatalysis and Electrocatalysis}





\section{Synthesis and Applications of Nanomaterials for Photocatalysis and Electrocatalysis}

Special Issue Editors

Giuseppe Cappelletti

Claudia Letizia Bianchi 
Special Issue Editors

Giuseppe Cappelletti

Universita' degli Studi Di Milano

Italy
Claudia Letizia Bianchi

University of Milan

Italy

\section{Editorial Office}

MDPI

St. Alban-Anlage 66

4052 Basel, Switzerland

This is a reprint of articles from the Special Issue published online in the open access journal Nanomaterials (ISSN 2079-4991) (available at: https://www.mdpi.com/journal/nanomaterials/ special_issues/nano_photocata_electrocata).

For citation purposes, cite each article independently as indicated on the article page online and as indicated below:

LastName, A.A.; LastName, B.B.; LastName, C.C. Article Title. Journal Name Year, Article Number, Page Range.

ISBN 978-3-03928-831-1 (Pbk)

ISBN 978-3-03928-832-8 (PDF)

Cover image courtesy of Claudia L. Bianchi.

(C) 2020 by the authors. Articles in this book are Open Access and distributed under the Creative Commons Attribution (CC BY) license, which allows users to download, copy and build upon published articles, as long as the author and publisher are properly credited, which ensures maximum dissemination and a wider impact of our publications.

The book as a whole is distributed by MDPI under the terms and conditions of the Creative Commons license CC BY-NC-ND. 


\section{Contents}

About the Special Issue Editors $\ldots \ldots \ldots \ldots \ldots \ldots \ldots$ vii

Preface to "Synthesis and Applications of Nanomaterials for Photocatalysis and

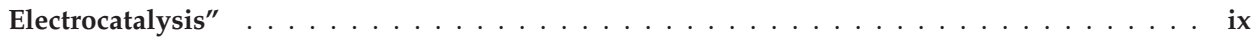

Prabhakarn Arunachalam, Maged N. Shaddad, Mohamed A. Ghanem,

Abdullah M. Al-Mayouf and Mark T. Weller

Zinc Tantalum Oxynitride $\left(\mathrm{ZnTaO}_{2} \mathrm{~N}\right)$ Photoanode Modified with Cobalt Phosphate Layers for the Photoelectrochemical Oxidation of Alkali Water

Reprinted from: Nanomaterials 2018, 8, 48, doi:10.3390/nano8010048 . . . . . . . . . . . . . . 1

Juan Yang, Jun You, Jun Dai, Yumei Chen and Yao Li

In-Situ Synthesis of Hydrogen Titanate Nanotube/Graphene Composites with a Chemically Bonded Interface and Enhanced Visible Photocatalytic Activity

Reprinted from: Nanomaterials 2018, 8, 229, doi:10.3390/nano8040229 . . . . . . . . . . . . 17

Shihao Chen, Yang Xiao, Yinhai Wang, Zhengfa Hu, Hui Zhao and Wei Xie

A Facile Approach to Prepare Black $\mathrm{TiO}_{2}$ with Oxygen Vacancy for Enhancing Photocatalytic Activity

Reprinted from: Nanomaterials 2018, 8, 245, doi:10.3390/nano8040245 . . . . . . . . . . . . 37

Yizeng Zhang, Zhiwu Chen and Zhenya Lu

A Facile Method for the Preparation of Colored $\mathrm{Bi}_{4} \mathrm{Ti}_{3} \mathrm{O}_{12-x}$ Nanosheets with Enhanced Visible-Light Photocatalytic Hydrogen Evolution Activity

Reprinted from: Nanomaterials 2018, 8, 261, doi:10.3390/nano8040261 . . . . . . . . . . . . 53

Jin Liu, Huihui Gan, Hongzhang Wu, Xinlei Zhang, Jun Zhang, Lili Li and Zhenling Wang Effect of Organic Substrates on the Photocatalytic Reduction of $\mathrm{Cr}(\mathrm{VI})$ by Porous Hollow $\mathrm{Ga}_{2} \mathrm{O}_{3}$ Nanoparticles

Reprinted from: Nanomaterials 2018, 8, 263, doi:10.3390/nano8040263 . . . . . . . . . . . .

Tran Thi Thuong Huyen, Tran Thi Kim Chi, Nguyen Duc Dung, Hendrik Kosslick and Nguyen Quang Liem

Enhanced Photocatalytic Activity of $\{110\}$-Faceted $\mathrm{TiO}_{2}$ Rutile Nanorods in the Photodegradation of Hazardous Pharmaceuticals

Reprinted from: Nanomaterials 2018, 8, 276, doi:10.3390/nano8050276 . . . . . . . . . . . . . .

Tiekun Jia, Ming Liu, Dongsheng Yu, Fei Long, Shuyi Mo, Zhao Deng and Weimin Wang

A Facile Approach for the Synthesis of $\mathrm{Zn}_{2} \mathrm{SnO}_{4} / \mathrm{BiOBr}$ Hybrid Nanocomposites with Improved Visible-Light Photocatalytic Performance

Reprinted from: Nanomaterials 2018, 8, 313, doi:10.3390/nano8050313

Meiyin Wang, Hui Wang, Yuanhang Ren, Cheng Wang, Zhewei Weng, Bin Yue and Heyong He

Construction of $\mathrm{g}^{-} \mathrm{C}_{3} \mathrm{~N}_{4}-\mathrm{mNb}_{2} \mathrm{O}_{5}$ Composites with Enhanced Visible Light

Photocatalytic Activity

Reprinted from: Nanomaterials 2018, 8, 427, doi:10.3390/nano8060427 . . . . . . . . . . . . 113

Siyu Xu, Jun Dai, Juan Yang, Jun You and Jingyi Hao

Facile Synthesis of Novel CaIn $\mathrm{S}_{4} / \mathrm{ZnIn}_{2} \mathrm{~S}_{4}$ Composites with Efficient Performance for Photocatalytic Reduction of $\mathrm{Cr}(\mathrm{VI})$ under Simulated Sunlight Irradiation

Reprinted from: Nanomaterials 2018, 8, 472, doi:10.3390/nano8070472 . . . . . . . . . . . . . 12 
Alexander Müller, Sandra Peglow, Michael Karnahl, Angela Kruth, Henrik Junge, Volker Brüser and Christina Scheu

Morphology, Optical Properties and Photocatalytic Activity of Photo- and Plasma-Deposited $\mathrm{Au}$ and $\mathrm{Au} / \mathrm{Ag}$ Core/Shell Nanoparticles on Titania Layers

Reprinted from: Nanomaterials 2018, 8,502, doi:10.3390/nano8070502 . . . . . . . . . . . . . . 145

Chiara Anna D'Amato, Rita Giovannetti, Marco Zannotti, Elena Rommozzi, Marco Minicucci, Roberto Gunnella and Andrea Di Cicco

Band Gap Implications on $\mathrm{Nano}^{-\mathrm{TiO}_{2}}$ Surface Modification with Ascorbic Acid for Visible Light-Active Polypropylene Coated Photocatalyst

Reprinted from: Nanomaterials 2018, 8,599, doi:10.3390/nano8080599 . . . . . . . . . . . . . . . 161

Mariangela Longhi, Camilla Cova, Eleonora Pargoletti, Mauro Coduri, Saveria Santangelo, Salvatore Patanè, Nicoletta Ditaranto, Nicola Cioffi, Anna Facibeni and Marco Scavini Synergistic Effects of Active Sites' Nature and Hydrophilicity on the Oxygen Reduction Reaction Activity of Pt-Free Catalysts

Reprinted from: Nanomaterials 2018, 8, 643, doi:10.3390/nano8090643 . . . . . . . . . . . . . 175

Marta Stucchi, Daria C. Boffito, Eleonora Pargoletti, Giuseppina Cerrato, Claudia L. Bianchi and Giuseppe Cappelletti

Nano- $\mathrm{MnO}_{2}$ Decoration of $\mathrm{TiO}_{2}$ Microparticles to Promote Gaseous Ethanol Visible Photoremoval

Reprinted from: Nanomaterials 2018, 8,686, doi:10.3390/nano8090686 . . . . . . . . . . . . . . . 189 


\section{About the Special Issue Editors}

Giuseppe Cappelletti is Associate Professor of Chemistry and Industrial Chemistry at the University of Milan in the field of Physical Chemistry. He is an expert in Colloids, Interfaces, and Formulations Science. His expertise also extends to electrocatalytic studies; composite materials for sensors in gas and liquid media; thin layers for medical applications; synthesis of ceramic materials; synthesis of nanomaterials for energetic applications; synthesis of nanocrystalline photocatalysts with tailored properties for water and air remediation; superhydrophobic and superhydrophilic transparent layers for the protection and conservation of natural and artificial stone materials; colloid stability and study of interfaces, including in addition of biosurfactant. He has authored more than 100 articles published in various international high-impact journals. His full profile and a complete list of publications can be accessed on Scopus: https:/ / www-scopus-com/authid/detail.uri?authorId=56274806100.

Claudia Letizia Bianchi is Full Professor of Industrial Chemistry, LCA Expert and Head of the Process and Plants Research Group for Industrial Chemistry at the University of Milan. She is Coordinator of the master's degree in Industrial Chemistry, a Board Member of the European Society of Sonochemistry and Ultrasonics Sonochemistry, and an Italian member of the ISO table (TC206) on Advanced Ceramics. Her expertise is in materials chemistry (preparation, characterisation, and testing of inorganic materials) for environmental applications. Her research group at the University of Milan includes researchers with interests covering an array of different fields, such as inorganic materials, surface science, and analytical and physical chemistry, mainly in the industrial chemistry sector. The kind of research being developed in these laboratories has spillover effects in both environmental and energy field. The competences of the group deal with the design and preparation of solid catalysts and microstructured materials, structure modulation during nanopowder syntheses, catalyst deposition techniques on different supports, catalytic and photocatalytic tests, transformation and reactivity of wastes in liquid and gas phase, and assessment of the environmental impact of products and processes through LCA calculations. She has authored more than 230 original research papers published in various international high-impact journals mainly in the field of applied materials science and environmental catalysis. Her full profile and complete list of publications can be accessed on Scopus: https:/ / www.scopus.com/authid/detail.uri?authorId=7202398527. 



\section{Preface to "Synthesis and Applications of Nanomaterials for Photocatalysis and Electrocatalysis"}

This book supplies fundamental aspects regarding the use of different nanostructures as heterogeneous catalysts for energy and environmental applications. In recent decades, the attention of both scientific and industrial communities has become increasingly focused on the implementation of groundbreaking nanomaterials in all fields of human activity, especially toward improving energy efficiency and fulfilling environmental demands. Energy and environment represent a perfect blend: energy-saving environmental remediations and promising energetic devices meeting environmental concerns represent potential future challenges that humankind will face. In this context, the fine control of the nanosized species is the real tool to overcome the current issues and to improve the final performances. Herein, from an energetic point of view, oxygen evolution and reduction reactions (OER and ORR) are key to deeply understanding the behaviour of water splitting devices and fuel cells as well as zinc/air batteries, respectively. Zinc tantalum oxynitride-based photoanodes and nitrogen-modified carbon doped with different metals will be presented and fully characterised. Concurrently, bismuth titanate nanosheets and noble metal core-shell nanoparticles can be adopted to enhance hydrogen evolution through photocatalytic water splitting, exploiting solar energy. Instead, for what concerns the environmental remediation, the use of pure (black, modified, and faceted $\mathrm{TiO} 2, \mathrm{Ga} 2 \mathrm{O} 3$ ) and composite (graphene/titanate, $\mathrm{Zn} 2-\mathrm{SnO} 4 / \mathrm{BiOBr}$, g-C3N4/Nb2O5, MnO2/TiO2 and CaIn2S4/ZnIn2S4) nanomaterials allow for air and water purification, especially under solar irradiation. Particularly, the complete photodegradation of noxious species (benzylic acid), organic dyes (rhodamine B, methylene blue and alizarin red), heavy metals (chromium), recalcitrant pharmaceutical active principles (cinnamic acid, ibuprofen and tetracycline), and VOCs (ethanol) will be thoroughly discussed. Finally, we would like to acknowledge all the authors who have contributed to this book with their scientific expertise, and we hope that the readers will find the arguments both useful and interesting.

Giuseppe Cappelletti, Claudia Letizia Bianchi Special Issue Editors 

Article

\title{
Zinc Tantalum Oxynitride $\left(\mathrm{ZnTaO}_{2} \mathrm{~N}\right)$ Photoanode Modified with Cobalt Phosphate Layers for the Photoelectrochemical Oxidation of Alkali Water
}

\author{
Prabhakarn Arunachalam ${ }^{1, *}$, Maged N. Shaddad ${ }^{1}$, Mohamed A. Ghanem ${ }^{1}$, \\ Abdullah M. Al-Mayouf ${ }^{1}$ and Mark T. Weller ${ }^{2}$ \\ 1 Electrochemistry Research Group, Chemistry Department, College of Science, King Saud University, \\ Riyadh 11451, Saudi Arabia; mshadad@ksu.edu.sa (M.N.S.); mghanem@ksu.edu.sa (M.A.G.); \\ amayouf@ksu.edu.sa (A.M.A.-M.) \\ 2 Department of Chemistry, University of Bath, Bath BA2 7AY, UK; m.t.weller@bath.ac.uk \\ * Correspondence: parunachalam@ksu.edu.sa or prabhuchemist@hotmail.com; Tel.: +966-114696026
}

Received: 18 November 2017; Accepted: 28 December 2017; Published: 18 January 2018

\begin{abstract}
Photoanodes fabricated by the electrophoretic deposition of a thermally prepared zinc tantalum oxynitride $\left(\mathrm{ZnTaO}_{2} \mathrm{~N}\right)$ catalyst onto indium tin oxide (ITO) substrates show photoactivation for the oxygen evolution reaction (OER) in alkaline solutions. The photoactivity of the OER is further boosted by the photodeposition of cobalt phosphate ( $\mathrm{CoPi}$ ) layers onto the surface of the $\mathrm{ZnTaO}_{2} \mathrm{~N}$ photoanodes. Structural, morphological, and photoelectrochemical (PEC) properties of the modified $\mathrm{ZnTaO}_{2} \mathrm{~N}$ photoanodes are studied using X-ray diffraction (XRD), scanning electron microscopy (SEM), ultraviolet visible (UV-Vis) diffuse reflectance spectroscopy, and electrochemical techniques. The presence of the CoPi layer significantly improved the PEC performance of water oxidation in an alkaline sulphate solution. The photocurrent-voltage behavior of the CoPi-modified $\mathrm{ZnTaO}_{2} \mathrm{~N}$ anodes was improved, with the influence being more prominent at lower oxidation potentials. A stable photocurrent density of about $2.3 \mathrm{~mA} \cdot \mathrm{cm}^{-2}$ at $1.23 \mathrm{~V}$ vs. RHE was attained upon visible light illumination. Relative to the $\mathrm{ZnTaO}_{2} \mathrm{~N}$ photoanodes, an almost three-fold photocurrent increase was achieved at the $\mathrm{CoPi} / \mathrm{ZnTaO}_{2} \mathrm{~N}$ photoelectrode. Perovskite-based oxynitrides are modified using an oxygen-evolution co-catalyst of $\mathrm{CoPi}$, and provide a new dimension for enhancing the photoactivity of oxygen evolution in solar-assisted water-splitting reactions.
\end{abstract}

Keywords: cobalt phosphate; tantalum oxynitride; water oxidation; photoelectrochemistry; solid-state synthesis

\section{Introduction}

The development of active and proficient semiconductor photocatalysts for the direct conversion of solar energy to chemical energy has gained attention in the desire to fulfil future energy and fuel demand [1,2]. The use of solar photocatalytic water splitting to produce $\mathrm{H}_{2}$ and $\mathrm{O}_{2}$ over a heterogeneous photocatalyst has been studied extensively for several years, and has been found to be a favorable process for clean and renewable hydrogen generation. The heterogeneous photocatalytic process function at a solar-energy conversion efficiency of $10 \%$ is theoretically able to generate hydrogen at a rate of $\$ 1.63 / \mathrm{kg} \mathrm{H}_{2}$ [3]. However, the development of a photocatalyst for the oxidation of water to yield oxygen gas remains the main hurdle that needs to be overcome in order to establish a technology that is based on water-splitting. The water oxidation reaction is the most difficult half reaction process as it includes four-electron transfer to generate an oxygen molecule, $\mathrm{O}_{2}$; therefore there are significant thermodynamic and kinetic limitations to this process [3]. Several polycrystalline photocatalyst materials have been established for solar-assisted water splitting [1,4]; on the other hand, the materials 
available for the fabrication of efficient photoelectrodes are still limited. The widely investigated photocatalyst is the $\mathrm{TiO}_{2}$ photoelectrode, with a band gap (BG) of $3.0 \mathrm{eV}$; however, this large band is not suitable for the absorption of visible light, and an external bias is generally required to achieve surface redox reactions [5-8]. Therefore, for improved photoelectrodes, it is indispensable to narrow the BG of the semiconductors used to expand light absorption into the visible region of the solar spectrum.

Significant attempts have been carried out to develop new types of oxide-based semiconductors [9-12]. In particular, n-type semiconductor photoanodes, such as $\mathrm{Fe}_{2} \mathrm{O}_{3}, \mathrm{WO}_{3}$, and $\mathrm{BiVO}_{4}$ [13-15], have been employed to accumulate the solar visible-light photons in stable and proficient water-splitting reactions. However, Scaife reported that it is inherently harder to progress an oxide-based photocatalyst that has an appropriately negative conduction band (CB) and a narrow BG (i.e., $<3 \mathrm{eV}$ ) for visible-light absorption due to their higher positive valence band (VB) (at ca. $+3.0 \mathrm{~V}$ vs. NHE) created by the O 2p orbital $[16,17]$. Other oxide-based photoelectrodes, such as La-doped $\mathrm{NaTaO}_{3}[18]$ and Rh-doped $\mathrm{SrTiO}_{3}$ [19], show reasonable quantum efficiencies (QEs) in the presence of UV light, and have been utilized as $\mathrm{H}_{2}$ evolution photocatalysts in visible-light irradiation.

Oxynitride-based photoanodes offer an alternative to oxide-based anodes for visible-light absorption to produce $\mathrm{H}_{2}$ and $\mathrm{O}_{2}$ from water at a stoichiometric ratio [17,20-25]. In these materials, atomic nitrogen is introduced into the oxygen sites, and it shifts the VB edge potentials to the more negative region via the hybridization of N 2p and O 2p orbitals. Domen et al. demonstrated $\mathrm{TaON} /$ co-catalyst-based photoanodes with an incident photon-to-electron conversion efficiency (IPCE) of $76 \%$ at $400 \mathrm{~nm}$ for water oxidation at a minimal or no external applied bias [20-26]. Since then, oxynitrides, such as $\mathrm{LaTiO}_{2} \mathrm{~N}$ [22], $\mathrm{SrNbO}_{2} \mathrm{~N}$ [27,28], $\mathrm{BaNbO}_{2} \mathrm{~N}$ [29], among other materials, have been similarly developed as photoanodes [30-35]. Few of these have attained superior IPCEs of the order of magnitude of several tens of percent with an externally applied bias that is less than the thermodynamically mandatory oxidation potential $(1.23 \mathrm{~V})$ for water electrolysis. Currently, significant research is underway to develop the smaller band-gap photoanodes with a BG of $<2 \mathrm{eV}$ (equivalent to $600 \mathrm{~nm}$ in the visible absorption spectrum) to oxidize water with the application of minimal bias [33]. Several such photoanodes have been developed, e.g., $\mathrm{BaNbO}_{2} \mathrm{~N}$ [21], $\mathrm{CoO}_{x} / \mathrm{LaTiO}_{2} \mathrm{~N}$ [22], and $\mathrm{BaZrO}_{3} / \mathrm{BaTaO}_{2} \mathrm{~N}$ [33], which have been found to utilize the absorption of visible-light in addition to appropriate sacrificial reagents. $\mathrm{SrNbO}_{2} \mathrm{~N}$-based photoanodes (BG $<2 \mathrm{eV}$ ), function as water-oxidation catalysts with the support of a co-catalyst in visible-light illuminations $[27,28,34]$. However, the recombination of the photoexcited carriers and poor photon absorption efficiencies are considered as major drawbacks with these systems, and these attributes need to be improved for application in water-splitting reactions. The incorporation of oxygen-evolution electro-catalysts (OECs) with a photon-absorbing substrate shows it to be a suitable plan to develop the field of photocatalysis chemistry, thus increasing the overall solar conversion efficiency [35]. Recently, the use of cobalt-based materials has also been promising for electrochemical applications [36-38]. To this end, the amorphous cobalt-phosphate ( $\mathrm{Co}-\mathrm{Pi})$ appears to be a promising candidate as a co-catalyst material that possesses the advantages of relatively high elemental earth abundances, a self-healing feature, and functionality under benign conditions [39,40]. Recently, we reported the PEC activity of $\mathrm{ZrO}_{2}$ - and $\mathrm{Fe}_{2} \mathrm{O}_{3}$ - modified $\mathrm{BiVO}_{4}$ and $\mathrm{CoPi} / \mathrm{La}(\mathrm{Ta}, \mathrm{Nb}) \mathrm{O}_{2} \mathrm{~N}$ photoelectrodes for water oxidation in alkaline media [32,41], which achieved up to a 5-fold enhancement in the water-oxidation photocurrent at a lower oxidation potential. In contribution to this research, the present work conveys a significance of engaging a cobalt-based electrocatalyst over tantalum oxynitrides via the electrophoretic deposition route to fabricate the photoanodes. Among the various oxynitrides, $\mathrm{ZnTaO}_{2} \mathrm{~N}$ belongs to a $\mathrm{LiNbO}_{3}$-type structure, which crystallizes in a high temperature paraelectric phase (HTLN-type) structure. $\mathrm{ZnTaO}_{2} \mathrm{~N}$ is a perovskite-type oxynitride containing comparatively earth-abundant metals and it offers a remarkable unique property compared to other available oxynitrides. Our aim in this work is to activate the $\mathrm{ZnTaO}_{2} \mathrm{~N}$ catalyst for the water oxidation process by incorporating the oxygen evolution reaction co-catalysts. The loading of the CoPi OER co-catalyst could amplify the charge 
separation and collection of holes generated at the surface of the photoanodes, subsequently improving photocatalytic performance.

Herein, we describe about the cocatalytic influence as well as the PEC performance of the Co-Pi incorporated $\mathrm{ZnTaO}_{2} \mathrm{~N}$ photoanodes. The PEC properties of the $\mathrm{ZnTaO}_{2} \mathrm{~N}$ electrodes are enhanced predominantly when modified with the Co-Pi catalyst, and its effect is greatest at a lower potential, while the photocurrent is enriched by a factor of 2.5 times relative to that of a bare electrode. The enhancement of the performance can be credited to an improvement in hole collection and charge-separation efficiency at the surface of the oxynitride photoanodes. The present work also demonstrates a viable way for an improvement in the energy-conversion efficiency by coupling OECs with oxynitride photoanodes.

\section{Results and Discussion}

\subsection{XRD and DRS Analysis}

The $\mathrm{ZnTaO}_{2} \mathrm{~N}$ catalyst was prepared using the conventional ammonolysis method, and for comparison, TaON was prepared using a similar procedure. The as-synthesized $\mathrm{ZnTaO}_{2} \mathrm{~N}$ powders show an orange-yellow color, while the TaON powder had a yellow color. The electrophoretic deposition (EPD) method was employed to prepare photoanodes of these materials. The average thickness of the $\mathrm{ZnTaO}_{2} \mathrm{~N}$-deposited film on the indium tin oxide (ITO) substrate was measured using a profilometer, and was about $2.5 \mu \mathrm{m}$. Figure 1 demonstrates the XRD patterns for the TaON, $\mathrm{ZnTaO}_{2} \mathrm{~N}$, and $\mathrm{CoPi} / \mathrm{ZnTaO}_{2} \mathrm{~N}$ photoanodes that were fabricated by EPD followed by loading CoPi using photodeposition methods on ITO substrates, and annealing in a nitrogen atmosphere at $450{ }^{\circ} \mathrm{C}$. The XRD pattern of as-synthesized $\mathrm{ZnTaO}_{2} \mathrm{~N}$ reveals that all the major peaks can be assigned to a perovskite-type phase that is structurally similar to that of $\mathrm{ZnTaO}_{2} \mathrm{~N}$ [28]. The TaON XRD pattern obtained was consistent with the formation of the baddeleyite (monoclinic $\mathrm{ZrO}_{2}$ ) structure. The XRD pattern of TaON photoanodes (Figure 1a) can be well indexed with the phase of TaON (JCPDS \# 70-1193). In $\mathrm{ZnTaO}_{2} \mathrm{~N}$ films, a small level of peak broadening was observed, which implies a reduction in particle size compared to the TaON photoanodes. The XRD pattern of the electrodeposited $\mathrm{ZnTaO}_{2} \mathrm{~N}$ photoanodes (Figure 1b) displays the mixed phase of ZnTa 2 O6 (JCPDS \# 39-1484) and TaON.

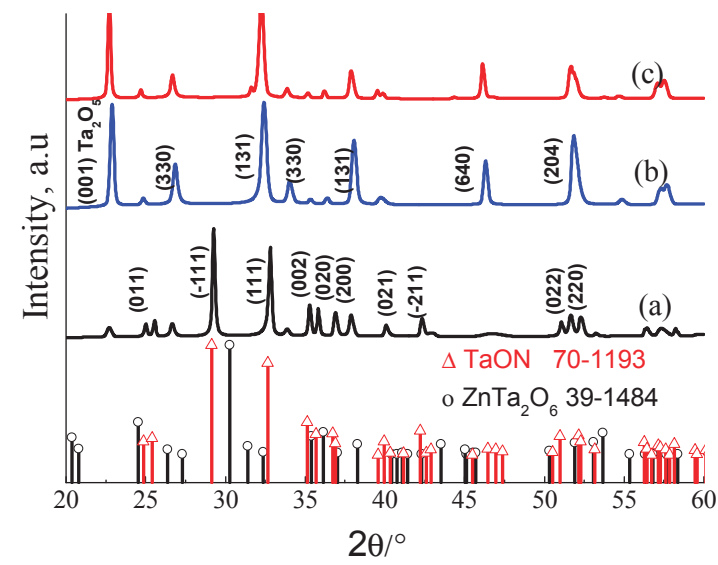

Figure 1. X-ray diffraction (XRD) patterns of (a) reference $\mathrm{TaON} ;(\mathbf{b}) \mathrm{ZnTaO}_{2} \mathrm{~N}$ and (c) $\mathrm{CoPi}_{2} \mathrm{ZnTaO}_{2} \mathrm{~N}$ photo-anodes prepared via electrophoretic and photodeposition.

The XRD patterns of the CoPi-loaded $\mathrm{ZnTaO}_{2} \mathrm{~N}$ photoanodes show that the CoPi deposition did not alter the crystalline phase of $\mathrm{ZnTaO}_{2} \mathrm{~N}$ photoanodes, and no XRD peaks corresponding to 
metal impurities or simple metal oxides were observed. This may be credited to the good dispersion of nanocrystalline CoPi particles over the $\mathrm{ZnTaO}_{2} \mathrm{~N}$. A small shift towards the lower $2 \theta$ values was observed in the presence of CoPi-loaded photoanodes, compared with the parent photoanodes, and this was due to a small difference in the sample height in the powder diffractometer. Figure 2 displays diffuse reflectance spectroscopy (DRS) spectra for the various TaON-based photoanodes. All fabricated TaON-based photoanodes have visible light, and the onset of light-absorption features of the band-gap excitation of $\mathrm{TaON}, \mathrm{ZnTaO}_{2} \mathrm{~N}$, and $\mathrm{CoPi} / \mathrm{ZnTaO}_{2} \mathrm{~N}$ was observed at 420, 447, and $452 \mathrm{~nm}$, respectively.

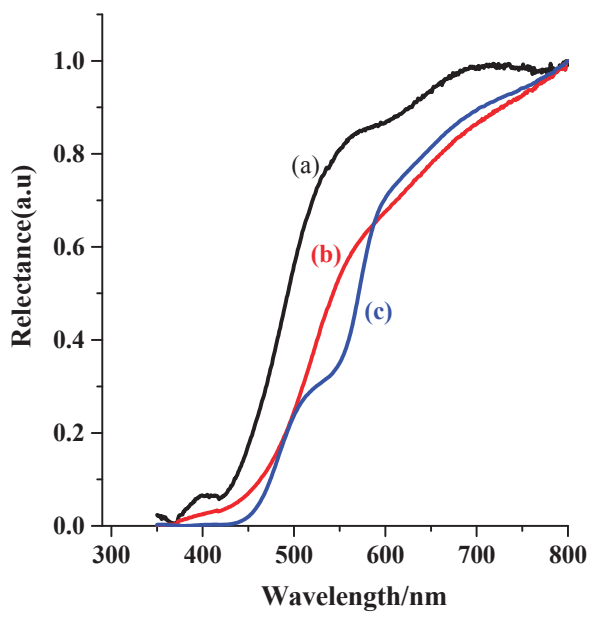

Figure 2. Ultraviolet visible (UV-Vis) reflectance spectra of perovskite-type tantalum oxynitride modified photoanodes of (a) $\mathrm{TaON}$; (b) $\mathrm{ZnTaO}_{2} \mathrm{~N}$ and (c) $\mathrm{CoPi} / \mathrm{ZnTaO}_{2} \mathrm{~N}$.

However, $\mathrm{CoPi} / \mathrm{ZnTaO}_{2} \mathrm{~N}$ photoanodes display dissimilar absorption spectra from that of $\mathrm{ZnTaO}_{2} \mathrm{~N}$, and the absorption edge point is mainly lifted to the higher wavelengths compared with TaON. The BG of the fabricated TaON-based photoanodes was estimated via Kublenka-Munk (K-M) functions, and the data are presented in Table 1. The assessed optical band gaps decreased in the order $\mathrm{TaON}>\mathrm{ZnTaO}_{2} \mathrm{~N}>\mathrm{CoPi} / \mathrm{ZnTaO}_{2} \mathrm{~N}>\mathrm{LaTa}_{0.3} \mathrm{Nb}_{0.7} \mathrm{O}_{2} \mathrm{~N}>\mathrm{LaNbO}_{2} \mathrm{~N}$ (Table 1), which is consistent with a similar effect for perovskite tantalum oxides [42].

Table 1. Structural properties and the band gap of various oxynitride based photoanodes.

\begin{tabular}{|c|c|c|}
\hline Electrophoretic Deposited Oxynitrides on ITO & Particle Size (nm) ${ }^{[a]}$ & Band Gap $E_{g}(\mathrm{eV})^{[\mathrm{b}]}$ \\
\hline $\mathrm{TaON}$ & 29.5 & 2.95 \\
\hline $\mathrm{ZnTaO}_{2} \mathrm{~N}$ & 22.7 & 2.75 \\
\hline $\mathrm{CoPi} / \mathrm{ZnTaO}_{2} \mathrm{~N}$ & 22.4 & $2.7,2.47$ \\
\hline $\mathrm{LaTa}_{0.3} \mathrm{Nb}_{0.7} \mathrm{O}_{2} \mathrm{~N}$ [32] & 18 & 1.84 \\
\hline $\mathrm{LaNbO}_{2} \mathrm{~N}$ & 40 & 1.65 \\
\hline
\end{tabular}

[a] Obtained using Scherer equation; ${ }^{[b]}$ Determined from the diffuse reflectance spectroscopy (DRS) analysis via $\mathrm{K}-\mathrm{M}$ function.

\subsection{Morphological Characteristics of $\mathrm{ZnTaO}_{2} \mathrm{~N}$ Photo-Anodes}

Figure 3 displays SEM images of the surface morphology of the $\mathrm{ZnTaO}_{2} \mathrm{~N}$ (Figure $3 \mathrm{a}, \mathrm{b}$ ) and $\mathrm{CoPi} / \mathrm{ZnTaO}_{2} \mathrm{~N}$ (Figure 3c) photoanodes. These display irregular shapes for both $\mathrm{ZnTaO}_{2} \mathrm{~N}$ and $\mathrm{CoPi} / \mathrm{ZnTaO}_{2} \mathrm{~N}$ materials with the presence of some voids between the particles. The particle sizes generally range from 30 to $200 \mathrm{~nm}$. The $\mathrm{ZnTaO}_{2} \mathrm{~N}$ particles had clearer crystal edges and 
faces, indicating a superior crystallinity of these anodes. This is likely to favor the process of photohole generation, which can reach the active reaction sites at the boundary between the electrode/electrolyte [30]. However, the presence of large quantities of grain boundaries and loose inter-particle connections may lead to the incoherence of electron transport between the particles. The SEM image in Figure $3 \mathrm{c}$ for $\mathrm{ZnTaO}_{2} \mathrm{~N}$ covered with CoPi clearly reveals that the loaded CoPi layer does not alter the morphology of $\mathrm{ZnTaO}_{2} \mathrm{~N}$ particles. In order to prove the deposition of the CoPi layer at the $\mathrm{ZnTaO}_{2} \mathrm{~N}$ surface, we examined the structure using energy-dispersive $\mathrm{X}$-Ray analysis (EDX), and the results are shown in Figure 3d. The EDX characterization confirms the existence of Ta, Co, and $\mathrm{P}$ elements in the photoanodes at $46.25,1.23$, and $0.58 \mathrm{wt} \%$, respectively.

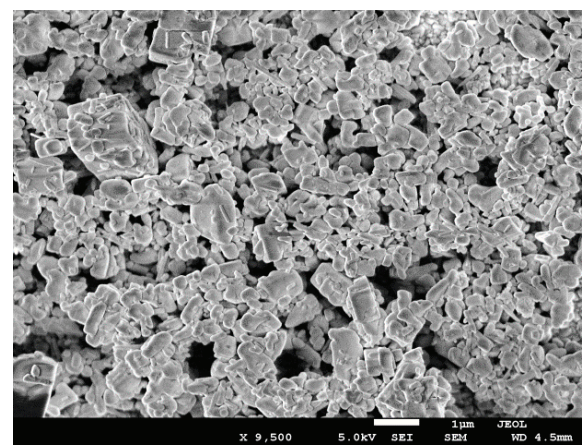

(a)

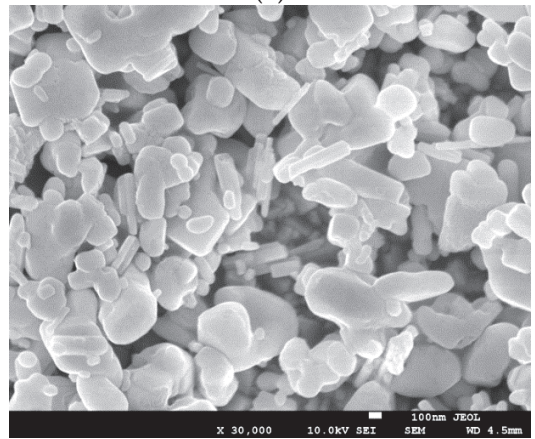

(c)

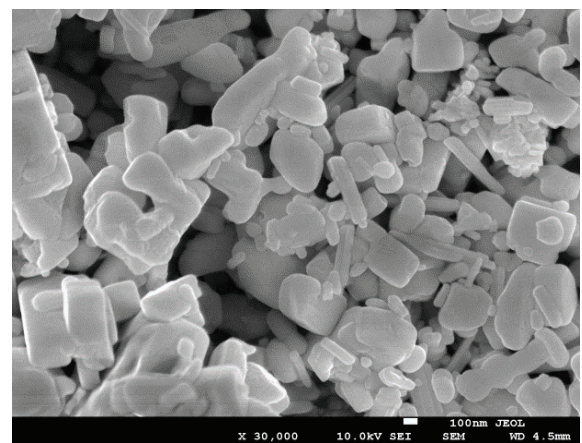

(b)

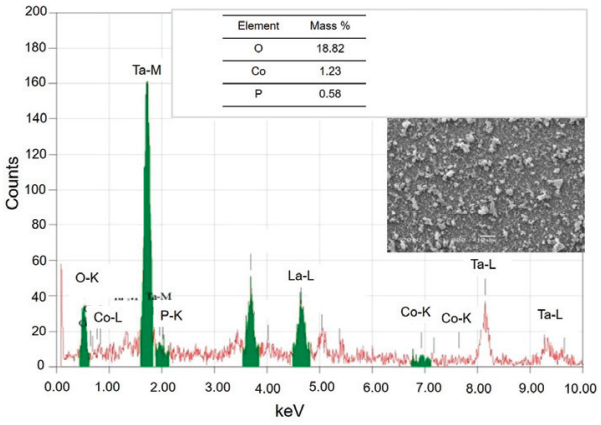

(d)

Figure 3. Scanning electron microscopy (SEM) images of (a) $\mathrm{ZnTaO}_{2} \mathrm{~N}$; (b) higher magnification of $\mathrm{ZnTaO}_{2} \mathrm{~N}$; (c) $\mathrm{CoPi} / \mathrm{ZnTaO}_{2} \mathrm{~N}$ photo-anodes prepared via electrophoretic and photo-deposition deposition onto ITO; (d) energy-dispersive X-Ray analysis (EDX) spectrum of $\mathrm{CoPi} / \mathrm{ZnTaO}_{2} \mathrm{~N}$.

\subsection{XPS Investigation of the $\mathrm{CoPi} / \mathrm{ZnTaO}{ }_{2} \mathrm{~N}$ Photoanodes}

Figure 4 shows the existence of $\mathrm{Co}, \mathrm{P}, \mathrm{Zn}, \mathrm{Ta}, \mathrm{O}$, and $\mathrm{N}$ in the wide-scan $\mathrm{X}$-ray photoelectron spectroscopy (XPS) spectrum of $\mathrm{CoPi} / \mathrm{ZnTaO}_{2} \mathrm{~N}$ photo-anodes. The molar ratio of $\mathrm{Co}$ and $\mathrm{P}$ in $\mathrm{CoPi} / \mathrm{ZnTaO}_{2} \mathrm{~N}$ was estimated to be 1:2.2. The major peaks of binding energies at 26.8 and $28.5 \mathrm{eV}$ related to the spin-orbit separation of the Ta $4 \mathrm{f}_{5 / 2}$ and Ta $4 \mathrm{f}_{7 / 2}$ ingredients, respectively (Figure $4 \mathrm{~b}$ ), demonstrating the development of the $\mathrm{Ta}^{5+}$ [43]. The two dissimilar binding energies of the $\mathrm{O}$ element can be allocated to the characteristics of the Ta-O bond (530.1 eV) and oxygen in carbonate species or hydroxyl groups (531.8 eV) (Figure 4c) [44]. The major peaks for Ta $4 \mathrm{P}_{2 / 3}$ and $\mathrm{N} 1 \mathrm{~s}$ in Figure $4 \mathrm{~d}$ indicate that the $\mathrm{N} 1 \mathrm{~s}$ region centered at $396.4 \mathrm{eV}$ is associated with the binding energy of about $403.5 \mathrm{eV}$ for Ta $4 \mathrm{P}_{2 / 3}$, further confirming the creation of various Ta-N bonds [44]. 

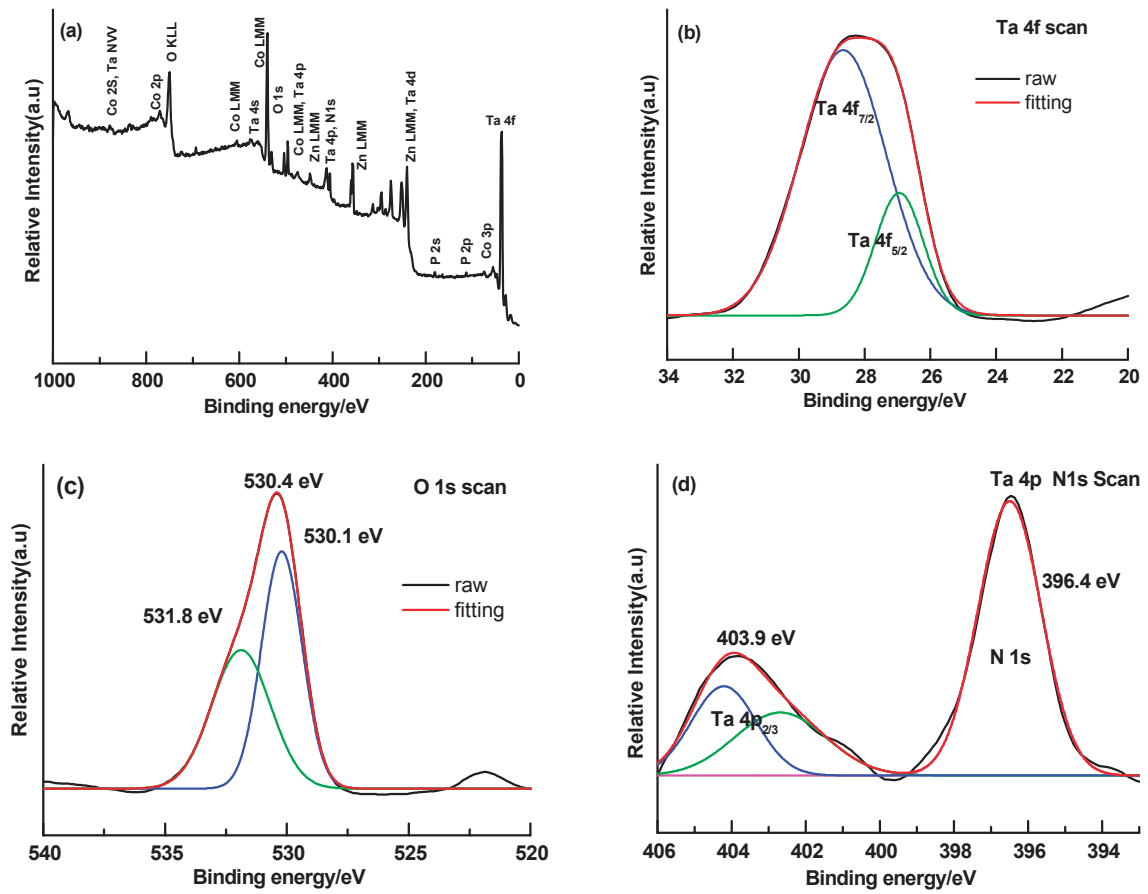

Figure 4. X-ray photoelectron spectroscopy (XPS) analysis of the $\mathrm{CoPi} / \mathrm{ZnTaO}_{2} \mathrm{~N}$ microsphere: (a) wide survey spectra scan for sample; narrow scan for (b) Ta element; (c) O element; (d) Ta and N element.

\subsection{Photoelectrochemical (PEC) Properties of the $\mathrm{ZnTaO}_{2} \mathrm{~N}$ Photoanodes}

The PEC properties of $\mathrm{ZnTaO}_{2} \mathrm{~N}$ photoanodes were examined by performing cyclic voltammetry (CV) and chronoamperometric (CA) measurements in an $\mathrm{H}$-shaped cell. Figure 5a shows the CV measurements logged at $50 \mathrm{mV} \cdot \mathrm{s}^{-1}$ in $1.0-\mathrm{M} \mathrm{Na}_{2} \mathrm{SO}_{4}$ for $\mathrm{ZnTaO}{ }_{2} \mathrm{~N} / \mathrm{ITO}$ photoanodes under AM $1.5 \mathrm{G}$ simulated sunlight at various thicknesses of the film prepared by varying the EPD deposition time duration. The results show that the current density of the photoanode changes dramatically as the deposition time increases. As shown in Figure 5b, the maximum current density (measured at $2.0 \mathrm{~V}$ vs. RHE) was observed around $0.5 \pm 0.05 \mathrm{mg}$ of loaded $\mathrm{ZnTaO}_{2} \mathrm{~N}$ on ITO substrate (equivalent to deposition for $4.0 \mathrm{~min}$ and a thickness of $2.0 \mu \mathrm{m})$, and at higher loading $(>0.5 \mathrm{mg})$, the photoanode current density significantly decreased. This can be clarified by the catalytic water oxidation reaction at the $\mathrm{CoPi}$ /electrolyte interface, and when CoPi loading at higher loading $(>0.5 \mathrm{mg})$, the photoholes need to be transferred in amid numerous CoPi molecules and CoPi/electrolyte interface, which affects the sluggish kinetics of the hole transfer, and subsequently, a smaller photocurrent is detected [32]. Moreover, as shown in Figure 5c (taken from Figure 5a), at a $\mathrm{ZnTaO}_{2} \mathrm{~N}$ loading of around $0.5 \pm 0.05 \mathrm{mg}$, the onset potential of water oxidation markedly shifted to a less positive value, indicating a more favorable process. To understand the effect of $\mathrm{pH}$ on the PEC behavior of the $\mathrm{ZnTaO}_{2} \mathrm{~N}$ photoanode, Figure $5 \mathrm{~d}$ shows the linear sweep voltammetry (LSV) plot for $\mathrm{ZnTaO}_{2} \mathrm{~N}$ photoanode at different $\mathrm{pH}$ in 1.0- $\mathrm{M} \mathrm{Na}_{2} \mathrm{SO}_{4}$ solution. It is evidenced that the current density of water oxidation was significantly enhanced at alkaline $\mathrm{pH}$ of 13 , which is almost eight times superior than that at $\mathrm{pH}$ of 12 . Additionally, the onset potential of water oxidation was shifted $120 \mathrm{mV}$ more cathodic compared with the value obtained at $\mathrm{pH}$ of 12 . 

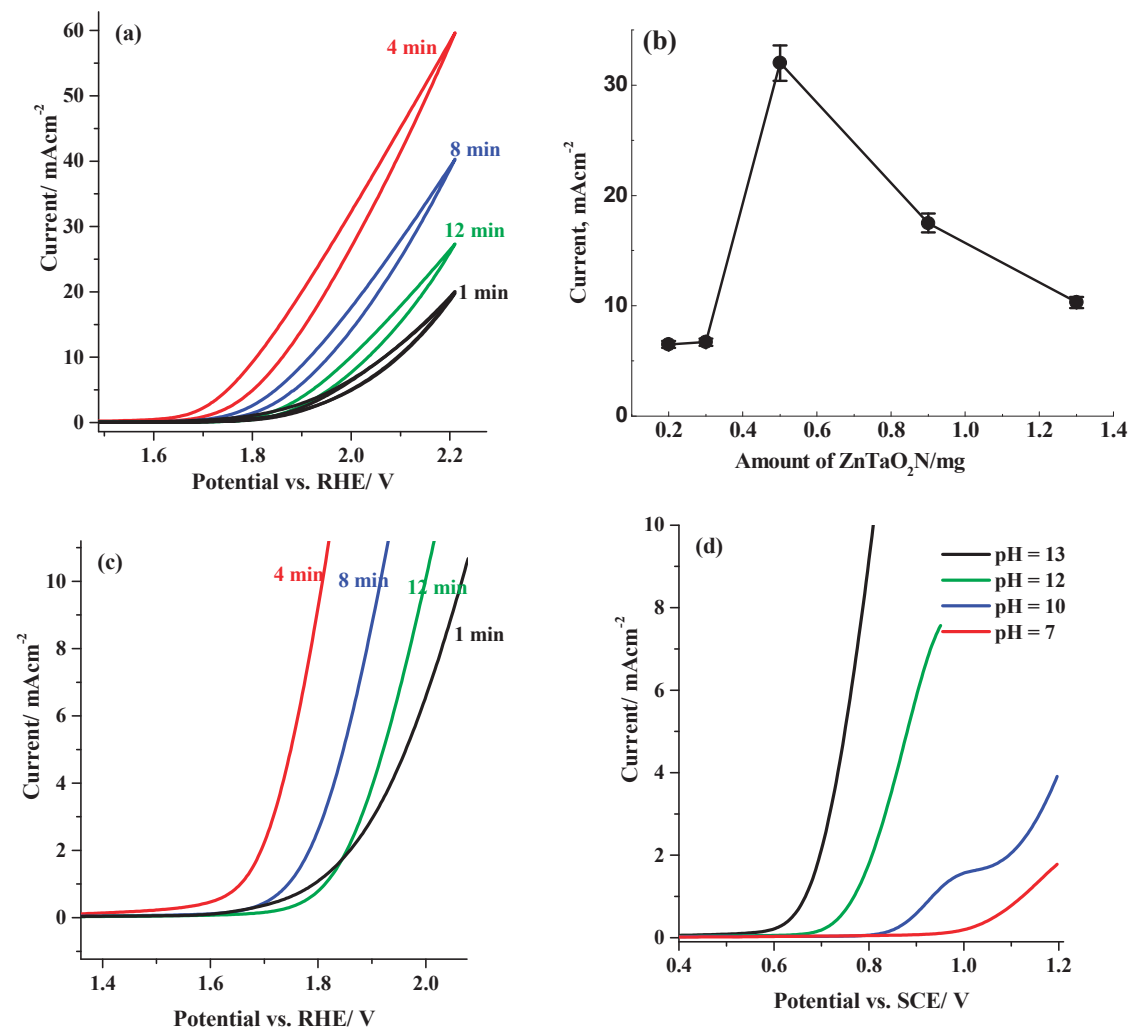

Figure 5. (a) Cyclic voltammetry $(\mathrm{CV})$ at $50 \mathrm{mV} \cdot \mathrm{s}^{-1}$ in $1.0 \mathrm{M} \mathrm{Na}_{2} \mathrm{SO}_{4}$ at $\mathrm{pH} 13$ for photocurrent response for various amounts of $\mathrm{ZnTaO}_{2} \mathrm{~N}$ loaded on ITO; (b) plot for photocurrent measured at $2.0 \mathrm{~V}$ vs. RHE and amount of loaded $\mathrm{ZnTaO}_{2} \mathrm{~N}$ deposited by electrophoretic deposition (EPD) onto ITO; (c) CV in (a) zoomed in current less than $10 \mathrm{~mA} \cdot \mathrm{cm}^{-2}$; (d) Linear sweep voltammetry (LSV) recorded at various $\mathrm{pH}$ of electrolyte solution in the presence of $1.0 \mathrm{M} \mathrm{Na}_{2} \mathrm{SO}_{4}$ solution.

To further improve the PEC behavior of the $\mathrm{ZnTaO}_{2} \mathrm{~N}$ photocatalyst for water oxidation reaction, the CoPi co-catalyst (OEC) was incorporated into the photoanodes using the photodeposition PD method [32,45]. Initially, the amount of $\mathrm{CoPi}$ loaded onto the $\mathrm{ZnTaO}_{2} \mathrm{~N}$ film was optimized by varying the PD duration, followed by measurement of the photocurrent response using chronoamperometry at $1.7 \mathrm{~V}$ vs. $\mathrm{RHE}$ in $1.0-\mathrm{M} \mathrm{Na}_{2} \mathrm{SO}_{4}$ solution. Figure $6 \mathrm{a}$ shows the current time transients with a $10 \mathrm{~s}$ light pulse (1.5 AM) for a $\mathrm{ZnTaO}_{2} \mathrm{~N}$ anode before and after the photodeposition of CoPi for a deposition time of $60 \mathrm{~min}$. For clarity, the background current in the dark was subtracted for both photoanodes. Once the light pulse was applied, the current of both photoanodes increased significantly and the photocurrent density obtained at the $\mathrm{ZnTaO}_{2} \mathrm{~N}$ anode was about $0.75 \mathrm{~mA} \cdot \mathrm{cm}^{-2}$, while the $\mathrm{CoPi} / \mathrm{ZnTaO}{ }_{2} \mathrm{~N}$ photoanode displayed a much superior photocurrent density of $2.9 \mathrm{~mA} \cdot \mathrm{cm}^{-2}$ under the similar conditions. Clearly, the photocurrent obtained at $\mathrm{CoPi} / \mathrm{ZnTaO}_{2} \mathrm{~N}$ is more than three times higher than in the case of the $\mathrm{ZnTaO}_{2} \mathrm{~N}$ electrode, which indicates that the separation and collection processes of the photogenerated electron/hole pairs are more efficient at $\mathrm{CoPi} / \mathrm{ZnTaO}_{2} \mathrm{~N}$ than at a simple $\mathrm{ZnTaO}_{2} \mathrm{~N}$ photoanode. 

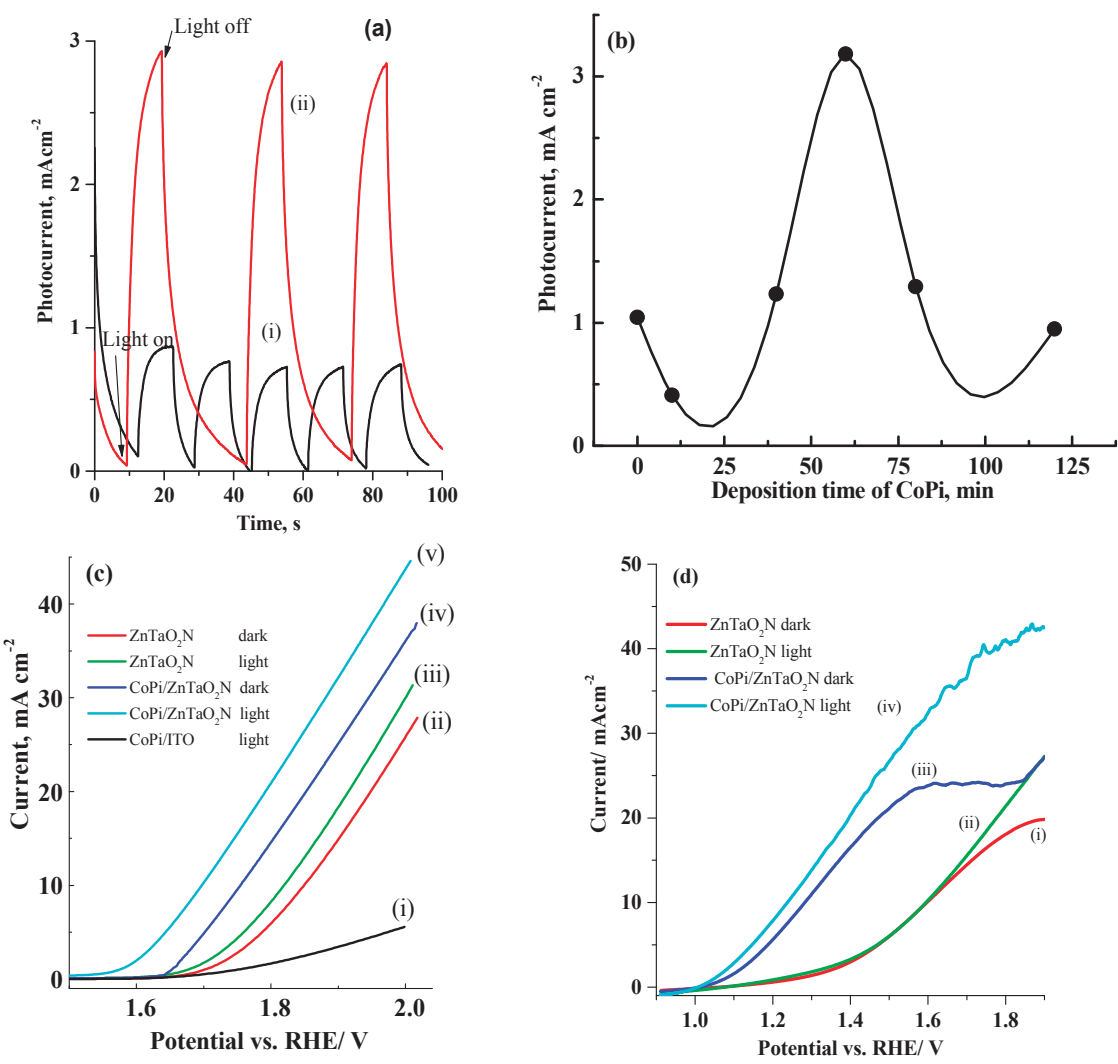

Figure 6. (a) Chronoamperometry diagram at $1.7 \mathrm{~V}$ vs. RHE during pulsing of light for $10 \mathrm{~s}$ in 1.0- $\mathrm{M} \mathrm{Na}_{2} \mathrm{SO}_{4}$ solution ( $\mathrm{pH}$ 13) for (i) $\mathrm{ZnTaO}_{2} \mathrm{~N}$ and (ii) $\mathrm{CoPi} / \mathrm{ZnTaO}_{2} \mathrm{~N}$ photoanode, photodeposition time $=60 \mathrm{~min}$; (b) plot for the photocurrent vs. deposition time of CoPi deposition on $\mathrm{ZnTaO}_{2} \mathrm{~N}$ photoanode; (c) LSV at $50 \mathrm{mV} \cdot \mathrm{s}^{-1}$ in dark and under $1.5 \mathrm{AM}$ light illumination for (i) CoPi/ITO in light, (ii) $\mathrm{ZnTaO}_{2} \mathrm{~N}$ in dark, (iii) $\mathrm{ZnTaO}_{2} \mathrm{~N}$ in light, (iv) $\mathrm{CoPi} / \mathrm{ZnTaO} \mathrm{O}_{2} \mathrm{~N}$ in dark, and (v) $\mathrm{CoPi} / \mathrm{ZnTaO}_{2} \mathrm{~N}$ in light; photo-anodes in 1.0- $\mathrm{M} \mathrm{Na}_{2} \mathrm{SO}_{4}$ solution ( $\mathrm{pH}$ 13) and (d) LSV spectra of $\mathrm{ZnTaO}_{2} \mathrm{~N}$-based photoanodes in the presence of $\mathrm{H}_{2} \mathrm{O}_{2}$ (i) $\mathrm{ZnTaO}{ }_{2} \mathrm{~N}$ in dark, (ii) $\mathrm{ZnTaO}_{2} \mathrm{~N}$ in light, (iii) $\mathrm{CoPi} / \mathrm{ZnTaO}_{2} \mathrm{~N}$ in dark, and (iv) $\mathrm{CoPi} / \mathrm{ZnTaO}_{2} \mathrm{~N}$ in light.

Figure $6 \mathrm{~b}$ shows the relationship between the CoPi PD time and the photocurrent obtained for the $\mathrm{CoPi} / \mathrm{ZnTaO}_{2} \mathrm{~N}$ anode at $1.7 \mathrm{~V}$ vs. RHE. Clearly, using our present PD methodology, the optimum period for CoPi photo-deposition on $\mathrm{ZnTaO}_{2} \mathrm{~N}$ photo-anodes was found to be around $60 \mathrm{~min}$. The PEC characteristics were compared for both $\mathrm{ZnTaO}_{2} \mathrm{~N}$ and $\mathrm{CoPi} / \mathrm{ZnTaO} \mathrm{O}_{2} \mathrm{~N}$ anodes to examine the effect of the photodeposited CoPi co-catalyst on the photocurrent response of the $\mathrm{ZnTaO}_{2} \mathrm{~N}$ photoanode. Figure $6 \mathrm{c}$ shows the LSV at $50 \mathrm{mV} \cdot \mathrm{s}^{-1}$ in the dark and under $1.5 \mathrm{AM}$ light illumination for $\mathrm{CoPi} / \mathrm{ZnTaO}{ }_{2} \mathrm{~N}$ and $\mathrm{ZnTaO}_{2} \mathrm{~N}$ photoanodes in 1.0-M Na $2 \mathrm{SO}_{4}$ solution ( $\mathrm{pH}$ 13). In comparison, the LSV of the control anode made by the PD of the CoPi catalyst directly onto the ITO substrate is also shown in Figure $6 \mathrm{c}$ (i). The LSV for the control anode of CoPi/ITO (i) shows a small level of the oxygen evolution current under light illumination. The $\mathrm{CoPi} / \mathrm{ZnTaO} \mathrm{N}_{2} \mathrm{~N}$ photoanode clearly shows negative potential shifts of about $120 \mathrm{mV}$ in the onset potential of oxygen evolution, and an increase in the photocurrent of more than $2.3 \mathrm{~mA} \cdot \mathrm{cm}^{-2}$ at $1.23 \mathrm{~V}$ vs. RHE relative to its parent $\mathrm{ZnTaO} \mathrm{O}_{2} \mathrm{~N}$ photoanode. For the $\mathrm{CoPi} / \mathrm{ZnTaO}_{2} \mathrm{~N}$ anode, the photocurrent was enhanced by a factor of three compared with 
the parent $\mathrm{ZnTaO}_{2} \mathrm{~N}$ electrode. It is clear that the magnitude of the CoPi loading is influenced by the photoanode morphology, time, and the employed deposition procedure. A larger amount of $\mathrm{CoPi}$ deposited on $\mathrm{ZnTaO}_{2} \mathrm{~N}$ ( $>60 \mathrm{~min}$ ) results in the suppression of the photocurrent, as revealed in Figure $6 \mathrm{~b}$. This phenomenon can be explained by considering that the water catalytic oxidation reaction takes place at the $\mathrm{CoPi} /$ electrolyte interface. For a thick layer of $\mathrm{CoPi}$, the photoholes have to transfer through a thick CoPi layer to reach the interface between the CoPi/electrolyte; consequently, the hole migration becomes very slow, and a decreased photocurrent is observed. On the contrary, for a thinner CoPi layer, the cobalt ions link more directly to the $\mathrm{ZnTaO}_{2} \mathrm{~N}$ surface, and rapidly acquire the photoholes in the water oxidation reaction [46,47].

Hydrogen peroxide $\left(\mathrm{H}_{2} \mathrm{O}_{2}\right)$ was introduced to the electrolyte $(0.1 \mathrm{M})$ as an electron donor to evaluate the maximum photocurrent that might be acquired while injecting a photoexcited holes from the anode surface to the electrolyte solution was perfectly facilitated. It is believed that $\mathrm{H}_{2} \mathrm{O}_{2}$ captures the photoexcited holes efficiently without substantial recombination [27]. To observe these behaviors on the prepared photoanodes, $\mathrm{LSV}$ plots of $\mathrm{CoPi} / \mathrm{ZnTaO}{ }_{2} \mathrm{~N}$ were logged in the presence and absence of $\mathrm{H}_{2} \mathrm{O}_{2}$ and the results are presented in Figure 6d. The LSV of $\mathrm{ZnTaO}_{2} \mathrm{~N}$ and $\mathrm{CoPi} / \mathrm{ZnTaO}{ }_{2} \mathrm{~N}$ photoanodes indicate that the photocurrent at applied potential values of more negative than $1.7 \mathrm{~V}$ vs. RHE was improved considerably in the presence of $\mathrm{H}_{2} \mathrm{O}_{2}$. This implies that the redox active Co species may be quickly oxidized at a lower applied potential ( $<1.4 \mathrm{~V}$ vs. RHE), while water could not. This results coincides with the results attained for $\mathrm{CoPi} / \mathrm{La}(\mathrm{Ta}, \mathrm{Nb}) \mathrm{O}_{2} \mathrm{~N}$ photoelectrodes [32]. These PEC performances show that the $\mathrm{CoPi} / \mathrm{ZnTaO}_{2} \mathrm{~N}$ photoelectrodes, photocurrent at $<1.4 \mathrm{~V}$ vs. RHE was comparable, irrespective of the introduction of $\mathrm{H}_{2} \mathrm{O}_{2}$, signifying that the CoPi had improved the surface redox reactions effectively.

\subsection{Band Positions of the $\mathrm{ZnTaO}{ }_{2} \mathrm{~N}$ Photoanodes}

As previously discussed, the band-edge position at the electrolyte and the carrier mobility in the semiconductor photocatalyst are both significant factors for the characterization of the PEC performance of the photoanodes. The Mott-Schottky (MS) method was performed and the Nyquist plot was obtained to determine the characteristics of $\mathrm{ZnTaO}_{2} \mathrm{~N}$ and $\mathrm{CoPi} / \mathrm{ZnTaO}{ }_{2} \mathrm{~N}$ electrodes in 1-M $\mathrm{Na}_{2} \mathrm{SO}_{4}(\mathrm{pH} 13)$ at a frequency of $100 \mathrm{~Hz}$. The valence-band and conduction-band potentials of TaON, $\mathrm{LaTaO}_{2} \mathrm{~N}$, and $\mathrm{ZnTaO}_{2} \mathrm{~N}$ were calculated using the Butler and Ginley method, and the values are précised in Table S1.

The conduction-band edge $\left(\mathrm{E}_{\mathrm{CB}}\right)$ for $\mathrm{ZnTaO}_{2} \mathrm{~N}$ was obtained at $0.32 \mathrm{~V}$ vs. SCE by employing the method proposed by Butler and Ginley [48] using the optical BG from the K-M spectra. As presented in Figure $7 \mathrm{a}$, the intercept on the potential axis of the $\mathrm{ZnTaO}_{2} \mathrm{~N}$ photoanode reveals a flat band potential $\left(\mathrm{E}_{\mathrm{FB}}\right)$ at $0.14 \mathrm{~V}$, while the intercept of the $\mathrm{CoPi} / \mathrm{ZnTaO}_{2} \mathrm{~N}$ photoanodes displays an $\mathrm{E}_{\mathrm{FB}}$ at $0.08 \mathrm{~V}$ vs. RHE at $\mathrm{pH}=13$. It is clear that $\mathrm{CoPi} / \mathrm{ZnTaO}_{2} \mathrm{~N}$ photoanodes have less positive $\mathrm{E}_{\mathrm{FB}}$ values than the parent photoanodes. The addition of the CoPi co-catalyst as a hole acceptor promotes the charge-separation reaction, which leads to the enhancement of the photocurrent during the water oxidation reaction. In addition, the CoPi co-catalyst can cause the oxygen evolution reaction to occur at lower oxidation potential by altering the reaction pathway [39]. The CoPi layer on the photoanode has to be thin enough to complement the fast transfer of the photogenerated hole from the $\mathrm{ZnTaO}_{2} \mathrm{~N}$ photoanode to the water oxidation reaction, which relieves the charge accumulation at the electrode/electrolyte interface.

Figure $7 \mathrm{~b}$ shows Nyquist plots of the $\mathrm{ZnTaO}_{2} \mathrm{~N}$ and $\mathrm{CoPi} / \mathrm{ZnTaO}_{2} \mathrm{~N}$ photo-anodes acquired in the light and in the dark. The equivalent circuit is shown in the inset of Figure $7 \mathrm{~b}$ and the fitting results of the photoanodes are summarized in Table 2. The $\mathrm{ZnTaO}_{2} \mathrm{~N}$ photo-anodes were perfect fitted to a RC circuit model which grasps a resistor and a RC circuit. RC circuit can be allocated to $\mathrm{ZnTaO}_{2} \mathrm{~N}$ /electrolyte interface. For the $\mathrm{CoPi} / \mathrm{ZnTaO}_{2} \mathrm{~N}$ photo-anode, capacitances increased, whereas the charge transfer resistances decreased, signifying that CoPi-loading sustained charge separation at the bulk photo-anode and, as a consequence, enriched PEC water oxidation ability. CoPi loading on photoanodes advances the PEC behaviour by endorsing the charge separation and 
water oxidation phenomenon on the $\mathrm{ZnTaO}_{2} \mathrm{~N}$ photo-anodes surface which is very consistent with the behavior of $\mathrm{CoPi} / \mathrm{LaTaNbO}_{2} \mathrm{~N}$ [32], $\mathrm{CoPi} / \mathrm{TiO}_{2}$ [39] and $\mathrm{CoPi} / \mathrm{BiVO}_{4}$ structures [47].

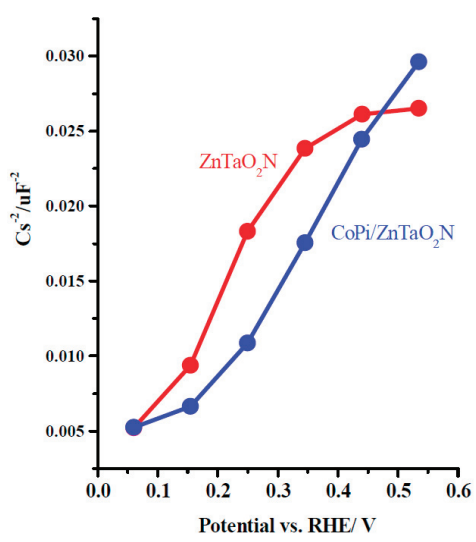

(a)

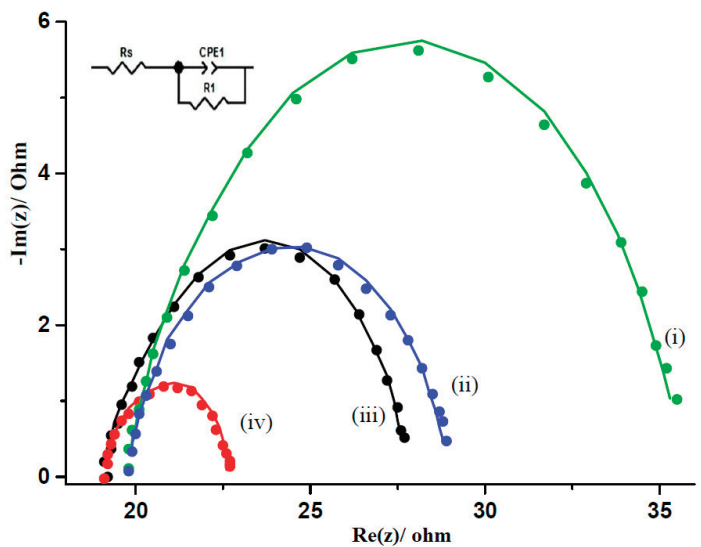

(b)

Figure 7. (a) Mott-Schottky plots for $\mathrm{ZnTaO}_{2} \mathrm{~N}$ and $\mathrm{CoPi} / \mathrm{ZnTaO}_{2} \mathrm{~N}$ photo-anodes; (b) Nyquist plot for the photoanodes of (i) $\mathrm{ZnTaO}_{2} \mathrm{~N}$ in dark, (ii) $\mathrm{ZnTaO}_{2} \mathrm{~N}$ in light, (iii) $\mathrm{CoPi} / \mathrm{ZnTaO}_{2} \mathrm{~N}$ in dark, and (iv) $\mathrm{CoPi} / \mathrm{ZnTaO}_{2} \mathrm{~N}$ in light; illumination conditions are $1.5 \mathrm{AM}$ and in $1.0-\mathrm{M} \mathrm{Na}_{2} \mathrm{SO}_{4}$ at $\mathrm{pH}=13$.

Table 2. Nyquist plot of equivalent circuit-model parameters obtained from the electrochemical impedance spectra of photoanodes.

\begin{tabular}{ccccc}
\hline Photoanode & & $R s / \Omega$ & Rct/ $\Omega$ & CPE1 (F) \\
\hline \multirow{2}{*}{$\mathrm{ZnTaO}_{2} \mathrm{~N}$} & Dark & 22.17 & 33.55 & $6.763 \times 10^{-5}$ \\
& Light & 22.17 & 27.23 & $5.714 \times 10^{-5}$ \\
\hline \multirow{2}{*}{$\mathrm{CoPi} / \mathrm{ZnTaO}_{2} \mathrm{~N}$} & Dark & 19.17 & 25.81 & $1.15 \times 10^{-4}$ \\
& Light & 19.17 & 22.46 & $2.303 \times 10^{-5}$ \\
\hline
\end{tabular}

\subsection{Quantification of Dioxygen Evolution during Photoactivation}

The irradiation of $\mathrm{ZnTaO}_{2} \mathrm{~N}$ and $\mathrm{CoPi} / \mathrm{ZnTaO}_{2} \mathrm{~N}$ photoanodes with visible-light photons eventually increases the evolution of dioxygen. Figure 8a shows the oxygen-evolution measurements obtained at $1.7 \mathrm{~V}$ vs. RHE using an oxygen sensor oxysense system. The corresponding photocurrent responses were obtained and the results are presented in Figure $8 \mathbf{b}$. As anticipated, under similar conditions, the $\mathrm{CoPi} / \mathrm{ZnTaO}_{2} \mathrm{~N}$ photoanodes and their parent photoanodes with visible-light photons $(\lambda>420 \mathrm{~nm})$ caused an increase in the dioxygen evolution. To obtain an estimate, the precise oxygen concentration was logged before and after PEC reactions. Figure 8a confirms that by switching on the photoelectrolysis, the concentration of oxygen starts to increase linearly with time, and no substantial quantity of oxygen was observed before $(<15 \mathrm{~min}$ ) or after $(>45 \mathrm{~min})$ the photoelectrolysis was turned off. The $\mathrm{CoPi} / \mathrm{ZnTaO}_{2} \mathrm{~N}$ photoanodes showed increased oxygen generation relative to parent $\mathrm{ZnTaO}_{2} \mathrm{~N}$, which is demonstrated by its oxygen-evolution rate. The oxygen-evolution rate is faster in the case of CoPi-coated $\mathrm{ZnTaO}_{2} \mathrm{~N}$ compared with the parent photoanode (Figure 8a). Conversely, it is evident that the incorporation of CoPi as a co-catalyst enhanced the photocurrent response and stability under continued illumination, as shown in Figure $8 \mathrm{~b}$. The durability of the $\mathrm{CoPi} / \mathrm{ZnTaO}_{2} \mathrm{~N}$ photoanodes was examined, and it displayed in Figure S1. The chronoamperometric results indicate that the photoanode remains stable until $180 \mathrm{~min}$, after which small changes are observed. The stability of the $\mathrm{CoPi} / \mathrm{ZnTaO}_{2} \mathrm{~N}$ photoanodes under light irradiation was investigated 
by relating their absorption spectrum before and after visible light irradiation, signifying that the photoanodes are stable under visible-light illumination (Figure S2). A more effective coupling of photoholes to reaction sites of the water-oxidation reaction can be anticipated, as discussed earlier, which validates the enhancement of oxygen-evolution performance as well as the stability of CoPi-loaded $\mathrm{ZnTaO}_{2} \mathrm{~N}$ photoelectrodes.

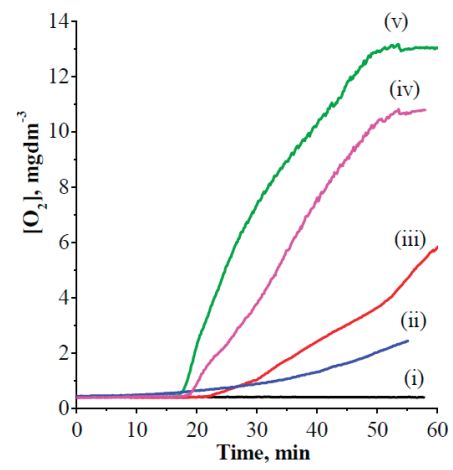

(a)

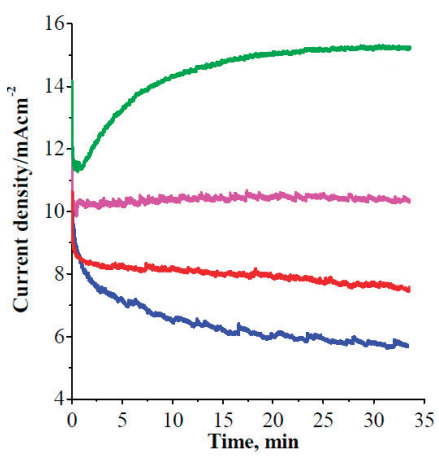

(b)

Figure 8. (a) Oxygen evolution and (b) its corresponding chronoamperometric measurements in a two-electrode setup in 1.0-M aqueous sulphate solution $(\mathrm{pH}=13)$ during prolonged irradiation by visible light $\left(\lambda>420 \mathrm{~nm}\right.$ ), (i) ITO blank, (ii) $\mathrm{ZnTaO}_{2} \mathrm{~N}$ dark, (iii) $\mathrm{CoPi} / \mathrm{ZnTaO}_{2} \mathrm{~N}$ dark, (iv) $\mathrm{ZnTaO}_{2} \mathrm{~N}$ light, and (v) $\mathrm{CoPi} / \mathrm{ZnTaO}_{2} \mathrm{~N}$ light; the working electrode was biased at $1.7 \mathrm{~V}$ vs. RHE.

\section{Experimental}

\subsection{Preparation of the $\mathrm{ZnTaO}{ }_{2} \mathrm{~N}$ Catalyst}

The $\mathrm{ZnTaO}_{2} \mathrm{~N}$ powder was fabricated via conventional solid-state reaction described in a previous work [49]. In the synthesis described here, stoichiometric quantities of $\mathrm{ZnCO}_{3}$ and $\mathrm{Ta}_{2} \mathrm{O}_{5}$ (Aldrich, $99.9 \%$, St. Louis, MO, USA) were well ground together in acetone in the presence of $\mathrm{KCl}(50 \%$ total weight), which is used as a mineralizer. The resulting mixture was heated at $850{ }^{\circ} \mathrm{C}$ under an ammonia flow (Air Products Electronic Grade, Riyadh, KSA) for $20 \mathrm{~h}$ at a flow rate of $7 \mathrm{dm}^{3} \cdot \mathrm{h}^{-1}$, and it was then permitted to cool to normal temperature under ammonia atmosphere. The mineralizer was leached from the products using excess de-ionized water, and the residual product was dried overnight at $80^{\circ} \mathrm{C}$. The TaON was prepared following similar procedure by heating pure $\mathrm{Ta}_{2} \mathrm{O}_{5}$ (Aldrich, $99.9 \%$ ) at $850{ }^{\circ} \mathrm{C}$ under flowing ammonia for $18 \mathrm{~h}$ at a flow rate of $7 \mathrm{dm}^{3} \cdot \mathrm{h}^{-1}$.

\subsection{Fabrication of the $\mathrm{ZnTaO}_{2} \mathrm{~N}$ Photoanodes}

$\mathrm{ZnTaO}_{2} \mathrm{~N}$ film photoanodes were fabricated using the EPD process, as described in our previous work [32]. For instance, the $\mathrm{ZnTaO}_{2} \mathrm{~N}$ (15 mg) and 3-mg iodine (Alfa-Aesar, Karlsruhe, Germany) powders were kept ultrasonically discrete in acetone $(15 \mathrm{~mL})$ to obtain a uniform suspension. The ITO substrates $(174 \mathrm{~nm}, 1.0 \times 1.0 \mathrm{~cm}$, Asahi glass Co., Ltd., Tokyo, Japan) were submerged and held parallel at about $1.0 \mathrm{~cm}$ apart from each other in the solution. A $+10 \mathrm{~V}$ bias was then applied to the two electrodes for 2 min using a potentiostat (Bio-Logic SAS, VSP 0478, Seyssinet-Pariset, France). This deposition process was repeated twice, and the electrode was then dried and annealed at $450{ }^{\circ} \mathrm{C}$ under a flow of $\mathrm{N}_{2}$ gas at a rate of $500 \mathrm{~mL} / \mathrm{min}$ for $1 \mathrm{~h}$. This process resulted in the development of a $\mathrm{ZnTaO}_{2} \mathrm{~N}$ layer (in total about $0.5 \mathrm{mg}$ ) with a comparatively uniform thickness of about $2 \mu \mathrm{m}$, as monitored using a surface profilometer. The cobalt phosphate (CoPi) co-catalyst layer was deposited on $\mathrm{ZnTaO}_{2} \mathrm{~N}$ photoanodes using the PD method, as described in the literature [32]. 
$\mathrm{CoPi} / \mathrm{ZnTaO}_{2} \mathrm{~N}$ electrodes with various $\mathrm{CoPi}$ depositions were fabricated by altering the PD time (indicated as $\mathrm{CoPi} / \mathrm{ZnTaO}{ }_{2} \mathrm{~N}$ ). Characterization and $\mathrm{XRD}$ measurements were carried out using a MiniFlex 600 (Rigaku, CuK $\alpha, 40$ kV, 15 mA, Tokyo, Japan). The photoanodes were further characterized using an ultraviolet visible (UV-Vis) spectrophotometer (Shimadzu UV-2600, Tokyo, Japan) and EDAX (JED-2200 series, Tokyo, Japan). Electrochemical impedance spectroscopy (EIS) analysis was performed using a biologic (VSP-0478) potentiostat electrochemical workstation. A solar simulator (Asahi spectra, MAX 303, Torrance, CA, USA) provided visible-light irradiation to the fabricated photoanodes.

\subsection{Photoelectrochemical Characterization}

The PEC properties of the $\mathrm{ZnTaO}_{2} \mathrm{~N}$ and $\mathrm{CoPi} / \mathrm{ZnTaO}{ }_{2} \mathrm{~N}$ photoanodes were obtained in $\mathrm{H}$-shaped two-compartment glass cells with a 2-cm diameter quartz window. The fabricated $\mathrm{ZnTaO}_{2} \mathrm{~N}$-based photoanode film was taken as a working electrode $\left(\mathrm{WE}, 0.25 \mathrm{~cm}^{2}\right)$, the saturated calomel electrode as a reference electrode, and $\mathrm{Pt}$ foil was served as the counter electrode in the electrolyte solution containing $1-\mathrm{M} \mathrm{Na}_{2} \mathrm{SO}_{4}$, and the $\mathrm{pH}$ of the electrolyte solution was modified to 13 with the addition of $\mathrm{KOH}$. Photoelectrochemical oxygen evolution was monitored by an oxygen analyzer (Oxysense Inc., Dallas, TX, USA, 300/5000 series). The compartment cell was sealed and argon gas was used for purging. Prior to the experiment, the electrolyte solution was bubbled with argon for $1 \mathrm{~h}$, and the atmosphere above the electrolyte was maintained as argon throughout the measurements. Before starting the electrolysis, the cell setup was purged for $20 \mathrm{~min}$ to attain the equilibrium.

\section{Conclusions}

A photocatalyst of $\mathrm{ZnTaO}_{2} \mathrm{~N}$ was initially synthesized via conventional solid state reaction and then photoanodes were fabricated by an electrophoretic deposition method into ITO. We studied the co-catalytic effect of a photo-assisted water oxidation reaction by photodeposition of CoPi oxygen electrocatalyst onto the $\mathrm{ZnTaO}_{2} \mathrm{~N}$ photoanodes. An electrochemical investigation revealed that the PEC performance of $\mathrm{ZnTaO}_{2} \mathrm{~N}$ was significantly enhanced after CoPi deposition and a $2.3 \mathrm{~mA} \cdot \mathrm{cm}^{-2}$ photocurrent density was reached at $1.23 \mathrm{~V} \mathrm{vs}$. RHE in a sulfate medium. Additionally, CoPi-loading assisted the PEC performance of $\mathrm{ZnTaO}_{2} \mathrm{~N}$ film by reducing the charge recombination process and stabilizing the photo-anode performance for the oxygen evolution reaction under visible light illumination.

Supplementary Materials: The following are available online at www.mdpi.com/2079-4991/8/1/48/s1, Table S1: Photophysical and structural properties of $\mathrm{TaO}_{2} \mathrm{~N}$ based photoandodes, Figure S1: Chronoamperometric measurements in two-electrode setup in $1 \mathrm{M}$ aqueous sulfate solution $(\mathrm{pH}=13)$, Figure S2: Absorption spectra of $\mathrm{CoPi} / \mathrm{ZnTaO}_{2} \mathrm{~N}$ photoanodes before and after visible-light irradiation for $10 \mathrm{~h}$.

Acknowledgments: The authors would like to extend their sincere appreciation to the Deanship of Scientific Research at King Saud University for funding this Research group NO: RG-1438-087.

Author Contributions: P.A. performed the experiments and wrote the manuscript. M.N.S. assisted in the photoelectrochemical characterization. M.A.G., A.M.A.-M. and M.T.W. provided suggestions and assistance in the experiment design, synthesis of materials and manuscript editing.

Conflicts of Interest: The authors declare no conflict of interest.

\section{References}

1. Kudo, A.; Miseki, Y. Heterogeneous photocatalyst materials for water splitting. Chem. Soc. Rev. 2009, 38, 253-278. [CrossRef] [PubMed]

2. Arunachalam, P.; Zhang, S.; Abe, T.; Komura, M.; Iyoda, T.; Nagai, K. Weak visible light $\left(\sim \mathrm{mw} / \mathrm{cm}^{2}\right)$ organophotocatalysis for mineralization of amine, thiol and aldehyde by biphasic cobalt phthalocyanine/fullerene nanocomposites prepared by wet process. Appl. Catal. B Environ. 2016, 193, 240-247. [CrossRef]

3. Bockris, J. Energy: The Solar-Hydrogen Alternative; Halsted Press: New York, NY, USA, 1975; p. 381. 
4. Osterloh, F.E. Inorganic materials as catalysts for photochemical splitting of water. Chem. Mater. 2008, 20, 35-54. [CrossRef]

5. Fujishima, A.; Honda, K. Electrochemical photolysis of water at a semiconductor electrode. Nature 1972, 238, 37-38. [CrossRef] [PubMed]

6. Sun, Y.; Zhao, Q.; Wang, G.; Yan, K. Influence of water content on the formation of $\mathrm{TiO}_{2}$ nanotubes and photoelectrochemical hydrogen generation. J. Alloys Compd. 2017, 711, 514-520. [CrossRef]

7. Sun, M.; Fang, Y.; Kong, Y.; Yuan, X.; Shi, J.; Umar, A. Direct in situ synthesis of $\mathrm{Fe}_{2} \mathrm{O}_{3}$-codoped n-doped $\mathrm{TiO}_{2}$ nanoparticles with enhanced photocatalytic and photo-electrochemical properties. J. Alloys Compd. 2017, 705, 89-97. [CrossRef]

8. Sun, W.; Wang, D.; Rahman, Z.U.; Wei, N.; Chen, S. 3D hierarchical $\mathrm{WO}_{3}$ grown on $\mathrm{TiO}_{2}$ nanotube arrays and their photoelectrochemical performance for water splitting. J. Alloys Compd. 2017, 695, 2154-2159. [CrossRef]

9. Watanabe, T.; Fujishima, A.; Honda, K.-I. Photoelectrochemical reactions at $\mathrm{SrTiO}_{3}$ single crystal electrode. Bull. Chem. Soc. Jpn. 1976, 49, 355-358. [CrossRef]

10. Kudo, A. Development of photocatalyst materials for water splitting. Int. J. Hydrogen Energy 2006, 31, 197-202. [CrossRef]

11. Melián, E.P.; López, C.R.; Méndez, A.O.; Díaz, O.G.; Suárez, M.N.; Rodríguez, J.D.; Navío, J.; Hevia, D.F. Hydrogen production using Pt-loaded $\mathrm{TiO}_{2}$ photocatalysts. Int. J. Hydrogen Energy 2013, 38, 11737-11748. [CrossRef]

12. Yuan, Y.; Zhang, X.; Liu, L.; Jiang, X.; Lv, J.; Li, Z.; Zou, Z. Synthesis and photocatalytic characterization of a new photocatalyst $\mathrm{BaZrO}_{3}$. Int. J. Hydrogen Energy 2008, 33, 5941-5946. [CrossRef]

13. Hu, Y.-S.; Kleiman-Shwarsctein, A.; Stucky, G.D.; McFarland, E.W. Improved photoelectrochemical performance of Ti-doped $\alpha-\mathrm{Fe}_{2} \mathrm{O}_{3}$ thin films by surface modification with fluoride. Chem. Commun. 2009, 19, 2652-2654. [CrossRef] [PubMed]

14. Amano, F.; Li, D.; Ohtani, B. Fabrication and photoelectrochemical property of tungsten (VI) oxide films with a flake-wall structure. Chem. Commun. 2010, 46, 2769-2771. [CrossRef] [PubMed]

15. Sayama, K.; Nomura, A.; Zou, Z.; Abe, R.; Abe, Y.; Arakawa, H. Photoelectrochemical decomposition of water on nanocrystalline $\mathrm{BiVO}_{4}$ film electrodes under visible light. Chem. Commun. 2003, 2908-2909. [CrossRef]

16. Scaife, D. Oxide semiconductors in photoelectrochemical conversion of solar energy. Sol. Energy 1980, 25, 41-54. [CrossRef]

17. Abe, R.; Takata, T.; Sugihara, H.; Domen, $\mathrm{K}$. The use of $\mathrm{TiCl}_{4}$ treatment to enhance the photocurrent in a TaON photoelectrode under visible light irradiation. Chem. Lett. 2005, 34, 1162-1163. [CrossRef]

18. Kato, H.; Asakura, K.; Kudo, A. Highly efficient water splitting into $\mathrm{H}_{2}$ and $\mathrm{O}_{2}$ over lanthanum-doped $\mathrm{NaTaO}_{3}$ photocatalysts with high crystallinity and surface nanostructure. J. Am. Chem. Soc. 2003, 125, 3082-3089. [CrossRef] [PubMed]

19. Sasaki, Y.; Iwase, A.; Kato, H.; Kudo, A. The effect of co-catalyst for Z-scheme photocatalysis systems with an $\mathrm{Fe}^{3+} / \mathrm{Fe}^{2+}$ electron mediator on overall water splitting under visible light irradiation. J. Catal. 2008, 259, 133-137. [CrossRef]

20. Si, W.; Pergolesi, D.; Haydous, F.; Fluri, A.; Wokaun, A.; Lippert, T. Investigating the behavior of various cocatalysts on $\mathrm{LaTaON}_{2}$ photoanode for visible light water splitting. Phys. Chem. Chem. Phys. 2017, 19, 656-662. [CrossRef] [PubMed]

21. Feng, X.; LaTempa, T.J.; Basham, J.I.; Mor, G.K.; Varghese, O.K.; Grimes, C.A. $\mathrm{Ta}_{3} \mathrm{~N}_{5}$ nanotube arrays for visible light water photoelectrolysis. Nano Lett. 2010, 10, 948-952. [CrossRef] [PubMed]

22. Nishimura, N.; Raphael, B.; Maeda, K.; Le Gendre, L.; Abe, R.; Kubota, J.; Domen, K. Effect of $\mathrm{TiCl}_{4}$ treatment on the photoelectrochemical properties of $\mathrm{LaTiO}_{2} \mathrm{~N}$ electrodes for water splitting under visible light. Thin Solid Films 2010, 518, 5855-5859. [CrossRef]

23. Maeda, K.; Teramura, K.; Lu, D.; Takata, T.; Saito, N.; Inoue, Y.; Domen, K. Photocatalyst releasing hydrogen from water. Nature 2006, 440, 295. [CrossRef] [PubMed]

24. Wang, X.; Maeda, K.; Lee, Y.; Domen, K. Enhancement of photocatalytic activity of $\left(\mathrm{Zn}_{1+\mathrm{x}} \mathrm{Ge}\right)\left(\mathrm{N}_{2} \mathrm{O}_{\mathrm{x}}\right)$ for visible-light-driven overall water splitting by calcination under nitrogen. Chem. Phys. Lett. 2008, 457, 134-136. [CrossRef]

25. Siritanaratkul, B.; Maeda, K.; Hisatomi, T.; Domen, K. Synthesis and photocatalytic activity of perovskite niobium oxynitrides with wide visible-light absorption bands. ChemSusChem 2011, 4, 74-78. [CrossRef] [PubMed] 
26. Abe, R.; Higashi, M.; Domen, K. Facile fabrication of an efficient oxynitride TaON photoanode for overall water splitting into $\mathrm{H}_{2}$ and $\mathrm{O}_{2}$ under visible light irradiation. J. Am. Chem. Soc. 2010, 132, 11828-11829. [CrossRef] [PubMed]

27. Urabe, H.; Hisatomi, T.; Minegishi, T.; Kubota, J.; Domen, K. Photoelectrochemical properties of $\mathrm{SrNbO}_{2} \mathrm{~N}$ photoanodes for water oxidation fabricated by the particle transfer method. Faraday Discuss. 2015, 176, 213-223. [CrossRef] [PubMed]

28. Kuno, Y.; Tassel, C.; Fujita, K.; Batuk, D.; Abakumov, A.M.; Shitara, K.; Kuwabara, A.; Moriwake, H.; Watabe, D.; Ritter, C. ZnTaO $2 \mathrm{~N}$ : Stabilized high-temperature $\mathrm{LiNbO}_{3}$-type structure. J. Am. Chem. Soc. 2016, 138, 15950-15955. [CrossRef] [PubMed]

29. Hisatomi, T.; Katayama, C.; Moriya, Y.; Minegishi, T.; Katayama, M.; Nishiyama, H.; Yamada, T.; Domen, K. Photocatalytic oxygen evolution using $\mathrm{BaNbO}_{2} \mathrm{~N}$ modified with cobalt oxide under photoexcitation up to 740 nm. Energy Environ. Sci. 2013, 6, 3595-3599. [CrossRef]

30. Zhang, L.; Song, Y.; Feng, J.; Fang, T.; Zhong, Y.; Li, Z.; Zou, Z. Photoelectrochemical water oxidation of $\mathrm{LaTaON}_{2}$ under visible-light irradiation. Int. J. Hydrogen Energy 2014, 39, 7697-7704. [CrossRef]

31. Landsmann, S.; Maegli, A.E.; Trottmann, M.; Battaglia, C.; Weidenkaff, A.; Pokrant, S. Design guidelines for high-performance particle-based photoanodes for water splitting: Lanthanum titanium oxynitride as a model. ChemSusChem 2015, 8, 3451-3458. [CrossRef] [PubMed]

32. Arunachalam, P.; Al-Mayouf, A.; Ghanem, M.A.; Shaddad, M.N.; Weller, M.T. Photoelectrochemical oxidation of water using $\mathrm{La}(\mathrm{Ta}, \mathrm{Nb}) \mathrm{O}_{2} \mathrm{~N}$ modified electrodes. Int. J. Hydrogen Energy 2016, 41, 11644-11652. [CrossRef]

33. Maeda, $\mathrm{K}$.; Domen, $\mathrm{K}$. Water oxidation using a particulate $\mathrm{BaZrO}_{3}-\mathrm{BaTaO}_{2} \mathrm{~N}$ solid-solution photocatalyst that operates under a wide range of visible light. Angew. Chem. Int. Ed. 2012, 51, 9865-9869. [CrossRef] [PubMed]

34. Wang, J.; Wang, X.; Liu, B.; Li, X.; Cao, M. Facile synthesis of $\mathrm{SrNbO}_{2} \mathrm{n}$ nanoparticles with excellent visible-light photocatalytic performances. Mater. Lett. 2015, 152, 131-134. [CrossRef]

35. Konta, R.; Ishii, T.; Kato, H.; Kudo, A. Photocatalytic activities of noble metal ion doped $\mathrm{SrTiO}_{3}$ under visible light irradiation. J. Phys. Chem. B 2004, 108, 8992-8995. [CrossRef]

36. Arunachalam, P.; Ghanem, M.A.; Al-Mayouf, A.M.; Al-shalwi, M. Enhanced electrocatalytic performance of mesoporous nickel-cobalt oxide electrode for methanol oxidation in alkaline solution. Mater. Lett. 2017, 196, 365-368. [CrossRef]

37. Ghanem, M.A.; Al-Mayouf, A.M.; Arunachalam, P.; Abiti, T. Mesoporous cobalt hydroxide prepared using liquid crystal template for efficient oxygen evolution in alkaline media. Electrochim. Acta 2016, 207, 177-186. [CrossRef]

38. Theerthagiri, J.; Thiagarajan, K.; Senthilkumar, B.; Khan, Z.; Senthil, R.A.; Arunachalam, P.; Madhavan, J.; Ashokkumar, M. Synthesis of hierarchical cobalt phosphate nanoflakes and their enhanced electrochemical performances for supercapacitor applications. Chem. Select. 2017, 2, 201-210. [CrossRef]

39. Ai, G.; Mo, R.; Li, H.; Zhong, J. Cobalt phosphate modified $\mathrm{TiO}_{2}$ nanowire arrays as co-catalysts for solar water splitting. Nanoscale 2015, 7, 6722-6728. [CrossRef] [PubMed]

40. Jo, W.J.; Jang, J.W.; Kong, K.J.; Kang, H.J.; Kim, J.Y.; Jun, H.; Parmar, K.; Lee, J.S. Phosphate doping into monoclinic $\mathrm{BiVO}_{4}$ for enhanced photoelectrochemical water oxidation activity. Angew. Chem. Int. Ed. 2012, 51,3147-3151. [CrossRef] [PubMed]

41. Shaddad, M.N.; Ghanem, M.A.; Al-Mayouf, A.M.; Gimenez, S.; Bisquert, J.; Herraiz-Cardona, I. Cooperative catalytic effect of $\mathrm{ZrO}_{2}$ and $\alpha-\mathrm{Fe}_{2} \mathrm{O}_{3}$ nanoparticles on $\mathrm{BiVO}_{4}$ photoanodes for enhanced photoelectrochemical water splitting. ChemSusChem 2016, 9, 2779-2783. [CrossRef] [PubMed]

42. Kato, $\mathrm{H}$.; Kudo, A. Water splitting into $\mathrm{H}_{2}$ and $\mathrm{O}_{2}$ on alkali tantalate photocatalysts $\mathrm{ATaO}_{3}(\mathrm{~A}=\mathrm{Li}, \mathrm{Na}$, and K). J. Phys. Chem. B 2001, 105, 4285-4292. [CrossRef]

43. Chen, Y.; Liang, S.; Wen, L.; Wu, W.; Yuan, R.; Wang, X.; Wu, L. A TaON nano-photocatalyst with low surface reduction defects for effective mineralization of chlorophenols under visible light irradiation. Phys. Chem. Chem. Phys. 2013, 15, 12742-12747. [CrossRef] [PubMed]

44. Ma, X.; Chen, Y.; Li, H.; Cui, X.; Lin, Y. Annealing-free synthesis of carbonaceous $\mathrm{Nb}_{2} \mathrm{O}_{5}$ microspheres by flame thermal method and enhanced photocatalytic activity for hydrogen evolution. Mater. Res. Bull. 2015, 66, 51-58. [CrossRef]

45. Li, P.; Jin, Z.; Xiao, D. A one-step synthesis of Co-P-B/rGO at room temperature with synergistically enhanced electrocatalytic activity in neutral solution. J. Mater. Chem. A 2014, 2, 18420-18427. [CrossRef] 
46. Pilli, S.K.; Furtak, T.E.; Brown, L.D.; Deutsch, T.G.; Turner, J.A.; Herring, A.M. Cobalt-phosphate (Co-Pi) catalyst modified Mo-doped $\mathrm{BiVO}_{4}$ photoelectrodes for solar water oxidation. Energy Environ. Sci. 2011, 4, 5028-5034. [CrossRef]

47. McAlpin, J.G.; Surendranath, Y.; Dinca, M.; Stich, T.A.; Stoian, S.A.; Casey, W.H.; Nocera, D.G.; Britt, R.D. EPR evidence for Co (IV) species produced during water oxidation at neutral pH. J. Am. Chem. Soc. 2010, 132, 6882-6883. [CrossRef] [PubMed]

48. Butler, M.; Ginley, D. Prediction of flatband potentials at semiconductor-electrolyte interfaces from atomic electronegativities. J. Electrochem. Soc. 1978, 125, 228-232. [CrossRef]

49. Rooke, J.; Weller, M. Synthesis and characterisation of perovskite-type oxynitrides. Sol. State Phenom. 2003, 90, 417-422. [CrossRef]

(C) 2018 by the authors. Licensee MDPI, Basel, Switzerland. This article is an open access article distributed under the terms and conditions of the Creative Commons Attribution (CC BY) license (http:/ / creativecommons.org/licenses/by/4.0/). 

Article

\title{
In-Situ Synthesis of Hydrogen Titanate Nanotube/Graphene Composites with a Chemically Bonded Interface and Enhanced Visible Photocatalytic Activity
}

\author{
Juan Yang ${ }^{1,2, *}$, Jun You ${ }^{1}$, Jun Dai ${ }^{1}$, Yumei Chen ${ }^{2, *}$ and Yao $\mathrm{Li}^{1}$ \\ 1 Institute of Chemical Safety, School of Safety Science and Engineering, Henan Polytechnic University, \\ Jiaozuo 454003, China; youjunhpu@163.com (J.Y.); daijun@hpu.edu.cn (J.D.); leayao35@hpu.edu.cn (Y.L.) \\ 2 Institute of Applied Chemistry, College of Chemistry and Chemical Engineering, Henan Polytechnic \\ University, Jiaozuo 454003, China \\ * Correspondence: yangjuanhpu@163.com (J.Y.); chenyumei@hpu.edu.cn (Y.C.); Tel.: +86-391-398-7881 (J.Y.)
}

Received: 21 March 2018; Accepted: 6 April 2018; Published: 8 April 2018

\begin{abstract}
Hydrogen titanate nanotube (HTT)/graphene nanocomposites are synthesized by hydrothermal reduction of graphene oxide (GO) and simultaneous preparation of nanotubular HTT via an alkaline hydrothermal process. By using this facile in-situ compositing strategy, HTT are densely supported upon the surface of graphene sheets with close interface contacts. The as-prepared HTT/graphene nanocomposites possess significantly enhanced visible light catalytic activity for the partial oxidation of benzylic alcohols. The amount of graphene has significant influence on catalytic activity and the optimal content of graphene is $1.0 \mathrm{wt} \%$, giving a normalized rate constant $k$ of $1.71 \times 10^{-3} \mathrm{~g} / \mathrm{m}^{2} \cdot \mathrm{h}$, which exceeds that of pure HTT and HTT/graphene- $1.0 \%$ mixed by a factor of 7.1 or 5.2. Other than the general role of graphene as a high-performance electron acceptor or transporter, the observed enhancement in photocatalytic activity over HTT/graphene can be ascribed to the improved interfacial charge migration from enhanced chemical bonding (Ti-C bonds) during the in-situ compositing process. The formation of Ti-C bonds is confirmed by XPS analysis and the resulting enhanced separation of photoinduced charge carriers is demonstrated by electrochemical impedance spectra and transient photocurrent response.
\end{abstract}

Keywords: photocatalytic selective oxidation; Ti-C bonds; hydrogen titanate; benzylic alcohols; interfacial charge transfer

\section{Introduction}

In the last several decades, the photocatalytic process in semiconductors has been attracting more and more attention as an advanced green technology for contaminant purification, energy production, and selective organic synthesis [1-3]. The effectiveness of photocatalysis is primarily dependent on three aspects: optical absorption, charge separation, and catalytic reaction upon the surface of the semiconductor catalyst. Further research shows only a small part of photoinduced charges can migrate successfully to the surface of catalysts and initiate catalytic reactions. As a result, the efficient charge transfer on the surface of a semiconductor photocatalyst is widely considered to be very critical, being an elementary process related to photocatalytic application.

Among various photocatalysts, $\mathrm{TiO}_{2}$-derived nanosized materials appear to be a potential candidate, owing largely to their excellent performance, long term stability, low toxicity, and cost $[4,5]$. In the field of photocatalysis, hydrogen titanate (HT), especially nanotubular HT has been principally used to fabricate diverse $\mathrm{TiO}_{2}$ nanostructures, such as $\mathrm{TiO}_{2}$ nanotubes, nanowires, and nanofibers [6-8]. Their unique one-dimensional structural characteristics provide the preconditions necessary for 
suitable catalysts under ultraviolet or visible illumination $[9,10]$. For example, HT calcined at $300-500{ }^{\circ} \mathrm{C}$, possessing $\mathrm{TiO}_{2}$ (B) or anatase phase, exhibits higher catalytic performance for pollutant degradation than $\mathrm{P}_{2}-\mathrm{TiO}_{2}[11,12]$. However, the inherently rapid recombination of photogenerated charge carriers within $\mathrm{TiO}_{2}$ or titanate remains problematic. Numerous strategies have been studied to tailor the photocatalytic process and promote catalytic performance. Particularly, fabrication of carbon-titanate heterojunction composites has been identified as one of the most feasible strategies to enhance the separation of electron-hole pairs [13-15].

Owing to the great surface area of graphene and its excellent electronic transport properties, many studies have been carried out on fabricating composite catalysts of graphene and semiconductor particles in an attempt to promote photocatalytic activity $[16,17]$. Under light illumination, it is found that photoinduced electrons migrate from photocatalysts to the surface of graphene and suppress the recombination of electron-hole pairs, thereby enhancing the oxidative or reductive reactivity of the photocatalytic process [18]. Further research demonstrated that the interfacial action between the semiconductor and graphene can notably influence the interfacial electron migration, which is thought to be a critical step of heterogeneous photocatalysis [19-22]. Zhang et al. have reported the synthesis of graphene- $\mathrm{Bi}_{2} \mathrm{WO}_{6}$ composites with strong covalent bonding between graphene and $\mathrm{Bi}_{2} \mathrm{WO}_{6}$ nanoparticles. The improved photocatalytic performance for $\mathrm{H}_{2}$ and $\mathrm{O}_{2}$ production were ascribed to the efficient electron migration and separation of photoinduced charge carriers through the chemically bonded interaction [20]. Xie et al. have recently reported the existence of a chemically bonded interface, via the formation of C-Ti bonds, between graphene sheets and $\mathrm{TiO}_{2}$ nanoparticles. This chemical bonding effect plays a pivotal role in the interfacial electron migration, which makes $\mathrm{TiO}_{2}$ /graphene composites possess an outstanding catalytic activity for the photo-oxidation of formaldehyde, compared to a mechanically mixed sample [22].

The selective oxidation of alcohol to carbonyl compounds is a significant chemical conversion process. Generally, the partial oxidations of alcohols are implemented with hazardous or toxic stoichiometric oxidants under high temperature and pressure conditions [23]. Deteriorating environmental problems caused by chemical production processes have compelled us to seek green and economic alternative reaction systems. Recently, photocatalysis-based organic synthesis reactions have attracted wide concerns because they can be carried out using green oxidants (such as molecular oxygen) and solar energy under ambient temperature or pressure $[3,24,25]$. Several types of catalysts have been studied to achieve photocatalytic conversion of alcohols to the corresponding carbonyl compounds, including g- $\mathrm{C}_{3} \mathrm{~N}_{4}, \mathrm{HNb}_{3} \mathrm{O}_{8}$ nanosheets, $\mathrm{CdS}$, and $\mathrm{TiO}_{2}$-based composites [24,26-28]. What's more, the selective oxidation of alcohols can be performed over $\mathrm{TiO}_{2}$ catalysts using visible light, although the photocatalysts themselves and the reactants can only absorb UV light [26,27]. In our previous report, hydrogen titanate (HT) nanotubes exhibited much higher visible light catalytic performance toward partial oxidation of benzylic alcohols, compared with HT nanosheets and nanofibers [28]. The superior photo-activity of HT nanotubes is primarily ascribed to their one-dimensional structural features, which include a high surface area, abundant unsaturated Ti sites, and efficient charge migration. Developing composite photocatalysts of HT nanotubes and graphene through an in-situ synthetic strategy can further improve catalytic performance for the selective oxidation of alcohols.

However, previously reported research on photocatalytic selective synthesis principally focused on reaction systems using $\mathrm{TiO}_{2}$ or $\mathrm{TiO}_{2}$ nanohybrids as photocatalysts [29-31]. The photocatalytic studies on titanate/graphene nanocomposites have largely focused on removing organic pollutants and splitting $\mathrm{H}_{2} \mathrm{O}$ for hydrogen production [32,33], whereas the selective chemical conversion using titanate/graphene composite photocatalysts has been scarcely researched. Furthermore, studies on the effects of chemical bonding on interfacial charge transfer and catalytic activity of titanate/graphene nanocomposites for photocatalytic partial oxidation of alcohols are also lacking.

In this paper, HT nanotube (HTT)/graphene nanohybrids with numerous heterogeneous interfaces are prepared via a facile hydrothermal method under basic conditions. Due to their 
one-dimensional structural characteristics, HT nanotubes can be uniformly coupled onto graphene to form close interfacial contacts. The presence of chemical Ti-C bonds between nanotubular HT and graphene are confirmed by XPS analysis. The HTT/graphene nanocomposites with chemically bonded interfaces exhibit exceptional photocatalytic reactivity toward the partial oxidation of benzylic alcohols under visible illumination. The influence of graphene content on the catalytic performance is investigated and a possible mechanism based on the experimental results is also proposed.

\section{Materials and Methods}

\subsection{Materials}

Graphite was purchased from Nanjing XFNANO Materials Tech Co., Ltd. (Nanjing, China). $\mathrm{KMnO}_{4}, \mathrm{H}_{2} \mathrm{SO}_{4}, \mathrm{H}_{3} \mathrm{PO}_{4}, \mathrm{H}_{2} \mathrm{O}_{2}(30 \%), \mathrm{NaOH}, \mathrm{P} 25 \mathrm{TiO}_{2}$, and ethanol were obtained from Aladdin Industrial Inc. (Shanghai, China). Benzyl alcohol and its derivatives were purchased from J\&K Scientific Ltd. (Beijing, China). 5,5-Dimethyl-1-pyrroline-N-oxide was obtained from TCI Development Ltd. (Shanghai, China). All the other chemicals were of analytical reagent grade and used as received without further purification. Deionized water was obtained using a Millipore Milli-Q system and used throughout the experiments.

\subsection{Synthesis of HTT/Graphene Nanohybrids}

To improve the hydrophilic and oxidation degree of graphite, a modified method was used to prepare graphite oxide [34]. In brief, a mixed solution of concentrated $\mathrm{H}_{2} \mathrm{SO}_{4} / \mathrm{H}_{3} \mathrm{PO}_{4}$ (volume ratio, 9:1) was added into a mixture of squama graphite and $\mathrm{KMnO}_{4}$ (weight ratio, 1:6). Then, the obtained mixture was heated for $12 \mathrm{~h}$ at $323 \mathrm{~K}$ under magnetic stirring. After being cooled down to room temperature, the mixture was poured into an icy solution of $30 \% \mathrm{H}_{2} \mathrm{O}_{2}$. The solid was recycled by filtration, washed by deionized water, and vacuum-dried at $298 \mathrm{~K}$ for $12 \mathrm{~h}$. The obtained graphite oxide (GO) was dispersed in water $(0.5 \mathrm{mg} / \mathrm{mL})$ and subjected to sonication for $60 \mathrm{~min}$ to form an aqueous dispersion of exfoliated GO.

In a typical synthesis process for HTT/graphene nanohybrids, $1.3 \mathrm{~g}$ of $\mathrm{P}_{2} 5 \mathrm{TiO}_{2}$ was added to $65 \mathrm{~mL}$ of concentrated $\mathrm{NaOH}$ solution $(10.0 \mathrm{M})$ and was stirred for $30 \mathrm{~min}$ to form a uniform suspension. Then, a specific amount of GO dispersion was added to the above-obtained suspension under magnetic stirring. The weight ratios of $\mathrm{GO}$ to $\mathrm{P} 25 \mathrm{TiO}_{2}$ were $0,0.2,0.4,1.0,2.0$, and $4.0 \%$, and the as-prepared samples are labeled as HTT/graphene- $\mathrm{x} \%$, where $\mathrm{x}$ refers to the mentioned weight ratios. After further stirring for $90 \mathrm{~min}$, the mixture was transferred into a $100 \mathrm{~mL}$ stainless steel autoclave and heated at $160{ }^{\circ} \mathrm{C}$ for $12 \mathrm{~h}$. The obtained precipitate was separated by centrifugation, washed by deionized water, and re-dispersed for several cycles until a $\mathrm{pH}$ value of nearly 8 was obtained. The precipitate was finally washed with absolute ethanol and dried at $90{ }^{\circ} \mathrm{C}$ for $10 \mathrm{~h}$ to obtain HTT/graphene-x\% nanocomposites.

For comparison, bare HTT and graphene samples were prepared using a similar process without GO or P25 $\mathrm{TiO}_{2}$ and $\mathrm{NaOH}$ solution. About $10 \mathrm{mg}$ of graphene was added into $50 \mathrm{~mL}$ of deionized water and sonicated for $1 \mathrm{~h}$. Then $1.0 \mathrm{~g}$ of as-made HTT was mixed into the graphene suspension under magnetic stirring. After being stirred for $2 \mathrm{~h}$, the homogeneous suspension was treated by centrifugation. The precipitate was washed with deionized water and dried in a vacuum oven at $90{ }^{\circ} \mathrm{C}$ for $10 \mathrm{~h}$. The as-obtained product is denoted as HTT/graphene- $1.0 \%$-mixed. For the preparation of the $\mathrm{P} 25 \mathrm{TiO}_{2} /$ graphene- $1.0 \%$ composite, $1.0 \mathrm{~g}$ of $\mathrm{P} 25 \mathrm{TiO}_{2}$ was added to $65 \mathrm{~mL}$ of deionized water and stirred for $30 \mathrm{~min} .10 \mathrm{~mL}$ of $\mathrm{GO}$ dispersion $(1.0 \mathrm{mg} / \mathrm{mL})$ was added into P25 $\mathrm{TiO}_{2}$ suspension under magnetic stirring. After further stirring for $90 \mathrm{~min}$, the mixture was transferred into a $100 \mathrm{~mL}$ Teflon-lined autoclave and heated at $160{ }^{\circ} \mathrm{C}$ for $12 \mathrm{~h}$. The obtained precipitate was washed with deionized water and dried at $90{ }^{\circ} \mathrm{C}$ overnight. The as-synthesized sample is named as P25 $\mathrm{TiO}_{2}$ /graphene-1.0\%. 


\subsection{Characterization}

X-ray diffraction measurements were conducted using a D8 Advance diffractometer (Bruker) with $\mathrm{Cu} \mathrm{K} \alpha$ radiation $(\lambda=0.15418 \mathrm{~nm})$. Raman spectra were recorded on a Labram HR 800 Raman spectrometer (Horiba Jobin Yvon, Paris, France) using $532 \mathrm{~nm}$ excitation light at room temperature. The morphological features of HTT/graphene nanohybrids were observed by a transmission electron microscope (TEM, Tecnai G20, FEI, Hillsboro, WA, USA) operating at $200 \mathrm{kV}$. FTIR spectra were acquired with a Nicolet 750 FTIR spectrometer in the range $400-4000 \mathrm{~cm}^{-1}$. X-ray photoelectron spectra were recorded using a Thermo Scientific ECALAB 250xi system with a monochromated Al Ka X-ray source. UV-visible diffuse reflectance spectra were collected on a UV-vis spectrophotometer (UV-2550, Shimadzu, Kyoto, Japan) using $\mathrm{BaSO}_{4}$ as the reflectance standard. The specific surface area of as-synthesized samples were measured by $\mathrm{N}_{2}$ adsorption-desorption with a Micrometrics ASAP 2020 apparatus.

Photoelectrochemical experiments were performed in a standard three-electrode system. Platinum foil and $\mathrm{Ag} / \mathrm{AgCl}$ were used as the counter and reference electrodes, respectively. The working electrode was prepared by the following method: $40 \mathrm{mg}$ of powder sample was dispersed in $0.2 \mathrm{~mL}$ of polyethylene glycol solution and ultrasonicated for $45 \mathrm{~min}$ to obtain a uniform slurry. The resulting slurry was then spread on a fluorine doped tin oxide (FTO) conducting glass and was dried at $90{ }^{\circ} \mathrm{C}$ to get HTT/graphene/FTO electrodes. The photocurrent was recorded at a bias voltage of $0.6 \mathrm{~V}$ on an electrochemical workstation (CHI-660C, Shanghai, China). The electrolyte was $0.1 \mathrm{M} \mathrm{LiClO}_{4}$ and nitrogen gas was continuously purged through the electrolyte solution. After being immersed in a benzyl alcohol solution for $1.5 \mathrm{~h}$, the working electrode was irradiated using a $300 \mathrm{~W}$ Xe lamp with a $400 \mathrm{~nm}$ cut-off filter. Electrochemical impedance spectra (EIS) were measured using the above-mentioned three-electrode cell at $0.0 \mathrm{~V}$ with $0.1 \mathrm{M} \mathrm{Na}_{2} \mathrm{SO}_{4}$ aqueous solution. Electron spin resonance (ESR) signals of the radicals trapped by DMPO were collected on a Bruker ER200-SRC spectrometer at ambient temperature.

\subsection{Photocatalytic Experiment of Alcohol Oxidation}

The partial conversion of benzyl alcohol was performed in a $20 \mathrm{~mL}$ round-bottom quartz glass flask. Benzyl alcohol ( $0.25 \mathrm{mmol})$ and the photocatalyst $(50 \mathrm{mg})$ were dispersed into $5 \mathrm{~mL}$ of acetonitrile and the obtained mixture was bubbled with $\mathrm{O}_{2}$ for $30 \mathrm{~min}$. This suspension was stirred magnetically for another $60 \mathrm{~min}$ to reach the adsorption-desorption equilibrium of the reactant alcohols and catalysts. The mixture was then irradiated using a $300 \mathrm{~W}$ Xe lamp with $400 \mathrm{~nm}$ cut-off filter under ambient temperature. At certain time intervals, a $0.5 \mathrm{~mL}$ mixture was withdrawn and filtered using a Millipore filter (pore size $0.45 \mu \mathrm{m}$ ) to remove the catalyst particles. The concentration changes of reactants in the remaining filtrate were quantitatively analyzed on a gas chromatograph (Agilent 7890) equipped with a standard FID detector and a DM-5 amine capillary column. Oxidation products were identified by comparing the retention times with the standards and further confirmed with GC-MS.

\subsection{Radical Scavenging Experiments}

In order to elucidate the photocatalytic mechanism, control experiments using different radical scavengers (tert-butyl alcohol, triethanolamine, and benzoquinone as the scavenger for the hydroxyl, photogenerated hole, and superoxide radicals, respectively) were performed via an analogous process of benzyl alcohol photo-oxidation, except that the radical scavenger $(0.2 \mathrm{mmol})$ was included. The primary role of the active species were revealed by analyzing the changes of the benzyl alcohol conversion yield. 


\section{Results and Discussion}

\subsection{XRD, FTIR and Raman Spectra}

Figure 1 shows the XRD patterns of as-synthesized samples including blank HTT and nanocomposites of HTT/graphene with different contents of graphene. Broad diffraction peaks are observed at $2 \theta=10.7^{\circ}, 24.7^{\circ}, 29.0^{\circ}$, and $48.5^{\circ}$, which can be assigned to the characteristic crystalline phase peaks of layered hydrogen titanate [13,35]. For the sample of pure GO (inset of Figure 1), the diffraction peak at $2 \theta=10.5^{\circ}$ corresponds to the (002) reflection of stacked GO sheets. Additionally, pure reduced GO obtained in the absence of HTT indicates a broad (002) graphene reflection at 26.5 , which clearly demonstrates the conversion of GO to graphene [36]. However, in comparison with the XRD patterns of GO and graphene (inset of Figure 1), no diffraction peaks belonging to GO or graphene are observed in the XRD spectra of HTT/graphene nanocomposites. It is hard to distinguish the characteristic peak at $2 \theta=10.5^{\circ}$ of pure GO and the broad peak at $2 \theta=10.7^{\circ}$ assigned to (200) crystallographic planes of hydrogen titanate. The absence of these peaks might also be due to the low weight content and weak diffraction intensity of GO and graphene.

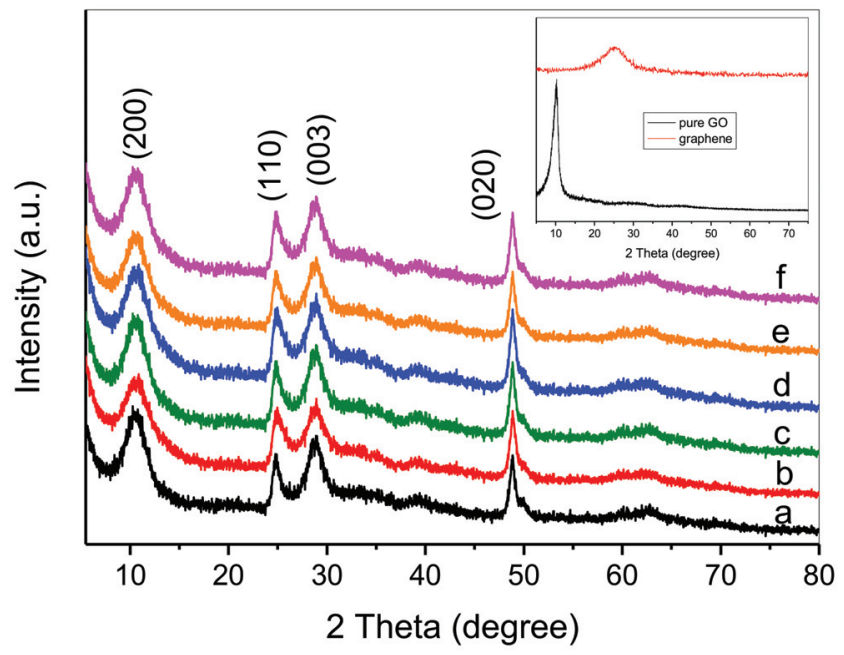

Figure 1. XRD patterns of hydrogen titanate nanotube (HTT)/graphene nanocomposites: (a) pure HTT, (b) HTT/graphene- $0.2 \%$, (c) HTT/graphene- $0.4 \%$, (d) HTT/graphene- $1.0 \%$, (e) HTT/graphene- $2.0 \%$, (f) HTT/graphene- $4.0 \%$. Inset: XRD patterns of pure GO and graphene.

The presence of graphene in the HTT/graphene nanocomposites could be confirmed using FTIR spectra (Figure 2). Bare GO exhibits several characteristic peaks belonging to oxygen functional groups, such as $\mathrm{C}=\mathrm{O}$ stretching at $1723 \mathrm{~cm}^{-1}, \mathrm{O}-\mathrm{H}$ deformation at $1389 \mathrm{~cm}^{-1}, \mathrm{C}-\mathrm{OH}$ stretching at $1220 \mathrm{~cm}^{-1}$, and $\mathrm{C}-\mathrm{O}$ stretching at $1053 \mathrm{~cm}^{-1}[20,34]$. Compared with that of bare GO, the spectrum of HTT/graphene-1.0\% shows a significant decline in intensity for peaks associated with oxygen-containing groups (i.e., $\mathrm{C}=\mathrm{O}, \mathrm{O}-\mathrm{H}, \mathrm{C}-\mathrm{OH}$, and $\mathrm{C}-\mathrm{O}$ ), indicating that $\mathrm{GO}$ in the composites is reduced. Additionally, the strong absorption band centered at $490 \mathrm{~cm}^{-1}$ can be assigned to the Ti-O-Ti stretching vibration in the pure HTT sample. A slight blue shift can be observed in the FTIR spectrum of HTT/graphene- $1.0 \%$ (centered at $502 \mathrm{~cm}^{-1}$ ), suggesting an interfacial interaction between graphene and HTT in the nanocomposites.

Raman spectroscopy is also widely employed to characterize the electronic structure of carbon products. Two bands are observed in the $850-2000 \mathrm{~cm}^{-1}$ range for GO and HTT/graphene 
nanocomposites, as shown in Figure 3. They are the D band and G band of carbonaceous materials [36]. The former denotes a common characteristic of carbon $\mathrm{sp}^{3}$ defects, and the latter gives information about the in-plane vibrations of $\mathrm{sp}^{2}$ bonded carbon [21,34]. The intensity ratio between $\mathrm{D}$ band and $\mathrm{G}$ band $\left(I_{\mathrm{D}} / I_{\mathrm{G}}\right)$ represents the relative concentration of defects in $\mathrm{GO}$ or graphene. Compared with bare GO, the calculated $I_{\mathrm{D}} / I_{\mathrm{G}}$ of the HTT/graphene composites are lower, demonstrating a lower concentration of defects in graphene. The decreased $I_{\mathrm{D}} / I_{\mathrm{G}}$ ratios in HTT/graphene nanohybrids imply the employed hydrothermal process facilitates the formation of more graphene without reducing the average size of $\mathrm{sp}^{2}$ domains. Furthermore, it is worth noting that a $\mathrm{G}$ band up-shift from 1588 to $1596 \mathrm{~cm}^{-1}$ is observed for HTT/graphene compared with GO and graphene, which gives evidence for chemical bonding of carbon materials $[37,38]$. The results indicate significant interaction between graphene and HTT, consistent with the results of the FTIR investigation.

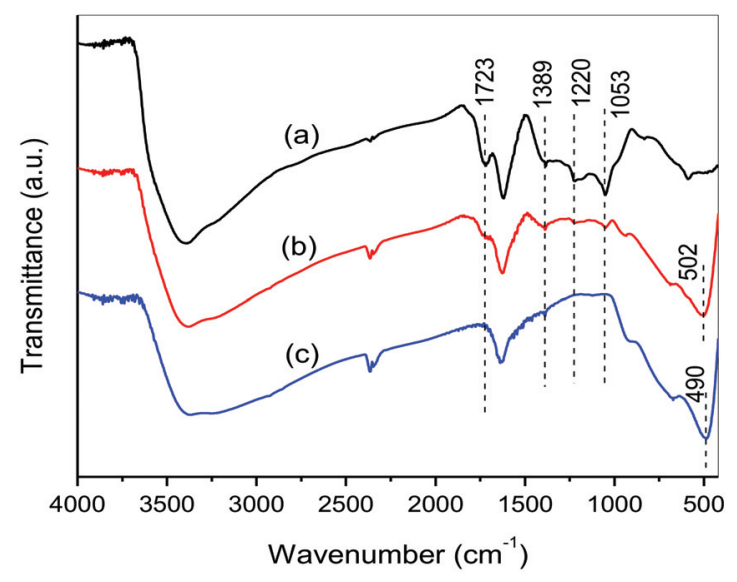

Figure 2. FTIR spectra of samples (a) GO, (b) HTT/graphene-1.0\%, and (c) pure HTT.

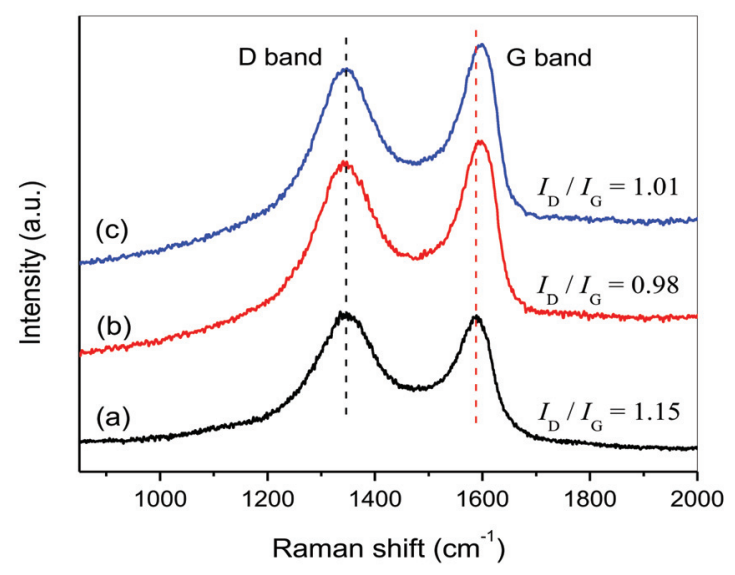

Figure 3. Raman spectra of (a) bare GO, (b) HTT/graphene-1.0\%, and (c) HTT/graphene-4.0\% composites. 


\subsection{TEM and Brunauer-Emmett-Teller (BET) Surface Area Analyses}

The morphologies of HTT/graphene composites can be observed by TEM, as shown in Figure 4 . Pure HTT exhibit a tubular framework structure, although, occasionally the aggregation of HTT can be seen (Figure 4a). Upon introducing GO, HTT are anchored onto the graphene sheets after hydrothermal treatment (Figure $4 \mathrm{~b}$ ). The surfaces of graphene sheets are covered by interconnected networks of HT nanotubes. The introduced GO acts as a substrate of the tightly packed HTT. It is noted from Figure $4 b$, that HTT occupy most of the available surface of graphene, leading to high loading amounts of HTT in as-synthesized nanocomposites. Compared to HTT/graphene- $1.0 \%$ obtained via the in-situ synthesis strategy, the HTT/graphene- $1.0 \%$-mixed sample, prepared by the mechanically mixing of HTT and graphene, exhibits an inhomogeneous distribution of HTT on graphene, as shown in Figure 4c. These results demonstrate that the oxygen-containing functional groups of GO facilitate the nucleation and growth of HTT upon the graphene surface. It is beneficial for HTT to anchor directly on graphene sheets, consequently forming a uniform distribution and close interfacial contact between HTT and graphene.
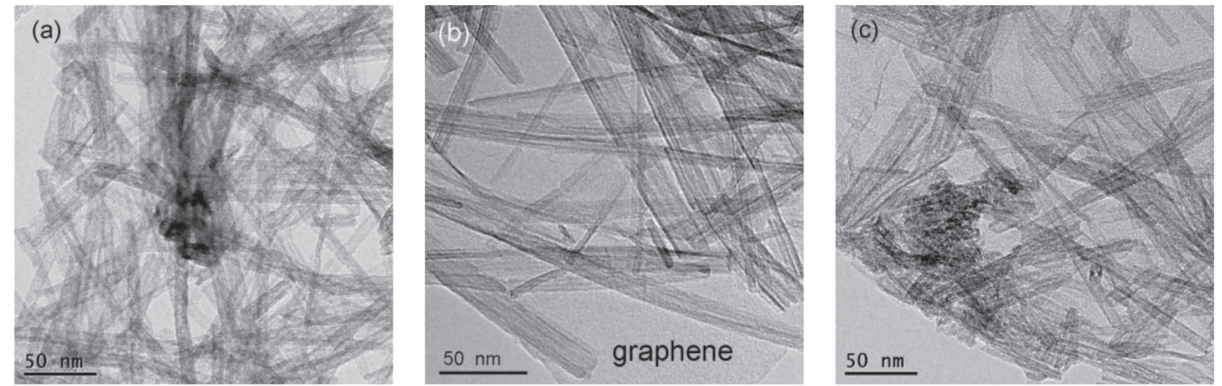

Figure 4. Typical TEM images of (a) pure HTT, (b) HTT/graphene-1.0\%, and (c) HTT/graphene-1.0\%mixed nanocomposites.

$\mathrm{N}_{2}$ adsorption-desorption experiments were used to investigate the textual properties of the as-synthesized nanocomposites. The specific surface area, $\mathrm{S}_{\mathrm{BET}}$ was calculated according to the classical Brunauer-Emmett-Teller (BET) theory and the corresponding data are summarized in Table 1. Table 1 indicates that all of the HTT/graphene composite samples possess larger $\mathrm{S}_{\mathrm{BET}}$ than bare HTT, which is due to the huge surface area of graphene [20]. Additionally, the BET surface area of HTT/graphene hybrids increases with an increasing amount of graphene, reconfirming the influence of graphene in improving the total surface area of HTT/graphene samples. For instance, $\mathrm{S}_{\mathrm{BET}}$ increases from 228.9 to $248.0 \mathrm{~m}^{2} \cdot \mathrm{g}^{-1}$ when the content of graphene increases from $0.2 \%$ to $4.0 \%$ for as-synthesized $\mathrm{HTT} /$ graphene composites. There is no doubt that the enhanced $\mathrm{S}_{\mathrm{BET}}$ can provide more surface active sites and facilitate the adsorption of the reactants, thus promoting heterogeneous catalytic reactions.

Table 1. Brunauer-Emmett-Teller (BET) surface area of as-prepared HTT/graphene composites and $S_{\mathrm{BET}}$ normalized rate constants $k$ for the selective oxidation of benzyl alcohol.

\begin{tabular}{ccccc}
\hline Catalyst & $\begin{array}{c}\text { BET Surface } \\
\text { Area } / \mathbf{m}^{\mathbf{2}} \cdot \mathbf{g}^{-\mathbf{1}}\end{array}$ & Conv./\% & $\begin{array}{c}\text { Rate Constant } \\
\boldsymbol{k} / \mathbf{h}^{-\mathbf{1}}\end{array}$ & $\begin{array}{c}\boldsymbol{S}_{\text {BET Normalized }} \\
\text { Rate Constants } \boldsymbol{k}\end{array}$ \\
\hline pure HTT & 225.1 & 27.6 & 0.053 & $0.24 \times 10^{-3}$ \\
HTT/graphene- $0.2 \%$ & 228.9 & 57.1 & 0.141 & $0.61 \times 10^{-3}$ \\
HTT/graphene- $0.4 \%$ & 234.4 & 78.0 & 0.252 & $1.08 \times 10^{-3}$ \\
\hline
\end{tabular}


Table 1. Cont.

\begin{tabular}{ccccc}
\hline Catalyst & $\begin{array}{c}\text { BET Surface } \\
\text { Area/ } \mathbf{m}^{\mathbf{2}} \cdot \mathbf{g}^{-\mathbf{1}}\end{array}$ & Conv./\% & $\begin{array}{c}\text { Rate Constant } \\
\boldsymbol{k}^{\mathbf{h}} \mathbf{h}^{-\mathbf{1}}\end{array}$ & $\begin{array}{c}\boldsymbol{S}_{\text {BET Normalized }} \\
\text { Rate Constants } \boldsymbol{k}\end{array}$ \\
\hline HTT/graphene-1.0\% & 240.5 & 91.8 & 0.411 & $1.71 \times 10^{-3}$ \\
HTT/graphene-2.0\% & 244.7 & 69.2 & 0.195 & $0.80 \times 10^{-3}$ \\
HTT/graphene-4.0\% & 248.0 & 43.8 & 0.097 & $0.39 \times 10^{-3}$ \\
HTT/graphene-1.0\%-mixed & 233.6 & 32.3 & 0.078 & $0.33 \times 10^{-3}$ \\
\hline
\end{tabular}

Reaction conditions: catalyst $50 \mathrm{mg}$, benzylic alcohol $0.25 \mathrm{mmol}$, acetonitrile $5 \mathrm{~mL}$, reaction temperature $298 \mathrm{~K}$, visible light irradiation $6 \mathrm{~h}$.

\subsection{XPS Analysis}

The interactions between HTT and graphene are further studied by XPS. The high-resolution $\mathrm{C} 1 \mathrm{~s}$ XPS spectrum of bare GO is shown in Figure 5a. Two characteristic peaks can be observed at 285.0 and $287.1 \mathrm{eV}$, which correspond to adventitious carbon or sp²-hybridized carbon of GO and the oxygen-containing carbonaceous bands $(\mathrm{C}-\mathrm{OH})[20,39]$. These oxygen-containing bands can provide active anchoring sites for HTT growth. The C 1s spectrum of the HTT/graphene-1.0\%-mixed sample is deconvoluted into three peaks at binding energies of $284.6,286.5$, and $288.6 \mathrm{eV}$. The $\mathrm{C} 1 \mathrm{~s}$ peaks located at 284.6 and $286.5 \mathrm{eV}$ can be assigned to $\mathrm{C}-\mathrm{O}$ or $\mathrm{C}=\mathrm{O}$ groups (Figure $5 \mathrm{~b}$ ). The relative weak peak at $288.6 \mathrm{eV}$ belongs to the $\mathrm{O}=\mathrm{C}-\mathrm{O}$ group. These results indicate that the $-\mathrm{OH}$ groups of HTT are likely to interact with the surface $-\mathrm{COOH}$ groups of $\mathrm{GO}$ via forming $\mathrm{O}=\mathrm{C}-\mathrm{O}$ bonds. Additionally, it can be seen the peak at $287.1 \mathrm{eV}$, belonging to the $\mathrm{C}-\mathrm{OH}$ groups of $\mathrm{GO}$, decreases significantly or disappears in the C 1s XPS spectra of HTT/graphene composites. This further demonstrates the successful reduction of GO to graphene through the hydrothermal process. The $\mathrm{C} 1 \mathrm{~s}$ spectrum of in-situ synthesized HTT/graphene-1.0\% can be deconvoluted into four peaks (Figure 5c). Besides the three peaks at 284.6, 286.5, and $288.6 \mathrm{eV}-$ belonging to the $\mathrm{C}-\mathrm{C}, \mathrm{C}-\mathrm{O}$, and $\mathrm{O}=\mathrm{C}-\mathrm{O}$ groups-another shoulder peak centered at $283.2 \mathrm{eV}$ is observed, which is attributed to forming chemical bonds (Ti-C) between carbon atoms and titanium atoms in the lattice of HTT. This is the first report on the formation of Ti-C bonds in nanocomposites of hydrogen titanate and graphene. The intimate interfacial contacts originated from the chemical bonding would benefit the migration of photogenerated charges and thus improve the photocatalytic activity of HTT.

Forming Ti-C bonds is also investigated and identified by analyzing the Ti $2 p$ XPS spectra of the HTT/graphene nanocomposites. As depicted in Figure $6 \mathrm{a}$, in the Ti $2 \mathrm{p}$ spectrum of HTT/graphene-1.0\%-mixed, two peaks are observed at binding energies of 464.4 and $458.7 \mathrm{eV}$. These peaks can be attributable to the Ti $2 \mathrm{p}_{1 / 2}$ and Ti $2 \mathrm{p}_{3 / 2}$ spin-orbital splitting photoelectrons of $\mathrm{Ti}^{4+}$. Two bands at binding energies of 463.3 and $457.7 \mathrm{eV}$ usually correspond to $\mathrm{Ti}^{3+}[21,36]$. In Figure $6 \mathrm{~b}$, besides the above-mentioned four characteristic peaks belonging to $\mathrm{Ti}^{4+}$ and $\mathrm{Ti}^{3+}$ in HTT, two other weak peaks located at 465.3 and $459.4 \mathrm{eV}$ are found and are likely due to the forming of Ti-C bonds in the HTT/graphene nanohybrids. This suggests that a chemical interaction between HTT and graphene is present in as-synthesized HTT/graphene composites and absent in the mixed samples. 

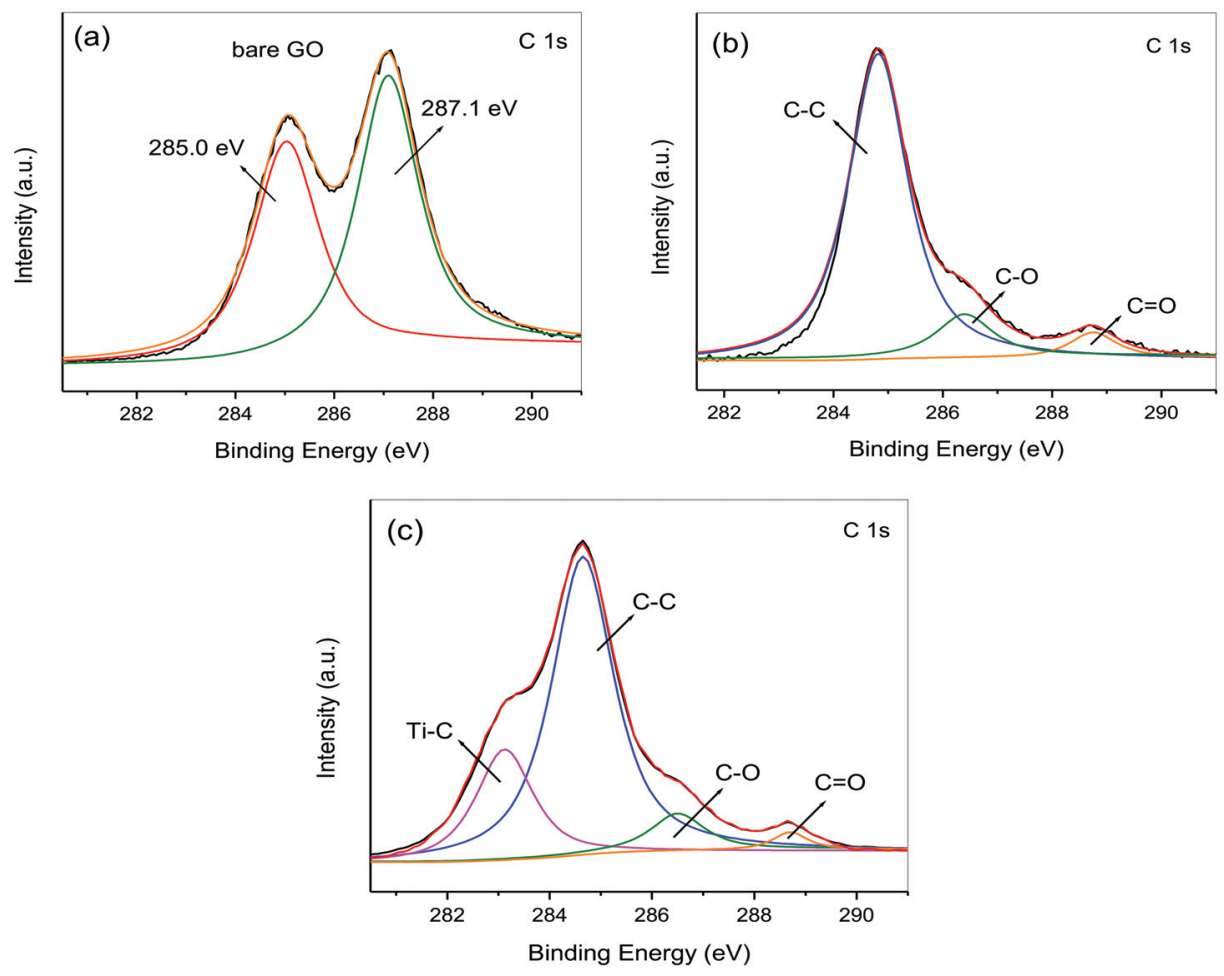

Figure 5. C 1s XPS spectra of (a) bare GO, (b) HTT/graphene-1.0\%-mixed, and (c) HTT/graphene-1.0\% chemically bonded nanocomposites.
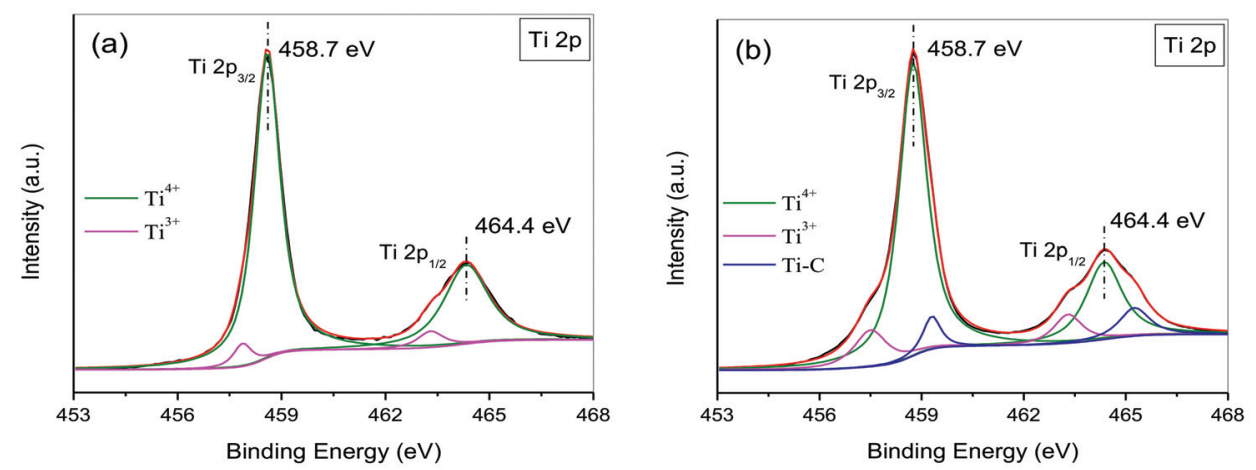

Figure 6. Ti 2p XPS spectra of (a) HTT/graphene-1.0\%-mixed and (b) HTT/graphene-1.0\% chemically bonded nanocomposites.

\subsection{Enhanced Visible Light Catalytic Activities}

To investigate the photocatalytic performance of HTT/graphene nanohybrids, the selective oxidation of benzylic alcohols was chosen as a model reaction. No product of aldehyde was obtained without visible radiation or the photocatalyst, indicating that the selective oxidation of benzyl alcohol 
is conducted through the photocatalytic reaction. Figure 7 shows a comparison of photocatalytic oxidation activity of pure HTT, HTT/graphene- $0.2 \%$, HTT/graphene- $0.4 \%$, HTT/graphene- $1.0 \%$, HTT/graphene- $2.0 \%$, HTT/graphene- $4.0 \%$, HTT/graphene- $1.0 \%$-mixed, and $\mathrm{P} 25 \mathrm{TiO}_{2} /$ graphene $-1.0 \%$. As depicted in Figure 7, without graphene, pure HTT shows moderate photocatalytic activity and $27.6 \%$ of benzyl alcohol was converted into benzaldehyde after $6 \mathrm{~h}$ of visible light irradiation. Even when the weight content of graphene is low $(0 \sim 4.0 \mathrm{wt} \%)$, HTT/graphene nanohybrids synthesized using the in-situ compositing approach exhibit remarkably enhanced photocatalytic activities, and the prepared photocatalysts possess high selectivity ( $>95 \%)$ for the conversion of benzyl alcohol to benzaldehyde. The photo-oxidation activity of HTT/graphene increases with graphene amount from 0.2 to $1.0 \mathrm{wt} \%$. The optimal conversion yield of benzyl alcohol, obtained in the sample HTT/graphene- $1.0 \%$, is $91.8 \%$, which exceeds by 3.3 times that of pure HTT. To our knowledge, this is the first report demonstrating that hydrogen titanate/graphene composites serve as efficient visible light catalysts toward the partial oxidation of benzylic alcohols. When the content of graphene is above $1.0 \%$, further increasing the graphene content results in a reduction of photo-activity. For instance, the conversion yield of benzyl alcohol over HTT/graphene- $4.0 \%$ has a sharp decline. This may be due to the increased turbidity and light scattering of HTT/graphene-4.0\%. Additionally, high loading of graphene shields HTT from absorbing light irradiation, which leads to an obvious reduction of illumination passing through the reaction suspension. The results are analogous to the previous studies of $\mathrm{TiO}_{2} /$ graphene nanohybrids for contaminant degradation and hydrogen production $[19,20]$.

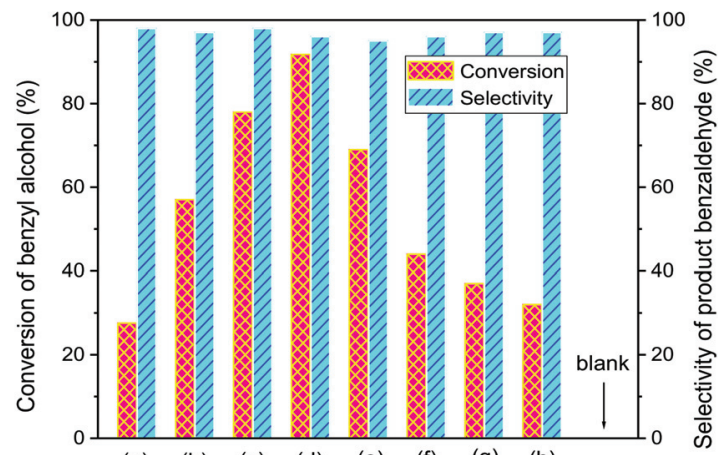

(a) (b) (c)

(d)

(e) (f)

(g) (h)

Photocatalysts

Figure 7. The selective oxidation of benzyl alcohol over HTT/graphene nanocomposites under visible light irradiation: (a) pure HTT, (b) HTT/graphene- $0.2 \%$, (c) HTT/graphene- $0.4 \%$, (d) HTT/graphene$1.0 \%$, (e) HTT/graphene-2.0\%, (f) HTT/graphene-4.0\%, (g) $\mathrm{P} 25 \mathrm{TiO}_{2} /$ graphene- $1.0 \%$, and (h) HTT/graphene-1.0\%-mixed. The blank column represents the experimental results in the absence of visible irradiation or photocatalyst.

For comparison, the selective conversion of benzyl alcohol in $\mathrm{P} 25 \mathrm{TiO}_{2} /$ graphene- $1.0 \%$ and HTT/graphene-1.0\%-mixed have also been tested and analyzed under the same experimental conditions. The sample of $\mathrm{P} 25 \mathrm{TiO}_{2} /$ graphene- $1.0 \%$ shows dramatically lower activity $(37.0 \%$ of alcohol is oxidized) than the HTT/graphene- $1.0 \%$ composites, suggesting that more direct contact and the resulting strong interactions between HTT and graphene sheets are critical for the enhancement of photocatalytic activity because of improved electron/hole separation and migration. The physical mixed sample (HTT/graphene-1.0\%-mixed) shows a significantly lower conversion yield than that of HTT/graphene- $1.0 \%$ synthesized via a one-step hydrothermal process. This suggests that simple mechanical-mixing with graphene has a small effect on improving the photocatalytic activity of HTT, and is due to the absence of a chemical-bonding interface between HTT and graphene. This also 
indicates that the interaction state between HTT and graphene has crucial influence on photocatalytic performance of HTT/graphene nanohybrids.

Additionally, the reaction kinetics of benzyl alcohol oxidation were investigated and the corresponding results are shown in Figure 8. As the reaction time is prolonged, slight decreases in the conversion yields of benzyl alcohol occur. Derived from the experimental data in Figure 8A, the kinetics of benzyl alcohol oxidation are shown in Figure $8 \mathrm{~B}$. A linear correlation between $\ln \left(\mathrm{C}_{0} / \mathrm{C}_{\mathrm{t}}\right)$ $\left(\mathrm{C}_{0}\right.$ and $\mathrm{C}_{\mathrm{t}}$ are the concentrations of benzyl alcohol at the initial time and at specific time intervals) and the reaction time is displayed, indicating the oxidation is pseudo-first order. The pseudo-first-order rate constant $(k)$ of the HTT/graphene photocatalysts can be obtained from the slope. The rate constant $(k)$ of benzyl alcohol oxidation over the optimal photocatalyst, HTT/graphene- $1.0 \%$, is $0.411 \mathrm{~h}^{-1}$, which is 5.3 and 6.4 times higher than those of the $\mathrm{P} 25 \mathrm{TiO}_{2} /$ graphene- $1.0 \%$ and HTT/graphene- $1.0 \%$ -mixed samples.
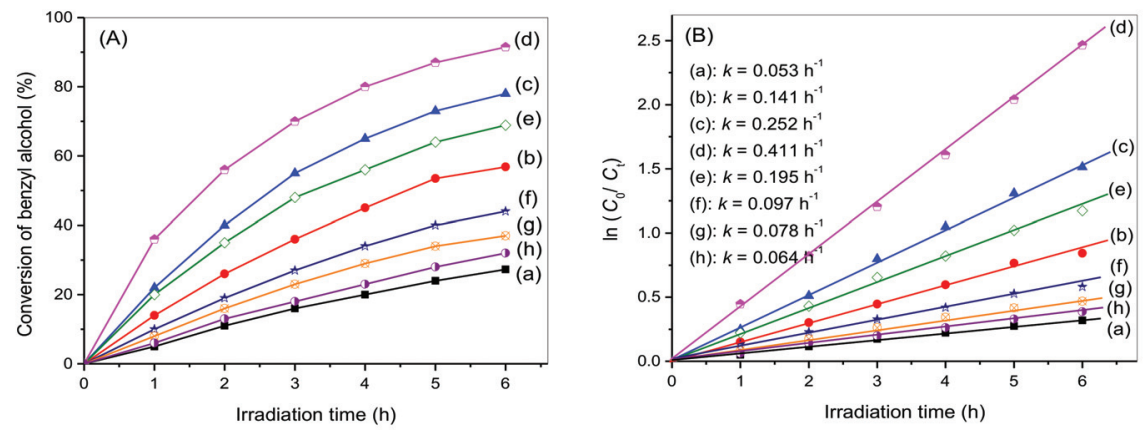

Figure 8. (A) Time involved photocatalytic conversion of benzyl alcohol over as-synthesized HTT/graphene nanocomposites: (a) pure HTT, (b) HTT/graphene- $0.2 \%$, (c) HTT/graphene- $0.4 \%$, (d) HTT/graphene-1.0\%, (e) HTT/graphene-2.0\%, (f) HTT/graphene -4.0\%, (g) P25 TiO 2 graphene- $1.0 \%$, and (h) HTT/graphene-1.0\%-mixed; (B) The corresponding first-order kinetics plots over these photocatalysts.

To investigate the general applicability of HTT/graphene composites, the oxidation of various benzylic alcohols over the optimal HTT/graphene-1.0\% were examined and the corresponding results are displayed in Table 2. It can be seen from Table 2 that the selective conversion of various benzylic alcohol derivatives proceeds, and the desirable aldehyde products are obtained in high selectivity (entries 1-5) under visible radiation. Additionally, it can be noted that the electron-donating substituents $\left(\mathrm{CH}_{3}-\right.$ and $\left.\mathrm{CH}_{3} \mathrm{O}-\right)$ facilitate the formation of aldehyde products; for example, $97.6 \%$ of 4 -methoxybenzyl alcohol can be converted in $4.5 \mathrm{~h}$ with $96 \%$ selectivity. Whereas, the electron-withdrawing substituents (such as $\mathrm{F}-$ and $\mathrm{Cl}-$ ) retard the conversion of alcohols. This suggests that the existence of an electron-donating group at the $p$-position of benzyl alcohol benefits the selective conversion over an HTT/graphene photocatalyst.

Table 2. Photocatalytic oxidation of various benzylic alcohols over HTT/graphene-1.0\%.

\begin{tabular}{cccccc}
\hline Entry & Substrate & Time (h) & Conv. (\%) & Sel. (\%) \\
\hline
\end{tabular}


Table 2. Cont.

\begin{tabular}{clcccc}
\hline Entry & Substrate & Time (h) & Conv. (\%) & Sel. (\%) \\
\hline & & 4.5 & 97.6 \\
\hline
\end{tabular}

Reaction conditions: catalyst $50 \mathrm{mg}$, benzylic alcohol $0.25 \mathrm{mmol}$, acetonitrile $5 \mathrm{~mL}$, reaction temperature $298 \mathrm{~K}$, visible light irradiation $(\lambda>400 \mathrm{~nm})$.

\subsection{Stability of Composite Photocatalysts}

The stability or recyclability of catalysts is another important practical issue. In order to study the stability and durability of HTT/graphene composites, cycle experiments are performed. After the catalytic reactions, HTT/graphene- $1.0 \%$ photocatalysts are separated and recovered by washing, and are reused. As depicted in Figure 9, there is only a small loss of activity and no obvious change of selectivity after five consecutive runs for partial photo-oxidation of benzyl alcohol. These results indicate that HTT/graphene is an efficient and stable photocatalyst for selective conversion of benzyl alcohol under the applied experimental conditions.

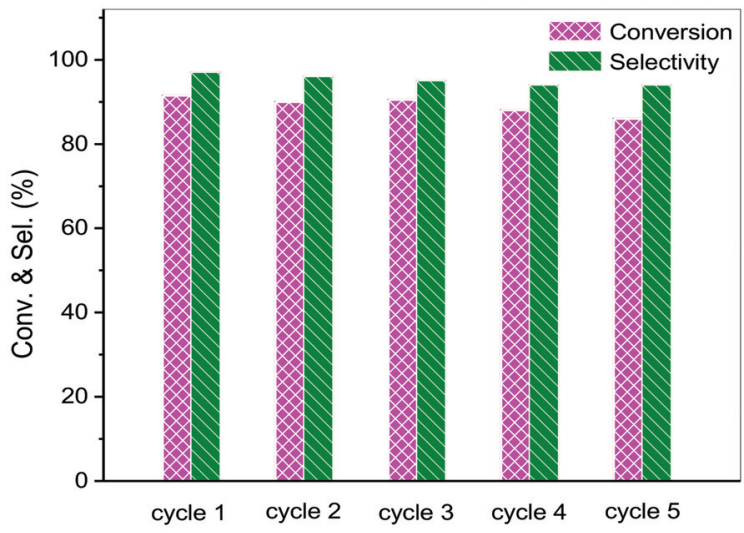

Figure 9. Recycled photoactivity test for five operational runs over the optimal HTT/graphene-1.0\%, on selective oxidation of benzyl alcohol.

\subsection{Visible Light Absorption Generated by Benzyl Alcohol Surface Adsorption}

Surface adsorption generally plays a critical role toward photocatalysis-driven selective oxidation of alcohols. The surface adsorption of benzyl alcohol on HTT/graphene composites is first investigated using FTIR spectra (Figure 10A). In comparison with free benzyl alcohol molecules, the characteristic peaks assigned to $\mathrm{C}-\mathrm{O}$ and $\mathrm{O}-\mathrm{H}$ groups shift to lower wavenumbers (at 1036 and $1363 \mathrm{~cm}^{-1}$ ) after being adsorbed over HTT/graphene-1.0\%. On the other hand, the characteristic peaks belonging to skeletal vibrations of the phenyl ring (at 1495 and $1451 \mathrm{~cm}^{-1}$ ) and the $\mathrm{C}-\mathrm{C}$ stretching vibration (at $1207 \mathrm{~cm}^{-1}$ ) show no changes [26,28]. These results imply that benzyl alcohol is adsorbed on the surface of HTT/graphene and the $-\mathrm{CH}_{2} \mathrm{OH}$ groups of the alcohol molecules interact with the unsaturated Ti sites of HTT, forming alcoholate species $-\mathrm{CH}_{2}-\mathrm{O}(\mathrm{H})-\mathrm{Ti}$. 

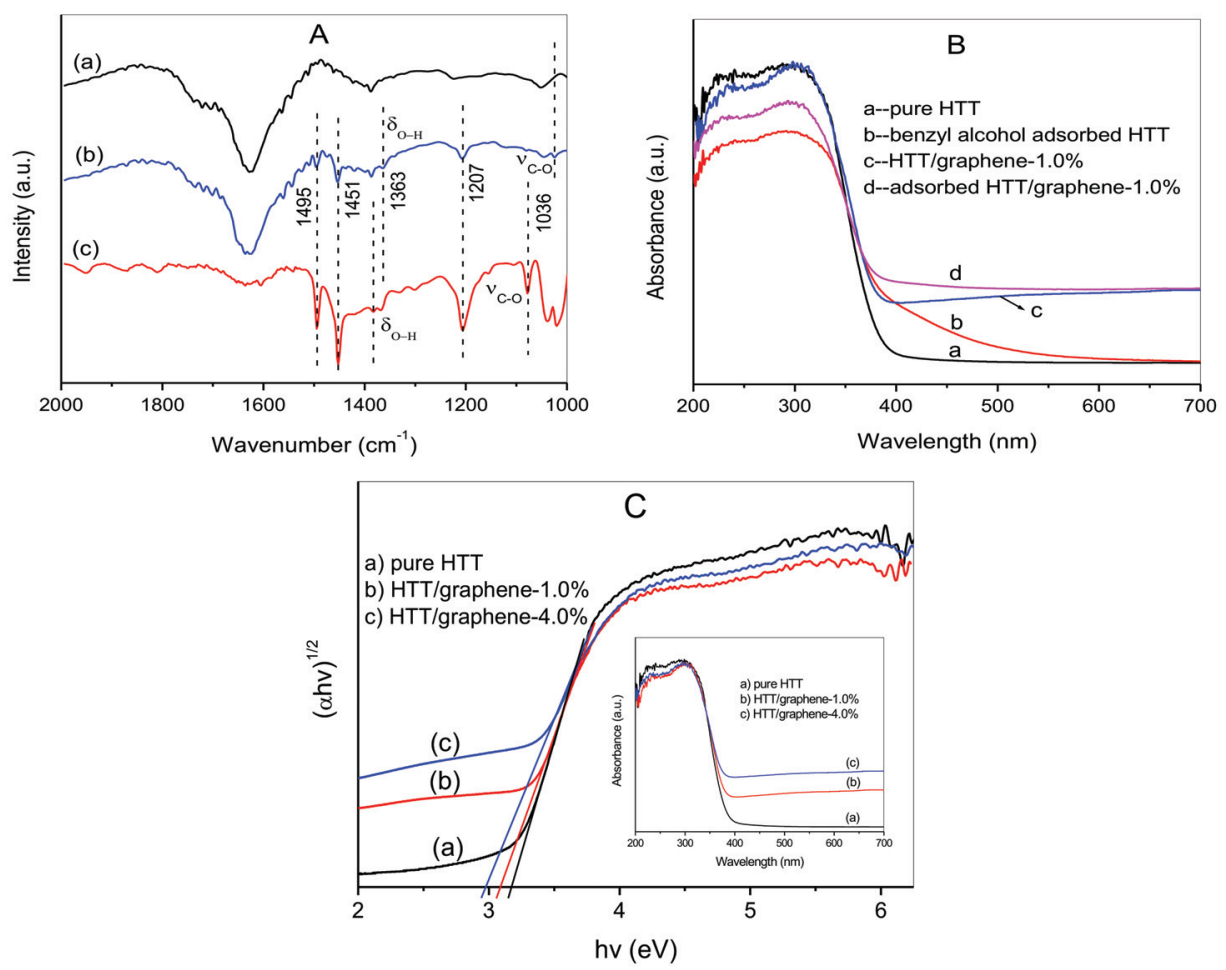

Figure 10. (A) FTIR spectra of (a) HTT/graphene-1.0\%, (b) benzyl alcohol adsorbed HTT/graphene-1.0\% and (c) free benzyl alcohol; (B) UV-vis DRS of pure HTT, benzyl alcohol adsorbed HTT, HTT/graphene-1.0\%, and benzyl alcohol adsorbed HTT/graphene-1.0\%; (C) Plot of transformed Kubelka-Munk function versus the energy of light (Inset: the corresponding UV-vis DRS).

The formation of surface complexes $-\mathrm{CH}_{2}-\mathrm{O}(\mathrm{H})-\mathrm{Ti}$ can produce visible absorption, which provides a prior condition for the selective conversion of benzylic alcohol to product aldehyde. This has been previously shown in research on photocatalytic reactions over $\mathrm{TiO}_{2}$ or $\mathrm{Nb}_{2} \mathrm{O}_{5}$ [40,41]. Based on the literature, surface-unsaturated metals (such as $\mathrm{Ti}$ or $\mathrm{Nb}$ ) can serve as Lewis acid sites and the alcohol molecules are adsorbed via Lewis acid-base interactions. The visible light absorption can be attributed to the ligand-to-metal charge transfer (LMCT) of in-situ formed surface complexes. The visible light absorption caused by the surface adsorption of benzyl alcohol over pure HTT and HTT/graphene-1.0\% is indicated in Figure 10B. As presented in Figure 10B, the pure HTT sample shows no visible light response, whereas the benzyl alcohol adsorbed HTT exhibits obvious visible light absorption. This absorption can be ascribed to the formation of surface complexes between adsorbed benzyl alcohol and the unsaturated surface Ti atoms of HTT. It can be concluded from Figure 10B that the incorporation of graphene results in continuous absorption bands in visible light range for HTT/graphene composites, which is analogous to results on $\mathrm{TiO}_{2} /$ graphene nanohybrids [42]. Although the HTT/graphene nanocomposites extend the wide background absorption in visible light region, additional visible light absorption can be observed for benzyl alcohol adsorbed composites. This demonstrates that the introduction of graphene has no influence on the formation of surface complexes.

The band gap energy of the photocatalyst is an important factor affecting the catalytic performance, especially for a visible light photocatalytic system. The band gap energies of pure HTT, HTT/graphene- $1.0 \%$, and HTT/graphene- $4.0 \%$ are estimated through a Tauc plot of the modified 
Kubelka-Munk function with linear extrapolations (Figure 10C). The calculated band gap energies are 3.16, 3.09, $2.98 \mathrm{eV}$ for pure HTT, HTT/graphene- $1.0 \%$, and HTT/graphene- $4.0 \%$, respectively. The reduction in band gap energy can be ascribed to chemical bonding between HTT and the graphene support. As shown in the inset of Figure 10C, a slight red-shift in the absorption edge of the HTT/graphene composites is observed. For instance, the absorption edge of HTT/graphene- $1.0 \%$ is about $401 \mathrm{~nm}$, which implies that HTT/graphene-1.0\% can hardly absorb visible light. That is, the red-shift originating from the chemical bonding between HTT and graphene is insufficient to bring forth excellent catalytic activity for the selective oxidation of benzylic alcohols. Hence, the visible light oxidation of benzylic alcohols over HTT/graphene nanocomposites is mainly driven by the formation of surface complexes.

\subsection{Improved Charge Transfer via the Chemically Bonded Interface between HTT and Graphene}

To investigate visible light induced charge transfer during the photo-oxidation of benzylic alcohols over HTT/graphene catalysts, the transient photocurrent responses were recorded over working electrodes made of pure HTT, HTT/graphene-1.0\%-mixed and in-situ compositing HTT/graphene-1.0\%. Figure 11A presents the I- $t$ curves of the above-mentioned three working electrodes in a benzyl alcohol containing electrolyte solution under visible light illumination. The photocurrent is primarily determined by the charge transfer from the adsorbed benzyl alcohols to the HTT conduction band and the subsequent graphene surface. The photocurrent density of the HTT/graphene- $1.0 \%$ electrode is enhanced $\sim 4.6$ times that of pure HTT, indicating the separation efficiency of photoinduced charges can be improved by the interfacial electronic interactions between HTT and graphene. Moreover, the photocurrent density of the in-situ composited HTT/graphene-1.0\% is enhanced 2.3 times that of the mechanical-mixed hybrid (HTT/graphene-1.0\%-mixed), which is primarily ascribed to the chemical interactions between HTT and the graphene sheets. Additionally, for the HTT / graphene-1.0\% electrode, the photocurrent density in the presence of benzyl alcohol is predominantly higher than that in its absence. This result implies the generation of anodic photocurrent is closely related to the surface adsorption of benzyl alcohol upon the HTT/graphene-1.0\% electrode. The photocurrent experiments offer direct evidence for electron migration from the adsorbed benzyl alcohol to the conduction band of HTT and subsequently to graphene surface under visible light.

Based on the experimental data in Figure 11A and Table 1, the photocurrent results are in accordance with the $S_{\mathrm{BET}}$ normalized rate constants of benzyl alcohol oxidation. This suggests that visible light induced charge transfer plays a pivotal role in the photocatalytic conversion of benzylic alcohol. For graphene-based photocatalytic systems, the enhanced charge separation efficiency is dominated by the high spatial charge transportation properties of graphene [43,44]. The extent of interaction between graphene and semiconductor catalysts determines the electron migration, further influencing the photocatalytic activity [19-22]. The formation of a chemically bonded interface between catalyst nanoparticles and graphene can improve the photocatalytic performance of semiconductor catalysts [19-22]. Based on the above characterization results (Figures 5, 6 and 11A) and photocatalytic experimental data (Figure 8 and Table 1), an efficient interfacial charge transfer based on a chemical-bonding effect is proposed to clarify the promoted catalytic activity of HTT/graphene nanocomposites, especially compared to mechanically mixed samples. The improved charge separation caused by the interaction extent between HTT and graphene sheets can be further investigated by EIS.

Figure 11B compares the EIS Nyquist curves of the in situ-synthesized and mechanically mixed HTT/graphene composites under irradiation by a xenon lamp. Figure 11B shows only one semicircle on the EIS plan, which suggests that charge migration is occurring, and the supposed equivalent circuit is given in the inset of Figure 11B. The charge transfer resistances of the pure HTT, HTT/graphene-1.0\%-mixed, and HTT/graphene-1.0\% samples are $4.9 \times 10^{5}, 2.2 \times 10^{5}$, and $1.0 \times 10^{5} \mathrm{ohm}$, determined by fitting with the equivalent circuit. This demonstrates that the introduction of graphene facilitates the charge transfer of HTT. Furthermore, the arc radius of the EIS Nyquist curve for HTT/graphene-1.0\% is smaller than that of both the physically mixed 
(HTT/graphene-1.0\%-mixed) and pure HTT samples. Generally, the arc radius of an EIS spectrum reflects the resistance of the interface layer at the surface of the electrodes $[37,45]$. The smaller semicircle size represents more efficient separation of electrons/holes and more rapid interfacial charge transfer $[37,45]$. These results clearly reveal that the chemical bonding of HTT and graphene can efficiently promote the migration and separation of photogenerated charges, contributing to improve the catalytic performance for selective oxidation of benzylic alcohols.
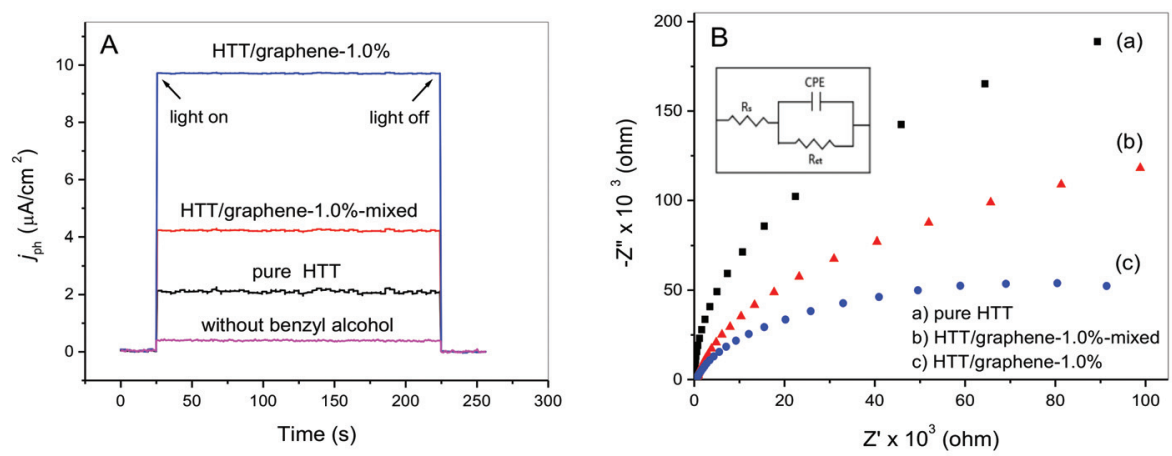

Figure 11. (A) Photocurrent curves of pure HTT, HTT/graphene-1.0\%-mixed, and HTT/graphene-1.0\% electrodes under visible light irradiation; the violet curve represents the photocurrent response over HTT/graphene-1.0\% electrode without benzyl alcohol in the electrolyte solution. (B) Electrochemical impedance spectra (EIS) Nyquist plots of the pure HTT, HTT/graphene-1.0\%-mixed, and HTT/graphene- $1.0 \%$ samples under light irradiation with a Xe lamp. Inset: Electrical equivalent circuit supposed for fitting of impedance spectra. $\mathrm{R}_{\mathrm{S}}, \mathrm{CPE}$, and $\mathrm{R}_{\mathrm{ct}}$ represent the electrolyte resistance, space charge capacitance, and the charge transfer resistance, respectively.

\subsection{Radical Trapping Experiments}

The involved catalytic mechanism of alcohol photo-oxidation on HTT/graphene composites is further studied. Control experiments on radical trapping were carried out and the obtained results are illustrated in Figure 12A. When adding tert-butyl alcohol (TBA) to the reaction solution [46], the conversion of benzyl alcohol is almost unchanged, indicating · OH has little effect on the selective conversion of benzyl alcohol. Removing $\mathrm{O}_{2}$ by sparging with $\mathrm{N}_{2}$ results in a low conversion of benzyl alcohol (ca. $15 \%$ ), indicating that $\mathrm{O}_{2}$ plays a critical role in photocatalytic oxidation of benzyl alcohol. When triethanolamine (TEA, a scavenger of photohole $\mathrm{h}^{+}$) is put into the reaction system, the oxidation of benzyl alcohol is remarkably inhibited, implying that partial oxidation of benzyl alcohol is primarily driven by photo-holes. Additionally, the introduction of benzoquinone (BQ) results in an obvious decrease in the conversion of benzyl alcohol, suggesting that $\mathrm{O}_{2}{ }^{-}$- is also involved during the photo-oxidation of benzyl alcohol. To confirm the formation of $\mathrm{O}_{2}{ }^{-}$, active radical species generated over HTT/graphene-1.0\% are detected by ESR using DMPO as the spin-trapping agent. As depicted in Figure 12B, after irradiation of the HTT suspension for $5 \mathrm{~min}$, the characteristic spectrum of the adduct $\mathrm{DMPO} / \mathrm{OOH}$ formed between DMPO and superoxide radicals can be clearly observed. In the presence of HTT/graphene- $1.0 \%$, the signal intensity of DMPO/.OOH increased. These results indicate that superoxide radicals can be formed upon pure HTT or HTT/graphene under light illumination, and that introduction of graphene significantly enhances the formation of $\mathrm{O}_{2}{ }^{--}$. 

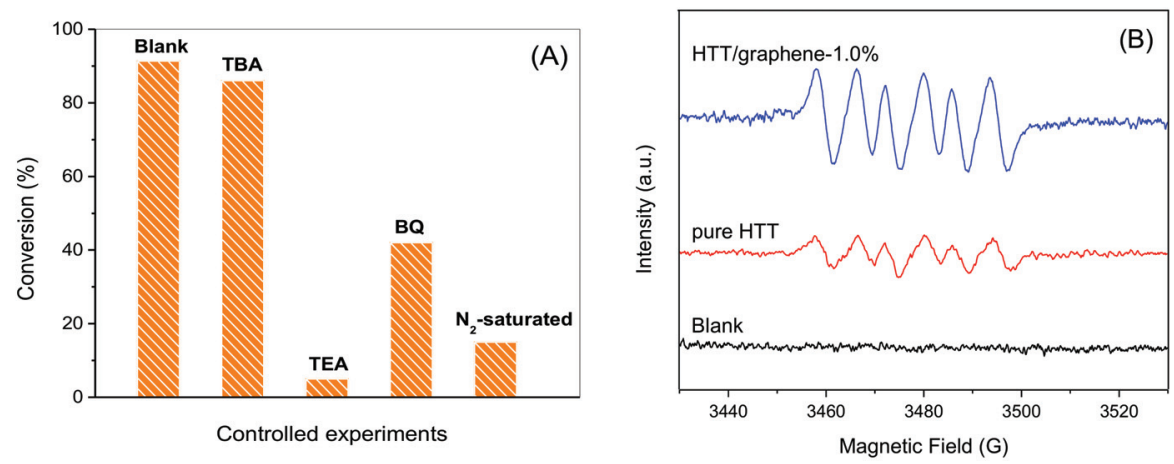

Figure 12. (A) Control experiments of photocatalytic selective oxidation of benzyl alcohol in the presence of various scavengers or in the absence of $\mathrm{O}_{2}$ over HTT/graphene-1.0\% under visible light irradiation for $6 \mathrm{~h}$. (B) Electron spin resonance (ESR) spectra of $\mathrm{O}_{2}{ }^{-}$trapped by DMPO over pure HTT and HTT/graphene-1.0\% suspensions in methanol solution, blank represents both the sample containing DMPO alone under light illumination and the sample containing DMPO and catalysts in dark.

\subsection{Mechanism of Improved Visible Light Catalytic Activity}

According to these results, a possible mechanism for the improved visible light catalytic activity over as-prepared HTT/graphene composites is proposed and depicted in Figure 13. Reactant benzylic alcohol is first adsorbed on unsaturated Ti site of HTT and generates the surface complex. A visible light induced LMCT process occurs, which produces an electron and a hole upon the in-situ formed surface complex. The photogenerated electron transfers into the conduction band of neighbor HTT and subsequently the surface of the graphene sheet via the in-situ formed Ti-C bonds, which can be trapped by adsorbed $\mathrm{O}_{2}$ to produce a superoxide anion radical. Meanwhile, the adsorbed benzylic alcohol transforms into an intermediate with a positive charge. Subsequently, the photogenerated hole drives the $\alpha$-deprotonation of the intermediate and gives rise to a neutral carbon radical. Then the reaction between the substrate radical and superoxide species yields the product aldehyde. Compared to the HTT/graphene-mixed samples, the in-situ composited HTT/graphene catalysts possess significantly enhanced photocatalytic activity for the selective oxidation of benzylic alcohols under visible light illumination, as indicated in Figure 8 and Table 1. It can be mainly ascribed to the chemical-bonding effect and the resulting intimate interactions between HTT and graphene sheets, which facilitate the interfacial electron transfer from adsorbed alcohols to HTT and finally to graphene. The close interfacial contacts between graphene and HTT are not being able to form in the mechanical mixed composites. In brief, the improved oxidation efficiency of as-synthesized HTT/graphene composites is primarily ascribed to the interfacial charge transfer effect, which inhibits the recombination of photoinduced electron-hole pairs and thus enhances the photoactivity of alcohol oxidation. 


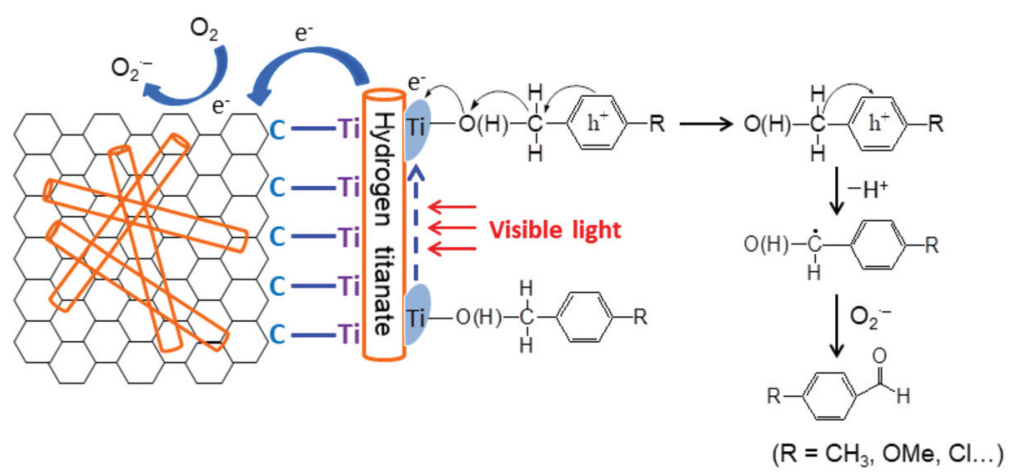

Figure 13. Schematic illustrations for the efficient interfacial charge transfer effect over HTT/graphene composites toward the selective oxidation of benzylic alcohols under visible light irradiation.

\section{Conclusions}

In summary, HTT/graphene nanohybrids with superior photocatalytic activity were fabricated through a facile hydrothermal process. Nanotubular HTT are densely supported upon the surface of graphene with close interfacial contacts. Introducing graphene can markedly improve the catalytic performance for the selective conversion of benzylic alcohols under visible illumination and the contents of graphene have significant effects on the catalytic activity of HTT. The optimal content of graphene is $1.0 \mathrm{wt} \%$ and the corresponding normalized rate constant $\mathrm{k}$ of benzyl alcohol oxidation is $1.71 \times 10^{-3} \mathrm{~g} / \mathrm{m}^{2} \cdot \mathrm{h}$, which exceeds that of pure HTT by more than seven times. Further characterization results indicate that HTT are chemically bonded with graphene surfaces via Ti-C bonds, which is supported by XPS analysis. More importantly, the chemical-bonded nanocomposite exhibits a remarkable enhancement of photocatalytic activity, which is 5.2 times that of a mechanical-mixed sample. Based on the results of transient photocurrent and EIS, this enhancement can be ascribed to the interfacial charge transfer effect, which provides favorable spatial conditions for electrons migration from in-situ generated surface complexes to neighboring HTT and finally to graphene. This effect inhibits the recombination of electrons and holes, and thus yields superior photocatalytic performance. Our study on the efficient interfacial charge transfer via a chemically bonded interface provides new insights for guiding the design of novel photocatalytic reaction systems, particularly for solar-light driven selective organic synthesis.

Acknowledgments: This works has been supported by the National Nature Science Foundation of China (21307027), the Natural Science Foundation of Henan Province (14A440007), the Funding Scheme for the Young Backbone Teachers of Higher Education Institutions in Henan Province (2015GGJS-071) and the Foundation for Distinguished Young Scientists of Henan Polytechnic University (J2016-4).

Author Contributions: Juan Yang proposed and planned the research, and supervised the experiments. Yumei Chen designed the synthesis of photocatalysts. Jun You and Jun Dai prepared the photocatalysts, and preformed the characterization and photocatalytic measurements. Jun Dai and Yao Li improved the data analysis. All the authors collaborated and participated in the writing of the manuscript.

Conflicts of Interest: The authors declare no conflict of interest.

\section{References}

1. Chen, C.C.; Ma, W.H.; Zhao, J.C. Semiconductor-mediated photodegradation of pollutants under visible-light irradiation. Chem. Soc. Rev. 2010, 39, 4206-4219. [CrossRef]

2. Kamat, P.V. Meeting the clean energy demand: Nanostructure architectures for solar energy conversion. J. Phys. Chem. C 2007, 111, 2834-2860. [CrossRef] 
3. Lang, X.J.; Ma, W.H.; Chen, C.C.; Ji, H.W.; Zhao, J.C. Selective aerobic oxidation mediated by $\mathrm{TiO}_{2}$ photocatalysis. Acc. Chem. Res. 2014, 47, 355-363. [CrossRef] [PubMed]

4. Humayun, M.; Li, Z.J.; Sun, L.Q.; Zhang, X.L.; Raziq, F.; Zada, A.; Qu, Y.; Jing, L.Q. Coupling of nanocrystalline anatase $\mathrm{TiO}_{2}$ to aporous nanosized $\mathrm{LaFeO}_{3}$ for efficient visible-light photocatalytic degradation of pollutants. Nanomaterials 2016, 6, 22. [CrossRef] [PubMed]

5. Yurdakal, S.; Palmisano, G.; Loddo, V.; Augugliaro, V.; Palmisano, L. Nanostructured rutile $\mathrm{TiO}_{2}$ for selective photocatalytic oxidation of aromatic alcohols to aldehydes in water. J. Am. Chem. Soc. 2008, 130, 1568-1569. [CrossRef] [PubMed]

6. Yang, D.J.; Liu, H.W.; Zheng, Z.F.; Yuan, Y.; Zhao, J.C.; Waclawik, E.R.; Ke, X.B.; Zhu, H.Y. An efficient photocatalyst structure: $\mathrm{TiO}_{2}$ (B) nanofibers with a shell of anatase nanocrystals. J. Am. Chem. Soc. 2009, 131, 17885-17893. [CrossRef] [PubMed]

7. Liu, Y.X.; Wang, Z.L.; Wang, W.D.; Huang, W.X. Engineering highly active $\mathrm{TiO}_{2}$ photocatalysts via the surface-phase junction strategy employing a titanate nanotube precursor. J. Catal. 2014, 310, 16-23. [CrossRef]

8. Zheng, Z.K.; Huang, B.B.; Lu, J.B.; Wang, Z.Y.; Qin, X.Y.; Zhang, X.Y.; Dai, Y.; Whangbo, M.H. Hydrogenated titania: Synergy of surface modification and morphology improvement for enhanced photocatalytic activity. Chem. Commun. 2012, 28, 5733-5735. [CrossRef]

9. Chatterjee, S.; Bhattacharyya, K.; Ayyub, P.; Tyagi, A.K. Photocatalytic properties of one-dimensional nanostructured titanates. J. Phys. Chem. C 2010, 114, 9424-9430. [CrossRef]

10. Yu, J.G.; Xiang, Q.J.; Zhou, M.H. Preparation, characterization and visible-light-driven photocatalytic activity of Fe-doped titania nanorods and first-principles study for electronic structures. Appl. Catal. B-Environ. 2009, 90, 595-602. [CrossRef]

11. Zheng, Z.F.; Liu, H.W.; Ye, J.P.; Zhao, J.C.; Waclawika, E.R.; Zhu, H.Y. Structure and contribution to photocatalytic activity of the interfaces in nanofibers with mixed anatase and $\mathrm{TiO}_{2}(\mathrm{~B})$ phases. J. Mol. Catal. A-Chem. 2010, 316, 75-82. [CrossRef]

12. Turki, A.; Kochkar, H.; Guillard, C.; Berhault, G.; Ghorbel, A. Effect of Na content and thermal treatment of titanate nanotubes on the photocatalytic degradation of formic acid. Appl. Catal. B-Environ. 2013, 138, 401-415. [CrossRef]

13. Tang, Z.R.; Li, F.; Zhang, Y.H.; Fu, X.Z.; Xu, Y.-J. Composites of titanate nanotube and carbon nanotube as photocatalyst with high mineralization ratio for gas-phase degradation of volatile aromatic pollutant. J. Phys. Chem. C 2011, 115, 7880-7886. [CrossRef]

14. Kim, I.Y.; Lee, J.M.; Kim, T.W.; Kim, H.N.; Kim, H.; Choi, W.; Hwang, S.-J. A strong electronic coupling between graphene nanosheets and layered titanate nanoplates: A soft-chemical route to highly porous nanocomposites with improved photocatalytic activity. Small 2012, 8, 1038-1048. [CrossRef] [PubMed]

15. Liu, G.G.; Han, K.; Ye, H.Q.; Zhu, C.Y.; Gao, Y.P.; Liu, Y.; Zhou, Y.H. Graphene oxide/triethanolamine modified titanate nanowires as photocatalytic membrane for water treatment. Chem. Eng. J. 2017, 320, 74-80. [CrossRef]

16. Kim, S.; Han, K.I.; Lee, I.G.; Park, W.K.; Yoon, Y.; Yoo, C.S.; Yang, W.S.; Hwang, W.S. A gallium oxide-graphene oxide hybrid composite for enhanced photocatalytic reaction. Nanomaterials 2016, 6, 127. [CrossRef] [PubMed]

17. Chen, Y.; Sun, H.Q.; Peng, W.C. 2D transition metal dichalcogenides and graphene-based ternary composites for photocatalytic hydrogen evolution and pollutants degradation. Nanomaterials 2017, 7, 62. [CrossRef] [PubMed]

18. Zhang, N.; Yang, M.-Q.; Tang, Z.-R.; Xu, Y.-J. CdS-graphene nanocomposites as visible light photocatalyst for redox reactions in water: A green route for selective transformation and environmental remediation. J. Catal. 2013, 303, 60-69. [CrossRef]

19. Zhang, H.; Lv, X.J.; Li, Y.M.; Wang, Y.; Li, J.H. P25-graphene composite as a high performance photocatalyst. ACS Nano 2010, 4, 380-386. [CrossRef] [PubMed]

20. Sun, Z.H.; Guo, J.J.; Zhu, S.M.; Mao, L.; Ma, J.; Zhang, D. A high-performance $\mathrm{Bi}_{2} \mathrm{WO}_{6}$-graphene photocatalyst for visible light-induced $\mathrm{H}_{2}$ and $\mathrm{O}_{2}$ generation. Nanoscale 2014, 6, 2186-2193. [CrossRef] [PubMed]

21. Gao, F.D.; Zeng, D.W.; Huang, Q.W.; Tian, S.Q.; Xie, C.S. Chemically bonded graphene/BiOCl nanocomposites as high-performance photocatalysts. Phys. Chem. Chem. Phys. 2012, 14, 10572-10578. [CrossRef] [PubMed] 
22. Huang, Q.W.; Tian, S.Q.; Zeng, D.W.; Wang, X.X.; Song, W.L.; Li, Y.Y.; Xiao, W.; Xie, C.S. Enhanced photocatalytic activity of chemically bonded $\mathrm{TiO}_{2}$ /graphene composites based on the effective interfacial charge transfer through the C-Ti bond. ACS Catal. 2013, 3, 1477-1485. [CrossRef]

23. Palmisano, G.; Augugliaro, V.; Pagliaro, M.; Palmisano, L. Photocatalysis: A promising route for 21st century organic chemistry. Chem. Commun. 2007, 43, 3425-3437. [CrossRef] [PubMed]

24. Zhang, M.; Wang, Q.; Chen, C.; Zang, L.; Ma, W.; Zhao, J. Oxygen atom transfer in the photocatalytic oxidation of alcohols by $\mathrm{TiO}_{2}$ : Oxygen isotope studies. Angezw. Chem. Int. Ed. 2009, 48, 6081-6084. [CrossRef] [PubMed]

25. Tanaka, A.; Hashimoto, K.J.; Kominami, H. Preparation of $\mathrm{Au} / \mathrm{CeO}_{2}$ exhibiting strong surface plasmon resonance effective for selective or chemoselective oxidation of alcohols to aldehydes or ketones in aqueous suspensions under irradiation by green light. J. Am. Chem. Soc. 2012, 134, 14526-14533. [CrossRef] [PubMed]

26. Liang, S.J.; Wen, L.R.; Lin, S.; Bi, J.H.; Feng, P.Y.; Fu, X.Z.; Wu, L. Monolayer $\mathrm{HNb}_{3} \mathrm{O}_{8}$ for selective photocatalytic oxidation of benzylic alcohols with visible light response. Angew. Chem. Int. Ed. 2014, 53, 2951-2955. [CrossRef] [PubMed]

27. Higashimoto, S.; Kitao, N.; Yoshida, N.; Sakura, T.; Azuma, M.; Ohue, H.; Sakata, Y. Selective photocatalytic oxidation of benzyl alcohol and its derivatives into corresponding aldehydes by molecular oxygen on titanium dioxide under visible light irradiation. J. Catal. 2009, 266, 279-285. [CrossRef]

28. Yang, J.; Shen, X.X.; Wei, J.P.; Zhang, L.N.; Zhao, D.; Yao, B.H. Selective oxidation of alcohols on hydrogen titanate nanotubes under visible light irradiation: Relationship between nanostructure and catalytic activity. Catal. Sci. Technol. 2016, 6, 7604-7614. [CrossRef]

29. Yu, L.H.; Lin, Y.M.; Li, D.Z. Visible-light-induced aerobic oxidation of alcohols in a green catalytic system of carbonate-like species doped $\mathrm{TiO}_{2}$. Appl. Catal. B-Environ. 2017, 216, 88-94. [CrossRef]

30. Andryushina, N.S.; Stroyuk, O.L. Influence of colloidal graphene oxide on photocatalytic activity of nanocrystalline $\mathrm{TiO}_{2}$ in gas-phase ethanol and benzene oxidation. Appl. Catal. B-Environ. 2014, 148, 543-549. [CrossRef]

31. Yang, X.; Zhao, H.; Feng, J.F.; Chen, Y.M.; Gao, S.Y.; Cao, R. Visible-light-driven selective oxidation of alcohols using a dye-sensitized $\mathrm{TiO}_{2}$-polyoxometalate catalyst. J. Catal. 2017, 351, 59-66. [CrossRef]

32. Zhai, Q.Q.; Bo, T.; Hu, G.X. High photoactive and visible-light responsive graphene/titanate nanotubes photocatalysts: Preparation and characterization. J. Hazard. Mater. 2011, 198, 78-86.

33. Dang, H.F.; Dong, X.F.; Dong, Y.C.; Huang, J.S. Facile and green synthesis of titanate nanotube/graphene nanocomposites for photocatalytic $\mathrm{H}_{2}$ generation from water. Int. J. Hydrog. Energy 2013, 38, 9178-9185. [CrossRef]

34. Zou, J.P.; Ma, J.; Huang, Q.; Luo, S.L.; Yu, J.; Luo, X.B.; Dai, W.L.; Sun, J.; Guo, G.C.; Au, C.T.; et al. Graphene oxide as structure-directing and morphology-controlling agent for the syntheses of heterostructured graphene- $\mathrm{Bi}_{2} \mathrm{MoO}_{6} / \mathrm{Bi}_{3.64} \mathrm{Mo}_{0.36} \mathrm{O}_{6.55}$ composites with high photocatalytic activity. Appl. Catal. B-Environ. 2014, 156, 447-455. [CrossRef]

35. Sun, X.; Li, Y. Synthesis and characterization of ion-exchangeable titanate nanotubes. Chem.-Eur. J. 2003, 9, 2229-2238. [CrossRef]

36. Perera, S.D.; Mariano, R.G.; Vu, K.; Nour, N.; Seitz, O.; Chabal, Y.; Balkus, K.J. Hydrothermal synthesis of graphene- $\mathrm{TiO}_{2}$ nanotube composites with enhanced photocatalytic activity. ACS Catal. 2012, 2, 949-956. [CrossRef]

37. Yang, J.; Wang, X.H.; Zhao, X.L.; Dai, J.; Mo, S.R. Synthesis of uniform $\mathrm{Bi}_{2} \mathrm{WO}_{6}$-reduced graphene oxide nanocomposites with significantly enhanced photocatalytic reduction activity. J. Phys. Chem. C 2015, 119, 3068-3078. [CrossRef]

38. Manna, A.K.; Pati, S.K. Tuning the electronic structure of graphene by molecular charge transfer: A computational study. Chem.-Asian J. 2009, 4, 855-860. [CrossRef] [PubMed]

39. Akhavan, O.; Ghaderi, E. Photocatalytic reduction of graphene oxide nanosheets on $\mathrm{TiO}_{2}$ thin Film for photoinactivation of bacteria in solar light irradiation. J. Phys. Chem. C 2009, 113, 20214-20220. [CrossRef]

40. Shishido, T.; Teramura, K.; Tanaka, T. A unique photo-activation mechanism by "in situ doping" for photo-assisted selective $\mathrm{NO}$ reduction with ammonia over $\mathrm{TiO}_{2}$ and photooxidation of alcohols over $\mathrm{Nb}_{2} \mathrm{O}_{5}$. Catal. Sci. Technol. 2011, 1, 541-551. [CrossRef]

41. Lang, X.; Ma, W.; Zhao, Y.; Chen, C.; Ji, H.; Zhao, J. Visible-light-induced selective photocatalytic aerobic oxidation of amines into imines on $\mathrm{TiO}_{2}$. Chem.-Eur. J. 2012, 18, 2624-2631. [CrossRef] 
42. Yang, M.Q.; Zhang, N.; Xu, Y.J. Synthesis of fullerene-, carbon nanotube-, and graphene-TiO 2 nanocomposite photocatalysts for selective oxidation: A comparative study. ACS Appl. Mater. Inter. 2013, 5, 1156-1164. [CrossRef] [PubMed]

43. Chen, D.; Zhang, H.; Liu, Y.; Li, J.H. Graphene and its derivatives for the development of solar cells, photoelectrochemical, and photocatalytic applications. Energy Environ. Sci. 2013, 6, 1362-1387. [CrossRef]

44. Xiang, Q.J.; Yu, J.G. Graphene-based photocatalysts for hydrogen generation. J. Phys. Chem. Lett. 2013, 4, 753-759. [CrossRef] [PubMed]

45. Xiao, F.X.; Wang, F.C.; Fu, X.Z.; Zheng, Y. A green and facile self-assembly preparation of gold nanoparticles/ZnO nanocomposite for photocatalytic and photoelectrochemical applications. J. Mater. Chem. 2012, 22, 2868-2877. [CrossRef]

46. Xiao, X.Y.; Jiang, J.; Zhang, L.Z. Selective oxidation of benzyl alcohol into benzaldehyde over semiconductors under visible light: The case of $\mathrm{Bi}_{12} \mathrm{O}_{17} \mathrm{Cl}_{2}$ nanobelts. Appl. Catal. B-Environ. 2013, 142, 487-493. [CrossRef]

(c) 2018 by the authors. Licensee MDPI, Basel, Switzerland. This article is an open access article distributed under the terms and conditions of the Creative Commons Attribution (CC BY) license (http:/ / creativecommons.org/licenses/by/4.0/). 


\title{
A Facile Approach to Prepare Black $\mathrm{TiO}_{2}$ with Oxygen Vacancy for Enhancing Photocatalytic Activity
}

\author{
Shihao Chen ${ }^{1}$, Yang Xiao ${ }^{1}$, Yinhai Wang ${ }^{1, *}$, Zhengfa Hu ${ }^{1}$, Hui Zhao ${ }^{1}$ and Wei Xie ${ }^{2}$ \\ 1 School of Physics \&Optoelectronic Engineering, Guangdong University of Technology, Guangzhou 510006, \\ China; shchenbhx@163.com (S.C.); xiaoyxy1023@163.com (Y.X.); zhfhu@gdut.edu.cn (Z.H.); \\ kkhui@gdut.edu.cn (H.Z.) \\ 2 School of Physics Science and Technology, Lingnan Normal University, Zhanjiang 524048, China; \\ xiewei@lingnan.edu.cn \\ * Correspondence: yhwang@gdut.edu.cn; Tel.: 86-020-39322265
}

Received: 14 March 2018; Accepted: 13 April 2018; Published: 16 April 2018

\begin{abstract}
Black} \mathrm{TiO}_{2}$ has triggered worldwide research interest due to its excellent photocatalytic properties. However, the understanding of its structure-property relationships and a more effective, facile and versatile method to produce it remain great challenges. We have developed a facile approach to synthesize black $\mathrm{TiO}_{2}$ nanoparticles with significantly improved light absorption in the visible and infrared regions. The experimental results show that oxygen vacancies are the major factors responsible for black coloration. More importantly, our black $\mathrm{TiO}_{2}$ nanoparticles have no $\mathrm{Ti}^{3+}$ ions. These oxygen vacancies could introduce localized states in the bandgap and act as trap centers, significantly decreasing the electron-hole recombination. The photocatalytic decomposition of both rhodamine $\mathrm{B}$ and methylene blue demonstrated that, under ultraviolet light irradiation, better photocatalytic performance is achieved with our black $\mathrm{TiO}_{2}$ nanoparticles than with commercial $\mathrm{TiO}_{2}$ nanoparticles.
\end{abstract}

Keywords: photocatalysis; black $\mathrm{TiO}_{2}$; oxygen vacancies; photodegradation

\section{Introduction}

Since the pioneering work of Fujishima and Honda in 1972 [1], titanium dioxide $\left(\mathrm{TiO}_{2}\right)$ has attracted extensive interest as a widely used semiconductor photocatalyst in the fields of hydrogen production, photocatalytic water-splitting [2], environmental protection technologies [3] and photocatalytic reduction of carbon dioxide [4].Especially in the area of environmental protection, textile dyes and other industrial dye stuffs constitute one of the largest group of organic compounds that represent an increasing environmental danger. Therefore, improving the efficiency of photocatalysis is a current research hotspot. Absorption of light to generate electron-hole pairs and effective charge separation are of great significance for enhancing the efficiency of the photocatalytic reaction in $\mathrm{TiO}_{2}$ semiconductor materials. In general, the more light $\mathrm{TiO}_{2}$ can absorb, the more excited charges are likely to be on its surface, improving its photocatalytic efficiency [5]. However, the large band gap of anatase $\mathrm{TiO}_{2}(\sim 3.2 \mathrm{eV})$ greatly limits its optical absorption in the UV region of the solar spectrum, resulting in poor efficiency for solar-driven photocatalysis.

Therefore, great efforts have been devoted to modifying the band structure to enhance the visible-light absorption, such as doping $\mathrm{TiO}_{2}$ with metal [6-9] or nonmetal $[10,11]$ elements and co-doping with metal and non-metal elements[12-14]. All these efforts have enhanced its visible light absorption and photocatalytic activity. However, the results are not yet satisfactory.

Recently, a hydrogenated black $\mathrm{TiO}_{2}\left(\mathrm{~B}-\mathrm{TiO}_{2}\right)$ material was reported by Mao and co-workers, having a narrow bandgap of $\sim 1.5 \mathrm{eV}$ with increased light harvesting efficiency in the visible and infrared regions and enhanced photocatalytic activity [15]. Unsurprisingly, this discovery has triggered 
worldwide research interest in black $\mathrm{TiO}_{2}$ nanomaterials, which represent a major breakthrough for $\mathrm{TiO}_{2}$ in photocatalysis. Since then, different methods for the synthesis of black $\mathrm{TiO}_{2}$ have been developed, which have allowed the preparation of hydrogenated or reduced $\mathrm{TiO}_{2}$ of different colors like yellow, blue, gray and black, by the use of different initial $\mathrm{TiO}_{2}$ materials and reaction conditions [16-18]. Most of these approaches can be divided into two types: reduction from $\mathrm{TiO}_{2}$ and incomplete oxidation from low-valence-state Ti species. To reduce white $\mathrm{TiO}_{2}$ to black $\mathrm{TiO}_{2}, \mathrm{Al}$, $\mathrm{Mg}, \mathrm{Zn}, \mathrm{H}_{2}, \mathrm{NaBH}_{4}$, imidazole and ascorbic acid have been used as reducing agents [19,20]. For example, Liu et al. reported black $\mathrm{TiO}_{2}$ nanotubes obtained by pressurized $\mathrm{H}_{2}$ reduction at high temperature $\left(500{ }^{\circ} \mathrm{C}, 20 \mathrm{bar}\right.$, for $\left.1 \mathrm{~h}\right)$, with a high photocatalytic hydrogen production rate [21]. Wang et al. reported a mass-production approach to synthesize black $\mathrm{TiO}_{2}$ with a unique crystalline-core amorphous-shell structure $\left(\mathrm{TiO}_{2} @ \mathrm{TiO}_{2-\mathrm{x}}\right)$, by using aluminum instead of hydrogen as the reducing agent [22]. Sinhamahapatra et al. developed a controlled magnesiothermic reduction to synthesize reduced black $\mathrm{TiO}_{2}$ under a $5 \% \mathrm{H}_{2} / \mathrm{Ar}$ atmosphere, with an optimum bandgap and band position, oxygen vacancies, surface defects and charge recombination centers and showing significantly improved optical absorption in the visible and infrared regions [23]. For the second approach, the $\mathrm{Ti}$ sources $\mathrm{TiH}_{2}, \mathrm{Ti}, \mathrm{TiO}, \mathrm{Ti}_{2} \mathrm{O}_{3}, \mathrm{TiCl}_{3}$ and $\mathrm{TiN}$ have been incompletely oxidized to synthesize black or hydrogenated $\mathrm{TiO}_{2}[18,24]$. For example, Liu et al. synthesized rice-shaped $\mathrm{Ti}^{3+}$ self-doped $\mathrm{TiO}_{2-x}$ nanoparticles by mild hydrothermal treatment of $\mathrm{TiH}_{2}$ in a $\mathrm{H}_{2} \mathrm{O}_{2}$ aqueous solution; the particles showed a strong absorption from the UV to the visible light regions and retained their light-blue color upon storage under ambient atmosphere or water, for one month at $40{ }^{\circ} \mathrm{C}$ [25].Pei et al. prepared gray $\mathrm{TiO}_{2-x}$ with enhanced visible light photocatalytic activity by a facile hydrothermal treatment of $\mathrm{TiO}$ in $\mathrm{HCl}$ solution [26]. All these synthetic approaches resulted in changes in the $\mathrm{TiO}_{2}$ color and enhancement of its light absorption. Surface lattice disorders, high-concentration of oxygen vacancies, $\mathrm{Ti}^{3+}$ ions, Ti-OH groups and Ti-H bands have been found in some black $\mathrm{TiO}_{2}$ and explain their color change, enhancement of light absorption and photocatalytic activity. These highly defective $\mathrm{TiO}_{2}$, referred to as $\mathrm{Ti}^{3+}$ ions / oxygen-vacancy self-doping $\left(\mathrm{TiO}_{2-\mathrm{x}}\right)$ and $\mathrm{H}$-doping $\left(\mathrm{TiO}_{2-\mathrm{x}} \mathrm{H}_{\mathrm{x}}\right)$, always present black color and possess strong visible light absorption. Some papers have also reported prepared black $\mathrm{TiO}_{2}$ that have only oxygen vacancies but no $\mathrm{Ti}^{3+}$ ions. For example, Wang et al. suggested the absence of $\mathrm{Ti}^{3+}$ in hydrogenated black $\mathrm{TiO}_{2}$ nanowires treated at $450{ }^{\circ} \mathrm{C}$ [27]. Dong et al. synthesized defective black $\mathrm{TiO}_{2-x}$ with a remarkable photocatalytic activity by a facile anodization technique and indicated that there were oxygen vacancies present but no $\mathrm{Ti}^{3+}$ [28]. This may be attributed to their lower preparation temperatures $\left(\leq 450{ }^{\circ} \mathrm{C}\right)$. Furthermore, the defect structure of black $\mathrm{TiO}_{2}$ is the major factor that determines its various properties, including color change, light absorption and photocatalytic activity [29]. According to previous papers, black $\mathrm{TiO}_{2}$ with disordered shell/hydroxyl groups can induce valence-band/conduction-band tails, that reduce their bandgap [15,30]. They can also induce oxygen vacancies, $\mathrm{Ti}^{3+}$ ions and $\mathrm{H}$-doping defects that reduce the bandgap and introduce mid-gap/localized-donor states below the conduction band, in addition to an upshift of the Fermi level $[31,32]$,which renders color changes. For example, for $\mathrm{Ti}^{3+}$ self-doping black $\mathrm{TiO}_{2}$, the localized excitation of the $\mathrm{Ti}^{3+}$ ions via $3 \mathrm{~d}$ transitions from the gap state to the empty excited state, significantly increases its light absorption and extends it to the visible region [22].

However, some questions still exist regarding black $\mathrm{TiO}_{2}$. For example, there is no consensus on what are the most essential modifications and the most effective synthetic method for their preparation. Some black $\mathrm{TiO}_{2}$ do not show the expected efficiency in visible light. Furthermore, their preparation is cumbersome and costly. The oxygen vacancies and $\mathrm{Ti}^{3+}$ species created during their synthesis are usually not stable enough because the $\mathrm{TiO}_{2}$ reduction occurs mainly on its surface. These factors severely limit their wide applicability. Therefore, developing a simple and economic strategy to synthesize a higher stability, higher performance black $\mathrm{TiO}_{2}$ photocatalyst is still a great challenge.

Inspired by the above-mentioned considerations, we have developed a facile technique for synthesizing black $\mathrm{TiO}_{2}$ nanoparticles, for the first time by low-temperature annealing in a vacuum-tube furnace. The obtained samples reveal very strong visible and infrared light absorption. 
The $\mathrm{B}-\mathrm{TiO}_{2}$ nanoparticles have oxygen vacancies and no $\mathrm{Ti}^{3+}$ ions. We evaluated the effectiveness of the as-prepared $\mathrm{B}-\mathrm{TiO}_{2}$ nanoparticles and the feasibility of applying them to photocatalytic degradation tests. Very promisingly, the resultant $\mathrm{B}-\mathrm{TiO}_{2}$ nanoparticles showed superior photocatalytic activity, far beyond that of commercial white $\mathrm{TiO}_{2}$ nanoparticles.

\section{Experimental}

\subsection{Materials}

Commercial catalyst white titanium dioxide nanoparticles $(20-30 \mathrm{~nm})$ and absolute ethanol were purchased from Macklin Biochemical. All the chemicals used in this study were analytical grade and were used as received. All the solutions were made using ultrapure Milli-Q (Millipore Corporation, Burlington, MA, USA) water.

\subsection{Synthesis of $\mathrm{B}-\mathrm{TiO}_{2}$ Nanoparticles}

In a simple synthetic procedure, commercially available $\left(\mathrm{W}-\mathrm{TiO}_{2}\right)$ nanoparticles were used as precursors. W- $\mathrm{TiO}_{2}$ nanoparticles $(0.5 \mathrm{~g})$ and absolute ethanol $(10 \mathrm{~mL})$ were mixed in a $50 \mathrm{~mL}$ quartz tube using a magnetic stirrer to form a milky-white suspension. The milky-white suspension was stirred for $10 \mathrm{~min}$. Then the suspension was poured into a sintering boat (length $6 \mathrm{~cm}$, width $3 \mathrm{~cm}$, height $1.5 \mathrm{~cm}$ ) and transferred to a vacuum tube furnace (SK-G06163, $\Phi 60 / 50 \times 1000 \mathrm{~mm}$ ). The suspension was annealed at $400{ }^{\circ} \mathrm{C}$ for $3 \mathrm{~h}$. The detailed annealing procedure is as follows: The initial temperature is set to $50{ }^{\circ} \mathrm{C}$ and the temperature is raised at a rate of $5^{\circ} \mathrm{C} / \mathrm{min}$ until reaches $400{ }^{\circ} \mathrm{C}$ and the temperature is maintained at $400{ }^{\circ} \mathrm{C}$ for three hours. Then, the temperature is lowered at a rate of $5{ }^{\circ} \mathrm{C} / \mathrm{min}$ until reaches $50^{\circ} \mathrm{C}$. Finally, the sample was allowed to cool to room temperature and a black mass of $\mathrm{B}-\mathrm{TiO}_{2}$ nanoparticles was obtained.

\subsection{Characterization}

The X-ray diffraction patterns (XRD) of the samples were obtained at room temperature using $\mathrm{Cu} \mathrm{K} \alpha$ irradiation $(\lambda=1.5406 \AA)$ operating at $36 \mathrm{kV}$ tube voltage and $20 \mathrm{~mA}$ tube current. Data were collected between $10^{\circ}$ and $70^{\circ}(2 \theta)$ with a $0.02^{\circ}$ step size. Raman spectra were recorded on a UV laser Raman spectrometer at $\lambda=785 \mathrm{~nm}$. UV-vis diffuse reflectance (DRUV-vis) absorption spectra were recorded on an UV-2700 Spectrophotometer in the range of 200-800 nm. X-ray photoelectron spectra (XPS) were measured on an ESCALAB 250Xi using the reference of C1s $(284.8 \mathrm{eV})$ with an excitation source of $150 \mathrm{~W} \mathrm{Al} \mathrm{K \alpha}(\mathrm{hv}=1486.6 \mathrm{eV}) \mathrm{X}$-rays. The electron paramagnetic resonance (EPR) spectra were obtained using a JES-FA200 spectrometer (JEOL, Tokyo, Japan) at room temperature and an FEI Tecnai G2 F20 (FEI, Hillsboro, OR, USA) model was used to determine the size and morphologies of the nanoparticles. Sample specimens for the transmission electron microscopy (TEM) measurement were prepared by briefly ultrasonicating the sample powders in ethanol, followed by placing a drop of the suspension onto lacey support films that were dried before imaging. Fourier transformed infra-red (FTIR, 80/80v Bruker TENSOR27, BRUKER OPTICS, Karlsruhe, Germany) was used to analyze the functional groups in the catalyst from 500 to $4000 \mathrm{~cm}^{-1}$. Photoluminescence (PL) emission spectrum was recorded on an FLS980 fluorescence spectrophotometer equipped with a $450 \mathrm{~W}$ xenon lamp as the excitation source, at room temperature (excitation wavelength $\lambda_{\mathrm{ex}}=300 \mathrm{~nm}$ ).

\subsection{Photocatalytic Test}

Rhodamine $\mathrm{B}(\mathrm{RhB})$ and methylene blue $(\mathrm{MB})$ are organic dye with a bright red color and blue color, respectively. They are widely applied as a test model pollutant in photocatalytic processes. Therefore, the photocatalytic activity of the two prepared samples was evaluated by monitoring the decomposition of (RhB)/(MB) in an aqueous solution under UV irradiation from a $500 \mathrm{~W} \mathrm{Hg}$ lamp. The lamp was positioned in a cylindrical Pyrex vessel and cooled by circulating water to control the reaction temperature at about $27^{\circ} \mathrm{C}$. A quartz tube was used as the photo catalytic reactor. The sample 
of $\mathrm{TiO}_{2}(0.01 \mathrm{~g})$ was mixed with an aqueous solution of $\mathrm{RhB} / \mathrm{MB}\left(40 \mathrm{~mL}, 4 \times 10^{-5} \mathrm{M}\right)$. After stirring for $30 \mathrm{~min}$ in the dark, to reach an adsorption equilibrium between the photocatalyst and the RhB/MB solution, the mixture was exposed to UV light. Vigorous magnetic stirring was maintained in order to keep the $\mathrm{B}-\mathrm{TiO}_{2}$ and $\mathrm{W}-\mathrm{TiO}_{2}$ nanoparticles suspended in the $\mathrm{RhB} / \mathrm{MB}$ solution. The concentration of aqueous $\mathrm{RhB} / \mathrm{MB}$ was determined with a UV-Vis spectrophotometer by measuring the peak intensity at $553 / 668 \mathrm{~nm}$, respectively. The percentage of degradation was recorded as $C / C_{0}$, where $C$ and $C_{0}$ refer to the absorbance of the $\mathrm{RhB} / \mathrm{MB}$ solution after a certain time interval (20 $\mathrm{min})$ and the initial absorbance, respectively.

The photocatalytic activity of $\mathrm{B}-\mathrm{TiO}_{2}$ and $\mathrm{W}-\mathrm{TiO}_{2}$ under visible light was also evaluated by monitoring the decomposition of $\mathrm{RhB} / \mathrm{MB}$. The apparatus for studying the photocatalytic decomposition of $\mathrm{RhB} / \mathrm{MB}$ was identical under visible and ultraviolet light, except that an $800 \mathrm{~W}$ Xe lamp was used instead of a Hg lamp and ultraviolet cut off filter (>420 nm) was applied to cut off the UV light. The amount of catalyst has also been increased to $0.02 \mathrm{~g}$.

\section{Results and Discussion}

\subsection{Characterization}

The prepared $\mathrm{B}-\mathrm{TiO}_{2}$ nanoparticles showed an outstanding stability. No color change was observed for the $\mathrm{B}-\mathrm{TiO}_{2}$ nanoparticles over one year after they were synthesized and stayed black even when annealed at $200{ }^{\circ} \mathrm{C}$ in air for 3 days. Figure 1 shows the UV-visible absorption spectra of the $\mathrm{B}-\mathrm{TiO}_{2}$ and $\mathrm{W}-\mathrm{TiO}_{2}$ nanoparticles. A large absorption peak is observed, for both, at wavelengths shorter than $400 \mathrm{~nm}(\sim 3.1 \mathrm{eV})$, which can be attributed to the intrinsic bandgap absorption of crystalline anatase $\mathrm{TiO}_{2}$. Compared with pristine $\mathrm{W}-\mathrm{TiO}_{2}$, the $\mathrm{B}-\mathrm{TiO}_{2}$ extended the absorption from UV light to the visible and infrared light regions. The extended absorption is consistent with the changes of sample color from white to black (photograph shown in the inset of Figure 1). Furthermore, for the $\mathrm{B}-\mathrm{TiO}_{2}$ nanoparticles, a step appeared at approximately $740 \mathrm{~nm}(\sim 1.67 \mathrm{eV})$. This step could be due to oxygen vacancies with a trapped electron and it is discussed in detail in the EPR-analysis section.

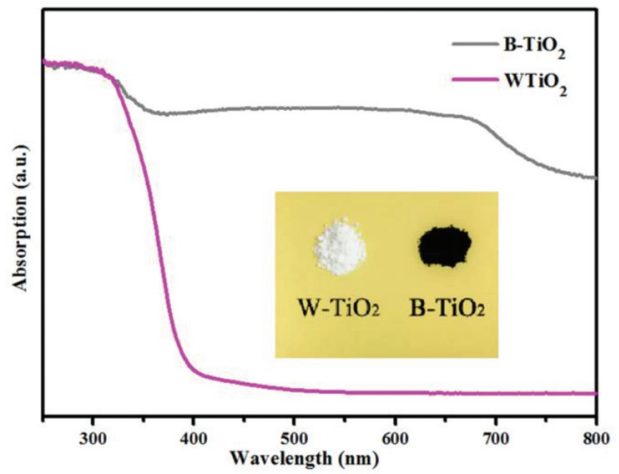

Figure 1. UV-Vis absorption spectra of black $\mathrm{B}-\mathrm{TiO}_{2}$ and $\mathrm{W}-\mathrm{TiO}_{2}$ nanoparticles. The insert is a photograph of $\mathrm{B}-\mathrm{TiO}_{2}$ and $\mathrm{W}-\mathrm{TiO}_{2}$ nanoparticles.

The crystalline structures of the $\mathrm{B}-\mathrm{TiO}_{2}$ and $\mathrm{W}-\mathrm{TiO}_{2}$ nanoparticles were determined by XRD analysis. The powder XRD patterns of the two samples, shown in Figure 2a, exhibited characteristic diffraction peaks matching the (101), (004), (200), (105) and (204) planes of anatase $\mathrm{TiO}_{2}$ (JCPDS Card No. 21-1272). It could also be seen that there was almost no phase change in the $\mathrm{B}^{-\mathrm{TiO}_{2}}$ nanoparticles and no other diffraction peaks could be observed after the low temperature annealing. However, from the local enlargement of diffraction peaks (inset of Figure 2a), the diffraction peaks of the $\mathrm{B}^{-\mathrm{TiO}_{2}}$ 
nanoparticles moved slightly to a higher angle. According to the Bragg equation $(2 \mathrm{~d} \sin \theta=\lambda$, where $\mathrm{d}$ is the crystal spacing, $\theta$ the diffraction angle and $\lambda$ the $X$-ray wavelength), the shift of peaks towards higher angles suggests that the lattice parameters decrease. This result can be explained in terms of the oxygen vacancies produced by the annealing of the samples [33].
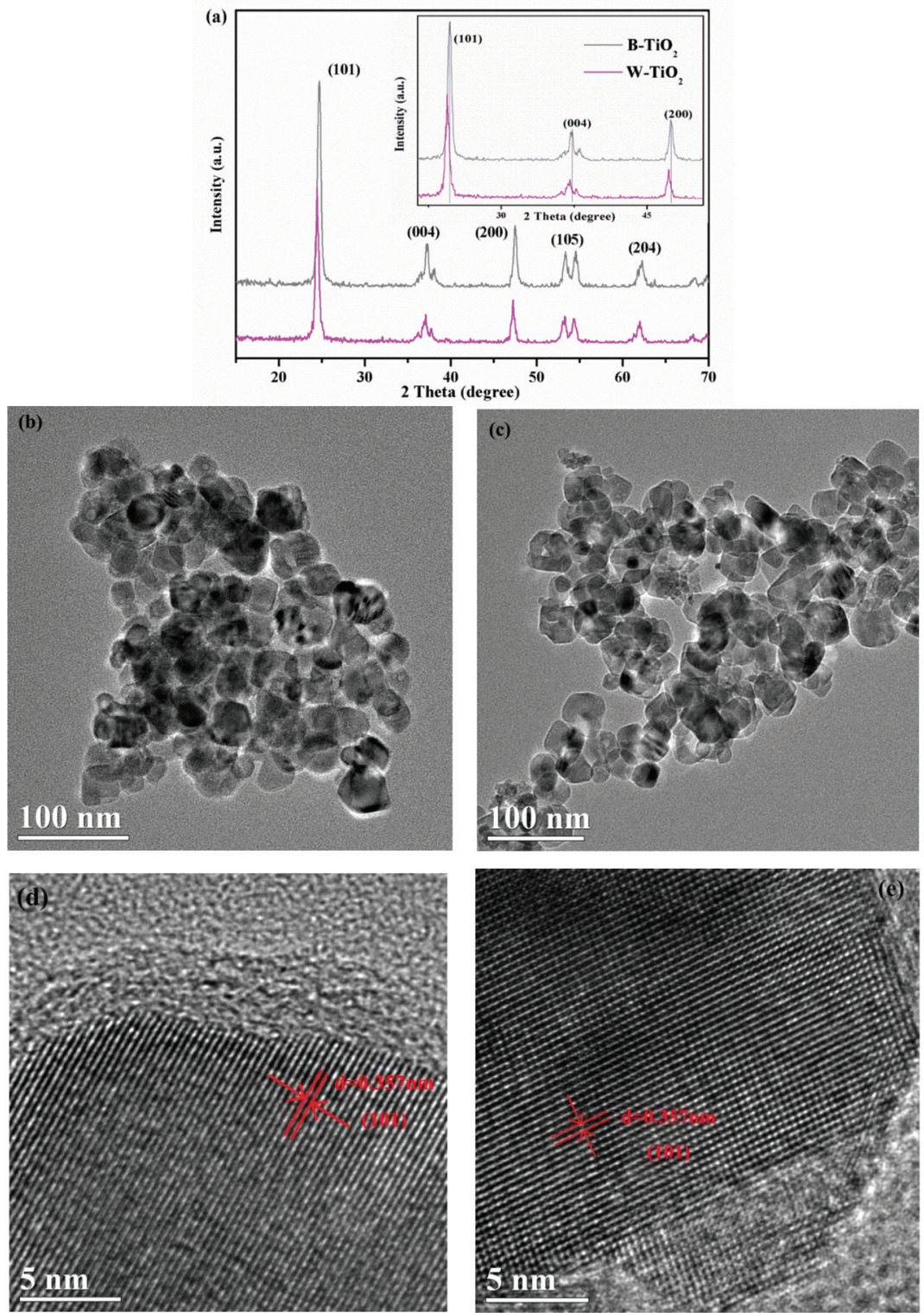

Figure 2. The XRD patterns of the as-prepared samples (a); TEM images of $\mathrm{TiO}_{2}$ nanoparticles before (b) $\mathrm{W}-\mathrm{TiO}_{2}$ and after (c) $\mathrm{B}-\mathrm{TiO}_{2}$ low temperature annealing; HRTEM images of $\mathrm{TiO}_{2}$ nanoparticles before (d) $\mathrm{W}-\mathrm{TiO}_{2}$ and after (e) $\mathrm{B}-\mathrm{TiO}_{2}$ low temperature annealing. 
The morphology and crystal structure of the $\mathrm{B}-\mathrm{TiO}_{2}$ and $\mathrm{W}-\mathrm{TiO}_{2}$ nanoparticles were examined by high-resolution transmittance microscopy (HR-TEM) analysis, as shown in Figure $2 b-e$. The TEM images showed similar particle sizes and morphologies for $\mathrm{B}-\mathrm{TiO}_{2}$ (Figure $2 \mathrm{~b}$ ) and $\mathrm{W}-\mathrm{TiO}_{2}$ (Figure $2 \mathrm{c}$ ), which proves that the low temperature annealing did not change its morphology. The lattice fringe pattern with a spacing of $\sim 0.35 \mathrm{~nm}$, shown in the high resolution TEM (HRTEM) images (Figure 2d,e), confirms the (101) plane of anatase $\mathrm{TiO}_{2}$ for the $\mathrm{W}-\mathrm{TiO}_{2}$ and $\mathrm{B}-\mathrm{TiO}_{2}$ nanoparticles (in agreement with the XRD analysis). Both the $\mathrm{W}-\mathrm{TiO}_{2}$ and $\mathrm{B}-\mathrm{TiO}_{2}$ nanoparticles were highly crystallized, as seen from the well resolved lattice features. However, other researchers have reported a disordered surface layer surrounding the crystalline core in the hydrogenated/aluminum-reduced black $\mathrm{TiO}_{2}$ nanoparticles obtained under high temperature $\left(>450{ }^{\circ} \mathrm{C}\right)$ and high pressure $(>5$ bar $)[22,34]$. In contrast, the $\mathrm{B}-\mathrm{TiO}_{2}$ nanoparticles prepared in this work used low temperature $\left(400{ }^{\circ} \mathrm{C}\right)$ and atmospheric pressure conditions that did not lead to the specific core/shell structure consisting of a disordered surface layer and a crystalline core. The specific surface areas using the Barrett-Emmett-Teller (BET) technique were 52.8 and $61.9 \mathrm{~m}^{2} / \mathrm{g}$ for the $\mathrm{B}-\mathrm{TiO}_{2}$ and $\mathrm{W}-\mathrm{TiO}_{2}$ nanoparticles, respectively. The similar BET specific surface areas confirmed that the crystal size of the $\mathrm{B}-\mathrm{TiO}_{2}$ nanoparticles did not increase with the low temperature annealing, consistent with the above-discussed TEM results.

Raman spectroscopy is very sensitive to short-range distortions arising from microstructural defects. The structural characteristics of the $\mathrm{B}-\mathrm{TiO}_{2}$ nanoparticles were further examined by Raman scattering, as shown in Figure 3. For the $\mathrm{W}-\mathrm{TiO}_{2}$ nanoparticles, five characteristic Raman peaks at 143.6, 199.8, 397.2, 516.3 and $639.6 \mathrm{~cm}^{-1}$ were assigned as the $E_{g}, E_{g}, B_{1 g}, A_{1 g}+B_{1 g}$ and $E_{g}$ modes of the anatase phase, respectively [35]. However, compared to the $\mathrm{W}_{-}-\mathrm{TiO}_{2}$ nanoparticles, it is clear that the frequency of the strongest $\mathrm{E}_{\mathrm{g}}$ mode $\left(\right.$ at $\left.143.6 \mathrm{~cm}^{-1}\right)$ in the $\mathrm{B}^{-} \mathrm{TiO}_{2}$ nanoparticles, which results from the external vibration of the Ti-O bonds, had a large blue shift to $152.5 \mathrm{~cm}^{-1}$, accompanied by peak broadening. As reported in previous studies, ruling out grain size effects, the blue shift and peak broadening of the anatase phase $\mathrm{TiO}_{2}$ can be ascribed to the oxygen stoichiometry [36]. Since the $\mathrm{B}-\mathrm{TiO}_{2}$ and $\mathrm{W}-\mathrm{TiO}_{2}$ nanoparticles had similar particle sizes, the blue shift and broadening of the strongest mode at $143.6 \mathrm{~cm}^{-1}$, can be attributed to a shortening of the correlation length due to the presence of oxygen vacancies (nonstoichiometric). Thus, Raman spectroscopy unambiguously supported the oxygen deficiency of the $\mathrm{B}-\mathrm{TiO}_{2}$ nanoparticles.

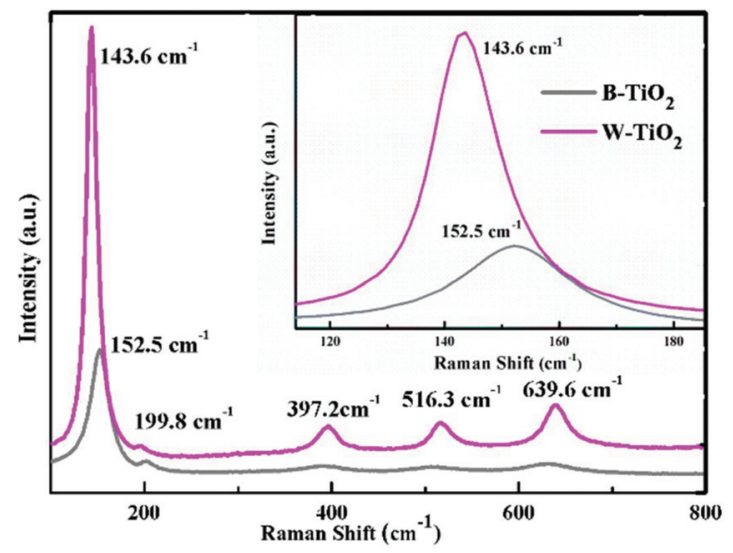

Figure 3. Raman spectra of $\mathrm{B}-\mathrm{TiO}_{2}$ nanoparticles and $\mathrm{W}-\mathrm{TiO}_{2}$, inset is the magnification of $\mathrm{E}_{\mathrm{g}}$ peak.

The existence of oxygen vacancies in the samples was also verified by electron paramagnetic resonance (EPR) at room temperature. EPR is widely-used to examine unpaired spins. In Figure 4, it is easily seen a strong EPR signal in the $\mathrm{B}-\mathrm{TiO}_{2}$ nanoparticles at $\mathrm{g}=2.003$, which is characteristic of 
oxygen vacancies with a trapped electron in $\mathrm{TiO}_{2}$ and not of $\mathrm{Ti}^{3+}$ ions $(\mathrm{g}=1.96-1.99)$ and consistent with the reported oxygen-deficient $\mathrm{TiO}_{2-x}[37,38]$. Upon removal of an oxygen atom, one or two electrons will be localized in an oxygen vacancy site (reaction 1) and form color centers. The color centers associated with oxygen vacancies in $\mathrm{TiO}_{2}$ are the $\mathrm{F}, \mathrm{F}^{+}$and $\mathrm{F}^{++}$centers (reactions 2-4) [39]. In our samples, one electron is localized in an oxygen vacancy state ( $\mathrm{F}^{+}$-centers).

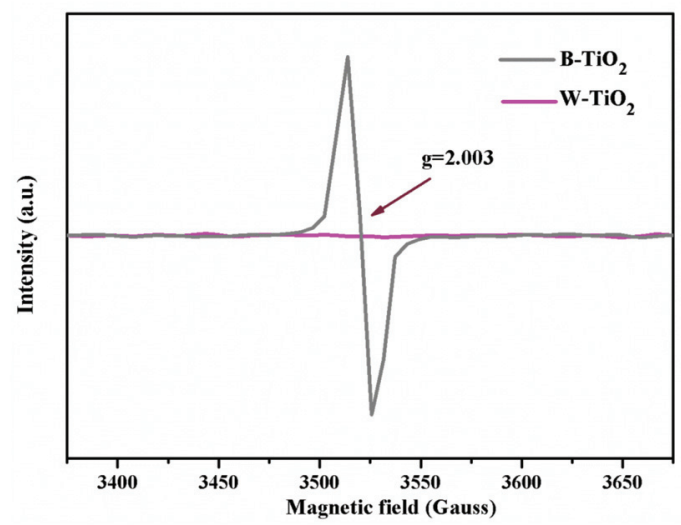

Figure 4. EPR spectra of $\mathrm{B}-\mathrm{TiO}_{2}$ and $\mathrm{W}-\mathrm{TiO}_{2}$ nanoparticles.

$$
\begin{gathered}
-\mathrm{O}^{2-} \rightarrow \mathrm{O}+\mathrm{V}_{\mathrm{O}}+2 \mathrm{e}^{-} \\
\mathrm{V}_{\mathrm{O}}+2 \mathrm{e}^{-} \rightarrow \mathrm{F} \\
\mathrm{V}_{\mathrm{O}}+1 \mathrm{e}^{-} \rightarrow \mathrm{F}^{+} \\
\mathrm{V}_{\mathrm{O}}+0 \mathrm{e}^{-} \rightarrow \mathrm{F}^{++}
\end{gathered}
$$

Furthermore, Chen et al. have proved that electrons transit from the color center energy level to the conduction band bottom. The calculated excited energy of the $\mathrm{F}^{+}$-center electron is $1.67 \mathrm{eV}$ [40], which is in reasonable agreement with the step value which appeared at approximately $740 \mathrm{~nm}(\sim 1.67 \mathrm{eV})$ in the UV-Vis absorption spectra (Figure 1). Thus, the absorption spectral features in the $1.67 \mathrm{eV}$ region $(740 \mathrm{~nm})$ are assigned to a transition from the ground state of the $\mathrm{F}^{+}$center to its corresponding excited $\mathrm{F}^{+^{*}}$ state. By contrast, the $\mathrm{W}-\mathrm{TiO}_{2}$ nanoparticles did not contain any paramagnetic site, as a flat line was observed for this sample. Thus, the strong EPR signal peak and also the blue shift of the Raman peak, indicated that $\mathrm{B}-\mathrm{TiO}_{2}$ nanoparticles had a high concentration of oxygen vacancies and that no $\mathrm{Ti}^{3+}$ ions existed.

$\mathrm{X}$-ray photo-electron spectroscopy (XPS) analysis was conducted to investigate the chemical states of the $\mathrm{Ti}$ and $\mathrm{O}$ elements, to gain further insight into the oxygen vacancies in the $\mathrm{B}^{-\mathrm{TiO}_{2}}$ nanoparticles and the valence band position on the sample surface. Figure 5 a shows the Ti $2 \mathrm{p} \mathrm{XPS}$ of the $\mathrm{B}^{-\mathrm{TiO}_{2}}$ and $\mathrm{W}-\mathrm{TiO}_{2}$ nanoparticles. For the $\mathrm{W}-\mathrm{TiO}_{2}$ nanoparticles, the Ti $2 \mathrm{p} 3 / 2$ and $2 \mathrm{p} 1 / 2$ XPS peaks were centered at binding energies (BE) 458.6 and $464.36 \mathrm{eV}$ and the calculated $\Delta \mathrm{BE}$ value between Ti 2p1/2 and Ti $2 \mathrm{p} 3 / 2(\triangle \mathrm{BE}=\mathrm{BE}(\mathrm{Ti} 2 \mathrm{p} 1 / 2)-\mathrm{BE}(\mathrm{Ti} 2 \mathrm{p} 3 / 2))$ was $5.76 \mathrm{eV}$. These features are typical for the $\mathrm{Ti}^{4+}$-O bonds in $\mathrm{TiO}_{2}$ [18]. The Ti 2p3/2 and 2p1/2 XPS peaks of the $\mathrm{B}-\mathrm{TiO}_{2}$ nanoparticles were located at 459.25 and $465.0 \mathrm{eV}$, respectively, showing a BE positive shift of about $0.65 \mathrm{eV}$ compared with the peaks of the $\mathrm{W}-\mathrm{TiO}_{2}$ nanoparticles. However, the $\Delta \mathrm{BE}$ value between Ti $2 \mathrm{p} 1 / 2$ and Ti $2 \mathrm{p} 3 / 2$ was $5.75 \mathrm{eV}$, indicating a normal state of $\mathrm{Ti}^{4+}$ in the $\mathrm{B}^{-\mathrm{TiO}_{2}}$ nanoparticles. According to previous papers on black $\mathrm{TiO}_{2}$, when the valence of $\mathrm{Ti}$ changes to $\mathrm{Ti}^{3+}$, additional peaks at lower binding energies can be observed, or the peaks will show a negative shift in binding energy [41,42]. Our results confirmed 
that the charge states of the $\mathrm{Ti}$ atoms at the surface of the $\mathrm{B}-\mathrm{TiO}_{2}$ sample were $\mathrm{Ti}^{4+}$ and that no $\mathrm{Ti}^{3+}$ existed at the surface. Additionally, the same phenomenon appeared in the O 1s XPS spectra. Figure 5b shows the high-resolution $\mathrm{O} 1 \mathrm{~s}$ XPS spectra of the $\mathrm{W}-\mathrm{TiO}_{2}$ nanoparticles: there are two peaks located at about 529.88 and $531.66 \mathrm{eV}$, which were attributed to the $\mathrm{Ti}^{4+}-\mathrm{O}$ bond and to surface hydroxyl groups (Ti-OH bonds), respectively. Compared with the $\mathrm{W}-\mathrm{TiO}_{2}$ nanoparticles, the $\mathrm{O} 1 \mathrm{~s}$ XPS peak of the B- $-\mathrm{TiO}_{2}$ nanoparticles (Figure $5 \mathrm{c}$ ) located at $\sim 530.54 \mathrm{eV}$, also showed a clear positive shift in binding energy of about $0.66 \mathrm{eV}$, which is consistent with the Ti $2 \mathrm{p}$. The extra peak existing in the $\mathrm{O} 1 \mathrm{~s}$ spectra of the $\mathrm{B}_{-} \mathrm{TiO}_{2}$ nanoparticles at higher $\mathrm{BE}(\sim 532.91 \mathrm{eV})$ was ascribed to surface free $-\mathrm{OH}$ species [43]. Furthermore, the calculated value $\Delta \mathrm{BE}=\mathrm{BE}(\mathrm{O} 1 \mathrm{~s})-\mathrm{BE}(\mathrm{Ti} 2 \mathrm{p} 3 / 2)=530.54 \mathrm{eV}-459.25 \mathrm{eV}=71.29 \mathrm{eV}$, is close to that of anatase $(71.4 \mathrm{eV})$ and quite different from that of the characteristic $\mathrm{Ti}^{3+}$-containing oxides (72.9-73.1 eV) [44]. These features indicated that the valence state of Ti did not change in the $\mathrm{B}-\mathrm{TiO}_{2}$ nanoparticles. Reasonably, the clear positive shifts of binding energies of $\mathrm{Ti} 2 \mathrm{p}$ and $\mathrm{O} 1 \mathrm{~s}$ were ascribed to the strong interaction between $\mathrm{Ti}^{4+}$ and oxygen vacancies, revealing lattice distortions on the $\mathrm{B}-\mathrm{TiO}_{2}$ nanoparticles. It is possible that the oxygen vacancies, sustaining a positive charge, rejected the Ti atoms toward the adjacent oxygen atoms in the crystal structure of $\mathrm{B}-\mathrm{TiO}_{2}$, consequently reducing the Ti-O bond length as well as increasing the BE of Ti $2 \mathrm{p}$ and $\mathrm{O} 1 \mathrm{~s}[45,46]$. Therefore, the positive shift of the XPS peak is due to the shortening of the correlation length because of the presence of oxygen vacancies. The valence-band maxima were estimated by a linear extrapolation of the peaks to the baselines, which gave a band edge position of $2.7 \mathrm{eV}$ below the Fermi energy for both the $\mathrm{B}-\mathrm{TiO}_{2}$ and the $\mathrm{W}-\mathrm{TiO}_{2}$ nanoparticles, as shown in Figure $5 \mathrm{~d}$. Thus, the oxygen vacancies had a negligible effect on the valence-band position of the $\mathrm{B}^{-\mathrm{TiO}_{2}}$ nanoparticles surface.
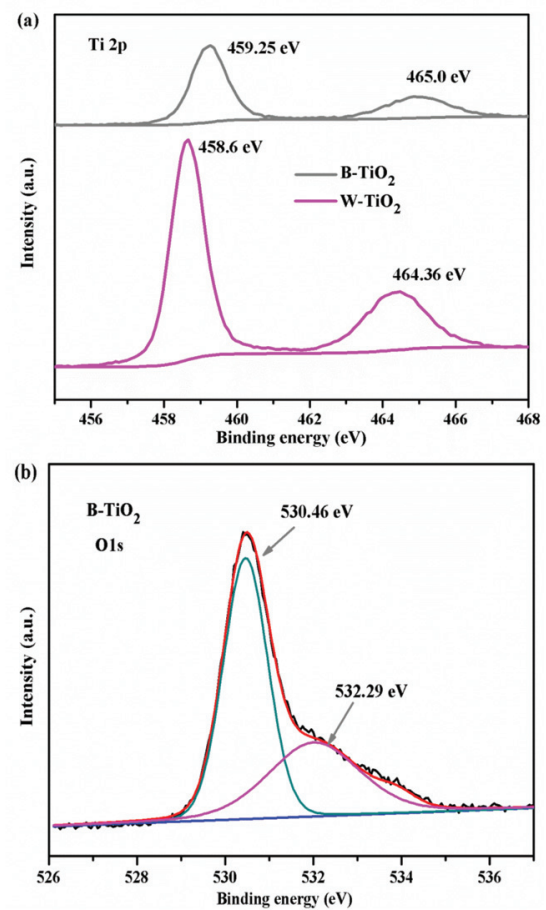

Figure 5. Cont. 

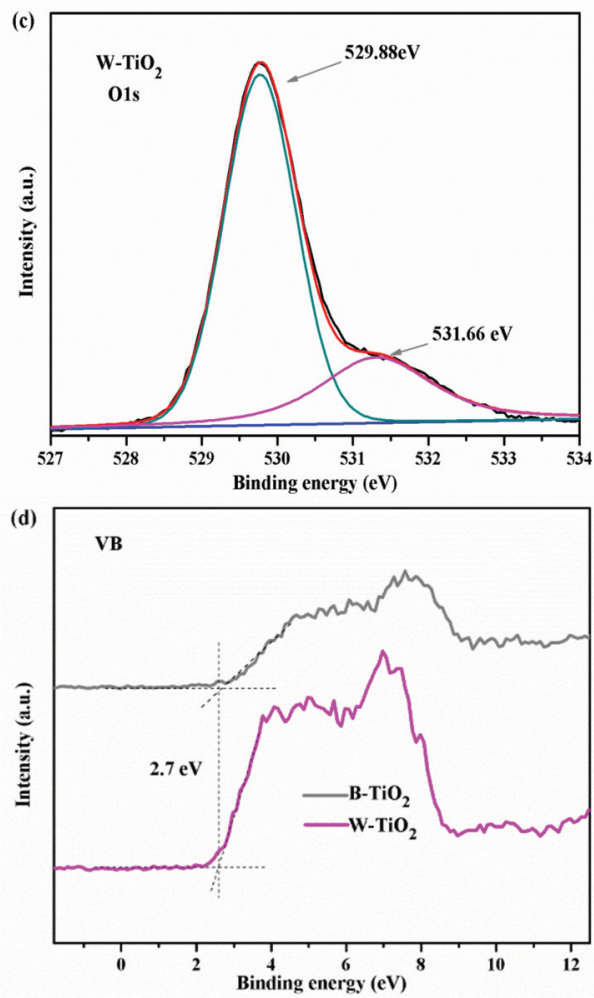

Figure 5. (a) The Ti 2p XPS spectra for the as-prepared $\mathrm{B}-\mathrm{TiO}_{2}$ and $\mathrm{W}-\mathrm{TiO}_{2}$ nanoparticles; (b) The O 1 s XPS spectra for $\mathrm{W}-\mathrm{TiO}_{2}$ nanoparticles and (c) the $\mathrm{O} 1$ s XPS spectra as-prepared $\mathrm{B}-\mathrm{TiO}_{2}$ nanoparticles along with the Gaussian fits; (d) Valence-band XPS spectra of $\mathrm{B}-\mathrm{TiO}_{2}$ and $\mathrm{W}-\mathrm{TiO}_{2}$ nanoparticles.

To gain further insights on the chemical changes produced in the $\mathrm{B}^{-\mathrm{TiO}_{2}}$ nanoparticles, Fourier transform infrared (FTIR) spectroscopic measurements were performed, as shown in Figure 6a. Both the $\mathrm{B}_{-}-\mathrm{TiO}_{2}$ and $\mathrm{W}-\mathrm{TiO}_{2}$ nanoparticles showed similar absorption features from $500 \mathrm{~cm}^{-1}$ to $4000 \mathrm{~cm}^{-1}$. Characteristic features of the spectrum are the presence of a band at $\sim 710 \mathrm{~cm}^{-1}$, due to the symmetric stretching vibrations of the Ti-O-Ti bonds of $\mathrm{TiO}_{2}$ and of a peak at about $\sim 3418 \mathrm{~cm}^{-1}$, attributed to the stretching vibration mode of hydroxyls and adsorbed water [47]. Compared with the $\mathrm{W}-\mathrm{TiO}_{2}$ nanoparticles, the infrared absorption of the $\mathrm{B}-\mathrm{TiO}_{2}$ nanoparticles decreased greatly at $\sim 710 \mathrm{~cm}^{-1}$. This change can be attributed to the presence of a high concentration of oxygen vacancies in the $\mathrm{B}-\mathrm{TiO}_{2}$ nanoparticles [48].

The photoluminescence (PL) spectra of the $\mathrm{B}-\mathrm{TiO}_{2}$ and $\mathrm{W}-\mathrm{TiO}_{2}$ nanoparticles were assessed to investigate the behavior of the electron-hole recombination, which are very important for the photocatalytic activity. Their emission spectra, in the wavelength range of 320-560 nm with excitation at $300 \mathrm{~nm}$, are shown in Figure $6 \mathrm{~b}$ and were very similar. The main emission peaks of the $\mathrm{W}-\mathrm{TiO}_{2}$ nanoparticles appeared at $395 \mathrm{~nm}(3.1 \mathrm{eV}), 436 \mathrm{~nm}(2.8 \mathrm{eV}), 451 \mathrm{~nm}(2.75 \mathrm{eV})$ and $459 \mathrm{~nm}(2.7 \mathrm{eV})$, respectively. The first one is attributed to the bandgap transition, corresponding to the bandgap energy of anatase. The peaks at $451 \mathrm{~nm}$ and $459 \mathrm{~nm}$ were attributed to band-edge free excitons [47]. The PL peak intensities of the $\mathrm{B}-\mathrm{TiO}_{2}$ nanoparticles showed a significant decrease compared with those of the $\mathrm{W}-\mathrm{TiO}_{2}$ nanoparticles. Furthermore, the main emission peak at $395 \mathrm{~nm}(3.1 \mathrm{eV})$, could not be observed, which indicated that the recombination rate of photo-generated electrons and holes had been considerably inhibited in the $\mathrm{B}-\mathrm{TiO}_{2}$ nanoparticles [49]. Given the fact that oxygen vacancies 
usually serve as electron traps, the weaker intensity of emission and disappearance of the emission peak at $395 \mathrm{~nm}$ should be due to the increased oxygen vacancies. All the results indicated that the $\mathrm{B}-\mathrm{TiO}_{2}$ nanoparticles had a relative low recombination rate of electrons and holes. Normally, the low recombination rate of electrons and holes favors high photocatalytic activity.
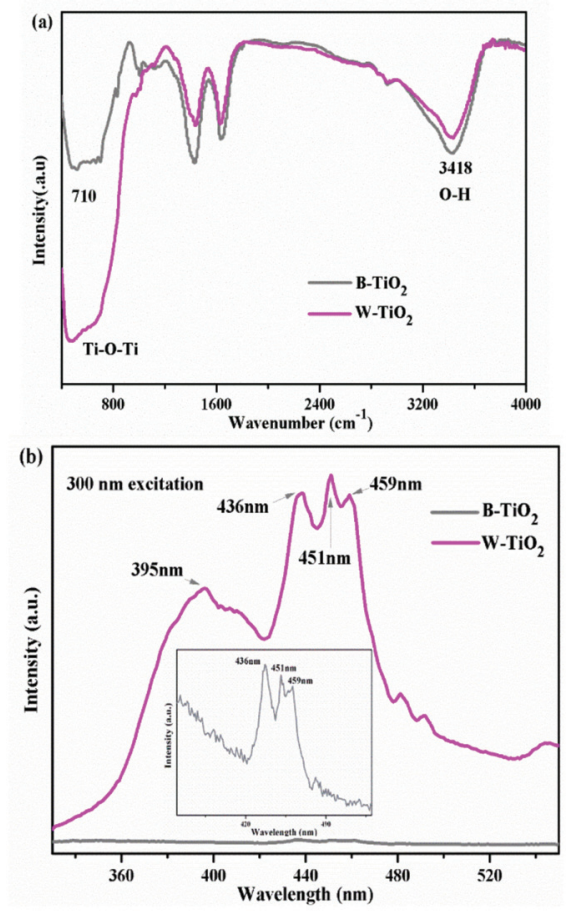

Figure 6. (a) FT-IR spectra of $\mathrm{B}-\mathrm{TiO}_{2}$ and $\mathrm{W}-\mathrm{TiO}_{2}$ nanoparticles; (b) Photoluminescence spectra of $\mathrm{B}-\mathrm{TiO}_{2}$ and $\mathrm{W}-\mathrm{TiO}_{2}$ nanoparticles.

\subsection{Photocatalytic Activity}

The photocatalytic activities of the as-prepared samples were evaluated by monitoring the decomposition of RhB in an aqueous solution under UV light irradiation. Commercial $\mathrm{W}-\mathrm{TiO}_{2}$ nanoparticles were used as the reference photocatalyst. Before the irradiation of these samples, an adsorption experiment was performed in the dark in order to ensure the adsorption equilibrium of $\mathrm{RhB}$ and $\mathrm{MB}$ on the catalyst surface. As shown in Figure $7 \mathrm{a}$, the $\mathrm{B}-\mathrm{TiO}_{2}$ nanoparticles distinctly showed much better photocatalytic activity than the $\mathrm{W}-\mathrm{TiO}_{2}$ nanoparticles. After 20 min of UV-light irradiation, the $\mathrm{B}-\mathrm{TiO}_{2}$ nanoparticles could decompose about $50 \%$ of the $\mathrm{RhB}$ dye, while the value for the $\mathrm{W}-\mathrm{TiO}_{2}$ nanoparticles was very low $(\sim 10 \%)$. When the irradiation time was prolonged to $60 \mathrm{~min}$, the RhB dye was almost completely decomposed $(96.2 \%)$ by the $\mathrm{B}-\mathrm{TiO}_{2}$ nanoparticles but the $\mathrm{W}-\mathrm{TiO}_{2}$ nanoparticles only decomposed about $40 \%$. The Figure 7 a also shows that the photocatalytic decomposition of RhB, for the two samples, followed a pseudo-first-order reaction [50]; the pseudo-first-order kinetics of the decompositions are illustrated in Figure $7 \mathrm{~b}$. The $\mathrm{B}-\mathrm{TiO}_{2}$ nanoparticles showed a first-order rate constant of $\mathrm{k}_{\mathrm{app}}=0.036 \mathrm{~min}^{-1}, 4.5$ times greater than that of the $\mathrm{W}-\mathrm{TiO}_{2}$ nanoparticles $\left(\mathrm{k}_{\mathrm{app}}=0.008 \mathrm{~min}^{-1}\right)$, under UV light irradiation. 

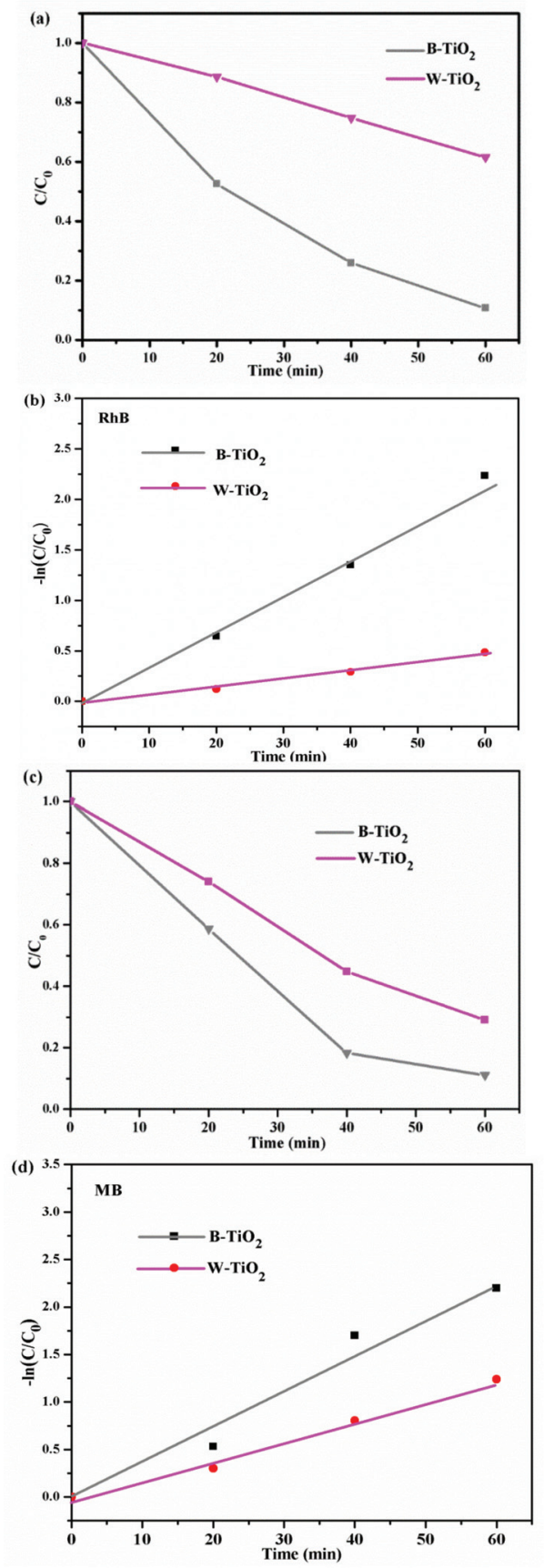

Figure 7. Cont. 

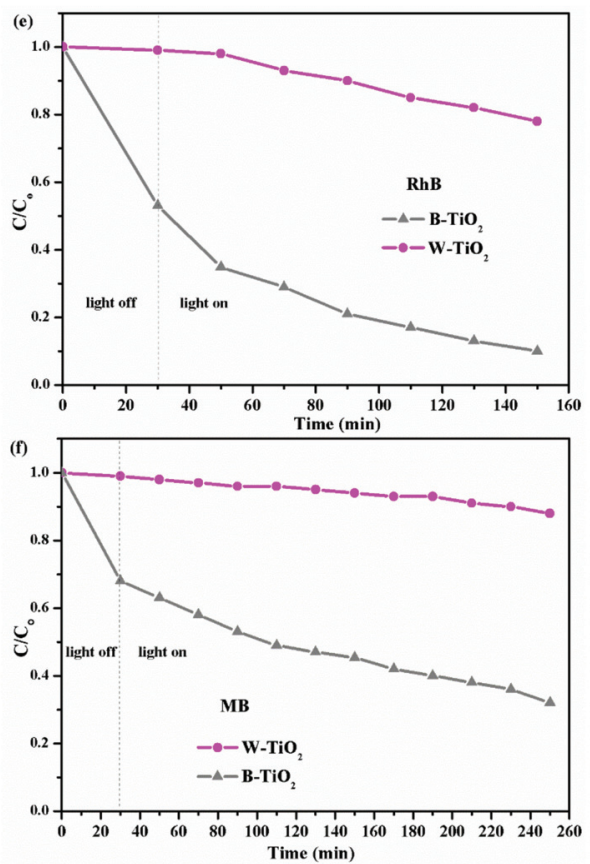

Figure 7. Comparison of photodecomposition of $\mathrm{RhB}(\mathbf{a})$ and $\mathrm{MB}$ (c) with different photocatalysts under UV light. $-\ln \left(\mathrm{C} / \mathrm{C}_{0}\right)$ of the $\mathrm{RhB}(\mathbf{b})$ and $\mathrm{MB}(\mathbf{d})$ concentration as a function of UV light irradiation time. Photodecomposition of $\mathrm{RhB}(\mathbf{e})$ and $\mathrm{MB}(\mathbf{f})$ with different photocatalysts under visible light.

The UV-light photocatalytic activity of the $\mathrm{B}-\mathrm{TiO}_{2}$ nanoparticles was further evaluated by measuring the photo-catalytic-degradation efficiency of the $\mathrm{MB}$ dye in aqueous solution. As shown in Figure 7c, under UV-light irradiation, in the short period of $20 \mathrm{~min}$, the $\mathrm{B}-\mathrm{TiO}_{2}$ nanoparticles could decomposed about $40 \%$ of the original organic MB dye. After 60 min irradiation, the MB dye had been almost completely decomposed $(95.2 \%)$ by the $\mathrm{B}-\mathrm{TiO}_{2}$ nanoparticles. In contrast, the $\mathrm{W}-\mathrm{TiO}_{2}$ nanoparticles photocatalyst were able to decompose only about $70 \%$ of the original $\mathrm{MB}$ after $60 \mathrm{~min}$ irradiation. Figure $7 \mathrm{~d}$ shows that the first-order rate constants of the $\mathrm{B}-\mathrm{TiO}_{2}$ and $\mathrm{W}-\mathrm{TiO}_{2}$ nanoparticles were $0.036 \mathrm{~min}^{-1}$ and $0.02 \mathrm{~min}^{-1}$, respectively. The as-prepared $\mathrm{B}-\mathrm{TiO}_{2}$ nanoparticles had about 1.8 times better MB-decomposing photocatalytic activity than the $\mathrm{W}-\mathrm{TiO}_{2}$ nanoparticles, under the same conditions.

The photocatalytic activity of the $\mathrm{B}-\mathrm{TiO}_{2}$ sample was also investigated under visible light $(\lambda>420 \mathrm{~nm})$ illumination, as shown in Figure 7e,f. Figure 7e shows the photodecomposition of $\mathrm{RhB}$ by $\mathrm{B}-\mathrm{TiO}_{2}$ and $\mathrm{W}-\mathrm{TiO}_{2}$ samples. Under visible light illumination, the $\mathrm{RhB}$ solutions containing the $\mathrm{B}-\mathrm{TiO}_{2}$ undergo significant decomposition and became nearly transparent within $150 \mathrm{~min}$. In contrast, $\mathrm{W}-\mathrm{TiO}_{2}$ exhibits limited activity on photodecomposition of $\mathrm{RhB}$ solution. We also evaluated the decomposition of $\mathrm{MB}$ dye solution as a model reaction under visible-light irradiation, shown in Figure 7f. The photocatalytic efficiency of $\mathrm{B}_{-} \mathrm{TiO}_{2}$ under these conditions is $34 \%$, which is higher than that of $\mathrm{W}-\mathrm{TiO}_{2}(88 \%)$ after an irradiation time of $250 \mathrm{~min}$. Thus, the $\mathrm{B}-\mathrm{TiO}_{2}$ samples clearly exhibit improved photocatalytic activity. 


\subsection{Mechanism}

In this work, the $\mathrm{B}_{-} \mathrm{TiO}_{2}$ nanoparticles greatly extended their absorption range from the UVto visible- to infrared-light regions and their photocatalytic activity was greatly improved. All the characterization results proved that this $\mathrm{B}-\mathrm{TiO}_{2}$ behavior is attributable to its high concentration of oxygen vacancies. The oxygen vacancies have been demonstrated to be electron donors in $\mathrm{TiO}_{2}$ [51] and have been considered to contribute to the enhanced donor density in $\mathrm{B}^{-\mathrm{TiO}_{2}}$ nanoparticles [27]. The electrons located on the oxygen vacancy states have a direct effect on the electronic structure of $\mathrm{TiO}_{2}$ by forming a donor level below the conduction band. The oxygen vacancies introduced localized states at $0.75-1.18 \mathrm{eV}$ below the $\mathrm{TiO}_{2}$ conduction band minimum [46]. Consequently, the visible and near infrared-light absorptions are associated with transitions from the $\mathrm{B}-\mathrm{TiO}_{2}$ valence band to the oxygen vacancy levels or from the oxygen vacancies to the $\mathrm{TiO}_{2}$ conduction band or with transitions from the ground state of the $\mathrm{F}^{+}$center to its corresponding excited state $\mathrm{F}^{+*}$. In order to further understand our $\mathrm{B}-\mathrm{TiO}_{2}$ nanoparticles, the energy band diagram of the $\mathrm{B}-\mathrm{TiO}_{2}$ nanoparticles is schematized in Figure 8. The valence band maximum (VBM) and conduction band minimum (CBM) of $\mathrm{TiO}_{2}$ are derived mainly from the $\mathrm{O} 2 \mathrm{p}$ orbitals and the $\mathrm{Ti} 3 \mathrm{~d}$ orbitals, respectively. According to the $\mathrm{UV}$-vis absorbance spectra, the bandgap of both the $\mathrm{B}-\mathrm{TiO}_{2}$ and the $\mathrm{W}-\mathrm{TiO}_{2}$ nanoparticles was $3.1 \mathrm{eV}$. Furthermore, the increased oxygen vacancies can improve charge transport in $\mathrm{TiO}_{2}$ and shift its Fermi level toward the conduction band, facilitating the charge separation at the semiconductor/electrolyte interface [52,53]. The PL results also indicated that, in our experiments, the $\mathrm{B}^{-} \mathrm{TiO}_{2}$ nanoparticles had a low recombination rate of electrons and holes. A low recombination rate leads to a large increase in photocatalytic activity.

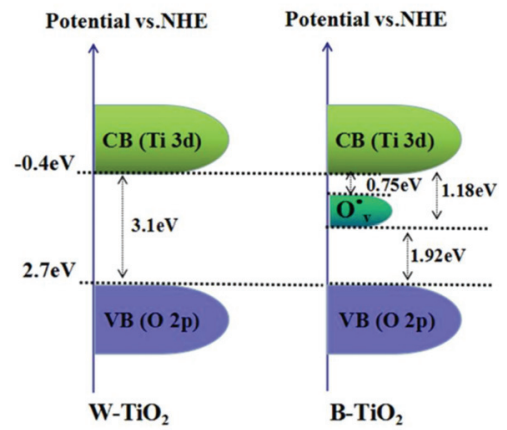

Figure 8. The band energy diagram of $\mathrm{B}-\mathrm{TiO}_{2}$ and $\mathrm{W}-\mathrm{TiO}_{2}$ nanoparticles.

\section{Conclusions}

The present work deals with the development of a facile method for the preparation of a highly active black $\mathrm{TiO}_{2}$ photocatalyst. The black $\mathrm{TiO}_{2}$ was prepared via low temperature annealing of commercial $\mathrm{W}-\mathrm{TiO}_{2}$ catalyst nanoparticles. The prepared $\mathrm{B}-\mathrm{TiO}_{2}$ nanoparticles showed remarkable photocatalytic activity for the degradation of the RhB and MB dyes. An appropriate amount of oxygen vacancies was introduced into the $\mathrm{B}-\mathrm{TiO}_{2}$ nanoparticles and $\mathrm{Ti}^{3+}$ ions were not found. The oxygen vacancies are responsible for the increased visible-and infrared-light absorption as they can introduce localized states into the bandgap. At the same time, the oxygen vacancies act as traps for reducing the recombination of electrons and holes and significantly improve the e-h separation efficiency, thus greatly enhancing the photocatalytic activity.

Acknowledgments: This work is supported by the National Nature Science Foundation of China (No. 21271048), Natural Science Foundation of China (11747074), Guangdong province science and technology plan project public welfare fund and ability construction project (2016A010103041, 2017A010103025), Doctoral Program of Lingnan Normal University (ZL1503), China Spark Program (2015GA780058). 
Author Contributions: Shihao Chen: performed photocatalysts synthesis, XRD, Raman, TEM, UV-visible absorption spectra analysis, photocatalytic activity tests and wrote the manuscript, Yang Xiao: supervised rhodamine B and methylene blue products analysis in cooperation with Shihao Chen, Yinhai Wang: conceived the concept, designed the experiments, analyzed the data and revised the manuscript, Zhengfa Hu: performed EPR analysis, Hui Zhao: performed XPS analysis, Wei Xie: performed FTIR and PL analysis .

Conflicts of Interest: The authors declare no conflict of interest.

\section{References}

1. Fujishima, A.; Honda, K. Electrochemical Photolysis of Water at a Semiconductor Electrode. Nature 1972, 238, 37-38. [CrossRef] [PubMed]

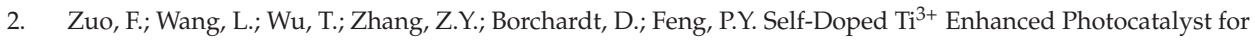
Hydrogen Production under Visible Light. J. Am. Chem. Soc. 2010, 132, 11856-11857. [CrossRef] [PubMed]

3. Shao, J.; Sheng, W.C.; Wang, M.S.; Lia, S.J.; Chen, J.R.; Zhang, Y.; Cao, S.S. In situ Synthesis of Carbon-doped $\mathrm{TiO}_{2}$ Single-crystal Nanorods with Aremarkably Photocatalytic Efficiency. Appl. Catal. B Environ. 2017, 209, 311-319. [CrossRef]

4. Yu, J.G.; Low, J.X.; Xiao, W.; Zhou, P.; Jaroniec, M. Enhanced Photocatalytic $\mathrm{CO}_{2}$-Reduction Activity of Anatase $\mathrm{TiO}_{2}$ by Coexposed $\{001\}$ and $\{101\}$ Facets. J. Am. Chem. Soc. 2014, 136, 8839-8842. [CrossRef] [PubMed]

5. Wang, W.; Ni, Y.R.; Lu, C.H.; Xu, Z.Z. Hydrogenation Temperature Related Inner Structures and Visible-light-driven Photocatalysis of N-F co-doped $\mathrm{TiO}_{2}$ Nanosheets. Appl. Surf. Sci. 2014, 290, 125-130. [CrossRef]

6. Liu, B.; Chen, H.M.; Liu, C.; Andrews, S.C.; Hahn, C.; Yang, P.D. Large-Scale Synthesis of Transition-Metal-Doped $\mathrm{TiO}_{2}$ Nanowires with Controllable Overpotential. J. Am. Chem. Soc. 2013, 135, 9995-9998. [CrossRef] [PubMed]

7. Inturi, S.N.R.; Boningari, T.; Suidan, M.; Smirniotis, P.G. Flame Aerosol Synthesized Cr Incorporated $\mathrm{TiO}_{2}$ for Visible Light Photodegradation of Gas Phase Acetonitrile. J. Phys. Chem. C 2014, 118, 231-242. [CrossRef]

8. Chen, Z.Y.; Fang, L.; Dong, W.; Zheng, F.G.; Shen, M.R.; Wang, J.L. Inverse Opal Structured Ag/ TiO Plasmonic Photocatalyst Prepared by Pulsed Current Deposition and its Enhanced Visible Light Photocatalytic Activity. J. Mater. Chem. A 2014, 2, 824-832. [CrossRef]

9. Kamegawa, T.; Matsuura, S.; Seto, H.; Yamashita, H. A Visible-Light-Harvesting Assembly with a Sulfocalixarene Linker between Dyes and a Pt-TiO ${ }_{2}$ Photocatalyst. Angew. Chem. Int. Ed. 2013, 52, 916-919. [CrossRef] [PubMed]

10. Pan, J.H.; Cai, Z.Y.; Yu, Y.; Zhao, X.S. Controllable Synthesis of Mesoporous $\mathrm{F}-\mathrm{TiO}_{2}$ Spheres for Effective Photocatalysis. J. Mater. Chem. 2011, 21, 11430-11438. [CrossRef]

11. Senna, M.; Myers, N.; Aimable, A.; Laporte, V.; Pulgarin, C.; Baghriche, O.; Bowen, P. Modification of titania nanoparticles for photocatalytic antibacterial activity via a colloidal route with glycine and subsequent annealing. J. Mater. Res. 2013, 28, 354-361. [CrossRef]

12. Milosevic, I.; Jayaprakash, A.; Greenwood, B.; van Driel, B.; Rtimi, S.; Bowen, P. Synergistic Effect of Fluorinated and $\mathrm{N}$ Doped $\mathrm{TiO}_{2}$ Nanoparticles Leading to Different Microstructure and Enhanced Photocatalytic Bacterial Inactivation. Nanomaterials 2017, 7, 391. [CrossRef] [PubMed]

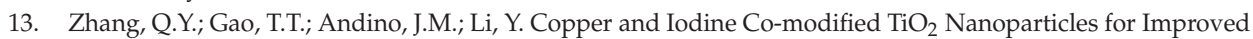
Activity of $\mathrm{CO}_{2}$ Photo Reduction with Water Vapor. Appl. Catal. B Environ. 2012, 123, 257-264. [CrossRef]

14. Zhang, M.; Wu, J.; Hou, J.; Yang, J.J. Molybdenum and Nitrogen Co-doped Titanium Dioxide Nanotube Arrays with Enhanced Visible Light Photocatalytic Activity. Sci. Adv. Mater. 2013, 5, 535-541. [CrossRef]

15. Chen, X.B.; Liu, L.; Yu, P.Y.; Mao, S.S. Increasing Solar Absorption for Photocatalysis with Black Hydrogenated Titanium Dioxide Nanocrystals. Science 2011, 331, 746-750. [CrossRef] [PubMed]

16. Shin, J.Y.; Joo, J.H.; Samuelis, D.; Maier, J. Oxygen-Deficient $\mathrm{TiO}_{2-\delta}$ Nanoparticles via Hydrogen Reduction for High Rate Capability Lithium Batteries. Chem. Mater. 2012, 24, 543-551. [CrossRef]

17. Samsudina, E.M.; Hamida, S.B.A.; Juana, J.C.; Basiruna, W.J.; Kandjani, A.E. Surface Modification of Mixed-phase Hydrogenated $\mathrm{TiO}_{2}$ and Corresponding Photocatalytic Response. Appl. Surf. Sci. 2015, 359, 883-896. [CrossRef]

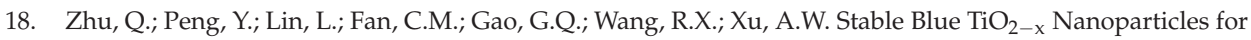
Efficient Visible Light Photocatalysts. J. Mater. Chem. A 2014, 2, 4429-4437. [CrossRef] 
19. Zou, X.X.; Liu, J.K.; Su, J.; Zuo, F.; Chen, J.S.; Feng, P.Y. Facile Synthesis of Thermal-and Photostable Titania with Paramagnetic Oxygen Vacancies for Visible-Light Photocatalysis. Chem. Eur. J. 2013, 19, 2866-2873. [CrossRef] [PubMed]

20. Kang, Q.; Cao, J.Y.; Zhang, Y.J.; Liu, L.Q.; Xu, H.; Ye, J.H. Reduced $\mathrm{TiO}_{2}$ Nanotube Arrays for Photoelectrochemical Water Splitting. J. Mater. Chem. A 2013, 1, 5766-5774. [CrossRef]

21. Liu, N.; Schneider, C.; Freitag, D.; Hartmann, M.; Venkatesan, U.; Müller, J.; Spiecker, E.; Schmuki, P. Black $\mathrm{TiO}_{2}$ Nanotubes: Cocatalyst-Free Open-Circuit Hydrogen Generation. Nano Lett. 2014, 14, 3309-3313. [CrossRef] [PubMed]

22. Wang, Z.; Yang, C.Y.; Lin, T.Q.; Yin, H.; Chen, P.; Wan, D.Y.; Xu, F.F.; Huang, F.Q.; Lin, J.H.; Xie, X.M.; et al. Visible-light Photocatalytic, Solar Thermal and Photoelectrochemical Properties of Aluminium-reduced Black Titania. Energy Environ. Sci. 2013, 6, 3007-3014. [CrossRef]

23. Sinhamahapatra, A.; Jeon, J.P.; Yu, J.S. A New Approach to Prepare Highly Active and Stable Black Titania for Visible Light-assisted Hydrogen Production. Energy Environ. Sci. 2015, 8, 3539-3544. [CrossRef]

24. Zhou, X.M.; Zolnhofer, E.M.; Nguyen, N.T.; Liu, N.; Meyer, K.; Schmuki, P. Stable Co-Catalyst-Free Photocatalytic $\mathrm{H}_{2}$ Evolution From Oxidized Titanium Nitride Nanopowders. Angew. Chem. Int. Ed. 2015, 54, 13385-13389. [CrossRef] [PubMed]

25. Liu, X.; Gao, S.; Xu, H.; Lou, Z.Z.; Wang, W.J.; Huang, B.B.; Dai, Y. Green Synthetic Approach for Ti ${ }^{3+}$ Self-doped $\mathrm{TiO}_{2-x}$ Nanoparticles with Efficient Visible Light Photocatalytic Activity. Nanoscale 2013, 5, 1870-1875. [CrossRef] [PubMed]

26. Pei, Z.X.; Ding, L.Y.; Lin, H.; Weng, S.X.; Zheng, Z.Y.; Hou, Y.D.; Liu, P. Facile Synthesis of Defect-mediated $\mathrm{TiO}_{2-\mathrm{x}}$ with Enhanced Visible Light Pphotocatalytic Activity. J. Mater. Chem. A 2013, 1, 10099-10102. [CrossRef]

27. Wang, G.M.; Wang, H.Y.; Ling, Y.C.; Tang, Y.C.; Yang, X.Y.; Fitzmorris, R.C.; Wang, C.C.; Zhang, J.Z.; Li, Y. Hydrogen-Treated $\mathrm{TiO}_{2}$ Nanowire Arrays for Photoelectrochemical Water Splitting. Nano Lett. 2011, 11, 3026-3033. [CrossRef] [PubMed]

28. Dong, J.Y.; Han, J.; Liu, Y.S.; Nakajima, A.; Matsushita, S.; Wei, S.H.; Gao, W. Defective Black $\mathrm{TiO}_{2}$ Synthesized via Anodization for Visible-Light Photocatalysis. ACS Appl. Mater. Interfaces 2014, 6, 1385-1388. [CrossRef] [PubMed]

29. Liu, X.Y.; Zhu, G.L.; Wang, X.; Yuan, X.T.; Lin, T.Q.; Huang, F.Q. Progress in Black Titania: A New Material for Advanced Photocatalysis. Adv. Energy Mater. 2016, 6, 1600452. [CrossRef]

30. Fan, C.Y.; Chen, C.; Wang, J.; Fu, X.X.; Ren, Z.M.; Qian, G.D.; Wang, Z.Y. Black Hydroxylated Titanium Dioxide Prepared via Ultrasonication with Enhanced Photocatalytic Activity. Sci. Rep. 2015, 5, 11712. [CrossRef] [PubMed]

31. Pan, H.; Zhang, Y.W.; Shenoy, V.B.; Gao, H.J. Effects of H-, N-, and (H, N)-Doping on the Photocatalytic Activity of $\mathrm{TiO}_{2}$. J. Phys. Chem. C 2011, 115, 12224-12231. [CrossRef]

32. Wang, Z.Q.; Wen, B.; Hao, Q.Q.; Liu, L.M.; Zhou, C.Y.; Mao, X.C.; Lang, X.F.; Yin, W.J.; Dai, D.X.; Selloni, A.; et al. Localized Excitation of $\mathrm{Ti}^{3+}$ Ions in the Photoabsorption and Photocatalytic Activity of Reduced Rutile $\mathrm{TiO}_{2}$. J. Am. Chem. Soc. 2015, 137, 9146-9152. [CrossRef] [PubMed]

33. Wang, W.; Lu, C.H.; Ni, Y.R.; Song, J.B.; Su, M.X.; Xu, Z.Z. Enhanced Visible-light Photoactivity of $\{001\}$ Facets Dominated $\mathrm{TiO}_{2}$ Nanosheets with Even Distributed Bulk Oxygen Vacancy and $\mathrm{Ti}^{3+}$. Catal. Commun. 2012, 22, 19-23. [CrossRef]

34. Chen, X.B.; Liu, L.; Liu, Z.; Marcus, M.A.; Wang, W.C.; Oyler, N.A.; Grass, M.E.; Mao, B.H.; Glans, P.A.; Yu, P.Y. Properties of Disorder-engineered Black Titanium Dioxide Nanoparticles Through Hydrogenation. Sci. Rep. 2013, 3, 1510. [CrossRef] [PubMed]

35. Gupta, S.K.; Desai, R.; Jha, P.K.; Sahoob, S.; Kirinc, D. Titanium Dioxide Synthesized Using Titanium Chloride: Size Effect Study Using Raman Spectroscopy and Photoluminescence. J. Raman Spectrosc. 2010, 41, 350-355. [CrossRef]

36. Parker, J.C.; Siegel, R.W. Calibration of the Raman Spectrum to the Oxygen Stoichiometry of Nanophase $\mathrm{TiO}_{2}$. Appl. Phys. Lett. 1990, 57, 943-945. [CrossRef]

37. Liu, H.; Ma, H.T.; Li, X.Z.; Li, W.Z.; Wu, M.; Bao, X.H. The Enhancement of $\mathrm{TiO}_{2}$ Photocatalytic Activity by Hydrogen Thermal Treatment. Chemosphere 2003, 50, 39-46. [CrossRef]

38. Mao, L.; Cai, X.Y.; Gao, H.; Diao, X.G.; Zhang, J.Y. A Newly Designed Porous Oxynitride Photoanode with Enhanced Charge Carrier Mobility. Nano Energy 2017, 39, 172-182. [CrossRef] 
39. Serpone, N. Is the Band Gap of Pristine $\mathrm{TiO}_{2}$ Narrowed by Anion-and Cation-Doping of Titanium Dioxide in Second-Generation Photocatalysts? J. Phys. Chem. B 2006, 110, 24287-24293. [CrossRef] [PubMed]

40. Chen, J.; Lin, L.B.; Jing, F.Q. Theoretical Study of F-type Color Center in Rutile $\mathrm{TiO}_{2}$. J. Phys. Chem. Solids 2001, 62, 1257-1262. [CrossRef]

41. Chen, J.; Song, W.X.; Hou, H.S.; Zhang, Y.; Jing, M.J.; Jia, X.N.; Ji, X.B. Ti ${ }^{3+}$ Self-Doped Dark Rutile $\mathrm{TiO}_{2}$ Ultrafine Nanorods with Durable High-Rate Capability for Lithium-Ion Batteries. Adv. Funct. Mater. 2015, 25, 6793-6801. [CrossRef]

42. Huo, J.C.; Hu, Y.J.; Jiang, H.; Li, C.Z. In Situ Surface Hydrogenation Synthesis of $\mathrm{Ti}^{3+}$ Self-doped $\mathrm{TiO}_{2}$ with Enhanced Visible Light Photoactivity. Nanoscale 2014, 6, 9078-9084. [CrossRef] [PubMed]

43. Ullattila, S.G.; Periyat, P. A 'One Pot' Gel Combustion Strategy towards Ti ${ }^{3+}$ Self-doped 'black' Anatase $\mathrm{TiO}_{2-\mathrm{x}}$ Solar Photocatalyst. J. Mater. Chem. A 2016, 4, 5854-5858. [CrossRef]

44. Atuchin, V.V. Comment on "A 'one pot' Gel Combustion Strategy towards Ti ${ }^{3+}$ Self-doped 'black' Anatase $\mathrm{TiO}_{2-x}$ Solar Photocatalyst," by S.G. Ullattil and P. Periyat, J. Mater. Chem. A, 2016, 4, 5854. J. Mater. Chem. A 2017, 5, 426-427. [CrossRef]

45. Pan, X.Y.; Yang, M.Q.; Fu, X.Z.; Zhang, N.; Xu, Y.J. Defective $\mathrm{TiO}_{2}$ with Oxygen Vacancies: Synthesis, Properties and Photocatalytic Applications. Nanoscale 2013, 5, 3601-3614. [CrossRef] [PubMed]

46. Moya, A.; Cherevan, A.; Marchesan, S.; Gebhardt, P.; Prato, M.; Eder, D.; Vilatela, J.J. Oxygen Vacancies and Interfaces Enhancing Photocatalytic Hydrogen Production in Mesoporous CNT/ $\mathrm{TiO}_{2} \mathrm{Hybrids}$. Appl. Catal. B Environ. 2015, 179, 574-582. [CrossRef]

47. Wang, Z.; Yang, C.Y.; Lin, T.Q.; Yin, H.; Chen, P.; Wan, D.Y.; Xu, F.F.; Huang, F.Q.; Lin, J.H.; Xie, X.M.; et al. H-Doped Black Titania with Very High Solar Absorption and Excellent Photocatalysis Enhanced by Localized Surface Plasmon Resonance. Adv. Funct. Mater. 2013, 23, 5444-5450. [CrossRef]

48. Sharma, P.K.; Pandey, A.C.; Zolnierkiewicz, G.; Guskos, N.; Rudowicz, C. Relationship between Oxygen Defects and the Photoluminescence Property of ZnO Nanoparticles: A Spectroscopic View. J. Appl. Phys. 2009, 106, 094314. [CrossRef]

49. Tian, Z.L.; Cui, H.L.; Zhu, G.L.; Zhao, W.L.; Xu, J.J.; Shao, F.; He, J.Q.; Huang, F.Q. Hydrogen Plasma Reduced Black $\mathrm{TiO}_{2}-\mathrm{B}$ Nanowires for Enhanced Photoelectrochemical Water-Splitting. J. Power Sources 2016, 325, 697-705. [CrossRef]

50. Komaguchi, K.; Maruoka, T.; Nakano, H.; Imae, I.; Ooyama, Y.; Harima, Y. Electron-Transfer Reaction of Oxygen Species on $\mathrm{TiO}_{2}$ Nanoparticles Induced by Sub-band-gap Illumination. J. Phys. Chem. C 2010, 114, 1240-1245. [CrossRef]

51. Janotti, A.; Varley, J.B.; Rinke, P.; Umezawa, N.; Kresse, G.; Van de Walle, C.G. Hybrid Functional Studies of the Oxygen Vacancy in $\mathrm{TiO}_{2}$. Phys. Rev. B 2010, 81, 085212. [CrossRef]

52. Cronemeyer, D.C. Infrared Absorption of Reduced Rutile $\mathrm{TiO}_{2}$ Single Crystals. Phys. Rev. 1959, 113, 1222-1226. [CrossRef]

53. $\mathrm{Hu}$, Y.H. A Highly Efficient Photocatalyst-Hydrogenated Black $\mathrm{TiO}_{2}$ for the Photocatalytic Splitting of Water. Angew. Chem. Int. Ed. 2012, 51, 12410-12412. [CrossRef] [PubMed]

(C) 2018 by the authors. Licensee MDPI, Basel, Switzerland. This article is an open access article distributed under the terms and conditions of the Creative Commons Attribution (CC BY) license (http:/ / creativecommons.org/licenses/by/4.0/). 
Article

\title{
A Facile Method for the Preparation of Colored $\mathrm{Bi}_{4} \mathrm{Ti}_{3} \mathrm{O}_{12-x}$ Nanosheets with Enhanced Visible-Light Photocatalytic Hydrogen Evolution Activity
}

\author{
Yizeng Zhang ${ }^{1}$, Zhiwu Chen ${ }^{1,2, *}$ and Zhenya $\mathrm{Lu}^{1}$ \\ 1 College of Materials Science and Engineering, South China University of Technology, Guangzhou 510640, \\ China; zyzdd286@163.com (Y.Z.); zhylu@scut.edu.cn (Z.L.) \\ 2 State Key Laboratory of Pulp and Paper Engineering, South China University of Technology, \\ Guangzhou 510640, China \\ * Correspondence: chenzw@scut.edu.cn; Tel.: +86-20-22236602
}

Received: 15 March 2018; Accepted: 16 April 2018; Published: 21 April 2018

\begin{abstract}
Bi}_{4} \mathrm{Ti}_{3} \mathrm{O}_{12-x}$ nanosheet photocatalysts with abundant oxygen vacancies are fabricated by a facile solid-state chemical reduction method for the first time. This method is simple in operation, has short reaction time, and can be conducted at mild temperatures $\left(300 \sim 400{ }^{\circ} \mathrm{C}\right)$. The electron paramagnetic resonance, thermogravimetric analysis, $\mathrm{X}$-ray photoelectron spectrometer, and positron annihilation lifetime spectra results indicate that oxygen vacancies are produced in $\mathrm{Bi}_{4} \mathrm{Ti}_{3} \mathrm{O}_{12-x}$, and they can be adjusted by tuning the reduction reaction conditions. Control experiments show that the reduction time and temperature have great influences on the photocatalytic activities of $\mathrm{Bi}_{4} \mathrm{Ti}_{3} \mathrm{O}_{12-x}$. The optimal $\mathrm{Bi}_{4} \mathrm{Ti}_{3} \mathrm{O}_{12-x}$ is the sample undergoing the reduction treatment at $350{ }^{\circ} \mathrm{C}$ for $60 \mathrm{~min}$ and it affords a hydrogen evolution rate of $129 \mu \mathrm{mol} \cdot \mathrm{g}^{-1} \cdot \mathrm{h}^{-1}$ under visible-light irradiation, which is about 3.4 times that of the pristine $\mathrm{Bi}_{4} \mathrm{Ti}_{3} \mathrm{O}_{12}$. The $\mathrm{Bi}_{4} \mathrm{Ti}_{3} \mathrm{O}_{12-x}$ photocatalysts have good reusability and storage stability and can be used to decompose formaldehyde and formic acid for hydrogen production. The surface oxygen vacancies states result in the broadening of the valence band and the narrowing of the band gap. Such energy level structure variation helps promote the separation of photo-generated electron-hole pairs thus leading to enhancement in the visible-light photocatalytic hydrogen evolution. Meanwhile, the narrowing of the band gap leads to a broader visible light absorption of $\mathrm{Bi}_{4} \mathrm{Ti}_{3} \mathrm{O}_{12-x}$.
\end{abstract}

Keywords: $\mathrm{Bi}_{4} \mathrm{Ti}_{3} \mathrm{O}_{12}$ nanosheets; photocatalytic hydrogen evolution; solid-state chemical reduction; oxygen vacancy

\section{Introduction}

The development of green energy has become one of the most prominent research fields. Among many energy sources, hydrogen gas has been considered one of the prime candidates for solving the emerging worldwide energy crisis, owing to the fact that it does not produce pollution and it has high energy density [1,2]. In recent years, hydrogen generation through photocatalytic water splitting utilizing solar energy has become an extremely active research area [2]. An ideal photocatalyst should be stable, non-toxic, easily available from nature, able to function under visible light, and highly efficient in separating photo-generated electron-hole pairs. So far, various types of photocatalysts, such as $\mathrm{TiO}_{2}$ [3], $\mathrm{ZnO}$ [4], and CdS [5], have been developed. However, none of the photocatalysts can meet all the above requirements simultaneously and most of them suffer from a narrow photo response wavelength range because of large band gaps, which lead to very low utilization efficiency of solar energy. Therefore, the exploration of novel, efficient visible-light photocatalysts for splitting water to produce $\mathrm{H}_{2}$ is of utmost importance [6,7]. 
Bismuth titanate $\left(\mathrm{Bi}_{4} \mathrm{Ti}_{3} \mathrm{O}_{12}\right)$ is well-known as a ferroelectric agent that has a special Aurivillius architecture with unique, electro-optic-converting performance. The Aurivillius phases of $\mathrm{Bi}_{4} \mathrm{Ti}_{3} \mathrm{O}_{12}$ have structures that are intergrown layers of $\left[\mathrm{Bi}_{2} \mathrm{O}_{2}\right]^{2+}$ alternating with perovskite-like $\left[\mathrm{Bi}_{2} \mathrm{Ti}_{3} \mathrm{O}_{10}\right]^{2-}$ blocks [8-10]. The advantage of such a layered structure is its ability to efficiently assist in diffusion and separation of the electron-hole pairs generated by light irradiation. Such separation increases the lifetime of the associated charge carriers, thus improving the quantum efficiency of photo-degradation $[8,9,11]$. Moreover, the hybridized $6 \mathrm{~s}^{2}$ of $\mathrm{Bi}^{3+}$ and $\mathrm{O} 2 \mathrm{p}$ generate a new valence band, which reduces the band gap of $\mathrm{Bi}_{4} \mathrm{Ti}_{3} \mathrm{O}_{12}$ [8,9]. Since the photocatalytic activity of $\mathrm{Bi}_{4} \mathrm{Ti}_{3} \mathrm{O}_{12}$ for water splitting was reported by Kudo et al., its photocatalytic properties have been receiving immense attention [12]. Various types of $\mathrm{Bi}_{4} \mathrm{Ti}_{3} \mathrm{O}_{12}$ photocatalysts, such as nanofibers [8,11], particles [12,13], platelets [14], and films [15] have been developed for processes involving alternative energy development or destruction of different pollutants. However, these $\mathrm{Bi}_{4} \mathrm{Ti}_{3} \mathrm{O}_{12}$ nanomaterials are not very efficient as visible-light photocatalysts because of the high recombination rate of photo-induced electron-hole pairs [16-18]. A widely adopted methodology to overcome this recombination problem is to couple $\mathrm{Bi}_{4} \mathrm{Ti}_{3} \mathrm{O}_{12}$ with semiconductors having narrower band gaps, such as $\mathrm{Bi}_{2} \mathrm{MoO}_{6}$ [11], $\mathrm{BiOI}$ [16], $\mathrm{Bi}_{2} \mathrm{Ti}_{2} \mathrm{O}_{7}$ [17], $\mathrm{BiOCl}$ [18], $\mathrm{Ag}_{3} \mathrm{PO}_{4}$ [19], and $\mathrm{g}-\mathrm{C}_{3} \mathrm{~N}_{4}$ [20]. However, the synthesis of composite compounds generally requires sophisticated synthesis techniques. Additionally, such synthesis increases the possibilities of introducing thermodynamic and structural instability due to the additionally introduced layer. Lastly, electrons would go through a multi-step transport process in such layered structures, which may diminish the efficient charge separation. Thus, catalysts comprised of single-phase metal oxides are highly desirable because they can provide both reliable stability and efficient electron-hole separation [21]. It is therefore very important to explore facile and economic techniques to prepare a single-phase $\mathrm{Bi}_{4} \mathrm{Ti}_{3} \mathrm{O}_{12}$ photocatalyst with increased absorbance of visible light and a low carrier recombination rate.

It has been found recently that the oxygen vacancy defects in $\mathrm{TiO}_{2}$ [22,23], $\mathrm{ZnO}[24,25]$, and $\mathrm{Fe}_{2} \mathrm{O}_{3}[26]$ are able to enhance photocatalytic performance. In particular, surface oxygen vacancies can first capture photo-generated electrons and then promote the reaction between these electrons with the adsorbed species, thus effectively preventing the recombination of photo-generated electron-hole pairs and improving the photocatalytic performance [22-26]. Bulk oxygen vacancies, on the contrary, are recombination centers of photo-generated electron-hole pairs and will reduce the photocatalytic performance [25]. The surface and bulk oxygen vacancies play different roles in the photocatalytic reaction. However, the effect of oxygen vacancies on the photocatalytic activity of $\mathrm{Bi}_{4} \mathrm{Ti}_{3} \mathrm{O}_{12}$ has not been thoroughly explored. Therefore, the development of cost-effective synthesis procedures for the production of $\mathrm{Bi}_{4} \mathrm{Ti}_{3} \mathrm{O}_{12-x}$ with oxygen vacancies and the in-depth understanding of its catalytic behavior are of profound importance in order to realize fully the great potential of $\mathrm{Bi}_{4} \mathrm{Ti}_{3} \mathrm{O}_{12-x}$ in water splitting for $\mathrm{H}_{2}$ production.

We recently reported a sol-gel hydrothermal technique to prepare highly crystalline $\mathrm{Bi}_{4} \mathrm{Ti}_{3} \mathrm{O}_{12}$ nanosheets with enhanced catalytic activity towards the photodegradation of Rhodamine B, especially when comparing with the calcined sample [9]. In the present work, to improve the photocatalytic activity even further, a $\mathrm{Bi}_{4} \mathrm{Ti}_{3} \mathrm{O}_{12}$ nanosheet photocatalyst with oxygen vacancies $\left(\mathrm{Bi}_{4} \mathrm{Ti}_{3} \mathrm{O}_{12-x}\right)$ was fabricated for the first time by the solid-state chemical reduction method using $\mathrm{NaBH}_{4}$ and $\mathrm{Bi}_{4} \mathrm{Ti}_{3} \mathrm{O}_{12}$ nanosheets. The reported methods on oxygen vacancy creation include heating the sample under an oxygen-deficient atmosphere (e.g., vacuum) or reducing conditions (e.g., $\mathrm{H}_{2}$ ) [25,26], chemical vapor deposition, high-energy particle (laser, electron, or $\mathrm{Ar}^{+}$) bombardment [27], combustion method [23], high pressure [28], high temperature aluminum vapor reduction [29], etc. For practical application, these strategies have a number of limitations, such as multiple steps, harsh synthesis conditions (high temperature $\left(>500^{\circ} \mathrm{C}\right)$ or high-pressure hydrogen $(20$ bar $)$ ), or expensive facilities. Compared with the above traditional methods, the solid-state chemical reduction method has many advantages, such as simple operation, moderate reaction temperature $\left(350{ }^{\circ} \mathrm{C}\right)$, short reaction time (less than $\left.80 \mathrm{~min}\right)$, simple equipment, etc. Using this method, several $\mathrm{Bi}_{4} \mathrm{Ti}_{3} \mathrm{O}_{12-x}$ samples with different reduction 
degrees and, as a consequence, with different colors (several shades of blue, as well as black) have been synthesized. The effects of reduction time and temperature on the visible-light photocatalytic properties of the as-prepared $\mathrm{Bi}_{4} \mathrm{Ti}_{3} \mathrm{O}_{12-x}$ nanosheets have been investigated systematically. The electron paramagnetic resonance (EPR), thermogravimetric analysis (TGA), and positron annihilation lifetime spectra (PALS) indicate that oxygen vacancies are produced on $\mathrm{Bi}_{4} \mathrm{Ti}_{3} \mathrm{O}_{12}$ nanosheets during the reduction process. It has been found that the aggregation of oxygen vacancies raises the valence band maximum (VBM), thus decreasing the band gap and extending the photo response wavelength range. Moreover, the energy level variation induced by oxygen vacancy can facilitate the separation efficiency of the photo-generated electron-hole pairs, which contributes significantly to the improvement of the photocatalytic performance of $\mathrm{Bi}_{4} \mathrm{Ti}_{3} \mathrm{O}_{12-x}$. In this paper, we also propose a mechanism for the decrease of the band gap of $\mathrm{Bi}_{4} \mathrm{Ti}_{3} \mathrm{O}_{12-x}$ and its photocatalytic activity improvement.

\section{Experimental Section}

\subsection{Synthesis of the $\mathrm{Bi}_{4} \mathrm{Ti}_{3} \mathrm{O}_{12-x}$ Nanosheet Photocatalyst}

$\mathrm{Bi}_{4} \mathrm{Ti}_{3} \mathrm{O}_{12}$ nanosheets were synthesized using a sol-gel hydrothermal technique reported in our previous work (see Supplementary Materials) [9]. $\mathrm{Bi}_{4} \mathrm{Ti}_{3} \mathrm{O}_{12-x}$ catalysts were prepared as follows: $4 \mathrm{~g}$ of the as-prepared $\mathrm{Bi}_{4} \mathrm{Ti}_{3} \mathrm{O}_{12}$ nanosheets and $1 \mathrm{~g} \mathrm{NaBH}_{4}$ were ground together for $45 \mathrm{~min}$. Then, the mixture was put into a quartz tube placed in a tubular furnace; the temperature of the furnace was controlled by a heating device. The mixture was calcined at $350{ }^{\circ} \mathrm{C}$ for $20 \sim 100 \mathrm{~min}$ or $300 \sim 400{ }^{\circ} \mathrm{C}$ for $60 \mathrm{~min}$ under a nitrogen atmosphere with a ramping up rate of $10^{\circ} \mathrm{C} / \mathrm{min}$. After the completion of this solid-state chemical reduction process, the powders were allowed to cool down to ambient temperature. Then, the final product was filtered, rinsed with deionized water and ethanol, and then dried at $80{ }^{\circ} \mathrm{C}$. The samples were marked as $\mathrm{Bi}_{4} \mathrm{Ti}_{3} \mathrm{O}_{12-x}(\mathrm{~T}, \mathrm{t})$, where $\mathrm{T}$ is the temperature and $\mathrm{t}$ is the time of the solid-state chemical reduction procedure.

\subsection{Characterization}

The crystalline structures of the samples were examined by an X-ray diffractometer (XRD, D/Max-3C, Rigaku Co., Tokyo, Japan) using Cu K $\alpha$ radiation $(\lambda=1.5418 \AA)$. The chemical states and composition were examined using an X-ray photoelectron spectrometer (XPS, Axis uhru DCD, Manchester, UK) with a monochromatic $\mathrm{Mg} \mathrm{K} \alpha$ X-ray source. The morphology was characterized using a scanning electron microscopy (SEM, LEO 1530 VP, Zeiss, Oberkochen, Germany) with $20 \mathrm{kV}$ of accelerating voltage, and the composition was examined using energy dispersive spectroscopy (EDS, Zeiss, Oberkochen, Germany) attached to the SEM. Transmission electron microscopy (TEM) and high-resolution transmission electron microscopy (HRTEM) were performed using JEOL-2011 instrument (JEOL, Tokyo, Japan). UV-Vis spectrophotometer (lambda 35, Perkin-Elmer, Shelton, WA, USA) was used to analyze the samples' diffuse reflection spectra with $\mathrm{BaSO}_{4}$ as a reference. TGAs over a temperature range of $25-800{ }^{\circ} \mathrm{C}$ were conducted during progressive heating $\left(10{ }^{\circ} \mathrm{C} / \mathrm{min}\right)$ in an air atmosphere by a thermogravimetric analyzer (SDTA 851e, Mettler Toledo, Zurich, Switzerland). The EPR analysis was performed on an Endor spectrometer JEOL ES-ED3X (JEOL, Tokyo, Japan). The specific surface areas of the powders were determined using the Brunauer-Emmett-Teller (BET) method after cooling down the samples with liquid nitrogen. PALS were obtained by ORTEC-583 fast-slow coincident system.

Photocurrent and electrochemical impedance spectroscopy (EIS) measurements were conducted at frequencies between $1 \times 10^{-5}$ and $100 \mathrm{kHz}$ by a $\mathrm{CHI} 660$ electrochemical instrument $(\mathrm{CH}$ Instruments, $\mathrm{CH}$ Instruments, Austin, TX, USA) in $0.5 \mathrm{M} \mathrm{Na}_{2} \mathrm{SO}_{4}$ electrolyte solution. A three-electrode cell system was implemented with ITO (Indium tin oxide) $/ \mathrm{Bi}_{4} \mathrm{Ti}_{3} \mathrm{O}_{12}\left(\right.$ or $\left.\mathrm{Bi}_{4} \mathrm{Ti}_{3} \mathrm{O}_{12-x}\right)$ as the working electrode, $\mathrm{Pt}$ wire as the counter electrode, and standard calomel electrode (SCE) as the reference. The true potentials were calculated in reference to the results from the SCE. The visible light source was a $300 \mathrm{~W}$ Xe lamp with a $400 \mathrm{~nm}$ cut-off filter. The photocatalyst photoelectric responses "on and off" 
were determined at $0.0 \mathrm{~V}$. Moreover, the ITO/ $\mathrm{Bi}_{4} \mathrm{Ti}_{3} \mathrm{O}_{12}\left(\right.$ or $\left.\mathrm{Bi}_{4} \mathrm{Ti}_{3} \mathrm{O}_{12-x}\right)$ electrodes were produced using the following recipe: First, $\mathrm{Bi}_{4} \mathrm{Ti}_{3} \mathrm{O}_{12}$ (or $\mathrm{Bi}_{4} \mathrm{Ti}_{3} \mathrm{O}_{12-x}$ ) samples $(5 \mathrm{mg}$ ) were mixed with ethyl alcohol $(0.15 \mathrm{~mL})$ and $5 \%$ Nafion DE 520 solution $(0.35 \mathrm{~mL})$. This solution was then homogenized under ultrasound agitation for $20 \mathrm{~min}$. Uniform film electrodes were prepared by casting $0.1 \mathrm{~mL}$ of the $\mathrm{Bi}_{4} \mathrm{Ti}_{3} \mathrm{O}_{12}$ (or $\mathrm{Bi}_{4} \mathrm{Ti}_{3} \mathrm{O}_{12-x}$ ) slurry onto pre-cleaned ITO glass ( $<7 \mathrm{ohm} /$ square). The ITO $/ \mathrm{Bi}_{4} \mathrm{Ti}_{3} \mathrm{O}_{12}$ (or $\mathrm{Bi}_{4} \mathrm{Ti}_{3} \mathrm{O}_{12-x}$ ) electrodes were finalized by sintering at $100{ }^{\circ} \mathrm{C}$ for $2 \mathrm{~h}$.

\subsection{Photocatalytic Activity}

Photocatalytic hydrogen evolution experiments were proceeded in a methanol-water mixture and performed in the outer quartz ampules attached to the airtight gas circulation system. In order to promote the dispersion of $\mathrm{Bi}_{4} \mathrm{Ti}_{3} \mathrm{O}_{12}$ or $\mathrm{Bi}_{4} \mathrm{Ti}_{3} \mathrm{O}_{12-x}$ in the methanol-water mixture, the optimal dispersing process was obtained through orthogonal tests. The $\mathrm{Bi}_{4} \mathrm{Ti}_{3} \mathrm{O}_{12}$ or $\mathrm{Bi}_{4} \mathrm{Ti}_{3} \mathrm{O}_{12-x}(0.25 \mathrm{~g})$ was dispersed by ultrasound agitation ( $15 \mathrm{~min}$ ) in the mixture of deionized water (DI water, $200 \mathrm{~mL}$ ) and methanol $(20 \mathrm{~mL})$, followed by constant stirring for $30 \mathrm{~min}$. To eliminate dissolved oxygen, the solution was purged with argon for $30 \mathrm{~min}$. This step is necessary to minimize the recombination reaction between $\mathrm{H}_{2}$ and $\mathrm{O}_{2}$ during the water splitting reaction. It also improves the purity of the hydrogen and reduces explosion risks.

Upon finishing the preparation steps, the reactor was irradiated by a $300 \mathrm{~W}$ Xe lamp for $4 \mathrm{~h}$. A cut-off filter for visible-light irradiation was used to obtain wavelengths above $400 \mathrm{~nm}$. The total amount of hydrogen evolved was measured by a gas chromatographer GC-3240/TCD (Perfect Light, Beijing, China), which used Ar carrier gas and was directly connected to a gas-circulation line. The suspensions of the photocatalyst were magnetically stirred continuously during the photocatalytic hydrogen evolution. An average of five measurements was adopted to determine the yield. To study the reusability and repeatability, the same $\mathrm{Bi}_{4} \mathrm{Ti}_{3} \mathrm{O}_{12-x}$ photocatalyst was used three times, and the amount of hydrogen evolved was recorded. After each measurement, the catalyst was centrifugated, filtrated, washed by DI water, and dried at $100{ }^{\circ} \mathrm{C}$ for $3 \mathrm{~h}$ for the next measurement. To check the dependency of $\mathrm{H}_{2}$ production on the additives, the same experiments were also performed with formaldehyde and formic acid instead of methanol.

\section{Results and Discussion}

\subsection{Morphology, Structure, and UV-Vis Spectra of $\mathrm{Bi}_{4} \mathrm{Ti}_{3} \mathrm{O}_{12}$ and $\mathrm{Bi}_{4} \mathrm{Ti}_{3} \mathrm{O}_{12-x}$}

The morphology and particle size distribution of a pristine $\mathrm{Bi}_{4} \mathrm{Ti}_{3} \mathrm{O}_{12}$ were scrutinized using SEM. As shown in Figure 1a, the $\mathrm{Bi}_{4} \mathrm{Ti}_{3} \mathrm{O}_{12}$ sample consists mostly of regular rectangular nanosheets with a narrow distribution of rim size and thin thickness. The average rim size of the rectangular nanosheets are about 100 and $150 \mathrm{~nm}$, respectively, and thickness is about $20 \mathrm{~nm}$. As shown in Figure 1b, only three elements of $\mathrm{Bi}, \mathrm{Ti}$, and $\mathrm{O}$ are observed with the EDS measurement. The ratio of the $\mathrm{Bi}, \mathrm{Ti}$, and O elements is 20.98:15.75:63.27, further demonstrating that the pure $\mathrm{Bi}_{4} \mathrm{Ti}_{3} \mathrm{O}_{12}$ was hydrothermally synthesized successfully at $160^{\circ} \mathrm{C}$.

When the mixture of $\mathrm{Bi}_{4} \mathrm{Ti}_{3} \mathrm{O}_{12}$ nanosheets and $\mathrm{NaBH}_{4}$ were heated at $350{ }^{\circ} \mathrm{C}$ for $20 \sim 100 \mathrm{~min}$ and $300 \sim 400{ }^{\circ} \mathrm{C}$ for 60 min under nitrogen, $\mathrm{NaBH}_{4}$ decomposed and produced active hydrogen. It has been reported that the reduction ability of this active hydrogen is greater than that of $\mathrm{H}_{2}$ and other reducing agents at these temperature $[23,30,31]$. Hydrogen is a strong reducing agent capable of reacting fast and generating oxygen vacancies in $\mathrm{Bi}_{4} \mathrm{Ti}_{3} \mathrm{O}_{12}$ at relatively low temperatures, as well as maintaining the original shape of the $\mathrm{Bi}_{4} \mathrm{Ti}_{3} \mathrm{O}_{12}$ nanosheets at the same time. As shown in Figure 2a, the color of the $\mathrm{Bi}_{4} \mathrm{Ti}_{3} \mathrm{O}_{12-x}$ samples is changed clearly after the solid-state chemical reduction. When the mixture of $\mathrm{Bi}_{4} \mathrm{Ti}_{3} \mathrm{O}_{12}$ nanosheets and $\mathrm{NaBH}_{4}$ were heated at $350{ }^{\circ} \mathrm{C}$, it could be seen that with the increased duration of the reaction, the colors of $\mathrm{Bi}_{4} \mathrm{Ti}_{3} \mathrm{O}_{12-x}$ changed from white-yellow to light blue, then to dark blue. Moreover, the colors of $\mathrm{Bi}_{4} \mathrm{Ti}_{3} \mathrm{O}_{12-x}$ also became darker with the increase in temperature. When the reaction temperature rises to $400{ }^{\circ} \mathrm{C}$, black $\mathrm{Bi}_{4} \mathrm{Ti}_{3} \mathrm{O}_{12-x}$ can be synthesized 
in $60 \mathrm{~min}$, suggesting that the solid-state chemical reduction process modifies the surface features of the $\mathrm{Bi}_{4} \mathrm{Ti}_{3} \mathrm{O}_{12}$ nanosheets. According to previous reports [32,33], it is highly possible that the color change could be caused by the formation of oxygen vacancies occurring during the reduction. The different colors of the $\mathrm{Bi}_{4} \mathrm{Ti}_{3} \mathrm{O}_{12-x}$ samples indicate that various reduction degrees of $\mathrm{Bi}_{4} \mathrm{Ti}_{3} \mathrm{O}_{12-x}$ can be obtained by adjusting the reaction time or temperature, which is helpful to understand the formation mechanism of reductive $\mathrm{Bi}_{4} \mathrm{Ti}_{3} \mathrm{O}_{12}$. Moreover, the XPS results show no residue of $\mathrm{B}$ and $\mathrm{Na}$ in $\mathrm{Bi}_{4} \mathrm{Ti}_{3} \mathrm{O}_{12-x}$ (see Figure $\mathrm{S} 1$ in Supplementary Materials), which means that the coproducts from $\mathrm{NaBH}_{4}$ during the solid-state chemical reduction method can be cleaned easily by washing with water and ethanol.

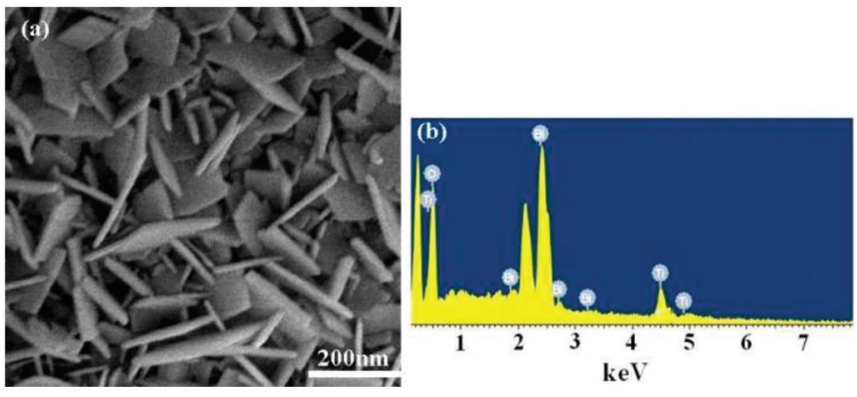

Figure 1. (a) SEM image; (b) energy dispersive spectroscopy (EDS) pattern of the pristine $\mathrm{Bi}_{4} \mathrm{Ti}_{3} \mathrm{O}_{12}$ powders synthesized using a sol-gel hydrothermal technique at $160^{\circ} \mathrm{C}$ for $16 \mathrm{~h}$.
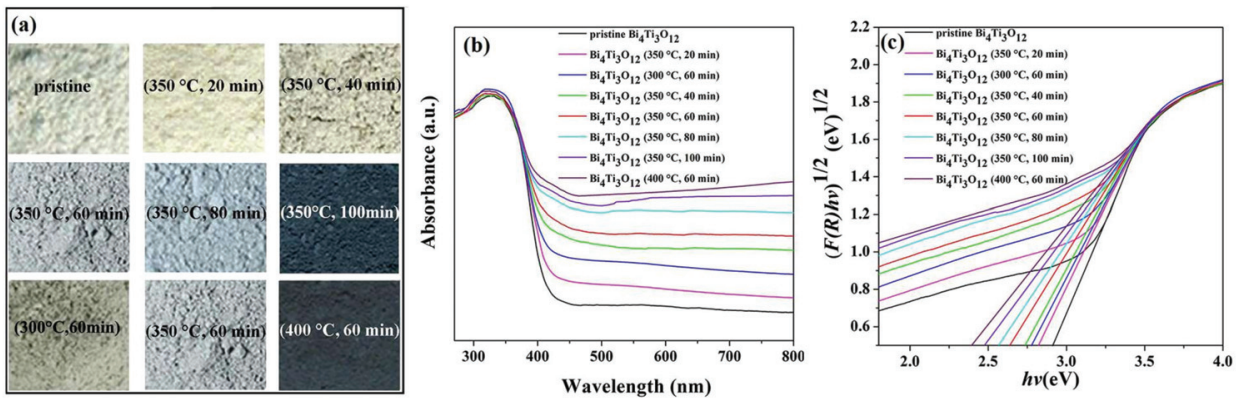

Figure 2. (a) photographs of pristine $\mathrm{Bi}_{4} \mathrm{Ti}_{3} \mathrm{O}_{12}$ and various colored $\mathrm{Bi}_{4} \mathrm{Ti}_{3} \mathrm{O}_{12-x}$; (b) UV-Vis absorption spectrum of the pristine $\mathrm{Bi}_{4} \mathrm{Ti}_{3} \mathrm{O}_{12}$ and various $\mathrm{Bi}_{4} \mathrm{Ti}_{3} \mathrm{O}_{12-x}$; (c) plot of the transformed Kubelka-Munk function $\left(\mathrm{F}(\mathrm{R} \infty)\right.$ ) versus the photon energy $(\mathrm{h} v)$ for various $\mathrm{Bi}_{4} \mathrm{Ti}_{3} \mathrm{O}_{12-x}$ and the pristine $\mathrm{Bi}_{4} \mathrm{Ti}_{3} \mathrm{O}_{12}$ nanosheets.

To understand the effect of the solid-state chemical reduction treatment on the optical absorption property of the photocatalyst, the UV-Vis diffuse reflectance spectra of various $\mathrm{Bi}_{4} \mathrm{Ti}_{3} \mathrm{O}_{12-x}$ and the pristine $\mathrm{Bi}_{4} \mathrm{Ti}_{3} \mathrm{O}_{12}$ nanosheets were examined, as shown in Figure $2 \mathrm{~b}$. It can be seen that the pristine $\mathrm{Bi}_{4} \mathrm{Ti}_{3} \mathrm{O}_{12}$ shows a typical spectrum with an absorption edge at about $420 \mathrm{~nm}$. Compared with the pristine $\mathrm{Bi}_{4} \mathrm{Ti}_{3} \mathrm{O}_{12}$ sample, the absorption edge of $\mathrm{Bi}_{4} \mathrm{Ti}_{3} \mathrm{O}_{12-x}$ exhibits a clear red shift to higher wavelengths. In addition, the absorbance intensity of $\mathrm{Bi}_{4} \mathrm{Ti}_{3} \mathrm{O}_{12-x}$ in the range of $400-800 \mathrm{~nm}$ increases with both reduction time and temperature, which agrees with the color variation in the samples. The red shift of the absorption edge and the enhanced absorbance intensity of $\mathrm{Bi}_{4} \mathrm{Ti}_{3} \mathrm{O}_{12-x}$ are probably because of the different surface conditions of different samples. Surface defects, such as oxygen 
vacancies, generally affect the atomic structure of a photocatalyst and its surface states, which play a very important role in the overall photocatalytic activity [33,34].

The band gap can be calculated using the UV-Vis data from the following equation [8]:

$$
\alpha \mathrm{h} v=\mathrm{A}\left(\mathrm{h} v-E_{\mathrm{g}}\right)^{\mathrm{n} / 2}
$$

where $\alpha$ is an absorption coefficient, $\mathrm{h}$ is Planck's constant, $v$ is light frequency, $E_{\mathrm{g}}$ is a band gap value, and $\mathrm{A}$ is a constant. The absorption behavior of $\mathrm{Bi}_{4} \mathrm{Ti}_{3} \mathrm{O}_{12}$ demonstrates indirect transition between bands; therefore, the value of $\mathrm{n}$ equal to 4 is used $[8,35]$. The value of the band gap is estimated by extrapolating the linear part of the $(\alpha h v)^{1 / 2}$ versus $(h v)$ plot at $\alpha=0$. Normally, the collected UV-Vis diffuse reflectance spectra can be converted into Kubelka-Munk function $\mathrm{F}\left(R_{\infty}\right)$ based on the relationship shown in Equations (2) and (3) [36]:

$$
\begin{gathered}
\mathrm{Abs}=-\log R_{\infty} \\
\mathrm{F}\left(R_{\infty}\right)=\left(1-R_{\infty}\right)^{2} / 2 R_{\infty}=\alpha
\end{gathered}
$$

where Abs is absorbance, and $R_{\infty}$ is reflectance. Therefore, Equation (1) can also be written as follows:

$$
\left[\mathrm{F}\left(R_{\infty}\right) \mathrm{h} v\right]=\mathrm{A}\left(\mathrm{h} v-E_{\mathrm{g}}\right)^{\mathrm{n} / 2}
$$

In addition, $\mathrm{h} v=\mathrm{hc} / \lambda \approx 1241 / \lambda(\mathrm{eV})$. Figure $2 \mathrm{c}$ shows the plot of the transformed Kubelka-Munk function versus the photon energy for various $\mathrm{Bi}_{4} \mathrm{Ti}_{3} \mathrm{O}_{12-x}$ and the pristine $\mathrm{Bi}_{4} \mathrm{Ti}_{3} \mathrm{O}_{12}$ nanosheets. The energy of the band gap values is obtained by extrapolating the linear part of $\left[\mathrm{F}\left(R_{\infty}\right) \mathrm{h} v\right]^{1 / 2}$ versus h $v$ plot at $\mathrm{F}\left(R_{\infty}\right)=0$. The band gap of the pristine $\mathrm{Bi}_{4} \mathrm{Ti}_{3} \mathrm{O}_{12}$ and various $\mathrm{Bi}_{4} \mathrm{Ti}_{3} \mathrm{O}_{12-x}$ samples are shown in Table 1. It is clear that the $\mathrm{Bi}_{4} \mathrm{Ti}_{3} \mathrm{O}_{12-x}$ samples show a decreased band gap value when compared with the pristine $\mathrm{Bi}_{4} \mathrm{Ti}_{3} \mathrm{O}_{12}$. Furthermore, it is also clear that the band gap of $\mathrm{Bi}_{4} \mathrm{Ti}_{3} \mathrm{O}_{12-x}$ decreases as reaction time and temperature increase.

Table 1. Band gaps of the pristine $\mathrm{Bi}_{4} \mathrm{Ti}_{3} \mathrm{O}_{12}$ and various $\mathrm{Bi}_{4} \mathrm{Ti}_{3} \mathrm{O}_{12-x}$ samples.

\begin{tabular}{cc}
\hline Samples & Band Gap (eV) \\
\hline $\mathrm{Bi}_{4} \mathrm{Ti}_{3} \mathrm{O}_{12}$ & 2.91 \\
$\mathrm{Bi}_{4} \mathrm{Ti}_{3} \mathrm{O}_{12-x}\left(350^{\circ} \mathrm{C}, 20 \mathrm{~min}\right)$ & 2.83 \\
$\mathrm{Bi}_{4} \mathrm{Ti}_{3} \mathrm{O}_{12-x}\left(350^{\circ} \mathrm{C}, 40 \mathrm{~min}\right)$ & 2.74 \\
$\mathrm{Bi}_{4} \mathrm{Ti}_{3} \mathrm{O}_{12-x}\left(350^{\circ} \mathrm{C}, 60 \mathrm{~min}\right)$ & 2.63 \\
$\mathrm{Bi}_{4} \mathrm{Ti}_{3} \mathrm{O}_{12-x}\left(350^{\circ} \mathrm{C}, 80 \mathrm{~min}\right)$ & 2.57 \\
$\mathrm{Bi}_{4} \mathrm{Ti}_{3} \mathrm{O}_{12-x}\left(350^{\circ} \mathrm{C}, 100 \mathrm{~min}\right)$ & 2.48 \\
$\mathrm{Bi}_{4} \mathrm{Ti}_{3} \mathrm{O}_{12-x}\left(300^{\circ} \mathrm{C}, 60 \mathrm{~min}\right)$ & 2.77 \\
$\mathrm{Bi}_{4} \mathrm{Ti}_{3} \mathrm{O}_{12-x}\left(400^{\circ} \mathrm{C}, 60 \mathrm{~min}\right)$ & 2.39 \\
\hline
\end{tabular}

XRD analyses were performed to characterize the changes of the crystalline structures of the $\mathrm{Bi}_{4} \mathrm{Ti}_{3} \mathrm{O}_{12-x}$ samples. Figure 3 shows a comparison of XRD patterns of the pristine $\mathrm{Bi}_{4} \mathrm{Ti}_{3} \mathrm{O}_{12}$ and various $\mathrm{Bi}_{4} \mathrm{Ti}_{3} \mathrm{O}_{12-x}$ samples after they were treated at $350{ }^{\circ} \mathrm{C}$ for $20 \sim 100 \mathrm{~min}$ and at $400{ }^{\circ} \mathrm{C}$ for $60 \mathrm{~min}$. No impurities can be seen for the $\mathrm{Bi}_{4} \mathrm{Ti}_{3} \mathrm{O}_{12-x}$ samples, indicating that the reduction process has no effect on the crystal structure. The diffraction peaks suggest that $\mathrm{Bi}_{4} \mathrm{Ti}_{3} \mathrm{O}_{12-x}$ samples have a high degree of crystalline similarity to $\mathrm{Bi}_{4} \mathrm{Ti}_{3} \mathrm{O}_{12}$. However, new peaks appear in the XRD patterns of the samples treated for a longer reaction time $\left(350{ }^{\circ} \mathrm{C}\right.$ for $\left.120 \mathrm{~min}\right)$ or at a higher temperature $\left(400{ }^{\circ} \mathrm{C}\right.$ for $80 \mathrm{~min}$ ) (Figure S2). We could not match these new peaks to any known powder diffraction file (PDF); thus, it is possible that new phases have been formed. 


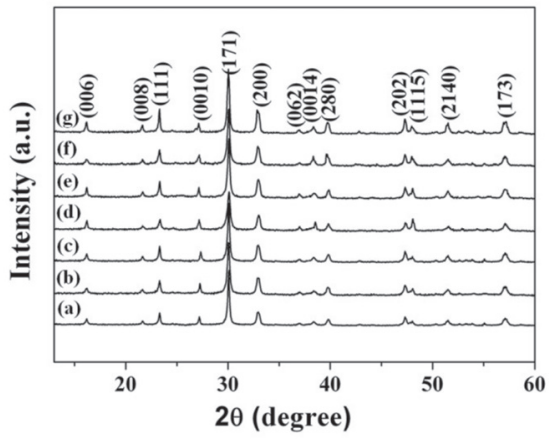

Figure 3. X-ray diffraction patterns of (a) the pristine $\mathrm{Bi}_{4} \mathrm{Ti}_{3} \mathrm{O}_{12}$; (b) $\mathrm{Bi}_{4} \mathrm{Ti}_{3} \mathrm{O}_{12-x}\left(350{ }^{\circ} \mathrm{C}, 20 \mathrm{~min}\right)$; (c) $\mathrm{Bi}_{4} \mathrm{Ti}_{3} \mathrm{O}_{12-x}\left(350{ }^{\circ} \mathrm{C}, 40 \mathrm{~min}\right) ;(\mathrm{d}) \mathrm{Bi}_{4} \mathrm{Ti}_{3} \mathrm{O}_{12-x}\left(350{ }^{\circ} \mathrm{C}, 60 \mathrm{~min}\right) ;(\mathrm{e}) \mathrm{Bi}_{4} \mathrm{Ti}_{3} \mathrm{O}_{12-x}\left(350{ }^{\circ} \mathrm{C}, 80 \mathrm{~min}\right)$; (f) $\mathrm{Bi}_{4} \mathrm{Ti}_{3} \mathrm{O}_{12-x}\left(350{ }^{\circ} \mathrm{C}, 100 \mathrm{~min}\right)$; and (g) $\mathrm{Bi}_{4} \mathrm{Ti}_{3} \mathrm{O}_{12-x}\left(400{ }^{\circ} \mathrm{C}, 60 \mathrm{~min}\right)$.

\subsection{Photocatalytic Performance and Stability}

Photocatalytic conversion of $\mathrm{H}_{2} \mathrm{O}$ into $\mathrm{H}_{2}$ using $\mathrm{Bi}_{4} \mathrm{Ti}_{3} \mathrm{O}_{12}$ or $\mathrm{Bi}_{4} \mathrm{Ti}_{3} \mathrm{O}_{12-x}$ in a methanol-water medium was performed in a quartz cell. Methanol was used to trap holes. Figure $4 \mathrm{a}, \mathrm{b}$ show the photocatalytic activity of the pristine $\mathrm{Bi}_{4} \mathrm{Ti}_{3} \mathrm{O}_{12}$ and $\mathrm{Bi}_{4} \mathrm{Ti}_{3} \mathrm{O}_{12-x}$ after chemical reduction treatment at $350{ }^{\circ} \mathrm{C}$ for various times and at various temperatures for $60 \mathrm{~min}$ for water splitting into $\mathrm{H}_{2}$ under visible-light irradiation. It is clear that both the reduction time and temperature have significant influences on the photocatalysis ability of $\mathrm{Bi}_{4} \mathrm{Ti}_{3} \mathrm{O}_{12-x}$. The pristine $\mathrm{Bi}_{4} \mathrm{Ti}_{3} \mathrm{O}_{12}$ photocatalyst displays the $\mathrm{H}_{2}$ evolution rate of around $38 \mu \mathrm{mol} \cdot \mathrm{g}^{-1} \cdot \mathrm{h}^{-1}$. After the solid-state chemical reduction treatment, the $\mathrm{Bi}_{4} \mathrm{Ti}_{3} \mathrm{O}_{12-x}$ samples all show enhanced photocatalytic activity of the hydrogen evolution. Figure $4 \mathrm{a}$,b show that the photocatalytic activity of $\mathrm{Bi}_{4} \mathrm{Ti}_{3} \mathrm{O}_{12-x}$ improves with both reduction time and temperature increase, until a maximum activity is achieved at $350{ }^{\circ} \mathrm{C}$ for $60 \mathrm{~min}$. The $\mathrm{H}_{2}$ evolution rate over $\mathrm{Bi}_{4} \mathrm{Ti}_{3} \mathrm{O}_{12-x}\left(350{ }^{\circ} \mathrm{C}, 60 \mathrm{~min}\right)$ reaches $129 \mu \mathrm{mol} \cdot \mathrm{g}^{-1} \cdot \mathrm{h}^{-1}$, which is 3.4 times that of the pristine $\mathrm{Bi}_{4} \mathrm{Ti}_{3} \mathrm{O}_{12}$. This value is also higher than those reported previously (as presented in Table 2). Further increases in the reaction time or temperature results in a reduced hydrogen evolution rate, even though the rates are still higher than when using a pristine $\mathrm{Bi}_{4} \mathrm{Ti}_{3} \mathrm{O}_{12}$ nanosheet photocatalyst.

Table 2. Comparison of $\mathrm{H}_{2}$ evolution rate of $\mathrm{Bi}_{4} \mathrm{Ti}_{3} \mathrm{O}_{12-x}\left(350{ }^{\circ} \mathrm{C}, 60 \mathrm{~min}\right)$ and other $\mathrm{Bi}_{4} \mathrm{Ti}_{3} \mathrm{O}_{12}$ photocatalysts recently reported.

\begin{tabular}{|c|c|c|c|c|}
\hline Sample & Light Source & $\begin{array}{l}\text { Reactant } \\
\text { Solution }\end{array}$ & $\begin{array}{c}\mathrm{H}_{2} \text { Evolution } \\
\text { Rate } / \mu \mathrm{mol} \cdot \mathrm{g}^{-1} \cdot \mathrm{h}^{-1}\end{array}$ & Reference \\
\hline $\begin{array}{c}\mathrm{Bi}_{4} \mathrm{Ti}_{3} \mathrm{O}_{12-x} \\
\left(350^{\circ} \mathrm{C}, 60 \mathrm{~min}\right)\end{array}$ & $\begin{array}{c}300 \mathrm{~W} \text { Xe Lamp } \\
(\lambda>400 \mathrm{~nm})\end{array}$ & $\begin{array}{l}200 \mathrm{~mL} \text { water }+ \\
20 \mathrm{~mL} \text { methanol }\end{array}$ & 129 & This work \\
\hline $\mathrm{Bi}_{4} \mathrm{Ti}_{3} \mathrm{O}_{12}$ & $\begin{array}{c}350 \mathrm{~W} \text { high pressure Xe } \\
\text { lamp }(\lambda>400 \mathrm{~nm})\end{array}$ & $\begin{array}{l}400 \mathrm{~mL} \text { water }+ \\
20 \mathrm{~mL} \text { methanol }\end{array}$ & 36 & [37] \\
\hline $\mathrm{Bi}_{4} \mathrm{Ti}_{2.6} \mathrm{Cr}_{0.4} \mathrm{O}_{12}$ & $\begin{array}{c}350 \mathrm{~W} \text { high pressure Xe } \\
\operatorname{lamp}(\lambda>400 \mathrm{~nm})\end{array}$ & $\begin{array}{c}400 \mathrm{~mL} \text { water }+ \\
20 \mathrm{~mL} \text { methanol }\end{array}$ & 58.1 & [37] \\
\hline $\mathrm{Bi}_{4} \mathrm{Ti}_{3} \mathrm{O}_{12}$ & $\begin{array}{l}300 \mathrm{~W} \text { Xe Lamp } \\
(\lambda>400 \mathrm{~nm})\end{array}$ & $\begin{array}{l}400 \mathrm{~mL} \text { water }+ \\
20 \mathrm{~mL} \text { methanol }\end{array}$ & 42 & [38] \\
\hline $\mathrm{Bi}_{4} \mathrm{Ti}_{2.6} \mathrm{Cr}_{0.4} \mathrm{O}_{12}$ & $\begin{array}{c}300 \mathrm{~W} \text { Xe Lamp } \\
(\lambda>400 \mathrm{~nm})\end{array}$ & $\begin{array}{l}400 \mathrm{~mL} \text { water }+ \\
20 \mathrm{~mL} \text { methanol }\end{array}$ & 98 & [38] \\
\hline $\mathrm{Bi}_{4} \mathrm{Ti}_{2.6} \mathrm{Cr}_{0.4} \mathrm{O}_{12}$ & $\begin{array}{l}300 \text { W Xe Lamp } \\
(\lambda>420 \mathrm{~nm})\end{array}$ & $\begin{array}{l}400 \mathrm{~mL} \text { water }+ \\
30 \mathrm{~mL} \text { methanol }\end{array}$ & 117 & [39] \\
\hline
\end{tabular}



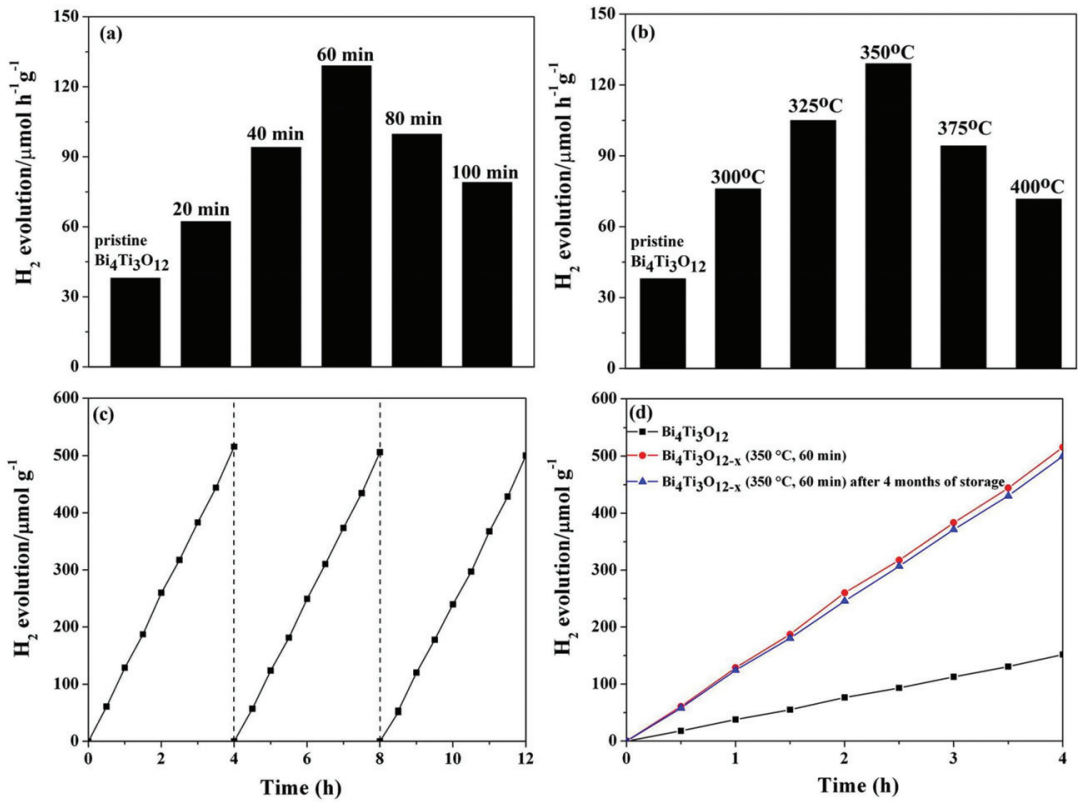

Figure 4. The hydrogen evolution rate over the pristine $\mathrm{Bi}_{4} \mathrm{Ti}_{3} \mathrm{O}_{12}$ and the $\mathrm{Bi}_{4} \mathrm{Ti}_{3} \mathrm{O}_{12-x}$ after chemical reduction treated (a) at $350^{\circ} \mathrm{C}$ for various times; (b) at various temperature for 60 min under visible-light irradiation $(\lambda>400 \mathrm{~nm})$; (c) recycling measure of hydrogen evolution with $\mathrm{Bi}_{4} \mathrm{Ti}_{3} \mathrm{O}_{12-x}\left(350{ }^{\circ} \mathrm{C}, 60 \mathrm{~min}\right)$ under visible-light irradiation $(\lambda>400 \mathrm{~nm})$; (d) visible-light photocatalytic hydrogen evolution by fresh $\mathrm{Bi}_{4} \mathrm{Ti}_{3} \mathrm{O}_{12-x}\left(350{ }^{\circ} \mathrm{C}, 60 \mathrm{~min}\right)$ and $\mathrm{Bi}_{4} \mathrm{Ti}_{3} \mathrm{O}_{12-x}\left(350{ }^{\circ} \mathrm{C}, 60 \mathrm{~min}\right)$ after four months of storage, compared with the pristine $\mathrm{Bi}_{4} \mathrm{Ti}_{3} \mathrm{O}_{12}$.

To study the reusability and stability of the photocatalyst, cycling experiments using the optimal $\mathrm{Bi}_{4} \mathrm{Ti}_{3} \mathrm{O}_{12-x}\left(350{ }^{\circ} \mathrm{C}, 60 \mathrm{~min}\right)$ under constant visible-light irradiation were performed. The results obtained from three consecutive experiments are shown in Figure 4c. The first run shows that around $517 \mu \mathrm{mol} \cdot \mathrm{g}^{-1}$ of the total hydrogen evolved after $4 \mathrm{~h}$ when $\mathrm{Bi}_{4} \mathrm{Ti}_{3} \mathrm{O}_{12-x}\left(350{ }^{\circ} \mathrm{C}, 60 \mathrm{~min}\right)$ is used. The second run of the experiment shows a $1.2 \%$ decrease in the hydrogen evolution rate comparing to the first run. The hydrogen evolution rate remains almost the same during the third run. The $\mathrm{H}_{2}$ evolution rates for the $\mathrm{Bi}_{4} \mathrm{Ti}_{3} \mathrm{O}_{12-x}\left(350^{\circ} \mathrm{C}, 60 \mathrm{~min}\right)$ photocatalyst remain stable over the three times of cycling testing, confirming good operational stability even after introducing oxygen vacancies into the $\mathrm{Bi}_{4} \mathrm{Ti}_{3} \mathrm{O}_{12}$ structure. Furthermore, in order to study the long-term stability of $\mathrm{Bi}_{4} \mathrm{Ti}_{3} \mathrm{O}_{12-x}$, the photocatalytic $\mathrm{H}_{2}$ production ability of fresh $\mathrm{Bi}_{4} \mathrm{Ti}_{3} \mathrm{O}_{12-x}\left(350{ }^{\circ} \mathrm{C}, 60 \mathrm{~min}\right)$ and $\mathrm{Bi}_{4} \mathrm{Ti}_{3} \mathrm{O}_{12-x}\left(350{ }^{\circ} \mathrm{C}\right.$, $60 \mathrm{~min}$ ) after four months of storage were also examined. As shown in Figure $4 \mathrm{~d}$, the visible-light photocatalytic activity of the sample stored for four months is only slightly reduced compared with the fresh one, and it is still much higher than that of the pristine $\mathrm{Bi}_{4} \mathrm{Ti}_{3} \mathrm{O}_{12}$. The results indicate that $\mathrm{Bi}_{4} \mathrm{Ti}_{3} \mathrm{O}_{12-x}$ has good reusability and storage stability. In addition, to measure the apparent quantum efficiency (AQE), the same photocatalytic hydrogen evolution experiment was performed under $420 \mathrm{~nm}$ monochromatic lights irradiation, which were obtained by using band-pass filters for $1 \mathrm{~h}$. The AQE was then calculated by the following Equation (5) [40]:

$$
\mathrm{AQE}=\frac{N_{e}}{N_{p}} \times 100 \%=\frac{2 M N_{A} h c}{S P t \lambda} \times 100 \%
$$


where $N_{e}$ is the amount of reaction electrons, $N_{p}$ is the amount of incident photons, $N_{A}$ is the Avogadro constant, $M$ is the amount of $\mathrm{H}_{2}$ molecules, $h$ is the Planck constant, $c$ is the speed of light, $S$ is irradiation area, $P$ is the average intensity of the irradiation, $t$ is the irradiation time, and $\lambda$ is the wavelength of the monochromatic light. For the AQE at $420 \mathrm{~nm}$, the average intensity of the irradiation $P$ was determined to be $40 \mathrm{~mW} / \mathrm{cm}^{2}$, and the irradiation area $S$ was $37.5 \mathrm{~cm}^{2}$. The calculated AQE for $\mathrm{Bi}_{4} \mathrm{Ti}_{3} \mathrm{O}_{12-x}\left(350{ }^{\circ} \mathrm{C}, 60 \mathrm{~min}\right)$ is $1.37 \%$ under irradiation at $420 \mathrm{~nm}$, which is the highest among all the samples.

In the present work, methanol acts as a sacrificial agent, which is consumed during the formation of $\mathrm{H}_{2}$. The photocatalytic mechanisms of methanol-assisted hydrogen evolution are as follows: the electron-hole pairs are produced when a $\mathrm{Bi}_{4} \mathrm{Ti}_{3} \mathrm{O}_{12}$ or $\mathrm{Bi}_{4} \mathrm{Ti}_{3} \mathrm{O}_{12-x}$ photocatalyst is irradiated with visible light (Equation (6)). The photo-generated carriers either recombine in the bulk or participate in the oxidation-reduction process on the surface of the photocatalyst. In a methanol-water mixture system, methanol can capture photo-generated holes and experience hole oxidation to form formaldehyde (Equation (7)), which reduces the recombination of the electron-hole pairs. Meanwhile, two protons are released during methanol oxidation, which react with the generated electrons to produce $\mathrm{H}_{2}$ gas (Equation (8)). When accumulated to a certain degree, formaldehyde is further oxidized into formic acid and releases hydrogen gas (Equations (9) and (10)). The formic acid eventually dissociates into $\mathrm{CO}_{2}$ and two protons (Equation (11)); then, the protons react with the photo-generated electrons and produce hydrogen gas (Equation (12)). Equation (13) can be used to represent the overall reaction. The aforementioned photocatalytic hydrogen evolution reactions are summarized below $[41,42]$ :

$$
\begin{gathered}
\mathrm{Bi}_{4} \mathrm{Ti}_{3} \mathrm{O}_{12} \stackrel{h v}{\rightarrow} \mathrm{h}^{+}+\mathrm{e}^{-} \\
\mathrm{CH}_{3} \mathrm{OH}+2 \mathrm{~h}^{+} \rightarrow \mathrm{HCHO}+2[\mathrm{H}]^{+} \\
2[\mathrm{H}]^{+}+2 \mathrm{e}^{-} \rightarrow \mathrm{H}_{2}(\mathrm{~g}) \\
\mathrm{HCHO}+2 \mathrm{~h}^{+}+\mathrm{H}_{2} \mathrm{O} \rightarrow \mathrm{HCOOH}+2[\mathrm{H}]^{+} \\
2[\mathrm{H}]^{+}+2 \mathrm{e}^{-} \rightarrow \mathrm{H}_{2}(\mathrm{~g}) \\
\mathrm{HCOOH}+2 \mathrm{~h}^{+} \rightarrow \mathrm{CO}_{2}(\mathrm{~g})+2[\mathrm{H}]^{+} \\
2[\mathrm{H}]^{+}+2 \mathrm{e}^{-} \rightarrow \mathrm{H}_{2}(\mathrm{~g})
\end{gathered}
$$

Overall:

$$
\mathrm{CH}_{3} \mathrm{OH}+\mathrm{H}_{2} \mathrm{O} \stackrel{h v, \mathrm{Bi}_{4} \mathrm{Ti}_{3} \mathrm{O}_{12}}{\longrightarrow} \mathrm{CO}_{2}(\mathrm{~g})+3 \mathrm{H}_{2}(\mathrm{~g})
$$

In addition, photocatalytic conversion of $\mathrm{H}_{2} \mathrm{O}$ into $\mathrm{H}_{2}$ using the pristine $\mathrm{Bi}_{4} \mathrm{Ti}_{3} \mathrm{O}_{12}$ and the optimal $\mathrm{Bi}_{4} \mathrm{Ti}_{3} \mathrm{O}_{12-x}\left(350{ }^{\circ} \mathrm{C}, 60 \mathrm{~min}\right)$ in pure water were also performed in a quartz cell. The results show that when no methanol is used as a sacrificial reagent, $\mathrm{Bi}_{4} \mathrm{Ti}_{3} \mathrm{O}_{12-x}\left(350{ }^{\circ} \mathrm{C}, 60 \mathrm{~min}\right)$ shows a very low photocatalytic $\mathrm{H}_{2}$ evolution rate of $18 \mu \mathrm{mol} \cdot \mathrm{g}^{-1} \cdot \mathrm{h}^{-1}$ under visible-light irradiation, and the pristine $\mathrm{Bi}_{4} \mathrm{Ti}_{3} \mathrm{O}_{12}$ exhibits no $\mathrm{H}_{2}$ evolution at all. In a pure water system, water can capture photo-generated holes produced from $\mathrm{Bi}_{4} \mathrm{Ti}_{3} \mathrm{O}_{12}$ (Equation (6)) and experience hole oxidation to form oxygen gas (Equation (14)). Meanwhile, two protons can be released during water oxidation, which react with the photo-generated electrons to generate hydrogen gas (Equation (15)). Equation (16) can be used to represent the overall reaction:

$$
\begin{gathered}
\mathrm{H}_{2} \mathrm{O}+2 \mathrm{~h}^{+} \rightarrow \frac{1}{2} \mathrm{O}_{2}+2[\mathrm{H}]^{+} \\
2[\mathrm{H}]^{+}+2 \mathrm{e}^{-} \rightarrow \mathrm{H}_{2}(\mathrm{~g}) \\
\mathrm{H}_{2} \mathrm{O} \stackrel{h v, \mathrm{Bi}_{4} \mathrm{Ti}_{3} \mathrm{O}_{12}}{\longrightarrow} \frac{1}{2} \mathrm{O}_{2}(\mathrm{~g})+\mathrm{H}_{2}(\mathrm{~g})
\end{gathered}
$$

However, to trigger this reaction, the energy of the absorbed photon must be at least $1.23 \mathrm{eV}$, which is much higher than the decomposition energy for methanol (0.7 eV, Equation (13)) [43]. It has 
been demonstrated that without the addition of a sacrificial agent, the water acts as an inefficient electron acceptor and donor [42-44]. As a result, the oxygen radicals and protons tend to recombine to form water, leading to limited hydrogen gas production [44].

The effect of the concentration of the $\mathrm{Bi}_{4} \mathrm{Ti}_{3} \mathrm{O}_{12-x}\left(350^{\circ} \mathrm{C}, 60 \mathrm{~min}\right)$ photocatalyst on $\mathrm{H}_{2}$ production was investigated. Photocatalytic hydrogen evolution experiments were proceeded in a methanol $(20 \mathrm{~mL})$-water $(200 \mathrm{~mL})$ mixture. The concentration of the photocatalyst ranged from $0.455 \mathrm{~g} / \mathrm{L}$ to $1.591 \mathrm{~g} / \mathrm{L}$. As shown in Figure $5 \mathrm{a}$, the $\mathrm{H}_{2}$ evolution rate increases with the increase of the concentration until a maximum rate is achieved with $1.136 \mathrm{~g} / \mathrm{L} \mathrm{Bi}_{4} \mathrm{Ti}_{3} \mathrm{O}_{12-x}\left(350{ }^{\circ} \mathrm{C}, 60 \mathrm{~min}\right)$. Further increase of the concentration results in a reduced hydrogen evolution rate. This reduction may be caused by the unsuited light scattering effect or the light shadowing due to the high turbidity of the solution that reduces the penetration depth of the visible light [45]. These effects reduce the effective incident light, thus significantly reducing the number of photo-induced electron-hole pairs necessary for the maintenance of the reaction. Therefore, the concentration of $1.136 \mathrm{~g} / \mathrm{L}$ catalyst (i.e., $0.25 \mathrm{~g} \mathrm{Bi}_{4} \mathrm{Ti}_{3} \mathrm{O}_{12-x}$ $\left(350^{\circ} \mathrm{C}, 60 \mathrm{~min}\right)$ ) is found to be the optimal concentration for $\mathrm{H}_{2}$ generation in the present work.

In addition, the influence of additives, such as formaldehyde and formic acid, on $\mathrm{H}_{2}$ production was further investigated. These two kinds of additives are considered mainly because they are byproducts/intermediates of methanol conversion (see Equations (7) and (9)) and also considered to be industrial wastes or model pollutants [46]. A mixture of water-formaldehyde $(200 / 20, v / v)$ or water-formic acid $(200 / 20, v / v)$ was used in the experiment. Figure $5 b$ shows how different aqueous mixtures (with water-formaldehyde, water-formic acid, and water-methanol) affect visible-light photocatalytic $\mathrm{H}_{2}$ production $(\lambda>400 \mathrm{~nm})$ when $0.25 \mathrm{~g}$ of the $\mathrm{Bi}_{4} \mathrm{Ti}_{3} \mathrm{O}_{12-x}\left(350{ }^{\circ} \mathrm{C}, 60 \mathrm{~min}\right)$ photocatalyst is used. It can be seen that the $\mathrm{H}_{2}$ evolution rate for formic acid reaches $218 \mu \mathrm{mol} \cdot \mathrm{g}^{-1} \cdot \mathrm{h}^{-1}$, which is much higher than that for methanol and formaldehyde. It is assumed that this phenomenon is due to the low dissociation energy $\left(-95.8 \mathrm{~kJ} \cdot \mathrm{mol}^{-1}\right)$ of formic acid that is much smaller than that of methanol $\left(64.1 \mathrm{~kJ} \cdot \mathrm{mol}^{-1}\right)$ and formaldehyde $\left(47.8 \mathrm{~kJ} \cdot \mathrm{mol}^{-1}\right)$ [42,47]. Therefore, the $-\mathrm{COOH}$ group of formic acid can dissociate spontaneously [42], which results in a large hydrogen evolution rate. The results show that the $\mathrm{Bi}_{4} \mathrm{Ti}_{3} \mathrm{O}_{12-x}$ photocatalyst can be used to decompose a variety of pollutants (such as formaldehyde and formic acid) for hydrogen production, and it also suggests a significant way to produce hydrogen by using formic acid as an additive.
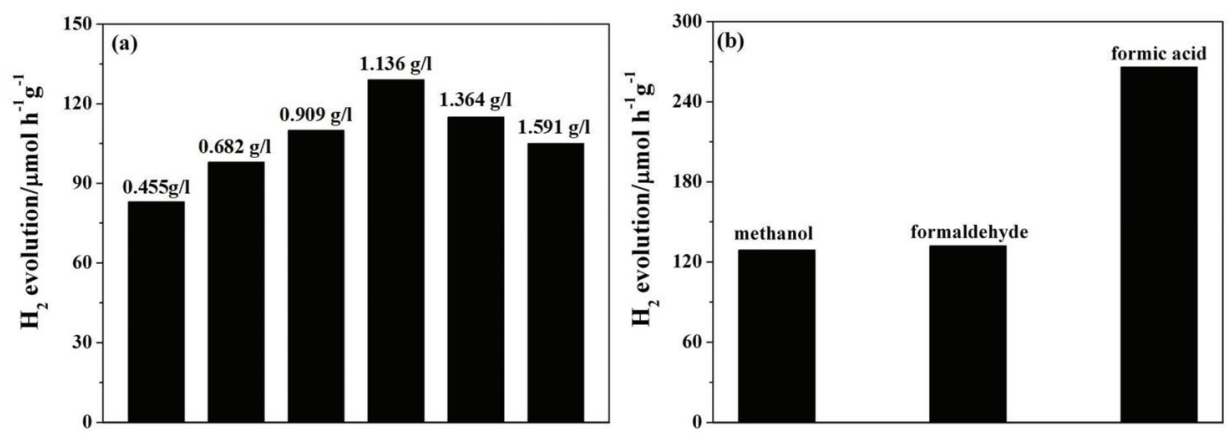

Figure 5. (a) Effect of the concentration of the photocatalyst on hydrogen production over the $\mathrm{Bi}_{4} \mathrm{Ti}_{3} \mathrm{O}_{12-x}\left(350^{\circ} \mathrm{C}, 60 \mathrm{~min}\right)$ nanosheets under visible-light irradiation $(\lambda>400 \mathrm{~nm})$; and (b) Effect of various wastes as additives on hydrogen production over the $\mathrm{Bi}_{4} \mathrm{Ti}_{3} \mathrm{O}_{12-x}\left(350{ }^{\circ} \mathrm{C}, 60 \mathrm{~min}\right)$ nanosheets under visible-light irradiation $(\lambda>400 \mathrm{~nm})$.

\subsection{Surface Oxygen Vacancy Formation}

As discussed above, it is highly probable that the color change of $\mathrm{Bi}_{4} \mathrm{Ti}_{3} \mathrm{O}_{12-x}$ (Figure 2a) could be caused by the formation of oxygen vacancies occurring during the chemical reduction process. 
To study the presence of oxygen vacancies, room temperature EPR was performed on the pristine $\mathrm{Bi}_{4} \mathrm{Ti}_{3} \mathrm{O}_{12}$ nanosheets and various $\mathrm{Bi}_{4} \mathrm{Ti}_{3} \mathrm{O}_{12-x}$ samples. It is known that EPR is a highly sensitive and immediate way to characterize oxygen defects $[48,49]$. As shown in Figure $6 a, b$, the intensity of the EPR signal at $\mathrm{g}$ factor $=2.001$ for $\mathrm{Bi}_{4} \mathrm{Ti}_{3} \mathrm{O}_{12-x}$ are all higher than for the pristine $\mathrm{Bi}_{4} \mathrm{Ti}_{3} \mathrm{O}_{12}$ nanosheets. Typically, a peak at 2.001 2.004 is attributed to natural surface oxygen vacancies as reported in the literature $[50,51]$. We attribute the enhancement of the EPR signal for $\mathrm{Bi}_{4} \mathrm{Ti}_{3} \mathrm{O}_{12-x}$ at $\mathrm{g}=2.001$ to the electron-trapped center located around the site of the oxygen vacancies [52]. In addition, it can be seen from Figure $6 \mathrm{a}, \mathrm{b}$ that the signal intensity at $\mathrm{g} \sim 2.001$ increases with the reduction time and temperature, demonstrating that the number of oxygen vacancies in $\mathrm{Bi}_{4} \mathrm{Ti}_{3} \mathrm{O}_{12-x}$ increases with the reduction reaction time and temperature.
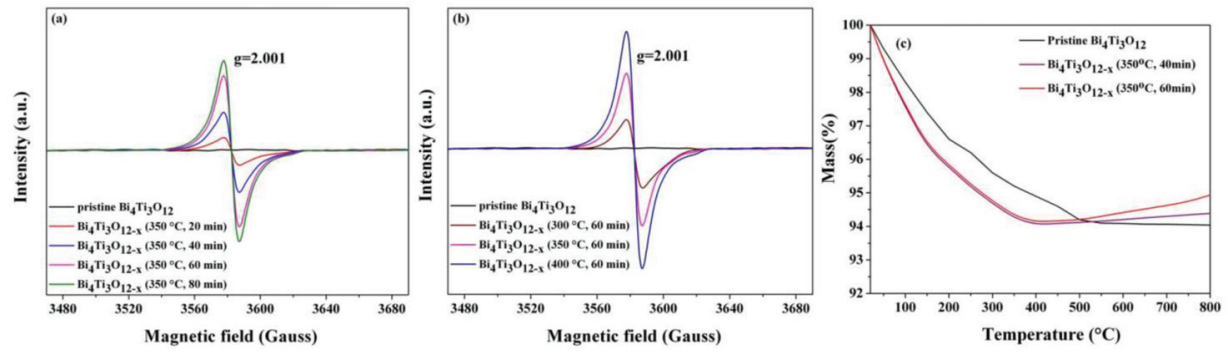

Figure 6. (a) electron paramagnetic resonance (EPR) spectra of pristine $\mathrm{Bi}_{4} \mathrm{Ti}_{3} \mathrm{O}_{12}$ and $\mathrm{Bi}_{4} \mathrm{Ti}_{3} \mathrm{O}_{12-x}$ after chemical reduction treatment (a) at $350{ }^{\circ} \mathrm{C}$ for different times; (b) at different temperatures for $60 \mathrm{~min}$; and (c) thermogravimetric analysis (TGA) curves of the pristine $\mathrm{Bi}_{4} \mathrm{Ti}_{3} \mathrm{O}_{12}, \mathrm{Bi}_{4} \mathrm{Ti}_{3} \mathrm{O}_{12-x}\left(350{ }^{\circ} \mathrm{C}\right.$, $40 \mathrm{~min})$, and $\mathrm{Bi}_{4} \mathrm{Ti}_{3} \mathrm{O}_{12-x}\left(350{ }^{\circ} \mathrm{C}, 60 \mathrm{~min}\right)$.

The existence of oxygen vacancies was also proven by TGA testing in the air atmosphere. As shown in Figure $6 c$, the mass of the pristine $\mathrm{Bi}_{4} \mathrm{Ti}_{3} \mathrm{O}_{12}$ decreases as the temperature increases because of the desorption of hydroxyl groups physically adsorbed on the surface [53]. When the temperature is above $510{ }^{\circ} \mathrm{C}$, the mass of the pristine $\mathrm{Bi}_{4} \mathrm{Ti}_{3} \mathrm{O}_{12}$ remains constant. While, as for $\mathrm{Bi}_{4} \mathrm{Ti}_{3} \mathrm{O}_{12-x}\left(350{ }^{\circ} \mathrm{C}\right.$, $60 \mathrm{~min}$ ), one can notice that when the temperature is below $405{ }^{\circ} \mathrm{C}$, the variation trend of the TGA curve is the same as that of the pristine $\mathrm{Bi}_{4} \mathrm{Ti}_{3} \mathrm{O}_{12}$. However, when the temperature exceeds $405{ }^{\circ} \mathrm{C}$, there is a clear difference between the mass loss of the pristine $\mathrm{Bi}_{4} \mathrm{Ti}_{3} \mathrm{O}_{12}$ and $\mathrm{Bi}_{4} \mathrm{Ti}_{3} \mathrm{O}_{12-x}\left(350{ }^{\circ} \mathrm{C}\right.$, $60 \mathrm{~min})$. A slight increase in the mass of $\mathrm{Bi}_{4} \mathrm{Ti}_{3} \mathrm{O}_{12-x}\left(350{ }^{\circ} \mathrm{C}, 60 \mathrm{~min}\right)$ is observed, which is finished at $800{ }^{\circ} \mathrm{C}$. The same phenomenon was also observed by Li et al. [54] and Yang et al. [55]. It was previously reported by $\mathrm{Li}$ et al. that an obvious mass difference between black $\mathrm{TiO}_{2-x}$ and white $\mathrm{TiO}_{2}$ existed during TGA testing. A mass gain for black $\mathrm{TiO}_{2-x}$ was assigned to the oxidation of oxygen vacancies on the surface [54]. Yang et al. also reported an obvious difference in weight loss between $\mathrm{TiO}_{2}-\mathrm{SO}\left(\mathrm{TiO}_{2}\right.$ with surface oxygen vacancies) and conventional $\mathrm{TiO}_{2}$ when the temperature exceeded $440{ }^{\circ} \mathrm{C}$ during TGA testing [55]. It was deduced that when the $\mathrm{TiO}_{2}-\mathrm{SO}$ sample was heated in air, its surface oxygen vacancies can be compensated by the external oxygen, resulting in the mass increase for $\mathrm{TiO}_{2}-\mathrm{SO}$. Therefore, it is postulated that the slight increase in the mass of $\mathrm{Bi}_{4} \mathrm{Ti}_{3} \mathrm{O}_{12-x}$ $\left(350{ }^{\circ} \mathrm{C}, 60 \mathrm{~min}\right.$ ) can be explained by the formation of oxygen vacancies on the surface of $\mathrm{Bi}_{4} \mathrm{Ti}_{3} \mathrm{O}_{12-x}$ $\left(350{ }^{\circ} \mathrm{C}, 60 \mathrm{~min}\right)$ in the present work. When $\mathrm{Bi}_{4} \mathrm{Ti}_{3} \mathrm{O}_{12-x}\left(350{ }^{\circ} \mathrm{C}, 60 \mathrm{~min}\right)$ with oxygen vacancies is heated in air, its unsaturated surface will be compensated by the external oxygen, leading to a mass increase. In addition, as shown in Figure $6 \mathrm{c}$, the variation trend of the TGA curve of $\mathrm{Bi}_{4} \mathrm{Ti}_{3} \mathrm{O}_{12-x}$ $\left(350{ }^{\circ} \mathrm{C}, 40 \mathrm{~min}\right)$ is the same as that of $\mathrm{Bi}_{4} \mathrm{Ti}_{3} \mathrm{O}_{12-x}\left(350{ }^{\circ} \mathrm{C}, 60 \mathrm{~min}\right)$. However, the mass increase of the former is smaller than that of the latter, which may be due to the smaller number of surface oxygen vacancies of $\mathrm{Bi}_{4} \mathrm{Ti}_{3} \mathrm{O}_{12-x}\left(350{ }^{\circ} \mathrm{C}, 40 \mathrm{~min}\right)$. 
XPS can provide useful information on the chemical states of elements and surface defects [56]. Figure 7 shows the high-resolution $\mathrm{Bi} 4 \mathrm{f}$ and $\mathrm{O} 1 \mathrm{~s}$ spectra of the pristine $\mathrm{Bi}_{4} \mathrm{Ti}_{3} \mathrm{O}_{12}$ and the optimal $\mathrm{Bi}_{4} \mathrm{Ti}_{3} \mathrm{O}_{12-x}\left(350{ }^{\circ} \mathrm{C}, 60 \mathrm{~min}\right)$. As shown in Figure $7 \mathrm{a}$, the $\mathrm{Bi}$ 4f spectrum of the pristine $\mathrm{Bi}_{4} \mathrm{Ti}_{3} \mathrm{O}_{12}$ sample exhibits two main peaks at $159.9 \mathrm{eV}\left(\mathrm{Bi}_{4 \mathrm{f}_{7 / 2}}\right)$ and $165.3 \mathrm{eV}\left(\mathrm{Bi}_{4} \mathrm{f}_{5 / 2}\right)$ ascribed to $\mathrm{Bi}^{3+}$, which are in accordance with the reported values of $\mathrm{Bi}_{2} \mathrm{O}_{3}$ powders $[57,58]$. Figure $7 \mathrm{~b}$ reveals the fitted $\mathrm{O} 1 \mathrm{~s}$ spectra, where the peaks correspond to the lattice oxygen $\left(\mathrm{O}_{\mathrm{L}}, 530.1 \mathrm{eV}\right)$ and chemisorbed oxygen species $\left(\mathrm{O}_{\mathrm{C}}, 532.4 \mathrm{eV}\right)$ on the pristine $\mathrm{Bi}_{4} \mathrm{Ti}_{3} \mathrm{O}_{12}$ sample, respectively. The oxygen vacancies $\left(\mathrm{O}_{\mathrm{V}}\right)$ peak, which should appear at $531.5 \mathrm{eV}$ is not observed in this spectrum, further revealing the stoichiometric properties of the pristine $\mathrm{Bi}_{4} \mathrm{Ti}_{3} \mathrm{O}_{12}$ sample [59,60]. Figure 7c,d show the high-resolution XPS spectra of the $\mathrm{Bi} 4 \mathrm{f}$ and $\mathrm{O} 1 \mathrm{~s}$ core levels for the optimal $\mathrm{Bi}_{4} \mathrm{Ti}_{3} \mathrm{O}_{12-x}\left(350{ }^{\circ} \mathrm{C}, 60 \mathrm{~min}\right)$. The $\mathrm{Bi} 4 \mathrm{f}$ spectrum shows two main peaks centered at 158.8 and $164.3 \mathrm{eV}$, which are identified as the $\mathrm{Bi} 4 \mathrm{f}_{7 / 2}$ and $\mathrm{Bi} 4 \mathrm{f}_{5 / 2}$, respectively. However, $4 f_{7 / 2}$ and $4 f_{5 / 2}$ peaks of the metallic Bi are located at 156.8 and $162.2 \mathrm{eV} \mathrm{[57].}$ The chemical shift of the Bi $4 \mathrm{f}$ doublet relative to the metallic $\mathrm{Bi}$ is about $2.1 \mathrm{eV}$, which is smaller than the reported value of $3.1 \mathrm{eV}$ between $\mathrm{Bi}_{2} \mathrm{O}_{3}$ and the metallic $\mathrm{Bi}$ [61]. This result indicates that the valence state of bismuth in the optimal $\mathrm{Bi}_{4} \mathrm{Ti}_{3} \mathrm{O}_{12-x}\left(350{ }^{\circ} \mathrm{C}, 60 \mathrm{~min}\right)$ should be $(+3-\mathrm{x})$ owing to an increased concentration of oxygen defects in the vicinity of $\mathrm{Bi}$ ions, which are probably in the $\mathrm{Bi}_{2} \mathrm{O}_{2}$ layer [61]. The XPS spectrum of O1s of the optimal $\mathrm{Bi}_{4} \mathrm{Ti}_{3} \mathrm{O}_{12-x}\left(350{ }^{\circ} \mathrm{C}, 60 \mathrm{~min}\right)$ is shown in Figure $7 \mathrm{~d}$. The O1s XPS spectrum is broad and unsymmetrical, indicating more than one chemical state for oxygen in the optimal $\mathrm{Bi}_{4} \mathrm{Ti}_{3} \mathrm{O}_{12-x}\left(350{ }^{\circ} \mathrm{C}, 60 \mathrm{~min}\right)$ sample. Gaussian divided features at $530.1 \mathrm{eV}, 531.5 \mathrm{eV}$, and $532.4 \mathrm{eV}$ are credited to the lattice oxygen, oxygen vacancies, and surface chemisorbed oxygen, respectively $[59,60]$. The $\mathrm{O}_{\mathrm{V}}$ peak appearing at $531.5 \mathrm{eV}$ indicates that oxygen vacancies are generated in the optimal $\mathrm{Bi}_{4} \mathrm{Ti}_{3} \mathrm{O}_{12-x}\left(350{ }^{\circ} \mathrm{C}, 60 \mathrm{~min}\right)$ during the solid-state chemical reduction process.
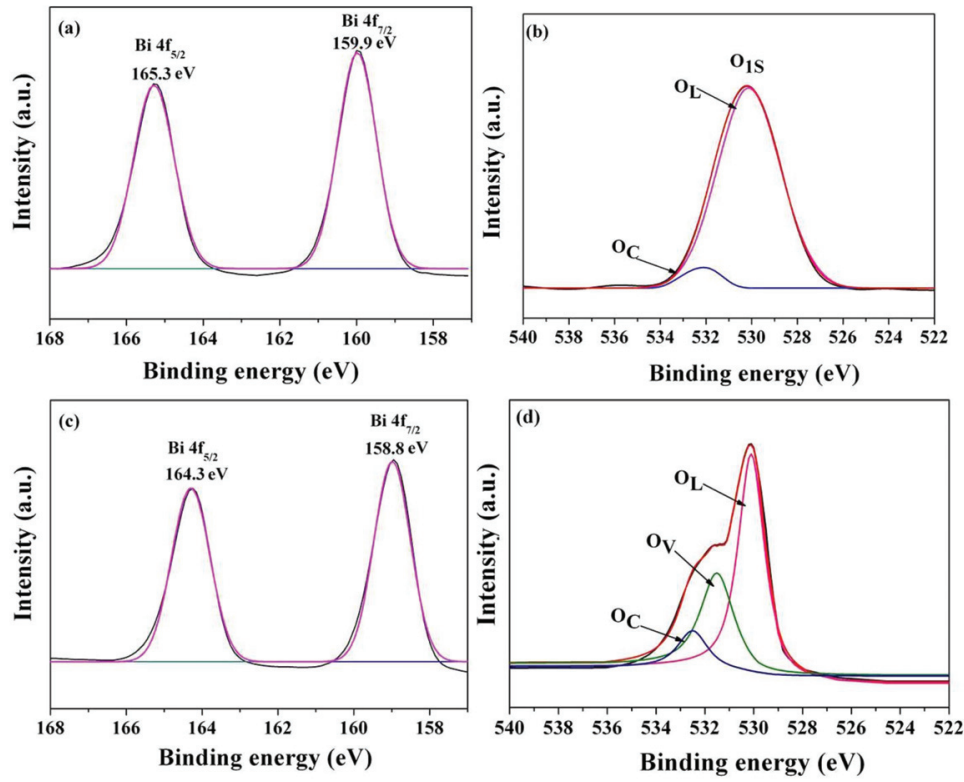

Figure 7. High-resolution X-ray photoelectron spectrometer (XPS) spectra: (a) Bi $4 \mathrm{f}$ and (b) O1s of the pristine $\mathrm{Bi}_{4} \mathrm{Ti}_{3} \mathrm{O}_{12} ;$ (c) $\mathrm{Bi} 4 \mathrm{f}$ and (d) $\mathrm{O} 1 \mathrm{~s}$ of $\mathrm{Bi}_{4} \mathrm{Ti}_{3} \mathrm{O}_{12-x}\left(350{ }^{\circ} \mathrm{C}, 60 \mathrm{~min}\right)$.

In addition, the change in morphology of the pristine $\mathrm{Bi}_{4} \mathrm{Ti}_{3} \mathrm{O}_{12}$ and $\mathrm{Bi}_{4} \mathrm{Ti}_{3} \mathrm{O}_{12-x}$ were also scrutinized to prove the formation of oxygen vacancies. Figure $8 \mathrm{a}, \mathrm{c}$ show representative TEM images of both the pristine $\mathrm{Bi}_{4} \mathrm{Ti}_{3} \mathrm{O}_{12}$ and the optimal $\mathrm{Bi}_{4} \mathrm{Ti}_{3} \mathrm{O}_{12-x}\left(350{ }^{\circ} \mathrm{C}, 60 \mathrm{~min}\right)$ photocatalyst, respectively. 
It is seen that both samples consist of rectangular nanosheets with sides around $\sim 100$ and $\sim 150 \mathrm{~nm}$. The particle size of $\mathrm{Bi}_{4} \mathrm{Ti}_{3} \mathrm{O}_{12-x}\left(350^{\circ} \mathrm{C}, 60 \mathrm{~min}\right)$ has not changed after the solid-state chemical reduction process. HRTEM micrographs offer a more complete view of the microstructures of the samples. As shown in Figure 8 b, the pristine $\mathrm{Bi}_{4} \mathrm{Ti}_{3} \mathrm{O}_{12}$ nanocrystals display a highly crystalline composition, as well as perfect lattice structures throughout the entire particles. The measured spacings are equal to $0.271 \mathrm{~nm}$ and to $0.273 \mathrm{~nm}$, which are in agreement with the (020) and (200) planes of $\mathrm{Bi}_{4} \mathrm{Ti}_{3} \mathrm{O}_{12}$, respectively [62]. However, after the solid-state reduction reaction process at $350{ }^{\circ} \mathrm{C}$ for $60 \mathrm{~min}$, a disordered layer is observed on the surface of the $\mathrm{Bi}_{4} \mathrm{Ti}_{3} \mathrm{O}_{12-x}\left(350{ }^{\circ} \mathrm{C}, 60 \mathrm{~min}\right)$ nanosheet (Figure $8 \mathrm{~d}$ ). Compared with the pristine $\mathrm{Bi}_{4} \mathrm{Ti}_{3} \mathrm{O}_{12}$ nanocrystals, the lattice features shown in the HRTEM image of $\mathrm{Bi}_{4} \mathrm{Ti}_{3} \mathrm{O}_{12-x}\left(350{ }^{\circ} \mathrm{C}, 60 \mathrm{~min}\right)$ became highly blurred. The surface structure of the $\mathrm{Bi}_{4} \mathrm{Ti}_{3} \mathrm{O}_{12-x}\left(350{ }^{\circ} \mathrm{C}\right.$, $60 \mathrm{~min}$ ) nanosheet is imperfect, which may have been damaged by the reduction reaction induced oxygen vacancies [33]. In summary, the EPR, XPS, TGA, and TEM results confirm the existence of oxygen vacancies on the $\mathrm{Bi}_{4} \mathrm{Ti}_{3} \mathrm{O}_{12-x}$ nanosheets, which can be attributed to the reduction of the active hydrogen produced by the decomposition of $\mathrm{NaBH}_{4}$.
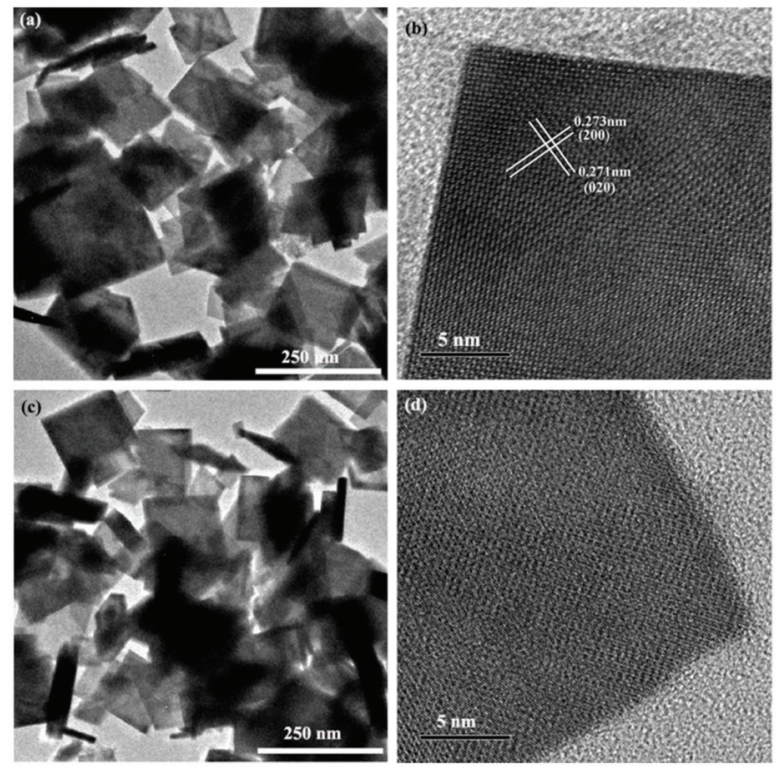

Figure 8. Transmission electron microscopy (TEM) images of (a) the pristine $\mathrm{Bi}_{4} \mathrm{Ti}_{3} \mathrm{O}_{12}$ and (c) $\mathrm{Bi}_{4} \mathrm{Ti}_{3} \mathrm{O}_{12-x}$ $\left(350{ }^{\circ} \mathrm{C}, 60 \mathrm{~min}\right)$; HRTEM images of $(\mathbf{b})$ the pristine $\mathrm{Bi}_{4} \mathrm{Ti}_{3} \mathrm{O}_{12}$ and $(\mathbf{d}) \mathrm{Bi}_{4} \mathrm{Ti}_{3} \mathrm{O}_{12-x}\left(350{ }^{\circ} \mathrm{C}, 60 \mathrm{~min}\right)$.

The concentration and species of the oxygen vacancies in the $\mathrm{Bi}_{4} \mathrm{Ti}_{3} \mathrm{O}_{12-x}$ nanosheets were studied using the positron annihilation life technique [55,63-66]. Lifetime components $\left(\tau_{1}, \tau_{2}\right.$, and $\left.\tau_{3}\right)$, as well as corresponding intensities $\left(I_{1}, I_{2}\right.$, and $\left.I_{3}\right)$ for the pristine $\mathrm{Bi}_{4} \mathrm{Ti}_{3} \mathrm{O}_{12}$ and the $\mathrm{Bi}_{4} \mathrm{Ti}_{3} \mathrm{O}_{12-x}$ samples are shown in Table 3. The longest component $\left(\tau_{3}\right)$ is typically ascribed to the annihilation of the orthopositronium atom in the material voids [63], and the shortest one $\left(\tau_{1}\right)$ is typically due to the annihilation of the positron in the small defects in the bulk, such as the bulk oxygen vacancies $[55,64]$. Another component $\left(\tau_{2}\right)$ arises from positrons trapped by larger-sized defects on the surface of the materials, such as surface oxygen vacancies $[55,65]$. The relative intensity $\left(I_{1} / I_{2}\right)$ reflects the ratio of the corresponding defects $[55,63]$ and in the present work, reflects the relative concentration ratio of bulk and surface oxygen vacancies [55]. As shown in Table 3, when the $\mathrm{Bi}_{4} \mathrm{Ti}_{3} \mathrm{O}_{12-x}$ samples were exposed to solid-state chemical reduction treatment at $350{ }^{\circ} \mathrm{C}$, the $I_{1} / I_{2}$ ratio decreased with the increasing 
chemical reduction reaction time and reached a minimum at $60 \mathrm{~min}$. With further increases in the reaction time and reaction temperature, the $I_{1} / I_{2}$ ratio increased instead. The results of the positron annihilation analysis indicate that the concentrations and types of oxygen vacancies can be controlled by adjusting the chemical reaction time and temperature. This means that due to the presence of active hydrogen produced from the decomposition of $\mathrm{NaBH}_{4}, \mathrm{Bi}_{4} \mathrm{Ti}_{3} \mathrm{O}_{12-x}$ nanosheets with different reduction degrees can be obtained by tuning the reduction reaction conditions.

Table 3. Positron lifetime and relative intensities of the pristine $\mathrm{Bi}_{4} \mathrm{Ti}_{3} \mathrm{O}_{12}$ and various $\mathrm{Bi}_{4} \mathrm{Ti}_{3} \mathrm{O}_{12-x}$ samples.

\begin{tabular}{cccccccc}
\hline Sample & $\boldsymbol{\tau}_{\mathbf{1}}(\mathbf{p s})$ & $\boldsymbol{\tau}_{\mathbf{2}}$ (ps) & $\boldsymbol{\tau}_{\mathbf{3}}(\mathbf{n s})$ & $\boldsymbol{I}_{\mathbf{1}}(\mathbf{\%})$ & $\boldsymbol{I}_{\mathbf{2}}(\mathbf{\%})$ & $\boldsymbol{I}_{\mathbf{3}}(\boldsymbol{\%})$ & $\boldsymbol{I}_{\mathbf{1}} / \boldsymbol{I}_{\mathbf{2}}$ \\
\hline $\mathrm{Bi}_{4} \mathrm{Ti}_{3} \mathrm{O}_{12}$ & 193 & 376 & 2.33 & 50.24 & 47.78 & 1.98 & 1.05 \\
$\mathrm{Bi}_{4} \mathrm{Ti}_{3} \mathrm{O}_{12-x}\left(350^{\circ} \mathrm{C}, 20 \mathrm{~min}\right)$ & 196 & 387 & 2.47 & 46.26 & 51.97 & 1.77 & 0.89 \\
$\mathrm{Bi}_{4} \mathrm{Ti}_{3} \mathrm{O}_{12-x}\left(350^{\circ} \mathrm{C}, 40 \mathrm{~min}\right)$ & 199 & 389 & 2.49 & 38.72 & 59.64 & 1.64 & 0.65 \\
$\mathrm{Bi}_{4} \mathrm{Ti}_{3} \mathrm{O}_{12-x}\left(350^{\circ} \mathrm{C}, 60 \mathrm{~min}\right)$ & 205 & 393 & 2.77 & 23.87 & 74.24 & 1.89 & 0.32 \\
$\mathrm{Bi}_{4} \mathrm{Ti}_{3} \mathrm{O}_{12-x}\left(350^{\circ} \mathrm{C}, 80 \mathrm{~min}\right)$ & 209 & 396 & 2.92 & 36.48 & 61.57 & 1.95 & 0.59 \\
$\mathrm{Bi}_{4} \mathrm{Ti}_{3} \mathrm{O}_{12-x}\left(350^{\circ} \mathrm{C}, 100 \mathrm{~min}\right)$ & 214 & 402 & 3.05 & 41.73 & 56.42 & 1.85 & 0.74 \\
$\mathrm{Bi}_{4} \mathrm{Ti}_{3} \mathrm{O}_{12-x}\left(400^{\circ} \mathrm{C}, 60 \mathrm{~min}\right)$ & 216 & 405 & 3.11 & 44.86 & 53.33 & 1.81 & 0.84 \\
\hline
\end{tabular}

\subsection{Mechanism of Enhanced Photocatalytic Activity of $\mathrm{Bi}_{4} \mathrm{Ti}_{3} \mathrm{O}_{12-x}$}

The photocatalyst's BET specific surface area was measured to examine a correlation between the surface area and the photocatalytic activity. This is because the large surface areas could influence the number of available active sites [67] and affect the interfacial charge transfer quantum efficiency [68]. As outlined in Table 4, the BET specific surface areas for the $\mathrm{Bi}_{4} \mathrm{Ti}_{3} \mathrm{O}_{12-x}$ samples are almost indistinguishable from the pristine $\mathrm{Bi}_{4} \mathrm{Ti}_{3} \mathrm{O}_{12}$. In addition, as described earlier, the crystal phase structures are not changed (Figure 3). These results strongly suggest that it is not the surface area or structural features that lead to the large divergence in photocatalysis ability. Therefore, this implies that the photocatalytic kinetics of the $\mathrm{Bi}_{4} \mathrm{Ti}_{3} \mathrm{O}_{12-x}$ samples are mainly enhanced by other factors.

Table 4. Brunauer-Emmett-Teller (BET) specific surface areas of the pristine $\mathrm{Bi}_{4} \mathrm{Ti}_{3} \mathrm{O}_{12}$ and various $\mathrm{Bi}_{4} \mathrm{Ti}_{3} \mathrm{O}_{12-x}$ samples.

\begin{tabular}{cc}
\hline Samples & BET Specific Surface Area $\left(\mathbf{m}^{2} / \mathbf{g}\right)$ \\
\hline $\mathrm{Bi}_{4} \mathrm{Ti}_{3} \mathrm{O}_{12}$ & 6.45 \\
$\mathrm{Bi}_{4} \mathrm{Ti}_{3} \mathrm{O}_{12-x}\left(350^{\circ} \mathrm{C}, 20 \mathrm{~min}\right)$ & 6.39 \\
$\mathrm{Bi}_{4} \mathrm{Ti}_{3} \mathrm{O}_{12-x}\left(350^{\circ} \mathrm{C}, 40 \mathrm{~min}\right)$ & 6.35 \\
$\mathrm{Bi}_{4} \mathrm{Ti}_{3} \mathrm{O}_{12-x}\left(350^{\circ} \mathrm{C}, 60 \mathrm{~min}\right)$ & 6.32 \\
$\mathrm{Bi}_{4} \mathrm{Ti}_{3} \mathrm{O}_{12-x}\left(350^{\circ} \mathrm{C}, 80 \mathrm{~min}\right)$ & 6.46 \\
$\mathrm{Bi}_{4} \mathrm{Ti}_{3} \mathrm{O}_{12-x}\left(350^{\circ} \mathrm{C}, 100 \mathrm{~min}\right)$ & 6.48 \\
$\mathrm{Bi}_{4} \mathrm{Ti}_{3} \mathrm{O}_{12-x}\left(300^{\circ} \mathrm{C}, 60 \mathrm{~min}\right)$ & 6.38 \\
$\mathrm{Bi}_{4} \mathrm{Ti}_{3} \mathrm{O}_{12-x}\left(400^{\circ} \mathrm{C}, 60 \mathrm{~min}\right)$ & 6.51 \\
\hline
\end{tabular}

As is well-known, generation and disassociation of photo-generated electron-hole pairs are crucial for a semiconductor photocatalyst. The efficiency of this disassociation is central to the enhancement of photocatalytic activity. EIS was used to fully probe this efficiency. Figure 9a shows the EIS of the pristine $\mathrm{Bi}_{4} \mathrm{Ti}_{3} \mathrm{O}_{12}$ and various $\mathrm{Bi}_{4} \mathrm{Ti}_{3} \mathrm{O}_{12-x}$ electrodes. Each sample diagram contains a semi-circular section, reflecting the process of the charge transfer, as well as a linear section with a $45^{\circ}$ slope corresponding to the diffusion-controlled step [69]. The value for the electron-transfer resistance $\left(R_{\mathrm{ct}}\right)$ is obtained by calculating the diameter of the semi-circle, and this acts as a proxy for the system's charge transfer effectiveness. In other words, a smaller $R_{\mathrm{ct}}$ value means a higher charge transfer efficiency of the system [70]. The order in the $R_{\mathrm{ct}}$ value is the pristine $\mathrm{Bi}_{4} \mathrm{Ti}_{3} \mathrm{O}_{12}>\mathrm{Bi}_{4} \mathrm{Ti}_{3} \mathrm{O}_{12-x}\left(350{ }^{\circ} \mathrm{C}\right.$, $40 \mathrm{~min})>\mathrm{Bi}_{4} \mathrm{Ti}_{3} \mathrm{O}_{12-x}\left(350{ }^{\circ} \mathrm{C}, 80 \mathrm{~min}\right)>\mathrm{Bi}_{4} \mathrm{Ti}_{3} \mathrm{O}_{12-x}\left(350{ }^{\circ} \mathrm{C}, 60 \mathrm{~min}\right)$, coinciding with the increased activity order of the photocatalysts. The $R_{\mathrm{ct}}$ of the $\mathrm{Bi}_{4} \mathrm{Ti}_{3} \mathrm{O}_{12-x}\left(350{ }^{\circ} \mathrm{C}, 60 \mathrm{~min}\right)$ electrode is the smallest 
among all the catalysts. Therefore, the photo-generated electron-hole pairs are most easily separated and transferred to the surface in the $\mathrm{Bi}_{4} \mathrm{Ti}_{3} \mathrm{O}_{12-x}\left(350{ }^{\circ} \mathrm{C}, 60 \mathrm{~min}\right)$ sample, thus leading to the highest photocatalytic activity of all the catalysts. The photocurrent analysis was also conducted to confirm the hindering efficiency of $\mathrm{Bi}_{4} \mathrm{Ti}_{3} \mathrm{O}_{12-x}$ during the recombination of electron-hole pairs. Figure $9 \mathrm{~b}$ details the photocurrent responses of the pristine $\mathrm{Bi}_{4} \mathrm{Ti}_{3} \mathrm{O}_{12}, \mathrm{Bi}_{4} \mathrm{Ti}_{3} \mathrm{O}_{12-x}\left(350{ }^{\circ} \mathrm{C}, 40 \mathrm{~min}\right), \mathrm{Bi}_{4} \mathrm{Ti}_{3} \mathrm{O}_{12-x}\left(350{ }^{\circ} \mathrm{C}\right.$, $60 \mathrm{~min})$, and $\mathrm{Bi}_{4} \mathrm{Ti}_{3} \mathrm{O}_{12-x}\left(350^{\circ} \mathrm{C}, 80 \mathrm{~min}\right)$ after their deposition on ITO electrodes under visible light. The results show that the responses are prompt, uniform, and reproducible with the light irradiation switched on and off. Under visible light, the photocurrent density of the $\mathrm{Bi}_{4} \mathrm{Ti}_{3} \mathrm{O}_{12-x}\left(350{ }^{\circ} \mathrm{C}, 60 \mathrm{~min}\right)$ electrode is the highest among the samples. The enhanced photocurrent indicates the amplification of the photo-induced carrier transport rate, as well as the dwindling photo-generated electron-hole pair recombination rate [71]. The results of the photocurrent investigation are in agreement with the changes in catalytic activity for the pristine $\mathrm{Bi}_{4} \mathrm{Ti}_{3} \mathrm{O}_{12-x}$ and $\mathrm{Bi}_{4} \mathrm{Ti}_{3} \mathrm{O}_{12-x}$ (Figure 4). Therefore, we believe that the improved charge separation and transportation are the major reasons for the enhanced photocatalytic activity of $\mathrm{Bi}_{4} \mathrm{Ti}_{3} \mathrm{O}_{12-x}$.
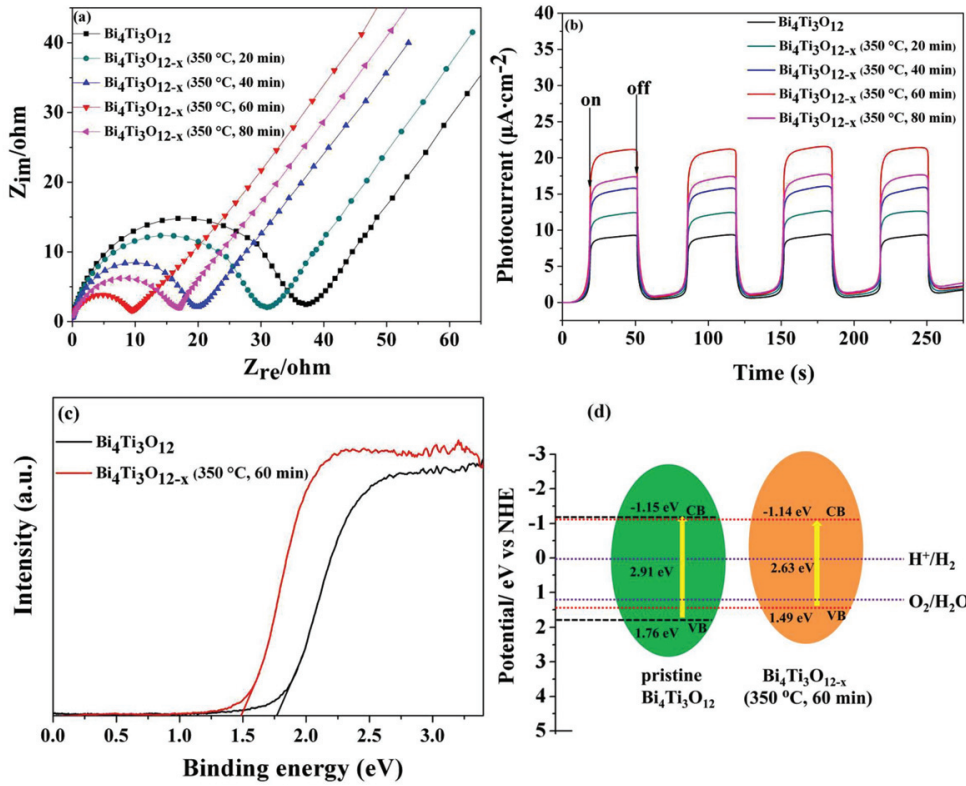

(d)

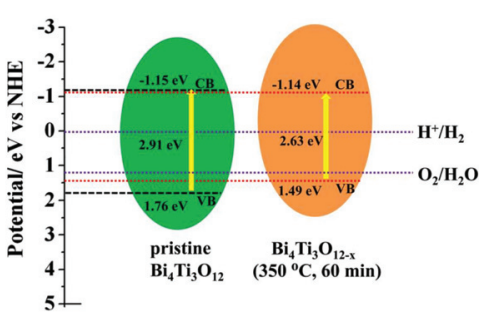

Figure 9. (a) The electrochemical impedance spectroscopy (EIS) Nyquist plots of the pristine $\mathrm{Bi}_{4} \mathrm{Ti}_{3} \mathrm{O}_{12}$ and various $\mathrm{Bi}_{4} \mathrm{Ti}_{3} \mathrm{O}_{12-x}$ samples after the buildup on the ITO electrodes with visible-light $(\lambda>400 \mathrm{~nm})$ irradiation; (b) Photocurrents of the pristine $\mathrm{Bi}_{4} \mathrm{Ti}_{3} \mathrm{O}_{12}$ and various $\mathrm{Bi}_{4} \mathrm{Ti}_{3} \mathrm{O}_{12-x}$ samples after the buildup on the ITO electrodes under visible-light irradiation $(\lambda>400 \mathrm{~nm})$; (c) valence band XPS spectra of the pristine $\mathrm{Bi}_{4} \mathrm{Ti}_{3} \mathrm{O}_{12}$ and $\mathrm{Bi}_{4} \mathrm{Ti}_{3} \mathrm{O}_{12-x}\left(350{ }^{\circ} \mathrm{C}, 60 \mathrm{~min}\right)$; (d) the probable band energy diagram of the pristine $\mathrm{Bi}_{4} \mathrm{Ti}_{3} \mathrm{O}_{12}$ and $\mathrm{Bi}_{4} \mathrm{Ti}_{3} \mathrm{O}_{12-x}\left(350{ }^{\circ} \mathrm{C}, 60 \mathrm{~min}\right)$.

The position of the valence band (VB) on top of the pristine $\mathrm{Bi}_{4} \mathrm{Ti}_{3} \mathrm{O}_{12}$ and $\mathrm{Bi}_{4} \mathrm{Ti}_{3} \mathrm{O}_{12-x}\left(350{ }^{\circ} \mathrm{C}\right.$, $60 \mathrm{~min}$ ) was determined by VB XPS spectra (see Figure 9c). The top of the valence band ( $\mathrm{E}_{\mathrm{VB}}$ ) of the pristine $\mathrm{Bi}_{4} \mathrm{Ti}_{3} \mathrm{O}_{12}$ and $\mathrm{Bi}_{4} \mathrm{Ti}_{3} \mathrm{O}_{12-x}\left(350{ }^{\circ} \mathrm{C}, 60 \mathrm{~min}\right)$ vs. the normal hydrogen electrode (NHE) are estimated to be 1.76 and $1.49 \mathrm{eV}$, respectively. Moreover, the band gaps of the pristine $\mathrm{Bi}_{4} \mathrm{Ti}_{3} \mathrm{O}_{12}$ and $\mathrm{Bi}_{4} \mathrm{Ti}_{3} \mathrm{O}_{12-x}\left(350{ }^{\circ} \mathrm{C}, 60 \mathrm{~min}\right)$ are 2.91 and $2.63 \mathrm{eV}$, respectively (Table 1$)$. Therefore, using the formula $\mathrm{E}_{\mathrm{CB}}=\mathrm{E}_{\mathrm{VB}}-\mathrm{Eg}$ [16], the bottom of conduction band $\left(\mathrm{E}_{\mathrm{CB}}\right)$ is -1.15 and $-1.14 \mathrm{eV}$ for the pristine $\mathrm{Bi}_{4} \mathrm{Ti}_{3} \mathrm{O}_{12}$ and $\mathrm{Bi}_{4} \mathrm{Ti}_{3} \mathrm{O}_{12-x}\left(350{ }^{\circ} \mathrm{C}, 60 \mathrm{~min}\right)$, respectively. According to the values of $\mathrm{E}_{\mathrm{VB}}$ 
and $E_{C B}$, a suggested band energy diagram is illustrated in Figure 9d. It can be observed that the conduction band energy of $\mathrm{Bi}_{4} \mathrm{Ti}_{3} \mathrm{O}_{12-x}\left(350{ }^{\circ} \mathrm{C}, 60 \mathrm{~min}\right)$ is almost the same as that of the pristine $\mathrm{Bi}_{4} \mathrm{Ti}_{3} \mathrm{O}_{12}$. However, compared to the pristine $\mathrm{Bi}_{4} \mathrm{Ti}_{3} \mathrm{O}_{12}$, the $\mathrm{VBM}$ of $\mathrm{Bi}_{4} \mathrm{Ti}_{3} \mathrm{O}_{12-x}\left(350{ }^{\circ} \mathrm{C}, 60 \mathrm{~min}\right)$ rises considerably, leading to a narrowing band gap of $\mathrm{Bi}_{4} \mathrm{Ti}_{3} \mathrm{O}_{12-x}\left(350{ }^{\circ} \mathrm{C}, 60 \mathrm{~min}\right)$. We attribute this rise in band gap to the formation of new energy states near the VB top because of the presence of oxygen vacancy in the $\mathrm{Bi}_{4} \mathrm{Ti}_{3} \mathrm{O}_{12-x}\left(350{ }^{\circ} \mathrm{C}, 60 \mathrm{~min}\right)$ sample [72].

Based on the discussion above, the reasons for the better photocatalytic activity of the $\mathrm{Bi}_{4} \mathrm{Ti}_{3} \mathrm{O}_{12-x}$ nanosheets could be explained from the point of view of surface defects. The surface oxygen vacancies are located on the top of the VBM or below the conduction band minimum (CBM) $[24,48,49,72]$ and are considered as shallow defects. Zhu et al. discovered that the surface oxygen defect states were formed on the top of the $\mathrm{VBM}$ for $\mathrm{ZnO}$ and $\mathrm{BiPO}_{4}[48,49]$. Huang et al. demonstrated that a high number of oxygen vacancies created an impurity energy level near the valence band and caused a decrease in the band gap [24]. Zhao et al. reported that under poor oxygen conditions, the oxygen vacancy states at the top of the valence band decreased the band gap of $\mathrm{LiTi}_{2}\left(\mathrm{PO}_{4}\right)_{3}$ significantly [73]. The rise of the VBM and the reduction of the band of anatase $\mathrm{TiO}_{2}$ have been observed by scanning tunneling microscopy [74]. In the present work, the EPR, TGA, and TEM confirm that oxygen vacancies are formed in $\mathrm{Bi}_{4} \mathrm{Ti}_{3} \mathrm{O}_{12-x}$ after the chemical reduction treatment. Figure 10 shows the schematic diagram of the charge separation and photocatalytic reaction for the $\mathrm{Bi}_{4} \mathrm{Ti}_{3} \mathrm{O}_{12-x}$ photocatalyst under visible-light irradiation. Many shallow surface oxygen vacancy states should be above the valence band and partially overlap with the valence band of $\mathrm{Bi}_{4} \mathrm{Ti}_{3} \mathrm{O}_{12-x}$, which can cause rise of the VBM to VBM'. Hence, the VBM of $\mathrm{Bi}_{4} \mathrm{Ti}_{3} \mathrm{O}_{12-x}\left(350^{\circ} \mathrm{C}, 60 \mathrm{~min}\right)$ is higher than that of the pristine $\mathrm{Bi}_{4} \mathrm{Ti}_{3} \mathrm{O}_{12}$, which is proven by the valence band XPS spectra (Figure 9c). Correspondingly, the rise of the VBM can further expand the valence band, which can increase the transport rate of photo-generated carriers, resulting in the improved separation efficiency of the photo-generated electron-hole pairs and leading to an obvious improvement of the photocatalytic activities of $\mathrm{Bi}_{4} \mathrm{Ti}_{3} \mathrm{O}_{12-x}$. In addition, due to the $\mathrm{VBM}^{\prime}$ rise, the band gap of $\mathrm{Bi}_{4} \mathrm{Ti}_{3} \mathrm{O}_{12-x}$ narrows, thus expanding the photoresponse range of $\mathrm{Bi}_{4} \mathrm{Ti}_{3} \mathrm{O}_{12-x}$ (from under $420 \mathrm{~nm}$ for the pristine $\mathrm{Bi}_{4} \mathrm{Ti}_{3} \mathrm{O}_{12}$ to above $460 \mathrm{~nm}$ for $\mathrm{Bi}_{4} \mathrm{Ti}_{3} \mathrm{O}_{12-x}\left(350{ }^{\circ} \mathrm{C}, 60 \mathrm{~min}\right.$ )).

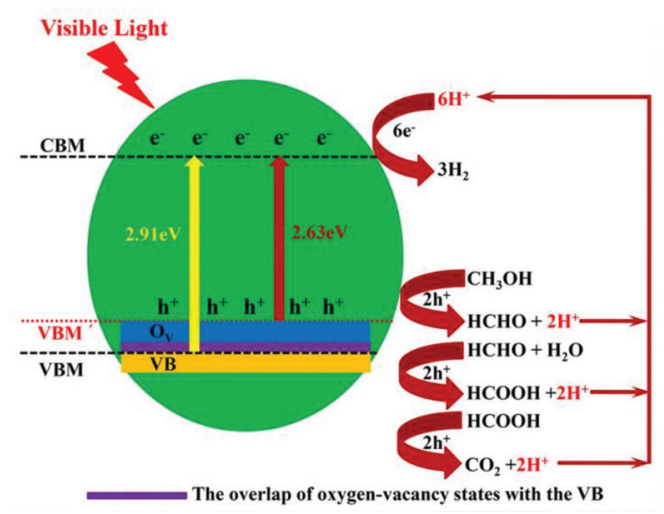

Figure 10. Schematic diagram illustrating the mechanism of the charge separation and photocatalytic reaction for the $\mathrm{Bi}_{4} \mathrm{Ti}_{3} \mathrm{O}_{12-x}$ photocatalyst under visible-light irradiation. VB: valence band; CBM: conduction band minimum; and VBM: valence band maximum.

Furthermore, as shown in Figure 4, both the reduction time and temperature have significant influence on the photocatalysis ability of the $\mathrm{Bi}_{4} \mathrm{Ti}_{3} \mathrm{O}_{12-x}$ photocatalysts. As discussed above, the positron annihilation analysis (Table 3) indicated that $\mathrm{Bi}_{4} \mathrm{Ti}_{3} \mathrm{O}_{12-x}$ nanosheets with different concentrations and types of oxygen vacancies can be obtained by tuning the conditions of the solid-state 
chemical reduction process. The relative intensity $\left(I_{1} / I_{2}\right)$ reflects the relative concentration ratios of bulk and surface oxygen vacancies [55]. When $\mathrm{Bi}_{4} \mathrm{Ti}_{3} \mathrm{O}_{12-x}$ is exposed to chemical reduction treatment at a low temperature or for a short time, the $I_{1} / I_{2}$ ratio continues to decrease with the increasing reaction time and temperature (Table 3 ), thus increasing the number of surface oxygen vacancies. These surface oxygen vacancies are located above the VB and even partially overlap with it. At the same time, the photocatalytic activity improves gradually with the duration of the treatment and temperature, until a maximum is achieved at $350{ }^{\circ} \mathrm{C}$ for $60 \mathrm{~min}$. With additional increases in temperature, as well as prolonged (or longer) reaction time, the $I_{1} / I_{2}$ ratio increases instead (Table 3 ), which means that the bulk oxygen vacancies continue to increase in $\mathrm{Bi}_{4} \mathrm{Ti}_{3} \mathrm{O}_{12-x}$. The bulk oxygen vacancies' defect levels form easily in the forbidden band and provide a position for the recombination of the electron-hole pairs, thus reducing the photocatalytic activity [63]. Therefore, the best activity of the $\mathrm{Bi}_{4} \mathrm{Ti}_{3} \mathrm{O}_{12-x}$ photocatalyst can be achieved when the minimum bulk oxygen vacancies exist simultaneously with large numbers of surface oxygen vacancies. Thus, not only the number but also the types of oxygen vacancies induced with varying chemical reduction temperature and duration are essential for a catalyst with high photoactivity.

\section{Conclusions}

In summary, a facile, economic solid-state chemical reduction method has been proposed to fabricate the $\mathrm{Bi}_{4} \mathrm{Ti}_{3} \mathrm{O}_{12-x}$ photocatalyst with abundant oxygen vacancies. The concentration and types of oxygen vacancies could be adjusted by changing the reduction reaction time and temperature. The $\mathrm{Bi}_{4} \mathrm{Ti}_{3} \mathrm{O}_{12-x}$ catalyst showed significantly improved photoactivity during visible-light driven hydrogen evolution from water compared to the pristine $\mathrm{Bi}_{4} \mathrm{Ti}_{3} \mathrm{O}_{12}$. The hydrogen production rate reaches up to $129 \mu \mathrm{mol} \cdot \mathrm{g}^{-1} \cdot \mathrm{h}^{-1}$ under visible-light irradiation for the optimal $\mathrm{Bi}_{4} \mathrm{Ti}_{3} \mathrm{O}_{12-x}$ photocatalyst (reduction treated at $350{ }^{\circ} \mathrm{C}$ for $60 \mathrm{~min}$ ), which is about 3.4 times that of the pristine $\mathrm{Bi}_{4} \mathrm{Ti}_{3} \mathrm{O}_{12}$. It is proposed that energy levels corresponding to the surface oxygen vacancies should be above and partially overlap with the $\mathrm{Bi}_{4} \mathrm{Ti}_{3} \mathrm{O}_{12-x}$ valence band. This can raise the top of the valence band maximum. The improved photoactivity of the photocatalyst is the result of the enhanced separation ability of photo-generated electron-hole pairs that originates from the valence band expansion by the surface oxygen vacancy states. The extended photoresponse is due to the decrease in the band gap caused by the rise of the top of the valence band maximum.

Supplementary Materials: The following are available online at http:/ /www.mdpi.com/2079-4991/8/4/261/s1.

Acknowledgments: We appreciate the financial support of the National Natural Science Foundation of China (No. 50702022), the Natural Science Foundation of Guangdong Province (No. 2014A030313245), and the State Key Laboratory of Pulp and Paper Engineering (No. 201624).

Author Contributions: Zhiwu Chen conceived of and designed the experiments; Yizeng Zhang and Zhiwu Chen performed the experiments; Yizeng Zhang, Zhiwu Chen, and Zhenya Lu analyzed the data; and Zhiwu Chen wrote the paper with input from all authors.

Conflicts of Interest: The authors declare no conflict of interest.

\section{References}

1. Wang, W.; Tadé, M.O.; Shao, Z.P. Research progress of perovskite materials in photocatalysis-and photovoltaics-related energy conversion and environmental treatment. Chem. Soc. Rev. 2015, 44, 5371-5408. [CrossRef] [PubMed]

2. Moniz, S.J.A.; Shevlin, S.A.; Martin, D.J.; Guo, Z.X.; Tang, J.W. Visible-light driven heterojunction photocatalysts for water splitting-a critical review. Energy Environ. Sci. 2015, 8, 731-759. [CrossRef]

3. Liu, L.; Chen, X. Titanium dioxide nanomaterials: Self-structural modifications. Chem. Rev. 2014, 114, 9890-9918. [CrossRef] [PubMed]

4. Wang, J.; Xia, Y.; Dong, Y.; Chen, R.S.; Xiang, L.; Komarneni, S. Defect-rich ZnO nanosheets of high surface area as an efficient visible-light photocatalyst. Appl. Catal. B 2016, 192, 8-16. [CrossRef] 
5. Yu, J.G.; Yu, Y.F.; Zhou, P.; Xiao, W.; Cheng, B. Morphology-dependent photocatalytic $\mathrm{H}_{2}$-production activity of CdS. Appl. Catal. B 2014, 156, 184-191. [CrossRef]

6. Kisch, H. Semiconductor photocatalysis-mechanistic and synthetic aspects. Angew. Chem. Int. Ed. 2013, 52, 812-847. [CrossRef] [PubMed]

7. Tong, H.; Ouyang, S.; Bi, Y.; Umezawa, N.; Oshikiri, M.; Ye, J. Nano-photocatalytic materials: Possibilities and challenges. Adv. Mater. 2012, 24, 229-251. [CrossRef] [PubMed]

8. Hou, D.F.; Luo, W.; Huang, Y.H.; Yu, J.C.; Hu, X.L. Synthesis of porous $\mathrm{Bi}_{4} \mathrm{Ti}_{3} \mathrm{O}_{12}$ nanofibers by electrospinning and their enhanced visible-light-driven photocatalytic properties. Nanoscale 2013, 5, 2028-2035. [CrossRef] [PubMed]

9. Chen, Z.W.; Jiang, H.; Jin, W.L.; Shi, C.K. Enhanced photocatalytic performance over $\mathrm{Bi}_{4} \mathrm{Ti}_{3} \mathrm{O}_{12}$ nanosheets with controllable size and exposed $\{001\}$ facets for Rhodamine B degradation. Appl. Catal. B 2016, 180, 698-706. [CrossRef]

10. Park, B.H.; Kang, B.S.; Bu, S.D.; Noh, T.W.; Lee, J.; Jo, W. Lanthanum-substituted bismuth titanate for use in non-volatile memories. Nature 1999, 401, 682-684. [CrossRef]

11. Liu, Y.; Zhang, M.; Li, L.; Zhang, X. One-dimensional visible-light-driven bifunctional photocatalysts based on $\mathrm{Bi}_{4} \mathrm{Ti}_{3} \mathrm{O}_{12}$ nanofiber frameworks and $\mathrm{Bi}_{2} \mathrm{XO}_{6}(\mathrm{X}=\mathrm{Mo}, \mathrm{W})$ nanosheets. Appl. Catal. B 2014, 160-161, 757-766. [CrossRef]

12. Kudo, A.; Hijii, $\mathrm{S} . \mathrm{H}_{2}$ or $\mathrm{O}_{2}$ Evolution from aqueous solutions on layered oxide photocatalysts consisting of $\mathrm{Bi}^{3+}$ with $6 s 2$ configuration and d0 transition metal ions. Chem. Lett. 1999, 28, 1103-1104. [CrossRef]

13. Yao, W.; Xu, X.; Wang, H.; Zhou, J.T.; Yang, X.; Zhang, Y.; Shang, S.; Huang, B. Photocatalytic property of perovskite bismuth titanate. Appl. Catal. B 2004, 52, 109-116. [CrossRef]

14. Zhao, W.; Jia, Z.; Lei, E.; Wang, L.; Li, Z.; Dai, Y. Photocatalytic degradation efficacy of $\mathrm{Bi}_{4} \mathrm{Ti}_{3} \mathrm{O}_{12}$ micro-scale platelets over methylene blue under visible light. J. Phys. Chem. Solids 2013, 74, 1604-1607. [CrossRef]

15. Zhang, H.; Lu, M.; Liu, S.; Wang, L.; Xiu, Z.; Zhou, Y.; Qiu, Z.; Zhang, A.; Ma, Q. Preparation and photocatalytic property of perovskite $\mathrm{Bi}_{4} \mathrm{Ti}_{3} \mathrm{O}_{12}$ films. Mater. Chem. Phys. 2009, 114, 716-721. [CrossRef]

16. Hou, D.F.; Hu, X.; Hu, P.; Zhang, W.; Zhang, M.; Huang, Y.H. $\mathrm{Bi}_{4} \mathrm{Ti}_{3} \mathrm{O}_{12}$ nanofibers-BiOI nanosheets p-n junction: Facile synthesis and enhanced visible-light photocatalytic activity. Nanoscale 2013, 5, 9764-9772. [CrossRef] [PubMed]

17. Shi, H.; Tan, H.; Zhu, W.B.; Sun, Z.; Ma, Y.; Wang, E. Electrospun Cr-doped $\mathrm{Bi}_{4} \mathrm{Ti}_{3} \mathrm{O}_{12} / \mathrm{Bi}_{2} \mathrm{Ti}_{2} \mathrm{O}_{7}$ heterostructure fibers with enhanced visible-light photocatalytic properties. J. Mater. Chem. A 2015, 3, 6586-6591. [CrossRef]

18. Zhang, M.; Liu, Y.; Li, L.; Gao, H.; Zhang, X. BiOCl nanosheet/ $\mathrm{Bi}_{4} \mathrm{Ti}_{3} \mathrm{O}_{12}$ nanofiber heterostructures with enhanced photocatalytic activity. Catal. Commun. 2015, 58, 122-126. [CrossRef]

19. Zheng, C.X.; Yang, H.; Cui, Z.M.; Zhang, H.M.; Wang, X.X. A novel $\mathrm{Bi}_{4} \mathrm{Ti}_{3} \mathrm{O}_{12} / \mathrm{Ag}_{3} \mathrm{PO}_{4}$ heterojunction photocatalyst with enhanced photocatalytic performance. Nanoscale Res. Lett. 2017, 12, 608. [CrossRef] [PubMed]

20. Guo, Y.; Li, J.H.; Gao, Z.Q.; Zhu, X.; Liu, Y.; Wei, Z.B.; Zhao, W.; Sun, C. A simple and effective method for fabricating novel p-n heterojunction photocatalyst $\mathrm{g}-\mathrm{C}_{3} \mathrm{~N}_{4} / \mathrm{Bi}_{4} \mathrm{Ti}_{3} \mathrm{O}_{12}$ and its photocatalytic performances. Appl. Catal. B 2016, 192, 57-71. [CrossRef]

21. Kim, H.G.; Hwang, D.; Lee, J. An undoped, single-phase oxide photocatalyst working under visible light. J. Am. Chem. Soc. 2004, 126, 8912-8913. [CrossRef] [PubMed]

22. Zhang, Y.H.; Dai, R.Y.; Hu, S.R. Study of the role of oxygen vacancies as active sites in reduced graphene oxide-modified $\mathrm{TiO}_{2}$. Phys. Chem. Chem. Phys. 2017, 19, 7307-7315. [CrossRef] [PubMed]

23. Zuo, F.; Wang, L.; Wu, T.; Zhang, Z.Y.; Borchardt, D.; Feng, P.Y. Self-doped $\mathrm{Ti}^{3+}$ enhanced photocatalyst for hydrogen production under visible light. J. Am. Chem. Soc. 2010, 132, 11856-11857. [CrossRef] [PubMed]

24. Wang, J.P.; Wang, Z.Y.; Huang, B.B.; Ma, Y.D.; Liu, Y.Y.; Qin, X.Y.; Zhang, X.Y.; Dai, Y. Oxygen vacancy induced band-gap narrowing and enhanced visible light photocatalytic activity of ZnO. ACS Appl. Mater. Interfaces 2012, 4, 4024-4030. [CrossRef] [PubMed]

25. Lv, Y.H.; Yao, W.Q.; Ma, X.G.; Pan, C.S.; Zong, R.L.; Zhu, Y.F. Surface oxygen vacancy induced visible activity and enhanced UV activity of $\mathrm{ZnO}_{1-x}$ photocatalyst. Catal. Sci. Technol. 2013, 3, 3136-3146. [CrossRef]

26. Ling, Y.C.; Wang, G.M.; Reddy, J.; Wang, C.C.; Zhang, J.Z.; Li, Y. The influence of oxygen content on the thermal activation of hematite nanowires. Angew. Chem. Int. Ed. 2012, 51, 4074-4079. [CrossRef] [PubMed] 
27. Thompson, T.L.; Yates, J.T. Surface science studies of the photoactivation of $\mathrm{TiO}_{2}$-new photochemical processes. Chem. Rev. 2006, 106, 4428-4453.

28. Chen, X.; Liu, L.; Yu, P.Y.; Mao, S.S. Increasing solar absorption for photocatalysis with black hydrogenated titanium dioxide nanocrystals. Science 2011, 331, 746-750. [CrossRef] [PubMed]

29. Wang, Z.; Yang, C.; Lin, T.; Yin, H.; Chen, P.; Wan, D.; Xu, F.; Huang, F.; Lin, J.; Xie, X.; et al. Visible-light photocatalytic, solar thermal and photoelectrochemical properties of aluminium- reduced black titania. Energy Environ. Sci. 2013, 6, 3007-3014. [CrossRef]

30. Wang, G.; Wang, H.; Ling, Y.; Tang, Y.; Yang, X.; Fitzmorris, R.C.; Wang, C.; Zhang, J.Z.; Li, Y. Hydrogen-treated $\mathrm{TiO}_{2}$ nanowire arrays for photoelectrochemical water splitting. Nano Lett. 2011, 11, 3026-3033. [CrossRef] [PubMed]

31. Wang, Z.; Yang, C.; Lin, T.; Yin, H.; Chen, P.; Wan, D.; Xu, F.; Huang, F.; Lin, J.; Xie, X.; et al. H-Doped black titania with very high solar absorption and excellent photocatalysis enhanced by localized surface plasmon resonance. Adv. Funct. Mater. 2013, 23, 5444-5450. [CrossRef]

32. Cushing, S.K.; Meng, F.; Zhang, J.Y.; Ding, B.F.; Chen, C.K.; Chen, C.J.; Liu, R.S.; Bristow, A.D.; Bright, J.; Zheng, P.; et al. Effects of defects on photocatalytic activity of hydrogen-treated titanium oxide nanobelts. ACS Catal. 2017, 7, 1742-1748. [CrossRef]

33. Lv, Y.H.; Yao, W.Q.; Zong, R.L.; Zhu, Y.F. Fabrication of wide-range-visible photocatalyst $\mathrm{Bi}_{2} \mathrm{WO}_{6-x}$ nanoplates via surface oxygen vacancies. Sci. Rep. 2016, 6, 19347. [CrossRef] [PubMed]

34. Wu, Q.; Krol, R.V.D. Selective photoreduction of nitric oxide to nitrogen by nanostructured $\mathrm{TiO}_{2}$ photocatalysts: Role of oxygen vacancies and iron dopant. J. Am. Chem. Soc. 2012, 134, 9369-9375. [CrossRef] [PubMed]

35. Wei, W.; Dai, Y.; Huang, B. Density functional characterization of the electronic structure and optical properties of N-doped, La-doped, and N/La-codoped $\mathrm{SrTiO}_{3}$. J. Phys. Chem. C 2009, 113, 5658-5663. [CrossRef]

36. Mou, P.; Pal, U.; Jiménez, J.M.G.Y.; Pérezrodríguez, F. Effects of crystallization and dopant concentration on the emission behavior of $\mathrm{TiO}_{2}$ : Eu nanophosphors. Nanoscale Res. Lett. 2012, 7, 1.

37. Zhang, H.J.; Chen, G.; Li, X. Synthesis and visible light photocatalysis water splitting property of chromium-doped $\mathrm{Bi}_{4} \mathrm{Ti}_{3} \mathrm{O}_{12}$. Solid State Ionics 2009, 180, 1599-1603. [CrossRef]

38. Hou, J.G.; Cao, R.; Wang, Z.; Jiao, S.Q.; Zhu, H.M. Chromium-doped bismuth titanate nanosheets as enhanced visible-light photocatalysts with a high percentage of reactive $\{110\}$ facets. J. Mater. Chem. 2011, 21, 7296-7301. [CrossRef]

39. Chen, Z.W.; Jiang, X.Y.; Zhu, C.B.; Shi, C.K. Chromium-modified $\mathrm{Bi}_{4} \mathrm{Ti}_{3} \mathrm{O}_{12}$ photocatalyst: Application forhydrogen evolution and pollutant degradation. Appl. Catal. B 2016, 199, 241-251. [CrossRef]

40. Yang, P.J.; Ou, H.H.; Fang, Y.X.; Wang, X.C. A facile steam reforming strategy to delaminate layered carbon nitride semiconductors for photoredox catalysis. Angew. Chem. Int. Ed. 2017, 56, 3992-3996. [CrossRef] [PubMed]

41. Chen, X.B.; Shen, S.H.; Guo, L.J.; Mao, S.S. Semiconductor-based photocatalytic hydrogen generation. Chem. Rev. 2010, 110, 6503-6570. [CrossRef] [PubMed]

42. Allured, B.; DelaCruz, S.; Darling, T.; Huda, M.N.; Subramanian, V. Enhancing the visible light absorbance of $\mathrm{Bi}_{2} \mathrm{Ti}_{2} \mathrm{O}_{7}$ through Fe-substitution and its effects on photocatalytic hydrogen evolution. Appl. Catal. B 2014, 144, 261-268. [CrossRef]

43. Choi, H.J.; Kang, M. Hydrogen production from methanol/water decomposition in a liquid photosystem using the anatase structure of $\mathrm{Cu}$ loaded $\mathrm{TiO}_{2}$. Int. J. Hydrogen Energy 2007, 32, 3841-3848. [CrossRef]

44. Yang, X.; Salzmann, C.; Shi, H.; Malcolm, L.; Green, H.; Xiao, T. The role of photoinduced defects in $\mathrm{TiO}_{2}$ and its effects on hydrogen evolution from aqueous methanol solution. J. Phys. Chem. C 2008, 112, 10784-10789. [CrossRef] [PubMed]

45. Bhosale, R.; Pujari, S.; Muley, G.; Pagare, B.; Gambhire, A. Visible-light-activated nanocomposite photocatalyst of $\mathrm{Cr}_{2} \mathrm{O}_{3} / \mathrm{SnO}_{2}$. J. Nanostruct. Chem. 2013, 3, 46. [CrossRef]

46. Chen, J.; Ollis, D.F.; Rulkens, W.H.; Bruning, H. Photocatalyzed oxidation of alcohols and organochlorides in the presence of native $\mathrm{TiO}_{2}$ and metallized $\mathrm{TiO}_{2}$ suspensions. Part (II): Photocatalytic mechanisms. Water Res. 1999, 33, 669-676. [CrossRef] 
47. Gupta, S.; De Leon, L.; Subramanian, V. Mn-modified $\mathrm{Bi}_{2} \mathrm{Ti}_{2} \mathrm{O}_{7}$ photocatalysts: Bandgap engineered multifunctional photocatalysts for hydrogen generation. Phys. Chem. Chem. Phys. 2014, 16, 12719-12727. [CrossRef] [PubMed]

48. Lv, Y.H.; Pan, C.S.; Ma, X.G.; Zong, R.L.; Bai, X.J.; Zhu, Y.F. Production of visible activity and UV performance enhancement of $\mathrm{ZnO}$ photocatalyst via vacuum deoxidation. Appl. Catal. B 2013, 138-139, 26-32. [CrossRef]

49. Lv, Y.H.; Liu, Y.F.; Zhu, Y.Y.; Zhu, Y.F. Surface oxygen vacancy induced photocatalytic performance enhancement of a $\mathrm{BiPO}_{4}$ nanorod. J. Mater. Chem. A 2014, 2, 1174-1182. [CrossRef]

50. Ischenko, V.; Polarz, S.; Grote, D.; Stavarache, V.; Fink, K. Zinc oxide nanoparticles with defects. Adv. Funct. Mater. 2005, 15, 1945-1954. [CrossRef]

51. Lv, Y.H.; Zhu, Y.Y.; Zhu, Y.F. Enhanced photocatalytic performance for the $\mathrm{BiPO}_{4-\mathrm{x}}$ nanorod induced by surface oxygen vacancy. J. Phys. Chem. C 2013, 117, 18520-18528. [CrossRef]

52. Zhang, L.W.; Wang, L.; Zhu, Y.F. Synthesis and performance of $\mathrm{BaAl}_{2} \mathrm{O}_{4}$ with a wide spectral range of optical absorption. Adv. Funct. Mater. 2007, 173, 781-790. [CrossRef]

53. Zhuang, W.; Li, L.; Zhu, J.; An, R.; Lu, L.; Lu, X.; Wu, X.; Ying, H. Facile synthesis of mesoporous $\mathrm{MoS}_{2}-\mathrm{TiO}_{2}$ nanofibers for ultrastable lithium ion battery anodes. Chemelectrochem 2015, 2, 374-381. [CrossRef]

54. Li, L.; Shi, K.; Tu, R.; Qian, Q.; Li, D.; Yang, Z.; Lu, X. Black $\mathrm{TiO}_{2}(\mathrm{~B}) /$ anatase bicrystalline $\mathrm{TiO}_{2-x}$ nanofibers with enhanced photocatalytic performance. Chin. J. Catal. 2015, 36, 1943-1948. [CrossRef]

55. Li, J.L.; Zhang, M.; Guan, Z.J.; Li, Q.Y.; He, C.Q.; Yang, J.J. Synergistic effect of surface and bulk single-electron-trapped oxygen vacancy of $\mathrm{TiO}_{2}$ in the photocatalytic reduction of $\mathrm{CO}_{2}$. Appl. Catal. B 2017, 206, 300-307. [CrossRef]

56. Haider, Z.; Kang, Y.S. Facile preparation of hierarchical TiO2 nano structures: Growth mechanism and enhanced photocatalytic $\mathrm{H}_{2}$ production from water splitting using methanol as a sacrificial reagent. ACS Appl. Mater. Interfaces 2014, 6, 10342-10352. [CrossRef] [PubMed]

57. Moulder, J.F.; Stickle, W.F.; Sobol, P.E.; Bomben, K.D. Handbook of X-ray Photoelectron Spectroscopy; Physical Electronics Inc.: Chanhassen, MN, USA, 1992.

58. Chu, M.W.; Ganne, M.; Caldes, M.T.; Brohan, L. X-ray photoelectron spectroscopy and high resolution electron microscopy studies of Aurivillius compounds: $\mathrm{Bi}_{4-\mathrm{x}} \mathrm{La}_{\mathrm{x}} \mathrm{Ti}_{3} \mathrm{O}_{12}(\mathrm{x}=0,0.5,0.75,1.0,1.5$, and 2.0). J. Appl. Phys. 2002, 91, 3178-3187. [CrossRef]

59. Leelavathi, A.; Madras, G.; Ravishankar, N. Origin of enhanced photocatalytic activity and photoconduction in high aspect ratio ZnO nanorods. Phys. Chem. Chem. Phys. 2013, 15, 10795-10802. [CrossRef] [PubMed]

60. Han, X.G.; He, H.Z.; Kuang, Q.; Zhou, X.; Zhang, X.H.; Xu, T.; Xie, Z.X.; Zheng, L.S. Controlling morphologies and tuning the related properties of nano/microstructured $\mathrm{ZnO}$ crystallites. J. Phys. Chem. C 2009, 113, 584-589. [CrossRef]

61. Jovalekic, C.; Pavlovic, M.; Osmokrovic, P.; Atanasoska, L. X-ray photoelectron spectroscopy study of $\mathrm{Bi}_{4} \mathrm{Ti}_{3} \mathrm{O}_{12}$ ferroelectric ceramics. Appl. Phys. Lett. 1998, 72, 1051-1053. [CrossRef]

62. He, H.; Yin, J.; Li, Y.; Zhang, Y.; Qiu, H.; Xu, J.; Xu, T.; Wang, C. Size controllable synthesis of single-crystal ferroelectric $\mathrm{Bi}_{4} \mathrm{Ti}_{3} \mathrm{O}_{12}$ nanosheet dominated with $\{001\}$ facets toward enhanced visible-light-driven photocatalytic activities. Appl. Catal. B 2014, 156-157, 35-43. [CrossRef]

63. Kong, M.; Li, Y.; Chen, X.; Tian, T.; Fang, P.; Zheng, F.; Zhao, X. Tuning the relative concentration ratio of bulk defects to surface defects in $\mathrm{TiO}_{2}$ nanocrystals leads to high photocatalytic efficiency. J. Am. Chem. Soc. 2011, 133, 16414-16417. [CrossRef] [PubMed]

64. Dutta, S.; Chattopadhyay, S.; Jana, D.; Banerjee, A.; Manik, S.; Pradhan, S.K.; Sutradhar, M.; Sarkar, A. Annealing effect on nano-ZnO powder studied from positron lifetime and optical absorption spectroscopy. J. Appl. Phys. 2006, 100, 114328. [CrossRef]

65. Liu, X.; Zhou, K.; Wang, L.; Wang, B.; Li, Y. Oxygen vacancy clusters promoting reducibility and activity of ceria nanorods. J. Am. Chem. Soc. 2009, 131, 3140-3141. [CrossRef] [PubMed]

66. Guan, M.; Xiao, C.; Zhang, J.; Fan, S.; An, R.; Cheng, Q.; Xie, J.; Zhou, M.; Ye, B.; Xie, Y. Vacancy associates promoting solar-driven photocatalytic activity of ultrathin bismuth oxychloride nanosheets. J. Am. Chem. Soc. 2013, 135, 10411-10417. [CrossRef] [PubMed]

67. Hoffmann, M.R.; Martin, S.T.; Choi, W.; Bahnemann, D.W. Environmental applications of semiconductor photocatalysis. Chem. Rev. 1995, 95, 69-96. [CrossRef] 
68. Becker, W.G.; Truong, M.M.; Ai, C.C.; Hamel, N.N. Interfacial factors that affect the photoefficiency of semiconductor-sensitized oxidations in nonaqueous media. ACS J. Phys. Chem. 1989, 93, 4882-4886. [CrossRef]

69. Pei, R.; Cheng, Z.; Wang, E.; Yang, X. Amplification of antigen-antibody interactions based on biotin labeled protein-streptavidin network complex using impedance spectroscopy. Biosens. Bioelectron. 2001, 16, 355-361. [CrossRef]

70. Wang, Y.; Wang, F.; He, J. Controlled fabrication and photocatalytic properties of a three-dimensional ZnO nanowire/reduced graphene oxide/CdS heterostructure on carbon cloth. Nanoscale 2013, 5, 1129-11297. [CrossRef] [PubMed]

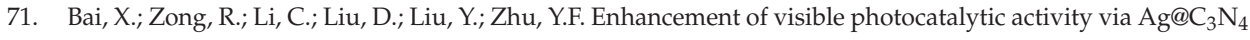
core-shell plasmonic composite. Appl. Catal. B 2014, 147, 82-91. [CrossRef]

72. Sinhamahapatra, A.; Jeon, J.P.; Kang, J.; Han, B.; Yu, J.S. Oxygen-deficient zirconia $\left(\mathrm{ZrO}_{2-\mathrm{x}}\right)$ : A new material for solar light absorption. Sci. Rep. 2016, 6, 27218. [CrossRef] [PubMed]

73. Chen, L.J.; Zhao, Y.J.; Luo, J.Y.; Xia, Y.Y. Oxygen vacancy in $\mathrm{LiTiPO} 5$ and $\mathrm{LiTi}_{2}\left(\mathrm{PO}_{4}\right)_{3}$ : A first-principles study. Phys. Lett. A 2011, 375, 934-938. [CrossRef]

74. Dette, C.; Perez-Osorio, M.A.; Kley, C.S.; Punke, P.; Patrick, C.E.; Jacobson, P.; Giustino, F.; Jung, S.J.; Kern, K. $\mathrm{TiO}_{2}$ anatase with a bandgap in the visible region. Nano Lett. 2014, 14, 6533-6538. [CrossRef] [PubMed]

(C) 2018 by the authors. Licensee MDPI, Basel, Switzerland. This article is an open access article distributed under the terms and conditions of the Creative Commons Attribution (CC BY) license (http:/ / creativecommons.org/licenses/by/4.0/). 



\title{
Article \\ Effect of Organic Substrates on the Photocatalytic Reduction of Cr(VI) by Porous Hollow $\mathrm{Ga}_{2} \mathrm{O}_{3}$ Nanoparticles
}

\author{
Jin Liu ${ }^{1}$, Huihui Gan ${ }^{2}$, Hongzhang Wu ${ }^{1}$, Xinlei Zhang ${ }^{1}$, Jun Zhang ${ }^{1}$, Lili Li ${ }^{1,3, *}$ \\ and Zhenling Wang ${ }^{1, *}$ \\ 1 Henan Key Laboratory of Rare Earth Functional Materials, International Joint Research Laboratory \\ for Biomedical Nanomaterials of Henan, The Key Laboratory of Rare Earth Functional Materials and \\ Applications, Zhoukou Normal University, Zhoukou 466001, China; jinliu@zknu.edu.cn (J.L.); \\ hongzhang_wu@zknu.edu.cn (H.W.); zhangxinlei@zknu.edu.cn (X.Z.); 18238260132@163.com (J.Z.) \\ 2 School of Civil Engineering and Architecture, Ningbo Institute of Technology, Zhejiang University, \\ Ningbo 315100, China; hhgan@nit.zju.edu.cn \\ 3 School of Life Science and Agriculture, Zhoukou Normal University, Zhoukou 466001, China \\ * Correspondence: lilili@zknu.edu.cn (L.L.); zlwang2007@hotmail.com (Z.W.); Tel.: +86-394-8178518 (Z.W.)
}

Received: 6 March 2018; Accepted: 19 April 2018; Published: 22 April 2018

\begin{abstract}
Porous hollow $\mathrm{Ga}_{2} \mathrm{O}_{3}$ nanoparticles were successfully synthesized by a hydrolysis method followed by calcination. The prepared samples were characterized by field emission scanning electron microscope, transmission electron microscope, thermogravimetry and differential scanning calorimetry, UV-vis diffuse reflectance spectra and Raman spectrum. The porous structure of $\mathrm{Ga}_{2} \mathrm{O}_{3}$ nanoparticles can enhance the light harvesting efficiency, and provide lots of channels for the diffusion of $\mathrm{Cr}(\mathrm{VI})$ and $\mathrm{Cr}(\mathrm{III})$. Photocatalytic reduction of $\mathrm{Cr}(\mathrm{VI})$, with different initial $\mathrm{pH}$ and degradation of several organic substrates by porous hollow $\mathrm{Ga}_{2} \mathrm{O}_{3}$ nanoparticles in single system and binary system, were investigated in detail. The reduction rate of $\mathrm{Cr}(\mathrm{VI})$ in the binary pollutant system is markedly faster than that in the single $\mathrm{Cr}(\mathrm{VI})$ system, because $\mathrm{Cr}(\mathrm{VI})$ mainly acts as photogenerated electron acceptor. In addition, the type and concentration of organic substrates have an important role in the photocatalytic reduction of $\mathrm{Cr}(\mathrm{VI})$.
\end{abstract}

Keywords: $\mathrm{Ga}_{2} \mathrm{O}_{3}$; porous; $\mathrm{Cr}(\mathrm{VI})$; organic pollutants

\section{Introduction}

Heavy metal ions from wastewater have become the primary threat to the human environment with the development of industrial civilization [1-4]. Hexavalent chromium $(\mathrm{Cr}(\mathrm{VI}))$ is a typical heavy metal contaminant with high solubility and toxicity, which originates from various industrial processes such as electroplating, leather tanning, and paint manufacture [5]. A common method of treating $\mathrm{Cr}(\mathrm{VI})$ in wastewater is to convert it into low toxic $\mathrm{Cr}(\mathrm{III})$, which can be precipitated as $\mathrm{Cr}(\mathrm{OH})_{3}$ in neutral or alkaline solutions, and removed as a solid waste [6]. Recently, photocatalytic reduction of $\mathrm{Cr}(\mathrm{VI})$ to $\mathrm{Cr}(\mathrm{III})$ has been recognized as an efficient and economical form of technology [7-11]. Briefly, photocatalytic reduction of $\mathrm{Cr}(\mathrm{VI})$ is based on the photogenerated electrons in the conduction band of semiconductor when it is irradiated by UV/visible light having energy greater than the band gap energy of the semiconductor. In addition, organic and inorganic pollutants usually co-exist in industrial wastewater and natural aqueous environment, and no doubt the presence of organic pollutants in wastewater will greatly increase the difficulty of photocatalytic reduction of $\mathrm{Cr}(\mathrm{VI})$ [12-14].

During the photocatalytic process, the photocatalyst is the key factor, and it is necessary to design and fabricate efficient and stable photocatalysts. $\mathrm{Ga}_{2} \mathrm{O}_{3}$ is one of most popular photocatalysts used 
in the photocatalytic degradation of organic pollutants and reduction of $\mathrm{CO}_{2}$ [15-18], owing to its high activity and environmental friendliness. Its activity can be further enhanced through a proper synthetic strategy to obtain nanostructured materials, as the morphology, size and pore structure of materials can significantly influence their properties and applications [19-21]. As one promising field of research, porous hollow nanostructures have been investigated for a long time. Compared with bulk materials, porous hollow materials have higher porosity, larger specific surface areas, and lots of active chemical sites, which could enhance light harvesting efficiency and provide lots of channels for the diffusion of pollutants, while also improving photocatalytic activity efficiently [22-24].

In this study, porous hollow $\mathrm{Ga}_{2} \mathrm{O}_{3}$ nanoparticles were prepared via a hydrolysis method followed by calcination. The effect of parameters including $\mathrm{pH}$ and concentration of metronidazole on the reduction rate of $\mathrm{Cr}(\mathrm{VI})$ by the porous hollow $\mathrm{Ga}_{2} \mathrm{O}_{3}$ nanoparticles was also studied. Meanwhile, the photocatalytic reduction of $\mathrm{Cr}(\mathrm{VI})$ was also systematically investigated in the absence and presence of organic substrates. To the best of our knowledge, this is the first report on the simultaneous treatment of organics and $\mathrm{Cr}(\mathrm{VI})$ using porous hollow $\mathrm{Ga}_{2} \mathrm{O}_{3}$.

\section{Materials and Methods}

\subsection{Materials}

$\mathrm{Ga}_{2} \mathrm{O}_{3}(99.999 \%), \mathrm{NaCO}_{3}(\mathrm{AR}, 99.8 \%)$, and $\mathrm{NaOH}(\mathrm{AR}, 96 \%)$ were purchased from Shanghai Aladdin Bio-Chem Technology Co., Ltd. (Shanghai, China) and $\mathrm{HCl}$ (AR, 36-38\%) were purchased from Sinopharm Chemical Reagent Co., Ltd. (Shanghai, China) Deionized water was used throughout the experiments.

\subsection{Synthesis of Porous Hollow $\mathrm{Ga}_{2} \mathrm{O}_{3}$ Nanoparticles}

Porous hollow $\mathrm{Ga}_{2} \mathrm{O}_{3}$ nanoparticles were synthesized via a thermal transformation of $\mathrm{GaOOH}$ precursor based on our previous study [25]. The $\mathrm{NaGaO}_{2}$ powders were prepared by heating a stoichiometric mixture of $\mathrm{Na}_{2} \mathrm{CO}_{3}$ and $\mathrm{Ga}_{2} \mathrm{O}_{3}$ at $850{ }^{\circ} \mathrm{C}$ for $12 \mathrm{~h}$. The $\mathrm{GaOOH}$ precursor was prepared by a hydrolysis reaction of $\mathrm{NaGaO}_{2}$ colloidal solution. The $\mathrm{NaGaO}_{2}$ powders $(1.0 \mathrm{~g})$ was dispersed in deionized water $(100 \mathrm{~mL})$ to obtain a colloidal solution with ultrasonic oscillations. Then, $5 \mathrm{~mol} / \mathrm{L}$ $\mathrm{HCl}$ solution was added to the $\mathrm{NaGaO}_{2}$ colloidal solution with magnetic stirring; the final $\mathrm{pH}$ value was kept at 9.0. The obtained white suspension was treated thermally at $80^{\circ} \mathrm{C}$ for $12 \mathrm{~h}$. The obtained $\mathrm{GaOOH}$ precursor was separated by centrifugation and dried at $70{ }^{\circ} \mathrm{C}$ for $10 \mathrm{~h}$. The $\mathrm{Ga}_{2} \mathrm{O}_{3}$ was prepared by calcining $\mathrm{GaOOH}$ precursor with a programmed temperature $\left(400{ }^{\circ} \mathrm{C}, 5 \mathrm{~h}\right.$ and $700{ }^{\circ} \mathrm{C}$, $\left.1.5 \mathrm{~h}, 1^{\circ} \mathrm{C} / \mathrm{min}\right)$.

\subsection{Characterization}

The Raman spectrum was recorded using a Raman spectrometer (RM2000) (Renishaw, Gloucestershire, UK). Field emission scanning electron microscope (FESEM) images were obtained using a MERLIN scanning microscope at an accelerating voltage of $10 \mathrm{kV}$ (ZEISS, Oberkochen, German). Scanning transmission electron microscopy (STEM), transmission electron microscope (TEM) and high-resolution transmission electron microscopy (HRTEM) images were obtained using a JEOL-2010 transmission electron microscope (JEOL Ltd., Kyoto, Japan) at an accelerating voltage of $200 \mathrm{kV}$. TEM is equipped with an energy-dispersive X-ray spectroscopy (EDS) analysis system. The quantitation method for $\mathrm{Ga}$ and $\mathrm{O}$ elements is Cliff Lorimer thin ratio section. Thermogravimetry and differential scanning calorimetry (TG-DSC) analysis was performed on a STA 6000 (Perkin Elmer, Waltham, MA, USA) instrument at a heating rate of $10{ }^{\circ} \mathrm{C} / \mathrm{min}$. UV-vis diffuse reflectance spectra (UV-vis DRS) were obtained by a UV-2600 UV-vis spectrophotometer (Shimadzu Corporation, Kyoto, Japan). 


\subsection{Photocatalytic Experiments}

Photoreduction of $\mathrm{Cr}(\mathrm{VI})\left(\mathrm{K}_{2} \mathrm{Cr}_{2} \mathrm{O}_{7}\right)$ and photocatalytic degradation of rhodamine $\mathrm{B}(\mathrm{RhB})$, acid red 1 (AR1), methyl orange (MO) and metronidazole (MNZ) as well as their binary mixtures, were adopted to evaluate the photocatalytic activity of the as-synthesized $\mathrm{Ga}_{2} \mathrm{O}_{3}$ sample. The concentration of $\mathrm{Cr}(\mathrm{VI})$ and organics is the same in single and binary pollutants (Table 1). Typically, $20 \mathrm{mg}$ of the $\mathrm{Ga}_{2} \mathrm{O}_{3}$ sample was added into a $50 \mathrm{~mL} \mathrm{Cr}(\mathrm{VI})$ aqueous solution. The initial $\mathrm{pH}$ of the $\mathrm{Cr}(\mathrm{VI})$ solution was adjusted to 2-9 by adding $\mathrm{HCl}$ or $\mathrm{NaOH}$. Prior to irradiation, the suspensions were magnetically stirred for $30 \mathrm{~min}$ to establish the adsorption-desorption equilibrium. The irradiation was performed with a $30 \mathrm{~W}$ UV light lamp $(\lambda=253.7 \mathrm{~nm})$. At a given time interval, about $3 \mathrm{~mL}$ suspension was taken for further analysis after centrifugation. The concentration of organic pollutants, including RhB, AR1, MO and MNZ, were analyzed by UV-vis spectroscopy at 554, 505, 464 and $320 \mathrm{~nm}$, respectively. Meanwhile, the concentration of $\mathrm{Cr}(\mathrm{VI})$ was analyzed by a 1,5-diphenylcarbazide spectrophotometric method with a spectrophotometer at $540 \mathrm{~nm}$ (GB 7466-87, Standards of China). The characteristic absorbance peaks of organic pollutants (rhodamine B, acid red 1, methyl orange, metronidazole) are different; their absorbances are different when the concentrations are same. In order to quickly measure the absorbance of organic pollutants by UV-vis spectroscopy, we created the proper concentrations.

Table 1. The concentration of $\mathrm{Cr}(\mathrm{VI})$ and organics in single and binary pollutant system.

\begin{tabular}{cccccc}
\hline \multirow{2}{*}{ Name } & Single Pollutant System, mg/L & & \multicolumn{3}{c}{ Binary Pollutant System, mg/L } \\
\cline { 3 - 6 } & & RhB + Cr(VI) & AR1 + Cr(VI) & MO + Cr(VI) & MNZ + Cr(VI) \\
\hline Cr(VI) & 2.5 & 2.5 & 2.5 & 2.5 & 2.5 \\
RhB & 5 & 5 & $\times$ & $\times$ & $\times$ \\
AR1 & 20 & $\times$ & $\times$ & 10 & $\times$ \\
MO & 10 & $\times$ & $\times$ & $\times$ & 20 \\
MNZ & 20 & $\times$ & $\times$ & $\times$ \\
\hline
\end{tabular}

\section{Results and Discussion}

\subsection{Composition and Morphology}

Previous X-ray diffraction (XRD) results show that the phase composition of the GaOOH precursor and its calcined product are $\alpha-\mathrm{GaOOH}$ (JCPDS No. 06-0180) and $\beta-\mathrm{Ga}_{2} \mathrm{O}_{3}$ (JCPDS No. 41-1103), respectively [25]. The average crystallite size of $\beta-\mathrm{Ga}_{2} \mathrm{O}_{3}$ sample is about $27.3 \mathrm{~nm}$ by the Scherrer equation. [26] The composition of $\mathrm{Ga}_{2} \mathrm{O}_{3}$ samples was further investigated by Raman spectra, owing to the greater sensitivity of Raman spectroscopy to the outer region of the solid samples than XRD [27]. The Raman spectra of $\mathrm{Ga}_{2} \mathrm{O}_{3}$ samples from the $\mathrm{GaOOH}$ precursor-calcined at $600{ }^{\circ} \mathrm{C}$ and $700{ }^{\circ} \mathrm{C}$ - are shown in Figure 1. The characteristic Raman bands of $\alpha-\mathrm{Ga}_{2} \mathrm{O}_{3}$ and $\beta-\mathrm{Ga}_{2} \mathrm{O}_{3}$ are shown in Figure $1 \mathrm{a}, \mathrm{b}$, respectively; this is consistent with the reported results $[28,29]$. This result indicates that the $\alpha-\mathrm{Ga}_{2} \mathrm{O}_{3}$ gradually transforms into $\beta-\mathrm{Ga}_{2} \mathrm{O}_{3}$ with the increase of calcination temperature; pure phase $\beta-\mathrm{Ga}_{2} \mathrm{O}_{3}$ is finally obtained at $700{ }^{\circ} \mathrm{C}$.

The composition of porous hollow $\mathrm{Ga}_{2} \mathrm{O}_{3}$ nanoparticles was also analyzed by EDS elemental mapping images and EDS spectrum. As shown in Figure 2, it is clearly seen that $\mathrm{Ga}_{2} \mathrm{O}_{3}$ nanoparticles possess a porous structure, and that $\mathrm{Ga}$ and $\mathrm{O}$ elements are distributed homogenously in the $\mathrm{Ga}_{2} \mathrm{O}_{3}$ sample and their atomic ratio was close to $2: 3$, which further indicates that the synthesized sample is pure $\mathrm{Ga}_{2} \mathrm{O}_{3}$. 


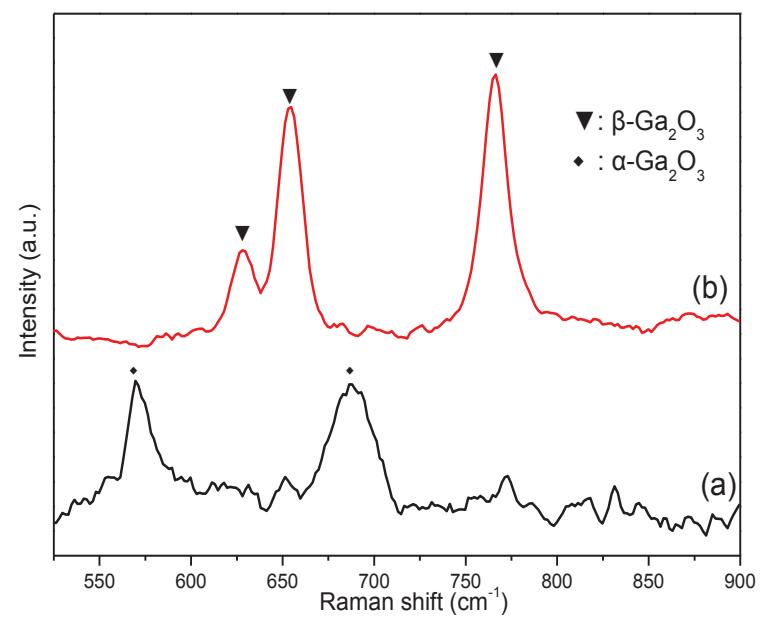

Figure 1. Raman spectra of $\mathrm{Ga}_{2} \mathrm{O}_{3}$ from the $\mathrm{GaOOH}$ precursor calcined at (a) $600{ }^{\circ} \mathrm{C}$ and (b) $700{ }^{\circ} \mathrm{C}$.
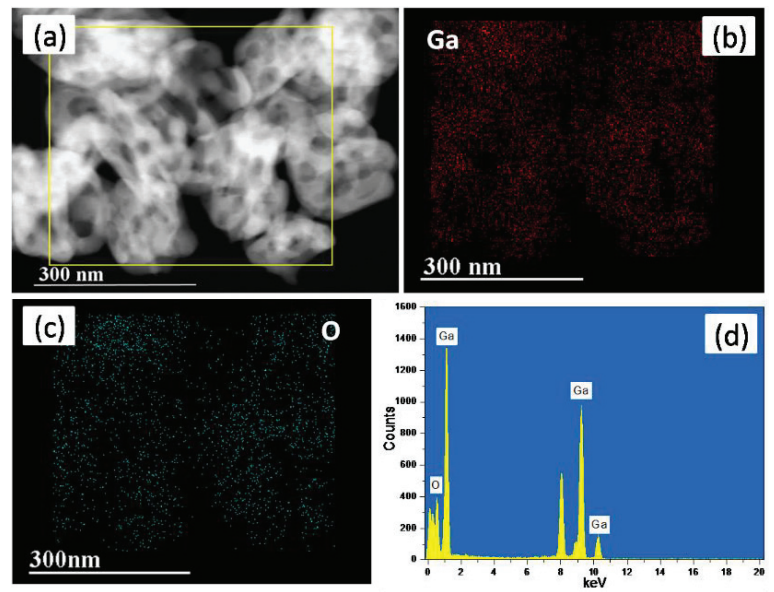

Figure 2. (a) Scanning transmission electron microscopy (STEM) image, (b,c) energy-dispersive X-ray spectroscopy (EDS) elemental mapping images and (d) EDS spectrum of $\mathrm{Ga}_{2} \mathrm{O}_{3}$.

The morphology and microstructure of $\mathrm{GaOOH}$ precursor and its calcined product $\mathrm{Ga}_{2} \mathrm{O}_{3}$ were investigated by TEM and SEM. As shown in Figure $3 \mathrm{a}, \mathrm{b}$, the $\mathrm{GaOOH}$ precursor presents monodisperse nanoplate-like structure. Compared with $\mathrm{GaOOH}$ (Figure 3a,b), $\mathrm{Ga}_{2} \mathrm{O}_{3}$ nanoparticles (Figure 3c) present porous hollow structures. Moreover, the clearly resolved lattice fringes with $\mathrm{d}$ spacing of $0.23 \mathrm{~nm}$ (distance between two arrow heads in Figure 3d) correspond to the (行1) lattice planes of monoclinic $\beta-\mathrm{Ga}_{2} \mathrm{O}_{3}$, which is in good agreement with the XRD result. Figure 4 also shows that the $\mathrm{Ga}_{2} \mathrm{O}_{3}$ nanoparticles possess hollow structures [25]. The porous hollow structure of $\mathrm{Ga}_{2} \mathrm{O}_{3}$ nanoparticles is mainly ascribed to the thermal dehydration of the $\mathrm{GaOOH}$ precursor. These porous structure can enhance the light harvesting efficiency and provide lots of channels for the diffusion of $\mathrm{Cr}(\mathrm{VI})$ and $\mathrm{Cr}(\mathrm{III})$, resulting in the improvement of photocatalytic efficiency [30]. The size distribution of $\mathrm{Ga}_{2} \mathrm{O}_{3}$ in Figure 5 was evaluated from the SEM image (Figure 4) by measuring the diamenter of about 100 nanoparticles. It is clearly seen that the size of most $\mathrm{Ga}_{2} \mathrm{O}_{3}$ nanoparticles is $160-230 \mathrm{~nm}$. 


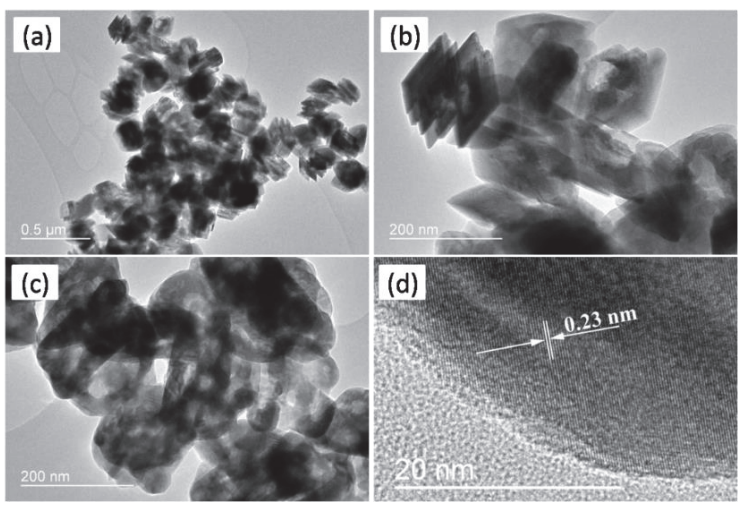

Figure 3. Transmission electron microscopy (TEM) and high-resolution transmission electron microscopy (HRTEM) images of $(\mathbf{a}, \mathbf{b}) \mathrm{GaOOH}$ and $(\mathbf{c}, \mathbf{d}) \mathrm{Ga}_{2} \mathrm{O}_{3}$.

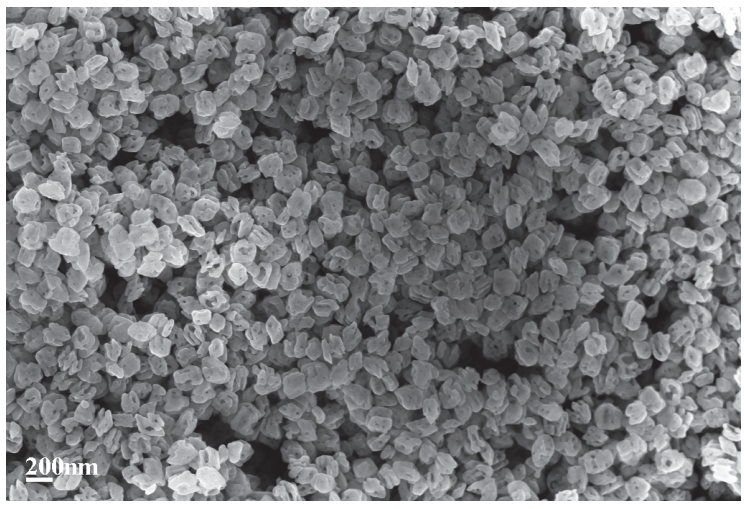

Figure 4. Scanning electron microscope (SEM) image of $\mathrm{Ga}_{2} \mathrm{O}_{3}$ nanoparticles.

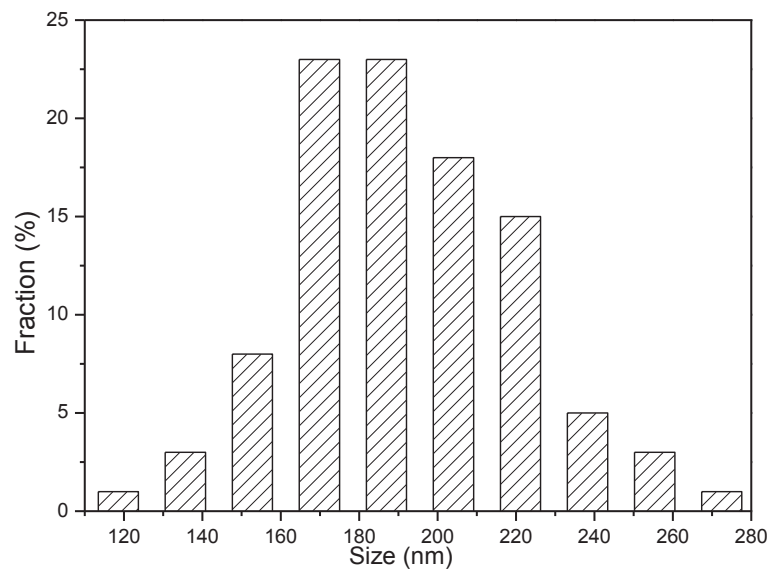

Figure 5. The size distribution of $\mathrm{Ga}_{2} \mathrm{O}_{3}$ nanoparticles. 


\subsection{Hermogravimetry and Differential Scanning Calorimetry TG-DSC Analysis}

To understand the thermal conversion of the $\mathrm{GaOOH}$ precursor to $\mathrm{Ga}_{2} \mathrm{O}_{3}$, a TG-DSC measurement was performed. The TG-DSC measurement, performed from 40 to $900{ }^{\circ} \mathrm{C}$ for the GaOOH precursor, is shown in Figure 6. The major exothermic peak at about $394{ }^{\circ} \mathrm{C}$ was probably caused by the phase transformation of the sample from $\mathrm{GaOOH}$ to $\mathrm{Ga}_{2} \mathrm{O}_{3}$, as evidenced by a weight loss of $12 \%$ in the range of $40-400{ }^{\circ} \mathrm{C}$ in TG curve. A weight loss of $3 \%$ in the range of $400-600{ }^{\circ} \mathrm{C}$, which is demarcated by weak endothermic peak in DSC curve, indicates the conversion of $\alpha-\mathrm{Ga}_{2} \mathrm{O}_{3}$ to $\beta-\mathrm{Ga}_{2} \mathrm{O}_{3}$ above $600{ }^{\circ} \mathrm{C}$ [31]. The result is consistent with the Raman band of the $\mathrm{GaOOH}$ precursor calcined at $600{ }^{\circ} \mathrm{C}$ (Figure 1). The XRD, Raman spectra, and TG-DSC results indicate that the pure phase $\beta-\mathrm{Ga}_{2} \mathrm{O}_{3}$ can be obtained at $700{ }^{\circ} \mathrm{C}$, and that $\alpha-\mathrm{Ga}_{2} \mathrm{O}_{3}$ gradually transforms into $\beta-\mathrm{Ga}_{2} \mathrm{O}_{3}$ in the temperature range of $600-700^{\circ} \mathrm{C}$.

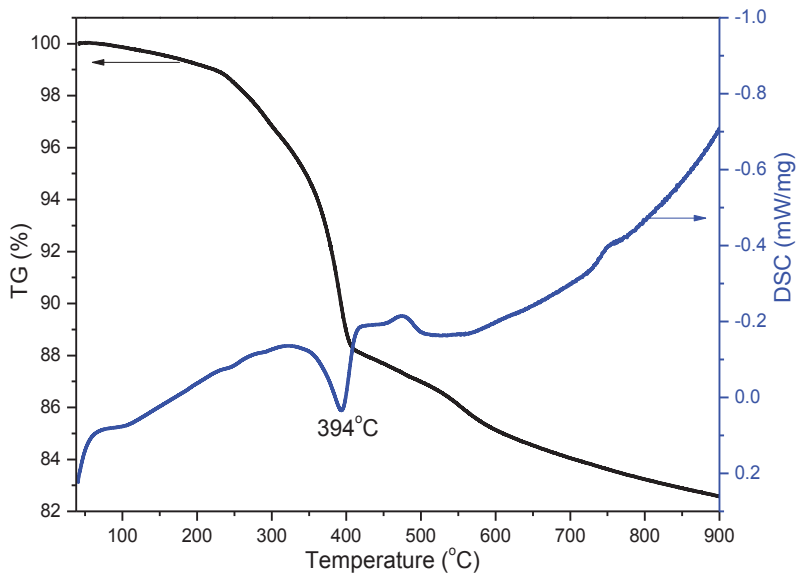

Figure 6. Hermogravimetry and Differential Scanning Calorimetry TG-DSC curve of the $\mathrm{GaOOH}$ precursor.

\subsection{Photocatalytic Experiments}

\subsubsection{Photocatalytic Reduction of Cr(VI)}

The $\mathrm{pH}$ of the solution is one of the most important parameters affecting the photocatalytic reduction of $\mathrm{Cr}(\mathrm{VI})$ on photocatalysts. The temporal concentration variation of $\mathrm{Cr}(\mathrm{VI})$ reduction by the porous hollow $\mathrm{Ga}_{2} \mathrm{O}_{3}$ nanoparticles at a $\mathrm{pH}$ range from 2.0 to 9.0 is shown in Figure 7. Obviously, the reduction of $\mathrm{Cr}(\mathrm{VI})$ is increased rapidly by decreasing the $\mathrm{pH}$ when the initial $\mathrm{pH}$ is in the range of 3-9. In general, the predominant form of $\mathrm{Cr}(\mathrm{VI})$ is $\mathrm{Cr}_{2} \mathrm{O}_{7}{ }^{2-}$ at a $\mathrm{pH}$ range of 2-6, while the major form was $\mathrm{CrO}_{4}{ }^{2-}$ at $\mathrm{pH}>7$ [32,33]. The photocatalytic reduction of $\mathrm{Cr}(\mathrm{VI})$ to $\mathrm{Cr}(\mathrm{III})$ consumes $\mathrm{H}^{+}$in an acidic solution (Equation (1)), and produces $\mathrm{OH}^{-}$in an alkaline solution (Equation (2)). At a low $\mathrm{pH}$, the $\mathrm{Ga}_{2} \mathrm{O}_{3}$ nanoparticles are highly protonated and have a strong affinity toward the anion $\mathrm{Cr}_{2} \mathrm{O}_{7}{ }^{2-}$, and thus enhance the photocatalytic reduction of $\mathrm{Cr}(\mathrm{VI})$. However, the photocatalytic reduction of $\mathrm{Cr}(\mathrm{VI})$ is decreased when the initial $\mathrm{pH}$ is kept at $2-2.5$, which may be attributed the dissolution of $\mathrm{Ga}_{2} \mathrm{O}_{3}$ nanoparticles. At a higher $\mathrm{pH}$, the surface charge of the $\mathrm{Ga}_{2} \mathrm{O}_{3}$ nanoparticles will be less positively charged, or even negatively charged, which tends to electrostatically repel the anionic $\mathrm{Cr}(\mathrm{VI})$, and adsorb the cationic $\mathrm{Cr}(\mathrm{III})[34,35]$. The electrostatical repulsion makes it more difficult for the anionic $\mathrm{Cr}(\mathrm{VI})$ to obtain the photogenerated electrons. Meanwhile, $\mathrm{Cr}(\mathrm{OH})_{3}$ precipitate will be formed at $\mathrm{pH}>6$, and occupies the active sites of $\mathrm{Ga}_{2} \mathrm{O}_{3}$ nanoparticles, leading to the decrease in the 
photocatalytic reduction of $\mathrm{Cr}(\mathrm{VI})$. Therefore, it is concluded that the photocatalytic reduction of $\mathrm{Cr}(\mathrm{VI})$ to $\mathrm{Cr}(\mathrm{III})$ is highly efficient at a suitable acidic condition, and is restrained at an alkaline condition.

$$
\begin{gathered}
\mathrm{Cr}_{2} \mathrm{O}_{7}^{2-}+14 \mathrm{H}^{+}+6 \mathrm{e}^{-} \rightarrow 2 \mathrm{Cr}^{3+}+7 \mathrm{H}_{2} \mathrm{O} \\
\mathrm{CrO}_{4}{ }^{2-}+4 \mathrm{H}_{2} \mathrm{O}+3 \mathrm{e}^{-} \rightarrow \mathrm{Cr}(\mathrm{OH})_{3}+5 \mathrm{OH}^{-}
\end{gathered}
$$

\subsubsection{Photocatalytic Degradation of Organic Pollutants}

Besides the photocatalytic reduction of $\mathrm{Cr}(\mathrm{VI})$, typical organic pollutants such as RhB, AR1, MO and MNZ were also used to evaluate the photocatalytic activity of porous hollow $\mathrm{Ga}_{2} \mathrm{O}_{3}$ nanoparticles. As shown in Figure 8, these four pollutants can be effectively degraded by the $\mathrm{Ga}_{2} \mathrm{O}_{3}$ nanoparticles in $60 \mathrm{~min}$ when they are in the single pollutant system (Table 1). The results indicate that the porous hollow $\mathrm{Ga}_{2} \mathrm{O}_{3}$ is a promising photocatalyst in water treatment.

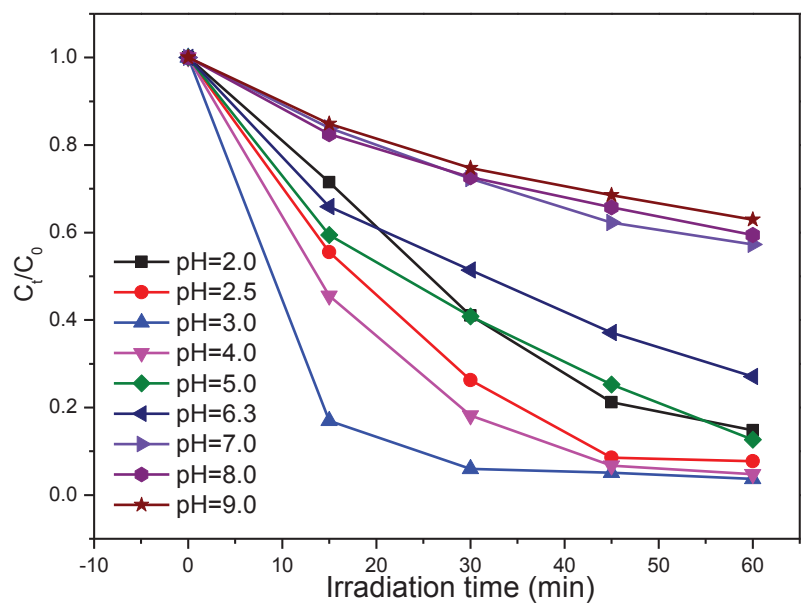

Figure 7. Photocatalytic reduction of $\mathrm{Cr}(\mathrm{VI})$ by $\mathrm{Ga}_{2} \mathrm{O}_{3}$ at different initial $\mathrm{pH}$.

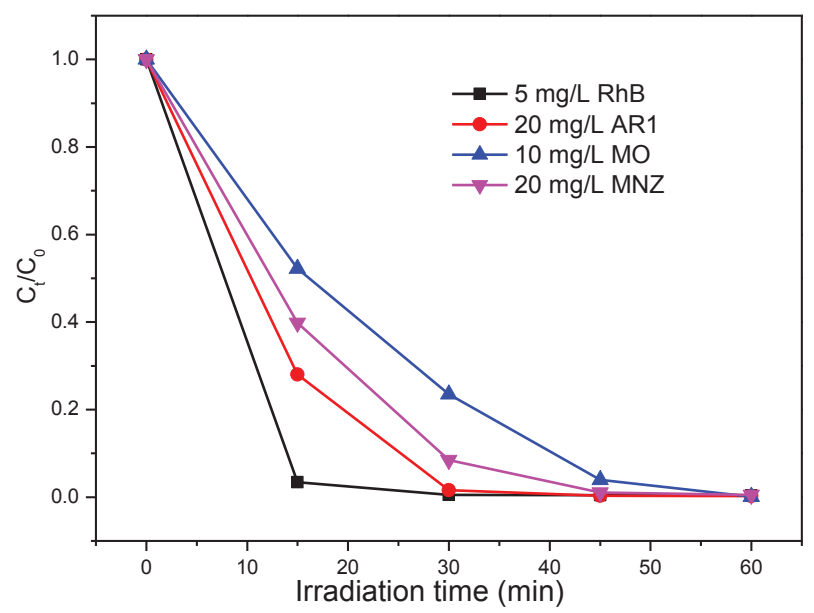

Figure 8. Photocatalytic degradation of single pollutant by $\mathrm{Ga}_{2} \mathrm{O}_{3}$. 


\subsubsection{Simultaneous Treatment of $\mathrm{Cr}(\mathrm{VI})$ and Organic Pollutants}

$\mathrm{Cr}(\mathrm{VI})$ is often discharged together with hazardous organics from industrial wastewater. To further study the photocatalytic activity of porous hollow $\mathrm{Ga}_{2} \mathrm{O}_{3}$ nanoparticles, several binary pollutants were simulated using organics as the additional substrates. As shown in Figure 9, the reduction rate of $\mathrm{Cr}(\mathrm{VI})$ in the binary pollutants is markedly faster than that of the single $\mathrm{Cr}(\mathrm{VI})$. $\mathrm{Cr}(\mathrm{VI})$ mainly acts as photogenerated electron acceptor. However, the degradation rate of the organic pollutants in the binary pollutant system is lower than that of the corresponding single pollutant system. Based on our previous study, the photogenerated electrons play an important role in the degradation of organic pollutants by $\mathrm{Ga}_{2} \mathrm{O}_{3}$. The photogenerated electrons in the conduction band of $\mathrm{Ga}_{2} \mathrm{O}_{3}$ are assumed by $\mathrm{Cr}(\mathrm{VI})$, reducing the degradation rate of organic pollutants. The photocatalytic stability of the prepared $\mathrm{Ga}_{2} \mathrm{O}_{3}$ for the treatment of pollutants has been investigated by the recycling experiments. However, the photocatalytic reduction rate of $\mathrm{Cr}(\mathrm{VI})$ is $67 \%$ after two cycling runs. In order to activate the recycled $\mathrm{Ga}_{2} \mathrm{O}_{3}$ photocatalyst, an ultrasound treatment is used; a photocatalytic reduction rate of $\mathrm{Cr}(\mathrm{VI})$ is able to maintain $81 \%$, under the same conditions. However, the photocatalytic reduction rate of $\mathrm{Cr}(\mathrm{VI})$ is only $44 \%$, even after four cycling runs with the ultrasound treatment. The photocatalytic degradation rate of organic pollutants (RhB, AR1, MO, MNZ) is stable, even after five cycling runs.

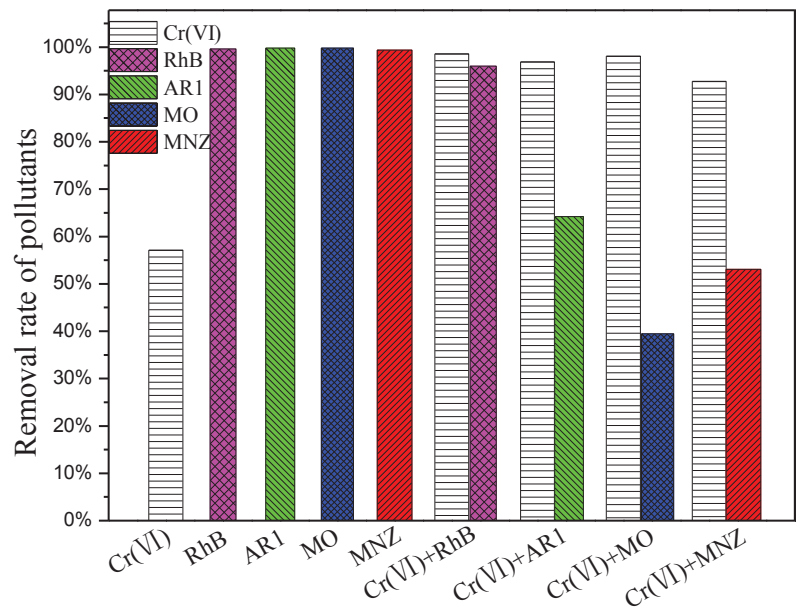

Figure 9. Photocatalytic treatment of single and binary pollutant system by $\mathrm{Ga}_{2} \mathrm{O}_{3}$.

\subsubsection{Effect of Substrate Concentration on Photocatalytic Reduction of Cr(VI)}

To further assess the effect of organic pollutants as substrates on the photocatalytic reduction of $\mathrm{Cr}(\mathrm{VI})$, several different concentrations of $\mathrm{MNZ}$ in the $\mathrm{Cr}(\mathrm{VI}) / \mathrm{MNZ}$ binary pollutants were investigated. As shown in Figure 10, only $57 \%$ of $\mathrm{Cr}(\mathrm{VI})$ is photocatalytically reduced in the absence of MNZ after $60 \mathrm{~min}$, and the reduction of $\mathrm{Cr}(\mathrm{VI})$ is increased striking when MNZ is added into the system. By increasing the concentration of MNZ to $10 \mathrm{mg} / \mathrm{L}, 94 \%$ of $\mathrm{Cr}(\mathrm{VI})$ is reduced. The reason may be that the presence of MNZ can consume the photogenerated holes in photocatalyst, and more photogenerated electrons are captured by $\mathrm{Cr}(\mathrm{VI})$, improving the photocatalytic reduction of $\mathrm{Cr}(\mathrm{VI})$. The reduction rate of $\mathrm{Cr}(\mathrm{VI})$ is not markedly changed when the concentration of $\mathrm{MNZ}$ is further increased. 


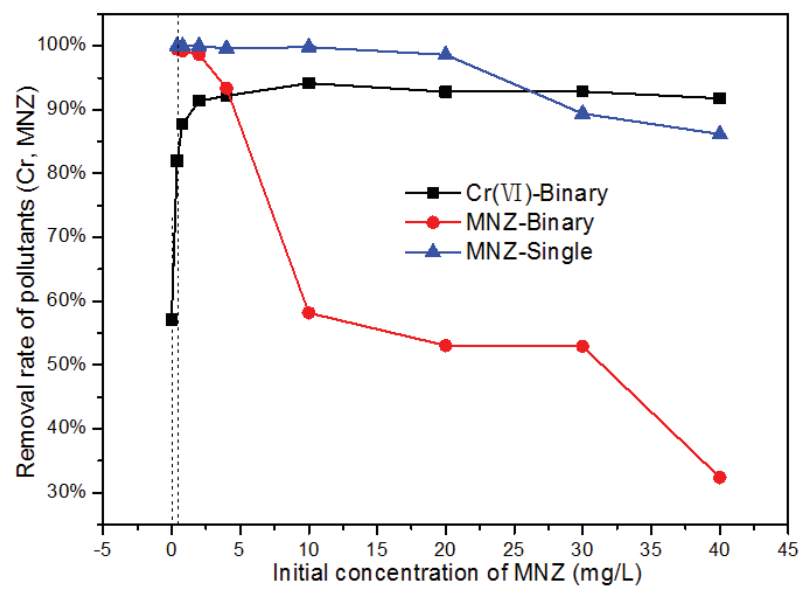

Figure 10. Photocatalytic treatment of $\mathrm{Cr}(\mathrm{VI})$ and $\mathrm{MNZ}$ in single and binary pollutant system.

\section{Conclusions}

In summary, porous hollow $\mathrm{Ga}_{2} \mathrm{O}_{3}$ nanoparticles were successfully synthesized by a hydrolysis method followed by calcination. It was demonstrated that the $\mathrm{Ga}_{2} \mathrm{O}_{3}$ photocatalyst is effective for the treatment of $\mathrm{Cr}(\mathrm{VI})$ and organic pollutants-as well as a mixture of them. The photocatalytic removal rate of $\mathrm{Cr}(\mathrm{VI})$ is highest when the initial $\mathrm{pH}$ of $\mathrm{Cr}(\mathrm{VI})$ is 3.0. The presence of organic pollutants in the reaction system improves the photocatalytic reduction of $\mathrm{Cr}(\mathrm{VI})$ by acting as a holes scavenger, leading to better charge carrier separation. The results broaden the range of approaches for the treatment of practical wastewater.

Acknowledgments: This work was supported by the National Natural Science Foundation of China (21477167, 51509220, 21701203), Key Scientific and Technological Project of Henan Province (182102210603, 172102210612), Zhejiang Provincial Natural Science Foundation of China (LQ14E090003) and Ningbo Science and Technology Plan Projects (2014C50007).

Author Contributions: Lili Li and Zhenling Wang conceived and designed the experiments; Jin Liu and Jun Zhang performed the experiments; Lili Li and Jin Liu analyzed the data; Huihui Gan, Hongzhang Wu and Xinlei Zhang contributed reagents/materials/analysis tools; all authors contributed to the writing of the paper.

Conflicts of Interest: The authors declare no conflict of interest.

\section{References}

1. Jiang, W.J.; Cai, Q.; Xu, W.; Yang, M.W.; Cai, Y.; Dionysiou, D.D.; O'Shea, K.E. Cr(VI) adsorption and reduction by humic acid coated on magnetite. Environ. Sci. Technol. 2014, 48, 8078-8085. [CrossRef] [PubMed]

2. Naimi-Joubani, M.; Shirzad-Siboni, M.; Yang, J.-K.; Gholami, M.; Farzadkia, M. Photocatalytic reduction of hexavalent chromium with illuminated $\mathrm{ZnO} / \mathrm{TiO}_{2}$ composite. J. Ind. Eng. Chem. 2015, 22, 317-323. [CrossRef]

3. Yuan, X.; Zhou, C.; Jing, Q.; Tang, Q.; Mu, Y.; Du, A.-K. Facile Synthesis of g-C $_{3} \mathrm{~N}_{4}$ Nanosheets $/ \mathrm{ZnO}$ Nanocomposites with Enhanced Photocatalytic Activity in Reduction of Aqueous Chromium(VI) under Visible Light. Nanomaterials 2016, 6, 173. [CrossRef] [PubMed]

4. Luo, S.; Qin, F.; Ming, Y.A.; Zhao, H.P.; Liu, Y.L.; Chen, R. Fabrication uniform hollow $\mathrm{Bi}_{2} \mathrm{~S}_{3}$ nanospheres via Kirkendall effect for photocatalytic reduction of $\mathrm{Cr}(\mathrm{VI})$ in electroplating industry wastewater. J. Hazard. Mater. 2017, 340, 253-262. [CrossRef] [PubMed] 
5. Abdel Moniem, S.M.; Ali, M.E.M.; Gad-Allah, T.A.; Khalil, A.S.G.; Ulbricht, M.; El-Shahat, M.F.; Ashmawy, A.M.; Ibrahim, H.S. Detoxification of hexavalent chromium in wastewater containing organic substances using simonkolleite- $\mathrm{TiO}_{2}$ photocatalyst. Process Saf. Environ. Prot. 2015, 95, 247-254. [CrossRef]

6. Zhang, Y.C.; Li, J.; Zhang, M.; Dionysiou, D.D. Size-tunable hydrothermal synthesis of $\mathrm{SnS}_{2}$ nanocrystals with high performance in visible light-driven photocatalytic reduction of aqueous $\mathrm{Cr}(\mathrm{VI})$. Environ. Sci. Technol. 2011, 45, 9324-9331. [CrossRef] [PubMed]

7. Xu, X.Y.; Zhou, X.S.; Zhang, L.L.; Xu, L.M.; Ma, L.; Luo, J.; Li, M.J.; Zeng, L.H. Photoredox degradation of different water pollutants $(\mathrm{MO}, \mathrm{RhB}, \mathrm{MB}$, and $\mathrm{Cr}(\mathrm{VI}))$ using Fe-N-S-tri-doped $\mathrm{TiO}_{2}$ nanophotocatalyst prepared by novel chemical method. Mater. Res. Bull. 2015, 70, 106-113. [CrossRef]

8. Meng, X.D.; Zhang, G.K.; Li, N. $\mathrm{Bi}_{24} \mathrm{Ga}_{2} \mathrm{O}_{39}$ for visible light photocatalytic reduction of $\mathrm{Cr}(\mathrm{VI})$ : Controlled synthesis, facet-dependent activity and DFT study. Chem. Eng. J. 2017, 314, 249-256. [CrossRef]

9. Wan, Z.; Zhang, G.K.; Wu, X.Y.; Yin, S. Novel visible-light-driven Z-scheme $\mathrm{Bi}_{12} \mathrm{GeO}_{20} / \mathrm{g}-\mathrm{C}_{3} \mathrm{~N}_{4}$ photocatalyst: Oxygen-induced pathway of organic pollutants degradation and proton assisted electron transfer mechanism of Cr(VI) reduction. Appl. Catal. B 2017, 207, 17-26. [CrossRef]

10. Wang, P.; Ji, W.D.; Li, M.M.; Zhang, G.K.; Wang, J.L. $\mathrm{Bi}_{25} \mathrm{VO}_{40}$ microcube with step surface for visible light photocatalytic reduction of $\mathrm{Cr}(\mathrm{VI})$ : Enhanced activity and ultrasound assisted regeneration. Ultrason. Sonochem. 2017, 38, 289-297. [CrossRef] [PubMed]

11. Vera, M.L.; Traid, H.D.; Henrikson, E.R.; Ares, A.E.; Litter, M.I. Heterogeneous photocatalytic Cr(VI) reduction with short and long nanotubular $\mathrm{TiO}_{2}$ coatings prepared by anodic oxidation. Mater. Res. Bull. 2018, 97, 150-157. [CrossRef]

12. Sun, B.; Reddy, E.P.; Smirniotis, P.G. Visible light $\mathrm{Cr}(\mathrm{VI})$ reduction and organic chemical oxidation by $\mathrm{TiO}_{2}$ photocatalysis. Environ. Sci. Technol. 2005, 39, 6251-6259. [CrossRef] [PubMed]

13. Huang, L.H.; Chan, Q.Z.; Wu, X.J.; Wang, H.J.; Liu, Y.L. The simultaneous photocatalytic degradation of phenol and reduction of $\mathrm{Cr}(\mathrm{VI})$ by $\mathrm{TiO}_{2} / \mathrm{CNTs}$. J. Ind. Eng. Chem. 2012, 18, 574-580. [CrossRef]

14. Liu, F.H.; Yu, J.; Tu, G.Y.; Qu, L.; Xiao, J.C.; Liu, Y.D.; Wang, L.Z.; Lei, J.Y; Zhang, J.L. Carbon nitride coupled Ti-SBA15 catalyst for visible-light-driven photocatalytic reduction of $\mathrm{Cr}(\mathrm{VI})$ and the synergistic oxidation of phenol. Appl. Catal. B 2017, 201,1-11. [CrossRef]

15. Li, X.F.; Zhen, X.Z.; Meng, S.G.; Xian, J.J.; Shao, Y.; Fu, X.Z.; Li, D.Z. Structuring $\beta-\mathrm{Ga}_{2} \mathrm{O}_{3}$ photonic crystal photocatalyst for efficient degradation of organic pollutants. Environ. Sci. Technol. 2013, 47, 9911-9917. [CrossRef] [PubMed]

16. Shao, T.; Zhang, P.Y.; Jin, L.; Li, Z.M. Photocatalytic decomposition of perfluorooctanoic acid in pure water and sewage water by nanostructured gallium oxide. Appl. Catal. B 2013, 142-143, 654-661. [CrossRef]

17. Girija, K.; Thirumalairajan, S.; Mastelaro, V.R.; Mangalaraj, D. Photocatalytic degradation of organic pollutants by shape selective synthesis of $\beta-\mathrm{Ga}_{2} \mathrm{O}_{3}$ microspheres constituted by nanospheres for environmental remediation. J. Mater. Chem. A 2015, 3, 2617-2627. [CrossRef]

18. Pan, Y.X.; Sun, Z.Q.; Cong, H.P.; Men, Y.L.; Xin, S.; Song, J.; Yu, S.H. Photocatalytic $\mathrm{CO}_{2}$ reduction highly enhanced by oxygen vacancies on Pt-nanoparticle-dispersed gallium oxide. Nano Res. 2016, 9, 1689-1700. [CrossRef]

19. Chen, S.L.; Li, D.; Liu, Y.X.; Huang, W.X. Morphology-dependent defect structures and photocatalytic performance of hydrogenated anatase $\mathrm{TiO}_{2}$ nanocrystals. J. Catal. 2016, 341, 126-135. [CrossRef]

20. Liu, J.; Lu, W.; Tian, B.S.; Hu, B.; Jin, L.; Shi, Y.R.; Li, L.; Wang, Z.L. Shape-controlled synthesis and facet-dependent performance of single-crystal $\mathrm{Bi}_{25} \mathrm{GaO}_{39}$ photocatalysts. CrystEngComm 2016, 18, 7715-7721. [CrossRef]

21. Liu, J.; Lu, W.; Zhong, Q.; Jin, X.D.; Wei, L.Y.; Wu, H.Z.; Zhang, X.L.; Li, L.L.; Wang, Z.L. Single-crystal $\mathrm{Bi}_{2} \mathrm{Ga}_{4} \mathrm{O}_{9}$ nanoplates with exposed $\{110\}$ facets for photocatalytic degradation of Acid Red 1. Mol. Catal. 2017, 433, 354-362. [CrossRef]

22. Parlett, C.M.A.; Wilson, K.; Lee, A.F. Hierarchical porous materials: Catalytic applications. Chem. Soc. Rev. 2013, 42, 3876-3893. [CrossRef] [PubMed]

23. Deng, Y.C.; Tang, L.; Zeng, G.M.; Zhu, Z.J.; Yan, M.; Zhou, Y.Y.; Wang, J.J.; Liu, Y.N.; Wang, J.J. Insight into highly efficient simultaneous photocatalytic removal of $\mathrm{Cr}(\mathrm{VI})$ and 2,4-diclorophenol under visible light irradiation by phosphorus doped porous ultrathin $\mathrm{g}-\mathrm{C}_{3} \mathrm{~N}_{4}$ nanosheets from aqueous media: Performance and reaction mechanism. Appl. Catal. B 2017, 203, 343-354. [CrossRef] 
24. Zhang, M.; Xu, J.; Zong, R.L.; Zhu, Y.F. Enhancement of visible light photocatalytic activities via porous structure of $\mathrm{g}-\mathrm{C}_{3} \mathrm{~N}_{4}$. Appl. Catal. B 2014, 147, 229-235. [CrossRef]

25. Liu, J.; Lu, W.; Zhong, Q.; Wu, H.Z.; Li, Y.L.; Li, L.L.; Wang, Z.L. Effect of pH on the microstructure of $\beta-\mathrm{Ga}_{2} \mathrm{O}_{3}$ and its enhanced photocatalytic activity for antibiotic degradation. J. Colloid Interface Sci. 2018, 519, 255-262. [CrossRef] [PubMed]

26. Liu, J.; Lu, W.; Wu, H.Z.; Jin, L.; Hu, B.; Li, L.L.; Wang, Z.L. In situ synthesis of rice-like $\mathrm{ZnGa}_{2} \mathrm{O}_{4}$ for the photocatalytic removal of organic and inorganic pollutants. Mater. Sci. Semicond. Process. 2016, 56, 251-259. [CrossRef]

27. Wang, X.; Xu, Q.; Li, M.R.; Shen, S.; Wang, X.L.; Wang, Y.C.; Feng, Z.C.; Shi, J.Y.; Han, H.X.; Li, C. Photocatalytic overall water splitting promoted by an $\alpha-\beta$ phase junction on $\mathrm{Ga}_{2} \mathrm{O}_{3}$. Angew. Chem. Int. Ed. 2012, 51, 13089-13092. [CrossRef] [PubMed]

28. Machon, D.; McMillan, P.F.; Xu, B.; Dong, J.J. High-pressure study of the $\beta$-to- $\alpha$ transition in $\mathrm{Ga}_{2} \mathrm{O}_{3}$. Phys. Rev. B 2006, 73, 094125. [CrossRef]

29. Hou, Y.D.; Wu, L.; Wang, X.C.; Ding, Z.X.; Li, Z.H.; Fu, X.Z. Photocatalytic performance of $\alpha-$, $\beta$-, and $\gamma-\mathrm{Ga}_{2} \mathrm{O}_{3}$ for the destruction of volatile aromatic pollutants in air. J. Catal. 2007, 250, 12-18. [CrossRef]

30. Guo, S.; Yuan, N.; Zhang, G.K.; Yu, J.C. Graphene modified iron sludge derived from homogeneous Fenton process as an efficient heterogeneous Fenton catalyst for degradation of organic pollutants. Microporous Mesoporous Mater. 2017, 238, 62-68. [CrossRef]

31. Girija, K.; Thirumalairajan, S.; Patra, A.K.; Mangalaraj, D.; Ponpandian, N.; Viswanathan, C. Enhanced photocatalytic performance of novel self-assembled floral $\beta-\mathrm{Ga}_{2} \mathrm{O}_{3}$ nanorods. Curr. Appl. Phys. 2013, 13, 652-658. [CrossRef]

32. Barrera-Díaz, C.E.; Lugo-Lugo, V.; Bilyeu, B. A review of chemical, electrochemical and biological methods for aqueous $\mathrm{Cr}(\mathrm{VI})$ reduction. J. Hazard. Mater. 2012, 223-224, 1-12. [CrossRef] [PubMed]

33. Alidokht, L.; Khataee, A.R.; Reyhanitabar, A.; Oustan, S. Reductive removal of Cr(VI) by starch-stabilized $\mathrm{Fe}^{0}$ nanoparticles in aqueous solution. Desalination 2011, 270, 105-110. [CrossRef]

34. Liang, R.W.; Shen, L.J.; Jing, F.F.; Wu, W.M.; Qin, N.; Lin, R.; Wu, L. $\mathrm{NH}_{2}$-mediated indium metal-organic framework as a novel visible-light-driven photocatalyst for reduction of the aqueous Cr(VI). Appl. Catal. B 2015, 162, 245-251. [CrossRef]

35. Wang, H.; Yuan, X.Z.; Wu, Y.; Zeng, G.M.; Chen, X.H.; Leng, L.J.; Wu, Z.B.; Jiang, L.B.; Li, H. Facile synthesis of amino-functionalized titanium metal-organic frameworks and their superior visible-light photocatalytic activity for Cr(VI) reduction. J. Hazard. Mater. 2015, 286, 187-194. [CrossRef] [PubMed]

(C) 2018 by the authors. Licensee MDPI, Basel, Switzerland. This article is an open access article distributed under the terms and conditions of the Creative Commons Attribution (CC BY) license (http:/ / creativecommons.org/licenses/by/4.0/). 

Article

\title{
Enhanced Photocatalytic Activity of \{110\}-Faceted $\mathrm{TiO}_{2}$ Rutile Nanorods in the Photodegradation of Hazardous Pharmaceuticals
}

\author{
Tran Thi Thuong Huyen ${ }^{1,2, *}$, Tran Thi Kim Chi ${ }^{1}$, Nguyen Duc Dung ${ }^{3}$, Hendrik Kosslick $^{2}$ and \\ Nguyen Quang Liem ${ }^{1}$ \\ 1 Institute of Materials Science (IMS), Vietnam Academy of Science and Technology (VAST), 18 Hoang Quoc Viet, \\ Cau Giay, Hanoi 100000, Vietnam; chittk@ims.vast.ac.vn (T.T.K.C.); liemnq@ims.vast.ac.vn (N.Q.L.) \\ 2 Institute of Chemistry, Department of Inorganic Chemistry, University of Rostock, Albert-Einstein-Str. 3a, \\ Rostock 18051, Germany; hendrik.kosslick@uni-rostock.de \\ 3 Advanced Institute of Science and Technology (AIST), Hanoi University of Science and Technology, \\ 1 Dai Co Viet, Hanoi 100000, Vietnam; dung.nguyenduc@hust.edu.vn \\ * Correspondence: huyenttt@ims.vast.ac.vn; Tel.: +84-243-756-4129 or +84-906-072-519
}

Received: 3 April 2018; Accepted: 20 April 2018; Published: 25 April 2018

\begin{abstract}
Rutile $\mathrm{TiO}_{2}$ with highly active facets has attracted much attention owing to its enhanced activity during the photocatalytic degradation of pollutants such as pharmaceuticals in wastewater. However, it is difficult to obtain by controlling the synthetic conditions. This paper reports a simple hydrothermal synthesis of rutile $\mathrm{TiO}_{2}$ nanorods with highly exposed $\{110\}$ facets. The obtained rutile was characterized by X-ray diffraction (XRD), scanning electron microscopy (SEM), high-resolution transmission electron microscopy (HR-TEM), and Raman spectroscopy. The main contribution to the photocatalytic activity comes from rutile nanorods with highly dominant active $\{110\}$ facets, which were studied in the photodegradation of reactive cinnamic acid and more recalcitrant ibuprofen. The contribution of active species was also investigated. The present work further confirmed the hydrothermal synthesis route for controlling the preparation of highly crystalline and active rutile nanocrystals.
\end{abstract}

Keywords: rutile; active facets; pharmaceutical; degradation; mineralization; active species

\section{Introduction}

Heterogeneous photocatalysis on semiconductor photocatalysts has attracted considerable interest due to its applicability in the treatment of hazardous organic pollutants [1-5]. Among the ultraviolet light driven photocatalysts, $\mathrm{TiO}_{2}$ has received much attention. The use of a $\mathrm{TiO}_{2}$ photocatalyst and a wide band gap $(\sim 3.2 \mathrm{eV})[6]$ offers several advantages including its low cost, chemical stability, high oxidizing ability, safety, and reusability [7-9]. $\mathrm{TiO}_{2}$ occurs in three main phases: anatase, brookite, and rutile, with anatase being the most commonly used in photocatalytic applications [10-14]. Recently, some photocatalytic studies on rutile $\mathrm{TiO}_{2}$ have been published. Kalaivani's group reported the enhanced photocatalytic decolourization efficiency of methylene blue over the bio-nanocomposite inulin- $\mathrm{TiO}_{2}$ rutile under ultraviolet (UV) irradiation [15]. In this case, the inulin- $\mathrm{TiO}_{2}$ rutile was obtained by embedding rutile nanoparticles into a novel biopolymer-inulin. The approach allowed the diminishing of the agglomeration of rutile nanoparticles, providing a larger surface area, thus improving the activity of rutile. In another report, Nair's group found that the high photocatalytic activity of three-dimensional rutile micro-flowers in the decolourization of Rhodamine B under UV light was due to the large surface area contributed by the highly dense spiky nanostructures [16]. In terms of enhanced activity, rutile nanocrystals with exposed active facets are relatively unknown due to its difficulty in synthesis. Therefore, acquiring a large percentage of active facets by controlling 
the synthetic conditions is highly desirable. According to the nature of rutile rods, the crystal growth is indeed a result of the competitive growth of $\{111\}$ facets and $\{110\}$ facets $[17,18]$. The reported rutile with exposed $\{111\}$ facets that had both the advantages of large specific surface area and exposed high active facets were active in the decolourization of methylene blue under UV irradiation [19]. In our work, the large-sized rutile nanocrystals with highly exposed $\{110\}$ facets were successfully prepared by hydrothermal synthesis and exhibited an enhanced activity in the photodegradation of reactive cinnamic acid (CA) and recalcitrant pharmaceutical ibuprofen (IBP). The photocatalytic performances were investigated under low power solarium lamps, high organic loading, and a small amount of the photocatalyst. Such testing conditions have been rarely reported in wastewater treatment. In addition, trapping experiments were carried out to analyze the contribution of active species to the photodegradation of organic compounds.

\section{Materials and Methods}

\subsection{Materials}

All chemicals were of analytical grade and used without further purification: titanium (IV) $i$-propoxide (TTIP, Merck, Kenilworth, NJ, USA, 98\%), hydrochloric acid ( $\mathrm{HCl}$, Chemsolute, Th. Geyer, Berlin, Germany, 35-38\%), cinnamic acid $\left(\mathrm{C}_{9} \mathrm{H}_{8} \mathrm{O}_{2}\right.$, Reachim, Moscow, Russia, 99\%), ibuprofen sodium salt $\left(\mathrm{C}_{13} \mathrm{H}_{17} \mathrm{O}_{2} \mathrm{Na}\right.$, Sigma-Aldrich, St. Louis, MA, USA, 98\%), ethylenediaminetetraacetic acid $\left(\mathrm{C}_{10} \mathrm{H}_{16} \mathrm{~N}_{2} \mathrm{O}_{8}\right.$, Sigma-Aldrich, 99\%), i-propanol $\left(\mathrm{C}_{3} \mathrm{H}_{8} \mathrm{O}\right.$, Sigma-Aldrich, $\left.>99 \%\right)$, tert-butanol $\left(\mathrm{C}_{4} \mathrm{H}_{10} \mathrm{O}\right.$, Sigma-Aldrich, 99\%), benzoquinone $\left(\mathrm{C}_{6} \mathrm{H}_{4} \mathrm{O}_{2}\right.$, Sigma-Aldrich, $\left.\geq 98 \%\right)$, and titania $\mathrm{P} 25\left(\mathrm{TiO}_{2}\right.$, Evonik, Essen, Germany, 99.5\%).

\subsection{Synthesis of $\mathrm{TiO}_{2}$ Rutile}

The rutile was prepared based on a previously reported procedure in [20] with improved synthesis parameters. The procedure consisted of two main steps:

(i) Sol-gel synthesis of an amorphous titania precursor: $20 \mathrm{~mL}$ of titanium (IV) $i$-propoxide was dissolved in $105 \mathrm{~mL}$ of $i$-propanol. The solution was kept at $0{ }^{\circ} \mathrm{C}$ under vigorous stirring. To this colorless solution, a stock solution containing $105 \mathrm{~mL}$ of $i$-propanol and $1 \mathrm{~mL}$ of distilled water prepared at room temperature (RT) was slowly dropped over a period of $5 \mathrm{~h}$. The suspension gradually changed into a white/milky color. This was further stirred at RT for $24 \mathrm{~h}$. Once the reaction was completed, the white product was removed from the suspension by centrifugation and the obtained clear colorless solution was again diluted with $1000 \mathrm{~mL}$ of distilled water and further stirred at RT for $24 \mathrm{~h}$. The obtained white amorphous titania was separated by centrifugation and washed with distilled water and ethanol, then dried under vacuum at $60^{\circ} \mathrm{C}$. The final white powder was used as the precursor for the hydrothermal treatment step.

(ii) Hydrothermal treatment of amorphous titania precursor: $1.0 \mathrm{~g}$ of amorphous titania was placed into a $120 \mathrm{~mL}$ Teflon cup and then an appropriate amount of concentrated aqueous $4.0 \mathrm{M}$ hydrochloric acid was added and stirred at RT for $30 \mathrm{~min}$. Next, the Teflon cup was transferred into a stainless steel-lined autoclave, which was placed into an oven and heated at $200{ }^{\circ} \mathrm{C}$ for $7 \mathrm{~h}$. Thereafter, the autoclave was allowed to cool down to RT. The precipitate was decanted from the reaction mixture, washed thoroughly with distilled water and ethanol, and finally dried at $60{ }^{\circ} \mathrm{C}$ overnight in an oven. The final product was ground in a porcelain mortar with a pistil to obtain fine powders.

\subsection{Characterization}

The morphology and microscopic structure of the samples were characterized by scanning electron microscopy (SEM) (FE-SEM S-4800, Hitachi, Tokyo, Japan) operating at $5 \mathrm{kV}$, and transmission electron microscopy (TEM) and high-resolution transmission electron microscopy (HR-TEM) (JEM 2100, JEOL, Tokyo, Japan) operating at $200 \mathrm{kV}$. 
The crystal structures and phases of the samples were measured using an X-ray diffractometer (STADI-P, STOE, Darmstadt, Germany) with monochromatic $\mathrm{Cu} K \alpha$ radiation $(\lambda=1.5406 \AA$ A ). Raman spectra were recorded using a LabRAM HR 800 Raman microscope system (Horiba Jobin YVON, Kyoto, Japan) equipped with a high stability BX40 microscope (Focus $1 \mu \mathrm{m})$. A blue laser (473 nm, $20 \mathrm{~mW}$ air-cooled solid-state laser) was used as an excitation source.

Brunauer-Emmett-Teller (BET) surface areas $\left(\mathrm{S}_{\mathrm{BET}}\right)$ were determined using the adsorption data in the relative pressure $\left(p / p_{0}\right)$ range of $0.05-0.35$. The measurements were performed at $77 \mathrm{~K}$ on a Thermo Sorptomatic 1990 nitrogen adsorption apparatus (Thermo Fisher Scientific, Waltham, MA, USA).

The weight loss of the samples was evaluated from the thermogravimetric curve analyzed on a TGA Labsys 1600 DSC instrument (Setaram, Caluire, France) under argon gas at a heating rate of $10 \mathrm{~K} / \mathrm{min}$ where $0.1 \mathrm{~cm}^{3}$ alumina $\left(\mathrm{Al}_{2} \mathrm{O}_{3}\right)$ crucibles were used.

\subsection{Photocatalysis}

The photocatalytic performance of the rutile samples was evaluated in the photocatalytic degradation reactions of CA and IBP under ultraviolet-visible (UV-Vis) irradiation using batch-conditions. In each experiment, a glass beaker containing $10 \mathrm{mg}$ of the photocatalyst and $250 \mathrm{~mL}$ of an aqueous $10 \mathrm{ppm}$ organic solution was used. The reaction mixture was magnetically stirred in the dark at RT for $30 \mathrm{~min}$ to reach the adsorption-desorption equilibrium. Four UV-Vis solarium lamps with a total power of $60 \mathrm{~W}$ were used as the light source. These lamps simulate the UV part of sunlight (by light energy distribution and intensity) and emit a continuous spectrum range of about $370-400 \mathrm{~nm}$. The distance between the applied lamps and the surface of the pollutant solution was $15 \mathrm{~cm}$. Parallel tests were performed by placing four batches into a closed aluminum box. Four magnetic stirrers were arranged below. After certain time intervals $(0 \mathrm{~min}, 15 \mathrm{~min}, 30 \mathrm{~min}$, $1 \mathrm{~h}, 2 \mathrm{~h}, 3 \mathrm{~h}, 4 \mathrm{~h}$, and $5 \mathrm{~h}$ ), $5 \mathrm{~mL}$ aliquots were taken from the reaction mixture, and $5 \mathrm{~mL}$ aliquots were taken from the reaction mixture with a syringe and separated from the catalyst by a $0.45 \mu \mathrm{m}$ polytetrafluoroethylene (PTFE) syringe filter. The abatement of IBP and CA was determined by the change in the absorbance at 221 and $273 \mathrm{~nm}$, respectively, as follows [21]:

$$
\text { abatement }(\%)=\left(A_{0}-A_{t}\right) / A_{0} \times 100,
$$

where $A_{0}$ and $A_{t}$ are the initial absorbance and the absorbance after various time intervals of UV-Vis irradiation $(t)$, respectively. All data were measured at RT using a Lambda $19 \mathrm{UV} /$ Vis spectrometer (Perkin Elmer, Waltham, MA, USA).

The trapping experiments using different scavengers $(1.46 \mathrm{mg}$ of ethylenediaminetetraacetic acid (EDTA) as scavenger for holes, $0.1 \mathrm{~mL}$ of tert-butanol $(t-\mathrm{BuOH})$ as scavenger for hydroxyl radicals, and $2.7 \mathrm{mg}$ of benzoquinone (BQ) as scavenger for superoxide anion radicals) were performed in a similar manner to the above photocatalytic degradation reaction of IBP and CA except that the mentioned scavengers were added to the reaction.

\section{Results}

\subsection{Characterization}

A combined study of the XRD pattern and Raman scattering spectrum was performed to confirm the formation of the pure rutile phase. The XRD pattern (Figure 1a) revealed that the obtained hydrothermal product was present in the rutile form with a high intense diffraction peak at $27.4^{\circ}(2 \theta)$ corresponding to the $\{110\}$ facets and others with high intensities located at $36.1^{\circ}, 41.2^{\circ}$, and $54.3^{\circ}$ representing the $\{101\},\{111\}$, and $\{211\}$ facets, respectively $[16,19]$. The results were consistent with the theoretical diffraction pattern from the JCPDS database (No. 96-900-7532). The average crystallite size $\mathrm{D}_{\mathrm{XRD}}$ of the rutile was calculated using the Scherrer equation from the width of the most intense rutile reflection $\left(2 \theta=27.4^{\circ}\right)$ [22] and determined to be about $90 \mathrm{~nm}$. Representative Raman spectrum 
(Figure 1b) showed that three bands appeared at 234, 447, and $608 \mathrm{~cm}^{-1}$, which are characteristic of the $\mathrm{TiO}_{2}$ rutile phase $[23,24]$.
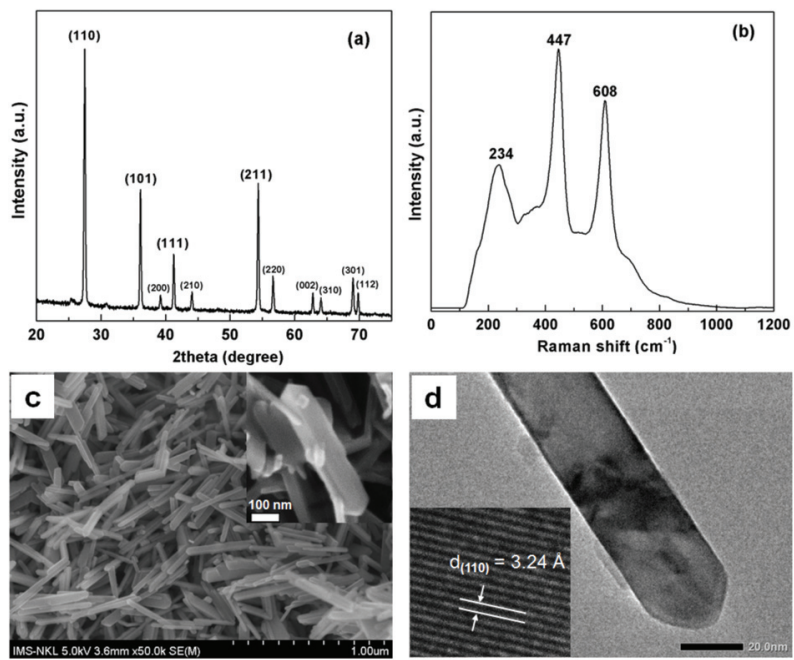

Figure 1. (a) XRD pattern; (b) Raman spectrum; and (c) SEM image of the as-synthesized rutile nanorods. The inset of (c) is the corresponding high-resolution SEM image; (d) Low resolution TEM image of rutile with exposed $\{110\}$ facets. Inset: HR-TEM image taken from the body of the rutile nanorods.

The SEM image of the rutile nanocrystals is shown in Figure 1c. Under the present hydrothermal treatment conditions, nearly uniformed rutile nanorods were formed with the size of about 50-100 nm in width and about 300-500 $\mathrm{nm}$ in length. Each nanorod consisted of four lateral smooth facets and two pyramidal ends (inset of Figure 1c), which were confirmed by the TEM image shown in Figure 1d. The inset of Figure $1 \mathrm{~d}$ revealed that the main exposed facets of the obtained rutile were $\{110\}$ facets corresponding to a spacing value of $3.24 \AA$.

Based on the weight loss and BET surface [25], the densities of the adsorbed water (physisorbed water) and surface hydroxyl groups (chemisorbed $\mathrm{OH}$ groups) were calculated in the temperature range of RT-250 ${ }^{\circ} \mathrm{C}$ and $250-700{ }^{\circ} \mathrm{C}$, respectively [26]. The amount of adsorbed water was estimated as follows: (weight loss $\times$ Avogadro's number)/(molecular mass of water $\times \mathrm{S}_{\mathrm{BET}}$ ), while surface hydroxyl groups were calculated as follows: (weight loss $\times$ Avogadro's number)/(molecular mass of $\mathrm{OH}$ group $\left.\times \mathrm{S}_{\mathrm{BET}}\right)$. The rutile was covered with about twice the amount of $\mathrm{OH}$ groups than with anatase and titania P25 (Table 1). This property correlated with the surface hydroxylation, which might explain the difference in the photocatalytic performances between rutile and anatase [27].

Table 1. Densities of the adsorbed water and surface hydroxyl groups calculated based on the weight loss and $\mathrm{S}_{\mathrm{BET}}$ for anatase, rutile, and titania P25.

\begin{tabular}{|c|c|c|c|c|c|}
\hline \multirow{2}{*}{ Sample } & \multicolumn{2}{|c|}{ Weight Loss (\%) } & \multirow{2}{*}{$\mathrm{S}_{\mathrm{BET}}{ }^{1)}\left(\mathrm{m}^{2} / \mathrm{g}\right)$} & \multirow{2}{*}{$\begin{array}{c}\text { Density of Adsorbed } \\
\text { Water (Molecules/nm²) }\end{array}$} & \multirow{2}{*}{$\begin{array}{l}\text { Density of Surface OH } \\
\text { Groups (Molecules } / \mathrm{nm}^{2} \text { ) }\end{array}$} \\
\hline & RT $-250^{\circ} \mathrm{C}$ & $250-700{ }^{\circ} \mathrm{C}$ & & & \\
\hline Rutile & 1.01 & 0.67 & 12 & 28 & 25 \\
\hline Titania P25 & 2.65 & 0.79 & 46 & 19 & 8 \\
\hline Anatase ${ }^{2)}$ & 4.86 & 3.03 & 132 & 12 & 10 \\
\hline
\end{tabular}




\subsection{Photocatalysis}

Photocatalyic Activity

The photocatalytic performance of rutile was investigated in the degradation of CA. For comparison, an identical assay was conducted using a commercial $\mathrm{TiO}_{2}$ (P25, Evonik, Essen, Germany). Figure 2a shows the CA abatement curves determined by the change in the CA absorbance. The CA adsorption on the surfaces of the rutile and P25 was similar (about 1.7\%). Through a comparison of the specific surface area of rutile $\left(12 \mathrm{~m}^{2} / \mathrm{g}\right)$ and $\mathrm{TiO}_{2} \mathrm{P} 25\left(46 \mathrm{~m}^{2} / \mathrm{g}\right)$ determined by the BET method using the relative pressure range of $0.05-0.35$ in the present nitrogen adsorption-desorption measurement (Table 1), the loading of CA molecules on the rutile surface was higher than that on the P25 surface. Obviously, the quite large planar facets of the rutile crystals allow for the alignment of an increased amount of CA molecules adsorbed on its surface. Such high loadings can be realized with aligned adsorbed molecule multilayers (Langmuir Blodgett-type) [28]. Therefore, the photocatalytic degradation of CA over low surface area rutile is not limited by mass transfer or adsorption.

After the first hour of exposure to UV irradiation, the rutile had slightly higher photocatalytic activity than the P25 (about 91\% and 84\% of CA was degraded with rutile and P25, respectively). Based on the Langmuir-Hinshelwood first-order kinetic model, the apparent first-order rate constant was derived from the slope of the linear transform $\ln \left(C / C_{0}\right)=f(t)$, where $C_{0}$ is the initial concentration of $C A$ and $C_{t}$ is the concentration of CA at various irradiation times $(0 \mathrm{~min}, 5 \mathrm{~min}, 15 \mathrm{~min}, 30 \mathrm{~min}$, and $60 \mathrm{~min}$ ). Rutile exhibited a fast reaction rate of 0.04214 , which was higher than that of the P25 (i.e., 0.03027) as seen in the insert of Figure 2a. A similar high CA abatement (98-99\%) was achieved at the end of the reaction (duration $5 \mathrm{~h}$ ) showing the unexpectedly high photocatalytic activity of the as-synthesized rutile even with its large crystal size and low surface area. It should be noted that the $\mathrm{TiO}_{2} \mathrm{P} 25$ photocatalyst, being a mixture of anatase (80\%) and rutile $(20 \%)$, consisted of spherical aggregated nanoparticles with a diameter of about $25 \mathrm{~nm}$ (Figure $2 \mathrm{~b}$ ). In a reported comparison with spherical anatase $\mathrm{TiO}_{2}$ nanoparticles prepared by a similar hydrothermal procedure [26], rutile was more active for the CA photodegradation. Anatase had a much smaller particle size $(10 \mathrm{~nm})$ and higher BET surface area $\left(132 \mathrm{~m}^{2} / \mathrm{g}\right)$. These findings showed that the shape, particle size, and surface area were not limiting factors when explaining the high activity of rutile in the CA photodegradation.

(a)

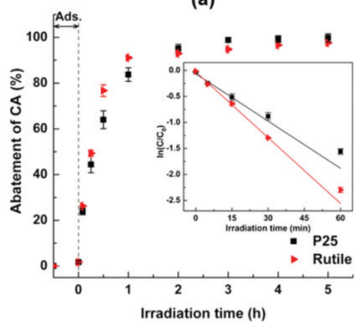

(b)

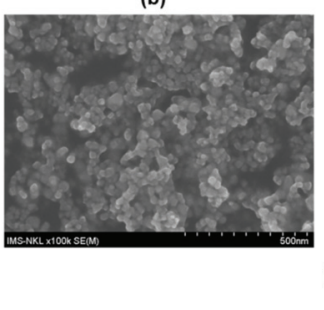

(c)

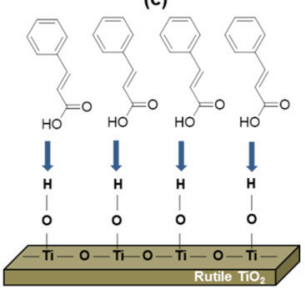

Figure 2. (a) Photocatalytic abatement of cinnamic acid (CA) in the photocatalytic performances of $\mathrm{TiO}_{2} \mathrm{P} 25$ and rutile, inset: corresponding plots for linear fitting followed by the apparent first-order reaction model. Reaction conditions: RT, 10 ppm CA, $250 \mathrm{~mL}$ reaction solution, $10 \mathrm{mg}$ catalyst loading; (b) SEM image of $\mathrm{TiO}_{2} \mathrm{P} 25$; (c) Langmuir-Blodgett assembly of CA molecules on the planar crystal rutile facets.

To further understand the photocatalytic behavior of rutile, the degradation of IBP, known as a recalcitrant compound [29], was studied. Figure 3 shows the abatement and mineralization curves determined by the change in the absorbance of CA, IBP, and in the total organic carbon (TOC) removal, respectively. Under UV irradiation, the CA and IBP molecules were degraded immediately, 
especially with cinnamic acid (Figure 3a). In the photodegradation of IBP, the aromatic ring opening occurred gradually with irradiation time. After $5 \mathrm{~h}$, about $80 \%$ of IBP and $98 \%$ of CA were degraded. The obtained abatement showed that rutile exhibited different photocatalytic activities depending on the reactivity or recalcitrance of the organic compounds. Namely, the reactive olefinic $(-\mathrm{C}=\mathrm{C}-)$ double bond presented in the side chain of the CA molecules was immediately attacked at the onset of photocatalytic reaction [30]. As a result, the CA was nearly completely degraded after $5 \mathrm{~h}$ of reaction, while the abatement of IBP might take a longer time. This behavior was more pronounced in the mineralization. Figure $3 b$ shows the markedly lower degree of mineralization when compared to the rapid degradation rate. This might be due to the formation of reaction intermediates and/or by-products such as hydroxylation products, ring-opened products, etc. About $98 \%$ (UV) and $69 \%$ (TOC) were achieved in the CA degradation after $5 \mathrm{~h}$ of the photocatalytic reaction, whereas about $80 \%$ (UV) and 28\% (TOC) were obtained in the IBP degradation. These results indicated that rutile behaves according to the chemical reactivity of the organic compounds. In this work, the recalcitrance of the studied organic compounds increased as follows: CA $<$ IBP.
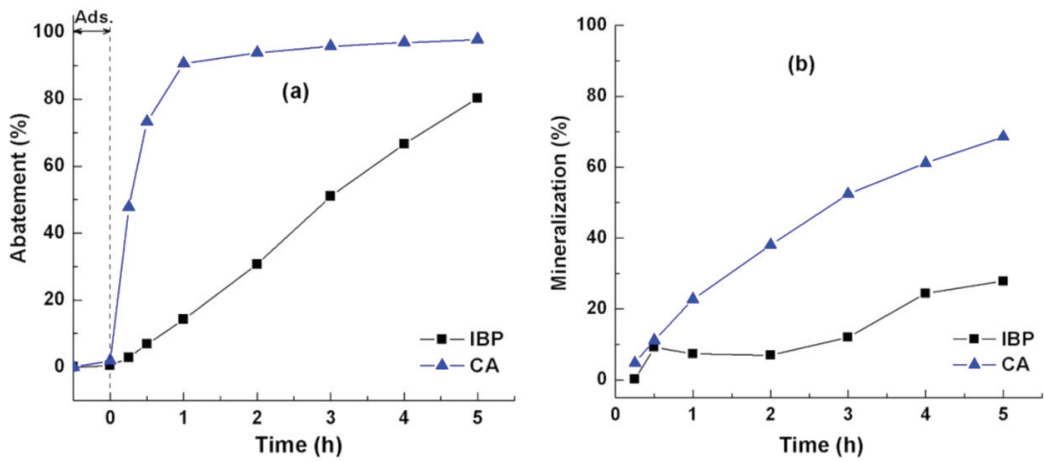

Figure 3. (a) Abatement and (b) mineralization of (CA) cinnamic acid and (IBP) ibuprofen in the photocatalytic performance of rutile. Reaction conditions: RT, $10 \mathrm{ppm}$ pollutant, $250 \mathrm{~mL}$ reaction solution, $10 \mathrm{mg}$ rutile loading.

The difference in the activity of rutile for the photodegradation of CA and IBP can be clarified in terms of the contribution of active species which are considered as practically involved in the photocatalytic reactions but have not been reported so far [31-34]. The role of active species was investigated by the impact of adding different scavengers ( $t$ - $\mathrm{BuOH}$ for ${ }^{\bullet} \mathrm{OH}$ scavenger, EDTA for holes scavenger, and $\mathrm{BQ}$ for $\mathrm{O}_{2}^{\bullet-}$ scavenger) on the photodegradation of IBP over rutile.

Figure 4 a shows that the addition of $t$ - $\mathrm{BuOH}$ remarkably reduced the photocatalytic IBP abatement from the original $80 \%$ to $30 \%$, indicating the strong contribution of ${ }^{\bullet} \mathrm{OH}$ radicals in the treatment with rutile. In contrast, the addition of a holes $\left(\mathrm{h}^{+}\right)$scavenger had an unexpectedly increase in the abatement of IBP, e.g., from 30\% (without addition of EDTA) to 50\% (addition of EDTA) after $2 \mathrm{~h}$ of reaction. This means that these holes were not directly involved in the oxidation of IBP and can migrate to the rutile surface and react with surface $\mathrm{OH}$ groups and/or water molecules surrounding the rutile particles that ultimately lead to the formation of $\bullet \mathrm{OH}$ radicals $[5,34,35]$. The increase in the abatement of IBP after the addition of holes also implied that EDTA injected more electrons into the valence band of rutile, thereby improving charge carrier separation by the excitation of electrons to the conduction band, thus causing an enhancement in the formation of $\mathrm{O}_{2}^{\bullet-}$ radical anions via the reduction of molecular oxygen by electrons. As a result, the photodegradation of IBP was completely inhibited after the addition of the $\mathrm{O}_{2}^{\bullet-}$ scavenger. 
In contrast with the photocatalytic performance of rutile, the holes contributed remarkably to the cleavage of the aromatic ring for the photodegradation of IBP treated with anatase, especially at the initial stage of reaction (Figure $4 \mathrm{~b}$ ). Obviously, the impact of $\bullet \mathrm{OH}$ radicals was minor. These results indicated that the lower activity of rutile when compared to anatase in the experiment without the addition of scavengers was due to the absence of oxidative holes. Interestingly, the $\mathrm{O}_{2}^{\bullet-}$ anions had a strong impact during the course of treatment with both photocatalysts (rutile and anatase).
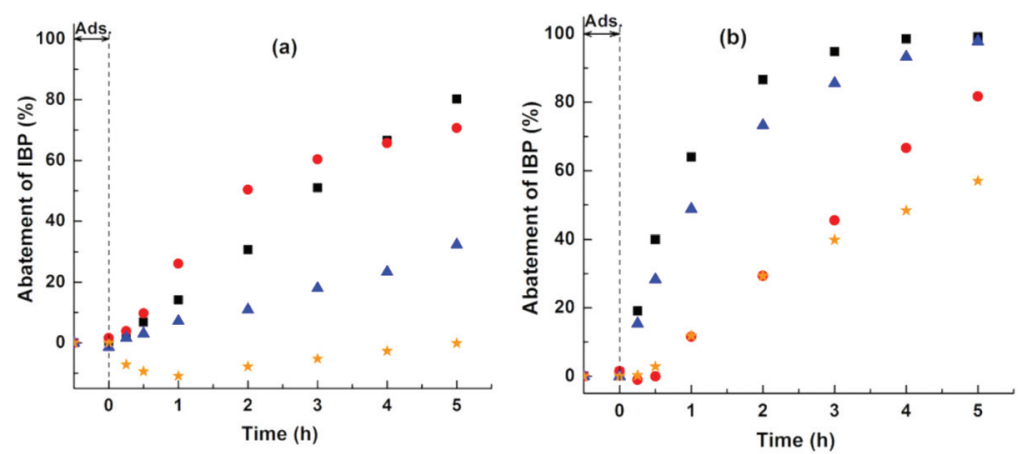

Figure 4. Impact of different scavengers on the photocatalytic abatement of IBP over (a) rutile and (b) anatase. Reaction conditions: RT, 10 ppm IBP, $250 \mathrm{~mL}$ aqueous reaction solution, $10 \mathrm{mg}$ catalyst loading. No scavenger: (black square). Scavengers: (red circle) EDTA, (blue triangle) $t$-BuOH, and (orange star) BQ.

By means of the scavenger experiments, we found that the holes were not directly involved in the photodegradation of IBP over rutile, but that they produced a relatively high number of ${ }^{\bullet} \mathrm{OH}$ radicals that acted as "door openers" via the oxidation of surface $\mathrm{OH}$ groups which were calculated and shown in Table 1. Murai et al. also suggested that holes were trapped at the titania surface in the adsorbed $\mathrm{OH}$ groups yielding the reactive ${ }^{\bullet} \mathrm{OH}$ radicals [36]. These findings explained the lower activity of rutile for the photodegradation of recalcitrant ibuprofen when compared to that of reactive cinnamic acid. Cinnamic acid does not require strong active species like holes but reacts with ${ }^{\bullet} \mathrm{OH}$ radicals to attack its olefinic double bond, therefore yielding a higher photodegradation efficiency.

In terms of the contribution of the active facets, the difference in the activity of rutile was further studied. Three different rutile samples were used for this purpose including R1 (directly synthesized by the hydrothermal method), R2 (separated from the brookite/rutile mixture by peptization with water), and R3 (obtained by the short-time grinding of R1). The morphology, crystal structures, and phases of the rutile samples are shown in Figure 5. Their XRD patterns indicated that the pure rutile phase was formed and well crystallized. Using the SEM data, the order of particle size was as follows: R1 > R2 > R3.

Figure 6 shows the photocatalytic abatement of IBP over different rutile samples. The difference in the activity between these samples was clearly observed. Only about 20\% of IBP over R3 was degraded after $5 \mathrm{~h}$ under UV irradiation, while a 2-4 times higher IBP abatement was achieved with R2 (55\%) and R1 (80\%), respectively. A decrease in the photocatalytic activity followed in the order: R1 > R2 > R3, which was not dependent on the order of particle size: R1 > R2 > R3. The largest rutile nanorods (R1) with the highest activity indicated the minor role of particle size. The photocatalytic activity of rutile nanorods was clearly independent of particle size for the photodegradation of cinnamic acid (Table 2). In general, the particle size reduction accompanied by an increase in the specific surface area led to an enhancement in the activity of the photocatalysts $[35,37]$. 

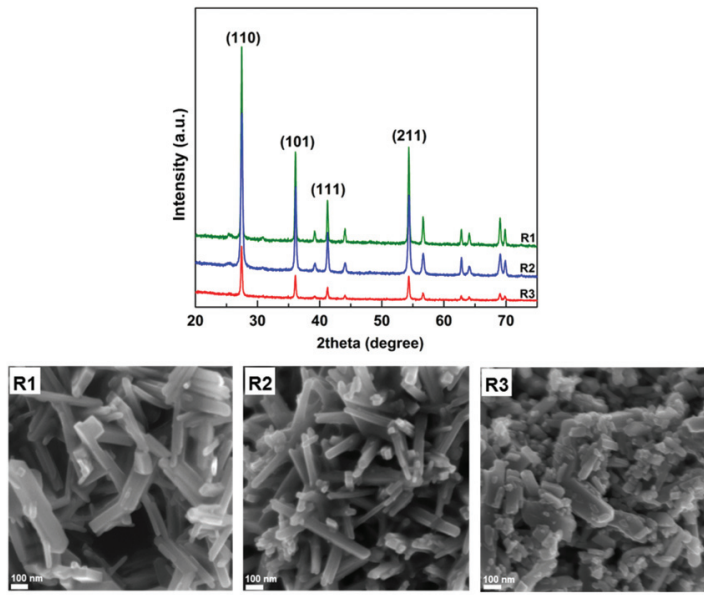

Figure 5. (Top) XRD and (bottom) SEM images of different rutile samples. R1, R2, and R3 represent the rutile synthesized by the hydrothermal method, rutile separated from the brookite/rutile mixture by peptization with water, and the rutile obtained by short-time grinding of R1, respectively.

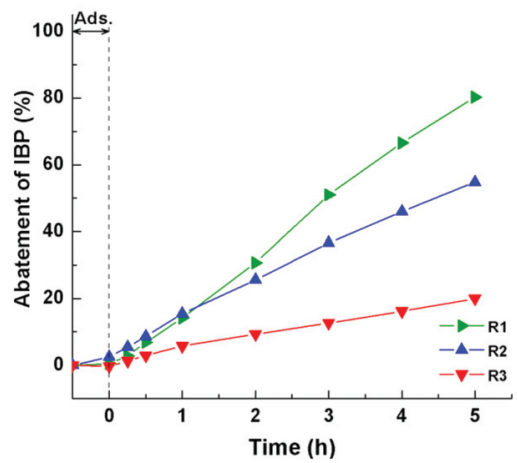

Figure 6. Photocatalytic abatement of IBP over different rutile samples (R1, R2, and R3 represent the rutile synthesized by the hydrothermal method, rutile separated from the brookite/rutile mixture by peptization with water, and the rutile obtained by the short-time grinding of R1, respectively). Reaction conditions: RT, 10 ppm IBP, $250 \mathrm{~mL}$ aqueous reaction solution, $10 \mathrm{mg}$ rutile loading.

Table 2. Photocatalytic abatement of CA (\%) over different rutile samples.

\begin{tabular}{ccccc}
\hline Time (h) & Photocatalysts & R1 $^{\text {a }}$ & R2 $^{\text {b }}$ & R3 $^{c}$ \\
\hline 1 & 90 & 84 & 87 \\
2 & 93 & 87 & 89 \\
3 & 95 & 91 & 90 \\
4 & 96 & 94 & 93 \\
5 & 97 & 96 & 94 \\
\hline
\end{tabular}

a Rutile synthesized by the hydrothermal method. ${ }^{\mathrm{b}}$ Rutile separated from the brookite/rutile mixture by peptization with water. ${ }^{c}$ Rutile obtained by the short-time grinding of R1.

Usually, rutile $\mathrm{TiO}_{2}$ crystals show a rod morphology with the competitive growth of $\{111\}$ facets and $\{110\}$ facets [38]. It has also been established that the $\{110\}$ facets include some point defect types, 
typically bridging oxygen vacancies, which are strongly related to the surface reactivity. Additionally, these facets have a tendency to trap holes and electrons, which greatly yields the improvement in the separation efficiency of electron-hole pairs, and thus the improvement in activity [39-43]. In our case, we found that the rutile $\mathrm{TiO}_{2}$ rods with exposed crystal facets that have been predominantly ascribed to the $\{110\}$ side and $\{111\}$ edge (sample R1) and \{011\} edge (sample R2) (Figure 7) had much higher photocatalytic activity than those with a mixture of exposed facets (sample R3 exposing $\{011\},\{020\}$, and $\{0 \overline{1} 1\}$ facets). Samples R1 and R2 were both hydrothermal products under different conditions given as $200{ }^{\circ} \mathrm{C}, \mathrm{HCl} 4 \mathrm{M}$ and $175^{\circ} \mathrm{C}, \mathrm{HCl} 3 \mathrm{M}$, respectively. Under a similar synthesis procedure, these rutile samples were both formed in the rod-shaped nanocrystals with the main active facets of $\{110\}$. In contrast, the grinding of R1 may have destroyed or decreased the number of this facet leading to its absence in the R3 sample, which was less active than samples R1 and R2. This finding confirmed the important role of the $\{110\}$ facets to explain the high photocatalytic activity of the rutile nanorods for the photodegradation of recalcitrant ibuprofen even with a large particle size and low surface area.
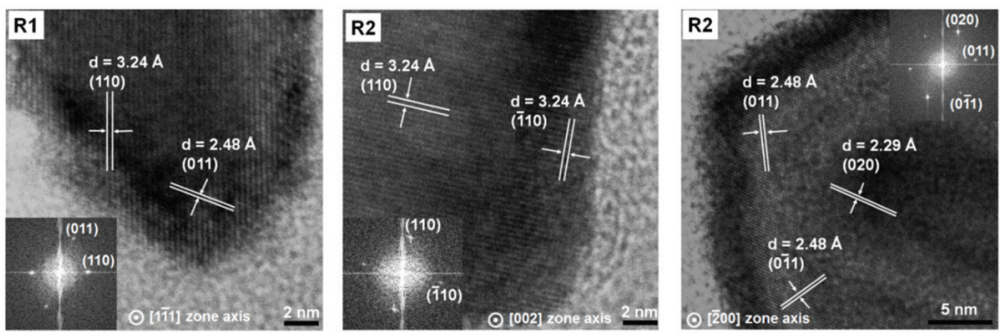

Figure 7. HR-TEM of different rutile samples (R1, R2, and R3 represent the rutile synthesized by the hydrothermal method, rutile separated from the brookite/rutile mixture by peptization with water, and the rutile obtained by the short-time grinding of R1, respectively). Inset: corresponding FFT patterns.

\section{Conclusions}

In conclusion, highly crystalline rutile $\mathrm{TiO}_{2}$ nanorods were obtained by hydrothermal synthesis at $200{ }^{\circ} \mathrm{C}$ using hydrochloric acid as an acidic agent. Rutile had an unexpectedly high photocatalytic activity in the photodegradation of reactive cinnamic acid even with a large crystal size and low specific surface area. The activity of rutile was correlated to the dominant $\{110\}$ facets in the photodegradation of recalcitrant ibuprofen. Larger proportion of surface exposed $\{110\}$ active facets has been formed, therefore, higher photocatalytic activity has been achieved. Rutile behaves according to the chemical reactivity of the organic compounds. The lack of oxidative holes caused a lower IBP aromatic ring opening efficiency, whereas the less strong $\bullet^{\circ} \mathrm{OH}$ radicals preferentially formed and easily attacked the cinnamic acid molecules.

Author Contributions: T.T.T.H. and H.K. provided guidance and advice; T.T.T.H., T.T.K.C., and N.D.D. performed the experiments and measurements; T.T.T.H., H.K., and N.Q.L. provided the discussion; T.T.T.H. wrote the paper. All authors contributed to discussion and reviewed the manuscript.

Acknowledgments: This work was supported by the European Union in the frame of the FP7 program, PCATDES project (Grant number 309846); the National Key Laboratory project (Grant number CSTĐ01.17); the National Key Laboratory for Electronic Materials and Devices, Institute of Materials Science, Vietnam Academy of Science and Technology.

Conflicts of Interest: The authors declare no conflicts of interest.

\section{References}

1. Ibhadon, A.; Fitzpatrick, P. Heterogeneous Photocatalysis: Recent Advances and Applications. Catalysts 2013, 3, 189-218. [CrossRef] 
2. Litter, M. Heterogeneous photocatalysis Transition metal ions in photocatalytic systems. Appl. Catal. B Environ. 1999, 23, 89-114. [CrossRef]

3. Kanakaraju, D.; Glass, B.D.; Oelgemöller, M. Titanium dioxide photocatalysis for pharmaceutical wastewater treatment. Environ. Chem. Lett. 2014, 12, 27-47. [CrossRef]

4. Hashimoto, K.; Irie, H.; Fujishima, A. Photocatalysis: A Historical Overview and Future Prospects. Jpn. J. Appl. Phys. 2005, 44, 8269-8285. [CrossRef]

5. Ribeiro, A.R.; Nunes, O.C.; Pereira, M.F.R.; Silva, A.M.T. An overview on the advanced oxidation processes applied for the treatment of water pollutants defined in the recently launched Directive 2013/39/EU. Environ. Int. 2015, 75, 33-51. [CrossRef] [PubMed]

6. Hoffmann, M.R.; Martin, S.T.; Choi, W.; Bahnemann, D.W. Environmental Applications of Semiconductor Photocatalysis. Chem. Rev. 1995, 95, 69-96. [CrossRef]

7. Herrmann, J. Heterogeneous photocatalysis: Fundamentals and applications to the removal of various types of aqueous pollutants. Catal. Today 1999, 53, 115-129. [CrossRef]

8. Xu, H.; Ouyang, S.; Liu, L.; Reunchan, P.; Umezawa, N.; Ye, J. Recent advances in $\mathrm{TiO}_{2}$-based photocatalysis. J. Mater. Chem. A 2014, 2, 12642. [CrossRef]

9. Tseng, T.K.; Lin, Y.S.; Chen, Y.J.; Chu, H. A review of photocatalysts prepared by sol-gel method for VOCs removal. Int. J. Mol. Sci. 2010, 11, 2336-2361. [CrossRef] [PubMed]

10. Hanaor, D.A.H.; Sorrell, C.C. Review of the anatase to rutile phase transformation. J. Mater. Sci. 2011, 46, 855-874. [CrossRef]

11. Kaplan, R.; Erjavec, B.; Pintar, A. Enhanced photocatalytic activity of single-phase, nanocomposite and physically mixed $\mathrm{TiO}_{2}$ polymorphs. Appl. Catal. A 2015, 489, 51-60. [CrossRef]

12. Li, Z.; Cong, S.; Xu, Y. Brookite vs. Anatase $\mathrm{TiO}_{2}$ in the Photocatalytic Activity for Organic Degradation in Water. ACS Catal. 2014, 4, 3273-3280. [CrossRef]

13. Zhang, J.; Zhou, P.; Liu, J.; Yu, J. New understanding of the difference of photocatalytic activity among anatase, rutile and brookite $\mathrm{TiO}_{2}$. Phys. Chem. Chem. Phys. 2014, 16, 20382-20386. [CrossRef] [PubMed]

14. Kaplan, R.; Erjavec, B.; Dražić, G.; Grdadolnik, J.; Pintar, A. Simple synthesis of anatase/rutile/brookite $\mathrm{TiO}_{2}$ nanocomposite with superior mineralization potential for photocatalytic degradation of water pollutants. Appl. Catal. B 2016, 181, 465-474. [CrossRef]

15. Jayanthi Kalaivani, G.; Suja, S.K. $\mathrm{TiO}_{2}$ (rutile) embedded inulin-A versatile bio-nanocomposite for photocatalytic degradation of methylene blue. Carbohydr. Polym. 2016, 143, 51-60. [CrossRef] [PubMed]

16. Nair, R.V.; Jijith, M.; Gummaluri, V.S.; Vijayan, C. A novel and efficient surfactant-free synthesis of Rutile $\mathrm{TiO}_{2}$ microflowers with enhanced photocatalytic activity. Opt. Mater 2016, 55, 38-43. [CrossRef]

17. Truong, Q.D.; Kato, H.; Kobayashi, M.; Kakihana, M. Hierarchical structures of rutile exposing high-index facets. J. Cryst. Growth 2015, 418, 86-91. [CrossRef]

18. Zhang, Q.; Li, R.; Li, Z.; Li, A.; Wang, S.; Liang, Z.; Liao, S.; Li, C. The dependence of photocatalytic activity on the selective and nonselective deposition of noble metal cocatalysts on the facets of rutile $\mathrm{TiO}_{2}$. J. Catal. 2016, 337, 36-44. [CrossRef]

19. Zhang, J.; Liu, P.; Lu, Z.; Xu, G.; Wang, X.; Qian, L.; Wang, H.; Zhang, E.; Xi, J.; Ji, Z. One-step synthesis of rutile nano- $\mathrm{TiO}_{2}$ with exposed $\{111\}$ facets for high photocatalytic activity. J. Alloys Compd. 2015, 632, 133-139. [CrossRef]

20. Reyes-Coronado, D.; Rodríguez-Gattorno, G.; Espinosa-Pesqueira, M.E.; Cab, C.; de Coss, R.; Oskam, G. Phase-pure $\mathrm{TiO}_{2}$ nanoparticles: Anatase, brookite and rutile. Nanotechnology 2008, 19, 145605-145615. [CrossRef] [PubMed]

21. Wei, X.; Zhu, G.; Fang, J.; Chen, J. Synthesis, Characterization, and Photocatalysis of Well-Dispersible Phase-Pure Anatase $\mathrm{TiO}_{2}$ Nanoparticles. Int. J. Photoenergy 2013, 2013, 726872. [CrossRef]

22. Mahshid, S.; Askari, M.; Ghamsari, M.S. Synthesis of $\mathrm{TiO}_{2}$ nanoparticles by hydrolysis and peptization of titanium isopropoxide solution. J. Mater. Process. Technol. 2007, 189, 296-300. [CrossRef]

23. Tompsett, G.A.; Bowmaker, G.A.; Cooney, R.P.; Metson, J.B.; Rodgers, K.A.; Seakins, J.M. The Raman spectrum of brookite, $\mathrm{TiO}_{2}(\mathrm{Pbca}, \mathrm{Z}=8)$. J. Raman Spectrosc. 1995, 26, 57-62. [CrossRef]

24. Yang, J.; Mei, S.; Ferreira, J.M.F.; Norby, P.; Quaresmâ, S. Fabrication of rutile rod-like particle by hydrothermal method: An insight into $\mathrm{HNO}_{3}$ peptization. J. Colloid Interface Sci. 2005, 283, 102-106. [CrossRef] [PubMed] 
25. Kakuma, Y.; Nosaka, A.Y.; Nosaka, Y. Difference in $\mathrm{TiO}_{2}$ photocatalytic mechanism between rutile and anatase studied by the detection of active oxygen and surface species in water. Phys. Chem. Chem. Phys. 2015, 17, 18691-18698. [CrossRef] [PubMed]

26. Tran, H.T.T.; Kosslick, H.; Ibad, M.F.; Fischer, C.; Bentrup, U.; Vuong, T.H.; Nguyen, L.Q.; Schulz, A. Photocatalytic Performance of Highly Active Brookite in the Degradation of Hazardous Organic Compounds Compared to Anatase and Rutile. Appl. Catal. B 2017, 200, 647-658. [CrossRef]

27. Bouras, P.; Stathatos, E.; Lianos, P. Pure versus metal-ion-doped nanocrystalline titania for photocatalysis. Appl. Catal. B 2007, 73, 51-59. [CrossRef]

28. Choina, J.; Bagabas, A.; Fischer, C.; Flechsig, G.-U.; Kosslick, H.; Alshammari, A.; Schulz, A. The influence of the textural properties of $\mathrm{ZnO}$ nanoparticles on adsorption and photocatalytic remediation of water from pharmaceuticals. Catal. Today 2015, 241, 47-54. [CrossRef]

29. Carballa, M.; Omil, F.; Alder, A.C.; Lema, J.M. Comparison between the conventional anaerobic digestion of sewage sludge and its combination with a chemical or thermal pre-treatment concerning the removal of pharmaceuticals and personal care products. Water Sci. Technol. 2006, 53, 109-117. [CrossRef] [PubMed]

30. Murakami, F.S.; Bernardi, L.S.; Pereira, R.N.; Valente, B.R. Comparative behavior studies of cinnamic acid using isothermal and nonisothermal kinetic methods. Pharm. Chem. J. 2009, 43, 716-720. [CrossRef]

31. Marques, R.R.N.; Sampaio, M.J.; Carrapiço, P.M.; Silva, C.G.; Morales-Torres, S.; Dražić, G.; Faria, J.L.; Silva, A.M.T. Photocatalytic degradation of caffeine: Developing solutions for emerging pollutants. Catal. Today 2013, 209, 108-115. [CrossRef]

32. Wang, Y.; Shi, R.; Lin, J.; Zhu, Y. Significant photocatalytic enhancement in methylene blue degradation of $\mathrm{TiO}_{2}$ photocatalysts via graphene-like carbon in situ hybridization. Appl. Catal. B Environ. 2010, 100, 179-183. [CrossRef]

33. Liu, J.; Liu, R.; Li, H.; Kong, W.; Huang, H.; Liu, Y.; Kang, Z. Au nanoparticles in carbon nanotubes with high photocatalytic activity for hydrocarbon selective oxidation. Dalton Trans. 2014, 43, 12982-12988. [CrossRef] [PubMed]

34. Yang, M.-Q.; Zhang, Y.; Zhang, N.; Tang, Z.-R.; Xu, Y.-J. Visible-light-driven oxidation of primary C-H bonds over CdS with dual co-catalysts graphene and $\mathrm{TiO}_{2}$. Sci. Rep. 2013, 3, 3314-3321. [CrossRef] [PubMed]

35. Zangeneh, H.; Zinatizadeh, A.A.L.; Habibi, M.; Akia, M.; Hasnain Isa, M. Photocatalytic oxidation of organic dyes and pollutants in wastewater using different modified titanium dioxides: A comparative review. J. Ind. Eng. Chem. 2015, 26, 1-36. [CrossRef]

36. Murai, M.; Tamaki, Y.; Furube, A.; Hara, K.; Katoh, R. Reaction of holes in nanocrystalline $\mathrm{TiO}_{2}$ films evaluated by highly sensitive transient absorption spectroscopy. Catal. Today 2007, 120, 214-219. [CrossRef]

37. Beydoun, D.; Amal, R.; Low, G.; McEvoy, S. Role of Nanoparticles in Photocatalysis. J. Nanopart. Res. 1999, 1, 439-458. [CrossRef]

38. Matsunaga, K.; Tanaka, Y.; Toyoura, K.; Nakamura, A.; Ikuhara, Y.; Shibata, N. Existence of basal oxygen vacancies on the rutile $\mathrm{TiO}_{2}$ (110) surface. Phys. Rev. B 2014, 90, 195303. [CrossRef]

39. Nakamura, R.; Okamura, T.; Ohashi, N.; Imanishi, A.; Nakato, Y. Molecular mechanisms of photoinduced oxygen evolution, PL emission, and surface roughening at atomically smooth (110) and (100) $n$ - $\mathrm{TiO}_{2}$ (rutile) surfaces in aqueous acidic solutions. J. Am. Chem. Soc. 2005, 127, 12975-12983. [CrossRef] [PubMed]

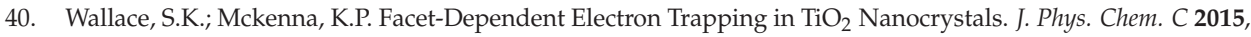
119, 1913-1920. [CrossRef]

41. Kowalski, P.M.; Camellone, M.F.; Nair, N.N.; Meyer, B.; Marx, D. Charge localization dynamics induced by oxygen vacancies on the $\mathrm{TiO}_{2}$ (110) surface. Phys. Rev. Lett. 2010, 105, 146405-146409. [CrossRef] [PubMed]

42. Zuo, F.; Bozhilov, K.; Dillon, R.J.; Le Wang, An; Smith, P.; Zhao, X.; Bardeen, C.; Feng, P. Active facets on titanium(III)-doped $\mathrm{TiO}_{2}$ : An effective strategy to improve the visible-light photocatalytic activity. Angew. Chem. Int. Ed. 2012, 51, 6223-6226. [CrossRef] [PubMed]

43. Ohno, T.; Murakami, N. Murakami. Spatial Separation of Reaction Sites on Rutile $\mathrm{TiO}_{2}$ Nanorod. In Controlled Nanofabrication: Advances and Applications; Liu, R.S., Ed.; Taylor \& Francis: New York, NY, USA, 2012; Volume 2, pp. 17-41.

(C) 2018 by the authors. Licensee MDPI, Basel, Switzerland. This article is an open access article distributed under the terms and conditions of the Creative Commons Attribution (CC BY) license (http:/ / creativecommons.org/licenses/by/4.0/). 

Article

\title{
A Facile Approach for the Synthesis of $\mathrm{Zn}_{2} \mathrm{SnO}_{4} / \mathrm{BiOBr}$ Hybrid Nanocomposites with Improved Visible-Light Photocatalytic Performance
}

\author{
Tiekun Jia ${ }^{1,2, *}$, Ming Liu ${ }^{1}$, Dongsheng Yu ${ }^{1}$, Fei Long ${ }^{2}$, Shuyi $\mathrm{Mo}^{2}$, Zhao Deng ${ }^{3, *}$ and \\ Weimin Wang ${ }^{3}$ \\ 1 School of Materials Science and Engineering, Luoyang Institute of Science and Technology, \\ Luoyang 471023, China; liumingming4455@163.com (M.L.); dongsh_yu@163.com (D.Y.) \\ 2 Guangxi Ministry-Province Jointly-Constructed Cultivation Base for State Key Laboratory of Processing for \\ Non-ferrous Metal and Featured Materials, Guilin University of Technology, Guilin, 541004, China; \\ longf@glut.edu.cn (F.L.); moshuyi@glut.edu.cn (S.M.) \\ 3 State Key Lab of Materials Synthesis and Processing, Wuhan University of Technology, \\ Wuhan 430070, China; wangwm@hotmail.com \\ * Correspondence: tiekunjia@126.com (T.J.); zhaodeng@whut.edu.cn (Z.D.); \\ Tel.: + 86-379-6592-8196 (T.J.); + 86-27-8765-1843 (Z.D.)
}

Received: 25 March 2018; Accepted: 3 May 2018; Published: 9 May 2018

\begin{abstract}
In this study, a novel $\mathrm{Zn}_{2} \mathrm{SnO}_{4} / \mathrm{BiOBr}$ hybrid photocatalyst was prepared via a mild hydrothermal synthesis combined with a chemical deposition method. The morphological structure, chemical composition, crystal structure, and optical properties were comprehensively characterized by a series of measurement techniques. Morphological observation showed that fine $\mathrm{Zn}_{2} \mathrm{SnO}_{4}$ nanoparticles were anchored on the nanoplate surface of a flower-like BiOBr 3D hierarchical structure. The experimental results of UV-vis diffuse reflection spectroscopy revealed that the visible-light absorptive capacity of the $\mathrm{Zn}_{2} \mathrm{SnO}_{4} / \mathrm{BiOBr}$ hybrid photocatalyst was promoted, as compared to that of pure $\mathrm{Zn}_{2} \mathrm{SnO}_{4}$. Evidenced by electro-negativity theoretical calculation, $\mathrm{Zn}_{2} \mathrm{SnO}_{4}$ and $\mathrm{BiOBr}$ possessed matched band edges for accelerating photogenerated charge separation at the interface. The $\mathrm{Zn}_{2} \mathrm{SnO}_{4} / \mathrm{BiOBr}$ hybrid photocatalyst exhibited enhanced photocatalytic performance in the degradation of Rhodamine B (RhB) under visible light irradiation. According to the band energy structure and the experimental results, the enhanced photocatalytic performance was ascribed to the improved visible-light absorptive capacity and the contact interface between $\mathrm{Zn}_{2} \mathrm{SnO}_{4}$ nanoparticles and $\mathrm{BiOBr}$ nanoplates, being able to favor the prompt charge migration and suppress the recombination of photogenerated carriers in the hybrid system.
\end{abstract}

Keywords: nanocomposites; $\mathrm{Zn}_{2} \mathrm{SnO}_{4} / \mathrm{BiOBr}$; visible light; photocatalytic performance

\section{Introduction}

Nowadays, photocatalysis is considered to be an effective and sustainable approach for resolving the disturbing issue of the energy crisis and environmental pollution. Owing to the high electrical conductivity and electron mobility [1-4], $\mathrm{Zn}_{2} \mathrm{SnO}_{4}$ (ZTO) has been confirmed the diversity in the photodegradation of organic contaminants [5-10], the evolution of hydrogen from ethanol solution [11], and the reduction of $\mathrm{CO}_{2}$ to $\mathrm{CH}_{4}$ [12]. For instance, Lou et al. demonstrated the photodegradation of three water-soluble organic dyes, using ZTO nanocrystals as photocatalyst under UV irradiation [5]. Moreover, the photodegradation of rhodamine B (RhB) [6], methyl blue [7,8], methyl orange [9], and direct black 38 azo-dye [10] was successfully achieved over ZTO nanostructured photocatalysts under UV irradiation. Besides these examples, as reported in the previous literature [11], the photocatalytic $\mathrm{H}_{2}$ production from methanol solution was successfully accomplished using a ZTO nanostructured 
material as a photocatalyst under UV irradiation. Despite of the merits mentioned above, ZTO has a wide bandgap $(\sim 3.6 \mathrm{eV})$, leading to the fact that it can only absorb a small portion of the total irradiated natural sunlight. Thus, most of the above mentioned studies on ZTO nanostructured material addressed the enhancement of photocatalytic activity under UV light illumination, owing to its wide band gap. That is to say, the spectral response of bare ZTO nanostructured photocatalysts is still limited to UV region, and the utilization efficiency of solar energy is not desirable for the low portion of UV light in the total solar energy. From another point of view, like other single-component photocatalysts, ZTO also suffers from the fast recombination rate of the photo-generated charge carriers, which is considered to be another critical cause for hindering bare ZTO photocatalysts from acquiring excellent photoactivity. Based on the aforementioned research background, it is particularly essential to design a simple and efficient strategy for achieving visible-light-active ZTO based photocatalysts with high photocatalytic efficiency.

Coupling semiconductor photocatalysts with matched band energy levels has been proven to be an effective strategy for facilitating efficient photogenerated charge separation [12-22]. Owing to its desirable band gap $(2.7 \mathrm{eV})$ and peculiar layered structure constituted by interlacing $\left[\mathrm{Bi}_{2} \mathrm{O}_{2}\right]$ slabs with double bromine slabs, $\mathrm{BiOBr}$ is emerging as a relatively efficient and stable visible-light-activated photocatalyst. As a sensitizer, $\mathrm{BiOBr}$ can extend the visible light response range of wide band gap semiconductors, and separate the photogenerated carriers efficiently. Until now, a series of coupled photocatalysts containing $\mathrm{BiOBr}$, such as, $\mathrm{ZnO} / \mathrm{BiOBr}$ [18], $\mathrm{Ni}_{2} \mathrm{FeO}_{4} / \mathrm{BiOBr}$ [19], $\mathrm{BiPO}_{4} / \mathrm{BiOBr}$ [20], $\mathrm{TiO}_{2} / \mathrm{BiOBr}$ [21], $\mathrm{ZnWO}_{4} / \mathrm{BiOBr}$ [22] have been reported to show improved photocatalytic performance for degrading organic pollutants. According to previous reports, $\mathrm{BiOBr}$ has matched the energy levels of the valence band (VB) and conduction band (CB) with those of ZTO, which provides a theoretical basis for the migration of photoinduced charge carriers in the photocatalytic process. Considering the above mentioned characteristics, $\mathrm{ZTO} / \mathrm{BiOBr}$ hybrid structures are anticipated to possess high photocatalytic efficiency and photostability compared with pure ZTO. To the best of our knowledge, the preparation and investigation on $\mathrm{ZTO} / \mathrm{BiOBr}$ hybrid structure has not been reported.

Herein, we developed a facile approach to fabricate $\mathrm{ZTO} / \mathrm{BiOBr}$ nanocomposites via a hydrothermal synthesis followed by in situ chemical deposition method. According to the determined experimental procedure, a series of $\mathrm{ZTO} / \mathrm{BiOBr}$ hybrid nanocomposites was obtained by loading different amounts of $\mathrm{BiOBr}$ nanoplates. Compared with pure ZTO, the resulting ZTO/BiOBr nanocomposites exhibited wider visible light response range and higher photocatalytic performance toward the degradation of RhB solution. The proposed mechanism of the enhanced photocatalytic performance was discussed based on the experimental results and energy band structure analysis.

\section{Results and Discussion}

The morphology and microstructure of pure $\mathrm{ZTO}$, pure $\mathrm{BiOBr}$, and $1 \mathrm{ZTO} / 1 \mathrm{BiOBr}$ samples were investigated by SEM and TEM images. As displayed in Figure 1a, pure ZTO consisted of abundant fine nanoparticles with sizes ranging from $25-40 \mathrm{~nm}$. From Figure 1b, it is clearly observed that pure BiOBr exhibited flower-like 3D hierarchical structure assembled by substantive nanoplates with thicknesses of 5-8 nm. As for the $1 \mathrm{ZTO} / 1 \mathrm{BiOBr}$ sample (Figure 1c), it can be distinctly observed that fine ZTO nanoparticles stacked onto the nanoplate surface of flower-like BiOBr 3D hierarchical structure. Comparatively, the morphology of $\mathrm{BiOBr}$ was substantially modified after the introduction of ZTO nanoparticles; the size of nanoplates decreased also. Notably, the linked and intercrossed nanoplates endowed the $1 \mathrm{ZTO} / 1 \mathrm{BiOBr}$ sample with an exceptive structure, which resulted in the formation of nano- and macro-pores. The existence of pores and the interface between ZTO and BiOBr are favorable for visible light harvesting and the transfer of photoinduced electron-hole pairs. 

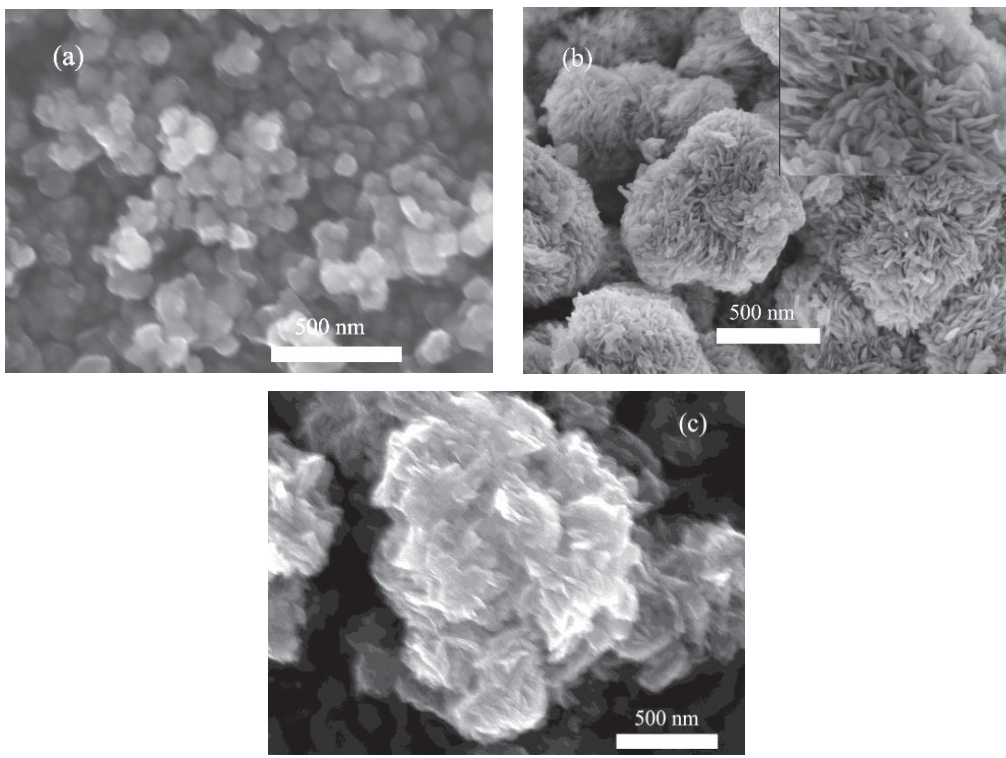

Figure 1. FESEM images of (a) pure ZTO; (b) pure BiOBr; and (c) $1 \mathrm{ZTO} / 1 \mathrm{BiOBr}$.

Figure 2a presents a typical TEM image of the $1 \mathrm{ZTO} / 1 \mathrm{BiOBr}$ sample, having 3D flower-like hierarchical structure with ZTO nanoparticles growing on the surface of $\mathrm{BiOBr}$ nanoplate. Clear and ordered lattice fringes with an interplanar distance of $0.35 \mathrm{~nm}$ are indexed to be (101) planes of $\mathrm{BiOBr}$ from Figure $2 b$, indicating high crystallinity. Another lattice fringe with $d$ value of $0.26 \mathrm{~nm}$ belongs to (311) plane of ZTO. The above microstructural observation demonstrated that BiOBr nanoplates accreted onto the surface of ZTO nanoparticles, and the intimate contact at the heterojunction, was accomplished along the interface of ZTO nanoparticles and $\mathrm{BiOBr}$ nanoplates. Figure $2 \mathrm{c}$ shows the typical high angle annular dark field (HAADF)-scanning transmission electron microscope (STEM) image of the $1 \mathrm{ZTO} / 1 \mathrm{BiOBr}$ sample. The result of elemental analysis validated the existence of $\mathrm{Zn}, \mathrm{Sn}$, $\mathrm{O}, \mathrm{Bi}$ and $\mathrm{Br}$, revealing a uniform distribution of the above elements throughout the hybrid system as well. Additionally, according to the Brunauer-Emmett-Teller (BET) method, the specific surface area of the $\mathrm{ZTO}$ and $1 \mathrm{ZTO} / 1 \mathrm{BiOBr}$ samples can be estimated to be $69.5 \mathrm{~m}^{2} / \mathrm{g}$ and $46.4 \mathrm{~m}^{2} / \mathrm{g}$ respectively, indicating that the BET surface area of the $1 \mathrm{ZTO} / 1 \mathrm{BiOBr}$ sample exhibits a slight decrease compared with that of pure ZTO photocatalyst.
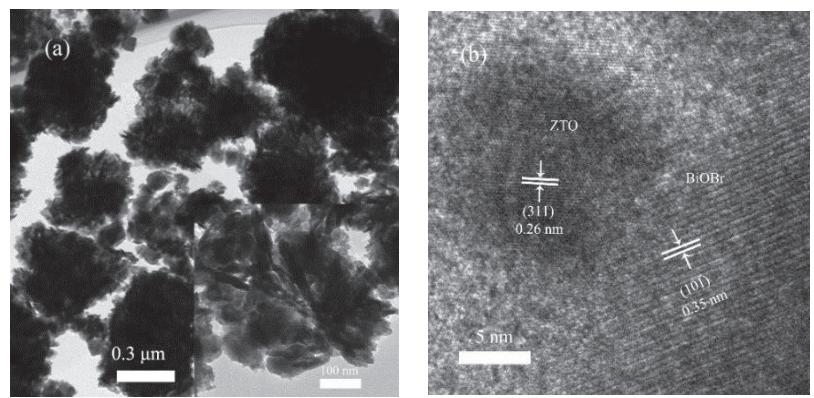

Figure 2. Cont. 


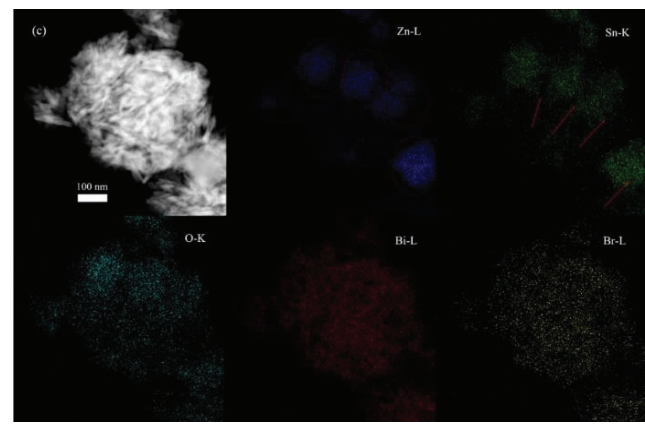

Figure 2. (a) TEM image and (b) HRTEM image of $1 \mathrm{ZTO} / 1 \mathrm{BiOBr}$; and (c) the corresponding EDS mapping of $\mathrm{Zn}, \mathrm{Sn}, \mathrm{O}, \mathrm{Bi}$ and $\mathrm{Br}$ elements.

Figure 3 presents the XRD patterns of $\mathrm{ZTO}, \mathrm{BiOBr}$ and $\mathrm{ZTO} / \mathrm{BiOBr}$ nanocomposites with different mass ratios. All the characteristic diffraction peaks of bare $\mathrm{ZTO}$ can be identified to the cubic $\mathrm{Zn}_{2} \mathrm{SnO}_{4}$ (JCPDS 74-2184). Four intense diffraction peaks at $2 \theta$ angles of $17.6^{\circ}, 28.9^{\circ}, 34.1^{\circ}, 41.4^{\circ}$ and $60.1^{\circ}$ are in high accordance with (111), (220), (311), (400) and (440) planes of ZTO, respectively. For bare BiOBr sample, six characteristic diffraction peaks correspond respectively to the planes of (001), (011), (012), (110), (020) and (212), which agree well with the standard card of the tetragonal phase of BiOBr (JCPDS 09-0393). Two sets of diffraction peaks resulting from $\mathrm{ZTO}$ and $\mathrm{BiOBr}$ are observable in the $\mathrm{ZTO} / \mathrm{BiOBr}$ spectra, indicating the coexistence of both ZTO and BiOBr phases in the nanocomposites. Moreover, the intensities of $\mathrm{BiOBr}$ tend to be greater with the decrease of ZTO. The grain size of the BiOBr and ZTO crystallites was calculated by means of the Debye-scherrer formula from the broadening of the (101) and (311) XRD reflections at $2 \theta$ of $25.304^{\circ}$ and $34.319^{\circ}$ respectively, after $\mathrm{K} \alpha_{2}$ correction. Full width at half-maximum (FWHM) values was obtained using the Highscore software program as $0.56^{\circ}$ and $0.199^{\circ}$. The calculated particle sizes for the $\mathrm{BiOBr}$ and $\mathrm{Zn}_{2} \mathrm{SnO}_{4}$ crystallites are $14.4 \mathrm{~nm}$ and $41.3 \mathrm{~nm}$ respectively. The XRD result revealed that the obtained samples are of high crystallinty, agreeing well with that of TEM and HRTEM analysis. Additionally, no other diffraction peaks from other impurities are found in the $\mathrm{ZTO} / \mathrm{BiOBr}$ nanocomposites, suggesting that the as-prepared samples are rather pure.

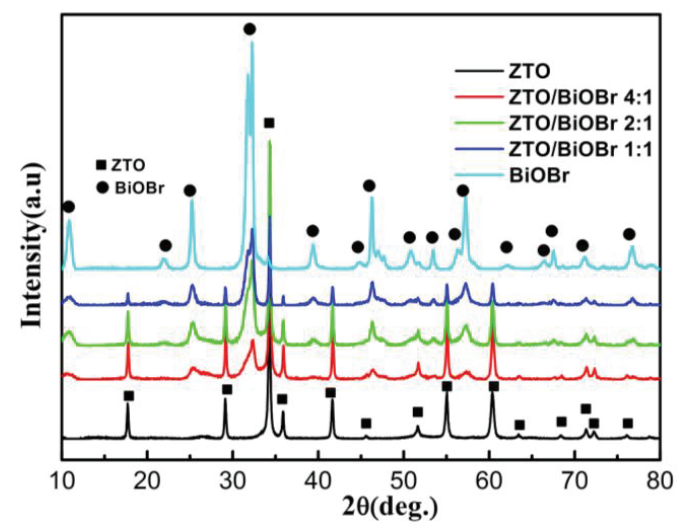

Figure 3. XRD patterns of ZTO, $\mathrm{BiOBr}$, and $\mathrm{ZTO} / \mathrm{BiOBr}$ nanocomposites.

Figure 4a shows the XPS survey spectrum of the 1ZTO/1BiOBr sample. From Figure 4a, we can observe that the as-obtained $1 \mathrm{ZTO} / 1 \mathrm{BiOBr}$ sample is composed of $\mathrm{Sn}, \mathrm{Zn}, \mathrm{O}, \mathrm{Bi}$ and $\mathrm{Br}$. High resolution 
XPS spectra of Zn 2p, Sn 3d, Bi 4f, Br 3d and O 1s are presented in Figure 4b-f. From Figure 4b, two typical peaks located at 1020.5 and $1043.4 \mathrm{eV}$ for bare ZTO sample correspond to $\mathrm{Zn} 2 \mathrm{p}_{3 / 2}$ and $\mathrm{Zn}$ $2 \mathrm{p}_{1 / 2}$ respectively. When $\mathrm{BiOBr}$ nanoflakes were introduced into the composite system to form the heterojunction, the $Z n 2 p_{1 / 2}$ and $Z n 2 p_{3 / 2}$ peaks shifted slightly toward higher binding energies by ca. $0.2 \mathrm{eV}$. Double peaks located at 485.9 and $494.3 \mathrm{eV}$ for bare ZTO sample (Figure $4 \mathrm{c}$ ) are respectively attributed to $S n 3 d_{5 / 2}$ and $S n 3 d_{3 / 2}$. Similarly, the $S n 3 d_{5 / 2}$ and $S n 3 d_{3 / 2}$ peaks of the $1 Z T O / 1 B i O B r$ sample exhibited an obvious shift toward high binding energies by ca. $0.5 \mathrm{eV}$ in comparison with those of bare ZTO. From Figure 4d, we can find that the peak position of $\mathrm{O} 1 \mathrm{~s}$ spectra for the $1 \mathrm{ZTO} / 1 \mathrm{BiOBr}$ sample is different from the counterparts of bare $\mathrm{ZTO}$ and $\mathrm{BiOBr}$, which is probably due to the presence of hybrid bonds of Bi-O, $\mathrm{Zn}-\mathrm{O}$ and $\mathrm{Sn}-\mathrm{O}$ in the nanocomposites. In terms of $\mathrm{Bi} 4 \mathrm{f}\left(158.9 \mathrm{eV}\right.$ for $\mathrm{Bi} 4 \mathrm{f}_{7 / 2}$ and $164.3 \mathrm{eV}$ for $\left.\mathrm{Bi} 4 \mathrm{f}_{5 / 2}\right)$ and $\mathrm{Br} 3 \mathrm{~d}\left(68.1 \mathrm{eV}\right.$ for $\mathrm{Br} 3 \mathrm{~d}_{5 / 2}$ and $68.8 \mathrm{eV}$ for $\left.\mathrm{Br}_{3 \mathrm{~d}_{3 / 2}}\right)$ for the $1 \mathrm{ZTO} / 1 \mathrm{BiOBr}$ sample (Figure $4 \mathrm{e}, \mathrm{f})$, the binding energies are a bit lower than the corresponding counterparts for pure ZTO and BiOBr. The phenomenon of the as-mentioned binding energy shift is most likely a result of the strong interaction between $\mathrm{ZTO}$ NPs and BiOBr nanoplates. From a theoretical point of view, the reinforcement of binding energies implies a weakened electron screening effect caused by decreased electron concentration, whereas the increase in electron concentration results in a decrease of binding energies, owing to the improved electron screening effect [23-26]. Based on the above demonstration, we think that the higher and lower shifts are respectively attributed to the decreased electron concentration of ZTO NPs and increased electron concentration of BiOBr nanoplates, due to the strong interaction between the ZTO NPs and BiOBr nanoplates, assisted by the interfacial charge carrier migration.
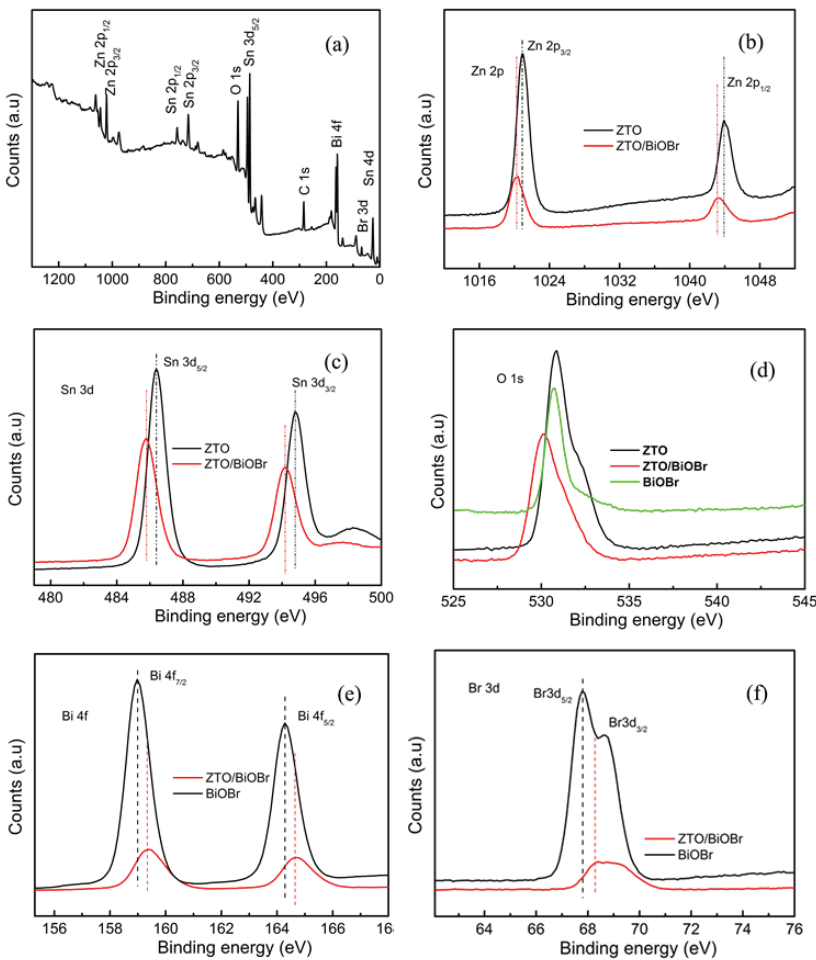

Figure 4. XPS spectra of pure ZTO, BiOBr, and 1ZTO/1BiOBr; (a) Survey spectrum; (b) Zn 2p; (c) Sn 3d; (d) O 1s; (e) Bi 4f; (f) Br 3d. 
In order to characterize the optical absorption properties, the obtained diffuse reflection spectra (DRS) are presented in Figure 5. The absorption edge was approximately located at the wavelength of $350 \mathrm{~nm}$ for pure ZTO photocatalyst, as displayed in Figure 5a. In addition, a steep slope was found for the absorption curve of pure ZTO, indicating the feature of strong UV light absorption capacity. Comparably, BiOBr exhibited visible light absorption with wavelengths of below $450 \mathrm{~nm}$. After hybridization of ZTO nanoparticles with $\mathrm{BiOBr}$ nanoplates, an evident redshift was seen from the absorption edge of $\mathrm{ZTO} / \mathrm{BiOBr}$ nanocomposites, as compared with pure ZTO, suggesting that $\mathrm{BiOBr}$ has the functionality of a visible light sensitizer. Therefore, we can infer that more photon efficiency will be acquired in a ZTO/BiOBr system, resulting in the generation of more photoinduced carriers for enhancing photocatalytic performance. Moreover, ZTO/BiOBr hybrid nanocomposites possessed enhanced UV light absorption, indicating the result of an absorbance superposition of the ZTO and BiOBr components.
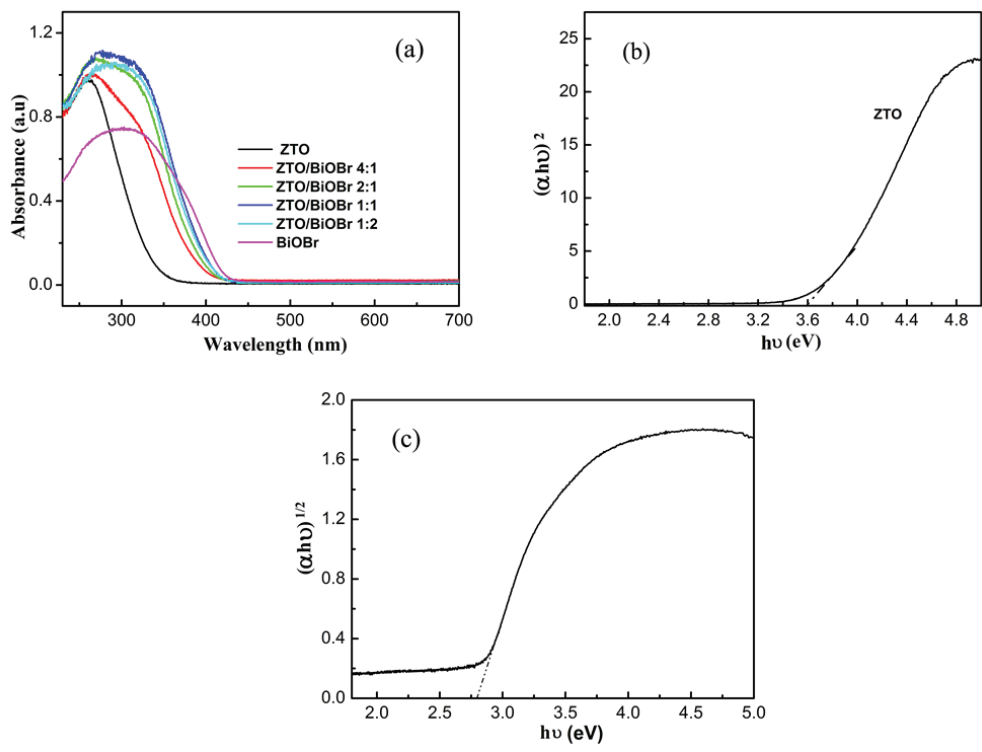

Figure 5. (a) UV-vis absorbance spectra of pure $\mathrm{ZTO}, \mathrm{BiOBr}$, and $\mathrm{ZTO} / \mathrm{BiOBr}$ nanocomposites; (b) the derived plot of $(\alpha \mathrm{h} v)^{2}$ versus $\mathrm{h} v$ from the absorption spectrum for pure ZTO; (c) the derived plot of $(\alpha \mathrm{h} v)^{1 / 2}$ versus $\mathrm{h} v$ from the absorption spectrum for pure BiOBr.

The band gap energy can be determined according to the empirical equation, as follows: $(\alpha \mathrm{h} v)^{2 / \mathrm{n}}=\mathrm{A}\left(\mathrm{h} v-\mathrm{E}_{\mathrm{g}}\right)$ [27]. In the empirical equation, $\alpha, \mathrm{h} v, \mathrm{E}_{\mathrm{g}}$ and $\mathrm{A}$ correspond to the absorption coefficient, photon energy, band-gap energy, and a constant. The $\mathrm{n}$ values are equal to 1 for ZTO (direct semiconductor) and 4 for $\mathrm{BiOBr}$ (indirect semiconductor), respectively, owing to their intrinsic characteristic of electronic transition. After calculation, the $\mathrm{E}_{\mathrm{g}}$ values of pure $\mathrm{ZTO}$ and $\mathrm{BiOBr}$ were respectively estimated to be $3.58 \mathrm{eV}$ and $2.79 \mathrm{eV}$ from the corresponding plots of hv against $(\alpha \mathrm{h} v)^{2}$ and $h v$ against $(\alpha h v)^{1 / 2}$ (Figure $\left.5 b, c\right)$. Moreover, the band edge positions of ZTO and BiOBr can be determined through the empirical formulas [28] as follows:

$$
\begin{gathered}
\mathrm{E}_{\mathrm{CB}}=\mathrm{X}-\mathrm{E}_{\mathrm{e}}-0.5 \mathrm{E}_{\mathrm{g}} \\
\mathrm{E}_{\mathrm{VB}}=\mathrm{E}_{\mathrm{CB}}+\mathrm{E}_{\mathrm{g}}
\end{gathered}
$$


$E_{C B}$ and $E_{V B}$ respectively represent the conduction band $(C B)$ and valence band potential. $X$ belongs to the electronegativity of $\mathrm{ZTO}$ and $\mathrm{BiOBr}$, whose values are 7.0 and $6.18 \mathrm{eV}$ respectively. $\mathrm{E}_{\mathrm{g}}$ and $\mathrm{E}_{\mathrm{e}}$ refer to the band gap energy and energy of free electrons on the hydrogen scale $(\sim 4.5 \mathrm{eV})$ respectively. After calculation, the $\mathrm{E}_{\mathrm{CB}}$ values of $\mathrm{ZTO}$ and $\mathrm{BiOBr}$ were determined to be 0.71 and $0.28 \mathrm{eV}$, while the $\mathrm{E}_{\mathrm{VB}}$ values of $\mathrm{ZTO}$ and $\mathrm{BiOBr}$ were respectively determined to be 4.3 and $3.07 \mathrm{eV}$.

Figure 6a shows the plots of absorbance with respect to irradiation time in the presence of pure ZTO. A stepwise decrease was found from the intensity of the absorption band at $554 \mathrm{~nm}$, indicating that RhB solution was gradually photodegraded over ZTO photocatalyst. Additionally, a slight hypsochromic shift deviating from characteristic absorption band of RhB was also found, with prolonged illumination time during the photodegradation process, agreeing well with previous report [29]. Figure $6 \mathrm{~b}$ displays the photodegradation activities of RhB over different photocatalysts. As seen in Figure 6b, pure ZTO and BiOBr exhibited low photocatalyitic performance, with only about $60 \%$ and $69 \%$ of the RhB photodegradation rate after $70 \mathrm{~min}$ of visible light illumination. After hybridizing $\mathrm{ZTO}$ with $\mathrm{BiOBr}$, the photocatalytic performance of $\mathrm{ZTO} / \mathrm{BiOBr}$ nanocomposites was obviously improved, as compared with that of single component photocatalyst. Specifically, the photodegradation rate of $\mathrm{RhB}$ continuously increased with an increase in $\mathrm{BiOBr}$ component, until the mass ratio of $\mathrm{BiOBr}$ reached up to $50 \%$. The photodegradation rate of $\mathrm{RhB}$ over $\mathrm{ZTO} / \mathrm{BiOBr}$ nanocomposites decreased steeply, relative to the maximum value $(\sim 96 \%)$, when the mass ratio of $\mathrm{BiOBr}$ exceeded the critical value of $50 \%$. This phenomenon may be attributed to the cooperative roles between ZTO nanoparticles and $\mathrm{BiOBr}$ nanoplates exerting a remarkable influence on the charge carrier migration between two semiconductors. At a low mass ratio of $\mathrm{BiOBr}$, the effect of the charge separation was not notable because of an insufficiency of BiOBr. Nevertheless, the introduction of an excessive amount of BiOBr affected the intimate contact between BiOBr nanoplates and ZTO nanoparticles, and the efficient charge carrier separation was hindered correspondingly when increasing $\mathrm{BiOBr}$ mass ratio beyond the optimum value (50\%). Thus, an appropriate mass ratio of $\mathrm{BiOBr}$ is pivotal to modulate the photodegradation behavior of $\mathrm{ZTO} / \mathrm{BiOBr}$ nanocomposites.
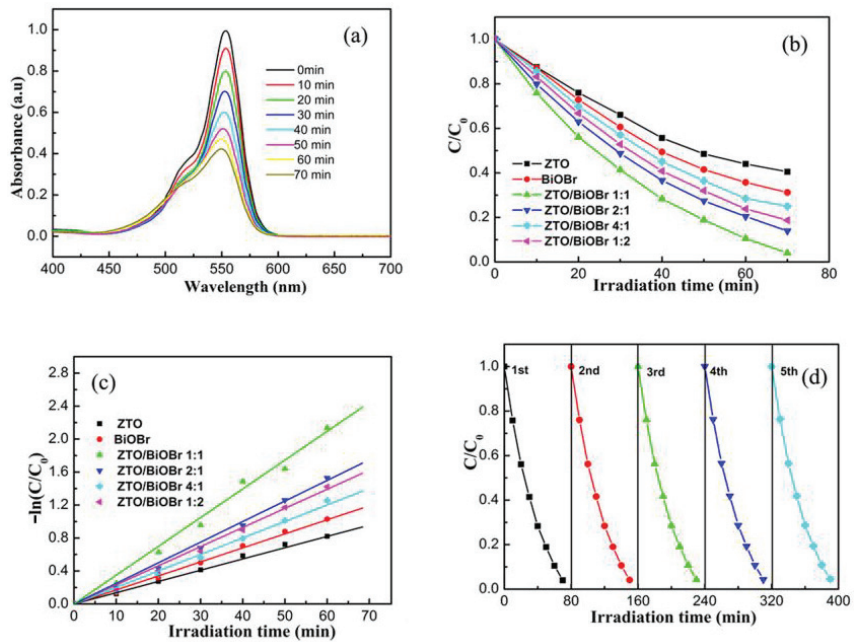

Figure 6. (a) Time dependent absorption spectra of RhB aqueous solution over pure ZTO; (b) the photodegradation performance of $\mathrm{RhB}$ solution over photocatalysts of pure $\mathrm{ZTO}, \mathrm{BiOBr}$, and $\mathrm{ZTO} / \mathrm{BiOBr}$ nanocomposites; (c) the plots of $-\ln \left(\mathrm{C} / \mathrm{C}_{0}\right)$ versus irradiation time for $\mathrm{RhB}$ degradation over pure $\mathrm{ZTO}, \mathrm{BiOBr}$, and $\mathrm{ZTO} / \mathrm{BiOBr}$ nanocomposites; (d) cycling performance of the photodegradation of RhB solution over $1 \mathrm{ZTO} / 1 \mathrm{BiOBr}$. 
Considering that the photolysis of $\mathrm{RhB}$ process approximately obeys a pseudo-first-order kinetic equation of $-\ln \left(C / C_{0}\right)=k t$, in which $C$ and $C_{0}$ refer to the RhB concentration at time $t(\min )$ and $\mathrm{t}=0 ; \mathrm{k}\left(\mathrm{min}^{-1}\right)$ represents the apparent reaction rate constant, the plots of $-\ln \left(\mathrm{C} / \mathrm{C}_{0}\right)$ with respect to irradiation time are depicted in Figure $6 \mathrm{c}$. The $\mathrm{k}$ value for RhB photodegradation over different photocatalysts followed the order of 1:1 $>$ 2:1 $>1: 2>4: 1>\mathrm{BiOBr}>\mathrm{ZTO}$. Particularly, the ZTO/BiOBr nanocomposites with mass ratio of $1: 1$ possess the highest $\mathrm{k}$ value $\left(0.037 \mathrm{~min}^{-1}\right)$, which is almost 2.7 and 2.1 times greater than that of pure $\mathrm{ZTO}$ and $\mathrm{BiOBr}$ respectively. The above result was consistent with the conclusions drawn from photocatalytic degradation plots. Taking consideration into practical applications, the stability of the $1 \mathrm{ZTO} / 1 \mathrm{BiOBr}$ photocatalyst was investigated by cyclic photodegradation experiments under identical conditions. From Figure $6 \mathrm{~d}$, we can observe that there was no evident deterioration in the photcatalytic performance after five cycle runs. The photodegradation rate even exceeded $93 \%$ after five cycles, suggesting that the $1 \mathrm{ZTO} / 1 \mathrm{BiOBr}$ photocatalyst takes on adequate stability and long life for degrading pollutants.

To definitively determine the role of the main active species, such as $\bullet \mathrm{OH}, \bullet \mathrm{O}_{2}{ }^{-}$, and $\mathrm{h}^{+}$, in RhB photodegradation process, different scavengers of EDTA disodium $\left(\mathrm{Na}_{2}\right.$-EDTA $\left.4 \mathrm{mmol} \mathrm{L}^{-1}\right)$, tert-butyl-alcohol $\left(t-\mathrm{BuOH} 4 \mathrm{mmol} \mathrm{L}^{-1}\right)$, and benzoquinone (BQ $4 \mathrm{mmol} \mathrm{L}^{-1}$ ) were employed as quenchers to capture $\mathrm{h}^{+}, \bullet \mathrm{OH}$, and $\bullet \mathrm{O}_{2}{ }^{-}$, respectively. Figure 7 displays the effect of various quenchers on the photodegradation of $\mathrm{RhB}$ after $70 \mathrm{~min}$ of visible light irradiation over a $1 \mathrm{ZTO} / 1 \mathrm{BiOBr}$ photocatalyst. Only a bit loss of photodegradation rate was found for the $1 \mathrm{ZTO} / 1 \mathrm{BiOBr}$ photocatalyst after the introduction of $\mathrm{BQ}$ or $\mathrm{Na}_{2}-\mathrm{EDTA}$, whereas the introduction of $t-\mathrm{BuOH}$ gave rise to a significant decrease of the photodegradation rate, demonstrating that $\bullet \mathrm{OH}$ acted as the main oxidative species, and dominated the photodegradation of $\mathrm{RhB}$ over the $\mathrm{ZTO} / \mathrm{BiOBr}$ nanocomposites under visible light irradiation.

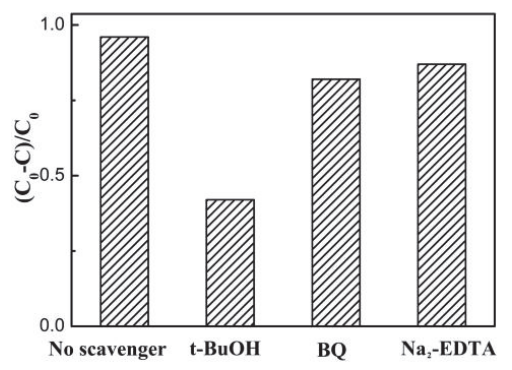

Figure 7. Effect of various scavengers on the visible light photocatalytic performance of $1 \mathrm{ZTO} / 1 \mathrm{BiOBr}$ toward the degradation of RhB.

As previous studies have documented [30,31], photoluminescence (PL) spectra of semiconductor photocatalysts are intimately related to the migration, transfer, and the recombination rate of photo-induced $\mathrm{e}_{\mathrm{CB}}{ }^{-} \mathrm{h}_{\mathrm{VB}}{ }^{+}$pairs. Theoretically, the PL emission originates from the recombination of charge carriers, and the intensity of PL emission peaks is approximately proportional to the recombination amount of the excited $\mathrm{e}_{\mathrm{CB}}{ }^{-} \mathrm{h}_{\mathrm{VB}}{ }^{+}$pairs. In other words, lower intensity of the PL emission peak means that the higher the separation efficiency of photo-induced $\mathrm{e}_{\mathrm{CB}}{ }^{-}-\mathrm{h}_{\mathrm{VB}}{ }^{+}$pairs is available; accordingly, high photodegradation performance will be achieved. Based on the above, PL spectra of the fabricated photocatalysts were measured, and the results are presented in Figure 8a. The strong emission peak located about $370 \mathrm{~nm}$ corresponds to the band-band PL phenomenon of the photo-induced charge carriers for ZTO. Two weak emission peaks located at about $420 \mathrm{~nm}$ and $480 \mathrm{~nm}$ could be attributed to either to oxygen vacancies or to other kinds of defects, e.g., tin vacancies and $\mathrm{O}_{2}$ interstitials [32,33]. Among these photocatalysts, pure ZTO showed the strongest PL emission intensity, suggesting a high charge carrier recombination rate. As for $\mathrm{ZTO} / \mathrm{BiOBr}$ nanocomposites, the PL 
emission peak intensity decreased continuously, indicating that the recombination of photo-generated charge carriers was effectively restricted due to the efficient charge injection between the two components. The $1 \mathrm{ZTO} / 1 \mathrm{BiOBr}$ photocatalyst showed the weakest recombination PL intensity compared to other photocatalysts, revealing the smallest recombination rate of photo-induced $\mathrm{e}_{\mathrm{CB}}{ }^{-} \mathrm{h}_{\mathrm{VB}}{ }^{+}$pairs in the hybrid system. The increased separation efficiency would provide more opportunities for photogenerated carriers to form active radicals involved into the photodegradation of RhB. The transient photocurrent test was also performed to examine the separation and transfer of photo-excited holes-electrons pairs over different photocatalysts. As displayed in Figure $8 \mathrm{~b}$, the photocurrents followed the order of $1 \mathrm{ZTO} / 1 \mathrm{BiOBr}>\mathrm{BiOBr}>\mathrm{ZTO}$, suggesting that $1 \mathrm{ZTO} / 1 \mathrm{BiOBr}$ photocatalyst has a more efficient separation and migration efficiency of the photoexcited carriers. Accordingly, the result of the photocurrent is in good agreement with that of PL spectra.
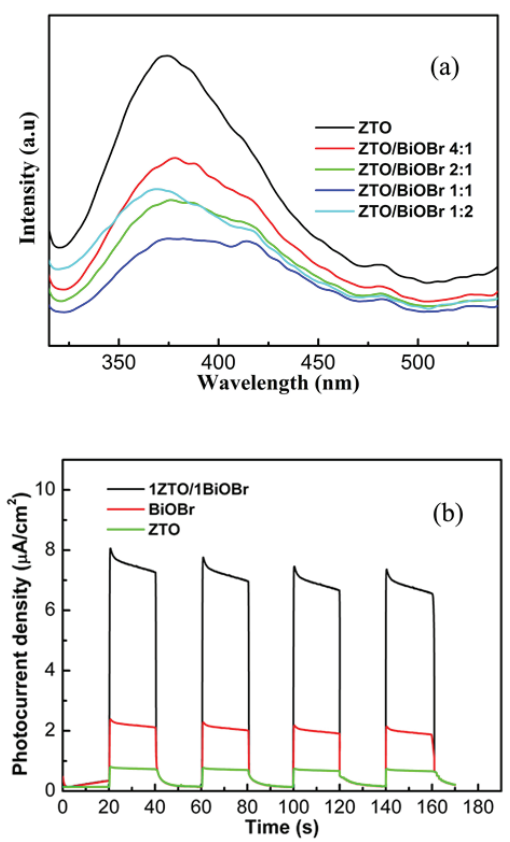

Figure 8. (a) PL spectra of pure $\mathrm{ZTO}, \mathrm{BiOBr}$, and $\mathrm{ZTO} / \mathrm{BiOBr}$ nanocomposites; (b) Photocurrents of pure $\mathrm{ZTO}, \mathrm{BiOBr}$, and $1 \mathrm{ZTO} / 1 \mathrm{BiOBr}$ electrodes under visible light irradiation $(\lambda>420 \mathrm{~nm})$.

As demonstrated above, the $1 \mathrm{ZTO} / 1 \mathrm{BiOBr}$ photocatalyst showed the greatest separation efficiency and highest photocatalytic performance. In order to disclose the enhancement of the photocatalytic performance of $\mathrm{ZTO} / \mathrm{BiOBr}$ nanocomposites, a possible photocatalytic mechanism is proposed and illustrated in Figure 9. Under visible light illumination, $\mathrm{BiOBr}$ can be easily excited to produce electron-hole pairs, owing to its appropriate band gap. For ZTO, a small portion of electrons located at the VB position of a shallow energy level is able to transfer to the CB portion, due to the existence of defects, subsequently, generated electron-hole pairs are also achieved on the surface of ZTO. On the basis of the calculation result, the two components of ZTO (n-type) and $\mathrm{BiOBr}$ ( $p$-type) have well-matched energy band structures. After contact, $p$ - $n$ junctions are formed along the interface of the two components. The arrangement of VB and CB energy band levels induced by the potentials' difference leads to the formation of an inner electric field with the direction from $n$-type ZTO to $p$-type BiOBr, promoting different Femi levels to reach an equilibrium between the two components. As depicted in Figure 9, the $\mathrm{CB}$ position of $\mathrm{BiOBr}$ is more negative than that of 
ZTO, so the photogenerated electrons in the $\mathrm{CB}$ of $\mathrm{BiOBr}$ are capable of transferring to the $\mathrm{CB}$ of $\mathrm{ZTO}$, based on the charge separation way. Simultaneously, the VB position of ZTO is more positive than that of BiOBr; thus, some available holes migrate from the surface of VB of ZTO to that of VB of BiOBr. Based on the above analysis, photogenerated electron-hole pairs are effectively separated by assisting the functionality of the inner electric field. Furthermore, the VB potential of of $\mathrm{BiOBr}(3.07 \mathrm{eV}$ vs. NHE) is more positive than that of $\mathrm{OH}^{-} / \bullet \mathrm{OH}(1.99 \mathrm{eV})[34,35]$; thus, more photogenerated holes can react with $\mathrm{OH}^{-}$to form $\bullet \mathrm{OH}$, affecting the oxidation reaction of the RhB molecules. This result is highly consistent with the conclusion of the trapping experiment, i.e., that $\mathrm{OH}$ played a dominant role in the oxidation reaction process.
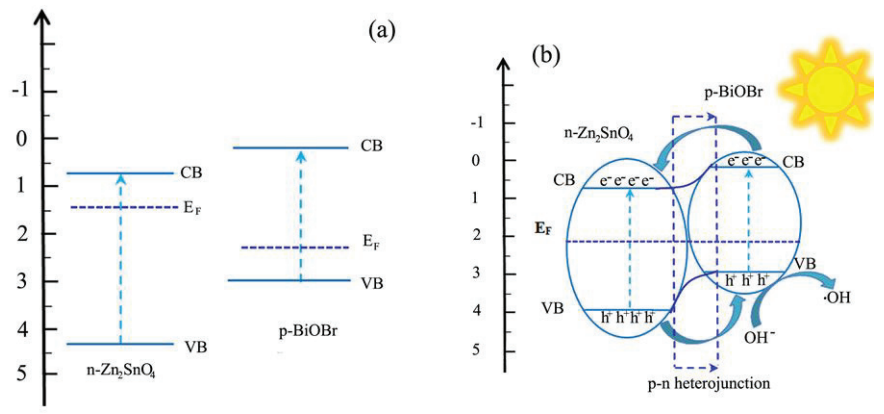

Figure 9. Schematic illustration of the energy band structures (a) for separate phases and (b) after the formation of $p$ - $n$ heterojunction of ZTO and BiOBr.

\section{Experimental Section}

\subsection{Materials}

All chemicals, including tin (IV) chloride penthydrate $\left(\mathrm{SnCl}_{4} \cdot 5 \mathrm{H}_{2} \mathrm{O}\right)$, zinc acetate dehydrate $\left(\mathrm{Zn}\left(\mathrm{CH}_{3} \mathrm{COO}\right)_{2} \cdot 2 \mathrm{H}_{2} \mathrm{O}\right)$, sodium hydroxide $(\mathrm{NaOH})$, bismuth nitrate pentahydrate $\left(\mathrm{Bi}\left(\mathrm{NO}_{3}\right)_{3} \cdot 5 \mathrm{H}_{2} \mathrm{O}\right)$, potassium bromide $(\mathrm{BiOBr})$, and rhodamine $\mathrm{B}(\mathrm{RhB})$ were purchased from Sinopharm Chemical Reagent CO., Ltd., Shanghai, China, and used as received.

\subsection{Synthesis $\mathrm{Zn}_{2} \mathrm{SnO}_{4}$ Nanoparticles (ZTO NPs)}

ZTO NPs were prepared via a simple hydrothermal synthesis route; the detailed procedure was already described in our previous studies [8]. Briefly, after the hydrothermal treatment, a white precipitate was collected, centrifuged and washed repeatedly with deioned water and ethanol respectively, followed by drying at $60{ }^{\circ} \mathrm{C}$ for $12 \mathrm{~h}$.

\subsection{Synthesis ZTO/BiOBr Nanocomposites}

Typically, ZTO/BiOBr nanocomposites were synthesized via a facile in situ precipitation method. $2 \mathrm{mmol}$ of $\mathrm{KBr}$ was dissolved into $60 \mathrm{~mL}$ deionized water under vigorous stirring and formed a transparent solution; then a certain amount of ZTO NPs was completely dispersed into solution containing $\mathrm{KBr}$ under vigorous magnetic stirring, followed by ultrasonic treatment for $30 \mathrm{~min}$.

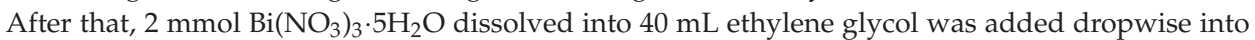
the previous suspension under constant stirring. Subsequently, the mixture was continuously stirred for another $3 \mathrm{~h}$ at $40^{\circ} \mathrm{C}$ to make the precipitation reaction complete. After centrifuging and washing with deioned water and ethanol repeatedly, the resulting product was dried at $60{ }^{\circ} \mathrm{C}$ in an oven overnight. By varying amount of ZTO NPs, a series of ZTO/BiOBr nanocomposites with mass ratios of 4:1, 2:1, and 1:1, 1:2 (denoted as 4ZTO/1BiOBr, 2ZTO/1BiOBr, 1ZTO/1BiOBr and1ZTO/2BiOBr) 
was obtained via the similar synthetic process. For comparison, bare $\mathrm{BiOBr}$ was also prepared by the similar procedure described above without the addition of ZTO NPs.

\subsection{Characterization}

Morphological observation and microstructural analysis was taken on a JEM 2100F transmission electron microscope (JEOL Ltd., Tokyo, Japan) and a Hitachi S-4800 field emission scanning electron microscope (Hitachi, Tokyo, Japan). The crystalline structure identification was accomplished on a D8 Advance X-ray diffractometer (Bruker, Billerica, MA, USA) with a $\mathrm{Cu} K \alpha$ source $(\lambda=0.15406 \mathrm{~nm}$ ). The XRD measurement was performed at $40 \mathrm{kV}$ and $40 \mathrm{~mA}$ in the range of $10^{\circ}-80^{\circ}$. The surface composition was analyzed by X-ray photoelectron spectroscopy (XPS) spectra on an ESCALAB 250Xi spectrometer (Thermo Fisher Scientific, NewYork, NY, USA) with a monochromatic Al-K $\alpha$ radiation source. UV-vis diffuse reflectance spectra and room temperature photoluminescence (PL) spectra were recorded on a TU 1901 UV-vis spectrophotometer (Puxi, Beijing, China) with $\mathrm{BaSO}_{4}$ as reference and a LS55 fluorescence spectrophotometer (PE, Waltham, MA, USA) with an excitation wavelength of $310 \mathrm{~nm}$, respectively. The Brunauer-Emmett-Teller (BET) specific surface area of the as-prepared pure ZTO and $1 \mathrm{ZTO} / \mathrm{BiOBr}$ samples was measured on a Quantachrome NOVA 2000e sorption analyzer.

\subsection{Photocatalytic Experiments}

The process of the photodegradation test was demonstrated in our previous studies [16,29,36,37]. In short, two daylight lamps $(60 \mathrm{~W}, \lambda \geq 420 \mathrm{~nm}$ ) were designated as the visible light source for triggering the photodegration reaction of RhB. In a typical run, a thin layer of film (100 $\mathrm{mg}$ photocatalyst) was dispersed into $40 \mathrm{~mL} \mathrm{RhB}$ aqueous solution $\left(1.0 \times 10^{-5} \mathrm{M}\right)$. After a certain interval of visible light illumination, the reacted solution treated by centrifuging was analyzed by using an UV-vis spectrophotometer at its characteristic absorbance wavelength of $554 \mathrm{~nm}$. The $\mathrm{C} / \mathrm{C}_{0}$ ratios of the $\mathrm{RhB}$ concentrations were employed to evaluate the degradation efficiency, in which $\mathrm{C}$ represented the concentration at a certain irradiation time, while $\mathrm{C}_{0}$ was the initial concentration after adsorption-desorption equilibrium.

\subsection{Photocatalytic Measurements}

Transient photocurrents of the prepared photocatalysts were performed on an electrochemical workstation (CHI660E, Chenhua Instruments Co., Shanghai, China) using a standard three electrode system with a Pt wire as the counter electrode, a saturated $\mathrm{Ag} / \mathrm{AgCl}$ electrode as the reference electrode, and the as-prepared photocatalysts as the working electrode, respectively. The detailed procedure of the measurement was reported in our previous study [38].

\section{Conclusions}

In summary, $\mathrm{ZTO} / \mathrm{BiOBr}$ hybrid nanocomposites have been successfully constructed via a facile approach. The introduction of $\mathrm{BiOBr}$ resulted in the establishment of the contact interface of $\mathrm{Zn}_{2} \mathrm{SnO}_{4} / \mathrm{BiOBr}$ heterojunctions that endowed the photocatalyst with an improved light harvesting capacity, high efficiency of photogenerated charge separation, as well as stronger oxidation ability. $\mathrm{Zn}_{2} \mathrm{SnO}_{4} / \mathrm{BiOBr}$ hybrid photocatalysts displayed enhanced photocatalytic performance and excellent anti-photocorrosion toward the photodegradation of RhB under visible light illumination. This study will open up a new way of constructing novel hybrid photocatalysts with efficient visible-light phtocatalytic activity for use in the fields of environmental remediation and hydrogen energy production.

Author Contributions: T.J. conceived and designed the experiments; M.L. and D.Y. carried out the synthetic experiment and photo-catalytic performance of the as-prepared samples; F.L. and S.M. measured the as-prepared samples; Z.D. and W.W. provided precise instruction and analyzed the data. T.J. wrote the paper. 
Funding: The authors express grateful thanks to the National Natural Science Foundation of China (Grant U1304520), Education Department of Henan Province for the fund support (18A 430020), Henan Provincial Natural Science Foundation (182300410252), and the Open Fund of Guangxi Ministry-Province Jointly-Constructed Cultivation Base for State Key Laboratory of Processing for Non-ferrous Metal and Featured Materials (No.15KF-7).

Acknowledgments: We express our thanks Xiaoqing Liu from Wuhan University of Technology for their assistance with the HRTEM characterizations.

Conflicts of Interest: The authors declare no conflict of interest.

\section{References}

1. Tan, B.; Toman, E.; Li, Y.G.; Wu, Y.Y. Zinc stannate $\left(\mathrm{Zn}_{2} \mathrm{SnO}_{4}\right)$ dye-sensitized solar cells. J. Am. Chem. Soc. 2007, 129, 4162-4163. [CrossRef] [PubMed]

2. Alpuche-Aviles, M.A.; Wu, Y. Photoelectrochemical study of the band structure of $\mathrm{Zn}_{2} \mathrm{SnO}_{4}$ prepared by the hydrothermal method. J. Am. Chem. Soc. 2009, 131, 3216-3224. [CrossRef] [PubMed]

3. Wang, K.; Huang, Y.; Huang, H.J.; Zhao, Y.; Qin, X.L.; Sun, X.; Wang, Y.L. Hydrothermal synthesis of flower-like $\mathrm{Zn}_{2} \mathrm{SnO}_{4}$ composites and their performance as anode materials for lithium-ion batteries. Ceram. Int. 2013, 39, 4569-4574. [CrossRef]

4. Wang, J.H.; Li, H.; Meng, S.G.; Zhang, L.; Fu, X.L.; Chen, S.F. One-pot hydrothermal synthesis of highly efficient $\mathrm{SnO}_{\mathrm{x}} / \mathrm{Zn}_{2} \mathrm{SnO}_{4}$ composite photocatalyst for the degradation of methyl orange and gaseous benzene. Appl. Catal. B Environ. 2017, 200, 19-30. [CrossRef]

5. Lou, X.; Jia, X.; Xu, J.; Liu, S.; Cao, Q. Hydrothermal synthesis, characterization and photocatalytic properties of $\mathrm{Zn}_{2} \mathrm{SnO}_{4}$ nanocrystal. Mater. Sci. Eng. A 2006, 432, 221-225. [CrossRef]

6. Zhao, Q.Q.; Deng, X.L.; Ding, M.; Huang, J.Z.; Ju, D.X; Xu, X.J. Synthesis of hollow cubic $\mathrm{Zn}_{2} \mathrm{SnO}_{4}$ sub-microstructures with enhanced photocatalytic performance. J. Alloys Compd. 2016, 671, 328-333. [CrossRef]

7. Junploy, P.; Phuruangrat, A.; Plubphon, N.; Thongtem, S.; Thongtem, T. Photocatalytic degradation of methylene blue by $\mathrm{Zn}_{2} \mathrm{SnO}_{4}-\mathrm{SnO}_{2}$ system under UV visible radiation. Mater. Sci. Semicond. Process. 2017, 66, 56-61. [CrossRef]

8. Jia, T.K.; Zhao, J.W.; Fu, F.; Deng, Z.; Wang, W.M.; Fu, Z.Y.; Meng, F.C. Synthesis, characterization and photcatalytic activity $\mathrm{Zn}$-doped $\mathrm{SnO}_{2} / \mathrm{Zn}_{2} \mathrm{SnO}_{4}$ coupled nanocomposites. Int. J. Photoenergy 2014, 2014, 197824. [CrossRef]

9. Fu, X.L.; Wang, X.; Long, J.; Ding, Z.; Yan, T.; Zhang, G.; Zhang, Z.; Lin, H.; Fu, X.Z. Hydrothermal synthesis, characterization, and photocatalytic properties of $\mathrm{Zn}_{2} \mathrm{SnO}_{4}$. J. Solid State Chem. 2009, 182, 517-524. [CrossRef]

10. Foletto, E.L.; Jahn, S.L.; Moreira, R.d.F.P.M. Hydrothermal of preparation of $\mathrm{Zn}_{2} \mathrm{SnO}_{4}$ nanocrystals and photocatalytic degradation of a leather dye. J. Appl. Electrochem. 2010, 40, 59-63. [CrossRef]

11. Núñez, J.; Fresno, F.; Collado, L.; Jana, P.; Coronado, J.M.; Serrano, D.P.; Víctor, A. Photocatalytic $\mathrm{H}_{2}$ production from aqueous methanol solutions using metal-co-catalysed $\mathrm{Zn}_{2} \mathrm{SnO}_{4}$ nanostructures. Appl. Catal. B Environ. 2016, 191, 106-115. [CrossRef]

12. Li, Z.; Zhou, Y.; Zhang, J.; Tu, W.; Liu, Q.; Yu, T.; Zou, Z. Hexagonal nanoplate-textured micro-octahedron $\mathrm{Zn}_{2} \mathrm{SnO}_{4}$ : combined effects toward enhanced efficiencies of dye-sensitized solar cell and photoreduction of $\mathrm{CO}_{2}$ into hydrocarbon fuels. Cryst. Growth Des. 2012, 12, 1476-1481. [CrossRef]

13. Jiang, Y.; Peng, Z.; Zhang, S.; Li, F.; Liu, Z.; Mhang, J.; Liu, Y.; Wang, K. Facile in-situ Solvothermal Method to synthesize double shell $\mathrm{ZnIn}_{2} \mathrm{~S}_{4}$ nanosheets $/ \mathrm{TiO}_{2}$ hollow nanosphere with enhanced photocatalytic activities. Ceram. Int. 2018, 44, 6115-6126. [CrossRef]

14. Yu, H.G.; Liu, R.; Wang, X.; Wang, P.; Yu, J.G. Enhanced visible-light photocatalytic activity of $\mathrm{Bi}_{2} \mathrm{WO}_{6}$ nanoparticles by $\mathrm{Ag}_{2} \mathrm{O}$ cocatalyst. Appl. Catal. B Environ. 2012, 111-112, 326-333. [CrossRef]

15. Yu, J.G.; Ran, J.R. Facile preparation and enhanced photocatalytic $\mathrm{H}_{2}$-production activity of $\mathrm{Cu}(\mathrm{OH})_{2}$ cluster modified $\mathrm{TiO}_{2}$. Energy Environ. Sci. 2011, 4, 1364-1371. [CrossRef]

16. Jia, T.K.; Li, J.L.; Long, F.; Fu, F.; Deng, Z.; Wang, Z.X.; Zhang, Y. Ultrathin g- $\mathrm{C}_{3} \mathrm{~N}_{4}$ Nanosheet-nodified BiOCl hierarchical flower-like plate heterostructure with enhanced photostability and photocatalytic performance. Crystal 2017, 7, 266. [CrossRef]

17. Hassan, S.M.; Ahmed, A.I.; Mannaa, M.A. Structural, photocatalytic, biological and catalytic properties of $\mathrm{SnO}_{2} / \mathrm{TiO}_{2}$ nanoparticles. Ceram. Int. 2018, 44, 6201-6211. [CrossRef] 
18. Duo, F.F.; Wang, Y.W.; Mao, X.M.; Fan, C.M.; Zhang, H. Double Br sources fabrication and photocatalytic property of p-n junction BiOBr/ZnO composites for phenol removal. Cryst. Res. Technol. 2014, 49, 721-730. [CrossRef]

19. Li, X.W.; Wang, L.; Zhang, L.; Zhuo, S.P. A facile route to the synthesis of magnetically separable $\mathrm{BiOBr} / \mathrm{NiFe}_{2} \mathrm{O}_{4}$ composites with enhanced photocatalytic performance. Appl. Surf. Sci. 2017, 419, 589-594. [CrossRef]

20. Gao, M.C.; Zhang, D.F.; Pu, X.P.; Ma, H.Y.; Su, C.H.; Gao, X.; Dou, J.M. Surface decoration of BiOBr with $\mathrm{BiPO}_{4}$ nanoparticles to build heterostructure photocatalysts with enhanced visible-light photocatalytic activity. Sep. Purif. Technol. 2016, 170, 183-189. [CrossRef]

21. Wang, X.J.; Yang, W.Y.; Li, F.T.; Zhao, J.; Liu, R.H.; Liu, S.J.; Li, B. Construction of amorphous $\mathrm{TiO}_{2} / \mathrm{BiOBr}$ heterojunctions via facets coupling for enhanced photocatalytic activity. J. Hazard. Mater. 2015, 292, 126-136. [CrossRef] [PubMed]

22. Song, X.C.; Li, W.T.; Huang, W.Z.; Zhou, H.; Zheng, Y.F.; Yin, H.Y. A novel p-n heterojunction BiOBr $/ \mathrm{ZnWO}_{4}$ : preparation and its improved visible lightphotocatalytic activity. Mater. Chem. Phys. 2015, 160, 251-256. [CrossRef]

23. Zhang, Z.; Huang, J.; Zhang, M.; Yuan, Q.; Dong, B. Ultrathin hexagonal $\mathrm{SnS}_{2}$ nanosheets coupled with g- $\mathrm{C}_{3} \mathrm{~N}_{4}$ nanosheets as 2D/2D heterojunction photocatalysts toward high photocatalytic activity. Appl. Catal. B Environ. 2015, 163, 298-305. [CrossRef]

24. Zhang, Z.Y.; Shao, C.L.; Li, X.; Wang, C.; Zhang, M.; Liu, Y.C. Electrospun nanofibers of $p$-type NiO/n-type ZnO heterojunctions with Enhanced photocatalytic activity. ACS Appl. Mater. Interfaces 2010, 2, 2915-2923. [CrossRef] [PubMed]

25. Zhang, Z.Y.; Shao, C.L.; Li, X.; Sun, Y.; Zhang, M.; Mu, J.; Zhang, P.; Guo, Z.; Liu, Y.C. Hierarchical assembly of ultrathin hexagonal $\mathrm{SnS}_{2}$ nanosheets onto electrospun $\mathrm{TiO}_{2}$ nanofibers: enhanced photocatalytic activity based on photoinduced interfacial charge transfer. Nanoscale 2013, 5, 606-618. [CrossRef] [PubMed]

26. Li, X.H.; Xu, H.Y.; Zhang, X.T.; Liu, Y.C.; Sun, J.W.; Lu, Y.M. Local chemical states and thermal stabilities of nitrogen dopants in $\mathrm{ZnO}$ film studied by temperature-dependent $\mathrm{X}$-ray photoelectron spectroscopy. Appl. Phys. Lett. 2009, 95, 191903. [CrossRef]

27. Zhu, A.; Zhao, Q.; Li, X.; Shi, Y. $\mathrm{BiFeO}_{3} / \mathrm{TiO}_{2}$ nanotube arrays composite electrode: Construction, characterization, and enhanced photoelectrochemical properties. ACS Appl. Mater. Interfaces 2014, 6, 671-679. [CrossRef] [PubMed]

28. Tang, C.; Liu, E.Z.; Wan, J.; Hu, X.; Fan, J. $\mathrm{Co}_{3} \mathrm{O}_{4}$ nanoparticles decorated Ag3PO4 tetrapods as an efficient visible-light-driven heterojunction photocatalysts. Appl. Catal. B Environ. 2016, 181, 707-315. [CrossRef]

29. Jia, T.K.; Fu, F.; Long, F.; Min, Z.Y.; Zhao, J.W.; Chen, J.; Li, J.L. Synthesis, characterization and enhanced visible-light photocatalytic activity of $\mathrm{Zn}_{2} \mathrm{SnO}_{4} / \mathrm{C}$ nanocomposites with truncated octahedron morphology. Ceram. Int. 2016, 42, 3808-3815. [CrossRef]

30. Li, Q.; Zhao, X.; Yang, J.; Jia, C.; Jin, Z.; Fan, W.L. Exploring the effects of nanocrystal facet orientations in g- $\mathrm{C}_{3} \mathrm{~N}_{4} / \mathrm{BiOCl}$ heterostructures on photocatalytic performance. Nanoscale 2015, 7, 18971-18983. [CrossRef] [PubMed]

31. Li, F.T.; Wang, Q.; Ran, J.R.; Hao, Y.J.; Wang, X.J.; Zhao, D.S.; Qiao, S.Z. Ionic liquid self-combustion synthesis of $\mathrm{BiOBr} / \mathrm{Bi}_{24} \mathrm{O}_{31} \mathrm{Br}_{10}$ heterojunctions with exceptional visible-light photocatalytic performances. Nanoscale 2015, 7, 1116-1126. [CrossRef] [PubMed]

32. Lin, H.F.; Liao, S.C.; Hung, W.W.; Hu, C.T. Thermal plasma synthesis and optical properties of $\mathrm{Zn}_{2} \mathrm{SnO}_{4}$ nanopowders. Mater. Chem. Phys. 2009, 117, 9-13. [CrossRef]

33. Pang, C.; Yan, B.; Liao, L.; Liu, B.; Zheng, Z.; Wu, T.; Yu, T. Synthesis, characterization and opto-electrical properties of ternary $\mathrm{Zn}_{2} \mathrm{SnO}_{4}$ nanowires. Nanotechnology 2010, 21, 465706. [CrossRef] [PubMed]

34. Li, Y.; Wang, J.; Yang, Y.; Zhang, Y.; He, D.; An, Q.; Cao, G.Z. Seed-induced growing various $\mathrm{TiO}_{2}$ on nanostructures on $\mathrm{g}-\mathrm{C}_{3} \mathrm{~N}_{4}$ nanosheets with much enhanced photocatalytic acitivity under visible light. $J$. Hazard. Mater. 2015, 292, 79-89. [CrossRef] [PubMed]

35. Fu, J.; Tian, Y.L.; Chang, B.B.; Xi, F.N.; Dong, X.P. BiOBr-carbon nitride heterojunctions: Synthesis, enhanced activity and photocatalytic mechanism. J. Mater. Chem. 2012, 22, 21159-21166. [CrossRef]

36. Jia, T.K.; Wang, W.M.; Long, F.; Fu, Z.Y.; Wang, H.; Zhang, Q.J. Synthesis, characterization, and photocatalytic activity of $\mathrm{Zn}$-doped $\mathrm{SnO}_{2}$ hierarchical architectures assembled by nanocones. J. Phys. Chem. C 2009, 113, 9071-9077. [CrossRef] 
37. Jia, T.K.; Wang, W.M.; Long, F.; Fu, Z.Y.; Wang, H.; Zhang, Q.J. Fabrication, characterization and photocatalytic activity of La-doped ZnO nanowires. J. Alloys Compd. 2009, 484, 410-415. [CrossRef]

38. Jia, T.K.; Fu, F.; Yu, D.; Cao, J.; Sun, G. Facile synthesis and characterization of $\mathrm{N}$-doped $\mathrm{TiO}_{2} / \mathrm{C}$ nanocomposites with enhanced visible-light photocatalytic performance. Appl. Surf. Sci. 2018, 430, 438-447. [CrossRef]

(c) (2)

(C) 2018 by the authors. Licensee MDPI, Basel, Switzerland. This article is an open access article distributed under the terms and conditions of the Creative Commons Attribution (CC BY) license (http:/ / creativecommons.org/licenses/by/4.0/). 


\title{
Article \\ Construction of g- $\mathrm{C}_{3} \mathrm{~N}_{4}-\mathrm{mNb}_{2} \mathrm{O}_{5}$ Composites with Enhanced Visible Light Photocatalytic Activity
}

\author{
Meiyin Wang, Hui Wang, Yuanhang Ren, Cheng Wang, Zhewei Weng, Bin Yue * and Heyong He * \\ Department of Chemistry and Shanghai Key Laboratory of Molecular Catalysis and Innovative Materials, \\ Collaborative Innovation Center of Chemistry for Energy Materials, Fudan University, Shanghai 200433, China; \\ 14110220018@fudan.edu.cn (M.W.); 17210220053@fudan.edu.cn (H.W.); YuanhangRen@fudan.edu.cn (Y.R.); \\ 15110220022@fudan.edu.cn (C.W.); 16210220004@fudan.edu.cn (Z.W) \\ * Correspondence: yuebin@fudan.edu.cn (B.Y.); heyonghe@fudan.edu.cn (H.H.); Tel.: +86-21-31242779 (B.Y.); \\ +86-21-31243916 (H.H.)
}

Received: 4 May 2018; Accepted: 8 June 2018; Published: 12 June 2018

\begin{abstract}
A series of composites consisting of g- $\mathrm{C}_{3} \mathrm{~N}_{4}$ sheet and mesoporous $\mathrm{Nb}_{2} \mathrm{O}_{5}\left(\mathrm{mNb}_{2} \mathrm{O}_{5}\right)$ microsphere were fabricated by in situ hydrolysis deposition of $\mathrm{NbCl}_{5}$ onto g- $\mathrm{C}_{3} \mathrm{~N}_{4}$ sheet followed by solvothermal treatment. The samples were characterized using powder X-ray diffraction (XRD), Fourier transform infrared spectroscopy (FT-IR), transmission electron microscopy (TEM), $\mathrm{N}_{2}$ adsorption-desorption, X-ray photoelectron spectroscopy (XPS), UV-vis diffuse reflectance spectroscopy (DRS) and photoluminescence spectroscopy (PL). The photocatalytic activity of the composites was studied by degradation of rhodamine $\mathrm{B}(\mathrm{RhB})$ and tetracycline hydrochloride (TC-HCl) in aqueous solution under visible light irradiation $(\lambda>420 \mathrm{~nm})$. Compared with g- $\mathrm{C}_{3} \mathrm{~N}_{4}$ and $\mathrm{mNb}_{2} \mathrm{O}_{5}, \mathrm{~g}-\mathrm{C}_{3} \mathrm{~N}_{4}-\mathrm{mNb}_{2} \mathrm{O}_{5}$ composites have higher photocatalytic activity due to synergistic effect between $\mathrm{g}-\mathrm{C}_{3} \mathrm{~N}_{4}$ and $\mathrm{mNb}_{2} \mathrm{O}_{5}$. Among these composites, $4 \% \mathrm{~g}-\mathrm{C}_{3} \mathrm{~N}_{4}-\mathrm{mNb}_{2} \mathrm{O}_{5}$ has the highest efficiency and good recyclability for degradation of both $\mathrm{RhB}$ and $\mathrm{TC}-\mathrm{HCl}$.
\end{abstract}

Keywords: photocatalytic degradation; g- $\mathrm{C}_{3} \mathrm{~N}_{4}$; mesoporous $\mathrm{Nb}_{2} \mathrm{O}_{5}$; organic pollutant

\section{Introduction}

Organic dyes and antibiotics are two types of important products which are widely used in textile and pharmaceutical industries, respectively. The direct discharge of these chemical compounds along with sewage to environment would be seriously harmful to ecosystem and human health. It is, therefore, desirable to explore efficient ways to remove them from water [1-3]. In the past decades, the methods of biological treatment, physical adsorption and chemical transformation have been employed in removal of the organic pollutants [1,4-7]. Among them, much attention has been focused on photocatalytic degradation of organic pollutants over semiconductors such as $\mathrm{TiO}_{2}[7,8]$, $\mathrm{WO}_{3}$ [9], $\mathrm{ZnO}$ [10], $\mathrm{MoS}_{2}$ [11], etc. due to their ability to oxidize organics through a redox process with low cost. Nevertheless, the majority of the above semiconductors still suffer from some problems such as limited absorption of visible light, difficult recycling of the catalyst, rapid recombination of photogenerated electrons, holes pairs, etc. n-Type transition metal oxide $\mathrm{Nb}_{2} \mathrm{O}_{5}$ attracts much interest in photocatalytic reactions due to its high chemical stability, water tolerance, and nontoxicity, although the light absorption of $\mathrm{Nb}_{2} \mathrm{O}_{5}$ with a wide band gap of $\sim 3.4 \mathrm{eV}$ limits its application only in the UV region [12-14]. Therefore, many efforts have been made to improve the absorption ability of $\mathrm{Nb}_{2} \mathrm{O}_{5}$ in the visible region, such as combination with other semiconductor material [15], ion doping [16] and deposition of noble metal [17].

Recently, graphitic carbon nitride $\left(\mathrm{g}-\mathrm{C}_{3} \mathrm{~N}_{4}\right)$ has been widely used in photocatalytic reactions such as degradation of pollutants, hydrogen generation and selective oxidation of alcohols under visible light due to its excellent chemical/thermal stability, small band gap of $2.7 \mathrm{eV}$ and low cost [18-20]. However, 
pure g- $\mathrm{C}_{3} \mathrm{~N}_{4}$ shows low photocatalytic efficiency owing to fast recombination of photogenerated electrons and holes and small specific surface area [21,22]. It was reported that the composites of $\mathrm{g}-\mathrm{C}_{3} \mathrm{~N}_{4}$ and other semiconductors, such as $\mathrm{TiO}_{2}$ [23-25], $\mathrm{WO}_{3}$ [26], $\mathrm{MoS}_{2}$ [27], and $\mathrm{ZnO}$ [28], could produce a certain number of heterojunction sites which is beneficial to promote electron-hole separation and restrain the recombination efficiently. In addition, some efforts have been paid to the $\mathrm{Nb}_{2} \mathrm{O}_{5} / g-\mathrm{C}_{3} \mathrm{~N}_{4}$ composite which exhibits photocatalytic activity in degradation of tetracycline hydrochloride (TC-HCl) [29], methylene blue (MB) and rhodamine B ( $\mathrm{RhB}$ ) under $\mathrm{UV}$ and visible light [30], and production of $\mathrm{H}_{2}$ under visible light [31]. However, it is still a challenge to prepare novel $\mathrm{Nb}_{2} \mathrm{O}_{5} / \mathrm{g}-\mathrm{C}_{3} \mathrm{~N}_{4}$ composites with strong interaction and high dispersion between mesoporous $\mathrm{Nb}_{2} \mathrm{O}_{5}$ microsphere and $\mathrm{g}-\mathrm{C}_{3} \mathrm{~N}_{4}$ layer which could be used as efficient photocatalysts.

Herein, a series of $\mathrm{g}-\mathrm{C}_{3} \mathrm{~N}_{4}-\mathrm{mNb}_{2} \mathrm{O}_{5}$ composites, prepared by in situ hydrolysis deposition of $\mathrm{NbCl}_{5}$ onto $\mathrm{g}-\mathrm{C}_{3} \mathrm{~N}_{4}$ sheet followed by solvothermal treatment, have been used as photocatalysts in degradation of $\mathrm{RhB}$ and $\mathrm{TC}-\mathrm{HCl}$ and characterized in details. The results indicate that $4 \%$ g- $\mathrm{C}_{3} \mathrm{~N}_{4}-\mathrm{mNb}_{2} \mathrm{O}_{5}$ exhibits low photoluminescence (PL) intensity and narrow band gap which account for its high catalytic activity.

\section{Materials and Methods}

\subsection{Materials}

Niobium chloride $\left(\mathrm{NbCl}_{5}\right)$ was purchased from Strem Chemicals, Inc (Newburyport, MA, USA). Melamine (99\%), absolute ethanol (analytical grade) and tetracycline hydrochloride (TC- $\mathrm{HCl}, 96 \%$ ) were purchased from Shanghai Aladdin Bio-Chem Technology Co., Ltd. (Shanghai, China). Rhodamine B (RhB) was purchased from Sinopharm Chemical Reagent Co., Ltd. (Shanghai, China). Pluronic 123 (PEG-PPG-PEG, P123) was purchased from Sigma-Aldrich, Co. (ST. Louis, MO, USA). All the reagents were used without further purification.

\subsection{Preparation}

The bulk $\mathrm{g}-\mathrm{C}_{3} \mathrm{~N}_{4}$ was prepared by heating $2.50 \mathrm{~g}$ of melamine in an alumina crucible with a cover in air at $550{ }^{\circ} \mathrm{C}$ with ramp rate of $2{ }^{\circ} \mathrm{C} / \mathrm{min}$ and maintained at $550{ }^{\circ} \mathrm{C}$ for $4 \mathrm{~h}$ [32]. After being cooled down to room temperature, the obtained product was ground into powder.

The g- $\mathrm{C}_{3} \mathrm{~N}_{4}-\mathrm{mNb}_{2} \mathrm{O}_{5}$ composites were prepared through in situ hydrolysis of $\mathrm{NbCl}_{5}$ onto g- $\mathrm{C}_{3} \mathrm{~N}_{4}$ and then solvothermal treatment. Typically, $0.99 \mathrm{~g}$ of P123 was added into $20 \mathrm{~g}$ of absolute ethanol with vigorous stirring until complete dissolution of P123. Bulk g- $\mathrm{C}_{3} \mathrm{~N}_{4}$ powder was dispersed into absolute ethanol and the suspension was sonicated for $1 \mathrm{~h}$. Then, $1.49 \mathrm{~g}$ of $\mathrm{NbCl}_{5}$ was added into a pear-shaped flask under $\mathrm{N}_{2}$ atmosphere in a glovebox. The solution of P123 and the suspension of g- $\mathrm{C}_{3} \mathrm{~N}_{4}$ were added and the mixture was stirred for $30 \mathrm{~min}$. After that, $0.50 \mathrm{~mL}$ of distilled water was pumped into the flask with a rate of $0.0167 \mathrm{~mL} / \mathrm{min}$ under stirring. After stirring for another $30 \mathrm{~min}$, the mixture was transferred into a $40 \mathrm{~mL}$ Teflon-lined stainless steel autoclave and heated at $180{ }^{\circ} \mathrm{C}$ for $24 \mathrm{~h}$. After being cooled down to room temperature, the precipitate was obtained by filtration and washing by ethanol for four times. The solid was dried at $30^{\circ} \mathrm{C}$ overnight in a drying oven under vacuum and then transferred to a tube furnace to be calcined at $400{ }^{\circ} \mathrm{C}$ for $3 \mathrm{~h}$ with a rate of $2{ }^{\circ} \mathrm{C} / \mathrm{min}$. The g- $\mathrm{C}_{3} \mathrm{~N}_{4}-\mathrm{mNb}_{2} \mathrm{O}_{5}$ composites prepared with the $\mathrm{g}^{-} \mathrm{C}_{3} \mathrm{~N}_{4}$ weight ratios of $1 \%, 4 \%$, $10 \%, 20 \%$ and $50 \%$ were denoted as $1 \%$ g- $\mathrm{C}_{3} \mathrm{~N}_{4}-\mathrm{mNb}_{2} \mathrm{O}_{5}, 4 \%$ g- $\mathrm{C}_{3} \mathrm{~N}_{4}-\mathrm{mNb}_{2} \mathrm{O}_{5}, 10 \%$ g- $\mathrm{C}_{3} \mathrm{~N}_{4}-\mathrm{mNb}_{2} \mathrm{O}_{5}$, $20 \%$ g- $\mathrm{C}_{3} \mathrm{~N}_{4}-\mathrm{mNb}_{2} \mathrm{O}_{5}, 50 \%$ g- $\mathrm{C}_{3} \mathrm{~N}_{4}-\mathrm{mNb}_{2} \mathrm{O}_{5}$, respectively. The pure $\mathrm{mNb}_{2} \mathrm{O}_{5}$ was prepared by the same procedure without adding g- $\mathrm{C}_{3} \mathrm{~N}_{4}$. In addition, the corresponding mechanic mixture of $\mathrm{g}_{-} \mathrm{C}_{3} \mathrm{~N}_{4}$ and $\mathrm{mNb}_{2} \mathrm{O}_{5}$ with the same weight ratio of $4 \% \mathrm{~g}_{-} \mathrm{C}_{3} \mathrm{~N}_{4}-\mathrm{mNb}_{2} \mathrm{O}_{5}$ was prepared by simple grinding and was denoted as $4 \% \mathrm{~g}-\mathrm{C}_{3} \mathrm{~N}_{4} / \mathrm{mNb}_{2} \mathrm{O}_{5}$. 


\subsection{Characterization}

Powder X-ray diffraction (XRD) patterns were carried out on a Bruker D8 Advance diffractometer (Karlsruhe, Germany) with $\mathrm{Cu} \mathrm{K} \alpha$ radiation $(\lambda=0.15418 \mathrm{~nm}$ ) operated at $40 \mathrm{kV}$ and $40 \mathrm{~mA}$ in the $2 \theta$ range of $5-70^{\circ}$. The Fourier transform infrared (FT-IR) spectra were recorded on a Thermo Fisher Nicolet iS10 instrument (Waltham, MA, USA) with $\mathrm{KBr}$ pellet from 4000 to $400 \mathrm{~cm}^{-1}$. X-ray photoelectron spectroscopy (XPS) was measured by a Perkin Elmer PHI 5000C spectroscope (Waltham, MA, USA). The spectra were recorded with $\mathrm{Mg} \mathrm{K} \alpha$ line as the excitation source $(h v=1253.6 \mathrm{eV})$ at $14 \mathrm{kV}$ and $20 \mathrm{~mA}$. UV-vis diffuse reflectance spectroscopy (DRS) was performed on a Perkin Elmer Lambda 650 spectrophotometer (Waltham, MA, USA) using $\mathrm{BaSO}_{4}$ as reference. The transmission electron microscopic (TEM) images were obtained using a FEI Tecnai $\mathrm{G}^{2}$ F20 S-Twin field emission transmission electron microscope (Hillsboro, Oregon, USA) with an accelerating voltage of $200 \mathrm{kV}$ and a JEOL JEM-2011 transmission electron microscope with an accelerating voltage of $200 \mathrm{kV}$. The samples were prepared by dropping the ethanol suspension of samples onto the copper grid. The $\mathrm{N}_{2}$ adsorption-desorption measurements were carried out at $77.3 \mathrm{~K}$ on a Micromeritics Tristar II 3020 analytical system. The specific surface area was calculated by the Brunauer-Emmett-Teller (BET) method. Pore size distributions were obtained from analysis of the desorption branch of the isotherms using the Barrett-Joyner-Halenda (BJH) model. Photoluminescence (PL) spectra were obtained on an Edinburgh Instruments FLS-980 spectrometer (Edinburgh, UK) with the excitation wavelength of $300 \mathrm{~nm}$.

\subsection{Photocatalytic Experiments}

The photocatalytic activity of the as-prepared catalysts was performed by photocatalytic degradation of $15 \mathrm{mg} / \mathrm{L} \mathrm{RhB}$ aqueous solution and $40 \mathrm{mg} / \mathrm{L} \mathrm{TC}-\mathrm{HCl}$ aqueous solution under visible light. The photocatalytic degradation tests were carried out in an instrument (CEL-HXF300, Beijing China Education Au-light Co., Ltd., Beijing, China) with a cylindrical glass reactor and a condensate water circulation equipment (Figure S1). The visible light was provided by a Xe lamp (14 V, $15 \mathrm{~A})$ with a $420 \mathrm{~nm}$ cut-off filter (Figure S2). In a typical photocatalytic degradation of $\mathrm{RhB}$ or TC-HCl experiment, $30 \mathrm{mg}$ of catalyst was added into $70 \mathrm{~mL}$ of RhB aqueous solution or $100 \mathrm{~mL}$ of TC-HCl aqueous solution. The suspension was firstly stirred in dark at room temperature to reach adsorption/desorption equilibrium. Then, the reaction was irradiated under visible light $(\lambda>420 \mathrm{~nm})$ and the solution was vigorously stirred with air bubbling. During the process, $3 \mathrm{~mL}$ of suspension was taken at intervals of $20 \mathrm{~min}$ (for $\mathrm{RhB}$ ) or intervals of $5 \mathrm{~min}$ (for $\mathrm{TC}-\mathrm{HCl}$ ). All suspensions were centrifuged to remove the catalyst and the concentration of the $\mathrm{RhB}$ and $\mathrm{TC}-\mathrm{HCl}$ were analyzed by $\mathrm{UV}$-vis spectrophotometer with the scanning ranges of 300-700 $\mathrm{nm}$ for RhB and 200-600 nm for TC-HCl. To be reused for next reaction cycle, the separated catalyst by centrifugation was washed by water and ethanol three times and then dried at $30{ }^{\circ} \mathrm{C}$ in a drying oven under vacuum.

\section{Results and Discussion}

\subsection{Characterization of the Catalysts}

\subsubsection{XRD}

XRD was employed to analyze $\mathrm{mNb}_{2} \mathrm{O}_{5}, \mathrm{~g}-\mathrm{C}_{3} \mathrm{~N}_{4}$ and $\mathrm{g}-\mathrm{C}_{3} \mathrm{~N}_{4}-\mathrm{mNb}_{2} \mathrm{O}_{5}$ composites with different contents of $g-\mathrm{C}_{3} \mathrm{~N}_{4}$ and the results are shown in Figure 1. For $\mathrm{mNb}_{2} \mathrm{O}_{5}$, the broad diffraction peak around $23.7^{\circ}$ corresponds to partial crystallized $\mathrm{Nb}_{2} \mathrm{O}_{5}$ (JCPDS number: 19-0862), which results from the relatively low calcination temperature of $400{ }^{\circ} \mathrm{C}$. The main diffractions of $\mathrm{g}-\mathrm{C}_{3} \mathrm{~N}_{4}$ are at $12.8^{\circ}$ and $27.1^{\circ}$, which are assigned to (100) plane due to in-plane tris-s-triazine frameworks and (002) plane due to interlayer stacking of aromatic systems, respectively. The latter reflects interlayer stacking of aromatic systems and the calculated interlayer distance is $0.338 \mathrm{~nm}$ [33-35]. In the composites, 
the diffractions of $\mathrm{mNb}_{2} \mathrm{O}_{5}$ are retained and the characteristic (002) diffraction of $\mathrm{g}-\mathrm{C}_{3} \mathrm{~N}_{4}$ is observed when the content of $\mathrm{g}-\mathrm{C}_{3} \mathrm{~N}_{4}$ increases to $20 \%$ and $50 \%$.

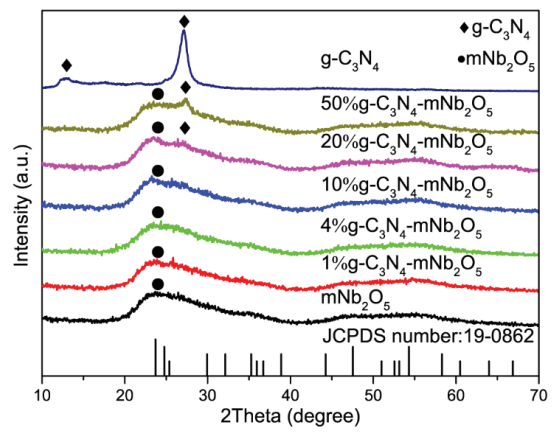

Figure 1. $\mathrm{XRD}$ patterns for $\mathrm{mNb}_{2} \mathrm{O}_{5}, \mathrm{~g}-\mathrm{C}_{3} \mathrm{~N}_{4}$ and $\mathrm{g}-\mathrm{C}_{3} \mathrm{~N}_{4}-\mathrm{mNb}_{2} \mathrm{O}_{5}$ composites with different contents of $\mathrm{g}-\mathrm{C}_{3} \mathrm{~N}_{4}$.

\subsubsection{FT-IR}

Figure 2 shows the FT-IR spectra of $\mathrm{mNb}_{2} \mathrm{O}_{5}, \mathrm{~g}-\mathrm{C}_{3} \mathrm{~N}_{4}$ and $\mathrm{g}-\mathrm{C}_{3} \mathrm{~N}_{4}-\mathrm{mNb}_{2} \mathrm{O}_{5}$ composites. For the $\mathrm{mNb}_{2} \mathrm{O}_{5}$ sample, a broad band around $3382 \mathrm{~cm}^{-1}$ is attributed to vibration of $\mathrm{O}-\mathrm{H}$ of the water molecules adsorbed on the sample [27,30]. The broad band at $615 \mathrm{~cm}^{-1}$ is ascribed to $\mathrm{Nb}-\mathrm{O}-\mathrm{Nb}$ angular vibration [36]. As for $\mathrm{g}-\mathrm{C}_{3} \mathrm{~N}_{4}$, the broad band ranging from 3000 to $3500 \mathrm{~cm}^{-1}$ is due to the stretching vibration of $\mathrm{N}-\mathrm{H}$ groups in $\mathrm{g}-\mathrm{C}_{3} \mathrm{~N}_{4}$ and $\mathrm{O}-\mathrm{H}$ of adsorbed water [25]. Other characteristic bands arisen from the typical stretching modes of $\mathrm{C}=\mathrm{N}$ and $\mathrm{C}-\mathrm{N}$ in heterocycles of $\mathrm{g}-\mathrm{C}_{3} \mathrm{~N}_{4}$ are at 1237, $1317,1405,1461,1574$ and $1640 \mathrm{~cm}^{-1}$. Additionally, the band at $803 \mathrm{~cm}^{-1}$ of $\mathrm{g}-\mathrm{C}_{3} \mathrm{~N}_{4}$ is assigned to the breathing mode of the triazine units $[33,34]$. For $g-\mathrm{C}_{3} \mathrm{~N}_{4}-\mathrm{mNb}_{2} \mathrm{O}_{5}$ composites, all the characteristic bands of $\mathrm{mNb}_{2} \mathrm{O}_{5}$ and $\mathrm{g}-\mathrm{C}_{3} \mathrm{~N}_{4}$ exist except $1 \%$ g- $\mathrm{C}_{3} \mathrm{~N}_{4}-\mathrm{mNb}_{2} \mathrm{O}_{5}$ due to small amount of $\mathrm{g}-\mathrm{C}_{3} \mathrm{~N}_{4}$, which confirm the existence of two components in the composites. With the increasing of $\mathrm{g}-\mathrm{C}_{3} \mathrm{~N}_{4}$, the band at $3382 \mathrm{~cm}^{-1}$ of $\mathrm{mNb}_{2} \mathrm{O}_{5}$ slightly shifts to smaller wavenumber for $\mathrm{g}-\mathrm{C}_{3} \mathrm{~N}_{4}-\mathrm{mNb}_{2} \mathrm{O}_{5}$ composites, which reveals the vibration of $\mathrm{N}-\mathrm{H}$. Moreover, the band of $\mathrm{g}-\mathrm{C}_{3} \mathrm{~N}_{4}$ at $1237 \mathrm{~cm}^{-1}$ slightly shifts to $1244 \mathrm{~cm}^{-1}$ for all $g-\mathrm{C}_{3} \mathrm{~N}_{4}-\mathrm{mNb}_{2} \mathrm{O}_{5}$ composites except $1 \% \mathrm{~g}-\mathrm{C}_{3} \mathrm{~N}_{4}-\mathrm{mNb}_{2} \mathrm{O}_{5}$ (Figure $2 \mathrm{~b}$ ), revealing the interaction between $\mathrm{g}-\mathrm{C}_{3} \mathrm{~N}_{4}$ and $\mathrm{mNb}_{2} \mathrm{O}_{5}$.

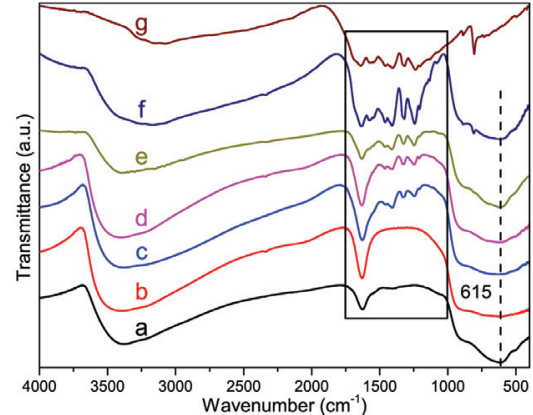

(a)

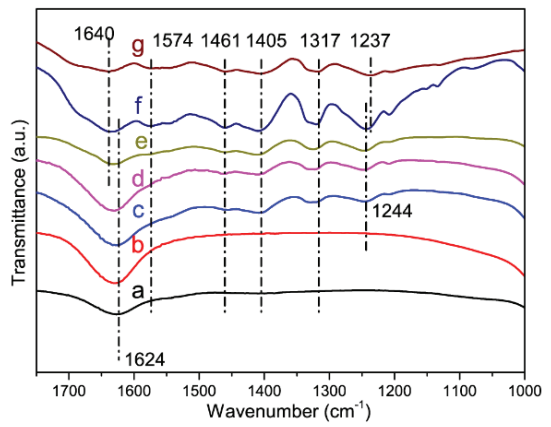

(b)

Figure 2. (a) FT-IR spectra of $\mathrm{mNb}_{2} \mathrm{O}_{5}, \mathrm{~g}-\mathrm{C}_{3} \mathrm{~N}_{4}$ and $\mathrm{g}-\mathrm{C}_{3} \mathrm{~N}_{4}-\mathrm{mNb}_{2} \mathrm{O}_{5}$ composites with different contents of g- $\mathrm{C}_{3} \mathrm{~N}_{4}$. (a, $\mathrm{mNb}_{2} \mathrm{O}_{5} ; \mathrm{b}, 1 \% \mathrm{~g}-\mathrm{C}_{3} \mathrm{~N}_{4}-\mathrm{mNb}_{2} \mathrm{O}_{5} ; \mathrm{c}, 4 \% \mathrm{~g}-\mathrm{C}_{3} \mathrm{~N}_{4}-\mathrm{mNb}_{2} \mathrm{O}_{5} ; \mathrm{d}, 10 \%$ g- $\mathrm{C}_{3} \mathrm{~N}_{4}-\mathrm{mNb}_{2} \mathrm{O}_{5}$; e, $20 \% \mathrm{~g}-\mathrm{C}_{3} \mathrm{~N}_{4}-\mathrm{mNb}_{2} \mathrm{O}_{5} ; \mathrm{f}, 50 \% \mathrm{~g}-\mathrm{C}_{3} \mathrm{~N}_{4}-\mathrm{mNb}_{2} \mathrm{O}_{5} ; \mathrm{g}, \mathrm{g}-\mathrm{C}_{3} \mathrm{~N}_{4}$ ); and (b) enlarged FT-IR spectra corresponding to rectangle region from (a). 


\subsubsection{TEM}

The prepared samples were investigated by field emission transmission electron microscope. Figure 3 shows the TEM images of $\mathrm{g}-\mathrm{C}_{3} \mathrm{~N}_{4}, \mathrm{mNb}_{2} \mathrm{O}_{5}$ and $4 \% \mathrm{~g}-\mathrm{C}_{3} \mathrm{~N}_{4}-\mathrm{mNb}_{2} \mathrm{O}_{5}$. The $\mathrm{mNb}_{2} \mathrm{O}_{5}$ sample is mesoporous materials with pore size of $3-5 \mathrm{~nm}$ and its lattice fringe spacing is $0.395 \mathrm{~nm}$ (Figure 3a). Figure $3 \mathrm{~b}$ shows that $\mathrm{g}-\mathrm{C}_{3} \mathrm{~N}_{4}$ is veil-like with lamellar structure. In Figure $3 \mathrm{c}$, we could measure that the interlayer distance $\mathrm{g}-\mathrm{C}_{3} \mathrm{~N}_{4}$ is $0.339 \mathrm{~nm}$, which is in accordance with XRD result. For the $4 \%$ $\mathrm{g}-\mathrm{C}_{3} \mathrm{~N}_{4}-\mathrm{mNb}_{2} \mathrm{O}_{5}$ sample, it can be observed that $\mathrm{mNb}_{2} \mathrm{O}_{5}$ microspheres are deposited on the surface of $g-\mathrm{C}_{3} \mathrm{~N}_{4}$ sheet in Figure 3d,e. Moreover, the corresponding EDS of Figure $3 \mathrm{e}$ indicates that the sample consists of C, N, O and Nb elements (Figure 3f). The relevant element contents are shown in Table S1.
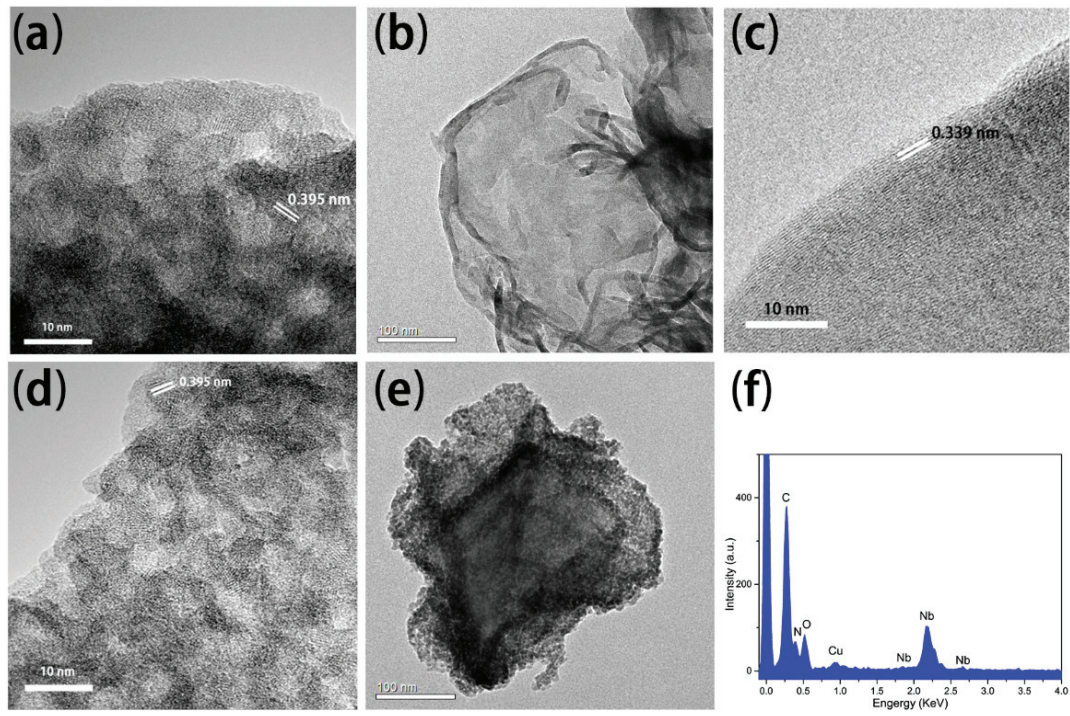

(f)

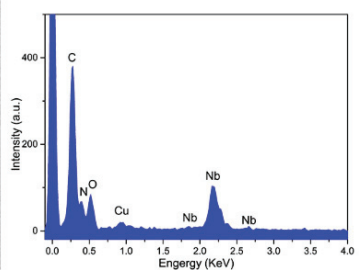

Figure 3. TEM images of: (a) $\mathrm{mNb}_{2} \mathrm{O}_{5}$; (b,c) g- $\mathrm{C}_{3} \mathrm{~N}_{4}$; and (d,e) $4 \%$ g- $\mathrm{C}_{3} \mathrm{~N}_{4}-\mathrm{mNb}_{2} \mathrm{O}_{5}$; (f) EDS analysis of $4 \%$ g- $\mathrm{C}_{3} \mathrm{~N}_{4}-\mathrm{mNb}_{2} \mathrm{O}_{5}$ corresponding to (e).

\subsection{4. $\mathrm{N}_{2}$ Adsorption-Desorption}

Figure 4 shows the nitrogen adsorption-desorption isotherms of $\mathrm{g}_{-} \mathrm{C}_{3} \mathrm{~N}_{4}, \mathrm{mNb}_{2} \mathrm{O}_{5}, 1 \%$ g- $\mathrm{C}_{3} \mathrm{~N}_{4}-\mathrm{mNb}_{2} \mathrm{O}_{5}, 4 \%$ g- $\mathrm{C}_{3} \mathrm{~N}_{4}-\mathrm{mNb}_{2} \mathrm{O}_{5}, 10 \% \mathrm{~g}-\mathrm{C}_{3} \mathrm{~N}_{4}-\mathrm{mNb}_{2} \mathrm{O}_{5}$ and $50 \%$ g- $\mathrm{C}_{3} \mathrm{~N}_{4}-\mathrm{mNb}_{2} \mathrm{O}_{5}$. The isotherm of $\mathrm{g}-\mathrm{C}_{3} \mathrm{~N}_{4}$ belongs to the type IV isotherm with the $\mathrm{H} 4$ type hysteresis loop. All isotherms of $\mathrm{mNb}_{2} \mathrm{O}_{5}$, $1 \%$ g- $\mathrm{C}_{3} \mathrm{~N}_{4}-\mathrm{mNb}_{2} \mathrm{O}_{5}, 4 \% \mathrm{~g}-\mathrm{C}_{3} \mathrm{~N}_{4}-\mathrm{mNb}_{2} \mathrm{O}_{5}, 10 \%$ g- $\mathrm{C}_{3} \mathrm{~N}_{4}-\mathrm{mNb}_{2} \mathrm{O}_{5}$ and $50 \%$ g- $\mathrm{C}_{3} \mathrm{~N}_{4}-\mathrm{mNb}_{2} \mathrm{O}_{5}$ are ascribed to the type $\mathrm{V}$ isotherm with the $\mathrm{H} 3$ type hysteresis loop, indicating the existence of mesoporous structure. The BET specific surface areas of $\mathrm{g}-\mathrm{C}_{3} \mathrm{~N}_{4}$ and $\mathrm{mNb}_{2} \mathrm{O}_{5}$ are 11.2 and $138 \mathrm{~m}^{2} / \mathrm{g}$, respectively. The surface area of the composites follows the sequence: $4 \% \mathrm{~g}-\mathrm{C}_{3} \mathrm{~N}_{4}-\mathrm{mNb}_{2} \mathrm{O}_{5}\left(190 \mathrm{~m}^{2} / \mathrm{g}\right)>10 \%$ $\mathrm{g}-\mathrm{C}_{3} \mathrm{~N}_{4}-\mathrm{mNb}_{2} \mathrm{O}_{5}\left(182 \mathrm{~m}^{2} / \mathrm{g}\right)>1 \% \mathrm{~g}-\mathrm{C}_{3} \mathrm{~N}_{4}-\mathrm{mNb}_{2} \mathrm{O}_{5}\left(152 \mathrm{~m}^{2} / \mathrm{g}\right)>50 \% \mathrm{~g}-\mathrm{C}_{3} \mathrm{~N}_{4}-\mathrm{mNb}_{2} \mathrm{O}_{5}\left(136 \mathrm{~m}^{2} / \mathrm{g}\right)$. Among them, $4 \% g-\mathrm{C}_{3} \mathrm{~N}_{4}-\mathrm{mNb}_{2} \mathrm{O}_{5}$ exhibits the largest surface area, which is 1.4 times larger than that of $\mathrm{mNb}_{2} \mathrm{O}_{5}$ and 17 times larger than that of $\mathrm{g}-\mathrm{C}_{3} \mathrm{~N}_{4}$. It may originate from that, after ultrasonication of $\mathrm{g}-\mathrm{C}_{3} \mathrm{~N}_{4}$, the interlayer distance of $\mathrm{g}-\mathrm{C}_{3} \mathrm{~N}_{4}$ increases and the addition of $\mathrm{g}-\mathrm{C}_{3} \mathrm{~N}_{4}$ leads to partial disaggregation of $\mathrm{mNb}_{2} \mathrm{O}_{5}[37,38]$. When the content of $g-\mathrm{C}_{3} \mathrm{~N}_{4}$ is $50 \%$, high content of $g-\mathrm{C}_{3} \mathrm{~N}_{4}$ in the composites results in $\mathrm{g}-\mathrm{C}_{3} \mathrm{~N}_{4}$ stacking together, thus $50 \%$ g- $\mathrm{C}_{3} \mathrm{~N}_{4}-\mathrm{mNb}_{2} \mathrm{O}_{5}$ sample shows almost the same specific surface as $\mathrm{mNb}_{2} \mathrm{O}_{5}$. 


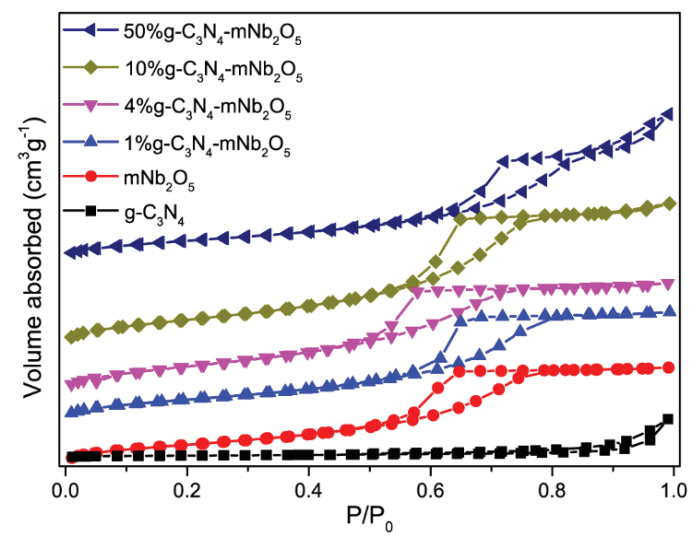

Figure 4. Nitrogen adsorption-desorption isotherms of $\mathrm{g}-\mathrm{C}_{3} \mathrm{~N}_{4}, \mathrm{mNb}_{2} \mathrm{O}_{5}, 1 \%$ g- $\mathrm{C}_{3} \mathrm{~N}_{4}-\mathrm{mNb}_{2} \mathrm{O}_{5}, 4 \%$ g- $\mathrm{C}_{3} \mathrm{~N}_{4}-\mathrm{mNb}_{2} \mathrm{O}_{5}, 10 \%$ g- $\mathrm{C}_{3} \mathrm{~N}_{4}-\mathrm{mNb}_{2} \mathrm{O}_{5}$ and $50 \%$ g- $\mathrm{C}_{3} \mathrm{~N}_{4}-\mathrm{mNb}_{2} \mathrm{O}_{5}$.

\subsubsection{UV-vis DRS}

UV-vis diffuse reflectance spectroscopy (DRS) was performed to estimate the band gap of the catalysts, which is important to determine if the catalysts can be excited in the visible-light region [39]. Figure 5 a shows the UV-vis diffuse reflectance spectra of $\mathrm{mNb}_{2} \mathrm{O}_{5}, \mathrm{~g}-\mathrm{C}_{3} \mathrm{~N}_{4}$ and $\mathrm{g}-\mathrm{C}_{3} \mathrm{~N}_{4}-\mathrm{mNb}_{2} \mathrm{O}_{5}$ composites with different content of $\mathrm{g}-\mathrm{C}_{3} \mathrm{~N}_{4}$. Due to the high band energy value of $\mathrm{mNb}_{2} \mathrm{O}_{5}(3.34 \mathrm{eV})$, $\mathrm{mNb}_{2} \mathrm{O}_{5}$ only absorbs ultraviolet light with its fundamental absorption edge near $371 \mathrm{~nm}$. However, g- $\mathrm{C}_{3} \mathrm{~N}_{4}$ possesses a broad peak in the visible region with an absorption edge at ca. $458 \mathrm{~nm}$. For g- $\mathrm{C}_{3} \mathrm{~N}_{4}-\mathrm{mNb}_{2} \mathrm{O}_{5}$ composites, the absorption edge exhibits an obvious red shift relative to pristine $\mathrm{mNb}_{2} \mathrm{O}_{5}$, indicating the composites could absorb more visible light than $\mathrm{mNb}_{2} \mathrm{O}_{5}$. The band gap energy $(E g)$ of the samples was determined by UV-vis DRS with the Tauc model according to the following equation:

$$
\alpha \mathrm{h} v=\mathrm{A}\left(\mathrm{h} v-E_{g}\right)^{\mathrm{n} / 2}
$$

where $\alpha, \mathrm{h}, v$ and A corresponds to absorption coefficient, Planck constant, light frequency and a constant, respectively, and the constant $n$ depends on whether the transition is direct $(n=1)$ or indirect $(\mathrm{n}=4)$ [40]. For both $\mathrm{g}-\mathrm{C}_{3} \mathrm{~N}_{4}$ and $\mathrm{mNb}_{2} \mathrm{O}_{5}$, the values of $\mathrm{n}$ are 1 [41,42]. Thus, the band gap values of $1 \%$ g- $\mathrm{C}_{3} \mathrm{~N}_{4}-\mathrm{mNb}_{2} \mathrm{O}_{5}, 4 \%$ g- $\mathrm{C}_{3} \mathrm{~N}_{4}-\mathrm{mNb}_{2} \mathrm{O}_{5}, 10 \%$ g- $\mathrm{C}_{3} \mathrm{~N}_{4}-\mathrm{mNb}_{2} \mathrm{O}_{5}, 20 \%$ g- $\mathrm{C}_{3} \mathrm{~N}_{4}-\mathrm{mNb}_{2} \mathrm{O}_{5}$ and $50 \%$ g- $\mathrm{C}_{3} \mathrm{~N}_{4}-\mathrm{mNb}_{2} \mathrm{O}_{5}$ are estimated as 3.34, 3.10, 3.19, 3.15 and $2.88 \mathrm{eV}$, respectively (Figure $5 \mathrm{~b}$ ). The narrowed band gaps of $4 \%$ g- $\mathrm{C}_{3} \mathrm{~N}_{4}-\mathrm{mNb}_{2} \mathrm{O}_{5}, 10 \%$ g- $\mathrm{C}_{3} \mathrm{~N}_{4}-\mathrm{mNb}_{2} \mathrm{O}_{5}$ and $20 \%$ g- $\mathrm{C}_{3} \mathrm{~N}_{4}-\mathrm{mNb}_{2} \mathrm{O}_{5}$ results from the formation of heterostructure between $\mathrm{g}-\mathrm{C}_{3} \mathrm{~N}_{4}$ and $\mathrm{mNb}_{2} \mathrm{O}_{5}$ [29]. It implies that $4 \%$ g- $\mathrm{C}_{3} \mathrm{~N}_{4}-\mathrm{mNb}_{2} \mathrm{O}_{5}$ can harvest more visible light, which is beneficial to improve the visible-light photocatalytic activity of catalysts. Interestingly, the band gap of $50 \%$ g- $\mathrm{C}_{3} \mathrm{~N}_{4}-\mathrm{mNb}_{2} \mathrm{O}_{5}$ is lower than that of other composites, due to high content of g- $\mathrm{C}_{3} \mathrm{~N}_{4}$ in $50 \%$ g- $\mathrm{C}_{3} \mathrm{~N}_{4}-\mathrm{mNb}_{2} \mathrm{O}_{5}$. 


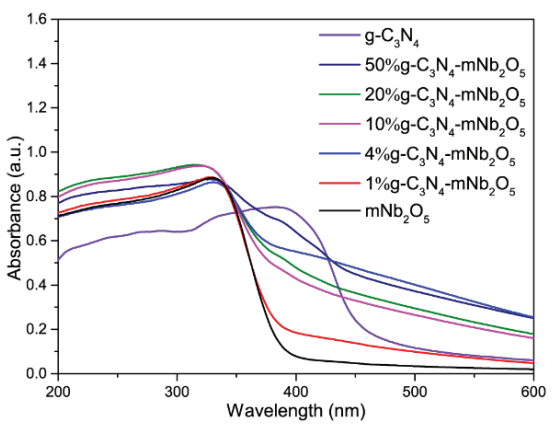

(a)

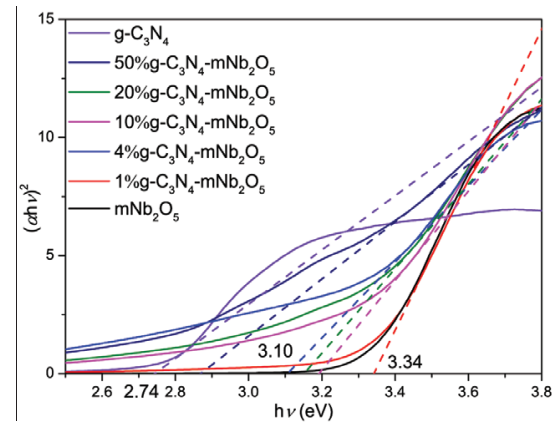

(b)

Figure 5. (a) UV-vis diffuse reflectance spectra; and (b) plots of the $(\alpha \mathrm{h} v)^{2} \mathrm{vs}$. (hv) of $\mathrm{mNb}_{2} \mathrm{O}_{5}, g-\mathrm{C}_{3} \mathrm{~N}_{4}$, and $\mathrm{g}-\mathrm{C}_{3} \mathrm{~N}_{4}-\mathrm{mNb}_{2} \mathrm{O}_{5}$ composites with different content of $\mathrm{g}-\mathrm{C}_{3} \mathrm{~N}_{4}$.

\subsubsection{XPS}

XPS was used to characterize the surface chemical composition and elemental valence states of the samples. As shown in Figure 6a, $\mathrm{C}$ and $\mathrm{N}$ elements are detected from g- $\mathrm{C}_{3} \mathrm{~N}_{4}$ and $\mathrm{Nb}$ and $\mathrm{O}$ elements are detected from $\mathrm{mNb}_{2} \mathrm{O}_{5}$. As for the spectrum of $4 \% \mathrm{~g}_{-} \mathrm{C}_{3} \mathrm{~N}_{4}-\mathrm{mNb}_{2} \mathrm{O}_{5}$, a very weak $\mathrm{N} 1 \mathrm{~s}$ peak is ascribed to small content of g- $\mathrm{C}_{3} \mathrm{~N}_{4}$. Figure $6 \mathrm{~b}$ presents the high resolution XPS spectra of $\mathrm{Nb}$ $3 \mathrm{~d}$ for $4 \% \mathrm{~g}-\mathrm{C}_{3} \mathrm{~N}_{4}-\mathrm{mNb}_{2} \mathrm{O}_{5}$ and $\mathrm{mNb}_{2} \mathrm{O}_{5}$. For $\mathrm{mNb}_{2} \mathrm{O}_{5}$, the signals of $\mathrm{Nb}_{3} \mathrm{~d}_{5 / 2}$ and $3 \mathrm{~d}_{3 / 2}$ locate at 207.0 and $209.6 \mathrm{eV}$, respectively, whereas the signals of $\mathrm{Nb} 3 \mathrm{~d}_{5 / 2}$ and $3 \mathrm{~d}_{3 / 2}$ shift slightly $(\Delta \mathrm{BE} \sim 0.4 \mathrm{eV})$ to a higher binding energy for $4 \%$ g- $\mathrm{C}_{3} \mathrm{~N}_{4}-\mathrm{mNb}_{2} \mathrm{O}_{5}$. The upshift may be attributed to band bending.

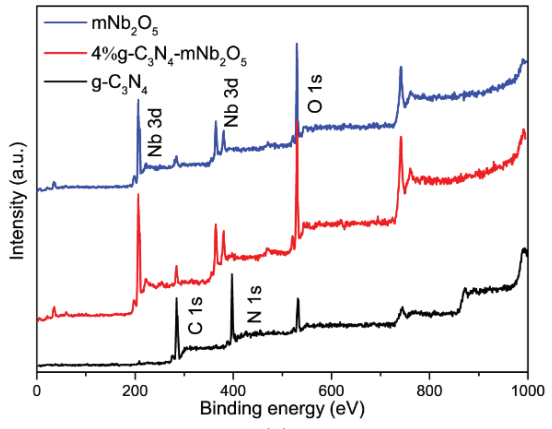

(a)

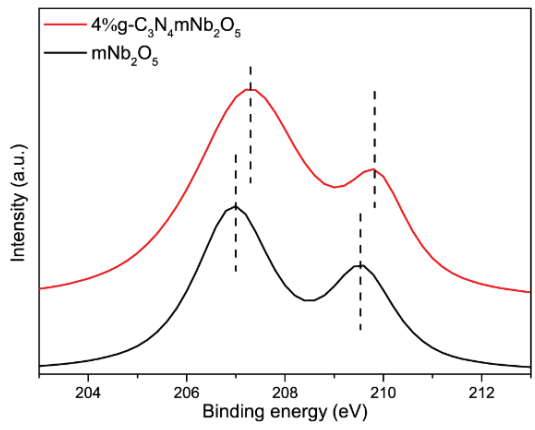

(b)

Figure 6. (a) XPS survey spectra of $\mathrm{g}-\mathrm{C}_{3} \mathrm{~N}_{4}, \mathrm{mNb}_{2} \mathrm{O}_{5}$ and $4 \% \mathrm{~g}-\mathrm{C}_{3} \mathrm{~N}_{4}-\mathrm{mNb}_{2} \mathrm{O}_{5}$; and (b) $\mathrm{Nb} 3 \mathrm{~d}$ spectra for $\mathrm{mNb}_{2} \mathrm{O}_{5}$ and $4 \% \mathrm{~g}-\mathrm{C}_{3} \mathrm{~N}_{4}-\mathrm{mNb}_{2} \mathrm{O}_{5}$.

\subsubsection{PL Spectroscopy}

To test the generation and recombination efficiency of photogenerated electrons and holes in semiconductors, PL spectroscopy is often conducted. The PL spectra of $\mathrm{mNb}_{2} \mathrm{O}_{5}, 4 \% \mathrm{~g}-\mathrm{C}_{3} \mathrm{~N}_{4}-\mathrm{mNb}_{2} \mathrm{O}_{5}$, $10 \%$ g- $\mathrm{C}_{3} \mathrm{~N}_{4}-\mathrm{mNb}_{2} \mathrm{O}_{5}, 20 \%$ g- $\mathrm{C}_{3} \mathrm{~N}_{4}-\mathrm{mNb}_{2} \mathrm{O}_{5}, 50 \%$ g- $\mathrm{C}_{3} \mathrm{~N}_{4}-\mathrm{mNb}_{2} \mathrm{O}_{5}$ and $\mathrm{g}-\mathrm{C}_{3} \mathrm{~N}_{4}$ with an excitation wavelength of $300 \mathrm{~nm}$ are shown in Figure 7. It can be observed that $\mathrm{mNb}_{2} \mathrm{O}_{5}$ has a strong emission peak at $474 \mathrm{~nm}$ and g- $\mathrm{C}_{3} \mathrm{~N}_{4}$ has a strong emission peak at $472 \mathrm{~nm}$. Compared to $\mathrm{mNb}_{2} \mathrm{O}_{5}$, the PL emission intensity of $\mathrm{g}-\mathrm{C}_{3} \mathrm{~N}_{4}-\mathrm{mNb}_{2} \mathrm{O}_{5}$ samples is significantly reduced, suggesting that the g- $\mathrm{C}_{3} \mathrm{~N}_{4}-\mathrm{mNb}_{2} \mathrm{O}_{5}$ composite has a lower recombination rate of photogenerated electrons and holes than $\mathrm{mNb}_{2} \mathrm{O}_{5}$. Among the composites, the $4 \% \mathrm{~g}-\mathrm{C}_{3} \mathrm{~N}_{4}-\mathrm{mNb}_{2} \mathrm{O}_{5}$ sample shows the lowest emission 
intensity at the similar emission peak position which means the lowest recombination efficiency of photogenerated electrons and holes $[27,43,44]$. Combined with the UV-vis DRS analysis result that $4 \%$ g- $\mathrm{C}_{3} \mathrm{~N}_{4}-\mathrm{mNb}_{2} \mathrm{O}_{5}$ has the lowest band gap, $4 \%$ g- $\mathrm{C}_{3} \mathrm{~N}_{4}-\mathrm{mNb}_{2} \mathrm{O}_{5}$ demonstrates best potential in photocatalytic degradation reactions among the catalysts studied in this work.

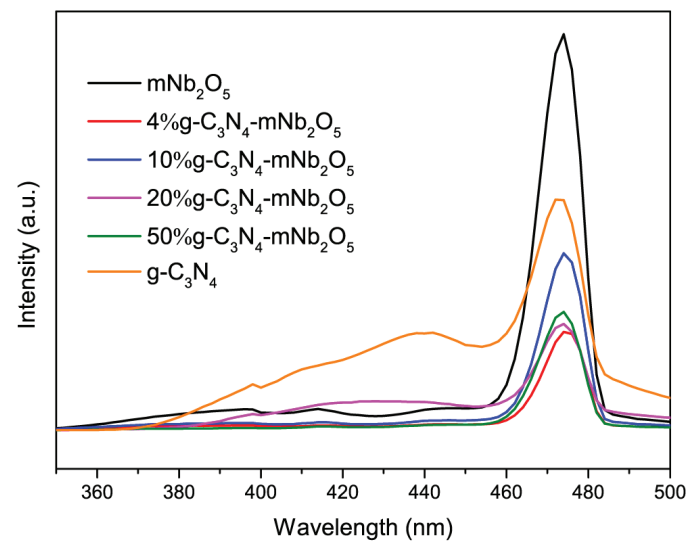

Figure 7. PL spectra of $\mathrm{mNb}_{2} \mathrm{O}_{5}, 4 \%$ g- $\mathrm{C}_{3} \mathrm{~N}_{4}-\mathrm{mNb}_{2} \mathrm{O}_{5}, 10 \%$ g- $\mathrm{C}_{3} \mathrm{~N}_{4}-\mathrm{mNb}_{2} \mathrm{O}_{5}, 20 \%$ g- $\mathrm{C}_{3} \mathrm{~N}_{4}-\mathrm{mNb}_{2} \mathrm{O}_{5}$, $50 \%$ g- $\mathrm{C}_{3} \mathrm{~N}_{4}-\mathrm{mNb}_{2} \mathrm{O}_{5}$ and $\mathrm{g}-\mathrm{C}_{3} \mathrm{~N}_{4}$.

\subsection{Visible-Light Photocatalytic Performance and Stability of the Catalysts}

The photocatalytic test of $\mathrm{mNb}_{2} \mathrm{O}_{5}, \mathrm{~g}-\mathrm{C}_{3} \mathrm{~N}_{4}$ and $\mathrm{g}-\mathrm{C}_{3} \mathrm{~N}_{4}-\mathrm{mNb}_{2} \mathrm{O}_{5}$ composites with different content of $\mathrm{g}-\mathrm{C}_{3} \mathrm{~N}_{4}$ in degradation of $\mathrm{RhB}$ and $\mathrm{TC}-\mathrm{HCl}$ were carried out under visible light irradiation $(\lambda>420 \mathrm{~nm})$.

\subsubsection{Photodegradation of RhB under Visible Light Irradiation}

The photocatalytic degradation results are shown in Figure 8a. The standard curve of the absorbance intensity (A) vs. concentration (C) of RhB solution is shown in Figure S4a. The RhB suspension was firstly stirred in dark for $2 \mathrm{~h}$ at room temperature to reach adsorption/desorption equilibrium (Figure S3a) $[45,46]$. No evident decrease of RhB concentration is observed in the absence of catalyst. Therefore, the direct photolysis of $\mathrm{RhB}$ could be ignored. Pure $\mathrm{mNb}_{2} \mathrm{O}_{5}$ and g- $\mathrm{C}_{3} \mathrm{~N}_{4}$ show low photocatalytic activities with only about $27.3 \%$ and $25.4 \%$ of RhB being degraded after $180 \mathrm{~min}$ of irradiation, respectively. The g- $\mathrm{C}_{3} \mathrm{~N}_{4}-\mathrm{mNb}_{2} \mathrm{O}_{5}$ composites show higher degradation efficiency than $\mathrm{mNb}_{2} \mathrm{O}_{5}$ and $\mathrm{g}-\mathrm{C}_{3} \mathrm{~N}_{4}$. For the catalysts containing different content of $\mathrm{g}-\mathrm{C}_{3} \mathrm{~N}_{4}$, the sample $4 \%$ g- $\mathrm{C}_{3} \mathrm{~N}_{4}-\mathrm{mNb}_{2} \mathrm{O}_{5}$ exhibits the highest degradation efficiency for RhB (97.5\%) within $180 \mathrm{~min}$, which is 3.6 and 3.9 times higher than that of $\mathrm{mNb}_{2} \mathrm{O}_{5}$ and $g-\mathrm{C}_{3} \mathrm{~N}_{4}$, respectively. Furthermore, the corresponding mechanic mixture $4 \%$ g- $\mathrm{C}_{3} \mathrm{~N}_{4} / \mathrm{mNb}_{2} \mathrm{O}_{5}$ shows $51 \%$ of degradation efficiency for $\mathrm{RhB}$, which is much smaller than that of $4 \% \mathrm{~g}-\mathrm{C}_{3} \mathrm{~N}_{4}-\mathrm{mNb}_{2} \mathrm{O}_{5}$ composite. Therefore, the high degradation efficiency of $4 \% \mathrm{~g}-\mathrm{C}_{3} \mathrm{~N}_{4}-\mathrm{mNb}_{2} \mathrm{O}_{5}$ is ascribed to the formation of heterostructure between $\mathrm{g}-\mathrm{C}_{3} \mathrm{~N}_{4}$ and $\mathrm{mNb}_{2} \mathrm{O}_{5}$, as found in the UV-vis DRS and PL studies. 


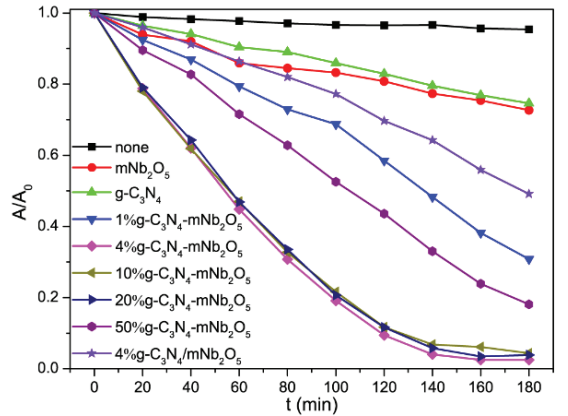

(a)

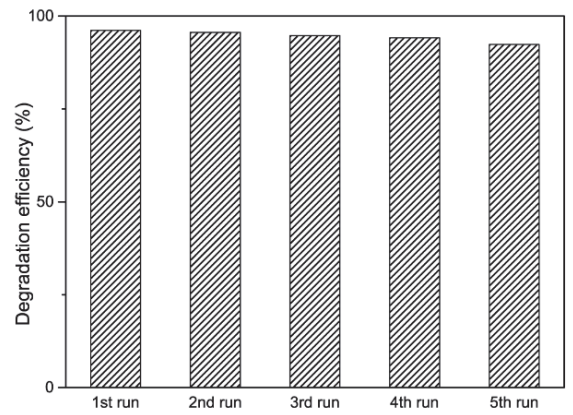

(b)

Figure 8. (a) Photolysis of RhB and photocatalytic activity over as-prepared photocatalysts for RhB; and (b) recyclability for the photodegradation of $\mathrm{RhB}$ in the presence of $4 \% \mathrm{~g}-\mathrm{C}_{3} \mathrm{~N}_{4}-\mathrm{mNb}_{2} \mathrm{O}_{5}$ under visible light irradiation.

In addition to photocatalytic efficiency, stability and recyclability of the catalysts are also important for application of the catalysts. The $4 \%$ g- $\mathrm{C}_{3} \mathrm{~N}_{4}-\mathrm{mNb}_{2} \mathrm{O}_{5}$ sample for photodegradation of $\mathrm{RhB}$ was further tested for five cycles. As shown in Figure $8 \mathrm{~b}$, after five cycles, the high efficiency for photocatalytic degradation of $\mathrm{RhB}$ by $4 \% \mathrm{~g}-\mathrm{C}_{3} \mathrm{~N}_{4}-\mathrm{mNb}_{2} \mathrm{O}_{5}$ is maintained, demonstrating good reusability and stability of $4 \% \mathrm{~g}-\mathrm{C}_{3} \mathrm{~N}_{4}-\mathrm{mNb}_{2} \mathrm{O}_{5}$.

\subsubsection{Photodegradation of $\mathrm{TC}-\mathrm{HCl}$ under Visible Light Irradiation}

The photocatalytic degradation of TC- $\mathrm{HCl}$ results are shown in Figure 9a. The standard curve of the absorbance intensity (A) vs. concentration (C) of TC- $\mathrm{HCl}$ solution can be seen in Figure $\mathrm{S} 4 \mathrm{~b}$. The TC-HCl suspension was firstly stirred in dark for $1 \mathrm{~h}$ at room temperature to reach adsorption/desorption equilibrium (Figure S3b) $[45,46]$. No evident decrease of TC-HCl concentration is observed in the absence of catalyst. The pure $\mathrm{mNb}_{2} \mathrm{O}_{5}$ and $\mathrm{g}-\mathrm{C}_{3} \mathrm{~N}_{4}$ show low photocatalytic efficiency in degradation of TC- $\mathrm{HCl}$ with about $49.7 \%$ and $5.3 \%$ after $60 \mathrm{~min}$ of irradiation, respectively. The degradation efficiency of $\mathrm{g}-\mathrm{C}_{3} \mathrm{~N}_{4}-\mathrm{mNb}_{2} \mathrm{O}_{5}$ composites within 60 min could be listed as the following order: $4 \%$ g- $-\mathrm{C}_{3} \mathrm{~N}_{4}-\mathrm{mNb}_{2} \mathrm{O}_{5}>10 \%$ g- $\mathrm{C}_{3} \mathrm{~N}_{4}-\mathrm{mNb}_{2} \mathrm{O}_{5} \approx 20 \%$ g- $\mathrm{C}_{3} \mathrm{~N}_{4}-\mathrm{mNb}_{2} \mathrm{O}_{5}>50 \%$ g- $\mathrm{C}_{3} \mathrm{~N}_{4}-\mathrm{mNb}_{2} \mathrm{O}_{5}>1 \%$ g- $\mathrm{C}_{3} \mathrm{~N}_{4}-\mathrm{mNb}_{2} \mathrm{O}_{5}$. All g- $\mathrm{C}_{3} \mathrm{~N}_{4}-\mathrm{mNb}_{2} \mathrm{O}_{5}$ composites display higher degradation efficiency than that of $\mathrm{mNb}_{2} \mathrm{O}_{5}$ and $\mathrm{g}-\mathrm{C}_{3} \mathrm{~N}_{4}$. For comparison, the corresponding mechanic mixture $4 \%$ g- $\mathrm{C}_{3} \mathrm{~N}_{4} / \mathrm{mNb}_{2} \mathrm{O}_{5}$ shows its degradation efficiency of $52 \%$. Overall, $4 \% \mathrm{~g}-\mathrm{C}_{3} \mathrm{~N}_{4}-\mathrm{mNb}_{2} \mathrm{O}_{5}$ is the optimal catalyst, for which the degradation efficiency of TC- $\mathrm{HCl}$ in $60 \mathrm{~min}$ is $75.7 \%$. After 30-min experimental run, for $4 \%$ g- $\mathrm{C}_{3} \mathrm{~N}_{4}-\mathrm{mNb}_{2} \mathrm{O}_{5}, 10 \%$ g- $\mathrm{C}_{3} \mathrm{~N}_{4}-\mathrm{mNb}_{2} \mathrm{O}_{5}$ and $20 \%$ g- $\mathrm{C}_{3} \mathrm{~N}_{4}-\mathrm{mNb}_{2} \mathrm{O}_{5}$, degradation reaction of $\mathrm{TC}-\mathrm{HCl}$ solution has approached the endpoint. Further degradation is hard to proceed so that the degradation rate is slow and the change of absorbance change is not evident. An appropriate content of $\mathrm{g}^{-} \mathrm{C}_{3} \mathrm{~N}_{4}$ leads to this composite with large surface area, narrow band gap and low PL intensity, which favors the titled photocatalytic reactions $[41,44,47]$. 


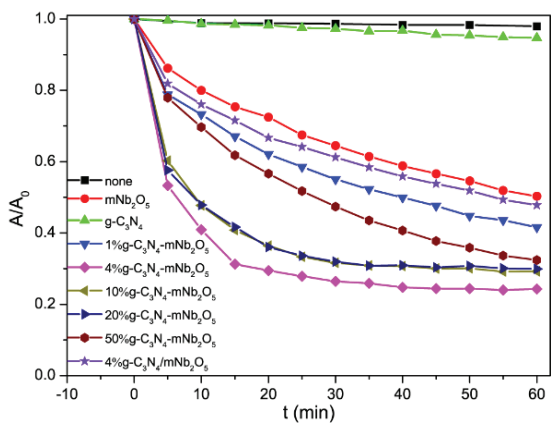

(a)

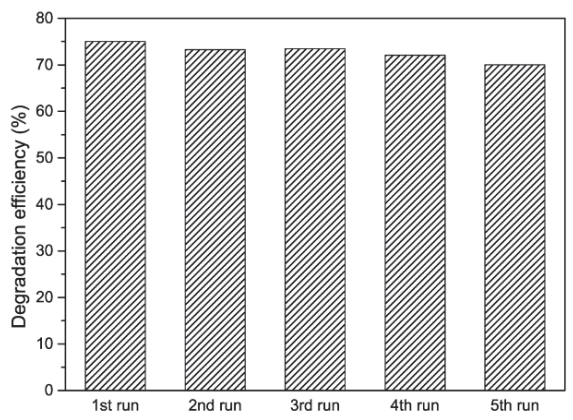

(b)

Figure 9. (a) Photolysis of $\mathrm{TC}-\mathrm{HCl}$ and photocatalytic activity over as-prepared photocatalysts for TC-HCl; and (b) recyclability for the photodegradation of $\mathrm{TC}-\mathrm{HCl}$ in the presence of $4 \%$ $\mathrm{g}-\mathrm{C}_{3} \mathrm{~N}_{4}-\mathrm{mNb}_{2} \mathrm{O}_{5}$ under visible light irradiation.

The stability and recyclability of $4 \%$ g- $\mathrm{C}_{3} \mathrm{~N}_{4}-\mathrm{mNb}_{2} \mathrm{O}_{5}$ catalysts for photocatalytic degradation of $\mathrm{TC}-\mathrm{HCl}$ were also tested for five cycles. As shown in Figure 9b, after five cycles, photodegradation efficiency of $4 \% \mathrm{~g}-\mathrm{C}_{3} \mathrm{~N}_{4}-\mathrm{mNb}_{2} \mathrm{O}_{5}$ for TC- $\mathrm{HCl}$ is almost unchanged. Thus, $4 \% \mathrm{~g}-\mathrm{C}_{3} \mathrm{~N}_{4}-\mathrm{mNb}_{2} \mathrm{O}_{5}$ sample could maintain good stability and it is able to be reused in the photodegradation reaction of TC- $\mathrm{HCl}$ as well as in photodegradation reaction of RhB.

In other words, in two photocatalytic reactions of $\mathrm{RhB}$ solution and TC- $\mathrm{HCl}$ solution under visible-light irradiation, $\mathrm{g}-\mathrm{C}_{3} \mathrm{~N}_{4}-\mathrm{mNb}_{2} \mathrm{O}_{5}$ composites showed enhanced photocatalytic activity than $\mathrm{mNb}_{2} \mathrm{O}_{5}$. The $4 \% \mathrm{~g}-\mathrm{C}_{3} \mathrm{~N}_{4}-\mathrm{mNb}_{2} \mathrm{O}_{5}$ sample shows the highest photocatalytic activity. The other photocatalytic performance of $\mathrm{Nb}_{2} \mathrm{O}_{5} / g-\mathrm{C}_{3} \mathrm{~N}_{4}$ composites were also tested by Ribeiro et al., Shi et al., and Li et al. [29-31]. Compared to the reported work, our work focus on the stability of catalysts, which is greatly distinct. The strategy based on the in situ hydrolysis can efficiently avoid the aggregation of $\mathrm{Nb}_{2} \mathrm{O}_{5}$, thus further facilitating the full exertion of catalyst activity. Besides, the interlayer of $\mathrm{g}-\mathrm{C}_{3} \mathrm{~N}_{4}$ sheets can be enlarged by the existence of $\mathrm{Nb}_{2} \mathrm{O}_{5}$, increasing the surface area of catalyst. The stability of our catalyst is superior to many reported literatures when evaluated in the photocatalytic of $\mathrm{RhB}$ and $\mathrm{TC}-\mathrm{HCl}$, which can be attributed to highly uniformity and tightly anchoring of $\mathrm{Nb}_{2} \mathrm{O}_{5}$ on g- $\mathrm{C}_{3} \mathrm{~N}_{4}$ sheets.

\section{Conclusions}

In summary, we have prepared a series of g- $\mathrm{C}_{3} \mathrm{~N}_{4}-\mathrm{mNb}_{2} \mathrm{O}_{5}$ composites by in situ $\mathrm{NbCl}_{5}$ hydrolysis, deposition and solvothermal treatment. It is found that the $\mathrm{g}-\mathrm{C}_{3} \mathrm{~N}_{4}-\mathrm{mNb}_{2} \mathrm{O}_{5}$ composites exhibit lower PL intensity than pure $\mathrm{mNb}_{2} \mathrm{O}_{5}$ and $\mathrm{g}-\mathrm{C}_{3} \mathrm{~N}_{4}$ and narrower band gap than pure $\mathrm{mNb}_{2} \mathrm{O}_{5}$, leading to a significant enhancement of photocatalytic activity with excellent stability and recyclability for degradation of $\mathrm{RhB}$ and TC- $\mathrm{HCl}$. Among the composites, $4 \%$ g- $\mathrm{C}_{3} \mathrm{~N}_{4}-\mathrm{mNb}_{2} \mathrm{O}_{5}$ sample shows the highest photocatalytic activity under visible-light irradiation $(\lambda>420 \mathrm{~nm})$, which is ascribed to the strong interaction between g- $\mathrm{C}_{3} \mathrm{~N}_{4}$ and $\mathrm{Nb}_{2} \mathrm{O}_{5}$, its smallest band gap and lowest PL intensity. Based on the above characterization and photocatalytic results, the excellent photocatalytic activity of $4 \%$ g- $\mathrm{C}_{3} \mathrm{~N}_{4}-\mathrm{mNb}_{2} \mathrm{O}_{5}$ can be attributed to combined effects between $\mathrm{g}-\mathrm{C}_{3} \mathrm{~N}_{4}$ and $\mathrm{mNb}_{2} \mathrm{O}_{5}$ as follows: (1) the induction of $\mathrm{g}-\mathrm{C}_{3} \mathrm{~N}_{4}$ into $\mathrm{mNb}_{2} \mathrm{O}_{5}$ leads to extension the absorption into visible light region; (2) the recombination of photogenerated electrons and holes is inhibited to some extent; (3) its highest surface area among all composites leads to more active sites; and (4) interaction exists between $\mathrm{mNb}_{2} \mathrm{O}_{5}$ and $\mathrm{g}-\mathrm{C}_{3} \mathrm{~N}_{4}$, as observed in XPS and FT-IR. These also account for the remarkable stability and recyclability of the catalyst $4 \%$ g- $\mathrm{C}_{3} \mathrm{~N}_{4}-\mathrm{mNb}_{2} \mathrm{O}_{5}$ in the degradation reaction. 


\section{Highlights:}

1. $\mathrm{g}_{-} \mathrm{C}_{3} \mathrm{~N}_{4}-\mathrm{mNb}_{2} \mathrm{O}_{5}$ composites were obtained by in situ hydrolysis deposition and solvothermal treatment.

2. Under the visible light irradiation, $4 \%$ g- $\mathrm{C}_{3} \mathrm{~N}_{4}-\mathrm{mNb}_{2} \mathrm{O}_{5}$ exhibited the highest photocatalytic activities to degrade rhodamine B (97.5\% degradation within $180 \mathrm{~min})$ and tetracycline hydrochloride $(75.7 \%$ degradation within $60 \mathrm{~min})$ solution with excellent stability and recyclability.

3. The g- $\mathrm{C}_{3} \mathrm{~N}_{4}-\mathrm{mNb}_{2} \mathrm{O}_{5}$ composites showed narrower band gap, lower PL intensity and larger surface area than pure $\mathrm{mNb}_{2} \mathrm{O}_{5}$ and $\mathrm{g}-\mathrm{C}_{3} \mathrm{~N}_{4}$, leading to a significant enhancement of their photocatalytic activity.

Supplementary Materials: The following are available online at http:/ /www.mdpi.com/2079-4991/8/6/427/s1, Figure S1: A schematic diagram of photocatalytic equipment, Figure S2: Emission spectrum of Xe lamp with $420 \mathrm{~nm}$ filter, Figure S3: Influence of adsorption process on: (a) RhB solution (15 mg/L, $70 \mathrm{~mL})$; and (b) TC- $\mathrm{HCl}$ solution $\left(40 \mathrm{mg} / \mathrm{L}, 100 \mathrm{~mL}\right.$ ) containing $30 \mathrm{mg} 4 \% \mathrm{~g}-\mathrm{C}_{3} \mathrm{~N}_{4}-\mathrm{mNb}_{2} \mathrm{O}_{5}$ powder under dark, Figure S4: Absorption changes of: (a) RhB solution ( $15 \mathrm{mg} / \mathrm{L}, 70 \mathrm{~mL})$; and (b) TC- $\mathrm{HCl}$ solution $(40 \mathrm{mg} / \mathrm{L}, 100 \mathrm{~mL})$ containing $30 \mathrm{mg} 4 \%$ g- $\mathrm{C}_{3} \mathrm{~N}_{4}-\mathrm{mNb}_{2} \mathrm{O}_{5}$ powder under visible light irradiation, Figure S5: Standard curves of absorbance intensity vs. concentration of: (a) RhB solution; and (b) TC- $\mathrm{HCl}$ solution, Table S1: The elements content of $4 \% \mathrm{~g}-\mathrm{C}_{3} \mathrm{~N}_{4}-\mathrm{mNb}_{2} \mathrm{O}_{5}$ by EDS analysis.

Author Contributions: M.W. managed all the experiments and initial writing; H.W., Y.R., C.W. and Z.W. contributed greatly to data analysis, discussion and manuscript preparation. B.Y. and H.H. supervised and managed the project.

Acknowledgments: This work was supported by the National Natural Science Foundation of China (21673046, 21473036, 91645201 and 21371035).

Conflicts of Interest: The authors declare no conflict of interest.

\section{References}

1. Barbosa, M.O.; Moreira, N.F.F.; Ribeiro, A.R.; Pereira, M.F.R.; Silva, A.M.T. Occurrence and removal of organic micropollutants: An overview of the watch list of EU Decision 2015/495. Water Res. 2016, 94, 257-279. [CrossRef] [PubMed]

2. Zhang, Q.Q.; Ying, G.G.; Pan, C.G.; Liu, Y.S.; Zhao, J.L. Comprehensive evaluation of antibiotics emission and fate in the river basins of China: Source analysis, multimedia modeling, and linkage to bacterial resistance. Environ. Sci. Technol. 2015, 49, 6772-6782. [CrossRef] [PubMed]

3. Molla, A.; Sahu, M.; Hussain, S. Synthesis of tunable band gap semiconductor nickel sulphide nanoparticles: Rapid and round the clock degradation of organic dyes. Sci. Rep. 2016, 6, 1-11. [CrossRef] [PubMed]

4. Gao, P.; Munir, M.; Xagoraraki, I. Correlation of tetracycline and sulfonamide antibiotics with corresponding resistance genes and resistant bacteria in a conventional municipal wastewater treatment plant. Sci. Total Environ. 2012, 421, 173-183. [CrossRef] [PubMed]

5. Lv, Z.Y.; Liu, X.J.; Jia, B.; Wang, H.; Wu, Y.; Lu, Z.P. Development of a novel high-entropy alloy with eminent efficiency of degrading azo dye solutions. Sci. Rep. 2016, 6, 1-11. [CrossRef] [PubMed]

6. Ahmed, M.B.; Zhou, J.L.; Ngo, H.H.; Guo, W.S. Adsorptive removal of antibiotics from water and wastewater: Progress and challenges. Sci. Total Environ. 2015, 532, 112-126. [CrossRef] [PubMed]

7. Gaya, U.I.; Abdullah, A.H. Heterogeneous photocatalytic degradation of organic contaminants over titanium dioxide: A review of fundamentals, progress and problems. J. Photochem. Photobiol. C 2008, 9, 1-12. [CrossRef]

8. Sorathiya, K.; Mishra, B.; Kalarikkal, A.; Reddy, K.P.; Gopinath, C.S.; Khushalani, D. Enhancement in rate of photocatalysis upon catalyst recycling. Sci. Rep. 2016, 6, 1-9. [CrossRef] [PubMed]

9. Szilagyi, I.M.; Forizs, B.; Rosseler, O.; Szegedi, A.; Nemeth, P.; Kiraly, P.; Tarkanyi, G.; Vajna, B.; Varga-Josepovits, K.; Laszlo, $\mathrm{K}$; et al. $\mathrm{WO}_{3}$ photocatalysts: Influence of structure and composition. J. Catal. 2012, 294, 119-127. [CrossRef]

10. Daneshvar, N.; Salari, D.; Khataee, A.R. Photocatalytic degradation of azo dye acid red 14 in water on $\mathrm{ZnO}$ as an alternative catalyst to $\mathrm{TiO}_{2}$. J. Photochem. Photobiol. A 2004, 162, 317-322. [CrossRef] 
11. Zhou, Z.H.; Lin, Y.L.; Zhang, P.A.; Ashalley, E.; Shafa, M.; Li, H.D.; Wu, J.; Wang, Z.M. Hydrothermal fabrication of porous $\mathrm{MoS}_{2}$ and its visible light photocatalytic properties. Mater. Lett. 2014, 131, 122-124. [CrossRef]

12. Zhao, Y.; Eley, C.; Hu, J.P.; Foord, J.S.; Ye, L.; He, H.Y.; Tsang, S.C.E. Shape-dependent acidity and photocatalytic activity of $\mathrm{Nb}_{2} \mathrm{O}_{5}$ nanocrystals with an active TT (001) surface. Angew. Chem. Int. Ed. 2012, 51, 3846-3849. [CrossRef] [PubMed]

13. Liu, H.; Gao, N.; Liao, M.Y.; Fang, X.S. Hexagonal-like $\mathrm{Nb}_{2} \mathrm{O}_{5}$ nanoplates-based photodetectors and photocatalyst with high performances. Sci. Rep. 2015, 5, 1-9. [CrossRef] [PubMed]

14. Zhao, W.L.; Zhao, W.; Zhu, G.L.; Lin, T.Q.; Xu, F.F.; Huang, F.Q. Black $\mathrm{Nb}_{2} \mathrm{O}_{5}$ nanorods with improved solar absorption and enhanced photocatalytic activity. Dalton Trans. 2016, 45, 3888-3894. [CrossRef] [PubMed]

15. Oliveira, L.C.A.; Oliveira, H.S.; Mayrink, G.; Mansur, H.S.; Mansur, A.A.P.; Moreira, R.L. One-pot synthesis of CdS@ $\mathrm{Nb}_{2} \mathrm{O}_{5}$ core shell nanostructures with enhanced photocatalytic activity. Appl. Catal. B 2014, 152, 403-412. [CrossRef]

16. Hu, C.Y.; Teoh, W.Y.; Ji, S.L.; Ye, C.H.; Iwase, A. In situ metal doping during modified anodization synthesis of $\mathrm{Nb}_{2} \mathrm{O}_{5}$ with enhanced photoelectrochemical water splitting. AIChE J. 2016, 62, 352-358. [CrossRef]

17. Zhang, H.L.; Lin, Q.Y.; Ning, S.B.; Zhou, Y.G.; Lin, H.X.; Long, J.L.; Zhang, Z.Z.; Wang, X.X. One-step synthesis of mesoporous $\mathrm{Pt}-\mathrm{Nb}_{2} \mathrm{O}_{5}$ nanocomposites with enhanced photocatalytic hydrogen production activity. RSC Adv. 2016, 6, 96809-96815. [CrossRef]

18. Zhao, Z.W.; Sun, Y.J.; Dong, F. Graphitic carbon nitride based nanocomposites: A review. Nanoscale 2015, 7, 15-37. [CrossRef] [PubMed]

19. Su, F.Z.; Mathew, S.C.; Lipner, G.; Fu, X.Z.; Antonietti, M.; Blechert, S.; Wang, X.C. mpg-C ${ }_{3} \mathrm{~N}_{4}$-catalyzed selective oxidation of alcohols using $\mathrm{O}_{2}$ and visible Light. J. Am. Chem. Soc. 2010, 132, 16299-16301. [CrossRef] [PubMed]

20. Yang, X.L.; Qian, F.F.; Zou, G.J.; Li, M.L.; Lu, J.R.; Li, Y.M.; Bao, M.T. Facile fabrication of acidified g- $\mathrm{C}_{3} \mathrm{~N}_{4} / \mathrm{g}-\mathrm{C}_{3} \mathrm{~N}_{4}$ hybrids with enhanced photocatalysis performance under visible light irradiation. Appl. Catal. B 2016, 193, 22-35. [CrossRef]

21. Wang, X.C.; Maeda, K.; Thomas, A.; Takanabe, K.; Xin, G.; Carlsson, J.M.; Domen, K.; Antonietti, M. A metal-free polymeric photocatalyst for hydrogen production from water under visible light. Nat. Mater. 2009, 8, 76-80. [CrossRef] [PubMed]

22. Wang, X.C.; Maeda, K.; Chen, X.F.; Takanabe, K.; Domen, K.; Hou, Y.D.; Fu, X.Z.; Antonietti, M. Polymer semiconductors for artificial photosynthesis: Hydrogen evolution by mesoporous graphitic carbon nitride with visible Light. J. Am. Chem. Soc. 2009, 131, 1680-1681. [CrossRef] [PubMed]

23. Yan, J.Q.; Wu, H.; Chen, H.; Zhang, Y.X.; Zhang, F.X.; Liu, S.F. Fabrication of $\mathrm{TiO}_{2} / \mathrm{C}_{3} \mathrm{~N}_{4}$ heterostructure for enhanced photocatalytic Z-scheme overall water splitting. Appl. Catal. B 2016, 191, 130-137. [CrossRef]

24. Tong, Z.W.; Yang, D.; Xiao, T.X.; Tian, Y.; Jiang, Z.Y. Biomimetic fabrication of $\mathrm{g}-\mathrm{C}_{3} \mathrm{~N}_{4} / \mathrm{TiO}_{2}$ nanosheets with enhanced photocatalytic activity toward organic pollutant degradation. Chem. Eng. J. 2015, 260, 117-125. [CrossRef]

25. Jiang, Y.H.; Li, F.; Liu, Y.; Hong, Y.Z.; Liu, P.P.; Ni, L. Construction of $\mathrm{TiO}_{2}$ hollow nanosphere $/ \mathrm{g}-\mathrm{C}_{3} \mathrm{~N}_{4}$ composites with superior visible-light photocatalytic activity and mechanism insight. J. Ind. Eng. Chem. 2016, 41, 130-140. [CrossRef]

26. Li, Y.G.; Wei, X.L.; Yan, X.Y.; Cai, J.T.; Zhou, A.N.; Yang, M.R.; Liu, K.Q. Construction of inorganic-organic $2 \mathrm{D} / 2 \mathrm{D} \mathrm{WO} 3 / \mathrm{g}-\mathrm{C}_{3} \mathrm{~N}_{4}$ nanosheet arrays toward efficient photoelectrochemical splitting of natural seawater. Phys. Chem. Chem. Phys. 2016, 18, 10255-10261. [CrossRef] [PubMed]

27. Wang, X.; Hong, M.Z.; Zhang, F.W.; Zhuang, Z.Y.; Yu, Y. Recyclable nanoscale zero valent iron doped g- $\mathrm{C}_{3} \mathrm{~N}_{4} / \mathrm{MoS}_{2}$ for efficient photocatalysis of $\mathrm{RhB}$ and $\mathrm{Cr}(\mathrm{VI})$ driven by visible light. ACS Sustain. Chem. Eng. 2016, 4, 4055-4062. [CrossRef]

28. Wang, J.; Xia, Y.; Zhao, H.Y.; Wang, G.F.; Xiang, L.; Xu, J.L.; Komarneni, S. Oxygen defects-mediated Z-scheme charge separation in $\mathrm{g}-\mathrm{C}_{3} \mathrm{~N}_{4} / \mathrm{ZnO}$ photocatalysts for enhanced visible-light degradation of 4-chlorophenol and hydrogen evolution. Appl. Catal. B 2017, 206, 406-416. [CrossRef]

29. Hong, Y.Z.; Li, C.S.; Zhang, G.Y.; Meng, Y.D.; Yin, B.X.; Zhao, Y.; Shi, W.D. Efficient and stable $\mathrm{Nb}_{2} \mathrm{O}_{5}$ modified g- $\mathrm{C}_{3} \mathrm{~N}_{4}$ photocatalyst for removal of antibiotic pollutant. Chem. Eng. J. 2016, 299, 74-84. [CrossRef] 
30. Carvalho, K.T.G.; Nogueira, A.E.; Lopes, O.F.; Byzynski, G.; Ribeiro, C. Synthesis of g- $\mathrm{C}_{3} \mathrm{~N}_{4} / \mathrm{Nb}_{2} \mathrm{O}_{5}$ heterostructures and their application in the removal of organic pollutants under visible and ultraviolet irradiation. Ceram. Int. 2017, 43, 3521-3530. [CrossRef]

31. Huang, Q.Z.; Wang, J.C.; Wang, P.P.; Yao, H.C.; Li, Z.J. In-situ growth of mesoporous $\mathrm{Nb}_{2} \mathrm{O}_{5}$ microspheres on $\mathrm{g}-\mathrm{C}_{3} \mathrm{~N}_{4}$ nanosheets for enhanced photocatalytic $\mathrm{H}_{2}$ evolution under visible light irradiation. Int. J. Hydrogen Energy 2017, 42, 6683-6694. [CrossRef]

32. Niu, P.; Zhang, L.L.; Liu, G.; Cheng, H.M. Graphene-like carbon nitride nanosheets for improved photocatalytic activities. Adv. Funct. Mater. 2012, 22, 4763-4770. [CrossRef]

33. Zheng, Y.; Lin, L.H.; Ye, X.J.; Guo, F.S.; Wang, X.C. Helical graphitic carbon nitrides with photocatalytic and optical activities. Angew. Chem. Int. Ed. 2014, 53, 11926-11930. [CrossRef] [PubMed]

34. Yan, S.C.; Li, Z.S.; Zou, Z.G. Photodegradation performance of $\mathrm{g}_{-} \mathrm{C}_{3} \mathrm{~N}_{4}$ fabricated by directly heating melamine. Langmuir 2009, 25, 10397-10401. [CrossRef] [PubMed]

35. Dong, F.; Wu, L.W.; Sun, Y.J.; Fu, M.; Wu, Z.B.; Lee, S.C. Efficient synthesis of polymeric g- $\mathrm{C}_{3} \mathrm{~N}_{4}$ layered materials as novel efficient visible light driven photocatalysts. J. Mater. Chem. 2011, 21, 15171-15174. [CrossRef]

36. Yue, Z.K.; Chu, D.M.; Huang, H.; Huang, J.; Yang, P.; Du, Y.K.; Zhu, M.S.; Lu, C. A novel heterogeneous hybrid by incorporation of $\mathrm{Nb}_{2} \mathrm{O}_{5}$ microspheres and reduced graphene oxide for photocatalytic $\mathrm{H}_{2}$ evolution under visible light irradiation. RSC Adv. 2015, 5, 47117-47124. [CrossRef]

37. Ding, J.; Liu, Q.Q.; Zhang, Z.Y.; Liu, X.; Zhao, J.Q.; Cheng, S.B.; Zong, B.N.; Dai, W.L. Carbon nitride nanosheets decorated with $\mathrm{WO}_{3}$ nanorods: Ultrasonic-assisted facile synthesis and catalytic application in the green manufacture of dialdehydes. Appl. Catal. B 2015, 165, 511-518. [CrossRef]

38. Yang, S.B.; Gong, Y.J.; Zhang, J.S.; Zhan, L.; Ma, L.L.; Fang, Z.Y.; Vajtai, R.; Wang, X.C.; Ajayan, P.M. Exfoliated Graphitic Carbon Nitride Nanosheets as Efficient Catalysts for Hydrogen Evolution Under Visible Light. Adv. Mater. 2013, 25, 2452-2456. [CrossRef] [PubMed]

39. Aguirre, M.E.; Zhou, R.X.; Eugene, A.J.; Guzman, M.I.; Grela, M.A. Cu $2 \mathrm{O} / \mathrm{TiO}_{2}$ heterostructures for $\mathrm{CO}_{2}$ reduction through a direct $\mathrm{Z}$-scheme: Protecting $\mathrm{Cu}_{2} \mathrm{O}$ from photocorrosion. Appl. Catal. B 2017, 217, 485-493. [CrossRef]

40. Butler, M.A. Photoelectrolysis and physical-properties of semiconducting electrode $\mathrm{WO}_{3}$. J. Appl. Phys. 1977, 48, 1914-1920. [CrossRef]

41. Shang, Y.Y.; Chen, X.; Liu, W.W.; Tan, P.F.; Chen, H.Y.; Wu, L.D.; Ma, C.; Xiong, X.; Pan, J. Photocorrosion inhibition and high-efficiency photoactivity of porous $\mathrm{g}_{-} \mathrm{C}_{3} \mathrm{~N}_{4} / \mathrm{Ag}_{2} \mathrm{CrO}_{4}$ composites by simple microemulsion-assisted co-precipitation method. Appl. Catal. B 2017, 204, 78-88. [CrossRef]

42. Lopes, O.F.; Paris, E.C.; Ribeiro, C. Synthesis of $\mathrm{Nb}_{2} \mathrm{O}_{5}$ nanoparticles through the oxidant peroxide method applied to organic pollutant photodegradation: A mechanistic study. Appl. Catal. B 2014, 144, 800-808. [CrossRef]

43. Liu, B.S.; Zhao, X.J.; Zhao, Q.N.; He, X.; Feng, J.Y. Effect of heat treatment on the UV-vis-NIR and PL spectra of $\mathrm{TiO}_{2}$ films. J. Electron Spectrosc. Relat. Phenom. 2005, 148, 158-163. [CrossRef]

44. Xiang, Q.J.; Lv, K.L.; Yu, J.G. Pivotal role of fluorine in enhanced photocatalytic activity of anatase $\mathrm{TiO}_{2}$ nanosheets with dominant (001) facets for the photocatalytic degradation of acetone in air. Appl. Catal. B 2010, 96, 557-564. [CrossRef]

45. Zhou, R.X.; Guzman, M.I. $\mathrm{CO}_{2}$ Reduction under Periodic Illumination of ZnS. J. Phys. Chem. C 2014, 118, 11649-11656. [CrossRef]

46. Zhou, R.X.; Guzman, M.I. Photocatalytic Reduction of Fumarate to Succinate on ZnS Mineral Surfaces. J. Phys. Chem. C 2016, 120, 7349-7357. [CrossRef]

47. Liu, D.; Fernandez, Y.; Ola, O.; Mackintosh, S.; Maroto-Valer, M.; Parlett, C.M.A.; Lee, A.F.; Wu, J.C.S. On the impact of $\mathrm{Cu}$ dispersion on $\mathrm{CO}_{2}$ photoreduction over $\mathrm{Cu} / \mathrm{TiO}_{2}$. Catal. Commun. 2012, 25, 78-82. [CrossRef] 

Article

\title{
Facile Synthesis of Novel CaIn ${ }_{2} \mathrm{~S}_{4} / \mathrm{ZnIn}_{2} \mathrm{~S}_{4}$ Composites with Efficient Performance for Photocatalytic Reduction of Cr(VI) under Simulated Sunlight Irradiation
}

\author{
Siyu Xu ${ }^{1}$, Jun Dai ${ }^{1,2}$, Juan Yang ${ }^{1,2,3, *}$, Jun You ${ }^{3}$ and Jingyi Hao ${ }^{3}$ \\ 1 Institute of Chemical Safety, School of Safety Science and Engineering, Henan Polytechnic University, \\ Jiaozuo 454003, China; xusiyu2017@163.com (S.X.); daijun@hpu.edu.cn (J.D.) \\ 2 The Collaborative Innovation Center of Coal Safety Production of Henan, Henan Polytechnic University, \\ Jiaozuo 454003, China \\ 3 Institute of Applied Chemistry, College of Chemistry and Chemical Engineering, \\ Henan Polytechnic University, Jiaozuo 454003, China; youjunhpu@163.com (J.Y.); \\ haojingyi2018@163.com (J.H.) \\ * Correspondence: yangjuanhpu@163.com; Tel.: +86-391-398-7881
}

Received: 29 May 2018; Accepted: 25 June 2018; Published: 27 June 2018

\begin{abstract}
A series of novel and efficient heterostructured composites CaIn $\mathrm{S}_{4} / \mathrm{ZnIn}_{2} \mathrm{~S}_{4}$ have been synthesized using a facile hydrothermal method. XRD patterns indicate the as-prepared catalysts are two-phase composites of cubic phase $\mathrm{CaIn}_{2} \mathrm{~S}_{4}$ and hexagonal phase $\mathrm{ZnIn}_{2} \mathrm{~S}_{4}$. FESEM (field emission scanning electron microscope) images display that the synthesized composites are composed of flower-like microspheres with wide diameter distribution. UV-Vis diffuse reflectance spectra (DRS) show that the optical absorption edges of the $\mathrm{CaIn}_{2} \mathrm{~S}_{4} / \mathrm{ZnIn}_{2} \mathrm{~S}_{4}$ composites shift toward longer wavelengths with the increase of the $\mathrm{CaIn}_{2} \mathrm{~S}_{4}$ component. The photocatalytic activities of the as-synthesized composites are investigated by using the aqueous-phase $\mathrm{Cr}(\mathrm{VI})$ reduction under simulated sunlight irradiation. This is the first report on the application of the $\mathrm{CaIn}_{2} \mathrm{~S}_{4} / \mathrm{ZnIn}_{2} \mathrm{~S}_{4}$ composites as stable and efficient photocatalysts for the $\mathrm{Cr}(\mathrm{VI})$ reduction. The fabricated $\mathrm{CaIn}_{2} \mathrm{~S}_{4} / \mathrm{ZnIn}_{2} \mathrm{~S}_{4}$ composites possess higher photocatalytic performance in comparison with pristine $\mathrm{CaIn}_{2} \mathrm{~S}_{4}$ or $\mathrm{ZnIn}_{2} \mathrm{~S}_{4}$. The $\mathrm{CaIn}_{2} \mathrm{~S}_{4} / \mathrm{ZnIn}_{2} \mathrm{~S}_{4}$ composite with a CaIn $\mathrm{S}_{4}$ molar content of $30 \%$ exhibits the optimum photocatalytic activity. The primary reason for the significantly enhanced photoreduction activity is proved to be the substantially improved separation efficiency of photogenerated electrons/holes caused by forming the CaIn $\mathrm{S}_{4} / \mathrm{ZnIn}_{2} \mathrm{~S}_{4}$ heterostructured composites. The efficient charge separation can be evidenced by steady-state photoluminescence spectra (PLs) and transient photocurrent response. Based on the charge transfer between $\mathrm{CaIn}_{2} \mathrm{~S}_{4}$ and $\mathrm{ZnIn}_{2} \mathrm{~S}_{4}$, an enhancement mechanism of photocatalytic activity and stability for the $\mathrm{Cr}(\mathrm{VI})$ reduction is proposed.
\end{abstract}

Keywords: $\mathrm{CaIn}_{2} \mathrm{~S}_{4} / \mathrm{ZnIn}_{2} \mathrm{~S}_{4}$ composites; $\mathrm{Cr}(\mathrm{VI})$; photocatalysis; simulated sunlight; hydrothermal method

\section{Introduction}

Semiconductor-based photocatalytic technology has exhibited great potential in green controlling of environmental contaminants and converting $\mathrm{CO}_{2}$ to valuable chemicals [1-6]. However, the most studied photocatalysts (such as $\mathrm{TiO}_{2}, \mathrm{ZnO}$, and $\mathrm{ZnS}$ ) are active only under ultraviolet light irradiation. In view of the practical applications, visible light active photocatalysts with narrow bandgaps are greatly desirable. A great deal of research and efforts have been devoted to fabricating and synthesizing visible-light-driven catalysts, [7-10]. For instance, visible-light photocatalysts based on metal sulfide, 
including the doped or functionalized $\mathrm{ZnS}$ [7,8], $\mathrm{CdIn}_{2} \mathrm{~S}_{4}$ [9], $\mathrm{ZnIn}_{2} \mathrm{~S}_{4}$ [10,11], $\mathrm{CdIn}_{2} \mathrm{~S}_{4} / \mathrm{ZnIn}_{2} \mathrm{~S}_{4}$ [12], and $\mathrm{Cu}_{2} \mathrm{ZnSnS}_{4}[13]$ have received broad attention in recent decades.

Among these metal sulfides, $\mathrm{ZnIn}_{2} \mathrm{~S}_{4}$, as a ternary chalcogenide semiconductor possessing a narrow bandgap (2.34-2.48 eV), has aroused great interest in the field of visible-light-driven contaminants' degradation and hydrogen production by water splitting [10,11]. Although the studies have revealed that $\mathrm{ZnIn}_{2} \mathrm{~S}_{4}$ has strong visible-light absorption, the catalytic activity of pristine $\mathrm{ZnIn}_{2} \mathrm{~S}_{4}$ is lower than expected due to fast recombination of photogenerated charge carriers. Many efforts have been made to solve these drawbacks, including morphologies control, metal doping, and heterostructured composites construction [14-17]. The fabrication of heterojunction catalysts by coupling two kinds of semiconductor particles with a suitable energy band structure is identified as a valid method to promote photocatalytic activity because of the resulting effective separation of the photoinduced charge [18,19]. To improve the photocatalytic activity of pure $\mathrm{ZnIn}_{2} \mathrm{~S}_{4}$, the heterojunction photocatalysts have been reported by hybridization with $\mathrm{TiO}_{2}, \mathrm{CdS}$, and $\mathrm{C}_{3} \mathrm{~N}_{4}$ [20-22]

On the other hand, the metal sulfide semiconductors with narrow bandgaps generally undergo photocorrosion induced by the oxidative process of photogenerated holes, which result in poor photostability or deactivation during long-term recycling use under sunlight irradiation. For instance, CdS particles possess excellent catalytic activity, acceptable stability, and photocorrosion resistance under visible-light illumination, whereas the catalyst becomes unstable when exposed to sunlight irradiation [23]. As a visible-light photocatalyst, $\mathrm{ZnIn}_{2} \mathrm{~S}_{4}$ also suffers from the critical drawback of high photocorrosion under sunlight illumination [24]. Very recently, Zhao et al. have synthesized chemically cross-linked $\mathrm{ZnIn}_{2} \mathrm{~S}_{4} /$ RGO heterostructured catalysts and investigated the sunlight-driven photocatalytic performance of 4-nitrophenol degradation. The experimental results demonstrate the as-fabricated $\mathrm{ZnIn}_{2} \mathrm{~S}_{4} / \mathrm{RGO}$ possessed not only the enhanced visible-light catalytic performance but also prominently improved sunlight stability [24]. Therefore, to practically utilize sunlight-driven photocatalytic technology to control contaminants, the employed catalysts must be not only visible-light active but also stable when subjected to sunlight illumination.

$\mathrm{CaIn}_{2} \mathrm{~S}_{4}$ is also an attractive ternary chalcogenide with a narrow bandgap $(\sim 1.9 \mathrm{eV})$ and meanwhile, is the cheapest alkaline earth metal-based semiconductor, which can serve as a potential visible-light catalyst. However, only a few of the investigations on the construction and synthesis of $\mathrm{CaIn}_{2} \mathrm{~S}_{4}$-based composite photocatalysts have been reported to date [25-27]. Similar to other narrow-bandgap catalysts, the photocatalytic degradation efficiency of $\mathrm{CaIn}_{2} \mathrm{~S}_{4}$ alone is very limited owing to the poor separation efficiency of photogenerated electrons and holes. By constructing the composite catalysts, such as $\mathrm{CaIn}_{2} \mathrm{~S}_{4}-\mathrm{RGO}, \mathrm{CaIn}_{2} \mathrm{~S}_{4} / \mathrm{g}-\mathrm{C}_{3} \mathrm{~N}_{4}$, and $\mathrm{CaIn}_{2} \mathrm{~S}_{4} / \mathrm{TiO}_{2}$, the photocatalytic activity of CaIn ${ }_{2} \mathrm{~S}_{4}$ has been significantly improved. For instance, direct Z-scheme $\mathrm{CaIn}_{2} \mathrm{~S}_{4} / \mathrm{TiO}_{2}$ catalysts with different $\mathrm{CaIn}_{2} \mathrm{~S}_{4}$ weight percentages were prepared, and the photocatalytic performance of these composite catalysts was investigated by the degradation of isoniazid and metronidazole in the pharmaceutical wastewater. The improved catalytic performance can be ascribed to the significantly suppressed recombination of photoinduced charge carriers based on the Z-scheme charge transfer over $\mathrm{CaIn}_{2} \mathrm{~S}_{4} / \mathrm{TiO}_{2}$ catalysts. The aforementioned $\mathrm{CaIn}_{2} \mathrm{~S}_{4}$-based composites show higher photocatalytic performance than the pure $\mathrm{CaIn}_{2} \mathrm{~S}_{4}$ or $\mathrm{TiO}_{2}$; nevertheless, the preparation processes are relatively complicated, and these composites cannot be obtained through one-step synthesis. Further research on the synthesis of the $\mathrm{CaIn}_{2} \mathrm{~S}_{4}$-based composite photocatalysts by one-step hydrothermal methods is highly necessary to improve the photocatalytic activity of $\mathrm{CaIn}_{2} \mathrm{~S}_{4}$.

Hexavalent $\mathrm{Cr}(\mathrm{VI})$ ions have been listed as one of the priority pollutants by the United States Environmental Protection Agency (US EPA) [28], due to the high toxicity, mutagenicity, and teratogenicity to the aquatic environment and human beings. The elimination of $\mathrm{Cr}(\mathrm{VI})$ ions have received increasing attention in the field of wastewater purification. The traditional techniques for removing $\mathrm{Cr}(\mathrm{VI})$ ions generally include precipitation, adsorption, ion-exchange, electro-coagulation [29], membrane separation, and photocatalytic reduction [30,31]. Considering solar energy conversion, photocatalytic reduction is postulated to be an efficient and green technology for 
the elimination of $\mathrm{Cr}(\mathrm{VI})$ ions from contaminated water. The highly toxic $\mathrm{Cr}(\mathrm{VI})$ can be photoreduced to less harmful $\mathrm{Cr}$ (III) by means of a certain photocatalyst and reaction system.

In this study, flower-like CaIn $\mathrm{S}_{4} / \mathrm{ZnIn}_{2} \mathrm{~S}_{4}$ heterojunction composites are successfully synthesized by using a one-step hydrothermal method, and the photocatalytic performance of the $\mathrm{Cr}(\mathrm{VI})$ reduction is investigated under simulated sunlight illumination. To our knowledge, this is the first report about the $\mathrm{CaIn}_{2} \mathrm{~S}_{4} / \mathrm{ZnIn}_{2} \mathrm{~S}_{4}$ heterojunction composites for the photocatalytic reduction of $\mathrm{Cr}(\mathrm{VI})$. The heterojunction composites exhibit much higher reduction efficiency of $\mathrm{Cr}(\mathrm{VI})$ than the pure $\mathrm{CaIn}_{2} \mathrm{~S}_{4}$ or $\mathrm{ZnIn}_{2} \mathrm{~S}_{4}$. Meanwhile, the CaIn $\mathrm{S}_{4} / \mathrm{ZnIn}_{2} \mathrm{~S}_{4}$ composites present excellent solar stability, and the photocorrosion of $\mathrm{ZnIn}_{2} \mathrm{~S}_{4}$ is dramatically inhibited by constructing the $\mathrm{CaIn}_{2} \mathrm{~S}_{4} / \mathrm{ZnIn}_{2} \mathrm{~S}_{4}$ composites. The detailed mechanism of enhanced photocatalytic performance for the $\mathrm{Cr}(\mathrm{VI})$ reduction over the CaIn $\mathrm{S}_{4} / \mathrm{ZnIn}_{2} \mathrm{~S}_{4}$ composites is also proposed.

\section{Materials and Methods}

\subsection{Materials}

All the chemicals were of analytical grade and used as received without further purification. Calcium nitrate $\left(\mathrm{Ca}\left(\mathrm{NO}_{3}\right)_{2}\right)$, zinc sulfate $\left(\mathrm{ZnSO}_{4}\right)$, indium chloride $\left(\mathrm{InCl}_{3}\right)$, thioacetamide (TAA), potassium dichromate, sulfuric acid $\left(\mathrm{H}_{2} \mathrm{SO}_{4}\right)$, and ammonium oxalate were obtained from Aladdin Industrial Inc. (Shanghai, China). Diphenylcarbazide (DPC) was purchased from J \& K Scientific Ltd. (Beijing, China). Double distilled water was used throughout this study.

\subsection{Synthesis of Composite Photocatalysts}

The $\mathrm{CaIn}_{2} \mathrm{~S}_{4} / \mathrm{ZnIn}_{2} \mathrm{~S}_{4}$ composite photocatalysts were prepared by hydrothermal route. Taking $20 \% \mathrm{CaIn}_{2} \mathrm{~S}_{4} / \mathrm{ZnIn}_{2} \mathrm{~S}_{4}$ as an example, in a typical synthesis process, $0.2 \mathrm{mmol} \mathrm{Ca}\left(\mathrm{NO}_{3}\right)_{3} \cdot 4 \mathrm{H}_{2} \mathrm{O}$ and $0.8 \mathrm{mmol} \mathrm{ZnSO} \mathrm{Zn}_{4} \cdot 7 \mathrm{H}_{2} \mathrm{O}$ were added into $40 \mathrm{~mL}$ of distilled water, followed by vigorous stirring for $30 \mathrm{~min}$ to form a clear solution. After that, $2 \mathrm{mmol} \mathrm{InCl}_{3} \cdot 4 \mathrm{H}_{2} \mathrm{O}$ and $8 \mathrm{mmol}$ TAA were put into the above-obtained mixed solution and stirred for additional $60 \mathrm{~min}$ at room temperature. The reaction mixture was then transferred into a Teflon-lined steel autoclave (Zhengxin Instrument, Yancheng, China), which was heated at $180{ }^{\circ} \mathrm{C}$ for $12 \mathrm{~h}$. Finally, the obtained yellow solid was collected by filtration, washed with distilled water several times, and dried at $60{ }^{\circ} \mathrm{C}$ for $8 \mathrm{~h}$. On that basis, different $\mathrm{CaIn}_{2} \mathrm{~S}_{4} / \mathrm{ZnIn}_{2} \mathrm{~S}_{4}$ composites with CaIn $\mathrm{S}_{4}$ molar ratios of $5 \%, 10 \%, 20 \%, 30 \%$, and $50 \%$ were synthesized and denoted as $5 \% \mathrm{CaIn}_{2} \mathrm{~S}_{4} / \mathrm{ZnIn}_{2} \mathrm{~S}_{4}, 10 \% \mathrm{CaIn}_{2} \mathrm{~S}_{4} / \mathrm{ZnIn}_{2} \mathrm{~S}_{4}, 20 \% \mathrm{CaIn}_{2} \mathrm{~S}_{4} / \mathrm{ZnIn}_{2} \mathrm{~S}_{4}$, $30 \% \mathrm{CaIn}_{2} \mathrm{~S}_{4} / \mathrm{ZnIn}_{2} \mathrm{~S}_{4}$, and $50 \% \mathrm{CaIn}_{2} \mathrm{~S}_{4} / \mathrm{ZnIn}_{2} \mathrm{~S}_{4}$, respectively.

For comparison, the pure $\mathrm{ZnIn}_{2} \mathrm{~S}_{4}$ was prepared by using a similar process without $\mathrm{Ca}\left(\mathrm{NO}_{3}\right)_{3}$. $1.0 \mathrm{mmol} \mathrm{ZnSO} \cdot 7 \mathrm{H}_{2} \mathrm{O}$ was put into $40 \mathrm{~mL}$ of distilled water and stirred for $30 \mathrm{~min}$. Then, $2 \mathrm{mmol} \mathrm{InCl}_{3} \cdot 4 \mathrm{H}_{2} \mathrm{O}$ and $8 \mathrm{mmol}$ TAA were added to the above-obtained solution and stirred for another $60 \mathrm{~min}$. This mixture was subsequently transferred into a Teflon-lined steel autoclave and heated at $180{ }^{\circ} \mathrm{C}$ for $12 \mathrm{~h}$. The precipitate was finally washed with deionized water and dried at $60^{\circ} \mathrm{C}$ for $8 \mathrm{~h}$ to obtain pure $\mathrm{ZnIn}_{2} \mathrm{~S}_{4}$. For the preparation of the pure $\mathrm{CaIn}_{2} \mathrm{~S}_{4}, 1.0 \mathrm{mmol} \mathrm{Ca}\left(\mathrm{NO}_{3}\right)_{3} \cdot 4 \mathrm{H}_{2} \mathrm{O}$ was added into $40 \mathrm{~mL}$ of distilled water and stirred for $30 \mathrm{~min}$. After that, $2 \mathrm{mmol} \mathrm{InCl}_{3} \cdot 4 \mathrm{H}_{2} \mathrm{O}$ and $8 \mathrm{mmol}$ TAA were put into the above solution and then stirred for another $60 \mathrm{~min}$. The obtained mixture was transferred into a Teflon-lined steel autoclave and heated at $180{ }^{\circ} \mathrm{C}$ for $12 \mathrm{~h}$. The orange precipitate was finally washed with deionized water and dried at $60{ }^{\circ} \mathrm{C}$ for $8 \mathrm{~h}$ to obtain pure $\mathrm{CaIn}_{2} \mathrm{~S}_{4}$.

\subsection{Material Characterization}

The crystal structures of the as-prepared composites were investigated by using an X-ray diffractometer (XRD, Bruker D8 Advance, Karlsruhe, Germany), with $\mathrm{Cu} \mathrm{K} \alpha$ radiation $(\lambda=0.15405 \mathrm{~nm})$. The morphologies of the synthesized samples were observed by a field emission scanning electron microscope (FEI, Quanta250, Hillsboro, OR, USA). The X-ray photoelectron spectroscopy (XPS) experiment was carried out by using a Thermo Scientific ESCALAB 250xi 
system (Waltham, MA, USA), equipped with an Al anode. The BET (Brunauer-Emmett-Teller) surface areas of the composite samples were determined on a surface area analyzer (Autosorb-IQ, Quantachrome, Boynton Beach, FL, USA). UV-visible diffuse reflectance spectra (DRS) were collected on a Shimadzu UV-2550 spectrometer (Kyoto, Japan) using $\mathrm{BaSO}_{4}$ as the reflectance standard. Photoluminescence spectra (PLs) were measured by using an Edinburgh FLS 980 fluorescence spectrometer (Livingston, UK), with a $330 \mathrm{~nm}$ excitation wavelength. The transient photocurrent measurement was performed on a CHI electrochemical workstation (CHI 760D, Shanghai, China) in the standard three-electrode system. $\mathrm{Ag} / \mathrm{AgCl}$ electrode and a platinum wire were employed as the reference electrode and the counter electrode, respectively. The working electrodes were prepared according to our previous report [32]. The photocurrent was measured in the electrolyte of a $0.5 \mathrm{~mol} / \mathrm{L}$ $\mathrm{Na}_{2} \mathrm{SO}_{4}$ aqueous solution ( $\mathrm{pH} \sim 6.8$ ) at a bias of $+0.5 \mathrm{~V}$. The light source was the same as that used in the photocatalytic experiments.

\subsection{Photocatalytic Reduction of $\mathrm{Cr}(\mathrm{VI})$}

For the photocatalytic reduction of $\mathrm{Cr}(\mathrm{VI})$ under simulated sunlight irradiation, a $300 \mathrm{~W}$ xenon lamp (PLS-SXE 300, Perfect Light Co. Ltd., Beijing, China) was used as the light source. The incident light intensity was $75 \mathrm{~mW} / \mathrm{cm}^{2}$. In the typical photocatalytic test, $50 \mathrm{mg}$ of photocatalyst was suspended in $50 \mathrm{~mL}$ of $20 \mathrm{mg} / \mathrm{L} \mathrm{Cr}(\mathrm{VI})$ aqueous solution. After adding $5 \mathrm{mg}$ of ammonium oxalate (a scavenger for photo-hole), the suspension was magnetically stirred in the dark for $30 \mathrm{~min}$ to establish an adsorption-desorption equilibrium. As the photocatalytic reduction proceeded, $3 \mathrm{~mL}$ of the reaction solution was taken out at a given time interval and centrifuged to remove the catalyst particles. The concentrations of $\mathrm{Cr}(\mathrm{VI})$ were determined colorimetrically at $540 \mathrm{~nm}$ using the diphenylcarbazide (DPC) method on a Shimadzu UV-160A UV-Vis spectrophotometer [33]. In addition, the total Cr ions concentrations were measured by an inductively coupled plasma-optical emission spectrophotometer (Agilent 725 ICP-OES, Palo Alto, CA, USA).

The apparent quantum efficiency (AQE) of $\mathrm{Cr}(\mathrm{VI})$ the photocatalytic reduction was measured under the same photocatalytic reaction conditions, except by using a $420 \mathrm{~nm}$ bandpass filter. The apparent quantum efficiencies were calculated according to the following equation:

$$
\begin{gathered}
\mathrm{AQE}(\%)=\frac{\text { Number of reacted electrons }}{\text { Number of incident photons }} \times 100=\frac{3 \times \text { number of reduced } \mathrm{Cr}(\mathrm{VI})}{\text { Number of incident photons }} \times 100 \\
\text { Number of incident photons }=\frac{I \times A \times t}{E(\lambda=420 \mathrm{~nm})} \\
E(\lambda=420 \mathrm{~nm})=\frac{h \times c}{\lambda}
\end{gathered}
$$

where $I, A, t, c, \lambda$, and $h$ are light intensity, light exposure area, irradiation time, light velocity, light wavelength, and Planck constant, respectively.

To evaluate the catalytic stability of the $\mathrm{CaIn}_{2} \mathrm{~S}_{4} / \mathrm{ZnIn}_{2} \mathrm{~S}_{4}$ composites, the photocatalysts-after the first run for the $\mathrm{Cr}(\mathrm{VI})$ reduction-were separated by centrifugation from the suspension and washed with $1 \mathrm{M}$ nitrite acid solution and deionized water. After being dried at $60^{\circ} \mathrm{C}$, the recovered photocatalysts were reused for the next run of the photocatalytic $\mathrm{Cr}(\mathrm{VI})$ reductions under the same experimental conditions.

\section{Results and Discussion}

\subsection{XRD Analysis and BET Surface Area}

The phase composition and crystalline properties of the CaIn $\mathrm{S}_{4} / \mathrm{ZnIn}_{2} \mathrm{~S}_{4}$ composite samples were analyzed by XRD. Figure 1 displays the XRD patterns of the pure $\mathrm{ZnIn}_{2} \mathrm{~S}_{4}, \mathrm{CaIn}_{2} \mathrm{~S}_{4}$, and $\mathrm{CaIn}_{2} \mathrm{~S}_{4} / \mathrm{ZnIn}_{2} \mathrm{~S}_{4}$ composites. As indicated in Figure 1, the diffraction peaks of the pure $\mathrm{ZnIn}_{2} \mathrm{~S}_{4}$ at $2 \theta=21.1^{\circ}, 27.6^{\circ}, 30.3^{\circ}, 47.4^{\circ}, 52.0^{\circ}$, and $55.6^{\circ}$ corresponded to (006), (102), (104), (110), (116), and (200) crystal planes of hexagonal phase $\mathrm{ZnIn}_{2} \mathrm{~S}_{4}$ (JCPDS NO. 65-2023), respectively [24]. No other 
diffraction peaks were detected in the XRD pattern of $\mathrm{ZnIn}_{2} \mathrm{~S}_{4}$, indicating that the obtained $\mathrm{ZnIn}_{2} \mathrm{~S}_{4}$ is highly pure. With the addition of $\mathrm{Ca}\left(\mathrm{NO}_{3}\right)_{3}$ in the preparation process, new diffraction peaks appeared in the XRD patterns, which belonged to the characteristic peaks of the cubic phase CaIn ${ }_{2} S_{4}$ (JCPDS No. 16-0341) [25-27]. It can be also observed from Figure 1 that the intensity of the diffraction peaks belonging to the cubic $\mathrm{CaIn}_{2} \mathrm{~S}_{4}$ phase increased gradually by increasing the mole proportion of CaIn $\mathrm{S}_{4}$, which indicated the existence of both $\mathrm{CaIn}_{2} \mathrm{~S}_{4}$ and $\mathrm{ZnIn}_{2} \mathrm{~S}_{4}$ in the as-synthesized composites. In addition, the diffraction peaks corresponding to binary sulfides, oxides, and other new compounds were not observed, indicating that $\mathrm{CaIn}_{2} \mathrm{~S}_{4}$ and $\mathrm{ZnIn}_{2} \mathrm{~S}_{4}$ maintained the pure phase and no impurities were formed in the obtained $\mathrm{CaIn}_{2} \mathrm{~S}_{4} / \mathrm{ZnIn}_{2} \mathrm{~S}_{4}$ composites.

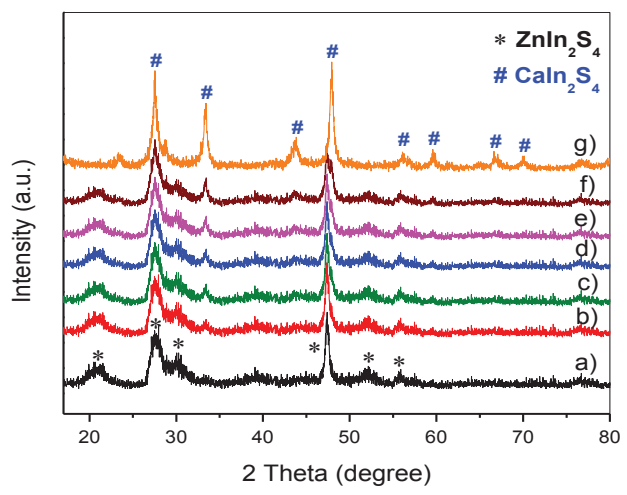

Figure 1. XRD patterns of pure $\mathrm{ZnIn}_{2} \mathrm{~S}_{4}, \mathrm{CaIn}_{2} \mathrm{~S}_{4}$, and $\mathrm{CaIn}_{2} \mathrm{~S}_{4} / \mathrm{ZnIn}_{2} \mathrm{~S}_{4}$ composites: (a) pure $\mathrm{ZnIn}_{2} \mathrm{~S}_{4}$ ，(b) $5 \% \mathrm{CaIn}_{2} \mathrm{~S}_{4} / \mathrm{ZnIn}_{2} \mathrm{~S}_{4}$ ，(c) $10 \% \mathrm{CaIn}_{2} \mathrm{~S}_{4} / \mathrm{ZnIn}_{2} \mathrm{~S}_{4}$ ，(d) $20 \% \mathrm{CaIn}_{2} \mathrm{~S}_{4} / \mathrm{ZnIn}_{2} \mathrm{~S}_{4}$ ，(e) $30 \%$ $\mathrm{CaIn}_{2} \mathrm{~S}_{4} / \mathrm{ZnIn}_{2} \mathrm{~S}_{4}$, (f) $50 \% \mathrm{CaIn}_{2} \mathrm{~S}_{4} / \mathrm{ZnIn}_{2} \mathrm{~S}_{4}$, and (g) pure CaIn $\mathrm{S}_{4}$.

The BET surface area of the pure $\mathrm{ZnIn}_{2} \mathrm{~S}_{4}, \mathrm{CaIn}_{2} \mathrm{~S}_{4}$, and $\mathrm{CaIn}_{2} \mathrm{~S}_{4} / \mathrm{ZnIn}_{2} \mathrm{~S}_{4}$ composites was measured, and the results are summarized in Table 1. As can be noted from Table 1, the specific surface area of the $\mathrm{CaIn}_{2} \mathrm{~S}_{4} / \mathrm{ZnIn}_{2} \mathrm{~S}_{4}$ composites decreased slightly with the continuous increment of $\mathrm{CaIn}_{2} \mathrm{~S}_{4}$ component. The actual molar ratios of $\mathrm{Ca}-\mathrm{Zn}$ in the $\mathrm{CaIn}_{2} \mathrm{~S}_{4} / \mathrm{ZnIn}_{2} \mathrm{~S}_{4}$ composites were determined by inductively coupled plasma elemental analysis, as presented in Table 1 . It can be observed from Table 1 that the experimentally measured molar ratios of $\mathrm{Ca}-\mathrm{Zn}$ in the synthesized composites were close to those of the added proportions in the preparation process.

Table 1. BET (Brunauer-Emmett-Teller) specific surface area, molar ratios of $\mathrm{Ca}-\mathrm{Zn}$ in the synthesized CaIn $\mathrm{S}_{4} / \mathrm{ZnIn}_{2} \mathrm{~S}_{4}$ and apparent quantum efficiency (AQE) of the $\mathrm{Cr}$ (VI) reduction over these composites.

\begin{tabular}{|c|c|c|c|}
\hline Samples & $\mathrm{S}_{\mathrm{BET}}\left(\mathrm{m}^{2} / \mathrm{g}\right)$ & Molar Ratios of Ca:Zn (\%) & AQE (\%) \\
\hline pure $\mathrm{ZnIn}_{2} \mathrm{~S}_{4}$ & 59.2 & 0 & 3.7 \\
\hline $5 \% \mathrm{CaIn}_{2} \mathrm{~S}_{4} / \mathrm{ZnIn}_{2} \mathrm{~S}_{4}$ & 56.3 & 5.05 & 4.1 \\
\hline $10 \% \mathrm{CaIn}_{2} \mathrm{~S}_{4} / \mathrm{ZnIn}_{2} \mathrm{~S}_{4}$ & 54.7 & 9.67 & 4.5 \\
\hline $20 \% \mathrm{CaIn}_{2} \mathrm{~S}_{4} / \mathrm{ZnIn}_{2} \mathrm{~S}_{4}$ & 53.4 & 18.30 & 5.2 \\
\hline $30 \% \mathrm{CaIn}_{2} \mathrm{~S}_{4} / \mathrm{ZnIn}_{2} \mathrm{~S}_{4}$ & 52.1 & 26.52 & 6.6 \\
\hline $50 \% \mathrm{CaIn}_{2} \mathrm{~S}_{4} / \mathrm{ZnIn}_{2} \mathrm{~S}_{4}$ & 50.5 & 43.29 & 5.5 \\
\hline pure $\mathrm{CaIn}_{2} \mathrm{~S}_{4}$ & 46.0 & - & 2.3 \\
\hline
\end{tabular}

\subsection{SEM and Elemental Mapping Analysis}

The SEM images of the as-synthesized pure $\mathrm{ZnIn}_{2} \mathrm{~S}_{4}, \mathrm{CaIn}_{2} \mathrm{~S}_{4}$, and $\mathrm{CaIn}_{2} \mathrm{~S}_{4} / \mathrm{ZnIn}_{2} \mathrm{~S}_{4}$ composites are indicated in Figure 2. As can be observed from Figure 2, the pure $\mathrm{ZnIn}_{2} \mathrm{~S}_{4}$ was composed of 
hierarchical microspheres with a wide distribution of diameter, which was consistent with the previous reports $[17,24]$. Introducing the Ca component had almost no influence on the morphologies of the $\mathrm{CaIn}_{2} \mathrm{~S}_{4} / \mathrm{ZnIn}_{2} \mathrm{~S}_{4}$ composites, which also exhibited flower-like microspheres constructed by numerous nanosheets in the form of random self-assembly. As a consequence, the porous structures with wide pore-size distribution could be expected. This would benefit the photocatalytic reaction by increasing the specific surface area. Moreover, the formation of the CaIn $\mathrm{S}_{4} / \mathrm{ZnIn}_{2} \mathrm{~S}_{4}$ heterojunction was evidenced by the elemental mapping of the as-synthesized composites (Figure 3). Maps of $\mathrm{Zn}-\mathrm{K}$, $\mathrm{Ca}-\mathrm{K}, \mathrm{In}-\mathrm{L}$, and S-K display the same shape and location, indicating the coexistence of $\mathrm{ZnIn}_{2} \mathrm{~S}_{4}$ and $\mathrm{CaIn}_{2} \mathrm{~S}_{4}$ components in the obtained composites. This provided solid evidence for the formation of $\mathrm{CaIn}_{2} \mathrm{~S}_{4} / \mathrm{ZnIn}_{2} \mathrm{~S}_{4}$ heterostructured composites.
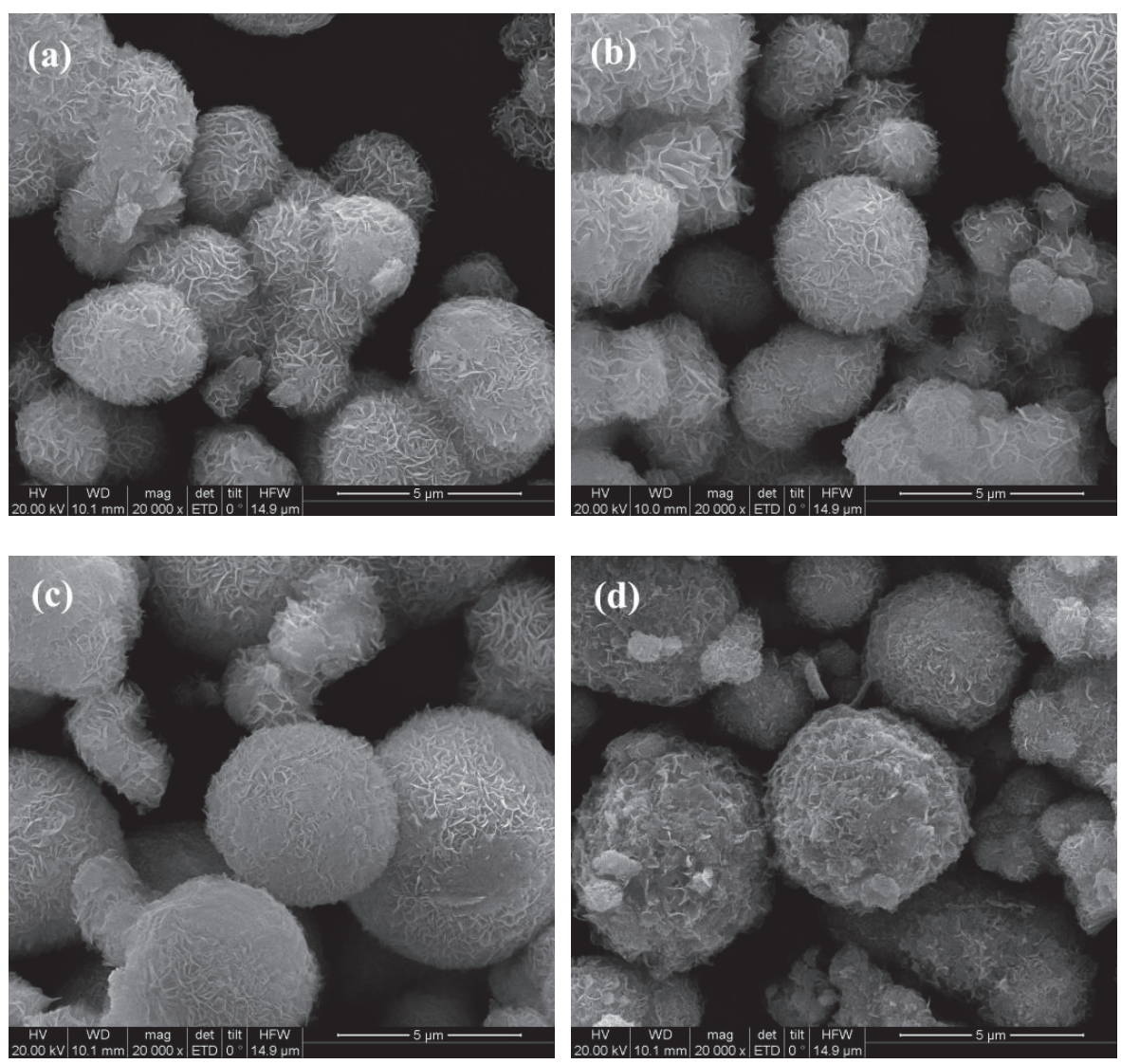

Figure 2. FE-SEM (field emission scanning electron microscope) images of (a) pure $\mathrm{ZnIn}_{2} \mathrm{~S}_{4}$, (b) $10 \%$ $\mathrm{CaIn}_{2} \mathrm{~S}_{4} / \mathrm{ZnIn}_{2} \mathrm{~S}_{4}$, (c) $30 \% \mathrm{CaIn}_{2} \mathrm{~S}_{4} / \mathrm{ZnIn}_{2} \mathrm{~S}_{4}$, and (d) pure CaIn $\mathrm{S}_{4}$. 


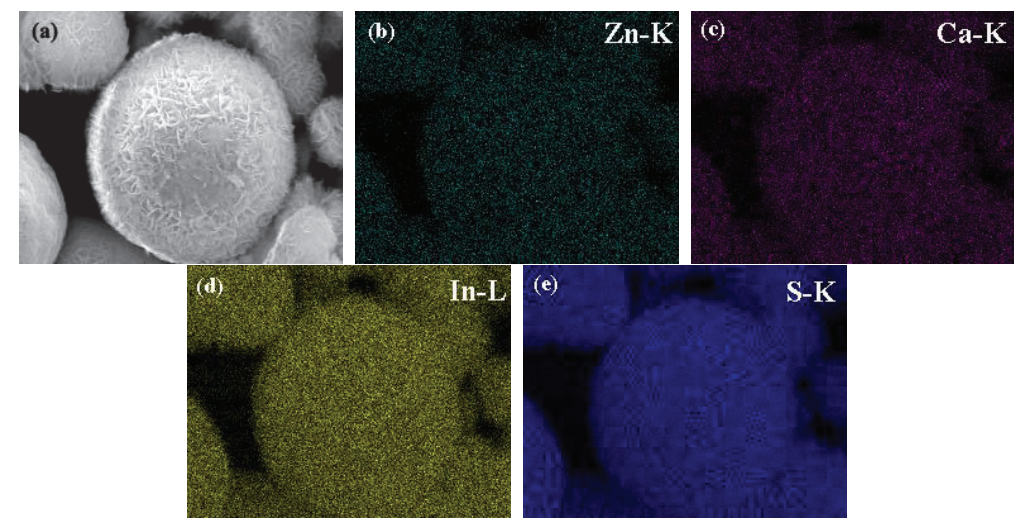

Figure 3. The EDS (Energy Dispersive Spectroscopy) elemental mapping images of the 30\% $\mathrm{CaIn}_{2} \mathrm{~S}_{4} / \mathrm{ZnIn}_{2} \mathrm{~S}_{4}$ sample: (a) SEM image, (b) Zn-K, (c) Ca-K, (d) In-L, and (e) S-K, respectively.

\subsection{XPS Analysis and Optical Properties}

To determine the elemental composition and the corresponding chemical states of the synthesized composites, the XPS spectra of the $30 \% \mathrm{CaIn}_{2} \mathrm{~S}_{4} / \mathrm{ZnIn}_{2} \mathrm{~S}_{4}$ sample are indicated in Figure 4 . As can be seen from Figure $4 \mathrm{a}$, the survey spectrum indicated the presence of $\mathrm{Zn}, \mathrm{Ca}$, In, and S elements in the $30 \% \mathrm{CaIn}_{2} \mathrm{~S}_{4} / \mathrm{ZnIn}_{2} \mathrm{~S}_{4}$ sample. The high-resolution XPS spectrum for $\mathrm{Zn}$ is presented in Figure $4 \mathrm{~b}$. Two characteristic XPS signals were observed at binding energies of 1022.4 and $1045.3 \mathrm{eV}$, which were ascribed to $\mathrm{Zn}^{2+} 2 \mathrm{p}_{1 / 2}$ and $\mathrm{Zn}^{2+} 2 \mathrm{p}_{3 / 2}$, respectively $[33,34]$. The high-resolution XPS spectrum of In $3 \mathrm{~d}$ is displayed in Figure 4c. The characteristic peaks centered at 444.7 and $452.3 \mathrm{eV}$ can be attributed to the $\operatorname{In} 3 d_{3 / 2}$ and In $3 d_{5 / 2}$ signals of $\operatorname{In}^{3+}$ species, respectively [27,34]. In Figure $4 d$, the two peaks at the binding energies of 351.1 and $347.6 \mathrm{eV}$ corresponded to the $2 \mathrm{p}_{3 / 2}$ and $2 \mathrm{p}_{1 / 2}$ levels of $\mathrm{Ca}^{2+}$. Figure $4 \mathrm{e}$ shows an XPS signal centered at $162.5 \mathrm{eV}$, which can be assigned to the $2 \mathrm{p}_{1 / 2}$ level of $\mathrm{S}^{2-}$ in the as-prepared CaIn $\mathrm{S}_{4} / \mathrm{ZnIn}_{2} \mathrm{~S}_{4}$ composites [34]. These results further indicate that $\mathrm{CaIn}_{2} \mathrm{~S}_{4} / \mathrm{ZnIn}_{2} \mathrm{~S}_{4}$ composites can be successfully synthesized through a one-step hydrothermal reaction process.
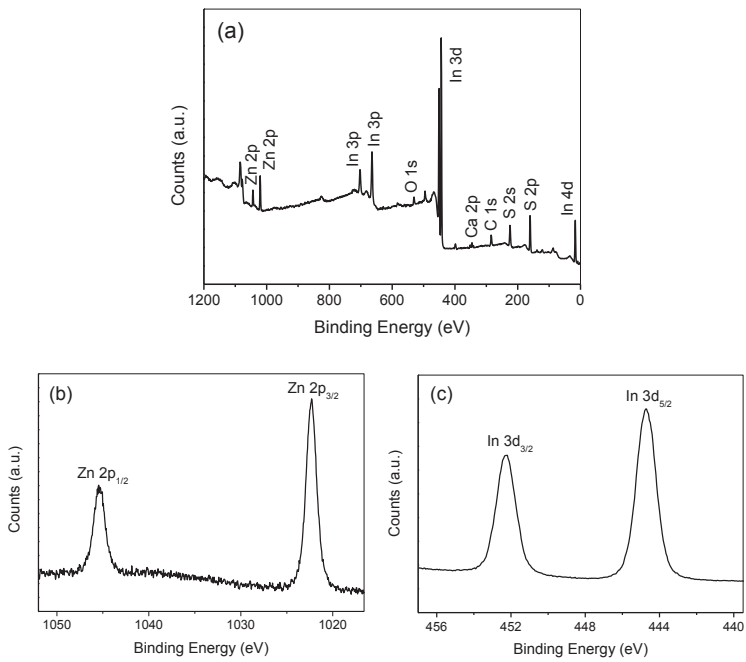

Figure 4. Cont. 

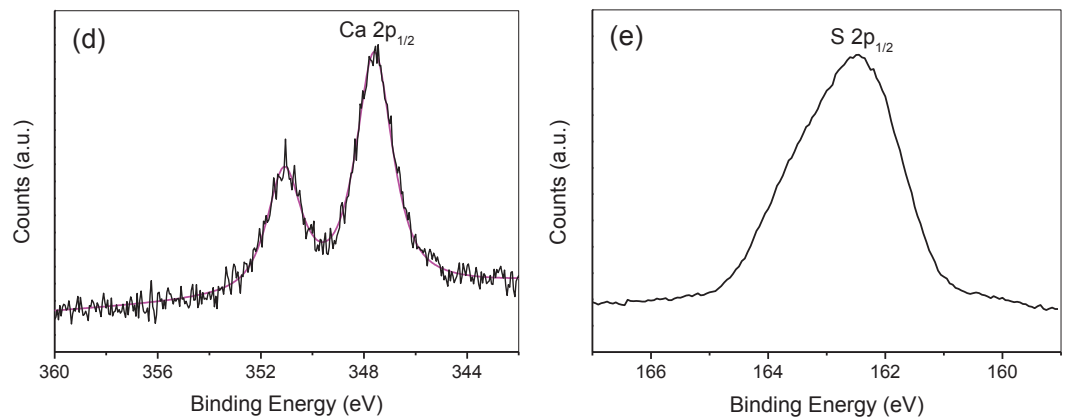

Figure 4. Typical XPS survey spectrum of $30 \%$ CaIn $_{2} \mathrm{~S}_{4} / \mathrm{ZnIn}_{2} \mathrm{~S}_{4}($ a), high-resolution XPS spectra of $\mathrm{Zn}$ $2 \mathrm{p}(\mathbf{b})$, In $3 \mathrm{~d}(\mathbf{c})$, Ca $2 \mathrm{p}(\mathbf{d})$, and S $2 \mathrm{p}(\mathbf{e})$, respectively.

The optical absorption properties of the as-obtained CaIn ${ }_{2} \mathrm{~S}_{4} / \mathrm{ZnIn}_{2} \mathrm{~S}_{4}$ composites were analyzed by UV-Vis DRS, and the results are depicted in Figure 5a. The absorption edges of the pure $\mathrm{ZnIn}_{2} \mathrm{~S}_{4}$ and $\mathrm{CaIn}_{2} \mathrm{~S}_{4}$ samples were at around $537 \mathrm{~nm}$ and $638 \mathrm{~nm}$, respectively. As can be also noted from Figure $5 \mathrm{a}$, the absorption edges of the $\mathrm{CaIn}_{2} \mathrm{~S}_{4} / \mathrm{ZnIn}_{2} \mathrm{~S}_{4}$ samples were gradually red-shifted from 537 to $570 \mathrm{~nm}$ as the molar percentage of the CaIn $\mathrm{S}_{4}$ component increased to $50 \%$. The photoresponse of the CaIn $\mathrm{S}_{4} / \mathrm{ZnIn}_{2} \mathrm{~S}_{4}$ composites in visible-light region was significantly improved by comparison with that of the pure $\mathrm{ZnIn}_{2} \mathrm{~S}_{4}$. Moreover, the UV-Vis DRS shown in Figure 5a were all very steep, demonstrating the visible-light absorption was ascribed to the intrinsic band transition instead of the transition from impurity levels [35]. Based on the optical absorption theory of the bandgap semiconductor, the bandgap energy of the pure $\mathrm{CaIn}_{2} \mathrm{~S}_{4}$ and $\mathrm{ZnIn}_{2} \mathrm{~S}_{4}$ can be calculated by the Equation (1) [36] as follows:

$$
\alpha h v=A\left(h v-E_{\mathrm{g}}\right)^{n / 2}
$$

where $\alpha, v, E_{\mathrm{g}}$, and $A$ represent the absorption coefficient, light frequency, bandgap energy, and a constant, respectively. The value of $n$ depends on the type of optical transition of a semiconductor ( $n=1$ for the direct transition and $n=4$ for the indirect transition). According to the previous literature [27,37], $\mathrm{ZnIn}_{2} \mathrm{~S}_{4}$ and $\mathrm{CaIn}_{2} \mathrm{~S}_{4}$ are direct-transition semiconductors, and thus, the bandgap energies of $\mathrm{CaIn}_{2} \mathrm{~S}_{4}$ and $\mathrm{ZnIn}_{2} \mathrm{~S}_{4}$ can be estimated from the plots of $(\alpha h v)^{2}$ versus light energy $(h v)$. As illustrated in Figure $5 \mathrm{~b}$, the estimated bandgaps were 2.03 and $2.43 \mathrm{eV}$ for the pure $\mathrm{CaIn}_{2} \mathrm{~S}_{4}$ and $\mathrm{ZnIn}_{2} \mathrm{~S}_{4}$, respectively, which matched well with the literature values $[15,27]$. For the composite catalysts, the photocatalytic performance was primarily determined by the valence band (VB) and conduction band (CB) energy levels of the constituent semiconductors. Based on the following equations, the VB and $\mathrm{CB}$ positions of the pristine $\mathrm{ZnIn}_{2} \mathrm{~S}_{4}$ and $\mathrm{CaIn}_{2} \mathrm{~S}_{4}$ can be obtained:

$$
\begin{gathered}
E_{\mathrm{VB}}=\chi-E_{\mathrm{e}}+0.5 E_{\mathrm{g}} \\
E_{\mathrm{CB}}=E_{\mathrm{VB}}-E_{\mathrm{g}}
\end{gathered}
$$

where $E_{\mathrm{VB}}$ and $E_{\mathrm{CB}}$ are the potential of the $\mathrm{VB}$ and $\mathrm{CB}$ edge, $E_{\mathrm{g}}$ is the bandgap energy, $\chi$ is the geometric mean of the absolute electronegativity of the constituent atoms in the semiconductor, and $E_{\mathrm{e}}$ is the energy of free electrons on the hydrogen scale with a value of $4.5 \mathrm{eV}$. The $\chi$ values of $\mathrm{ZnIn}_{2} \mathrm{~S}_{4}$ and $\mathrm{CaIn}_{2} \mathrm{~S}_{4}$ were 4.86 and $4.39 \mathrm{eV}$, respectively. Based on the above empirical equations, the $E_{\mathrm{VB}}$ values of $\mathrm{ZnIn}_{2} \mathrm{~S}_{4}$ and $\mathrm{CaIn}_{2} \mathrm{~S}_{4}$ were estimated to be +1.58 and $+0.91 \mathrm{eV}$. The corresponding $E_{\mathrm{CB}}$ values were also calculated to be -0.85 and $-1.12 \mathrm{eV}$, respectively. 

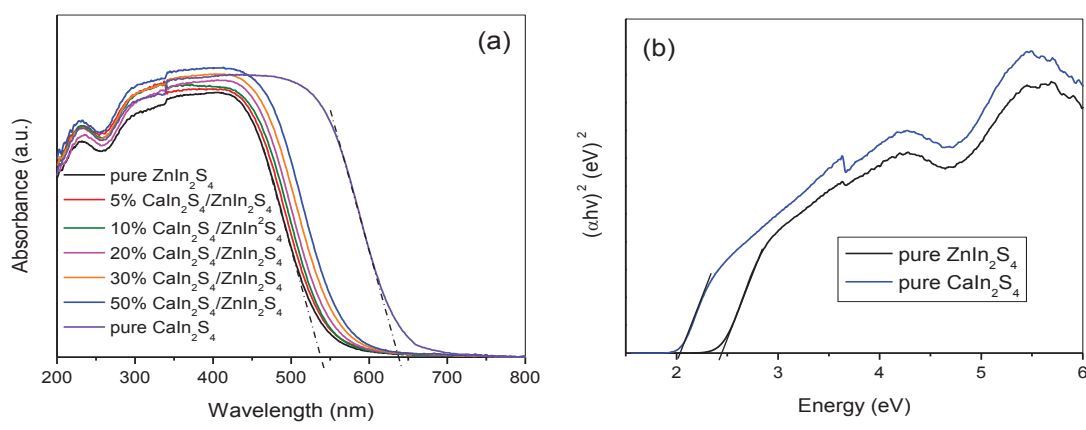

Figure 5. (a) UV-Vis DRS of the pure $\mathrm{ZnIn}_{2} \mathrm{~S}_{4}, \mathrm{CaIn}_{2} \mathrm{~S}_{4}$, and CaIn $\mathrm{S}_{4} / \mathrm{ZnIn}_{2} \mathrm{~S}_{4}$ composites, (b) Plots of $(\alpha h v)^{2}$ vs. light energy $(h v)$ of the pure $\mathrm{ZnIn}_{2} \mathrm{~S}_{4}$ and $\mathrm{CaIn}_{2} \mathrm{~S}_{4}$.

\subsection{Photocatalytic Activity}

The photocatalytic performances of the $\mathrm{ZnIn}_{2} \mathrm{~S}_{4}, \mathrm{CaIn}_{2} \mathrm{~S}_{4}$, and $\mathrm{CaIn}_{2} \mathrm{~S}_{4} / \mathrm{ZnIn}_{2} \mathrm{~S}_{4}$ composites were investigated by the aqueous-phase $\mathrm{Cr}(\mathrm{VI})$ reduction under simulated sunlight irradiation (Figure 6A). $\mathrm{Cr}(\mathrm{VI})$ cannot be reduced in the absence of light illumination or photocatalysts. The pure $\mathrm{ZnIn}_{2} \mathrm{~S}_{4}$ displayed a relatively higher photocatalytic activity of the $\mathrm{Cr}(\mathrm{VI})$ reduction than the $\mathrm{CaIn}_{2} \mathrm{~S}_{4}$ sample. About $42 \%$ of $\mathrm{Cr}(\mathrm{VI})$ was reduced over the pure $\mathrm{CaIn}_{2} \mathrm{~S}_{4}$, while $\mathrm{ZnIn}_{2} \mathrm{~S}_{4}$ can reduce $63 \%$ of $\mathrm{Cr}(\mathrm{VI})$ after irradiation of $30 \mathrm{~min}$. All the $\mathrm{CaIn}_{2} \mathrm{~S}_{4} / \mathrm{ZnIn}_{2} \mathrm{~S}_{4}$ composites exhibited higher photocatalytic efficiency than the pristine CaIn $\mathrm{S}_{4}$ and $\mathrm{ZnIn}_{2} \mathrm{~S}_{4}$, indicating that the combination of $\mathrm{CaIn}_{2} \mathrm{~S}_{4}$ and $\mathrm{ZnIn}_{2} \mathrm{~S}_{4}$ can improve the photocatalytic reduction performance of these composites.
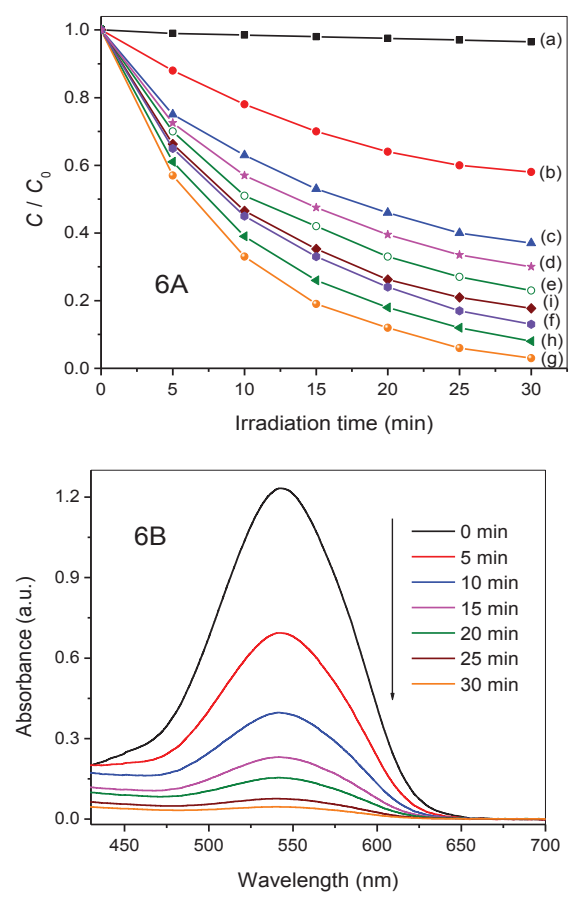

Figure 6. Cont. 

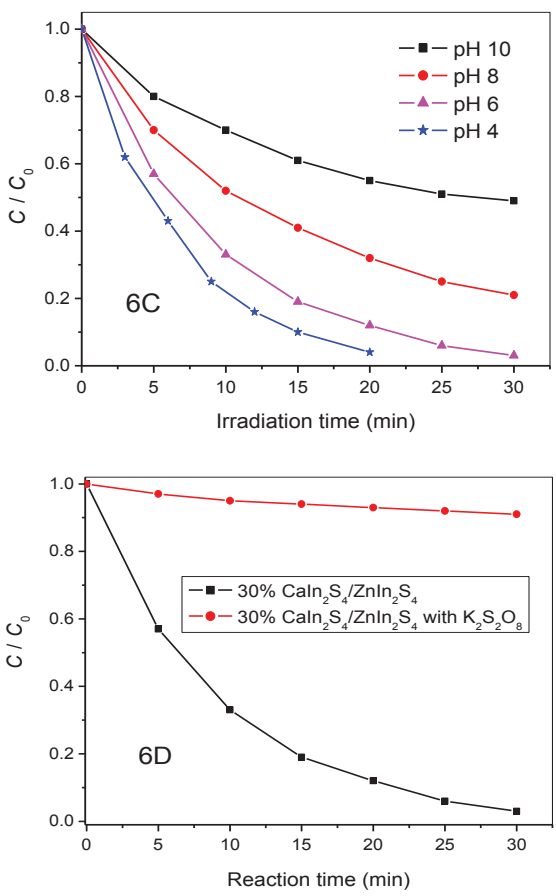

Figure 6. (A) Photocatalytic reduction of $\mathrm{Cr}(\mathrm{VI})$ as a function of irradiation time over different catalysts: (a) no catalyst, (b) pure $\mathrm{CaIn}_{2} \mathrm{~S}_{4}$, (c) pure $\mathrm{ZnIn}_{2} \mathrm{~S}_{4}$, (d) $5 \% \mathrm{CaIn}_{2} \mathrm{~S}_{4} / \mathrm{ZnIn}_{2} \mathrm{~S}_{4}$, (e) $10 \%$ $\mathrm{CaIn}_{2} \mathrm{~S}_{4} / \mathrm{ZnIn}_{2} \mathrm{~S}_{4}$, (f) $20 \% \mathrm{CaIn}_{2} \mathrm{~S}_{4} / \mathrm{ZnIn}_{2} \mathrm{~S}_{4}$, (g) $30 \% \mathrm{CaIn}_{2} \mathrm{~S}_{4} / \mathrm{ZnIn}_{2} \mathrm{~S}_{4}$, (h) $50 \% \mathrm{CaIn}_{2} \mathrm{~S}_{4} / \mathrm{ZnIn}_{2} \mathrm{~S}_{4}$, and (i) mechanically mixed $30 \% \mathrm{CaIn}_{2} \mathrm{~S}_{4}+70 \% \mathrm{ZnIn}_{2} \mathrm{~S}_{4}$; (B) time-dependent absorption spectral pattern of diphenylcarbazide (DPC)-Cr(VI) complex solutions after the reduction over $30 \% \mathrm{CaIn}_{2} \mathrm{~S}_{4} / \mathrm{ZnIn}_{2} \mathrm{~S}_{4}$ $(\mathrm{pH}=6)$; (C) photocatalytic reduction of $\mathrm{Cr}(\mathrm{VI})$ under different $\mathrm{pH}$ values over $30 \% \mathrm{CaIn}_{2} \mathrm{~S}_{4} / \mathrm{ZnIn}_{2} \mathrm{~S}_{4}$; (D) the controlled experiment for photocatalytic reduction of $\mathrm{Cr}(\mathrm{VI})$ over the $30 \% \mathrm{CaIn}_{2} \mathrm{~S}_{4} / \mathrm{ZnIn}_{2} \mathrm{~S}_{4}$ composites with the addition of $\mathrm{K}_{2} \mathrm{~S}_{2} \mathrm{O}_{8}(0.1 \mathrm{mmol})$ as a scavenger for photoinduced electrons.

For the synthesized $\mathrm{CaIn}_{2} \mathrm{~S}_{4} / \mathrm{ZnIn}_{2} \mathrm{~S}_{4}$ composite catalysts, the photocatalytic were closely associated with the contents of the $\mathrm{CaIn}_{2} \mathrm{~S}_{4}$ component. As can be noted from Figure $6 \mathrm{~A}$, the photocatalytic activities of the $\mathrm{CaIn}_{2} \mathrm{~S}_{4} / \mathrm{ZnIn}_{2} \mathrm{~S}_{4}$ composite catalysts increased with the increment of component CaIn $\mathrm{S}_{4}$. The $30 \% \mathrm{CaIn}_{2} \mathrm{~S}_{4} / \mathrm{ZnIn}_{2} \mathrm{~S}_{4}$ composite photocatalyst exhibited the highest activity for the $\mathrm{Cr}(\mathrm{VI})$ reduction, whereas the greater increase in the amount of $\mathrm{CaIn}_{2} \mathrm{~S}_{4}$ resulted in a decrease in the $\mathrm{Cr}(\mathrm{VI})$ reduction rates. It can be ascribed to the low photocatalytic activity of the pure $\mathrm{CaIn}_{2} \mathrm{~S}_{4}$ because of the slow separation of the photogenerated charge carriers. Moreover, the apparent quantum efficiencies (AQE) of the $\mathrm{Cr}(\mathrm{VI})$ photocatalytic reduction over the synthesized composites were also calculated, and the corresponding results are summarized in Table 1. As indicated in Table 1, the AQE of the $30 \% \mathrm{CaIn}_{2} \mathrm{~S}_{4} / \mathrm{ZnIn}_{2} \mathrm{~S}_{4}$ nanocomposite catalyst reached $6.6 \%$, which presented higher than that of the pure $\mathrm{ZnIn}_{2} \mathrm{~S}_{4}(3.7 \%)$ or pure $\mathrm{CaIn}_{2} \mathrm{~S}_{4}(2.3 \%)$. In addition, the AQE for the $\mathrm{Cr}(\mathrm{VI})$ reduction increased gradually with the increase of the CaIn $\mathrm{S}_{4}$ constituent when the addition ratio of the $\mathrm{CaIn}_{2} \mathrm{~S}_{4}$ precursor was no more than $30 \%$. However, further increasing the molar ratio of $\mathrm{CaIn}_{2} \mathrm{~S}_{4}$ led to a decrease in the AQE. This suggests that the heterostructured composites containing a suitable amount of $\mathrm{CaIn}_{2} \mathrm{~S}_{4}$ and $\mathrm{ZnIn}_{2} \mathrm{~S}_{4}$ contributed to improving optimally the photoactivity for the $\mathrm{Cr}(\mathrm{VI})$ reduction. Therefore, the optimal $30 \% \mathrm{CaIn}_{2} \mathrm{~S}_{4} / \mathrm{ZnIn}_{2} \mathrm{~S}_{4}$ has been chosen as a representative catalyst for the following studies. 
To further clarify the influence of the heterostructure on the photocatalytic performance of the $\mathrm{Cr}(\mathrm{VI})$ reduction, the $30 \% \mathrm{CaIn}_{2} \mathrm{~S}_{4} / \mathrm{ZnIn}_{2} \mathrm{~S}_{4}$ sample was compared to its mechanical mixing counterpart sample $30 \% \mathrm{CaIn}_{2} \mathrm{~S}_{4}+70 \% \mathrm{ZnIn}_{2} \mathrm{~S}_{4}$. The photocatalytic activity of the $\mathrm{Cr}(\mathrm{VI})$ reduction over the physical mixture was much lower than that of the $30 \% \mathrm{CaIn}_{2} \mathrm{~S}_{4} / \mathrm{ZnIn}_{2} \mathrm{~S}_{4}$ composite obtained via the one-step hydrothermal method. This result shows that the heterojunction formed between the $\mathrm{CaIn}_{2} \mathrm{~S}_{4}$ and $\mathrm{ZnIn}_{2} \mathrm{~S}_{4}$ contributed to improving photocatalytic efficiency of the $\mathrm{Cr}(\mathrm{VI})$ reduction.

When using the optimal $30 \% \mathrm{CaIn}_{2} \mathrm{~S}_{4} / \mathrm{ZnIn}_{2} \mathrm{~S}_{4}$ as a photocatalyst, the change in the temporal absorption spectra of the DPC-Cr(VI) complex solution is illustrated in Figure 6B. The absorption peak at $540 \mathrm{~nm}$ belonging to the DPC-Cr(VI) complex decreased rapidly with the increase of light irradiation time, and it almost vanished after light illumination for $30 \mathrm{~min}$. To gain more insight into the photocatalytic process, the total $\mathrm{Cr}$ ions concentrations over the $30 \% \mathrm{CaIn}_{2} \mathrm{~S}_{4} / \mathrm{ZnIn}_{2} \mathrm{~S}_{4}$ photocatalyst after the treated samples were measured by ICP emission spectrometer (Figure S1, Supplementary Materials). As indicated in Figure S1, the initial concentration of $\mathrm{Cr}(\mathrm{VI})$ is $19.6 \mathrm{ppm}$. The measured total $\mathrm{Cr}$ ions concentration after $30 \mathrm{~min}$ light irradiation were found to be $19.1 \mathrm{ppm}$. This result demonstrates that almost no $\mathrm{Cr}(0)$ was produced in the present photocatalytic system. That is to say, $\mathrm{Cr}(\mathrm{VI}) \mathrm{was}$ primarily reduced to $\mathrm{Cr}$ (III) by the photogenerated electrons of the $\mathrm{CaIn}_{2} \mathrm{~S}_{4} / \mathrm{ZnIn}_{2} \mathrm{~S}_{4}$ composites .

In addition, the photocatalytic experiments for the $\mathrm{Cr}(\mathrm{VI})$ reduction under different $\mathrm{pH}$ conditions with $30 \% \mathrm{CaIn}_{2} \mathrm{~S}_{4} / \mathrm{ZnIn}_{2} \mathrm{~S}_{4}$ were also carried out, and the corresponding results are presented in Figure 6C. In a photocatalytic system, the reduction efficiency of the aqueous $\mathrm{Cr}(\mathrm{VI})$ was greatly influenced by the $\mathrm{pH}$ value according to the previous reports [30]. $\mathrm{Cr}$ (VI) existed in two forms in alkaline and acid medium, respectively. $\mathrm{CrO}_{4}{ }^{2-}$ is predominant in the alkaline medium, whereas $\mathrm{Cr}_{2} \mathrm{O}_{7}{ }^{2-}$ plays a major role in the acid medium. The chemical redox reaction can be outlined as follows:

$$
\begin{gathered}
\mathrm{CrO}_{4}{ }^{2-}+4 \mathrm{H}_{2} \mathrm{O}+3 \mathrm{e}^{-} \rightarrow \mathrm{Cr}(\mathrm{OH})_{3} \downarrow+5 \mathrm{OH}^{-} \text {(alkaline) } \\
14 \mathrm{H}^{+}+\mathrm{Cr}_{2} \mathrm{O}_{7}{ }^{2-}+6 \mathrm{e}^{-} \rightarrow 2 \mathrm{Cr}^{3+}+7 \mathrm{H}_{2} \mathrm{O} \text { (acid) }
\end{gathered}
$$

As depicted in Figure 6C, the reduction rate of $\mathrm{Cr}(\mathrm{VI})$ increased with the decrease of the $\mathrm{pH}$ value. About $38.7 \%, 58.8 \%, 80.6 \%$, and $89.0 \%$ of $\mathrm{Cr}(\mathrm{VI})$ are reduced at $\mathrm{pH} 10,8,6$, and 4 in the first $15 \mathrm{~min}$, respectively. This could be due to the fact that the $\mathrm{Cr}(\mathrm{OH})_{3}$ precipitate produced in the alkaline medium covers the activity sites of the photocatalysts [38]. The results demonstrate the acidic condition was more beneficial to the photocatalytic reduction of $\mathrm{Cr}(\mathrm{VI})$ over the synthesized $\mathrm{CaIn}_{2} \mathrm{~S}_{4} / \mathrm{ZnIn}_{2} \mathrm{~S}_{4}$ composites.

Additionally, the controlled experiment by adding $\mathrm{K}_{2} \mathrm{~S}_{2} \mathrm{O}_{8}$ (the trapping agent of photo-generated electrons, $0.1 \mathrm{mmol}$ ) [39] into the photocatalytic system of the $\mathrm{Cr}(\mathrm{VI})$ reduction was performed, and the corresponding result is depicted in Figure 6D. It can be seen clearly that the $\mathrm{Cr}(\mathrm{VI})$ reduction over the optimal photocatalyst $30 \% \mathrm{CaIn}_{2} \mathrm{~S}_{4} / \mathrm{ZnIn}_{2} \mathrm{~S}_{4}$ hardly occurs in the presence of $\mathrm{K}_{2} \mathrm{~S}_{2} \mathrm{O}_{8}$, which indicates that the reduction of $\mathrm{Cr}(\mathrm{VI})$ is conducted by photogenerated electrons under simulated sunlight irradiation. These results also indicate that a suitable amount of $\mathrm{CaIn}_{2} \mathrm{~S}_{4}$ can effectively improve the photocatalytic performance of $\mathrm{ZnIn}_{2} \mathrm{~S}_{4}$ toward the $\mathrm{Cr}(\mathrm{VI})$ reduction.

\subsection{Catalytic Stability}

The stability of a given photocatalyst was also an important factor in the practical application [40]. Furthermore, narrow bandgap semiconductors are generally more unstable when exposed to the sunlight illumination [24]. To study the effect of the $\mathrm{CaIn}_{2} \mathrm{~S}_{4} / \mathrm{ZnIn}_{2} \mathrm{~S}_{4}$ heterostructure on the catalytic stability, the cycle experiments of the $\mathrm{Cr}(\mathrm{VI})$ reduction were carried out and compared by using $\mathrm{ZnIn}_{2} \mathrm{~S}_{4}$ and $30 \% \mathrm{CaIn}_{2} \mathrm{~S}_{4} / \mathrm{ZnIn}_{2} \mathrm{~S}_{4}$ as photocatalysts under simulated sunlight irradiation (Figure 7). The results indicate that for the pristine $\mathrm{ZnIn}_{2} \mathrm{~S}_{4}$, the reduction efficiency of $\mathrm{Cr}(\mathrm{VI})$ decreased about $20.9 \%$ after five repeated uses, demonstrating that $\mathrm{ZnIn}_{2} \mathrm{~S}_{4}$ was unstable to some extent under simulated sunlight illumination. In comparison, a relatively low decrease in the reduction efficiency of $\mathrm{Cr}(\mathrm{VI})$ over $30 \% \mathrm{CaIn}_{2} \mathrm{~S}_{4} / \mathrm{ZnIn}_{2} \mathrm{~S}_{4}$ was observed, and only a ca. $2.6 \%$ decrease of the reduction 
efficiency is obtained after reusing five cycles. This suggests that the sunlight stability of $\mathrm{ZnIn}_{2} \mathrm{~S}_{4}$ can be improved through forming the heterojunction composites with $\mathrm{CaIn}_{2} \mathrm{~S}_{4}$. Additionally, the XPS analysis of the used $30 \% \mathrm{CaIn}_{2} \mathrm{~S}_{4} / \mathrm{ZnIn}_{2} \mathrm{~S}_{4}$ catalyst was also performed, and the obtained results are displayed in Figure S2 of the Supplementary Materials. As can be found from Figure S2, the surface element composition and the chemical state of the $30 \% \mathrm{CaIn}_{2} \mathrm{~S}_{4} / \mathrm{ZnIn}_{2} \mathrm{~S}_{4}$ sample before and after the photocatalytic reaction show no obvious difference. The results confirm the superior stability of the $\mathrm{CaIn}_{2} \mathrm{~S}_{4} / \mathrm{ZnIn}_{2} \mathrm{~S}_{4}$ composite photocatalysts under simulated sunlight, which is more promising for the practical photocatalytic applications in environmental restoration.

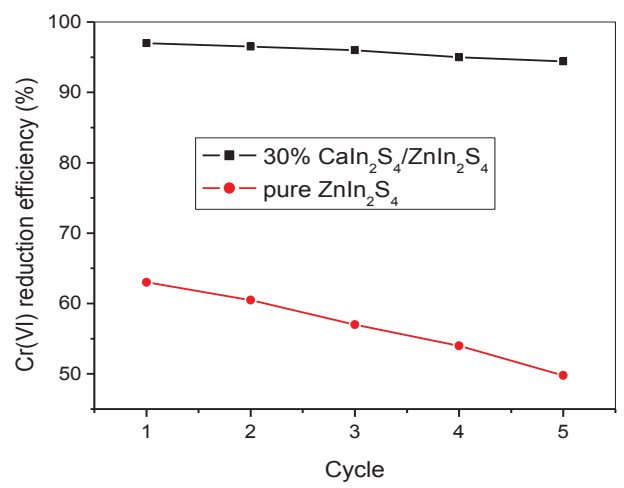

Figure 7. Photocatalytic stability tests of $\mathrm{ZnIn}_{2} \mathrm{~S}_{4}$ and $30 \% \mathrm{CaIn}_{2} \mathrm{~S}_{4} / \mathrm{ZnIn}_{2} \mathrm{~S}_{4}$ toward the $\mathrm{Cr}(\mathrm{VI})$ reduction.

\subsection{Enhancement Mechanism of Photocatalytic Activity and Stability}

On the basis of the above discussion and results, it is obvious that coupling a suitable amount of $\mathrm{CaIn}_{2} \mathrm{~S}_{4}$ can dramatically improve the photocatalytic performance for the $\mathrm{Cr}(\mathrm{VI})$ reduction, including the reduction efficiency and cycling stability of the $\mathrm{CaIn}_{2} \mathrm{~S}_{4} / \mathrm{ZnIn}_{2} \mathrm{~S}_{4}$ composites. The remarkably enhanced photocatalytic activity of the CaIn ${ }_{2} \mathrm{~S}_{4} / \mathrm{ZnIn}_{2} \mathrm{~S}_{4}$ samples, compared with the pure $\mathrm{CaIn}_{2} \mathrm{~S}_{4}$ and $\mathrm{ZnIn}_{2} \mathrm{~S}_{4}$, can be ascribed to the effective separation of the photogenerated electron/hole pairs due to the forming of flower-like heterostructures between $\mathrm{ZnIn}_{2} \mathrm{~S}_{4}$ and $\mathrm{CaIn}_{2} \mathrm{~S}_{4}$. Generally, the photoluminescence spectrum (PLs) is considered as a vital technology to study the migration and fate of photoinduced charge carriers [39,41]. Higher intensities of PL signals usually represent higher recombination rates of photogenerated charge carriers, thus resulting in a lower photocatalytic performance. The comparison of the PL spectrum for the pristine $\mathrm{ZnIn}_{2} \mathrm{~S}_{4}$ and $30 \% \mathrm{CaIn}_{2} \mathrm{~S}_{4} / \mathrm{ZnIn}_{2} \mathrm{~S}_{4}$ with an excitation wavelength of $330 \mathrm{~nm}$ is presented in Figure 8 . The pristine $\mathrm{ZnIn}_{2} \mathrm{~S}_{4}$ showed emissions at 520,571, and $656 \mathrm{~nm}$. The strong emission peak centered at $520 \mathrm{~nm}$ for the pristine $\mathrm{ZnIn}_{2} \mathrm{~S}_{4}$ was attributed to the intrinsic luminescence of $\mathrm{ZnIn}_{2} \mathrm{~S}_{4}$. The relatively weak PL peaks at 571 , and $656 \mathrm{~nm}$ can be ascribed to the surface state emissions, which were mainly caused by the surface defects in the $\mathrm{ZnIn}_{2} \mathrm{~S}_{4}$ structure. In comparison with the pristine $\mathrm{ZnIn}_{2} \mathrm{~S}_{4}$, there was no new emission signal in the PL spectrum of $30 \% \mathrm{CaIn}_{2} \mathrm{~S}_{4} / \mathrm{ZnIn}_{2} \mathrm{~S}_{4}$, but the intensities of the PL peaks decreased obviously. The results imply that the photogenerated electrons and holes can transfer effectively between $\mathrm{CaIn}_{2} \mathrm{~S}_{4}$ and $\mathrm{ZnIn}_{2} \mathrm{~S}_{4}$, thus suppressing the recombination of charge carriers. This can be a primary reason for the $\mathrm{CaIn}_{2} \mathrm{~S}_{4} / \mathrm{ZnIn}_{2} \mathrm{~S}_{4}$ composites possessing excellent photocatalytic reduction performance under simulated sunlight irradiation. 


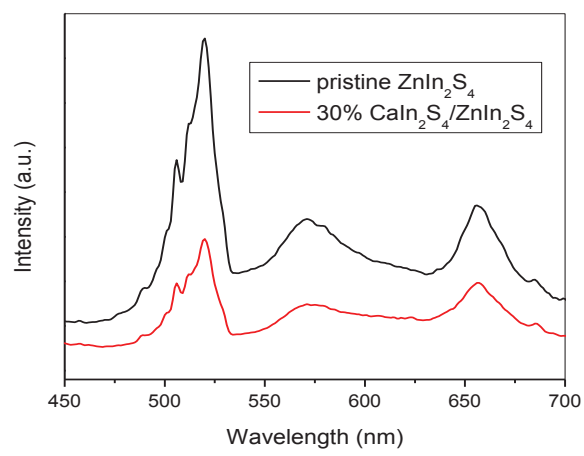

Figure 8. Room temperature photoluminescence spectra (PLs) of the pure $\mathrm{ZnIn}_{2} \mathrm{~S}_{4}$ and $30 \%$ CaIn ${ }_{2} \mathrm{~S}_{4} / \mathrm{ZnIn}_{2} \mathrm{~S}_{4}$ under the excitation wavelength of $330 \mathrm{~nm}$.

Most of the heterostructured nanocomposites follow the bidirectional charge transfer mechanism [42,43]. For instance, Kumar and his colleagues have reported on the photoinduced electrons enriched on the conduction band of $\mathrm{Ag}_{3} \mathrm{PO}_{4}$ and holes on the valence band of $\mathrm{g}-\mathrm{C}_{3} \mathrm{~N}_{4}$, which was conducted through a bidirectional charge transfer process between $\mathrm{Ag}_{3} \mathrm{PO}_{4}$ and $g-\mathrm{C}_{3} \mathrm{~N}_{4}$ [42]. As for the as-prepared $\mathrm{CaIn}_{2} \mathrm{~S}_{4} / \mathrm{ZnIn}_{2} \mathrm{~S}_{4}$ composites, the aforementioned bidirectional charge transfer was also the primary charge migration process. Based on the bandgap energies of $\mathrm{CaIn}_{2} \mathrm{~S}_{4}$ and $\mathrm{ZnIn}_{2} \mathrm{~S}_{4}$ estimated from Figure 5 and Equations (2) and (3), the energy band structure diagram of $\mathrm{CaIn}_{2} \mathrm{~S}_{4}$ and $\mathrm{ZnIn}_{2} \mathrm{~S}_{4}$ can be schematically illustrated, as shown in Figure 9. Under light illumination, the components of $\mathrm{CaIn}_{2} \mathrm{~S}_{4}$ and $\mathrm{ZnIn}_{2} \mathrm{~S}_{4}$ were simultaneously excited, generating photoinduced electron/hole pairs. Due to the more negative conduction-band edge of $\mathrm{CaIn}_{2} \mathrm{~S}_{4}(-1.12 \mathrm{eV})$ than that of $\mathrm{ZnIn}_{2} \mathrm{~S}_{4}(-0.85 \mathrm{eV})$, the photogenerated electrons prefer to transfer from the CB of CaIn $\mathrm{S}_{4}$ to $\mathrm{ZnIn}_{2} \mathrm{~S}_{4}$, whereas the photogenerated holes on the more positive $\mathrm{VB}$ of $\mathrm{ZnIn}_{2} \mathrm{~S}_{4}(+1.58 \mathrm{eV})$ would migrate to that of $\mathrm{CaIn}_{2} \mathrm{~S}_{4}(+0.91 \mathrm{eV})$. This bidirectional charge transfer process results in efficient separation of photogenerated electron/hole pairs in the synthesized $\mathrm{CaIn}_{2} \mathrm{~S}_{4} / \mathrm{ZnIn}_{2} \mathrm{~S}_{4}$ composites.

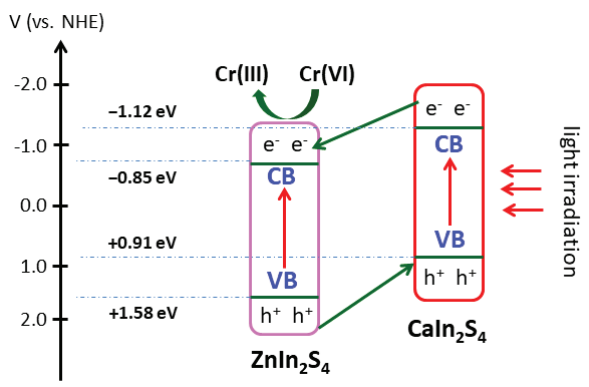

Figure 9. Schematic diagram of the transfer and separation of photogenerated charges in the $\mathrm{CaIn}_{2} \mathrm{~S}_{4} / \mathrm{ZnIn}_{2} \mathrm{~S}_{4}$ composites under simulated sunlight irradiation.

To further investigate the important function of heterostructures in enhancing the separation of charge carriers, the transient photocurrent responses were measured over working electrodes made of the pure $\mathrm{CaIn}_{2} \mathrm{~S}_{4}, \mathrm{ZnIn}_{2} \mathrm{~S}_{4}$, and $30 \% \mathrm{CaIn}_{2} \mathrm{~S}_{4} / \mathrm{ZnIn}_{2} \mathrm{~S}_{4}$ composite. As depicted in Figure 10, the fast and steady photocurrent response can be detected for each light-on and light-off cycle over the pure $\mathrm{CaIn}_{2} \mathrm{~S}_{4}, \mathrm{ZnIn}_{2} \mathrm{~S}_{4}$, and $30 \% \mathrm{CaIn}_{2} \mathrm{~S}_{4} / \mathrm{ZnIn}_{2} \mathrm{~S}_{4}$ composite. The pristine CaIn $\mathrm{S}_{4}$ exhibited a very low photocurrent density, whereas the pure $\mathrm{ZnIn}_{2} \mathrm{~S}_{4}$ showed a relatively higher photocurrent than that of 
$\mathrm{CaIn}{ }_{2} \mathrm{~S}_{4}$ under simulated sunlight irradiation. This could be due to the fact that $\mathrm{CaIn}_{2} \mathrm{~S}_{4}$ possesses a narrower bandgap than $\mathrm{ZnIn}_{2} \mathrm{~S}_{4}$, which is unfavorable for the effective separation of photoinduced electron/hole pairs. This would result in the short survival time of photogenerated electrons and weak photocurrent density. However, the composite sample of $30 \% \mathrm{CaIn}_{2} \mathrm{~S}_{4} / \mathrm{ZnIn}_{2} \mathrm{~S}_{4}$ exhibits a dramatically enhanced photocurrent density compared with that of the pure $\mathrm{ZnIn}_{2} \mathrm{~S}_{4}$ and $\mathrm{CaIn}_{2} \mathrm{~S}_{4}$, which further substantiates the efficient separation of the photoinduced electron/hole pairs in the obtained $\mathrm{CaIn}_{2} \mathrm{~S}_{4} / \mathrm{ZnIn}_{2} \mathrm{~S}_{4}$ composites.

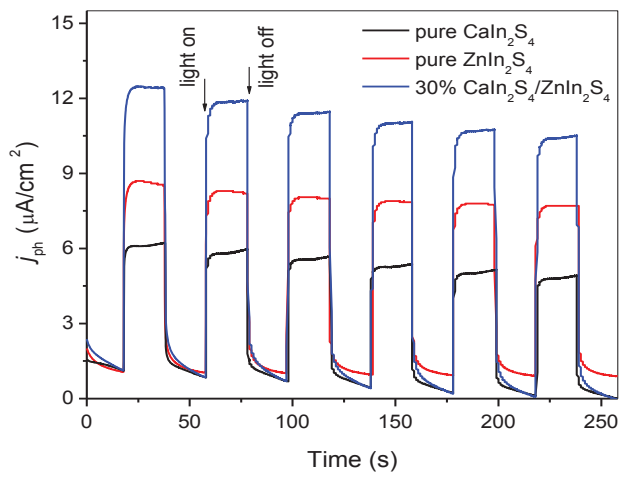

Figure 10. Photocurrent spectra of the as-synthesized pure $\mathrm{CaIn}_{2} \mathrm{~S}_{4}, \mathrm{ZnIn}_{2} \mathrm{~S}_{4}$, and $30 \%$ $\mathrm{CaIn}_{2} \mathrm{~S}_{4} / \mathrm{ZnIn}_{2} \mathrm{~S}_{4}$ samples under simulated sunlight irradiation with $20 \mathrm{~s}$ light on/off cycles.

Based on the above experimental results and the charge transfer process depicted in Figure 9, a possible enhancement mechanism of photocatalytic activity and stability for the $\mathrm{Cr}(\mathrm{VI})$ reduction can be proposed. Under simulated sunlight irradiation, the components of CaIn $\mathrm{S}_{4}$ and $\mathrm{ZnIn}_{2} \mathrm{~S}_{4}$ are excited to produce photoinduced holes and electrons. Owing to the relatively high recombination rate of photogenerated electron/hole pairs, the pristine CaIn $\mathrm{S}_{4}$ and $\mathrm{ZnIn}_{2} \mathrm{~S}_{4}$ exhibited low photocatalytic performance. Due to the well-matched energy band structures and the intimate interfacial contact between $\mathrm{CaIn}_{2} \mathrm{~S}_{4}$ and $\mathrm{ZnIn}_{2} \mathrm{~S}_{4}$ in the as-synthesized composites, the photoinduced electrons located on the $\mathrm{CB}$ of $\mathrm{CaIn}_{2} \mathrm{~S}_{4}$ can easily migrate to that of $\mathrm{ZnIn}_{2} \mathrm{~S}_{4}$, and on the contrary, the photoinduced holes on the VB of $\mathrm{ZnIn}_{2} \mathrm{~S}_{4}$ spontaneously transfer to that of $\mathrm{CaIn}_{2} \mathrm{~S}_{4}$ (Figure 9). These photoelectrons $\left(\mathrm{e}^{-}\right)$accumulated on the $\mathrm{CB}$ of $\mathrm{ZnIn}_{2} \mathrm{~S}_{4}$ possess a strong reduction ability $(-0.85 \mathrm{eV}$ vs. NHE (normal hydrogen electrode)), which can reduce toxic $\mathrm{Cr}(\mathrm{VI})$ to $\mathrm{Cr}(\mathrm{III})\left(E_{\mathrm{Cr}(\mathrm{VI}) / \mathrm{Cr}(\mathrm{III})}=+0.55 \mathrm{eV}\right.$ vs. NHE) $[44,45]$. The photoholes located on the $\mathrm{VB}$ of $\mathrm{CaIn}_{2} \mathrm{~S}_{4}$ react with the sacrificial reagents immediately. The heterostructured composites formed between $\mathrm{CaIn}_{2} \mathrm{~S}_{4}$ and $\mathrm{ZnIn}_{2} \mathrm{~S}_{4}$ effectively prevent the recombination of photogenerated electrons and holes, and thus, the photocatalytic activities of the $\mathrm{Cr}(\mathrm{VI})$ reduction are enhanced greatly. Meanwhile, the effective transfer of photogenerated holes from the VB of $\mathrm{ZnIn}_{2} \mathrm{~S}_{4}$ to that of $\mathrm{CaIn}_{2} \mathrm{~S}_{4}$ is beneficial for preventing the oxidation of $\mathrm{S}^{2-}$ by holes, which significantly improves the photostability of $\mathrm{ZnIn}_{2} \mathrm{~S}_{4}$ in the composite catalysts.

\section{Conclusions}

In short, the $\mathrm{CaIn}_{2} \mathrm{~S}_{4} / \mathrm{ZnIn}_{2} \mathrm{~S}_{4}$ composite photocatalysts were successfully prepared through a one-step hydrothermal process. XRD patterns show that the as-synthesized flower-like composites consist of hexagonal phase $\mathrm{ZnIn}_{2} \mathrm{~S}_{4}$ and cubic phase CaIn $\mathrm{S}_{4}$. Compared with the pristine $\mathrm{ZnIn}_{2} \mathrm{~S}_{4}$, the heterostructured composites $\mathrm{CaIn}_{2} \mathrm{~S}_{4} / \mathrm{ZnIn}_{2} \mathrm{~S}_{4}$ show significantly improved photocatalytic activity and stability for the $\mathrm{Cr}(\mathrm{VI})$ reduction under simulated sunlight illumination. The molar content of $\mathrm{CaIn}_{2} \mathrm{~S}_{4}$ has a great influence on the photocatalytic activity of the CaIn $\mathrm{S}_{4} / \mathrm{ZnIn}_{2} \mathrm{~S}_{4}$ composites, and $30 \% \mathrm{CaIn}_{2} \mathrm{~S}_{4} / \mathrm{ZnIn}_{2} \mathrm{~S}_{4}$ exhibits the optimal photocatalytic performance for the $\mathrm{Cr}(\mathrm{VI})$ reduction. 
A possible mechanism of the photogenerated charge transfer was proposed to illustrate the superior photocatalytic performance and photostability of the $\mathrm{CaIn}_{2} \mathrm{~S}_{4} / \mathrm{ZnIn}_{2} \mathrm{~S}_{4}$ composite catalysts. This study is of great importance in the design and synthesis of heterostructured sulfide composites with excellent photocatalytic performance and consistent stability toward the elimination of toxic metal ions in water.

Supplementary Materials: The following are available online at http://www.mdpi.com/2079-4991/8/7/472/s1, Figure S1: Concentrations of $\mathrm{Cr}(\mathrm{VI})$ and total $\mathrm{Cr}$ ions in the photocatalytic reaction solution over $30 \%$ CaIn2S4/ZnIn2S4 catalyst under simulated sunlight irradiation., Figure S2: XPS survey spectra (a), high-resolution XPS spectra of Zn 2p (b), In 3d (c), Ca 2p (d), and S 2p (e) of 30\% CaIn2S4/ZnIn2S4 composite sample before and after the photocatalytic reaction, respectively.

Author Contributions: J.Y. (Juan Yang) proposed and planned the research and supervised the experiments. J.D. designed the synthesis of the photocatalysts. S.X. and J.Y. (Jun You) prepared the photocatalysts and performed the characterization and photocatalytic measurements. J.D. and J.H. improved the data analysis. All the authors collaborated and participated in writing of the manuscript.

Acknowledgments: This works has been supported by the National Nature Science Foundation of China (21307027), the Scientific and Technological Project of Henan Province (172102310725), the Funding Scheme for the Young Backbone Teachers of Higher Education Institutions in Henan Province (2015GGJS-071), the Fundamental Research Funds for the Universities of Henan Province (NSFRF170303), the Foundation for Distinguished Young Scientists (J2016-4), and the Innovative Research Team (T2018-2) of Henan Polytechnic University.

Conflicts of Interest: The authors declare no conflict of interest.

\section{References}

1. Yang, L.X.; Luo, S.L.; Li, Y.; Xiao, Y.; Kang, Q.; Cai, Q.Y. High efficient photocatalytic degradation of p-nitrophenol on a unique $\mathrm{Cu}_{2} \mathrm{O} / \mathrm{TiO}_{2}$ p-n heterojunction network catalyst. Environ. Sci. Technol. 2010, 44, 7641-7646. [CrossRef] [PubMed]

2. Liu, Y.M.; Hou, C.L.; Jiao, T.F.; Song, J.W.; Zhang, X.; Xing, R.R.; Zhou, J.X.; Zhang, L.X.; Peng, Q.M. Self-assembled AgNP-containing nanocomposites constructed by electrospinning as efficient dye photocatalyst materials for wastewater treatment. Nanomaterials 2018, 8, 35. [CrossRef] [PubMed]

3. Wang, X.L.; Pehkonen, S.O.; Ray, A.K. Removal of aqueous $\mathrm{Cr}(\mathrm{VI})$ by a combination of photocatalytic reduction and coprecipitation. Ind. Eng. Chem. Res. 2004, 43, 1665-1672. [CrossRef]

4. Yin, H.B.; Wada, Y.; Kitamura, T.; Yanagida, S. Photoreductive dehalogenation of halogenated benzene derivatives using ZnS or CdS nanocrystallites as photocatalysts. Environ. Sci. Technol. 2001, 35, 227-231. [CrossRef] [PubMed]

5. Zhou, R.X.; Guzman, M.I. $\mathrm{CO}_{2}$ reduction under periodic illumination of ZnS. J. Phys. Chem. C 2014, 118, 11649-11656. [CrossRef]

6. Zhou, R.X.; Guzman, M.I. Photocatalytic reduction of fumarate to succinate on ZnS mineral surfaces. J. Phys. Chem. C 2016, 120, 7349-7357. [CrossRef]

7. Baran, T.; Wojtyla, S.; Dibenedetto, A.; Aresta, M.; Macyk, W. Zinc sulfide functionalized with ruthenium nanoparticles for photocatalytic reduction of $\mathrm{CO}_{2}$. Appl. Catal. B Environ. 2015, 178, 170-176. [CrossRef]

8. Wojtyla, S.; Baran, T. Insight on doped $\mathrm{ZnS}$ and its activity towards photocatalytic removing of $\mathrm{Cr}(\mathrm{VI})$ from wastewater in the presence of organic pollutants. Mater. Chem. Phys. 2018, 212, 103-112. [CrossRef]

9. Wang, W.J.; Ng, T.W.; Ho, W.K.; Huang, J.H.; Liang, S.J.; An, T.C.; Li, G.Y.; Yu, J.C.; Wong, P.K. $\mathrm{CdIn}{ }_{2} \mathrm{~S}_{4}$ microsphere as an efficient visible-light-driven photocatalyst for bacterial inactivation: Synthesis, characterizations and photocatalytic inactivation mechanisms. Appl. Catal. B Environ. 2013, 129, 482-490. [CrossRef]

10. Tu, X.L.; Lu, J.; Li, M.; Su, Y.J.; Yin, G.L.; He, D.N. Hierarchically $\mathrm{ZnIn}_{2} \mathrm{~S}_{4}$ nanosheet-constructed microwire arrays: Template-free synthesis and excellent photocatalytic performances. Nanoscale 2018, 10, 4735-4744. [CrossRef] [PubMed]

11. Gou, X.L.; Cheng, F.Y.; Shi, Y.H.; Zhang, L.; Peng, S.J.; Chen, J.; Shen, P.W. Shape-controlled synthesis of ternary chalcogenide $\mathrm{ZnIn}_{2} \mathrm{~S}_{4}$ and $\mathrm{CuIn}(\mathrm{S}, \mathrm{Se})(2)$ nano-/microstructures via facile solution route. J. Am. Chem. Soc. 2006, 128, 7222-7229. [CrossRef] [PubMed]

12. Li, L.L.; Peng, S.J.; Wang, N.; Srinivasan, M.; Mhaisalkar, S.G.; Yan, Q.Y.; Ramakrishna, S. A general strategy toward carbon cloth-based hierarchical films constructed by porous nanosheets for superior photocatalytic activity. Small 2015, 11, 2429-2436. [CrossRef] [PubMed] 
13. Yu, X.; Shavel, A.; An, X.Q.; Luo, Z.S.; Ibáñez, M.; Cabot, A. $\mathrm{Cu}_{2} \mathrm{ZnSnS}_{4}-\mathrm{Pt}$ and $\mathrm{Cu}_{2} \mathrm{ZnSnS}_{4}-\mathrm{Au}$ heterostructured nanoparticles for photocatalytic water splitting and pollutant degradation. J. Am. Chem. Soc. 2014, 136, 9236-9239. [CrossRef] [PubMed]

14. Gao, B.; Liu, L.F.; Liu, J.D.; Yang, F.L. Photocatalytic degradation of 2,4,6-tribromophenol over Fe-doped $\mathrm{ZnIn}_{2} \mathrm{~S}_{4}$ : Stable activity and enhanced debromination. Appl. Catal. B Environ. 2013, 129, 89-97. [CrossRef]

15. Guan, Z.J.; Xu, Z.Q.; Li, Q.Y.; Wang, P.; Li, G.Q.; Yang, J.J. AgIn ${ }_{5} S_{8}$ nanoparticles anchored on 2D layered $\mathrm{ZnIn}_{2} \mathrm{~S}_{4}$ to form OD/2D heterojunction for enhanced visible-light photocatalytic hydrogen evolution. Appl. Catal. B Environ. 2018, 227, 512-518. [CrossRef]

16. Yuan, Y.J.; Chen, D.Q.; Zhong, J.S.; Yang, L.X.; Wang, J.J.; Liu, M.J.; Tu, W.G.; Yu, Z.T.; Zou, Z.G. Interface engineering of a noble-metal-free 2D-2D MoS $2 / C u-Z_{2} n_{2} \mathrm{~S}_{4}$ photocatalyst for enhanced photocatalytic $\mathrm{H}_{2}$ production. J. Mater. Chem. A 2017, 5, 15771-15779. [CrossRef]

17. Tan, C.W.; Zhu, G.Q.; Hojamberdiev, M.; Lokesh, K.S.; Luo, X.C.; Jin, L.; Zhou, J.P.; Liu, P. Adsorption and enhanced photocatalytic activity of the $\{0001\}$ faceted Sm-doped $\mathrm{ZnIn}_{2} \mathrm{~S}_{4}$ microspheres. J. Hazard. Mater. 2014, 278, 572-583. [CrossRef] [PubMed]

18. Xu, F.Y.; Zhang, J.J.; Zhu, B.C.; Yu, J.G.; Xu, J.S. CuInS 2 sensitized $\mathrm{TiO}_{2}$ hybrid nanofibers for improved photocatalytic $\mathrm{CO}_{2}$ reduction. Appl. Catal. B Environ. 2018, 230, 194-202. [CrossRef]

19. Aguirre, M.E.; Zhou, R.X.; Eugene, A.J.; Guzman, M.I.; Grela, M.A. Cur $\mathrm{O} / \mathrm{TiO}_{2}$ heterostructures for $\mathrm{CO}_{2}$ reduction through a direct Z-scheme: Protecting $\mathrm{Cu}_{2} \mathrm{O}$ from photocorrosion. Appl. Catal. B Environ. 2017, 217, 485-493. [CrossRef]

20. Wu, Z.; Gong, C.; Yu, J.; Sun, L.; Xiao, W.; Lin, C. Enhanced visible light photoelectrocatalytic activity over $\mathrm{Cu}_{\mathrm{x}} \mathrm{Zn}_{1-\mathrm{x}} \mathrm{In}_{2} \mathrm{~S}_{4} @ \mathrm{TiO}_{2}$ nanotube array hetero-structures. J. Mater. Chem. A 2017, 5, 1292-1299. [CrossRef]

21. Hou, J.; Yang, C.; Cheng, H.; Wang, Z.; Jiao, S.; Zhu, H. Ternary 3D architectures of CdS QDs/graphene/ZnIn $\mathrm{S}_{4}$ heterostructures for efficient photocatalytic $\mathrm{H}_{2}$ production. Phys. Chem. Chem. Phys. 2013, 15, 15660-15668. [CrossRef] [PubMed]

22. Zhang, Z.; Liu, K.; Feng, Z.; Bao, Y.; Dong, B. Hierarchical sheet-on-sheet $Z \mathrm{Zn}_{2} \mathrm{~S}_{4} / \mathrm{g}_{-} \mathrm{C}_{3} \mathrm{~N}_{4}$ heterostructure with highly efficient photocatalytic $\mathrm{H}_{2}$ production based on photoinduced interfacial charge transfer. Sci. Rep. 2016, 6, 19221. [CrossRef] [PubMed]

23. Huang, S.; Lin, Y.; Yang, J.H.; Yu, Y. CdS-based semiconductor photocatalysts for hydrogen production from water splitting under solar light. ACS Symp. Ser. 2013, 1140, 219-241. [CrossRef]

24. Chen, J.Y.; Zhang, H.M.; Liu, P.R.; Li, Y.B.; Liu, X.L.; Li, G.Y.; Wong, P.K.; An, T.C.; Zhao, H.J. Cross-linked $\mathrm{ZnIn}_{2} \mathrm{~S}_{4} / \mathrm{rGO}$ composite photocatalyst for sunlight-driven photocatalytic degradation of 4-nitrophenol. Appl. Catal. B Environ. 2015, 168-169, 266-273. [CrossRef]

25. Yuan, W.H.; Yang, S.; Li, L. Synthesis of $\mathrm{g}-\mathrm{C}_{3} \mathrm{~N}_{4} / \mathrm{CaIn}_{2} \mathrm{~S}_{4}$ composites with enhanced photocatalytic activity under visible light irradiation. Dalton Trans. 2015, 44, 16091-16098. [CrossRef] [PubMed]

26. Ding, J.J.; Yan, W.H.; Sun, S.; Bao, J.; Gao, C. Hydrothermal synthesis of CaIn ${ }_{2} \mathrm{~S}_{4}$-reduced graphene oxide nanocomposites with increased photocatalytic performance. ACS Appl. Mater. Interfance 2014, 6, 12877-12884. [CrossRef] [PubMed]

27. Jo, W.K.; Natarajan, T.S. Facile synthesis of novel redox-mediator-free direct Z-Scheme Caln ${ }_{2} \mathrm{~S}_{4}$ marigold-flower-like $/ \mathrm{TiO}_{2}$ photocatalysts with superior photocatalytic efficiency. ACS Appl. Mater. Interfance 2015, 7, 17138-17154. [CrossRef] [PubMed]

28. Testa, J.J.; Grela, M.A.; Litter, M.I. Heterogeneous photocatalytic reduction of chromium(VI) over $\mathrm{TiO}_{2}$ particles in the presence of oxalate: Involvement of $\mathrm{Cr}(\mathrm{V})$ species. Environ. Sci. Technol. 2004, 38, 1589-1594. [CrossRef] [PubMed]

29. Fu, F.L.; Wang, Q. Removal of heavy metal ions from wastewaters: A review. J. Environ. Manag. 2011, 92, 407-418. [CrossRef] [PubMed]

30. Liu, F.H.; Yu, J.; Tu, G.Y.; Qu, L.; Xiao, J.C.; Liu, Y.D.; Wang, L.Z.; Lei, J.Y.; Zhang, J.L. Carbon nitride coupled Ti-SBA15 catalyst for visible-light-drivenphotocatalytic reduction of $\mathrm{Cr}(\mathrm{VI})$ and the synergistic oxidation of phenol. Appl. Catal. B Environ. 2017, 201,1-11. [CrossRef]

31. Nayak, A.K.; Lee, S.; Choi, Y.I.; Yoon, H.J.; Sohn, Y.; Pradhan, D. Crystal phase and size-controlled synthesis of tungsten trioxide hydrate nanoplates at room temperature: Enhanced $\mathrm{Cr}(\mathrm{VI})$ photoreduction and methylene blue adsorption properties. ACS Sustain. Chem. Eng. 2017, 5, 2741-2750. [CrossRef] 
32. Yang, J.; You, J.; Dai, J.; Chen, Y.M.; Li, Y. In-situ synthesis of hydrogen-titanate nanotubes/graphene composites with chemically bonded interface and enhanced visible photocatalytic activity. Nanomaterials 2018, 8, 229. [CrossRef] [PubMed]

33. Wang, L.; Zhang, C.B.; Gao, F.; Mailhot, G.; Pan, G. Algae decorated $\mathrm{TiO}_{2} /$ Ag hybrid nanofiber membrane with enhanced photocatalytic activity for Cr(VI) removal under visible light. Chem. Eng. J. 2017, 314, 622-630. [CrossRef]

34. Ye, L.; Fu, J.L.; Xu, Z.; Yuan, R.S.; Li, Z.H. Facile one-pot solvothermal method to synthesize sheet-on-sheet reduced graphene oxide (RGO)/ $\mathrm{ZnIn}_{2} \mathrm{~S}_{4}$ nanocomposites with superior photocatalytic performance. ACS Appl. Mater. Interfaces 2014, 6, 3483-3490. [CrossRef] [PubMed]

35. Ding, J.; Sun, S.; Yan, W.; Bao, J.; Gao, C. Photocatalytic $\mathrm{H}_{2}$ evolution on a novel $\mathrm{CaIn}_{2} \mathrm{~S}_{4}$ photocatalyst under visible light irradiation. Int. J. Hydrogen Energy 2013, 38, 13153-13158. [CrossRef]

36. Zhang, X.; Zhang, J.; Yu, J.Q.; Zhang, Y.; Cui, Z.X.; Sun, Y.; Hou, B.R. Fabrication of $\mathrm{InVO}_{4} / \mathrm{AgVO}_{3}$ heterojunctions with enhanced photocatalytic antifouling efficiency under visible-light. Appl. Catal. B Environ. 2018, 220, 57-66. [CrossRef]

37. Shi, L.; Yin, P.Q.; Dai, Y.M. Synthesis and photocatalytic performance of $\mathrm{ZnIn}_{2} \mathrm{~S}_{4}$ nanotubes and nanowires. Langmuir 2013, 29, 12818-12822. [CrossRef] [PubMed]

38. Deng, Y.C.; Tang, L.; Zeng, G.M.; Zhu, Z.J.; Yan, M.; Zhou, Y.Y.; Wang, J.J.; Liu, Y.N.; Wang, J.J. Insight into highly efficient simultaneous photocatalytic removal of $\mathrm{Cr}(\mathrm{VI})$ and 2,4-diclorophenol under visible light irradiation by phosphorus doped porous ultrathin $\mathrm{g}-\mathrm{C}_{3} \mathrm{~N}_{4}$ nanosheets from aqueous media: Performance and reaction mechanism. Appl. Catal. B Environ. 2017, 203, 343-354. [CrossRef]

39. Liu, S.Q.; Yang, M.Q.; Tang, Z.R.; Xu, Y.J. A nanotree-like CdS/ZnO nanocomposite with spatially branched hierarchical structure for photocatalytic fine-chemical synthesis. Nanoscale 2014, 6, 7193-7198. [CrossRef] [PubMed]

40. Gilja, V.; Novakovic, K.; Travas-Sejdic, J.; Hrnjak-Murgic, Z.; Rokovic, M.K.; Zic, M. Stability and synergistic effect of polyaniline/ $\mathrm{TiO}_{2}$ photocatalysts in degradation of Azo dye in wastewater. Nanomaterials 2017, 7, 412. [CrossRef] [PubMed]

41. Wu, N.; Wang, J.; Tafen, D.N.; Wang, H.; Zheng, J.-G.; Lewis, J.P.; Liu, X.; Leonard, S.S.; Manivannan, A. Shape-enhanced photocatalytic activity of single-crystalline anatase $\mathrm{TiO}_{2}$ (101) nanobelts. J. Am. Chem. Soc. 2010, 132, 6679-6685. [CrossRef] [PubMed]

42. Kumar, S.; Surendar, T.; Baruah, A.; Shanker, V. Synthesis of a novel and stable $\mathrm{g}-\mathrm{C}_{3} \mathrm{~N}_{4}-\mathrm{Ag}_{3} \mathrm{PO}_{4}$ hybrid nanocomposite photocatalyst and study of the photocatalytic activity under visible light irradiation. J. Mater. Chem. A 2013, 1, 5333-5340. [CrossRef]

43. Xiong, P.; Zhu, J.W.; Wang, X. Cadmium sulfide-ferrite nanocomposite as a magnetically recyclable photocatalyst with enhanced visible-light-driven photocatalytic activity and photostability. Ind. Eng. Chem. Res. 2013, 52, 17126-17133. [CrossRef]

44. Qiu, J.H.; Zhang, X.F.; Zhang, X.G.; Feng, Y.; Li, Y.X.; Yang, L.Y.; Lu, H.Q.; Yao, J.F. Constructing $\mathrm{Cd}_{0.5} \mathrm{Zn}_{0.5} \mathrm{~S} @ \mathrm{ZIF}-8$ nanocomposites through self-assembly strategy to enhance $\mathrm{Cr}(\mathrm{VI})$ photocatalytic reduction. J. Hazard. Mater. 2018, 349, 234-241. [CrossRef] [PubMed]

45. Yuan, Y.J.; Chen, D.Q.; Shi, X.F.; Tu, J.R.; Hu, B.; Yang, L.X.; Yu, Z.T.; Zou, Z.G. Facile fabrication of "green" $\mathrm{SnS}_{2}$ quantum dots/reduced graphene oxide composites with enhanced photocatalytic performance. Chem. Eng. J. 2017, 313, 1438-1446. [CrossRef]

(c) 2018 by the authors. Licensee MDPI, Basel, Switzerland. This article is an open access article distributed under the terms and conditions of the Creative Commons Attribution (CC BY) license (http:/ / creativecommons.org/licenses/by/4.0/). 

Article

\title{
Morphology, Optical Properties and Photocatalytic Activity of Photo- and Plasma-Deposited Au and Au/Ag Core/Shell Nanoparticles on Titania Layers
}

\author{
Alexander Müller ${ }^{1,2, t, \ddagger}$, Sandra Peglow ${ }^{3, \dagger}$, Michael Karnahl ${ }^{4, \S}$, Angela Kruth ${ }^{3}$, Henrik Junge ${ }^{4}$, \\ Volker Brüser ${ }^{3}$ and Christina Scheu ${ }^{1, *}$ \\ 1 Max-Planck-Institut für Eisenforschung GmbH (MPIE), Max-Planck-Straße 1, 40237 Düsseldorf, Germany; \\ amueller@lbl.gov \\ 2 Department of Chemistry and Center for NanoScience (CeNS), University of Munich (LMU), \\ Butenandtstrasse 5-13, 81377 Munich, Germany \\ 3 Leibniz Institute for Plasma Science and Technology (INP), Felix-Hausdorff-Straße 2, \\ 17489 Greifswald, Germany; sandra.peglow@inp-greifswald.de (S.P.); \\ angela.kruth@inp-greifswald.de (A.K.); brueser@inp-greifswald.de (V.B.) \\ 4 Leibniz Institute for Catalysis at the University of Rostock (LIKAT), Albert-Einstein-Straße 29a, \\ 18059 Rostock, Germany; michael.karnahl@oc.uni-stuttgart.de (M.K.); henrik.junge@catalysis.de (H.J.) \\ * Correspondence: scheu@mpie.de; Tel.: +49-211-6792-720 \\ $\dagger$ These authors contributed equally to this work. \\ ‡ Current Address: National Center for Electron Microscopy, Molecular Foundry, Lawrence Berkeley National \\ Laboratory, 1 Cyclotron Rd, Berkeley, CA 94720, USA.
}

Received: 4 June 2018; Accepted: 4 July 2018; Published: 6 July 2018

\begin{abstract}
Titania is a promising material for numerous photocatalytic reactions such as water splitting and the degradation of organic compounds (e.g., methanol, phenol). Its catalytic performance can be significantly increased by the addition of co-catalysts. In this study, Au and Au/Ag nanoparticles were deposited onto mesoporous titania thin films using photo-deposition $(\mathrm{Au})$ and magnetron-sputtering ( $\mathrm{Au}$ and $\mathrm{Au} / \mathrm{Ag}$ ). All samples underwent comprehensive structural characterization by grazing incidence X-ray diffraction (XRD), scanning electron microscopy (SEM), and transmission electron microscopy (TEM). Nanoparticle distributions and nanoparticle size distributions were correlated to the deposition methods. Light absorption measurements showed features related to diffuse scattering, the band gap of titania and the local surface plasmon resonance of the noble metal nanoparticles. Further, the photocatalytic activities were measured using methanol as a hole scavenger. All nanoparticle-decorated thin films showed significant performance increases in hydrogen evolution under UV illumination compared to pure titania, with an evolution rate of up to $372 \mu \mathrm{L} \mathrm{H}_{2} \mathrm{~h}^{-1} \mathrm{~cm}^{-2}$ representing a promising approximately 12 -fold increase compared to pure titania.
\end{abstract}

Keywords: noble metal nanoparticles; core-shell structures; photodeposition; magnetron sputtering; photocatalysis; hydrogen production; localized surface plasmon resonance; structureproperty relationships

\section{Introduction}

For decades, mankind has relied heavily on unsustainable energy sources such as coal, oil, gas or nuclear power [1-3]. In recent years, concerns over climate change, environmental pollution, resource depletion, and safety issues have led to global efforts towards the development of sustainable and clean energy sources [1-5], with some of the most promising approaches making use of the almost unlimited energy of the sun $[2,6-12]$. One of these approaches is photocatalytic water splitting, where solar energy is used to photogenerate charge carriers in a semiconductor. The excited electrons then reduce 
protons, producing "green" hydrogen, which can be stored, transported, and finally converted back to energy using fuel cells. This approach therefore opens a promising route towards a carbon-neutral energy landscape.

Titania in the rutile phase was the first material found to have conduction and valence band positions suitable for photocatalytic water splitting [13-15]. It also has several other desirable properties such as high corrosion-resistance, abundance, low price, and non-toxicity [16]. Therefore, titania, both in the rutile and in the low-temperature anatase modification, is still one of the most studied materials for water splitting and other photocatalytic applications like the degradation of organic compounds [5,15,17-19]. Its biggest drawback is the comparatively large band gaps of $3.2 \mathrm{eV}$ for anatase and of $3.0 \mathrm{eV}$ for rutile, corresponding to absorption edges at wavelengths of 386 and $416 \mathrm{~nm}$, respectively $[13,16,17,20]$. Accordingly, significant light absorption and photogeneration of charge carriers can only occur within or near the UV region, which accounts for merely $5 \%$ of the total energy of the solar spectrum [21,22]. This limits the theoretical maximum efficiency to $1.3 \%$ for anatase and $2.2 \%$ for rutile [17]. As the performance strongly depends on the band gap, it can be enhanced by either introducing additional electronic states into the band gap via doping and/or by depositing a second light-absorbing material that absorbs within the visible region and acts as a photosensitizer for titania $[21,23,24]$. Popular photosensitizers, that are also used in solar cells, are (metal) organic dyes [25-30]. They are, however, often unstable under UV radiation and in the chemical environment present during water splitting [25].

More suitable for this application are nanoparticles based on noble metals such as $\mathrm{Au}, \mathrm{Ag}$ or $\mathrm{Cu}$. In these metals, light can induce a localized collective electron oscillation, a so-called "plasmon", near the nanoparticle surface $[22,23,31,32]$. The energy of this surface plasmon strongly depends on the size, shape and dielectric constant of the nanoparticle as well as of the surrounding medium $[22,23,32,33]$. By optimizing these parameters, the wavelength of the localized surface plasmon resonance (LSPR) can be shifted to the desired range, allowing for visible or even near-infrared light absorption [22,23,32-35]. These plasmon-induced electrons can transfer to an electron-acceptor such as titania [24], increasing visible light-induced charge separation and enhancing the efficiency of photoreactions. If the LSPR frequency is at or near the semiconductor band gap, the electromagnetic field stemming from the plasmon excitation can lead to charge carrier formation in the supporting semiconductor [36-38]. Under these conditions, the large scattering cross section of the plasmon oscillation in noble metal nanoparticles enhances the optical pathway of the incident photons leading to increased light absorption [39]. In addition to their function as photosensitizer, noble metal nanoparticles can enhance the performance of the semiconductor as co-catalysts by providing chemically active sites with low activation barriers [40], prolonging charge carrier lifetime [40], and serve as a reservoir for electrons generated in the titania by UV light [24,41-43].

Several studies on photosensitizing titania using noble metal nanoparticles were carried out on suspended powders [40,42,44-48]. In contrast, we deposited Au-based nanoparticles onto anatase thin films. Compared to powdered samples, immobilizing the catalyst allows for precise control over morphology, light absorption and catalytic behavior, and therefore for high reproducibility of the measured photocatalytic performance [49,50]. The samples are also easier to handle, and agglomeration of particles is not an issue. The performance typically depends greatly on the morphology of the sample, and studying the correlation of synthesis conditions, morphology and properties is of paramount importance. In this study, two different methods were used to deposit metallic nanoparticles. First, gold nanoparticles were prepared by in situ photodeposition, which is a widely established approach that works well at the laboratory scale [51]. Second, both gold and silver/gold nanoparticles, which often show significantly increased catalytic activity compared to the respective monometallic nanoparticles [52,53], were deposited by a radio frequency (RF) magnetron sputtering process followed by an annealing step [54,55]. In comparison to photodeposition, physical deposition processes such as this one can often be scaled up to an industrial scale. Care was taken that the noble-metal loading of the two $\mathrm{Au}-\mathrm{TiO}_{2}$ samples was comparable. The crystal structures of all 
phases were confirmed via grazing incidence $X$-ray diffraction, and the morphologies of the samples were analyzed using scanning and transmission electron microscopy. As expected, both synthesis methods resulted in considerably different particle distributions, particle size distributions and defect structures. We further measured the UV-vis spectra and the photocatalytic evolution of hydrogen from water using the sacrificial electron donor methanol. Methanol was chosen as past studies had shown it to be an excellent hole scavenger, allowing us to neglect surface kinetics in the discussion and simplifying the complex behavior of this system [56-58]. All results were correlated to each other, and we hope that our combined findings contribute to an in-depth understanding of the interplay between synthesis, structure, and properties.

\section{Materials and Methods}

Titania films were deposited onto fluorine-doped tin oxide substrates (fluorine doped tin oxide (FTO), TCO 22-7, Solaronix, $25 \times 25 \mathrm{~mm}$, Aubonne, Switzerland) by a direct current (DC) reactive magnetron sputtering process previously described by Kruth et al. [54]. The cylindrical Ti target (Ti-133, Bekaert Advanced Coatings NV, Deinze, Belgium, $135 \mathrm{~mm}$ diameter, $58.5 \mathrm{~mm}$ length) was sputter-cleaned in an Ar atmosphere at $8 \mathrm{~kW}$ for $5 \mathrm{~min}$. After stabilizing the process conditions in an $\mathrm{O}_{2} / \mathrm{N}_{2} /$ Ar atmosphere (6 standard $\mathrm{cm}^{3} / \min (\mathrm{sccm}) \mathrm{O}_{2}, 3 \mathrm{sccm} \mathrm{N}_{2}$, and $60 \mathrm{sccm} \mathrm{Ar}$ ) at 3 Pa for $8 \mathrm{~min}, \mathrm{TiO}_{2}$ was plasma-deposited at a magnetron power of about $5.3 \mathrm{~kW}$ and a magnetron voltage of $450 \mathrm{~V}$. To transform the resulting amorphous $\mathrm{TiO}_{2}$ into anatase, the samples were annealed for $1 \mathrm{~h}$ at $400{ }^{\circ} \mathrm{C}$ with a heating rate of $10^{\circ} \mathrm{C} / \mathrm{min}$ in an oxygen atmosphere at a flow rate of 0.05 standard $\mathrm{L} / \mathrm{min}(\operatorname{slm})$.

$\mathrm{Au}$ and $\mathrm{Au} / \mathrm{Ag}$ core-shell nanoparticles were deposited onto the titania films described above using a RF-magnetron sputtering process previously published by Peglow et al. [55]. Au and Ag sputtering targets (both of $3 \mathrm{~mm}$ thickness, two inch diameter and purity of $99.999 \%$, MaTeck, Juelich, Germany, were placed at respective distances of 9.5 and $5.5 \mathrm{~cm}$ from the substrate. Small sputtering rates were achieved by shielding the magnetic field with a $1 \mathrm{~mm}$ thick iron disk (99.95\%, MaTeck) placed between the magnetron and the two targets. The deposition was performed at a magnetron power of $50 \mathrm{~W}$ at a working pressure of $5 \mathrm{~Pa}$ in an argon atmosphere (15 sccm gas flow). After each deposition, the samples were annealed by placing them in a quartz tube that was inserted into a tube furnace (Zirox $\mathrm{GmbH}$, Greifswald, Germany, kept at $400^{\circ} \mathrm{C}$ by a thermal controller (Eurotherm 2416, Limburg an der Lahn, Germany) for $30 \mathrm{~min}$. The $\mathrm{O}_{2}$ atmosphere $(0.05 \mathrm{slm})$ was regulated using a gas flow controller (MKS Instruments Multi Gas Controller 647B, Andover, MA, USA). Au nanoparticles were synthesized by depositing gold over a period of $300 \mathrm{~s}$, resulting in a nominal layer thickness of $(6.6 \pm 0.7) \mathrm{nm}$. Deposition was followed by an annealing step, a second, $300 \mathrm{~s}$ long deposition step and a final annealing step leading to an estimated total layer thickness of (13.2 \pm 1.5$) \mathrm{nm}$. To obtain Au/Ag core-shell nanoparticles, Au-deposition for $188 \mathrm{~s}$ resulted in a nominal layer thickness of (4.1 \pm 0.5$)$ $\mathrm{nm}$ and was followed by Ag-deposition over $36 \mathrm{~s}$, resulting in a nominal layer thickness of (2.5 \pm 0.1$)$ $\mathrm{nm}$, and one final annealing step.

A second series of Au nanoparticles was prepared by in situ photodeposition onto titania films following a synthesis procedure described by Gärtner et al. [40]. The temperature of a double-walled reaction vessel was adjusted to $25^{\circ} \mathrm{C}$ by a thermostat. The titania film $(25 \times 25 \mathrm{~mm})$ was inserted into the reactor with a glass holder. Subsequently, the gold precursor $\left(\mathrm{NaAuCl}_{4} \cdot 2 \mathrm{H}_{2} \mathrm{O}, 3.1 \mathrm{mg}\right)$ was added. The whole system was evacuated and flushed with argon to remove any other gases. Then, $40 \mathrm{~mL}$ freshly distilled water and $40 \mathrm{~mL}$ methanol were added under argon counter flow, resulting in a final concentration of the gold precursor of about $0.1 \mathrm{mmol} / \mathrm{L}$. The photodeposition was initiated with a Hg-lamp (7.2 W output, Lumatec Superlite 400, Deisenhofen, Germany) equipped with a 320-500 nm filter [40]. A swift color change from light yellow to dark red occurred, with the formed hydrogen escaping by a bubbler. The reaction was stopped after $3 \mathrm{~h}$ and the sample was washed with deionized water and ethanol prior to drying in air. 
Phase identity and average crystallite sizes were determined by grazing incidence $X$-ray diffractometry (GIXRD). Diffractograms were obtained using a Bruker D8 Advance (Billerica, MA, USA) with a $\mathrm{Cu}-\mathrm{K} \alpha$ source. The measurement was carried out in a $2 \theta$-range of $20^{\circ}-80^{\circ}$ at an incident angle of $0.5^{\circ}$, with a step width of $0.02^{\circ}$ and a measurement time of $5 \mathrm{~s}$ per step. Crystallite sizes were calculated from the (200) reflection of Au as well as the (200) and (101) reflections of anatase using a combination of the Stokes-Wilson and the Variance model and fitting the correlated integral widths by a Pearson VII function [59].

Scanning electron microscopy (SEM) was performed on a JEOL JSM 7500F (Tokyo, Japan) with a field emission gun, a semi-in-lens conical objective lens, and a secondary electron in-lens detector. At an acceleration voltage of $15 \mathrm{keV}$, a resolution of $1.0 \mathrm{~nm}$ was achieved.

A comprehensive structural analysis was carried out using a FEI Titan 80-300 transmission electron microscope (TEM, Hillosboro, OR, USA). Bright-field (BF) and high-resolution TEM (HRTEM) images were recorded on a Gatan UltraScan 1000 CCD (Pleasanton, CA, USA), scanning TEM (STEM) images with a Fischione Model 3000 high angle annular dark-field (HAADF) detector (Export, PA, USA) and energy-dispersive X-ray (EDX) spectra with an EDAX detector (Mahwah, NJ, USA). Samples were prepared by either scratching material of the substrate and depositing it onto a TEM grid with a holey carbon film or by preparing a cross-section according to a procedure adapted from Strecker et al. so that the sample was prepared at room temperature [60].

The optical properties of the different samples were investigated using a PerkinElmer Lambda UV-vis 850 spectrophotometer with a L6020322 $150 \mathrm{~mm}$ integrating sphere and a Spectralon Reflectance Standard (>99\% R, USRS-99-020, PerkinElmer Inc., Waltham, MA, USA). The UV-vis spectra were recorded by measuring the diffuse transmission at wavelengths from $250 \mathrm{~nm}$ to $850 \mathrm{~nm}$. Calculation of the absorbance A was carried out under the assumption that no reflection occurs at the sample using Equation (1) [54,61],

$$
\mathrm{A}=-\log 10\left(I_{\mathrm{T}} / I_{0}\right),
$$

where $\mathrm{A}$ is the absorbance in arbitrary units, $I_{\mathrm{T}}$ is the measured transmission intensity in percent and $I_{0}$ is the incident light intensity, which equals $100 \%$.

Photocatalytic hydrogen evolution experiments were performed under argon atmosphere and the strict exclusion of oxygen using freshly distilled and degassed solvents. The sample was introduced into a double-walled, thermostatically-controlled reaction vessel by a glass holder and aligned in parallel to the planar optical window. This setup allowed for a reproducible experimental arrangement and a direct illumination of the sample without blocking by the cooling water. Furthermore, a complete irradiation of the $25 \times 25 \mathrm{~mm}$ thin film layer was ensured. Subsequently, the photoreactor was connected to an automatic gas burette and repeatedly evacuated and filled with argon in order to exclude any oxygen. Then, the solvent mixture $(80 \mathrm{~mL})$, composed of water and methanol in a ratio of $1 / 1(v / v)$, was added, fully covering the layer. The temperature of the whole system was maintained at $25^{\circ} \mathrm{C}$ by a thermostat. After stirring for at least $10 \mathrm{~min}$ at 300 rounds per minute to reach thermal equilibrium, the reaction was started by switching on a Hg-lamp (Lumatec Superlite 400, Deisenhofen, Germany) equipped with either a $320-500 \mathrm{~nm}$ or a $400-700 \mathrm{~nm}$ filter. In both cases, the light intensity was set to $7.2 \mathrm{~W}$. The amount of evolved gases was continuously monitored by the automatic gas burette, while the gas composition was analyzed by gas chromatography. A more detailed description of the experimental setup can be found in the literature [40].

\section{Results and Discussion}

\subsection{Structural and Morphological Characterization}

GIXR diffractograms (Figure 1a) indicate the phase identities of all samples [62-64]. Annealing of the titania films led to crystallization of the material in the anatase modification, with an average crystallite size of approximately $25 \mathrm{~nm}$. This is in agreement with earlier results [27,54]. Monometallic $\mathrm{Au}$ and bimetallic $\mathrm{Au} / \mathrm{Ag}$ nanoparticles crystallize in the face-centered cubic Fm-3m symmetry 
(space group 225), with the lattice parameters of Ag and Au being too similar to differentiate between the two phases. The (200) peaks of $\mathrm{Au}$ and $\mathrm{Au} / \mathrm{Ag}$ did not show any overlap with those of other phases and were used for further analysis (Figure 1b). The intensities of the (200) peaks of Au in photodeposited and plasma-deposited $\mathrm{Au}-\mathrm{TiO}_{2}$ are similar, indicating similar metal loading. In contrast, a weaker peak is observed for plasma-deposited $\mathrm{Au} / \mathrm{Ag}-\mathrm{TiO}_{2}$, explicable by the lower metal loading. Calculated average crystallite sizes of all three samples were comparable at around 6-7 nm, with no drop for the bimetallic sample with significantly lower metal loading. It should, however, be considered that crystallite size calculations from XRD are limited to average values for crystalline domains and only assume the presence of ideal, spherical crystallites.

a)

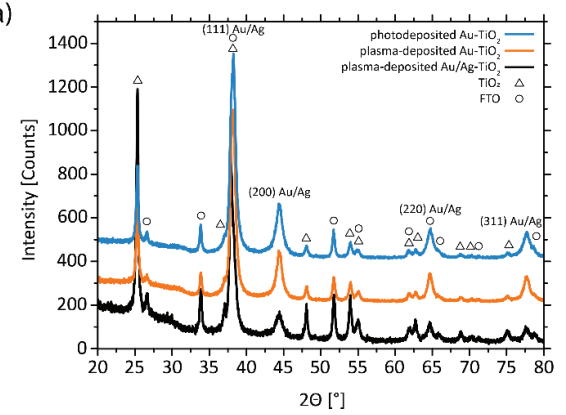

b)

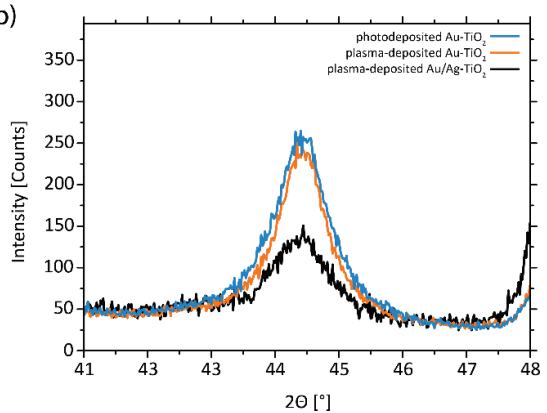

Figure 1. (a) Grazing incidence X-ray (GIXR) diffractograms of the three noble metal-decorated samples and (b) close-up of the Au/Ag (200) peaks. The intensities of the curves in (a) were shifted vertically by constant factors, as they would overlap otherwise.

In Figure 2, electron microscopy images of the three samples are shown. Top-view images were acquired by scanning electron microscope (SEM) (Figure 2a-c), cross-sections by HAADF-STEM (high angle annular dark-field cross-section scanning transmission electron microscopy) (Figure 2d-f).
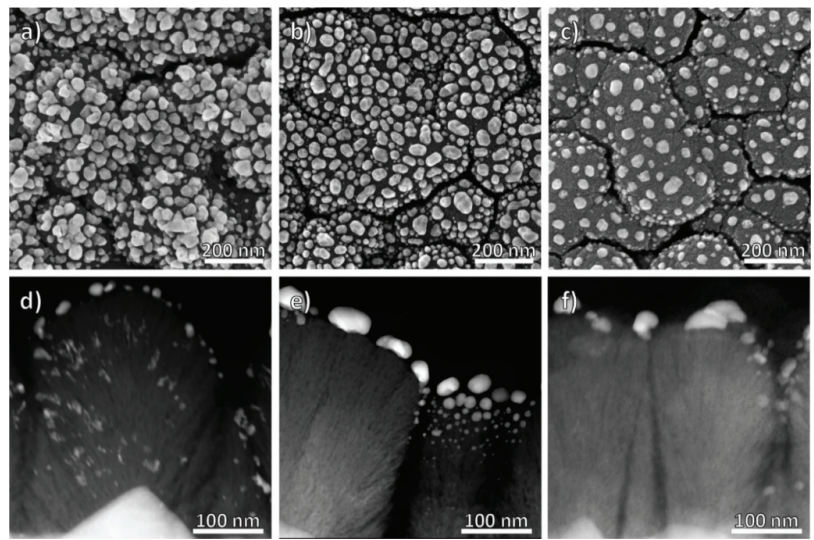

Figure 2. Top-view SEM (scanning electron microscopy) and cross-section scanning transmission electron microscopy (STEM) images of photodeposited $\mathrm{Au}-\mathrm{TiO}_{2}(\mathbf{a}, \mathbf{d})$, plasma-deposited $\mathrm{Au}-\mathrm{TiO}_{2}(\mathbf{b}, \mathbf{e})$ and plasma-deposited $\mathrm{Au} / \mathrm{Ag}-\mathrm{TiO}_{2}$ films (c,f).

The titania layer is polycrystalline, approximately $300 \mathrm{~nm}$ thick and composed of individual pillars, each of them grown on top of a FTO pyramid. This microstructure is typical for ZI thin 
film growth $[65,66]$. The fibrous titania pillars are in the anatase modification, with $3-5 \mathrm{~nm}$ wide pores elongated in the direction perpendicular to the $\mathrm{TiO}_{2} / \mathrm{FTO}$ interface. The porosity of the titania was quantified from HAADF-STEM images. The signal intensity I in such images scales with the mean atomic number $Z$ raised by an exponent $y$ (Equation (2)) [67]. As the FTO and the underlying $\mathrm{SiO}_{2}$ substrate are compact layers, y can be calculated. This calculation, as well as those following, were done using several hundred acquisition points for each material and working with average values. The mean atomic number of the titania layer is given by:

$$
\frac{I_{\text {Titania }}}{I_{\text {FTO }}}=\left(\frac{Z_{\text {Titania }}}{Z_{\text {FTO }}}\right)^{\mathrm{y}} \rightarrow Z_{\text {Titania }}=Z_{\text {FTO }} \cdot \sqrt[y]{\frac{I_{\text {Titania }}}{I_{\text {FTO }}}},
$$

The porosity is then equal to the ratio of the mean atomic numbers of the measured, porous and the theoretical, compact layer and was determined as $\sim 10 \%$, indicating low porosity.

The photodeposited Au nanoparticles are found both on top of the columns and incorporated into pores of the $\mathrm{TiO}_{2}$ layer. The latter indicates that some of the pores are open at the surface and can be filled with the gold precursor solution during the photodeposition process. In contrast, RF-sputtered $\mathrm{Au}$ and $\mathrm{Au} / \mathrm{Ag}$ nanoparticles are found on top of the titania layer which is typical for such sputter deposition processes. The particles located in the cavities are significantly smaller than the grains formed on top of the columns (Figure 2). Compared to plasma-deposited $\mathrm{Au}-\mathrm{TiO}_{2}$, approximately half of the nominal layer thickness was deposited during the synthesis of plasma-deposited $\mathrm{Au} / \mathrm{Ag}-\mathrm{TiO}_{2}$ (Figure $2 b, c)$. This reduction leads to a sparser distribution of nanoparticles of roughly the same size. The half-as-high loading was also confirmed by EDX measurements (Table 1). The noble metal content could be determined by calculating the mass of the $\mathrm{TiO}_{2}$ layer from the thickness and the density and comparing it with the ratio of noble metals to Ti. In contrast to $\mathrm{Au} / \mathrm{Ag}-\mathrm{TiO}_{2}$, the Au-loading in photodeposited $\mathrm{Au}-\mathrm{TiO}_{2}$ and plasma-deposited $\mathrm{Au}-\mathrm{TiO}_{2}$ is very similar.

Table 1. Noble metal content of the three samples.

\begin{tabular}{ccc}
\hline Sample & Au-Content $\left(\mu \mathrm{g} / \mathrm{cm}^{2}\right)$ & Ag-Content $\left(\mu \mathrm{g} / \mathrm{cm}^{2}\right)$ \\
\hline photodeposited $\mathrm{Au}$ & $17.5 \pm 3.7$ & - \\
plasma-deposited $\mathrm{Au}$ & $19.6 \pm 6.5$ & - \\
plasma-deposited $\mathrm{Au} / \mathrm{Ag}$ & $7.8 \pm 3.4$ & $1.4 \pm 0.8$ \\
\hline
\end{tabular}

In Figure 3, the size distributions of all three samples are shown. As already mentioned, photodeposited Au nanoparticles grew both inside and on top of the titania layer, which is reflected by the two different log-normal size distributions used to describe the experimentally determined size distribution. Photodeposited Au nanoparticles inside the titania layer, which account for $66 \%$ of all $\mathrm{Au}$ nanoparticles, have a different size distribution than those found on top of the titania layer (Figure 3a). However, a log-normal distribution, which has previously been applied to the size distributions of $\mathrm{Au}$ nanoparticles synthesized by several, solution-based synthesis procedures, could be used to describe both [68]. The size distribution of Au nanoparticles inside the titania is shifted towards smaller diameters, indicating that the growth is slowed down or stopped within the pores of the $\mathrm{TiO}_{2}$ layer.

To interpret the size distributions of plasma-deposited particles (Figure $3 b, c)$, two underlying processes, deposition and annealing, have to be considered. Previous studies have shown that sputter deposition produces thin films, which dewet during annealing $[55,69,70]$. Some of these isolated particles then grow via a coarsening mechanism. This coarsening step is expected to depend strongly on a low surface roughness to prevent particle pinning and facilitate particle diffusion. We used these assumptions to split each size distribution in two by considering large nanoparticles on top of smooth $\mathrm{TiO}_{2}$ surfaces as resulting from a coarsening mechanism. With this assumption, the non-coarsened particles, which account for $86 \%$ in plasma-deposited $\mathrm{Au}-\mathrm{TiO}_{2}$ and $83 \%$ in plasma-deposited $\mathrm{Au} / \mathrm{Ag}-\mathrm{TiO}_{2}$, can be fit very well to a log-normal distribution. Attempts to model the other particle fraction with a size distribution failed due to their relative scarcity. Compared 
to pure plasma-deposited Au nanoparticles, the maximum of the log-normal distribution of the smaller, non-coarsened Au/Ag nanoparticles is shifted from 4 to $10 \mathrm{~nm}$ (Figure 3b,c). In spite of the reduced nominal layer thickness, the increase in size indicates that the initial deposition of Au directs their size, and not the subsequent Ag deposition or the annealing step. This hints at the observed shift resulting from Ag being added to a pre-existing Au nanostructure. Of course, this argument only applies to non-coarsened, small nanoparticles.

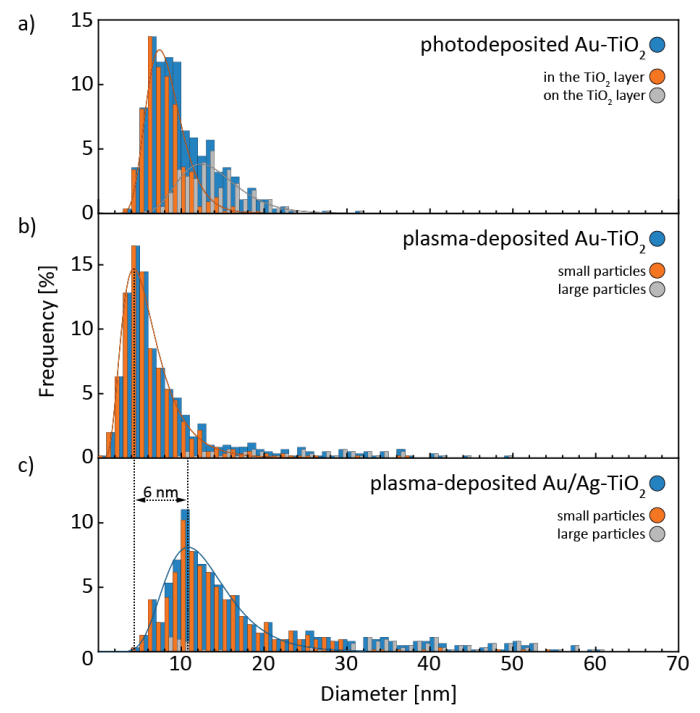

Figure 3. Size distributions of the noble metal nanoparticles in (a) photodeposited $\mathrm{Au}-\mathrm{TiO}_{2}$, (b) plasma-deposited $\mathrm{Au}-\mathrm{TiO}_{2}$ and (c) plasma-deposited $\mathrm{Ag} / \mathrm{Au}-\mathrm{TiO}_{2}$. All size distributions were split into two sub-distributions each. As explained in the main text, "large particles" refers to particles we believe have coarsened, "small particles" to those that have not. Please note that the frequency values only apply to the size distribution of the whole sample, but not to the sub-distributions.

The nanoparticles can possess several different defect structures (Figure 4). The photodeposited Au nanoparticles can be inside and outside of the titania layer, with each fraction having its own predominant defect structure. Photodeposited nanoparticles on top of the titania are predominantly five-fold twinned (Figure 4a), with few occurrences of other defect structures such as grain boundaries. Such a twinning is energetically favorable for small nanoparticles and therefore very common [71-75]. In contrast, all particles observed within the titania layer were monocrystalline (Figure 4b). However, a definite correlation of nanoparticle size and defect structure could not be concluded. The existence of defects not inherent to the metal or of an oxide surface layer large enough to form a defined crystal structure could be excluded from HRTEM images.

For the plasma-deposited nanoparticles, single-crystallinity, five-fold twinning, stacking faults, and grain boundaries were observed (Figure $4 \mathrm{~d}, \mathrm{e}$ ). As with photodeposited nanoparticles, we could not conclude a correlation of size and defect structure, with the exception of grain boundaries, which were very common in big nanoparticles. We tentatively ascribe these to the coarsening process. These particles also often have little protrusions that fill nooks in the titania substrate. Once again, other defects can be excluded from HRTEM images.

Bimetallic Au/Ag nanoparticles could potentially be alloyed or form core-shell nanoparticles [76,77]. The melting temperatures of $\mathrm{Ag}$ and Au decreases with the nanoparticle size, but are always high compared to the highest temperature reached during synthesis $\left(400^{\circ} \mathrm{C}\right)$ [78-80]. Alloying therefore seems 
unlikely. In accordance, EDX maps confirmed the formation of a uniform, 2-3 nm thick Ag shell around the Au core. As both metals crystallize in the face-centered cubic structure and their lattice parameters differ by only $0.2 \%$, we observe defect-free continuation of the crystal structure of Au by Ag without any phase boundary (Figure 5c) [81]. Previous studies have shown inhomogeneous deposition of gold and silver, and the core-shell nanoparticles presumably result from nanoparticle attachment during the annealing treatment $[82,83]$. Interestingly, former experiments by one of the co-authors, in which the $\mathrm{Ag} / \mathrm{Au}$ deposition order was reversed, also yielded Au/Ag-core-shell nanoparticles [55]. The deposition order can therefore not be the decisive factor when determining which metal becomes the core and which the shell. Unfortunately, growth mechanism studies so far mostly focus on wet-chemical synthesis methods and do not apply to our synthesis method $[82,83]$. Looking at the thermodynamics of the two possible core-shell configurations, four different energies contribute to the total energy: those of bulk Au and bulk Ag, the interface energy of the interface between Ag and Au, and the surface energy of the shell material. Assuming the amount of bulk material is the same in both possible configuration, the volumes and therefore the enthalpies associated with the interface and the two bulk phases are identical for both and only the contribution of the surface changes when exchanging core and shell material. As the surface energy of $\mathrm{Au}$ is approximately $40 \%$ higher than that of $\mathrm{Ag}$, the total enthalpy is reduced by forming a silver instead of a gold shell. We assume this to be the dominant driving force for the preferred creation of Au/Ag core-shell nanoparticles over Ag/ Au core-shell nanoparticles [84].
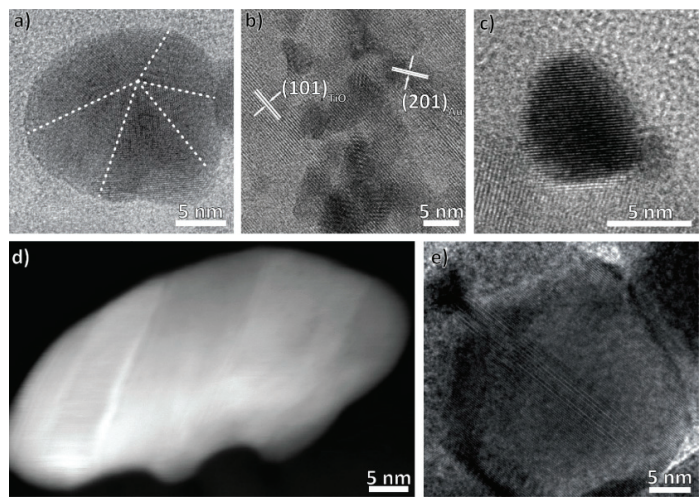

Figure 4. Representative images of different defect structures of the noble metal nanoparticles. In (a) and (b) high-resolution TEM (HRTEM) images of the photodeposited Au nanoparticles are shown: (a) is a five-fold twinned particle on top of the titania and (b) defect-free nanoparticles inside the titania. (c-e) show plasma-deposited nanoparticles: (c) is representative for small, defect free nanoparticles, (d) of those with stacking faults and (e) of those with grain boundaries.
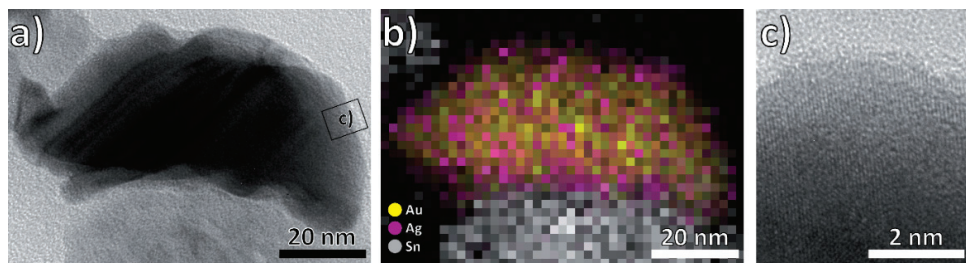

Figure 5. (a) BF (Bright-field) images of a representative Au/Ag nanoparticle; (b) energy dispersive X-ray (EDX) map of the same particle, showing an accumulation of Ag at the surface; (c) HRTEM image of the nanoparticle surface. 


\subsection{Optical Properties}

Figure 6 shows the absorbance spectra of the $\mathrm{Au}, \mathrm{Au} / \mathrm{Ag}$ and pure $\mathrm{TiO}_{2}$ samples calculated from diffuse transmission measurements using Equation (1). The strong absorbance at wavelengths shorter than approximately $400 \mathrm{~nm}$ corresponds to the anatase band gap of $3.2 \mathrm{eV}[13,16,17,20]$. Throughout the measurement range, the absorbance of the samples never reach an intensity of zero, which is attributed to Rayleigh scattering at crystalline domains as well as pores of the $\mathrm{TiO}_{2}$ layer, with the noble metal nanoparticles acting as additional scattering sites [85-88]. Consequently, the intensities of this background absorption can be correlated to nanoparticle loading and distribution of the different samples. Nanoparticle-decoration leads to stronger absorbance than pure $\mathrm{TiO}_{2}$, with photodeposited $\mathrm{Au}-\mathrm{TiO}_{2}$ reaching the highest background absorbance, followed by plasma deposited $\mathrm{Au}-\mathrm{TiO}_{2}$ and then plasma-deposited $\mathrm{Au} / \mathrm{Ag}-\mathrm{TiO}_{2}$. The total noble metal mass in $\mathrm{Au} / \mathrm{Ag}-\mathrm{TiO}_{2}$ is roughly half that of both $\mathrm{Au}-\mathrm{TiO}_{2}$ samples (Table 1), and it consequently absorbs less than those two. The high absorbance of photodeposited $\mathrm{Au}-\mathrm{TiO}_{2}$ could be attributed to the dense coverage of the titania surface (Figure 2a) and the additional presence of nanoparticles embedded in $\mathrm{TiO}_{2}$ pores (Figure 2d).

Both plasma- and photodeposited $\mathrm{Au}-\mathrm{TiO}_{2}$ have additional absorption bands at $550-800 \mathrm{~nm}$ and 480-580 nm, respectively, caused by the excitation of localized surface plasmon resonances (LSPR). The positions and shapes of these bands are determined by the particle shape [89], the contact area with the titania [90], the size [91], and the size distribution [92]. An overlap of these factors hinders the interpretation of polydispersed particle ensembles. The center of the absorption band of photodeposited $\mathrm{Au}-\mathrm{TiO}_{2}$ matches the LSPR frequency of $520 \mathrm{~nm}$ previously described for isolated spherical gold nanoparticles [93,94]. TEM images confirm the existence of such particles (Figure 4a), however, many irregularly shaped nanoparticles with diameters more than $100 \mathrm{~nm}$ are found in top view SEM micrographs (Figure 2a). The intense band of plasma-deposited $\mathrm{Au}-\mathrm{TiO}_{2}$, however, is red-shifted. This could be explained by the non-spherical shape of the large Au nanoparticles [39,94-96], plasmon-coupling [22,94,95,97,98], and/or a large contact area with the $\mathrm{TiO}_{2}$ [97] as suggested by SEM and TEM micrographs (Figures 2 and 4). Although embedded nanoparticles were not found in plasma-deposited samples, the particles adapt to the titania surface (Figures 4 and 5). The band broadening could result from large nanoparticle size and/or shape distributions. No distinct bands were observed for plasma-deposited $\mathrm{Au} / \mathrm{Ag}-\mathrm{TiO}_{2}$, even though two would be expected: one stemming from the outer shell surface, and one from the Au/Ag interface [99-101]. A possible explanation is the significantly lower metal loading than the two $\mathrm{Au}-\mathrm{TiO}_{2}$ samples, which should lead to weaker plasmon bands. Furthermore, the peak related to the outer silver shell (which would be expected at around $400 \mathrm{~nm}$ ) could overlap with the absorbance band of the $\mathrm{TiO}_{2}$ substrate [99].

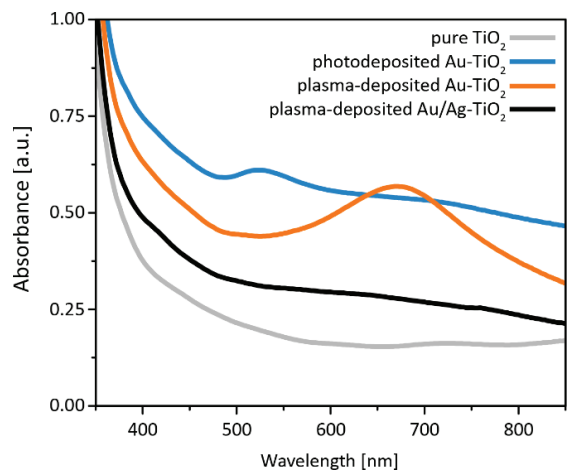

Figure 6. UV-vis spectra showing the absorbance of all samples. 


\subsection{Catalytic Properties}

The photocatalytic performance of the different layers to reduce protons to molecular hydrogen was studied under visible light illumination $(400-700 \mathrm{~nm})$ and under UV-vis illumination (320-500 nm) with methanol as a hole scavenger (Figure 7, Table 2).

All hydrogen evolution curves (Figure 7) show a strong initial increase during the first minutes, followed by a smaller, but constant hydrogen evolution rate. The steep rise at the beginning of each measurement is caused by an increase in pressure in the automatic gas burette due to heating of the photoreactor upon irradiation with UV-vis light. Within an hour, thermal equilibrium is reached by external cooling with a thermostat $\left(25^{\circ} \mathrm{C}\right)$. Therefore, the later, constant region is more representative of the catalytic activity and the first hour of each measurement was disregarded when discussing the curves (Figure 7) or determining the hydrogen evolution rates presented in Table 2. No further loss in activity could be observed for up to $18 \mathrm{~h}$, indicating stable operation.

Under visible light illumination, the hydrogen evolution rate was zero and no hydrogen was measured apart from the initial rise (Figure 7). In this regime, light is absorbed in the noble metal nanoparticles via surface plasmon resonance, and then electrons are injected into $\mathrm{TiO}_{2}[42,44]$. Given this mechanism and the UV-vis spectra (Figure 6), which show only weak bands attributed to plasmon formation, the weak hydrogen evolution can be explained.

Under UV illumination, only $\mathrm{TiO}_{2}$ absorbs light and the noble metal nanoparticles act as co-catalysts (Figure 6) $[40-42,44,45]$ by providing chemically active sites with low activation barriers [40], prolonging charge carrier lifetime [40], and by serving as an electron reservoir [24,41-43]. Previous photocatalytic experiments under similar conditions revealed a drastic increase in $\mathrm{H}_{2}$ evolution upon deposition of noble metal nanoparticles [40-42,44,45]. This is confirmed in our experiments, with all samples having a significantly increased hydrogen evolution rate compared to pure $\mathrm{TiO}_{2}$.

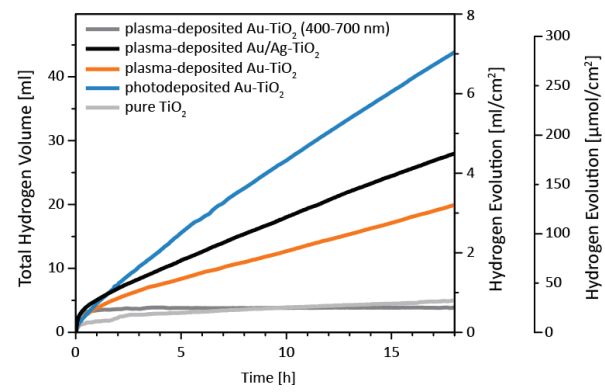

Figure 7. Hydrogen evolution of all samples from a methanol/water mixture. Conditions: $80 \mathrm{~mL} \mathrm{MeOH} / \mathrm{H}_{2} \mathrm{O}(1 / 1, v / v)$, Lumatec $\mathrm{Hg}$-light source equipped with a 320-500 nm filter, $7.2 \mathrm{~W}$ output, $25{ }^{\circ} \mathrm{C}$. In addition, the $\mathrm{H}_{2}$ evolution of plasma-deposited $\mathrm{Au}-\mathrm{TiO}_{2}$, acquired using a 400-700 nm filter, is plotted exemplarily (dark grey). Measurements of all samples under the same visible light illumination yielded perfectly overlapping curves and we therefore chose to present only the measurement of the sample with the strongest localized surface plasmon resonances (LSPR) band.

Table 2. Comparison of the produced amount of hydrogen and the respective photocatalytic activities normalized to the evolution of hydrogen per area and time.

\begin{tabular}{cccc}
\hline Sample & Total $\mathbf{H}_{\mathbf{2}}$ Volume $(\mathbf{m L})$ & $\mathbf{H}_{\mathbf{2}}$ evolution Rate ${ }^{\mathbf{a}}\left(\mu \mathbf{L ~ h}^{-\mathbf{1}} \mathbf{c m}^{-\mathbf{2}}\right)$ & $\mathbf{H}_{\mathbf{2}}$ evolution Rate ${ }^{\mathbf{b}}\left(\mu \mathbf{m o l ~ h} \mathbf{h}^{-\mathbf{1}} \mathbf{c m}^{-\mathbf{2}}\right)$ \\
\hline pure $\mathrm{TiO}_{2}$ & 5.0 & 31 & 1.3 \\
photodeposited $\mathrm{Au}-\mathrm{TiO}_{2}$ & 44.1 & 372 & 15.2 \\
plasma-deposited $\mathrm{Au}-\mathrm{TiO}_{2}$ & 20.0 & 152 & 6.2 \\
plasma-deposited $\mathrm{Ag} / \mathrm{Au}-\mathrm{TiO}_{2}$ & 28.2 & 217 & 8.9 \\
\hline
\end{tabular}

${ }^{a}$ calculated as an average over $17 \mathrm{~h}$, starting after the first hour. ${ }^{\mathrm{b}}$ calculated by applying the van der Waals equation at $25^{\circ} \mathrm{C}$, which yields a molar volume of $24.48 \mu \mathrm{L} / \mu \mathrm{mol}$. 
As mentioned above, all samples onto which noble metal nanoparticles were deposited outperform pure $\mathrm{TiO}_{2}$. The largest hydrogen evolution rate of $372 \mu \mathrm{L} \mathrm{h}^{-1} \mathrm{~cm}^{-2}$ was measured for photodeposited $\mathrm{Au}-\mathrm{TiO}_{2}$, representing a 12-fold increase. This was followed by plasma-deposited $\mathrm{Au} / \mathrm{Ag}-\mathrm{TiO}_{2}\left(217 \mu \mathrm{L} \mathrm{h}^{-1} \mathrm{~cm}^{-2}\right.$, 7-fold $)$ and plasma-deposited Au-TiO $2\left(152 \mu \mathrm{L} \mathrm{h}^{-1} \mathrm{~cm}^{-2}, 5\right.$-fold).

To interpret this order, we first consider the influence of the hole scavenger methanol. Two reactions compete at the surface of the noble metal nanoparticle co-catalysts: the transfer of holes to the electrolyte and the recombination with photogenerated electrons. Adding hole scavengers leads to the transfer reaction being favored over recombination, and the latter is suppressed. Methanol is a very efficient hole scavenger, near-perfect transfer can be assumed [56-58], and the kinetics of surface reactions can be neglected. In contrast, light absorption plays an important role and the order in which the samples perform is indeed closely correlated to the amount of light being absorbed in the UV-region. Only plasma-deposited $\mathrm{Au} / \mathrm{Ag}-\mathrm{TiO}_{2}$ is more efficient than expected from light absorption measurements. We attribute this behavior to a reduction of bulk recombination caused by the electric field gradient at the $\mathrm{Au} / \mathrm{Ag}$ interface, which is known to positively affect the efficiencies of catalytic reactions [52,53].

\section{Conclusions}

$\mathrm{Au}$ nanoparticles were deposited onto a mesoporous anatase thin film using two different deposition methods, photo- and plasma-deposition. The second method was further used to prepare bimetallic $\mathrm{Au} / \mathrm{Ag}$ nanoparticles. Both methods resulted in different particle distributions and particle size distributions. Photodeposited nanoparticles both infiltrated the titania itself and were deposited on top of it, with the latter group of particles being larger on average. In contrast, plasma-deposited nanoparticles were found only at the surface of the titania.

These differences in the morphology could then be correlated to several materials properties. Strong light absorption up to about $400 \mathrm{~nm}$ is due to the band gap of titania. Above $400 \mathrm{~nm}$, Rayleigh scattering at crystalline domain boundaries and pores within the $\mathrm{TiO}_{2}$ layer, as well as at noble metal nanoparticles, leads to a strong background. Both samples with pure Au nanoparticles further show peaks attributed to LSPR.

The light absorption properties, in turn, strongly influence the photocatalytic performance of the hydrogen evolution reaction from a methanol/water solution under UV illumination. In this wavelength range, Au only acts as a co-catalyst and the performance of all samples but one, plasma-deposited $\mathrm{Au} / \mathrm{Ag}-\mathrm{TiO}_{2}$, was correlated to the light absorption efficiency. The higher-than-expected performance of plasma-deposited $\mathrm{Au} / \mathrm{Ag}-\mathrm{TiO}_{2}$ can be explained by an electric field gradient at the $\mathrm{Au} / \mathrm{Ag}$ interface, concluding a comprehensive correlation of structure and properties. Consequently, this study shows that a systematic investigation of the interplay of synthesis method, structure and catalytic activity plays an important role in furthering our understanding of such complex systems. We believe that similar studies, along with those on different hole scavenger, surface reaction kinetics, thermal stability etc., will eventually lead to commercial applications and thereby contribute to a sustainable energy mix.

Author Contributions: Conceptualization, All authors; Methodology, All authors; Investigation, A.M., S.P., M.K., A.K.; Writing-Original Draft Preparation, A.M., S.P.; Writing-Review \& Editing, All authors; Visualization, A.M., S.P.; Supervision, C.S., V.B., H.J.; Funding Acquisition, C.S., V.B., H.J.

Funding: This research was funded by the German Research Foundation (Deutsche Forschungsgesellschaft, DFG) via the Schwepunktsprogramm (SPP) 1613.

Acknowledgments: We are grateful to Markus Döblinger and Steffen Schmidt for support with TEM measurements, Christoph Heinzl for additional SEM measurements, Harm Wulff for in-depth analysis of the GIXRD measurements and Petra Bartels for performing photocatalytic experiments.

Conflicts of Interest: The authors declare no conflict of interest. The funders had no role in the design of the study; in the collection, analyses, or interpretation of data; in the writing of the manuscript, and in the decision to publish the results. 


\section{References}

1. Armaroli, N.; Balzani, V. The future of energy supply: Challenges and opportunities. Angezv. Chem. Int. Ed. 2007, 46, 52-66. [CrossRef] [PubMed]

2. Schiermeier, Q.; Tollefson, J.; Scully, T.; Witze, A.; Morton, O. Electricity without carbon. Nature 2008, 5, 10-15. [CrossRef]

3. Lewis, N.S.; Nocera, D.G. Powering the planet: Chemical challenges in solar energy utilization. Proc. Natl. Acad. Sci. USA 2006, 103, 15729-15735. [CrossRef] [PubMed]

4. Styring, S. Artificial photosynthesis for solar fuels. Faraday Discuss. 2012, 155, 357-376. [CrossRef] [PubMed]

5. Concepcion, J.J.; House, R.L.; Papanikolas, J.M.; Meyer, T.J. Chemical approaches to artificial photosynthesis. Proc. Natl. Acad. Sci. USA 2012, 109, 15560-15564. [CrossRef] [PubMed]

6. Grätzel, M. Photoelectrochemical cells. Nature 2001, 414, 338-344. [CrossRef] [PubMed]

7. Choi, J.; Amaranatha Reddy, D.; Han, N.S.; Jeong, S.; Hong, S.; Praveen Kumar, D.; Song, J.K.; Kim, T.K. Modulation of charge carrier pathways in CdS nanospheres by integrating $\mathrm{MoS}_{2}$ and $\mathrm{Ni}_{2} \mathrm{P}$ for improved migration and separation toward enhanced photocatalytic hydrogen evolution. Catal. Sci. Technol. 2017, 7, 641-649. [CrossRef]

8. Reddy, D.A.; Park, H.; Gopannagari, M.; Kim, E.H.; Lee, S.; Kumar, D.P.; Kim, T.K. Designing CdS Mesoporous Networks on Co-C@Cog $\mathrm{S}_{8}$ Double-Shelled Nanocages as Redox-Mediator-Free Z-Scheme Photocatalyst. ChemSusChem 2018, 11, 245-253. [CrossRef] [PubMed]

9. Reddy, D.A.; Park, H.; Ma, R.; Kumar, D.P.; Lim, M.; Kim, T.K. Heterostructured $\mathrm{WS}_{2}-\mathrm{MoS}_{2}$ Ultrathin Nanosheets Integrated on CdS Nanorods to Promote Charge Separation and Migration and Improve Solar-Driven Photocatalytic Hydrogen Evolution. ChemSusChem 2017, 10, 1563-1570. [CrossRef] [PubMed]

10. Reddy, D.A.; Choi, J.; Lee, S.; Kim, Y.; Hong, S.; Kumar, D.P.; Kim, T.K. Hierarchical dandelion-flower-like cobalt-phosphide modified CdS/reduced graphene oxide- $\mathrm{MoS}_{2}$ nanocomposites as a noble-metal-free catalyst for efficient hydrogen evolution from water. Catal. Sci. Technol. 2016, 6, 6197-6206. [CrossRef]

11. Reddy, D.A.; Park, H.; Hong, S.; Kumar, D.P.; Kim, T.K. Hydrazine-assisted formation of ultrathin $\mathrm{MoS}_{2}$ nanosheets for enhancing their co-catalytic activity in photocatalytic hydrogen evolution. J. Mater. Chem. A 2017, 5, 6981-6991. [CrossRef]

12. Reddy, D.A.; Kim, H.K.; Kim, Y.; Lee, S.; Choi, J.; Islam, M.J.; Kumar, D.P.; Kim, T.K. Multicomponent transition metal phosphides derived from layered double hydroxide double-shelled nanocages as an efficient non-precious co-catalyst for hydrogen production. J. Mater. Chem. A 2016, 4, 13890-13898. [CrossRef]

13. Scanlon, D.O.; Dunnill, C.W.; Buckeridge, J.; Shevlin, S.A.; Logsdail, A.J.; Woodley, S.M.; Catlow, C.R.A.; Powell, M.J.; Palgrave, R.G.; Parkin, I.P.; et al. Band alignment of rutile and anatase $\mathrm{TiO}_{2}$. Nat. Mater. 2013, 12, 798-801. [CrossRef] [PubMed]

14. Reddy, K.M.; Manorama, S.V.; Reddy, A.R. Bandgap studies on anatase titanium dioxide nanoparticles. Mater. Chem. Phys. 2003, 78, 239-245. [CrossRef]

15. Fujishima, A.; Honda, K. Electrochemical photolysis of water at a semiconductor electrode. Nature 1972, 238, 37-38. [CrossRef] [PubMed]

16. Zhang, J.; Zhou, P.; Liu, J.; Yu, J. New understanding of the difference of photocatalytic activity among anatase, rutile and brookite $\mathrm{TiO}_{2}$. Phys. Chem. Chem. Phys. 2014, 16, 20382-20386. [CrossRef] [PubMed]

17. Chen, X.; Shen, S.; Guo, L.; Mao, S.S. Semiconductor-based Photocatalytic Hydrogen Generation. Chem. Rev. 2010, 110, 6503-6570. [CrossRef] [PubMed]

18. Primo, A.; Corma, A.; García, H. Titania supported gold nanoparticles as photocatalyst. Phys. Chem. Chem. Phys. 2011, 13, 886-910. [CrossRef] [PubMed]

19. Ahmed, S.; Rasul, M.G.; Brown, R.; Hashib, M.A. Influence of parameters on the heterogeneous photocatalytic degradation of pesticides and phenolic contaminants in wastewater: A short review. J. Environ. Manag. 2011, 92, 311-330. [CrossRef] [PubMed]

20. Lan, Y.; Lu, Y.; Ren, Z. Mini Review on photocatalysis of titanium dioxide nanoparticles and their solar applications. Nano Energy 2013, 2, 1031-1045. [CrossRef]

21. Pu, Y.C.; Wang, G.; Chang, K.D.; Ling, Y.; Lin, Y.K.; Fitzmorris, B.C.; Liu, C.M.; Lu, X.; Tong, Y.; Zhang, J.Z.; et al. Au nanostructure-decorated $\mathrm{TiO}_{2}$ nanowires exhibiting photoactivity across entire UV-visible region for photoelectrochemical water splitting. Nano Lett. 2013, 13, 3817-3823. [CrossRef] [PubMed] 
22. Linic, S.; Christopher, P.; Ingram, D.B. Plasmonic-metal nanostructures for efficient conversion of solar to chemical energy. Nat. Mater. 2011, 10, 911-921. [CrossRef] [PubMed]

23. Wang, C.; Astruc, D. Nanogold plasmonic photocatalysis for organic synthesis and clean energy conversion. Chem. Soc. Rev. 2014, 43, 7188-7216. [CrossRef] [PubMed]

24. Furube, A.; Du, L.; Hara, K.; Katoh, R.; Tachiya, M. Ultrafast plasmon-induced electron transfer from gold nanodots into $\mathrm{TiO}_{2}$ nanoparticles. J. Am. Chem. Soc. 2007, 129, 14852-14853. [CrossRef] [PubMed]

25. Youngblood, W.J.; Lee, S.A.; Maeda, K.; Mallouk, T.E. Visible Light Water Splitting Using Dye- Sensitized Oxide Semiconductors. Acc. Chem. Res. 2009, 42, 1966-1973. [CrossRef] [PubMed]

26. Yum, J.-H.; Chen, P.; Grätzel, M.; Nazeeruddin, M.K. Recent developments in solid-state dye-sensitized solar cells. ChemSusChem 2008, 1, 699-707. [CrossRef] [PubMed]

27. Kruth, A.; Quade, A.; Brüser, V.; Weltmann, K.-D. Plasma-Enhanced Synthesis of Poly (allylamine)Encapsulated Ruthenium Dye-Sensitized Titania Photocatalysts. J. Phys. Chem. C 2013, 117, 3804-3811. [CrossRef]

28. Kruth, A.; Peglow, S.; Rockstroh, N.; Junge, H.; Brüser, V.; Weltmann, K.D. Enhancement of photocatalyic activity of dye sensitised anatase layers by application of a plasma-polymerized allylamine encapsulation. J. Photochem. Photobiol. A Chem. 2014, 290, 31-37. [CrossRef]

29. Kruth, A.; Hansen, S.; Beweries, T.; Brüser, V.; Weltmann, K.D. Plasma synthesis of polymer-capped dye-sensitised anatase nanopowders for visible-light-driven hydrogen evolution. ChemSusChem 2013, 6, 152-159. [CrossRef] [PubMed]

30. Karnahl, M.; Mejía, E.; Rockstroh, N.; Tschierlei, S.; Luo, S.P.; Grabow, K.; Kruth, A.; Brüser, V.; Junge, H.; Lochbrunner, S.; et al. Photocatalytic hydrogen production with copper photosensitizer-titanium dioxide composites. ChemCatChem 2014, 6, 82-86. [CrossRef]

31. Warren, S.C.; Thimsen, E. Plasmonic solar water splitting. Energy Environ. Sci. 2012, 5, 5133-5146. [CrossRef]

32. Petryayeva, E.; Krull, U.J. Localized surface plasmon resonance: Nanostructures, bioassays and biosensing-A review. Anal. Chim. Acta 2011, 706, 8-24. [CrossRef] [PubMed]

33. Noguez, C. Surface Plasmons on Metal Nanoparticles: The Influence of Shape and Physical Environment. J. Phys. Chem. C 2007, 111, 3806-3819. [CrossRef]

34. Link, S.; El-Sayed, M.A. Shape and size dependence of radiative, non-radiative and photothermal properties of gold nanocrystals. Int. Rev. Phys. Chem. 2000, 19, 409-453. [CrossRef]

35. Jain, P.K.; Lee, K.S.; El-Sayed, I.H.; El-Sayed, M.A. Calculated absorption and scattering properties of gold nanoparticles of different size, shape, and composition: Applications in biological imaging and biomedicine. J. Phys. Chem. B 2006, 110, 7238-7248. [CrossRef] [PubMed]

36. Pu, Y.; Zhang, J.Z. Mechanisms Behind Plasmonic Enhancement of Photocurrent in Metal Oxides. Austin J. Nanomed. Nanotechnol. 2014, 2,1-4.

37. Cushing, S.K.; Li, J.; Meng, F.; Senty, T.R.; Suri, S.; Zhi, M.; Li, M.; Bristow, A.D.; Wu, N. Photocatalytic Activity Enhanced by Plasmonic Resonant Energy Transfer Transfer from Metal to Semiconductor. J. Am. Chem. Soc. 2012, 134, 105033-105041. [CrossRef] [PubMed]

38. Ma, X.C.; Dai, Y.; Yu, L.; Huang, B.B. Energy transfer in plasmonic photocatalytic composites. Light Sci. Appl. 2016, 5, 1-13. [CrossRef]

39. Garcia, M.A. Surface plasmons in metallic nanoparticles: Fundamentals and applications. J. Phys. D Appl. Phys. 2012, 45, 389501. [CrossRef]

40. Gärtner, F.; Losse, S.; Boddien, A.; Pohl, M.-M.; Denurra, S.; Junge, H.; Beller, M. Hydrogen evolution from water/Alcohol mixtures: Effective in situ generation of an active $\mathrm{Au} / \mathrm{TiO}_{2}$ catalyst. ChemSusChem 2012, 5, 530-533. [CrossRef] [PubMed]

41. Yang, J.; Wang, D.; Han, H.; Li, C. Roles of cocatalysts in photocatalysis and photoelectrocatalysis. Acc. Chem. Res. 2013, 46, 1900-1909. [CrossRef] [PubMed]

42. Priebe, J.B.; Karnahl, M.; Junge, H.; Beller, M.; Hollmann, D.; Brückner, A. Water Reduction with Visible Light: Synergy between Optical Transitions and Electron Transfer in $\mathrm{Au}^{-\mathrm{TiO}_{2}}$ Catalysts Visualized by In situ EPR Spectroscopy. Angew. Chem. Int. Ed. 2013, 52, 11420-11424. [CrossRef] [PubMed]

43. Tian, Y.; Tatsuma, T. Plasmon-induced photoelectrochemistry at metal nanoparticles supported on nanoporous $\mathrm{TiO}_{2}$. Chem. Commun. 2004, 1810-1811. [CrossRef] [PubMed] 
44. Priebe, J.B.; Radnik, J.; Lennox, A.J.J.; Pohl, M.-M.; Karnahl, M.; Hollmann, D.; Grabow, K.; Bentrup, U.; Junge, H.; Beller, M.; et al. Solar Hydrogen Production by Plasmonic Au-TiO ${ }_{2}$ Catalysts: Impact of Synthesis Protocol and $\mathrm{TiO}_{2}$ Phase on Charge Transfer Efficiency and $\mathrm{H}_{2}$ Evolution Rates. ACS Catal. 2015, 5, 2137-2148. [CrossRef]

45. Silva, C.G.; Juárez, R.; Marino, T.; Molinari, R.; García, H. Influence of Excitation Wavelength (UV or Visible Light) on the Photocatalytic Activity of Titania Containing Gold Nanoparticles for the Generation of Hydrogen or Oxygen from Water. J. Am. Chem. Soc. 2011, 133, 595-602. [CrossRef] [PubMed]

46. Kowalska, E.; Rau, S.; Ohtani, B. Plasmonic titania photocatalysts active under UV and visible-light irradiation: Influence of gold amount, size, and shape. J. Nanotechnol. 2012, 2012, 1-11. [CrossRef]

47. Yan, J.; Wu, G.; Guan, N.; Li, L. Synergetic promotion of the photocatalytic activity of $\mathrm{TiO}_{2}$ by gold deposition under UV-visible light irradiation. Chem. Commun. 2013, 49, 11767-11769. [CrossRef] [PubMed]

48. Su, R.; Tiruvalam, R.; Logsdail, A.J.; He, Q.; Downing, C.A.; Jensen, M.T.; Dimitratos, N.; Kesavan, L.; Wells, P.P.; Bechstein, R.; et al. Designer titania-supported Au-Pd nanoparticles for efficient photocatalytic hydrogen production. ACS Nano 2014, 8, 3490-3497. [CrossRef] [PubMed]

49. Osterloh, F.E. Inorganic nanostructures for photoelectrochemical and photocatalytic water splitting. Chem. Soc. Rev. 2013, 42, 2294-2320. [CrossRef] [PubMed]

50. Zhang, P.; Gao, L.; Song, X.; Sun, J. Micro- and Nanostructures of Photoelectrodes for Solar-Driven Water Splitting. Adv. Mater. 2015, 27, 562-568. [CrossRef] [PubMed]

51. Wenderich, K.; Mul, G. Methods, Mechanism, and Applications of Photodeposition in Photocatalysis: A Review. Chem. Rev. 2016, 116, 14587-14619. [CrossRef] [PubMed]

52. Zhang, H.; Haba, M.; Okumura, M.; Akita, T.; Hashimoto, S.; Toshima, N. Novel formation of Ag/Au bimetallic nanoparticles by physical mixture of monometallic nanoparticles in dispersions and their application to catalysts for aerobic glucose oxidation. Langmuir 2013, 29, 10330-10339. [CrossRef] [PubMed]

53. Jiang, H.; Akita, T.; Ishida, T. Synergistic Catalysis of Au@Ag Core-Shell Nanoparticles Stabilized on Metal-Organic Framework. J. Am. Chem. Soc. 2011, 133, 1304-1306. [CrossRef] [PubMed]

54. Kruth, A.; Peglow, S.; Quade, A.; Pohl, M.-M.; Weltmann, K.-D. Structural and Photoelectrochemical Properties of DC Magnetron- Sputtered $\mathrm{TiO}_{2}$ Layers on FTO. J. Phys. Chem. C 2014, 118, 25234-25244. [CrossRef]

55. Peglow, S.; Pohl, M.-M.; Kruth, A.; Brüser, V. Plasma Based Synthesis, Electron Microscopy, and Optical Characterization of Au-, Ag-, and Ag/Au-Core-Shell Nanoparticles. J. Phys. Chem. C 2015, 119, 563-572. [CrossRef]

56. Schneider, J.; Bahnemann, D.W. Undesired Role of Sacrificial Reagents in Photocatalysis. J. Phys. Chem. Lett. 2013, 4, 3479-3483. [CrossRef]

57. Nada, A.A.; Barakat, M.H.; Hamed, H.A.; Mohamed, N.R.; Veziroglu, T.N. Studies on the photocatalytic hydrogen production using suspended modified $\mathrm{TiO}_{2}$ photocatalysts. Int. J. Hydrogen Energy 2005, 30, 687-691. [CrossRef]

58. Kawai, T.; Sakata, T. Conversion of carbohydrate into hydrogen fuel by a photocatalytic process. Nature 1980, 286, 474-476. [CrossRef]

59. Wulff, H. Introduction to Complex Plasmas; Bonitz, M., Horing, N., Ludwig, P., Eds.; Springer: Berlin/ Heidelberg, Germany, 2010.

60. Strecker, A.; Salzberger, U.; Mayer, J. Specimen Preparation for Transmission Electron Microscopy: Reliable Method for Cross-Sections and Brittle Materials. Prakt. Metallogr. 1993, 30, 482-495.

61. Gottwald, W.; Heinrich, K.H. UV/VIS-Spektroskopie für Anwender; Wiley VCH: Weinheim, Germany, 1999.

62. Djerdj, I.; Tonejc, A.M. Structural investigations of nanocrystalline $\mathrm{TiO}_{2}$ samples. J. Alloys Compd. 2006, 413, 159-174. [CrossRef]

63. Suh, I.; Ohta, H.; Waseda, Y. High-temperature thermal expansion of six metallic elements measured by dilatation method and X-ray diffraction. J. Mater. Sci. 1988, 23, 757-760. [CrossRef]

64. Yamanaka, T.; Kurashima, R.; Mimaki, J. X-ray diffraction study of bond character of rutile-type $\mathrm{SiO}_{2}$, $\mathrm{GeO}_{2}$ and $\mathrm{SnO}_{2}$. Z. Kristallogr. 2000, 215, 424-428. [CrossRef]

65. Petrov, I.; Barna, P.B.; Hultman, L.; Greene, J.E. Microstructural evolution during film growth. J. Vac. Sci. Technol. A 2003, 21, 117-128. [CrossRef]

66. Thornton, J.A. The microstructure of sputter-deposited coatings. J. Vac. Sci. Technol. A 1986, 4, 3059-3065. [CrossRef] 
67. Williams, D.; Carter, C. Transmission Electron Microscopy-A Textbook for Materials Science; Springer: Boston, MA, USA, 1996; ISBN 9780387765006.

68. Claus, P.; Brückner, A.; Mohr, C.; Hofmeister, H. Supported Gold Nanoparticles from Quantum Dot to Mesoscopic Size Scale: Effect of Electronic and Structural Properties on Catalytic Hydrogenation of Conjugated Functional Groups. J. Am. Chem. Soc. 2000, 122, 11430-11439. [CrossRef]

69. Söderlund, J.; Kiss, L.; Niklasson, G.; Granqvist, C. Lognormal Size Distributions in Particle Growth Processes without Coagulation. Phys. Rev. Lett. 1998, 80, 2386-2388. [CrossRef]

70. Robson, J.D. Modelling the evolution of particle size distribution during nucleation, growth and coarsening. Mater. Sci. Technol. 2004, 20, 441-448. [CrossRef]

71. Cleveland, C.; Luedtke, W.; Landman, U. Melting of Gold Clusters: Icosahedral Precursors. Phys. Rev. Lett. 1998, 81, 2036-2039. [CrossRef]

72. Marks, L.D. Experimental studies of small particle structures. Rep. Prog. Phys. 1999, 57, 603-649. [CrossRef]

73. Nam, H.-S.; Hwang, N.; Yu, B.; Yoon, J.-K. Formation of an Icosahedral Structure during the Freezing of Gold Nanoclusters: Surface-Induced Mechanism. Phys. Rev. Lett. 2002, 89, 1-4. [CrossRef] [PubMed]

74. Ascencio, J.A.; Gutiérrez-Wing, C.; Espinosa, M.E.; Marín, M.; Tehuacanero, S.; Zorrilla, C.; José-Yacamán, M. Structure determination of small particles by HREM imaging: Theory and experiment. Surf. Sci. 1998, 396, 349-368. [CrossRef]

75. Barnard, A.S. A thermodynamic model for the shape and stability of twinned nanostructures. J. Phys. Chem. B 2006, 110, 24498-24504. [CrossRef] [PubMed]

76. Hubenthal, F.; Ziegler, T.; Hendrich, C.; Alschinger, M.; Träger, F. Tuning the surface plasmon resonance by preparation of gold-core/silver-shell and alloy nanoparticles. Eur. Phys. J. D 2005, 34, 165-168. [CrossRef]

77. Douglas, F.; Yañez, R.; Ros, J.; Marín, S.; De La Escosura-Muñiz, A.; Alegret, S.; Merkoçi, A. Silver, gold and the corresponding core shell nanoparticles: Synthesis and characterization. J. Nanopart. Res. 2008, 10, 97-106. [CrossRef]

78. Shyjumon, I.; Gopinadhan, M.; Ivanova, O.; Quaas, M.; Wulff, H.; Helm, C.A.; Hippler, R. Structural deformation, melting point and lattice parameter studies of size selected silver clusters. Eur. Phys. J. D 2006, 37, 409-415. [CrossRef]

79. Buffat, P.; Borel, J.-P. Size Effect on the Melting Temperature of Gold Particles. Phys. Rev. A 1976, 13, 2287-2298. [CrossRef]

80. Jiang, Q.; Zhang, S.; Zhao, M. Size-dependent melting point of noble metals. Mater. Chem. Phys. 2003, 82, 225-227. [CrossRef]

81. Jette, E.R.; Foote, F. Precision Determination of Lattice Constants. J. Chem. Phys. 1935, 3, 605-616. [CrossRef]

82. Tsuji, M.; Yamaguchi, D.; Matsunaga, M.; Alam, M.J. Epitaxial growth of Au@Cu core-shell nanocrystals prepared using the PVP-assisted polyol reduction method. Cryst. Growth Des. 2010, 10, 5129-5135. [CrossRef]

83. Fan, F.R.; Liu, D.Y.; Wu, Y.F.; Duan, S.; Xie, Z.X.; Jiang, Z.Y.; Tian, Z.Q. Epitaxial growth of heterogeneous metal nanocrystals: From gold nano-octahedra to palladium and silver nanocubes. J. Am. Chem. Soc. 2008, 130, 6949-6951. [CrossRef] [PubMed]

84. Skriver, H.L.; Rosengaard, N.M. Surface energy and work function of elemental metals. Phys. Rev. B 1992, 46, 7157-7168. [CrossRef]

85. Koo, J.B.; Hong, K.J.; Park, J.S.; Shin, D.C. Effect of grain size on transmittance and mechanical strength of sintered alumina. Mater. Sci. Eng. A 2004, 374, 191-195. [CrossRef]

86. Apetz, R.; Bruggen, M.P.B. Van Transparent Alumina: A Light-Scattering Model. J. Am. Ceram. Soc. 2003, 86, 480-486. [CrossRef]

87. Dericioglu, A.F.; Kagawa, Y. Effect of grain boundary microcracking on the light transmittance of sintered transparent $\mathrm{MgAl}_{2} \mathrm{O}_{4}$. J. Eur. Ceram. Soc. 2003, 23, 951-959. [CrossRef]

88. Barbe, C.J.; Arendse, F.; Comte, P.; Jirousek, M.; Lenzmann, F.; Shklover, V.; Gra, M. Nanocrystalline Titanium Oxide Electrodes for Photovoltaic Applications. J. Am. Ceram. Soc. 1997, 71, 3157-3171. [CrossRef]

89. Nehl, C.L.; Hafner, J.H. Shape-dependent plasmon resonances of gold nanoparticles. J. Mater. Chem. 2008, 2415-2419. [CrossRef]

90. Rubio, A.; Serra, L. Dielectric screening effects on the photoabsorption cross section of embedded metallic clusters. Phys. Rev. B 1993, 48, 18222-18229. [CrossRef]

91. Amendola, V.; Meneghetti, M. Size Evaluation of Gold Nanoparticles by UV-vis Spectroscopy. J. Phys. Chem. C 2009, 4277-4285. [CrossRef] 
92. Zook, J.M.; Rastogi, V.; Maccuspie, R.I.; Keene, A.M.; Fagan, J. Measuring Agglomerate Size Distribution and Dependence of Localized Surface Plasmon Resonance Absorbance on Gold Nanoparticle Agglomerate Size Using Analytical Ultracentrifugation. ACS Nano 2011, 5, 8070-8079. [CrossRef] [PubMed]

93. Huang, X.; El-Sayed, M.A. Gold nanoparticles: Optical properties and implementations in cancer diagnosis and photothermal therapy. J. Adv. Res. 2010,1,13-28. [CrossRef]

94. Jain, P.K.; El-Sayed, M.A. Plasmonic coupling in noble metal nanostructures. Chem. Phys. Lett. 2010, 487, 153-164. [CrossRef]

95. Hayashi, S.; Okamoto, T. Plasmonics: Visit the past to know the future. J. Phys. D. Appl. Phys. 2012, 45, 433001. [CrossRef]

96. Hartland, G. V Optical Studies of Dynamics in Noble Metal Nanostructures. Chem. Rev. 2011, 111, 3858-3887. [CrossRef] [PubMed]

97. Stockman, M.I. Nanoplasmonics: The physics behind the applications. Phys. Today 2011, 39-44. [CrossRef]

98. Romero, I.; Aizpurua, J.; Bryant, G.W.; Abajo, F.J.G. De Plasmons in nearly touching metallic nanoparticles: Singular response in the limit of touching dimers. Opt. Express 2006, 14, 1627-1631. [CrossRef]

99. Zhu, J. Surface Plasmon Resonance from Bimetallic Interface in Au-Ag Core-Shell Structure Nanowires. Nanoscale Res. Lett. 2009, 977-981. [CrossRef] [PubMed]

100. Chen, Y.; Wu, H.; Li, Z.; Wang, P. The Study of Surface Plasmon in Au/Ag Core/Shell Compound Nanoparticles. Plasmonics 2012, 509-513. [CrossRef]

101. Zhang, C.; Chen, B.-Q.; Li, Z.-Y.; Xia, Y.; Chen, Y.-G. Surface Plasmon Resonance in Bimetallic Core-Shell Nanoparticles. J. Phys. Chem. C 2015, 119, 16836-16845. [CrossRef]

(C) 2018 by the authors. Licensee MDPI, Basel, Switzerland. This article is an open access article distributed under the terms and conditions of the Creative Commons Attribution (CC BY) license (http:/ / creativecommons.org/licenses/by/4.0/). 
Article

\title{
Band Gap Implications on $\mathrm{Nano}^{-\mathrm{TiO}_{2}}$ Surface Modification with Ascorbic Acid for Visible Light-Active Polypropylene Coated Photocatalyst
}

\author{
Chiara Anna D'Amato ${ }^{1, *}$, Rita Giovannetti ${ }^{1, *}$, Marco Zannotti ${ }^{1, *}$, Elena Rommozzi ${ }^{1}$, \\ Marco Minicucci ${ }^{2}$, Roberto Gunnella ${ }^{2}$ and Andrea Di Cicco ${ }^{2}$ \\ 1 School of Science and Technology, Chemistry Division, University of Camerino, 62032 Camerino, Italy; \\ elena.rommozzi@unicam.it \\ 2 School of Science and Technology, Physics Division, University of Camerino, 62032 Camerino, Italy; \\ marco.minicucci@unicam.it (M.M.); roberto.gunnella@unicam.it (R.G.); andrea.dicicco@unicam.it (A.D.C.) \\ * Correspondence: chiaraanna.damato@unicam.it (C.A.D.); rita.giovannetti@unicam.it (R.G.); \\ marco.zannotti@unicam.it (M.Z.); Tel.: +39-0737402272 (C.A.D. \& R.G. \& M.Z.); \\ Fax: +39-0737404508 (C.A.D. \& R.G. \& M.Z.)
}

Received: 16 July 2018; Accepted: 4 August 2018; Published: 7 August 2018

\begin{abstract}
The effect of surface modification using ascorbic acid as a surface modifier of nano- $\mathrm{TiO}_{2}$ heterogeneous photocatalyst was studied. The preparation of supported photocatalyst was made by a specific paste containing ascorbic acid modified $\mathrm{TiO}_{2}$ nanoparticles used to cover Polypropylene as a support material. The obtained heterogeneous photocatalyst was thoroughly characterized (scanning electron microscope (SEM), RAMAN, X-ray diffraction (XRD), X-ray photoelectron spectroscopy (XPS), photoluminescence (PL), and Diffuse Reflectance Spectra (DRS) and successfully applied in the visible light photodegradation of Alizarin Red $S$ in water solutions. In particular, this new supported $\mathrm{TiO}_{2}$ photocatalyst showed a change in the adsorption mechanism of dye with respect to that of only $\mathrm{TiO}_{2}$ due to the surface properties. In addition, an improvement of photocatalytic performances in the visible light photodegration was obtained, showing a strict correlation between efficiency and energy band gap values, evidencing the favorable surface modification of $\mathrm{TiO}_{2}$ nanoparticles.
\end{abstract}

Keywords: heterogeneous photocatalysis; $\mathrm{TiO}_{2}$; ascorbic acid; surface modification; band gap energy; Alizarin Red S

\section{Introduction}

In recent years, progress in industrialized society has caused serious environmental problems due, for example, to the discharge of a wide variety of environmental contaminants from residential, commercial, and industrial sources [1]. Azo-dyes and contaminants released from the textile industry are mostly non-biodegradable pollutants, toxic, and also resistant to degradation using the traditional treatment methods. For these reasons they represent an important source of environmental contamination. Color removal from wastewater is an important issue because only small amounts of dyes present high effects both on the color and water quality. Consequently, it is necessary to find an effective method of wastewater treatment to remove dye pollutants and their colors from textile effluents [2]. Nowadays, a greater challenge in the environmental field relies on the treatment of contaminants and advanced oxidation processes (AOPs) have been considered as alternatives to traditional water treatment technologies [1,3]. Among several AOPs, $\mathrm{TiO}_{2}$ based photocatalysis has received huge attention as one of the most viable environmental clean-up technologies [1]; $\mathrm{TiO}_{2}$ has been considered as among the most promising materials due to its high chemical stability, low cost, chemical inertness, commercial availability, and outstanding photocatalytic activity [4-7]. $\mathrm{TiO}_{2}$ has been extensively used in many industrially relevant processes ranging from environmental 
applications to clean energy, from paints to cosmetics and medicine [7]. The semiconductor materials find application in medicine as a photosensitizer for photodynamic and photothermal therapy of cancer, as well as for drug delivery [7-9]. In particular, $\mathrm{TiO}_{2}$ photocatalysis is used to destroy hazardous compounds in water or air $[2,10]$ through a process that require low energy, operates at ambient conditions and is able to mineralize organic pollutants using only atmospheric oxygen as the additional chemical species [11]. Unlike the bulk counterpart, nanosized $\mathrm{TiO}_{2}$ demonstrated improved performance, thanks to its high surface-to-volume ratio that greatly increases the density of active surface sites available for adsorption and catalysis. In addition, the size-dependent band gap of nanosized semiconductors allows to adjust the redox potentials of photogenerated electron-hole pairs to selectively control the photochemical reactions. Therefore, the reduced dimensions of the nanocatalyst allow the photo-generated charges to reach the catalyst surface, thus reducing the probability of undesired bulk recombination $[4,12,13]$. As a drawback, large bandgap semiconductors like $\mathrm{TiO}_{2}$ (3.2 eV for Anatase) respond only to UV light, thus resulting in low efficiency for the visible spectrum. The band gap excitation of semiconductor causes charge separation followed by the scavenging of electrons and holes by surface adsorbed species [14]. Visible-light-driven photocatalytic processes can thus be realized by doping $\mathrm{TiO}_{2}$ with non-metal [15-18], noble metal [19-21] or reduced and defect $\mathrm{TiO}_{2}$ engineering [22] etc., which represent different methods widely employed to narrow the wide band gap of $\mathrm{TiO}_{2}$. By controlling the surface treatment and medium conditions, it is possible to fine-tune photocatalytic properties of $\mathrm{TiO}_{2}$ to desired applications [14]. It is also well-known that, due to large curvature, $\mathrm{TiO}_{2}$ particles with sizes smaller than $20 \mathrm{~nm}$ have under-coordinated surface structure with square pyramidal geometry instead of an octahedral one $[7,23]$. Therefore, Ti atoms surface are very reactive, leading to the formation of charge transfer (CT) complexes with a red absorption shift, due to their binding with electron-donating ligands. The visible light activation of $\mathrm{TiO}_{2}$ has been observed upon the surface modification of colloidal $\mathrm{TiO}_{2}$ with $\mathrm{L}(+)$-Ascorbic Acid (AA) $[2,24,25]$. AA, known as Vitamin C, is an important natural compound in the biology and chemistry fields, and particular interest is tuned towards its complex with metals. Complexes of AA with titanium (IV) should be relative strong and not prone to the metal catalyzed ligand oxidation that renders many metal ascorbate complexes so reactive [26]. The surface modifiers tend to enhance the surface coverage of the pollutant molecules on $\mathrm{TiO}_{2}$, inhibit the recombination process by separating the charge pairs, and extend the wavelength response [24]. It was found that compounds such as AA modify the surface of particles through the formation of $\pi-\pi$ donor-acceptor complexes $[2,24,27,28]$.

Our previous studies regarded the preparation of Polypropylene (PP) coated with only $\mathrm{TiO}_{2}, \mathrm{TiO}_{2}$ in combination with graphene and with gold nanoparticles and their application in the visible light photodegradation of Alizarin Red S (1,2-dihydroxy-9,10-anthraquinonesulfonic acid sodium salt or ARS) obtaining highly efficient dye degradation with an easy separation of the photocatalyst from the solution [29-32]. ARS is a widely used synthetic water soluble dye considered a refractory pollutant because of the difficulty in removing it through general treatments [29-32].

In this study, we want to continue our efforts regarding the extension of $\mathrm{TiO}_{2}$ light absorption into the visible range. For this purpose, AA modified $\mathrm{TiO}_{2} \mathrm{NPs}$ supported on PP were prepared and investigated for the first time as visible light photocatalysts in water. We focused on three main points: first in the establishing a procedure for the preparation of specific new paste of AA modified $\mathrm{TiO}_{2}$ nanoparticles (NPs), second, to use this to obtain supported photocatalyst of defined qualities and third, to demonstrate the increasing photocatalytic ability in the degradation of ARS as target pollutants under visible light irradiation. This new photocatalyst showed a change in the adsorption mechanism with respect to that of pure $\mathrm{TiO}_{2} \mathrm{NPs}$ and an improvement of the photocatalytic efficiency. The main advantages of the present approach were the easy preparation of the photocatalyst together with the use of the green compound AA. A comprehensive and in-depth characterization of the obtained photocatalyst permitted us to understand the reasons and types of surface modifications and the correlation between all the results. 


\section{Materials and Methods}

\subsection{Photocatalyst Preparation}

Different types of new modified $\mathrm{TiO}_{2}$ pastes, named $\left[\mathrm{AA}-\mathrm{TiO}_{2}\right]_{\mathrm{A}}$ were prepared by the addition of $6 \mathrm{~g}$ of Titanium (IV) dioxide Anatase nano-powdered $(<25 \mathrm{~nm})$, into $10 \mathrm{~mL}$ of distilled water containing different amounts of AA from 0.5 to $3.4 \mathrm{wt} \%$, acetyl acetone $10 \% v / v$ and few drops of Triton X-100 with continuous grinding for 3 min. All the used chemicals were Sigma Aldrich products (Sigma Aldrich, St. Louis, MO, USA). Five different heterogeneous photocatalysts, named $\left[\mathrm{PP} @ \mathrm{AA}-\mathrm{TiO}_{2}\right]_{\mathrm{A}}$, and containing different amount wt \% of AA were prepared through the dip-coating technique on $20 \mathrm{~cm}^{2}$ surface of Polypropylene (PP) strips (3 M 2500 material). After the preparation, the photocatalyst was thermally dried in the oven at $110{ }^{\circ} \mathrm{C}$.

\subsection{Photocatalyst Characterization}

A morphological study on the modified $\left[\mathrm{AA}-\mathrm{TiO}_{2}\right]_{\mathrm{A}}$ and pure $\left[\mathrm{TiO}_{2}\right]_{\mathrm{A}}$ photocatalyst was made using Field Emission Scanning Electron Microscopy (FE-SEM, Sigma Family, Zeiss, Oberkochen, Germany) operated at 5-7 KV. All samples have been carefully prepared by removing the $\mathrm{TiO}_{2}$ paste from the plastic support material without a change of its properties. Then the obtained powder was deposited on aluminum stabs using self-adhesive carbon conductive tabs. The samples were sputtered with chromium (5 nm) by Quorum QT150 (Quorum, Laughton, UK) to prevent charging during the analysis. To study the structural variations of two compounds, pure $\left[\mathrm{TiO}_{2}\right]_{\mathrm{A}}$ and modified $\left[\mathrm{AA}-\mathrm{TiO}_{2}\right]_{\mathrm{A}}$ were removed from the PP support and characterized by using the X-ray diffraction (XRD) technique. A customized horizontal Debye-Scherrer diffractometer was used for XRD measurements; this instrument is equipped with an INEL CPS 180 (INEL, Artenay, France) curved position sensitive detector in order to reduce drastically the acquisition time for each pattern. In order to optimize the efficiency this detector is filled with a $\mathrm{Kr} / \mathrm{CO}_{2}$ gas mixture while, the absence of moving parts eliminates the need for mechanical scanning devices such as complex scanning goniometers used in conventional XRD instruments. A Mo K-alpha (lambda $=0.7093 \AA$ ) X-ray source is used generated by a Philips sealed X-ray tube and monochromatized through a graphite crystal along the 002 plane. The samples were positioned on the beam into glass capillaries (diameter 100 microns).

X-ray photoelectron spectroscopy (XPS) analysis has been obtained by means of an unmonochromatized $\mathrm{X}$-ray source $(\mathrm{Al} \mathrm{K} \alpha)$ and CLAM IV hemispherical spectrometer (VG Scientific Ltd., East Grinstead, UK) a constant passing energy (50 eV) for an overall lower than $1 \mathrm{eV}$ half width at half-maximum (HWHM). The Raman analysis was performed using a micro-Raman spectrometer iHR320 (Horiba, Kyoto, Japan) in which the photocatalysts were excited with a green laser emitting at $\lambda=532 \mathrm{~nm}$, at room temperature and the objective outlet was $100 \times$. The photoluminescence (PL) measurements were achieved using a Perkin Elmer LS 45 luminescence spectrometer (Perkin Elmer, Waltham, MA, USA) equipped with a pulsed Xe flash lamp and, in particular, the PL spectra were collected at room temperature using an excitation wavelength of $290 \mathrm{~nm}$ in the range from 300-900 nm. The Diffuse Reflectance Spectra (DRS) were collected using an UV-Vis Spectrometer Lambda35 (Perkin Elmer, Waltham, MA, USA) with an integration sphere (P/N C6951014) in a range of wavelength from 200-1100 nm.

\subsection{Adsorption and Photodegradation Processes}

The adsorption isotherms of $\left[\mathrm{PP} @ \mathrm{AA}-\mathrm{TiO}_{2}\right]_{\mathrm{A}}$ in the ARS adsorption under dark condition were analyzed by using four different concentration of ARS from $2.92 \times 10^{-5}$ to $7.30 \times 10^{-5} \mathrm{~mol} \mathrm{~L}^{-1}$.

The photocatalytic performance of $\left[\mathrm{PP} @ \mathrm{AA}-\mathrm{TiO}_{2}\right]_{\mathrm{A}}$ photocatalyst was evaluated in the degradation of ARS $5.843 \times 10^{-5} \mathrm{~mol} \mathrm{~L}^{-1}$ by using nine equal strips of [PP@AA-TiO $]_{\mathrm{A}}$ inserted in a typical thermostated photoreactor system [29] connected with Cary 8454 Diode Array System spectrophotometer (Agilent Technologies, Santa Clara, CA, USA) with a continuous flux quartz cuvette (178.710-QS, light path $10 \mathrm{~mm}$, Hellma Analytics, Müllheim, Germany) allowing a real-time analysis; the photoreactor was irradiated with visible light by using a tubular lamp (100 W, 1800 Lumen, 
LYVIA, (Arteleta International S.p.A., Milano, Italy); the spectral features are reported in Figure S1. All the spectrophotometric data were collected monitoring the decrease of ARS absorbance at fixed wavelength of $424 \mathrm{~nm}$. The adsorption kinetics was evaluated in the same way under dark conditions.

\section{Results and Discussion}

\subsection{Morphological and Structure Characterization}

The overall procedure of the photocatalyst is schematically presented in Figure 1 where the addition of $\mathrm{AA}$ in the $\mathrm{TiO}_{2}$ pastes preparation, give the formation of yellow-brown color paste of $\left[\mathrm{AA}-\mathrm{TiO}_{2}\right]_{\mathrm{A}}$ at $\mathrm{pH}$ equal to 5 with an increase color intensity as a function of AA amount wt $\%$.

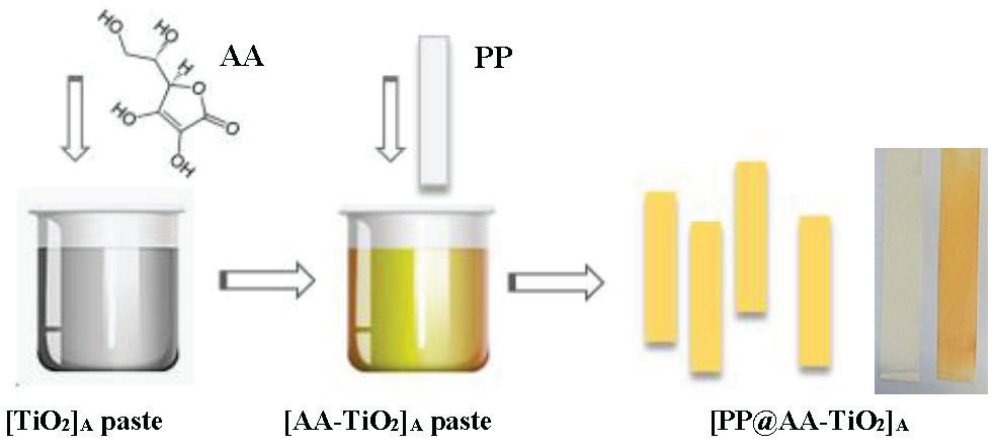

Figure 1. Schematic representation of the operative steps for the preparation of the new modified heterogeneous $\left[\mathrm{PP} @ \mathrm{AA}-\mathrm{TiO}_{2}\right]_{\mathrm{A}}$ photocatalyst and photograph of $\left[\mathrm{PP} @ \mathrm{AA}-\mathrm{TiO}_{2}\right]_{\mathrm{A}}$ prepared with two different AA amount wt \%.

SEM analysis was performed on the photocatalyst removed from the PP support; Figure 2 shows the SEM micrographs of pure $\left[\mathrm{TiO}_{2}\right]_{\mathrm{A}}$ and modified $\left[\mathrm{AA}-\mathrm{TiO}_{2}\right]_{\mathrm{A}}$ samples at the same magnification revealing that the presence of $\mathrm{AA}$ as a surface modifier changes the morphological aspect of $\left[\mathrm{AA}-\mathrm{TiO}_{2}\right]_{\mathrm{A}}$ photocatalyst.
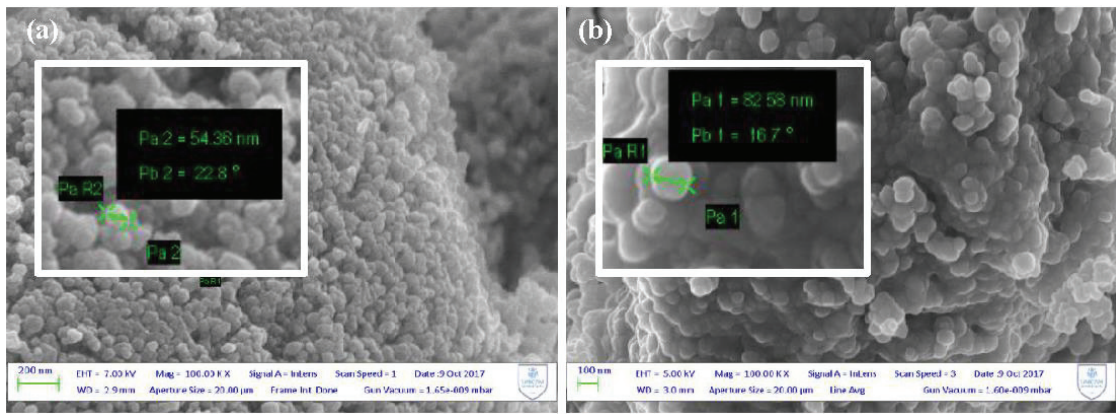

Figure 2. Scanning electron microscope (SEM) micrographs of (a) pure $\left[\mathrm{TiO}_{2}\right]_{\mathrm{A}} ;(\mathbf{b})$ modified $\left[\mathrm{AA}-\mathrm{TiO}_{2}\right]_{\mathrm{A}}$ containing $2.5 \mathrm{wt} \%$ of AA.

In particular, the images reveal that the particle sizes change as a consequence of the addition of AA to $\mathrm{TiO}_{2}$ from around $55 \mathrm{~nm}$ for the pure $\left[\mathrm{TiO}_{2}\right]_{\mathrm{A}}$ photocatalyst (Figure 2a) to around $80 \mathrm{~nm}$ for the modified $\left[\mathrm{AA}-\mathrm{TiO}_{2}\right]_{\mathrm{A}}$ (Figure $2 \mathrm{~b}$ ). 
To investigate the effect of $\mathrm{AA}$ as a surface modifier, the structural features of pure $\left[\mathrm{TiO}_{2}\right]_{\mathrm{A}}$ were characterized by XRD measurements and compared to that of $\left[\mathrm{AA}-\mathrm{TiO}_{2}\right]_{\mathrm{A}}$ samples. Figure 3 a showed the diffraction patterns of pure $\left[\mathrm{TiO}_{2}\right]_{\mathrm{A}}$ (black circle) and the modified $\left[\mathrm{AA}-\mathrm{TiO}_{2}\right]_{\mathrm{A}}$ samples containing $2.5 \mathrm{wt} \%$ of AA (blue circle), the unit cell refinement (red and green lines), and the theoretical pattern of $\mathrm{TiO}_{2}$-anatase (orange line). From the analysis of these spectra, it is clearly visible that both samples exhibited a series of well-defined diffraction peaks attributable to the Anatase $\mathrm{TiO}_{2}$ crystal structure and no extra peaks have been observed in the XRD patterns. The values for the structural parameters of the cells obtained by the data refinement are shown in the Table 1 . We found a close agreement between $\mathrm{TiO}_{2}$ [33] and $\left[\mathrm{TiO}_{2}\right]_{\mathrm{A}}$ values, while there is evidence of a parameter cell expansion of the $\left[\mathrm{AA}-\mathrm{TiO}_{2}\right]_{\mathrm{A}}$ especially along the c-axis: this effect is clearly visible in Figure $3 \mathrm{~b}$ where the data, in the range of 20-23 deg, show the shift of the 004 reflection directly connected with the vertical axis. It is known that the $\mathrm{pH}$ has an important role on the change of average crystallite size and the results obtained at about five $\mathrm{pH}$ derive from an increase of the average crystallite size as a consequence of the tensile strain [33]. The obtained results may be attributed to the lattice expansion with consequent incorporation of AA inside the crystalline lattice of the semiconductor material.
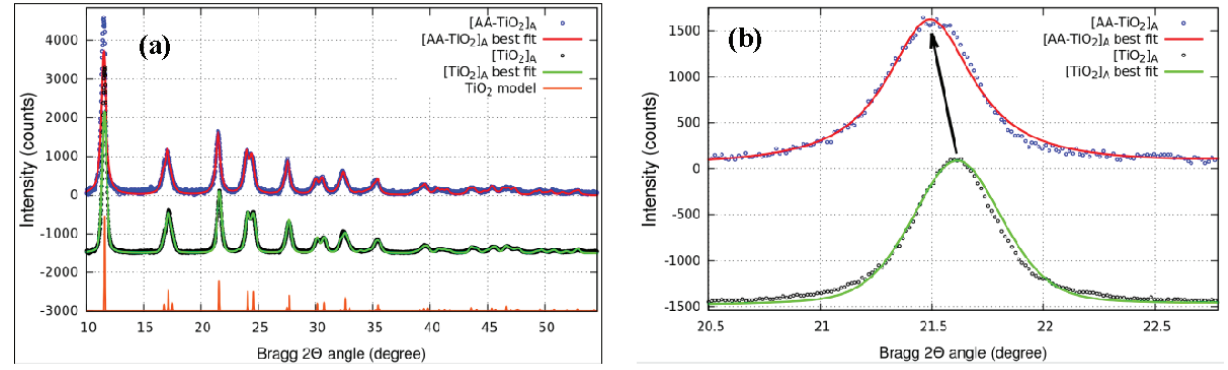

Figure 3. X-ray diffraction (XRD) patterns of (a) $\left[\mathrm{TiO}_{2}\right]_{\mathrm{A}}$ and $\left[\mathrm{AA}-\mathrm{TiO}_{2}\right]_{\mathrm{A}}$ containing $2.5 \mathrm{wt} \%$ of AA; (b) Magnification of the 004 peak in the range in the range 20.5-23.0 deg.

Table 1. Parameter cell values for $\mathrm{TiO}_{2}[33],\left[\mathrm{TiO}_{2}\right]_{\mathrm{A}}$ and $\left[\mathrm{AA}-\mathrm{TiO}_{2}\right]_{\mathrm{A}}$.

\begin{tabular}{|c|c|c|}
\hline Sample & a $(\AA)$ & c (Å) \\
\hline $\mathrm{TiO}_{2}$ [33] & 3.785 & 9.514 \\
\hline$\left[\mathrm{TiO}_{2}\right]_{\mathrm{A}}$ & 3.787 & 9.526 \\
\hline$\left[\mathrm{AA}-\mathrm{TiO}_{2}\right]_{\mathrm{A}}$ & 3.808 & 9.565 \\
\hline
\end{tabular}

The high resolution XPS spectra shown in Figure 4 for commercial Anatase, pure $\left[\mathrm{TiO}_{2}\right]_{\mathrm{A}}$ paste and modified $\left[\mathrm{AA}-\mathrm{TiO}_{2}\right]_{\mathrm{A}}$ samples were realized in order to analyze the surface modification due to the presence of AA through the formation of the bidentate binuclear binding-bridging of $\mathrm{AA}^{-\mathrm{TiO}_{2}}$. All the obtained spectra were calibrated to the $C$ 1s electron peak at $284.6 \mathrm{eV}$. Figure $4 \mathrm{a}, \mathrm{b}$ show the peaks deconvolution of XPS spectra for Ti 2p and O 1s respectively. In Figure 4a (top), for commercial Anatase, two binding energy peaks at 458 and $463.5 \mathrm{eV}$ are observed and are assigned to the $\mathrm{Ti}^{4+} 2 \mathrm{p}_{3 / 2}$ and $2 \mathrm{p}_{1 / 2}$ core levels, respectively [34-37]. Figure $4 \mathrm{a}$ (in the middle) for the pure $\left[\mathrm{TiO}_{2}\right]_{\mathrm{A}}$ heterogeneous photocatalyst shows additional strong peaks at 456.2 and $461.6 \mathrm{eV}$ that are attributed to the $\mathrm{Ti}^{3+} 2 \mathrm{p}_{3 / 2}$ and $2 \mathrm{p}_{1 / 2}$ respectively formed on the $\mathrm{TiO}_{2}$ surface [38]. These peaks derived from a change of the $\mathrm{TiO}_{2}$ surface because of the paste preparation, in which the presence of water and acetylacetone obtain a partial complexation of monomeric Ti precursor [39] and the concomitant presence of Ti-OH. Figure 4a (bottom) shows strong binding energy peaks at 458.4 and $464 \mathrm{eV}$ that are ascribed to the $2 \mathrm{p}_{3 / 2}$ and $2 \mathrm{p}_{1 / 2}$ core levels of $\mathrm{Ti}^{4+}$ and assigned to the chemical interaction between $\mathrm{TiO}_{2}$ and $\mathrm{AA}$ molecules [34-37]. The $\mathrm{O} 1 \mathrm{~s}$ spectrum of commercial Anatase showed in Figure $4 \mathrm{~b}$ (top) present two binding energy peaks 
at 528.6 and $532.1 \mathrm{eV}$ that are attributed to $\mathrm{Ti}-\mathrm{O}$ bond of lattice oxygen of $\mathrm{TiO}_{2}$ and non-lattice oxygen respectively as the Ti-OH terminal groups $[40,41]$. The pure $\left[\mathrm{TiO}_{2}\right]_{\mathrm{A}}$ sample is shown in Figure $4(\mathrm{~b}$, in the middle) in which two binding energy peaks at 531.2 and $533.6 \mathrm{eV}$ are visible due to the presence of the $\mathrm{OH}$ group with oxygen at the bridging oxygen site $\left(\mathrm{Ti}-\mathrm{OH}_{\mathrm{b}}\right)$ [42] and to the physiosorbed $\mathrm{H}_{2} \mathrm{O}$ which is present as a consequence of the influence of water molecules on the sample surface due to the paste preparation [41,42]. Figure $4 \mathrm{~b}$ (bottom) for the modified [AA- $\left.\mathrm{TiO}_{2}\right]_{\mathrm{A}}$ sample shows strong binding energy peaks at 529.8 and $532.4 \mathrm{eV}$ that are assigned to the Ti-O surface bulk oxide lattice of $\mathrm{TiO}_{2}$ and $\mathrm{OH}$ as a terminal group with oxygen attached to the five-coordinated $\mathrm{Ti}^{4+}$ with an $\mathrm{O}-\mathrm{Ti}^{4+}$ covalent bond [42] or $\mathrm{C}-\mathrm{OH}$ due to the interaction of $\mathrm{TiO}_{2}$ with the $\mathrm{AA}$ [43]. It is known that almost $40 \%$ of the $\mathrm{TiO}_{2}$ surface consist of $\mathrm{Ti}$ atoms with incomplete coordination [24] that are four-fold coordinated to oxygen with two unfilled orbitals; consequently, they can accept two lone pair from electron donors to complete the octahedral coordination. The most possible conformation that leads to chelate ring structure that also offers higher stability derived by AA binding as a bidentate ligand through the two ene-diolate oxygen atoms with the function of the electron donor [27]. The five member AA ring structure is favorable for the Ti surface atoms, showing little distortion of bond angles and distances, while no evidence shows the involvement of glycolic side chain in the complex formation [27].

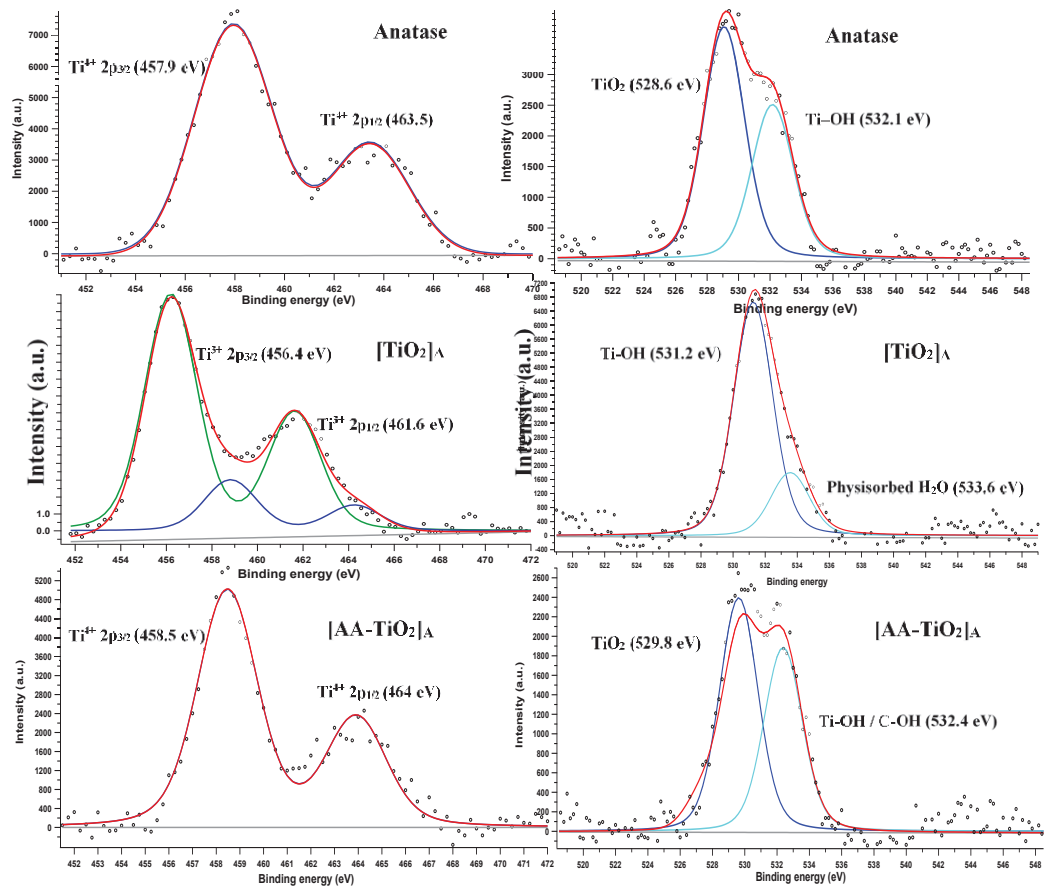

(a) $\operatorname{Ti} 2 \mathrm{p}$

(b) $\mathrm{O} 1 \mathrm{~s}$

Figure 4. X-ray photoelectron spectroscopy (XPS) spectra of commercial Anatase (top), pure $\left[\mathrm{TiO}_{2}\right]_{\mathrm{A}}$ (in the middle) and modified $\left[\mathrm{AA}-\mathrm{TiO}_{2}\right]_{\mathrm{A}}$ (bottom) containing $2.5 \mathrm{wt} \%$ of AA for (a) Ti $2 \mathrm{p}$ and (b) for O $1 \mathrm{~s}$.

Raman spectra collected at room temperature did not show significant change with respect to the same in the absence of AA (Figure S2), the Raman active modes typical of $\mathrm{TiO}_{2}$ anatase remain unchanged, only a broadened band at $2800 \mathrm{~cm}^{-1}$ is detected that can be attributed to the fluorescence of AA. These results are in accordance also with the same sample modified by AuNPs, evidencing that AA not influences the crystallinity, crystallite size, and defects of $\mathrm{TiO}_{2}$ [32]. 
PL spectra (Figure 5) for pure $\left[\mathrm{TiO}_{2}\right]_{\mathrm{A}}$ and modified $\left[\mathrm{AA}-\mathrm{TiO}_{2}\right]_{\mathrm{A}}$ sample with $\mathrm{AA}$ amount of $2.5 \mathrm{wt} \%$, were also achieved in order to monitor the electron-hole pair recombination in response to the photon irradiation occurring on $\mathrm{TiO}_{2}$ surface mediated by the presence of AA as a surface modifier.

The PL spectra shows the peaks attributed to $\mathrm{TiO}_{2}$ [32], which decrease in intensity in the case of modified $\left[\mathrm{AA}-\mathrm{TiO}_{2}\right]_{\mathrm{A}}$, indicated that the recombination process has been suppressed, resulting in higher photocatalytic activity. A de-convoluted PL emission spectra of both samples were reported in Figure S3a,b respectively.

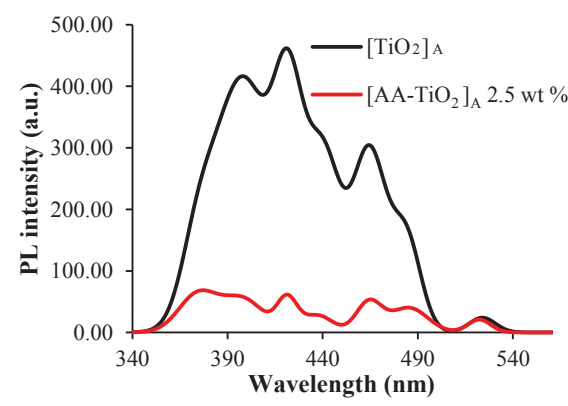

Figure 5. Photoluminescence (PL) spectra of $\left[\mathrm{TiO}_{2}\right]_{\mathrm{A}}$ (black line) and $\left[\mathrm{AA}-\mathrm{TiO}_{2}\right]_{\mathrm{A}}$ with $\mathrm{AA}$ amount of $2.5 \mathrm{wt} \%$ (red line) excited at $290 \mathrm{~nm}$ in the wavelength range of 300-900 nm.

\subsection{Optical Characterization}

Figure 6a shows the UV-Vis spectral change due to different AA amounts wt \% of [PP@AA-TiO $]_{\mathrm{A}}$ photocatalysts, demonstrating an increase in the absorption in the range of $370-570 \mathrm{~nm}$. The appearance of a yellow-brown color on the modified $\left[\mathrm{AA}-\mathrm{TiO}_{2}\right]_{\mathrm{A}}$ paste can be explained as a result of an intense ligand to metal charge transfer (LMCT) transition [27]; this is also clearly evidenced in the DRS spectra reported in Figure $6 \mathrm{~b}$ that shows the change of optical properties of modified $\left[\mathrm{PP} @ \mathrm{AA}-\mathrm{TiO}_{2}\right]_{\mathrm{A}}$ as a function of the AA amount.
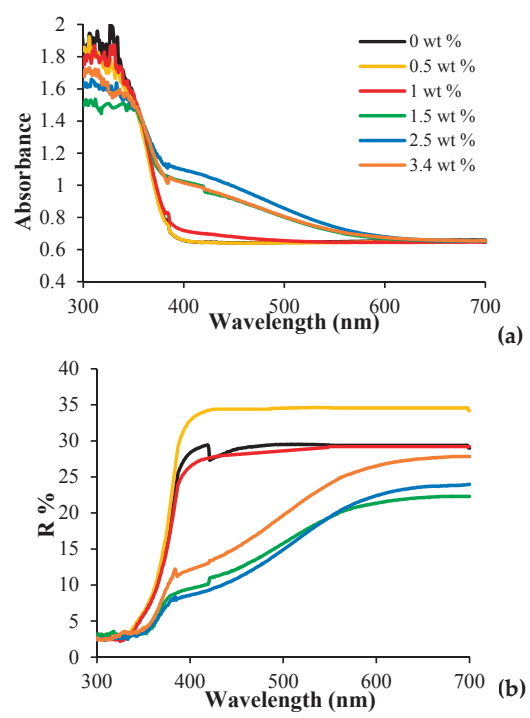

Figure 6. Cont. 


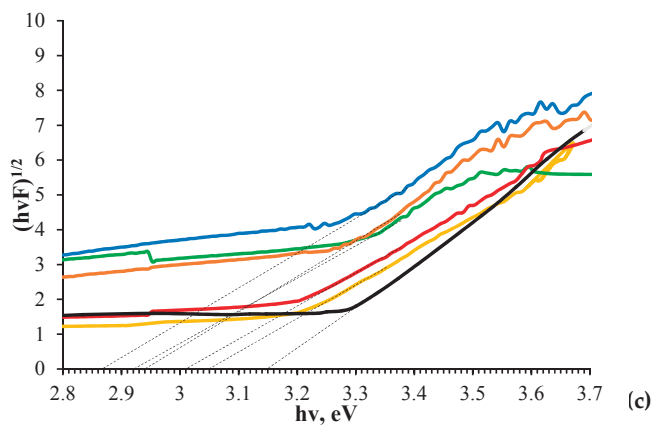

Figure 6. (a) UV-Vis Light Diffuse Reflectance spectra (DRS); (b) DRS spectra; (c) $E_{g}$ values, calculated with Kubelka-Munk method of [PP@AA-TiO $]_{\mathrm{A}}$ photocatalysts containing different AA from 0 to 3.4 wt \%.

The DRS spectrum of pure $\left[\mathrm{PP} @ \mathrm{TiO}_{2}\right]_{\mathrm{A}}$ presents a sharp adsorption edge around $390 \mathrm{~nm}$ attributed to the electron's excitation from the VB to CB (band gap 3.2 for Anatase [27] while AA does not absorb any light above $300 \mathrm{~nm}$ [27]). Generally, activated samples show a shift of absorption peak in the visible part of spectrum and, in particular, contain an extended absorption edge above $400 \mathrm{~nm}$ and a broad absorption peak between 550 and $900 \mathrm{~nm}$ [44]. The formation of a $\mathrm{Ti}^{\mathrm{IV}}$-AA surface complex results from a change of the absorption threshold [27] of the modified [PP@AA-TiO $]_{\mathrm{A}}$ photocatalyst that shifted towards the visible part of the spectrum. In fact, in this case, the modified sample presents a long tail extending up to ca. $600 \mathrm{~nm}$ as a consequence of the charge transfer complex formation between $\mathrm{Ti}^{\mathrm{IV}}$ atoms. AA introduces electronic states that are spread across the band gap, resulting in a diffused absorption spectrum [24]. These results confirm the formation of the $\mathrm{AA}^{-\mathrm{TiO}_{2}}$ charge-transfer complex into $\mathrm{TiO}_{2}$ paste that could narrow the energy band gap $\left(E_{g}\right)$ of the modified $\left[\mathrm{PP} @ \mathrm{AA}-\mathrm{TiO}_{2}\right]_{\mathrm{A}}$ photocatalyst. $E_{g}$ values of pure and modified samples were calculated by applying the Kubelka-Munk method [32] by the linear fit of the curves of Figure 6c, where F represents the Kubelka-Munk function, obtaining the respective values (Table 2 ) by the intercept in the $\mathrm{x}$-axis.

The results of Table 2 clearly show that the surface modification with AA positively influences the $E_{g}$, improving the photocatalytic activity. In fact, the $E_{g}$ value is around $3.15 \mathrm{eV}$ for $\left[\mathrm{PP}_{\mathrm{TiO}}\right]_{\mathrm{A}}[32]$, while the minimum $E_{g}$ value of $2.87 \mathrm{eV}$ is obtained for $\left[\mathrm{PP} @ \mathrm{AA}-\mathrm{TiO}_{2}\right]_{\mathrm{A}}$ in the presence of AA $2.5 \mathrm{wt} \%$.

Table 2. $E_{g}, k_{a d s}$ and $k_{\text {photo }}$ values for $\left[\mathrm{PP} @ \mathrm{AA}-\mathrm{TiO}_{2}\right]_{\mathrm{A}}$ containing different $\mathrm{AA} w \mathrm{wt}$.

\begin{tabular}{cccc}
\hline AA wt $\%$ & $\boldsymbol{E}_{g}$ & $\mathbf{1 0}^{\mathbf{2}} \boldsymbol{k}_{\text {ads }}\left(\mathrm{min}^{-\mathbf{1}}\right)$ & $\mathbf{1 0}^{\mathbf{2}} \boldsymbol{k}_{\text {photo }}\left(\mathrm{min}^{-\mathbf{1}}\right)$ \\
\hline 0 & 3.15 & 3.75 & 1.99 \\
0.5 & 3.05 & 3.55 & 3.50 \\
1 & 3.01 & 3.47 & 3.72 \\
1.5 & 2.92 & 3.46 & 4.04 \\
2.5 & 2.87 & 3.18 & 4.15 \\
3.4 & 2.94 & 3.09 & 3.85 \\
\hline
\end{tabular}

\subsection{Equilibrium and Kinetic Studies of ARS Adsorption}

In order to study the presence of surface modifiers and how they influence ARS adsorption on $\left[\mathrm{PP} @ \mathrm{AA}-\mathrm{TiO}_{2}\right]_{\mathrm{A}}$ photocatalyst, the adsorption data has been analyzed by the application of the adsorption isotherm models of Freundlich and Langmuir [29]. While ARS adsorption on $\left[\mathrm{PP}_{\mathrm{TiO}}\right]_{\mathrm{A}}$ photocatalyst occurred according to the Freundlich isotherm model [29], instead the results obtained with [PP@AA-TiO $]_{\mathrm{A}}$ (Figure 7) showed that the dye adsorption fitted well the Langmuir isotherm model $C_{e} / Q_{e}=1 / K_{L}+a_{L} C_{e} / K_{L}$, where $C_{e}$ is the ARS solution concentration (mol L $\left.{ }^{-1}\right), Q_{e}$ is the adsorbed ARS amount at equilibrium $\left(\mathrm{mol} \mathrm{L}^{-1}\right)$. The results showed Langmuir constants $K_{L}$ and 
$a_{L}$ of 8.16 and $1.24 \times 10^{5}$, respectively, a theoretical saturation capacity of the $\mathrm{TiO}_{2}$ surface $Q_{0}$ of $6.56 \times 10^{-5}$ indicating therefore a change in the adsorption mechanism due to the presence of AA. $\left[\mathrm{PP} @ \mathrm{AA}-\mathrm{TiO}_{2}\right]_{\mathrm{A}}$ permitted therefore the adsorption of AA molecules in monolayer mode and with the same adsorption energy.

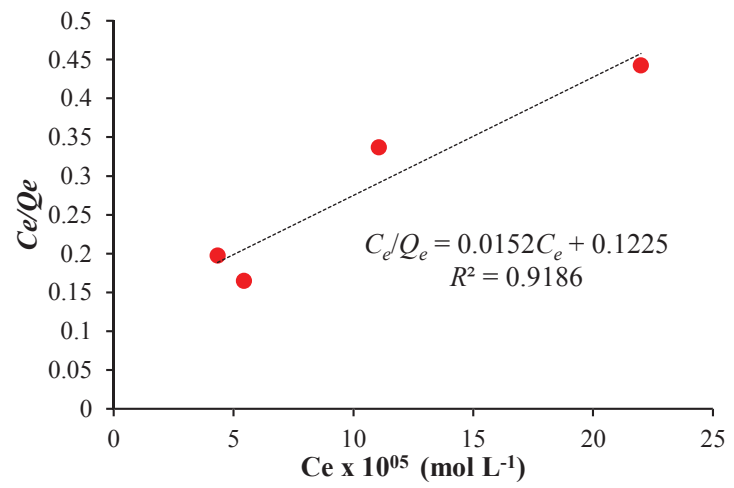

Figure 7. Langmuir isotherm graph for ARS adsorption on $\left[\mathrm{PP} @ \mathrm{AA}-\mathrm{TiO}_{2}\right]_{\mathrm{A}}$.

\subsection{Visible Light Photoactivity of $\left[P P @ A A-\mathrm{TiO}_{2}\right]_{A}$}

ARS adsorption under dark condition and photodegradation under visible light were monitored by the decrease of the ARS absorption spectra at $424 \mathrm{~nm}$ in acidic conditions.

As reported in Figure 8a, the adsorption of ARS on the modified [PP@AA- $\left.\mathrm{TiO}_{2}\right]_{\mathrm{A}}$ photocatalyst follows a pseudo first order kinetic in which the adsorption kinetic constant $k_{a d s}$ is expressed by the equation $\ln \left[\left(q_{e}-q_{t}\right)\right] / q_{e}=k_{a d s} t$, where $q_{t}$ and $q_{e}$ are the amount of adsorbed dye at time $t$ and its equilibrium concentration, respectively [29-32].

In addition, in the presence of $\left[\mathrm{PP} @ \mathrm{AA}-\mathrm{TiO}_{2}\right]_{\mathrm{A}}$ the photodegradation rate becomes proportional to the ARS concentration during time, in accordance with zero order kinetic, $[A R S]_{t}=-k_{\text {photo }} t[45]$, where $k_{\text {photo }}$ is the photodegradation kinetic constant, while $[A R S]_{t}$ is ARS concentration at time $t$. In particular, in this case, the simultaneous presence of two components as AA and ARS onto $\mathrm{TiO}_{2}$, influenced the kinetic order of the photodegradation process with respect to that of first-order kinetics with only $\mathrm{TiO}_{2}$, probably due to AA distribution on the $\mathrm{TiO}_{2}$ surface. Table 2 reports the results obtained for $k_{a d s}$ and $k_{\text {photo }}$ values relative to the process of ARS $5.84 \times 10^{-5} \mathrm{~mol} \mathrm{~L}^{-1}$ on $\left[\mathrm{PP} @ \mathrm{AA}-\mathrm{TiO}_{2}\right]_{\mathrm{A}}$ prepared with different AA wt \%, while in Figure 8 shows the linear graphs about the kinetics of adsorption (Figure 8a) and photodegradation (Figure 8b).

According to Table 2, as shown in Figure 8c, a correlation among the $k_{a d s}$ and the AA amount used for the preparation of the modified photocatalyst is observed demonstrating that by increasing the concentration of $\mathrm{AA}$ in the $\mathrm{TiO}_{2}$ paste, a decrease of the $k_{a d s}$ was found. In addition, an increase of the concentration of AA, corresponds to a decrease of $E_{\mathrm{g}}$ and an increase of $k_{\text {photo }}$ until the sample with AA concentration of $2.5 \mathrm{wt} \%$ after which both show a reverse trend (Figure $8 \mathrm{~d}$ ). 


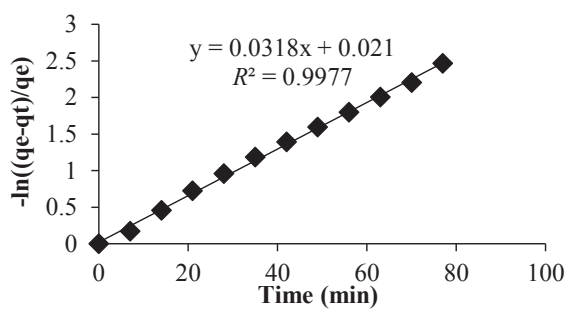

(a)

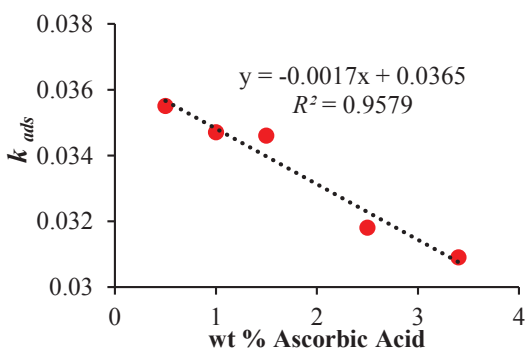

(c)

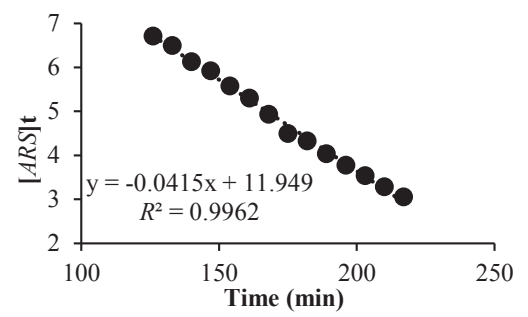

(b)

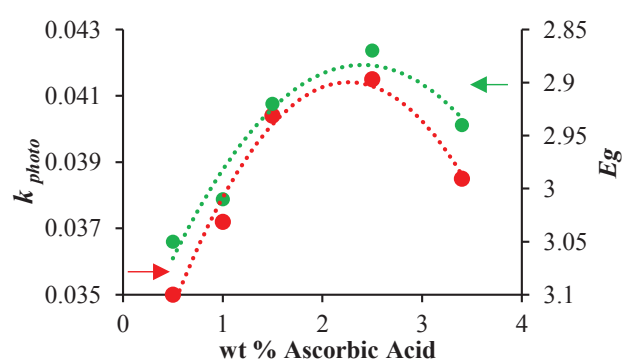

(d)

Figure 8. (a) Pseudo first order adsorption kinetic; (b) zero order photodegradation kinetic by using [PP@AA-TiO $]_{\mathrm{A}}$ containing $2.5 \mathrm{wt} \%$; (c) correlation between $k_{a d s}$ and AA wt \%; (d) correlations between the $k_{\text {photo }}$ and $E_{g}$ vs. AA wt \%.

In Figure 9 is reported the ARS photodegradation time for different $\left[\mathrm{PP} @ \mathrm{AA}-\mathrm{TiO}_{2}\right]_{\mathrm{A}},\left[\mathrm{PP} @-\mathrm{TiO}_{2}\right]_{\mathrm{A}}$ photocatalysts, and without photocatalyst under visible light, these results show the positive effects of the presence of AA; in particular the best condition is obtained with AA $2.5 \mathrm{wt} \%$.

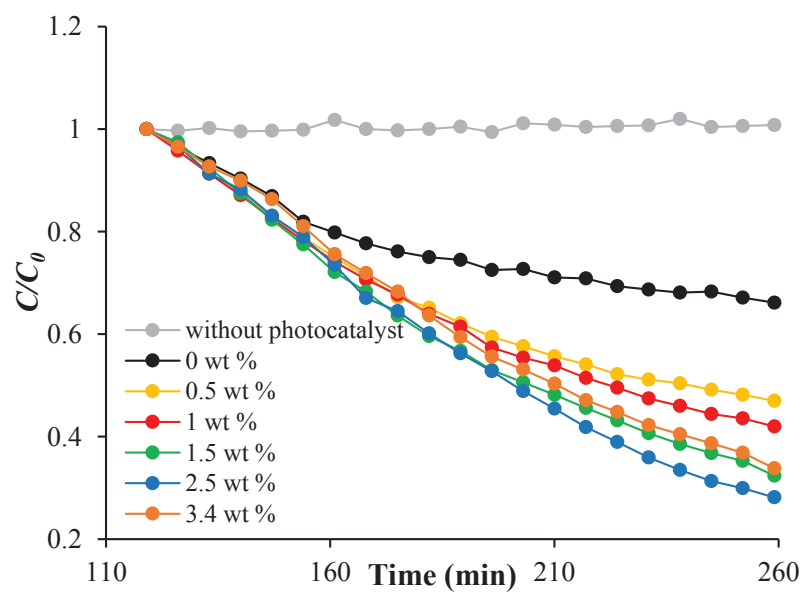

Figure 9. ARS photodegradation versus time for $\left[\mathrm{PP} @-\mathrm{TiO}_{2}\right]_{\mathrm{A}}$, different $\left[\mathrm{PP} @ \mathrm{AA}-\mathrm{TiO}_{2}\right]_{\mathrm{A}}$ photocatalysts and without photocatalyst under visible light. 
The mechanism of the photocatalytic process under visible light of the modified $\left[\mathrm{PP} @ \mathrm{AA}-\mathrm{TiO}_{2}\right]_{\mathrm{A}}$ photocatalyst can be resumed as reported in Figure 10. When [PP@AA-TiO $]_{\mathrm{A}}$ is irradiated by visible light, an electron transfer from the AA to $\mathrm{CB}$ semiconductor occurred and superoxide molecular ions are formed by the presence of molecular oxygen. Then, the formed radicals drive the photocatalytic degradation of ARS adsorbed on a modified photocatalyst [46].

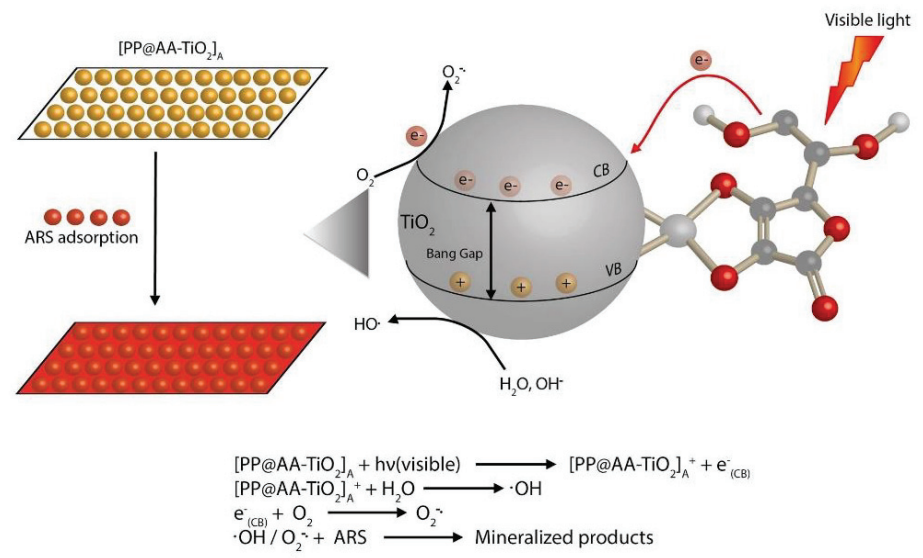

Figure 10. Mechanism of photocatalytic process by using $\left[\mathrm{PP} @ \mathrm{AA}-\mathrm{TiO}_{2}\right]_{\mathrm{A}}$ for the degradation of ARS solution.

\section{Conclusions}

A $\left[\mathrm{PP} @ \mathrm{AA}-\mathrm{TiO}_{2}\right]_{\mathrm{A}}$ yellow-brown photocatalyst with high visible-light photocatalytic activity in the ARS dye degradation was successfully and for the first time realized by cover PP material with a specific $\mathrm{TiO}_{2}$ paste modified with AA.

The new modified photocatalyst has been widely characterized by using SEM, XRD, XPS, PL and Raman techniques. SEM images reveal that the particle sizes changed as a consequence of the addition of $\mathrm{AA}$ to $\mathrm{TiO}_{2}$, XRD measurements demonstrate a lattice expansion with consequent incorporation of AA inside the crystalline lattice of $\mathrm{TiO}_{2}$ material, while XPS measurements showed a superficial change of Ti oxidation state that change from $\mathrm{Ti}(\mathrm{III})$ to $\mathrm{Ti}(\mathrm{IV})$.

In addition, due to the interaction of $\mathrm{AA}$ with $\mathrm{TiO}_{2}$, a lower PL emission intensity has been obtained, demonstrating a lower charge recombination that enhances the photo-produced electron transition to AA with an improved electron-hole separation.

The experimentally calculated $E_{g}$ values, by using $\left[\mathrm{PP} @ \mathrm{AA}-\mathrm{TiO}_{2}\right]_{\mathrm{A}}$ photocatalysts, decreased with the increase of surface modifier concentration according to the increase of performances. The best $E_{g}$ value of $2.87 \mathrm{eV}$ obtained with $2.5 \mathrm{wt} \%$ of AA corresponds to a $k_{\text {photo }}$ of 0.0415 . The obtained results have demonstrated that this new photocatalyst has proved to be 2.08 times more effective of only $\mathrm{TiO}_{2}$ prepared in absence of AA.

In addition, a change in the adsorption mechanism with respect to that of pure $\left[\mathrm{PP} @ \mathrm{TiO}_{2}\right]_{\mathrm{A}}$ has been observed, while kinetic studies on the photocatalytic performance of $\left[\mathrm{PP} @ \mathrm{AA}-\mathrm{TiO}_{2}\right]_{\mathrm{A}}$ in the visible light photodegradation of ARS showed an improvement of the photocatalytic efficiency that is strictly correlated with $E_{g}$ values.

Supplementary Materials: The following are available online at http://www.mdpi.com/2079-4991/8/8/599/s1, Figure S1: Raman spectra of $\left[\mathrm{PP} @ \mathrm{TiO}_{2}\right]_{\mathrm{A}}$ and $\left[\mathrm{PP} @ \mathrm{AA}-\mathrm{TiO}_{2}\right]_{\mathrm{A}}$ containing $2.5 \mathrm{wt} \%$ of AA. Figure S2. Raman spectra of $\left[\mathrm{PP} @ \mathrm{TiO}_{2}\right]_{\mathrm{A}}$ and $\left[\mathrm{PP} @ \mathrm{AA}-\mathrm{TiO}_{2}\right]_{\mathrm{A}}$ containing $2.5 \mathrm{wt} \%$ of AA. Figure S3. Gaussian fitted PL spectra of $\left[\mathrm{TiO}_{2}\right]_{\mathrm{A}}(\mathrm{a})$ and $\left[\mathrm{AA}-\mathrm{TiO}_{2}\right]_{\mathrm{A}}(\mathrm{b})$, dotted line: fitting of deconvolution study. 
Author Contributions: C.A.D. and R.G. proposed and designed the experiments; C.A.D., M.Z. performed the experiments; M.Z. and E.R. analyzed the data; M.M., R.G. and A.D.C. physically characterized the materials. R.G. contributed to reagents, materials, analysis tools; C.A.D., R.G. and M.Z. wrote the paper. All the authors participated in discussions of the research.

Funding: Financial support derived from the FAR Project 2015-2017 of Camerino University.

Conflicts of Interest: The authors declare no conflict of interest.

\section{References}

1. Park, H.; Park, Y.; Kim, W.; Choi, W. Surface modification of $\mathrm{TiO}_{2}$ photocatalyst for environmental applications. J. Photochem. Photobiol. C 2013, 15, 1-20. [CrossRef]

2. Ou, Y.; Lin, J.D.; Zou, H.M.; Liao, D.W. Effects of surface modification of $\mathrm{TiO}_{2}$ with ascorbic acid on photocatalytic decolorization of an azo dye reactions and mechanisms. J. Mol. Catal. A Chem. 2005, 241, 59-64. [CrossRef]

3. Daghrir, R.; Drogui, P.; Robert, D. Modified $\mathrm{TiO}_{2}$ for environmental photocatalytic applications: A review. Ind. Eng. Chem. Res. 2013, 52, 3581-3599. [CrossRef]

4. Truppi, A.; Petronella, F.; Placido, T.; Striccoli, M.; Agostiano, A.; Curri, M.L.; Comparelli, R. Visible-light-active $\mathrm{TiO}_{2}$-based hybrid nanocatalysts for environmental applications. Catalysts 2017, 7, 100. [CrossRef]

5. Petronella, F.; Truppi, A.; Ingrosso, C.; Placido, T.; Striccoli, M.; Curri, M.L.; Agostiano, A.; Comparelli, R. Nanocomposite materials for photocatalytic degradation of pollutants. Catal. Today 2017, 281, 85-100. [CrossRef]

6. Schneider, J.; Matsuoka, M.; Takeuchi, M.; Zhang, J.; Horiuchi, Y.; Anpo, M.; Bahnemann, D.W. Understanding $\mathrm{TiO}_{2}$ Photocatalysis: Mechanisms and Materials. Chem. Rev. 2014, 114, 9919-9986. [CrossRef] [PubMed]

7. Bajic, V.; Spremo-Potparevic, B.; Zivkovic, L.; Cabarkapa, A.; Kotur-Stevuljevic, J.; Isenovic, E.; Sredojevic, D.; Vukojea, I.; Lazic, V.; Ahrenkiel, S.P.; et al. Surface-modified $\mathrm{TiO}_{2}$ nanoparticles with ascorbic acid: Antioxidant properties and efficiency against DNA damage in vitro. Colloids Surf. B 2017, 155, 323-331. [CrossRef] [PubMed]

8. Shetty, P.K.; Venuvanka, V.; Jagani, H.V.; Chethan, G.H.; Ligade, V.S.; Musmade, P.M.; Nayak, U.Y.; Reddy, M.S.; Kalthur, G.; Udupa, N.; et al. Development and evaluation of sunscreen creams containing morin-encapsulated nanoparticles for enhanced UV radiation protection and antioxidant activity. Int. J. Nanomed. 2015, 10, 6477-6491. [CrossRef]

9. Wang, Q.; Huang, J.Y.; Li, H.Q.; Zhao, A.Z.; Wang, Y.; Zhang, K.Q.; Sun, H.T.; Lai, Y.K. Recent advances on smart $\mathrm{TiO}_{2}$ nanotube platforms for sustainable drug delivery applications. Int. J. Nanomed. 2017, 12, 151-165. [CrossRef] [PubMed]

10. Schneider, J.; Bahnemann, D.; Ye, J.; Li Puma, G.; Dionysios, D.D. Photocatalysis: Fundamentals and Perspectives; Royal Society of Chemistry: London, UK, 2016; ISBN 978-1-78262-041-9.

11. Cinar, Z. The role of molecular modeling in $\mathrm{TiO}_{2}$ photocatalysis. Molecules 2017, 22, 556. [CrossRef] [PubMed]

12. Panniello, A.; Curri, M.L.; Diso, D.; Licciulli, A.; Locaputo, V.; Agostiano, A.; Comparelli, R.; Mascolo, G. Nanocrystalline $\mathrm{TiO}_{2}$ based films onto fibers for photocatalytic degradation of organic dye in aqueous solution. Appl. Catal. B Environ. 2012, 121-122, 190-197. [CrossRef]

13. Stolarczyk, J.K.; Bhattacharyya, S.; Polavarapu, L.; Feldmann, J. Challenges and Prospects in Solar Water Splitting and $\mathrm{CO}_{2}$ Reduction with Inorganic and Hybrid Nanostructures. ACS Catal. 2018, 8, 3602-3635. [CrossRef]

14. Ibhadon, A.O.; Fitzpatrick, P. Heterogeneous Photocatalysis: Recent Advances and Applications. Catalysts 2013, 3, 189-218. [CrossRef]

15. Ma, Y.; Wang, X.; Jia, Y.; Chen, X.; Han, H.; Li, C. Titanium dioxide-based nanomaterials for photocatalytic fuel generations. Chem. Rev. 2014, 114, 9987-10043. [CrossRef] [PubMed]

16. Zaleska, A. Doped-TiO 2 : A Review. Recent Patents Eng. 2008, 2, 157-164. [CrossRef]

17. Di Valentin, C.; Pacchioni, G. Trends in non-metal doping of anatase $\mathrm{TiO}_{2}$ : B, C, N and F. Catal. Today 2013, 206, 12-18. [CrossRef]

18. Zhuang, H.; Zhang, Y.; Chu, Z.; Long, J.; An, X.; Zhang, H.; Lin, H.; Zhang, Z.; Wang, X. Synergy of metal and nonmetal dopants for visible-light photocatalysis: A case-study of $\mathrm{Sn}$ and $\mathrm{N}$ co-doped $\mathrm{TiO}_{2}$. Phys. Chem. Chem. Phys. 2016, 18, 9636-9644. [CrossRef] [PubMed] 
19. Roy, N.; Sohn, Y.; Leung, K.T.; Pradhan, D. Engineered electronic states of transition metal doped $\mathrm{TiO}_{2}$ nanocrystals for low overpotential oxygen evolution reaction. J. Phys. Chem. C 2014, 118, 29499-29506. [CrossRef]

20. Ola, O.; Maroto-Valer, M.M. Transition metal oxide based $\mathrm{TiO}_{2}$ nanoparticles for visible light induced $\mathrm{CO}_{2}$ photoreduction. Appl. Catal. A Gen. 2015, 502, 114-121. [CrossRef]

21. Jang, D.M.; Kwak, I.H.; Kwon, E.L.; Jung, C.S.; Im, H.S.; Park, K.; Park, J. Transition-metal doping of oxide nanocrystals for enhanced catalytic oxygen evolution. J. Phys. Chem. C 2015, 119, 1921-1927. [CrossRef]

22. Das, T.K.; Ilaiyaraja, P.; Mocherl, P.S.V.; Bhalerao, G.M.; Sudakar, C. Influence of surface disorder, oxygen defects and bandgap in $\mathrm{TiO}_{2}$ nanostructures on the photovoltaic properties of dye sensitized solar cells. Sol. Energy Mater. Sol. Cells C 2016, 144, 194-209. [CrossRef]

23. Chen, L.X.; Rajh, T.; Jäger, W.; Nedeljkovic, J.; Thurnauer, M.C. X-ray absorption reveals surface structure of titanium dioxide nanoparticles. J. Synchrotron Rad. 1999, 6, 445-447. [CrossRef] [PubMed]

24. Mert, E.H.; Yalçın, Y.; Kılıç, M.; San, N.; Çınar, Z. Surface modification of $\mathrm{TiO}_{2}$ with ascorbic acid for heterogeneous photocatalysis: Theory and experiment. J. Adv. Oxid. Technol. 2008, 11, 199-207. [CrossRef]

25. Shah, M.W.; Zhu, Y.; Fan, X.; Zhao, J.; Li, Y.; Asim, S.; Wang, C. Facile Synthesis of Defective $\mathrm{TiO}_{2-x}$ Nanocrystals with High Surface Area and Tailoring Bandgap for Visible-light Photocatalysis. Sci. Rep. 2015, 5, 15804. [CrossRef] [PubMed]

26. Buettner, K.M.; Collins, J.M.; Valentine, A.M. Titanium(IV) and Vitamin C: Aqueous complexes of a bioactive form of Ti(IV). Inorg. Chem. 2012, 51, 11030-11039. [CrossRef] [PubMed]

27. Xagas, A.P.; Bernard, M.C.; Hugot-Le Goff, A.; Spyrellis, N.; Loizos, Z.; Falaras, P. Surface modification and photosensitisation of $\mathrm{TiO}_{2}$ nanocrystalline films with ascorbic acid. Photochem. Photobiol. A 2000, 132, 115-120. [CrossRef]

28. Pichat, P. Photon-Involving Purification of Water and Air; MDPI: Basel, Switzerland, 2018; ISBN 978-3-03842-700-1.

29. Giovannetti, R.; D’Amato, C.A.; Zannotti, M.; Rommozzi, E.; Gunnella, R.; Minicucci, M.; Di Cicco, A. Visible light photoactivity of polypropylene coated nano- $\mathrm{TiO}_{2}$ for dyes degradation in water. Sci. Rep. 2015, 5, 17801. [CrossRef] [PubMed]

30. Giovannetti, R.; Rommozzi, E.; D'Amato, C.A.; Zannotti, M. Kinetic model for simultaneous adsorption/photodegradation process of Alizarin Red S in water solution by nano- $\mathrm{TiO}_{2}$ under visible light. Catalysts 2016, 6, 84. [CrossRef]

31. Giovannetti, R.; Rommozzi, E.; Zannotti, M.; D'Amato, C.A.; Ferraro, S.; Cespi, M.; Bonacucina, G.; Minicucci, M.; Di Cicco, A. Exfoliation of graphite into graphene in aqueous solution: An application as graphene/ $\mathrm{TiO}_{2}$ nanocomposite to improve visible light photocatalytic activity. RSC Adv. 2016, 6, 93048-93055. [CrossRef]

32. D'Amato, C.A.; Giovannetti, R.; Zannotti, M.; Rommozzi, E.; Ferraro, S.; Seghetti, C.; Minicucci, M.; Gunnella, R.; Di Cicco, A. Enhancement of visible-light photoactivity by polypropylene coated plasmonic $\mathrm{Au} / \mathrm{TiO}_{2}$ for dye degradation in water solution. Appl. Surf. Sci. 2018, 441, 575-587. [CrossRef]

33. Tsega, M.; Dejene, F.B. Influence of acidic $\mathrm{pH}$ on the formulation of $\mathrm{TiO}_{2}$ nanocrystalline powders with enhanced photoluminescence property. Heliyon 2017, 3, e00246. [CrossRef] [PubMed]

34. Li, L.; Yan, J.; Wang, T.; Zhao, Z.J.; Zhang, J.; Gong, J.; Guan, N. Sub-10 nm rutile titanium dioxide nanoparticles for efficient visible-light-driven photocatalytic hydrogen production. Nat. Commun. 2015, 6, 5881. [CrossRef] [PubMed]

35. Lin, Z.; Liu, P.; Yana, J.; Yang, G. Matching energy levels between $\mathrm{TiO}_{2}$ and $\alpha-\mathrm{Fe}_{2} \mathrm{O}_{3}$ in a core-shell nanoparticle for visible-light photocatalysis. J. Mater. Chem. A 2015, 3, 14853-14863. [CrossRef]

36. Pan, S.S.; Lu, W.; Zhao, Y.H.; Tong, W.; Li, M.; Jin, L.M.; Choi, J.Y.; Qi, F.; Chen, S.G.; Fei, L.F.; et al. Self-doped rutile titania with high performance for direct and ultrafast assay of $\mathrm{H}_{2} \mathrm{O}_{2}$. Appl. Mater. Interfaces 2013, 5, 12784-12788. [CrossRef] [PubMed]

37. An, H.R.; Park, S.Y.; Kim, H.; Lee, C.Y.; Choi, S.; Lee, S.C.; Seo, S.; Park, E.C.; Oh, Y.K.; Song, C.G.; et al. Advanced nanoporous $\mathrm{TiO}_{2}$ photocatalysts by hydrogen plasma for efficient solar-light photocatalytic application. Sci. Rep. 2016, 6, 29683. [CrossRef] [PubMed]

38. Mehta, M.; Kodan, N.; Kumar, S.; Kaushal, A.; Mayrhofer, L.; Walter, M.; Moseler, M.; Dey, A.; Krishnamurthy, S.; Basu, S.; et al. Hydrogen treated anatase $\mathrm{TiO}_{2}$ : A new experimental approach and further insights from theory. J. Mater. Chem. A 2016, 4, 2670-2681. [CrossRef] 
39. Fernández-González, R.; Julián-López, B.; Cordoncillo, E.; Escribano, P. New insights on the structural and optical properties of Ce-Ti mixed oxide nanoparticles doped with praseodymium. J. Mater. Chem. 2011, 21, 497-504. [CrossRef]

40. Bharti, B.; Kumar, S.; Lee, H.N.; Kuma, R. Formation of oxygen vacancies and $\mathrm{Ti}^{3+}$ state in $\mathrm{TiO}_{2}$ thin film and enhanced optical properties by air plasma treatment. Sci. Rep. 2016, 6, 32355. [CrossRef] [PubMed]

41. Wu, C.Y.; Tu, K.J.; Deng, J.P.; Lo, Y.S.; Wu, C.H. Markedly enhanced surface hydroxyl groups of $\mathrm{TiO}_{2}$ nanoparticles with superior water-dispersibility for photocatalysis. Materials 2017, 10, 566. [CrossRef] [PubMed]

42. Krishnan, P.; Liu, M.; Itty, P.A.; Liu, Z.; Rheinheimer, V.; Zhang, M.H.; Monteiro, P.J.M.; Yu, L.E. Characterization of photocatalytic $\mathrm{TiO}_{2}$ powder under varied environments using near ambient pressure X-ray photoelectron spectroscopy. Sci. Rep. 2017, 7, 43298. [CrossRef] [PubMed]

43. Kim, H.B.; Jang, D.J. Morphological variation of anatase $\mathrm{TiO}_{2}$ crystals via formation of titanium glycerolate precursors under microwave irradiation. CrystEngComm 2015, 17, 3325-3332. [CrossRef]

44. Choudhury, B.; Dey, M.; Choudhury, A. Defect generation, d-d transition, and band gap reduction in Cu-doped $\mathrm{TiO}_{2}$ nanoparticles. Int. Nano Lett. 2013, 3, 25. [CrossRef]

45. Rumamurthy, V.; Schanze, K.S. Semiconductor Photochemistry and Photophysics; Marcel Dekker, Inc.: New York, NY, USA, 2003; Volume 10, ISBN 0824709586.

46. Zhou, N.; Lopez-Puente, V.; Wang, Q.; Polavarapu, L.; Pastoriza-Santos, I.; Xu, Q.-H. Plasmon-enhanced light harvesting: Applications in enhanced photocatalysis, photodynamic therapy and photovoltaics. RSC Adv. 2015, 5, 29076-29097. [CrossRef]

(C) 2018 by the authors. Licensee MDPI, Basel, Switzerland. This article is an open access article distributed under the terms and conditions of the Creative Commons Attribution (CC BY) license (http:/ / creativecommons.org/licenses/by/4.0/). 
Article

\title{
Synergistic Effects of Active Sites' Nature and Hydrophilicity on the Oxygen Reduction Reaction Activity of Pt-Free Catalysts
}

\author{
Mariangela Longhi ${ }^{1, *}$, Camilla Cova ${ }^{1}$, Eleonora Pargoletti ${ }^{1}$, Mauro Coduri ${ }^{2}$, \\ Saveria Santangelo ${ }^{3}$, Salvatore Patanè ${ }^{4}$, Nicoletta Ditaranto ${ }^{5}$, Nicola Cioffi ${ }^{5}$, Anna Facibeni ${ }^{6}$ \\ and Marco Scavini ${ }^{1}$ \\ 1 Dipartimento di Chimica, Università degli Studi di Milano, Via Golgi 19, 20133 Milano, Italy; \\ camilla.cova@studenti.unimi.it (C.C.); eleonora.pargoletti@unimi.it (E.P.); marco.scavini@unimi.it (M.S.) \\ 2 ESRF-The European Synchrotron, 71, Avenue des Martyrs, 38043 Grenoble, France; mauro.coduri@esrf.fr \\ 3 Dipartimento di Ingegneria Civile, dell'Energia, dell'Ambiente e dei Materiali, Università "Mediterranea", \\ Via Graziella, Loc. Feo di Vito, 89122 Reggio Calabria, Italy; saveria.santangelo@unirc.it \\ 4 Dipartimento di Scienze Matematiche e Informatiche, Scienze Fisiche e Scienze della Terra, \\ Università di Messina, Viale Stagno d'Alcontres 31, 98166 Messina, Italy; salvatore.patane@unime.it \\ 5 Dipartimento di Chimica, Università degli Studi di Bari Aldo Moro, Via Orabona 4, 70125 Bari, Italy; \\ nicola.cioffi@uniba.it (N.D.); nicoletta.ditaranto@uniba.it (N.C.) \\ 6 Dipartimento di Energia and NEMAS-Centre for NanoEngineered MAterials and Surfaces, \\ Politecnico di Milano, Via Ponzio 34/3, 20133 Milano, Italy; anna.facibeni@polimi.it \\ * Correspondence: mariangela.longhi@unimi.it; Tel.: +39-02-5031-4226
}

Received: 27 July 2018; Accepted: 21 August 2018; Published: 22 August 2018

\begin{abstract}
This work highlights the importance of the hydrophilicity of a catalyst's active sites on an oxygen reduction reaction (ORR) through an electrochemical and physico-chemical study on catalysts based on nitrogen-modified carbon doped with different metals $(\mathrm{Fe}, \mathrm{Cu}$, and a mixture of them). BET, X-ray Powder Diffraction (XRPD), micro-Raman, X-ray Photoelectron Spectroscopy (XPS), Scanning Electron Microscopy (SEM), Scanning Transmission Electron Microscopy (STEM), and hydrophilicity measurements were performed. All synthesized catalysts are characterized not only by a porous structure, with the porosity distribution centered in the mesoporosity range, but also by the presence of carbon nanostructures. In iron-doped materials, these nanostructures are bamboo-like structures typical of nitrogen carbon nanotubes, which are better organized, in a larger amount, and longer than those in the copper-doped material. Electrochemical ORR results highlight that the presence of iron and nitrogen carbon nanotubes is beneficial to the electroactivity of these materials, but also that the hydrophilicity of the active site is an important parameter affecting electrocatalytic properties. The most active material contains a mixture of $\mathrm{Fe}$ and $\mathrm{Cu}$.
\end{abstract}

Keywords: oxygen reduction reaction; Pt-free catalysts; CNT N-doped carbons; active site hydrophilicity

\section{Introduction}

An oxygen reduction reaction (ORR) is a fundamental step in many electrochemical applications, e.g., fuel cells and zinc/air batteries. Being kinetically hindered, an ORR requires efficient catalysts typically based on Platinum Group Metals [1-3]. These materials, though very efficient, present some drawbacks, such as costs, availability, and technological problems. Finding cheaper substitutes with similar or better electrocatalytic properties and stability is a challenge for the scientific community [4-17]. Effective candidates are based on metal-nitrogen-carbon catalysts, in which the metal is usually iron or cobalt [4-11]. Many studies have been devoted to highlighting the complex nature and chemical environment of catalytic sites $[12,13,18]$. Principal results show that several 
types of active sites are present on the catalyst surface [14], and that iron coordination complexes with nitrogen promote ORRs to water [15]. Moreover, all these active centers are embedded in graphene planes [19]. Recently, by using N-doped carbon catalysts with supported and not embedded metal centers with different natures, specific surface areas, types, and amounts of surface nitrogen, it has been proposed that the hydrophilicity of the catalyst support has an important role on ORR activity [20]. In fact, a high hydrophilicity allows for a high dispersion of metal-containing active sites and a better accessibility of oxygen to catalytic centers [20]. However, a recent work has shown that, for nanoporous nitrogen-doped carbons, the adsorption of water molecules depends on the local density of nitrogen atoms rather than their nature [21]. Therefore, the simultaneous use of different hydrophilic supports, nitrogen amounts, and specific surface areas [20] could lead to cumulative effects, masking the importance of hydrophilicity either of the supporting carbon, as stated in [20], or of the active centers.

The aim of this work is to demonstrate the importance of the hydrophilicity of the active sites for ORRs. For this purpose, an electrochemical and physico-chemical study was carried out on catalysts based on nitrogen-modified carbon doped with different metals ( $\mathrm{Fe}, \mathrm{Cu}$, and a mixture of them), having a comparable specific surface area and amount of nitrogen to avoid hiding cumulative effects.

The studied catalysts were synthesized by thermal decomposition of a mixture of a sugar, guanidine acetate, metal salts, and silica as templating agent. In the following, catalysts containing Fe, $\mathrm{Cu}$, and $\mathrm{Fe}-\mathrm{Cu}$ will be respectively labelled S_GA_Fe, S_GA_Cu, and S_GA_FeCu, whereas S_GA will indicate a metal-free (reference) sample.

\section{Materials and Methods}

\subsection{Catalyst Preparation}

All chemicals/solvents were purchased from Sigma Aldrich (Milano, Italy) and used as received without further purification. Gelling sugar (Südzucher AG, Mannheim, Germany) was purchased in a market (sucrose:pectin $=98 \%: 2 \%$, from NMR). A Pt-based commercial catalyst (EC20, 20\% Pt/carbon) was tested and used as a reference material.

In the synthesis, gelling sugar $(3 \mathrm{~g})$, guanidine acetate $(2 \mathrm{~g})$, and metal $(\mathrm{Me})$ acetate $(1 \mathrm{wt} . \%$ total metal ion calculated on the total mass of sugar and guanidine acetate, $\mathrm{Me}=\mathrm{Fe}, \mathrm{Cu}$, or a $\mathrm{Fe}: \mathrm{Cu}=0.5 \mathrm{wt} . \%: 0.5 \mathrm{wt} . \%$ mixture) were added to silica powder $(4.3 \mathrm{~g})$ and mixed. This mixture underwent a first heating step $\left(\mathrm{T}=600{ }^{\circ} \mathrm{C}, 1 \mathrm{~h}, \mathrm{~N}_{2}\right.$ flow rate $\left.=100 \mathrm{~cm}^{3} \mathrm{~min}^{-1}\right)$ followed by lixiviation in boiling $\mathrm{NaOH}\left(3 \mathrm{~mol} \mathrm{dm}{ }^{-3}\right)$ to remove silica. After washing, the carbon was dried $\left(\mathrm{T}=110^{\circ} \mathrm{C}, 24 \mathrm{~h}\right.$, $\mathrm{N}_{2}$ ) and, finally, pyrolysed $\left(\mathrm{T}=900^{\circ} \mathrm{C}, 3 \mathrm{~h}, \mathrm{~N}_{2}\right.$ flow rate $\left.=100 \mathrm{~cm}^{3} \mathrm{~min}^{-1}\right)$ to activate catalytic sites.

\subsection{Physical Characterizations}

Specific surface area and porosity distribution were obtained from $\mathrm{N}_{2}$ adsorption/desorption isotherms at $77 \mathrm{~K}$ using a Micromeritics Tristar II 3020 (Micromeritics, Milano, Italy) apparatus and the instrumental software (Version 1.03) and applying Brunauer-Emmett-Teller (BET) and Barrett-Joyner-Halenda analyses, respectively. Prior to measuring, sample powders were heat-treated $\left(\mathrm{T}=150^{\circ} \mathrm{C}, 4 \mathrm{~h}, \mathrm{~N}_{2}\right)$ to remove adsorbed foreign species.

Micro-Raman spectra were recorded in air at room temperature using a NTEGRA-Spectra SPM spectrometer (NT-MDT, Moscow, Russia) (350 mm monochromator, MS3504i, ANDOR Idus CCD cooled at $\mathrm{T}=-60{ }^{\circ} \mathrm{C}$ ). Raman scattering was excited by a thermo-cooled solid-state laser $(\lambda=532 \mathrm{~nm} ; 2.33 \mathrm{eV})$. The scattered light from the sample was collected using a 100x (0.75 Numerical Aperture) Mitutoyo objective. Spectra acquired from different random positions on each specimen were averaged to have a reliable picture of the sample bulk. The average spectra were analyzed by using a commercially available software package [22] to assess the graphitization degree of samples.

X-ray Photoelectron Spectroscopy (XPS) analyses were run on a PHI 5000 Versa Probe II Scanning XPS Microprobe spectrometer (ULVAC-PHI Inc., Kanagawa, Japan). Measurements were done with 
a monochromatic $\mathrm{Al} \mathrm{K} \alpha$ source (X-ray spot $100 \mu \mathrm{m})$ at a power of $24.8 \mathrm{~W}$. Wide scans and detailed spectra were acquired in Fixed Analyzer Transmission (FAT) mode with a pass energy of $117.40 \mathrm{eV}$ and $29.35 \mathrm{eV}$, respectively. An electron gun was used for charge compensation (1.0 V $20.0 \mu \mathrm{A})$. Data processing was performed by using the MultiPak software v. 9.5.0.8 (ULVAC-PHI Inc., Kanagawa, Japan).

X-ray Powder Diffraction (XRPD) patterns were collected at room temperature at the ID22 beamline of the ESRF with a wavelength $\lambda=0.399946(4) \AA$ up to $2 \theta=40^{\circ}$ and a $\sim 0.5 \mathrm{~h} /$ pattern counting time. Data recorded continuously have been then merged using different step sizes spanning from $\Delta 2 \theta=0.005^{\circ}$ to $0.050^{\circ}$ to highlight different features in the patterns. Patterns merged with the former step size were analyzed via the Rietveld method using the General Structure Analysis System (GSAS) suite of the program [23].

Scanning Electron Microscopy (SEM) observations were carried out using a Leo 1430 SEM (Zeiss, Oberkochen, Germany).

Scanning Transmission Electron Microscopy (STEM) measurements were performed by using a Zeiss Supra 40 Field Emission Scanning Electron Microscope (FE-SEM) (Zeiss, Oberkochen, Germany) working in high vacuum conditions and equipped with the GEMINI column.

Wettability features of carbons were evaluated by a Krüss Easy Drop instrument (Krüss, Hamburg, Germany) using a water drop $(\mathrm{V}=7 \mu \mathrm{L})$ gently placed on the surface of the samples compacted as a flat layer. By taking into account the complexity of the system and the relationship between the wetting properties and the physico-chemical features of the materials (the size of particles, the roughness of the samples, and their intrinsic surface free energy and packing degree) only the time necessary to achieve complete spreading was measured [20].

Electrochemical characterization was performed in $0.1 \mathrm{~mol} \mathrm{dm}^{-3} \mathrm{KOH}$ by the Thin Film Rotating Disk Electrode method using Cyclic Voltammetry (CV) as in [16]. ORR onset potential was evaluated at $j=1 \mathrm{~mA} \mathrm{~cm}{ }^{-2}$ and the number of exchanged electrons was determined as described in Ref. [16].

The stability of materials was evaluated by comparing CV curves at $1600 \mathrm{rpm}$ in $\mathrm{O}_{2}$ at the beginning and at the end of electrochemical measurements (results not reported). In all cases, the stability was good.

\section{Results and Discussion}

Figure 1 shows experimental BET adsorption isotherms. All the samples exhibit a type IV isotherm with a H3-type hysteresis loop [24] characteristic of mesoporous materials and attributable to a non-fixed aggregation of plate-like particles giving rise to slit-shaped pores [25].
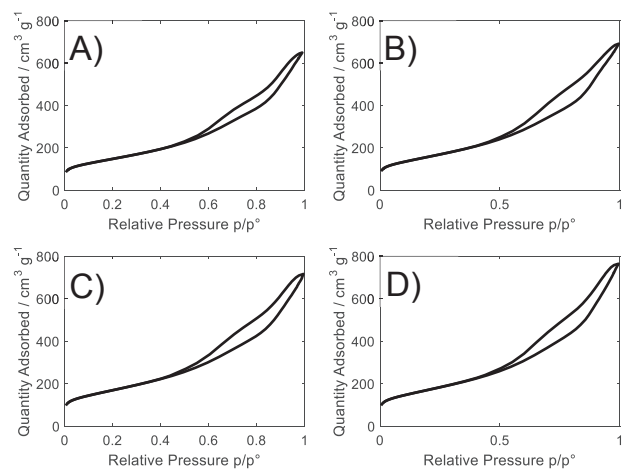

Figure 1. Adsorption and desorption nitrogen isotherms for (A) S_GA; (B) S_GA_Cu; (C) S_GA_Fe; and (D) S_GA_FeCu. 
The specific surface area (Table 1) of samples is between $\sim 520$ and $600 \mathrm{~m}^{2} \mathrm{~g}^{-1}$ without important differences among metal-doped samples $\left(\sim 560-600 \mathrm{~m}^{2} \mathrm{~g}^{-1}\right.$, with a difference of $\left.7 \%\right)$. A high mesoporosity $(\sim 55 \%)$, centered between 2 and $5 \mathrm{~nm}$, characterizes all these materials (Table 1 and Figure S1). ORRs benefit from this pore range, since it favors the diffusion of reactants/products to/from active centers [26-28].

Table 1. Specific Surface Area (SSA) and Pore Area Distribution.

\begin{tabular}{cccccc}
\hline Sample Name & $\mathbf{S S A} / \mathbf{m}^{\mathbf{2}} \mathbf{g}^{-\mathbf{1}}$ & Pores $\% \boldsymbol{d}<\mathbf{2} \mathbf{~ n m}$ & Pores $\% \mathbf{2}<\boldsymbol{d}<\mathbf{5} \mathbf{~ n m}$ & Pores $\% \mathbf{5}<\boldsymbol{d}<\mathbf{2 0} \mathbf{n m}$ & Pores $\% \boldsymbol{d}>\mathbf{2 0} \mathbf{n m}$ \\
\hline S_GA & 523 & 7.2 & 53.7 & 34.5 & 4.6 \\
S_GA_Cu & 556 & 3.9 & 56.3 & 35.6 & 4.2 \\
S_GA_Fe & 598 & 5.7 & 56.9 & 33.2 & 4.2 \\
S_GA_FeCu & 602 & 5.0 & 54.7 & 35.7 & 4.6 \\
\hline
\end{tabular}

The influence of a metal precursor on the crystalline arrangement of the carbon phase in the catalysts was investigated by means of micro-Raman spectroscopy. Regardless of the presence and type of the metal, these materials exhibit the Raman profile peculiar to highly disordered graphitic carbons (Figure 2). Two very intense bands peaking at $\sim 1360 \mathrm{~cm}^{-1}$ and $\sim 1590 \mathrm{~cm}^{-1}$ dominate the lower frequency region $\left(<2000 \mathrm{~cm}^{-1}\right)$ of the spectra. The band peaking at $\sim 1360 \mathrm{~cm}^{-1}$ (D-band) is associated with the in-plane breathing mode of the $C$ hexagonal rings [29]; the band peaking at $\sim 1590 \mathrm{~cm}^{-1}$ ( $\mathrm{G}$-band) originates from the stretching of $\mathrm{C}=\mathrm{C}$ pairs [29]. Moreover, a weaker and broader featureless second-order structure, typical of highly disordered carbon nanostructures, is detected at $\sim 2700 \mathrm{~cm}^{-1}$.

Since the D-band is generated by finite size effects and by lattice defects breaking the translational symmetry of graphitic layers [29], while the G-band is the fingerprint of the graphitic crystalline arrangement, the G/D integrated intensity ratio (IG/ID) is commonly regarded as a graphitization index [30] (the higher its value, the higher the graphitization degree of the sample).

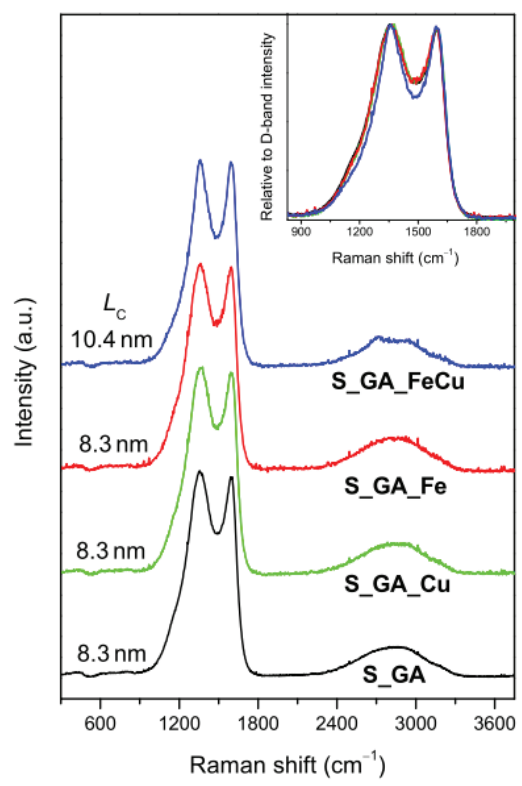

Figure 2. Micro-Raman spectra of the investigated catalysts (the average size of the graphitic crystallites $\left(L_{C}\right)$, estimated from the G/D intensity ratio [31] is reported). Inset: comparison of the D- and G-band regions of the spectra. 
No evident difference is observed in the lower frequency region of the spectra (inset of Figure 2) $[22,29,30]$, but a slight D-band shrinking in the spectrum of S_GA_FeCu was observed. This hints at a little influence of both the presence and type of the metal on the crystalline arrangement of the carbon phase. The results of spectra decomposition, reported in detail in the Supplementary Material (Figure S2, Table S1), show that the highest graphitization degree (i.e., the greatest IG/ID value, 0.55 against $0.43-0.44$ ) pertains to S_GA_FeCu. In this sample, the D-band is narrower than in the other metal-containing catalysts (183 against $211-215 \mathrm{~cm}^{-1}$ ) and the average size of the graphitic crystallites, estimated from the relationship proposed by Cançado et al. [31] for nanographites, is larger (10.4 against $8.3 \mathrm{~nm}$ ).

The results of XRPD analysis (Figure 3) fully agree with this picture. Despite the presence of different metals, all samples show broad signals at $\sim 6.5,11.1^{\circ}, 13.3^{\circ}$, and $19.3^{\circ}$ related to disordered graphitic carbon [16]. To highlight these peaks, in this figure patterns with a $\Delta 2 \theta=0.050^{\circ}$ step size are shown with the corresponding Miller (hkl) indexes (Figure 3A). These signals are the only ones present in S_GA and S_GA_Fe patterns; conversely, in the other samples, Bragg peaks prove the presence of crystalline metal phases with a crystallite size of the order of $\sim 400 \mathrm{~nm}$. Rietveld refinements reveal that both S_GA_Cu and S_GA_FeCu patterns (Figure 3B,C) are suitably fitted by using one single ccp structure (space group Fm-3m) with sharp peaks and a carbon graphitic one (space group P63mc) where only a few broad peaks are apparent. In this case, a $\Delta 2 \theta=0.005^{\circ}$ step size was adopted due to the sharpness of peaks of the metal phase.

The refined parameters are reported in Table S2. The lattice constants of the Fm-3m phase are 3.61711(1) and 3.61774(1) $\AA$ for S_GA_Cu and S_GA_FeCu, respectively. Though the difference is very small, the high resolution of the ID22 instrument makes it significant. Such a small expansion observed in S_GA_FeCu is consistent with a Cu-rich Cu1-xFex solid solution [32] as observed for $\mathrm{xCu} \cong 0.03$ at a $\mathrm{T}=900{ }^{\circ} \mathrm{C}$ calcination temperature [33]. Biphasic Rietveld refinements show that the weight fraction of the metal phase is $2.6 \%$ and $1.6 \%$ in S_GA_Cu and S_GA_FeCu samples, respectively. We must warn the reader that, due to the noise in the broad peaks of the graphitic carbon peaks and to some arbitrariness in background subtraction, this phase analysis has to be considered as semi-quantitative. However, it points to an almost iron-free crystalline phase in the S_GA_FeCu sample. As in the case of S_GA_Fe one, most of the iron does not form extended crystalline phases.

Figures S3-S6 and Figure 4A,B report XPS results. The concentration of metal species on the surface ranges between 0.2 and $0.4 \%$. Nitrogen and oxygen species are detected in all the samples (Figure S3, Table 2), but their concentration depends neither on the presence nor on the nature of the metal (Table 2), though, according to data in the literature, it would be expected to vary with the specific metal used in the synthesis [34]. This singular behavior, combined with the picture emerging from the micro-Raman and XRPD analyses, evidences the peculiarity of the present materials with respect to those generally described in the literature.

Table 2. Samples' Surface Atomic Composition *.

\begin{tabular}{cccccc}
\hline Sample Name & $\% \mathbf{C}$ & $\mathbf{\% N}$ & $\% \mathbf{O}$ & $\% \mathbf{F e}$ & $\% \mathbf{C u}$ \\
\hline S_GA & $88.6 \pm 0.7$ & $8.3 \pm 0.5$ & $3.1 \pm 0.6$ & - & - \\
S_GA_Cu & $88.0 \pm 0.5$ & $6.9 \pm 0.9$ & $4.7 \pm 1.3$ & - & $0.4 \pm 0.2$ \\
S_GA_Fe & $88.6 \pm 0.5$ & $7.1 \pm 0.5$ & $4.0 \pm 0.5$ & $0.3 \pm 0.2$ & - \\
S_GA_FeCu & $89.4 \pm 1.2$ & $7.1 \pm 0.5$ & $3.0 \pm 1.0$ & $0.3 \pm 0.2$ & $0.2 \pm 0.2$
\end{tabular}

* The values are averaged out of three replicates. Error is expressed as the larger value between the error associated with a single quantification ( $0.2 \%$ for $\mathrm{Cu}$ and $\mathrm{Fe}, 0.5 \%$ for other elements) and one standard deviation. 

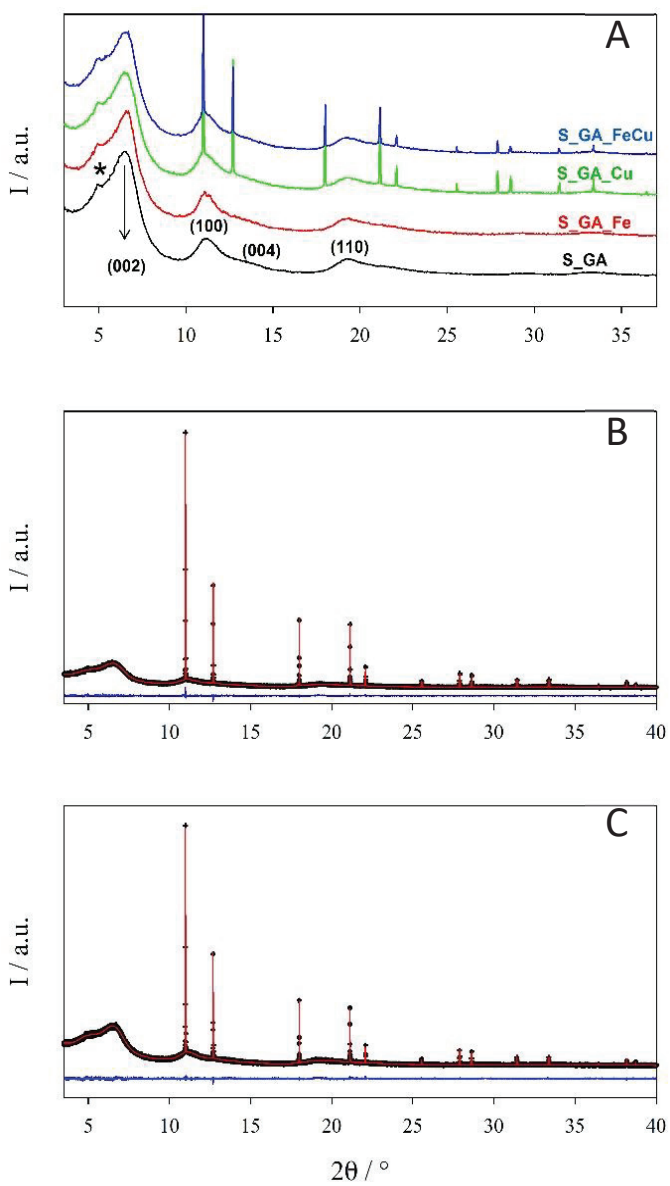

Figure 3. (A) $\mathrm{XRPD}$ patterns merged using a $\Delta 2 \theta=0.050^{\circ}$ step size highlighting the graphitic contribution. Numbers in brackets are the Miller indexes of the hexagonal graphite phase. A star highlights a broad bump due to the kapton capillary. Rietveld refinements for samples (B) S_GA_Cu and (C)S_GA_FeCu. Observed (crosses) and calculated (continuous line) profiles and residuals (bottom).

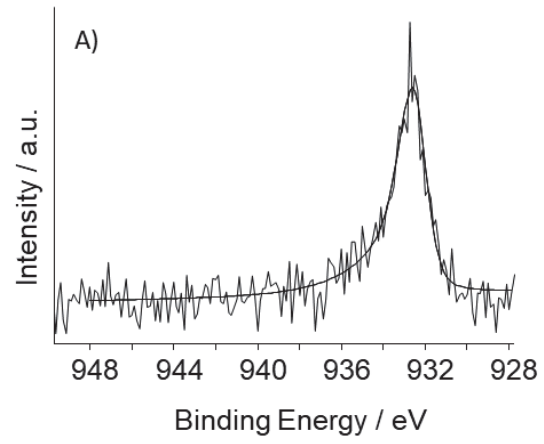

Figure 4. Cont. 


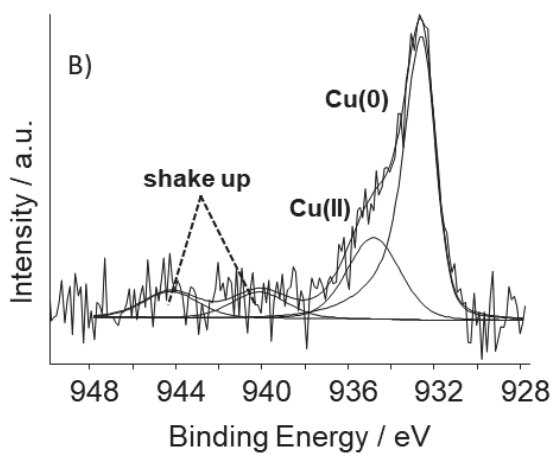

Figure 4. High-resolution photoelectron spectra of the Cu2 $\mathrm{p}^{3 / 2}$ core level of: (A) S_GA_FeCu; (B) S_GA_Cu.

The analysis of the high resolution photoelectron spectra of the N1s core level (Figure S4 and Table 3) evidences different types of nitrogen species on the surface of carbon [19,35]. Pyridinic, pyrrolic, and $\mathrm{N}_{\mathrm{x}} \mathrm{Me}$ nitrogen are the most important for ORR electroactivity [19]. Considering standard deviation, no appreciable differences among metal-doped samples are observed.

In Figure S5, high resolution spectra of the C1s core level for all synthesized samples are reported. It can be observed that in the range of the explored binding energies, all the spectra are overlapped. Therefore, the total amount of carbon-oxygen functionalities $\left(\mathrm{C}_{\mathrm{x}} \mathrm{O}_{\mathrm{y}}\right)$ on the carbon surface, considered as a measure of defects or edge sites in the graphene-like network [19], and the $\mathrm{sp}^{2} / \mathrm{sp}^{3}$ ratio related to the graphitization degree [36], are the same for all materials. These data further confirm the results reported above.

The high resolution photoelectron spectrum of the Cu2 $\mathrm{p}^{3 / 2}$ core level in S_GA_FeCu (Figure 4A) can be fitted to a single peak attributable to $\mathrm{Cu}(0)$, while in S_GA_Cu, in addition to shake-up satellite peaks, two contributions assignable to $\mathrm{Cu}(0)$ and $\mathrm{Cu}(\mathrm{II})$ are found (Figure 4B) [37]. The absence of $\mathrm{Cu}$ (II) in S_GA_FeCu could be due to a $\mathrm{Cu}$ (II) surface concentration lower than the detection limit. On the other hand, the standard potentials of the redox couples $\mathrm{Cu}^{2+} / \mathrm{Cu}$ and $\mathrm{Fe}^{2+} / \mathrm{Fe}\left(\mathrm{E}^{\circ} \mathrm{Cu}^{2+} /\right.$ $\mathrm{Cu}=+0.34 \mathrm{~V} / \mathrm{SHE}$ and $\left.\mathrm{E}^{\circ} \mathrm{Fe}^{2+} / \mathrm{Fe}=-0.44 \mathrm{~V} / \mathrm{SHE}\right)$, suggest that the presence of iron during the synthesis lowers the stability of $\mathrm{Cu}$ (II) species.

The low signal-to-noise ratio of the Fe2p high resolution regions (Figure S6) might make unreliable the results of the curve-fitting procedure. Nevertheless, the main peak is centered at the same binding energy (B.E. $=\sim 710 \mathrm{eV})$ in the two samples.

Table 3. Relative Peak Areas (RPA\%) of N1s peaks *.

\begin{tabular}{ccccccc}
\hline $\begin{array}{c}\text { Peak } \\
\text { Number }\end{array}$ & $\begin{array}{c}\text { Binding } \\
\text { Energies/eV }\end{array}$ & Functional Group & S_GA & S_GA_Cu & S_GA_Fe & S_GA_FeCu \\
\hline$(1)$ & $398.3-398.5$ & Pyridinic N & $25 \pm 1$ & $26 \pm 2$ & $29 \pm 1$ & $27 \pm 2$ \\
$(2)$ & $399.2-399.6$ & N -Me or amine & $13 \pm 4$ & $16 \pm 4$ & $13 \pm 1$ & $14 \pm 1$ \\
$(3)$ & $400.9-401.0$ & Pyrrolic N & $37 \pm 2$ & $35 \pm 2$ & $36 \pm 1$ & $31 \pm 4$ \\
$(4)$ & $402.0-403.0$ & Quaternary N & $12 \pm 3$ & $10 \pm 2$ & $10 \pm 1$ & $11 \pm 3$ \\
$(5)$ & $403.3-403.6$ & Graphitic N & $6 \pm 1$ & $5 \pm 1$ & $5 \pm 1$ & $7 \pm 1$ \\
$(6)$ & $404.8-405.1$ & Shake-up $\pi-\pi^{*}$ & $3 \pm 2$ & $4 \pm 2$ & $5 \pm 1$ & $6 \pm 1$ \\
$(7)$ & $406.8-406.9$ & Shake-up $\pi-\pi^{*}$ & $4 \pm 1$ & $4 \pm 1$ & $2 \pm 1$ & $4 \pm 1$ \\
\hline
\end{tabular}

* The error is expressed as the larger value between the error associated with a single curve-fitting procedure $(1 \%$, at worst) and one standard deviation averaged out of three replicates. 
Figure 5A-G report SEM images of the samples. In accordance with the porosity distribution results, all carbons are characterized by a porous structure (Figure 5A,B,D,F) due to the use of a hard templating agent lixiviated at the end of the synthetic process [38]. Interestingly, with respect to the other synthetic path [39], filamentous nanotubes are also evidenced in metal-doped samples (Figure 5C,E,G). In iron-doped carbons, these nanostructures are in a larger amount, are more well-organized, and longer than in S_GA_Cu. The high catalytic activity of iron to form ordered carbon nanostructures [40] might account for this behavior.

The results of STEM analysis shown in Figure 6A-D corroborate the picture emerging from the SEM observations and reveal that the filaments present in the sample S_GA_Fe are featured by a bamboo-like structure peculiar to N-doped carbon nanotubes (N-CNTs). A few nanoparticles ( 20-30 nm in diameter) are entrapped within the nanotubes. Since XRPD does not evidence any Bragg peaks related to iron metal phases (Figure 3B,C), if crystalline, their concentration should be below the detection limit of our synchrotron radiation diffraction measurements.

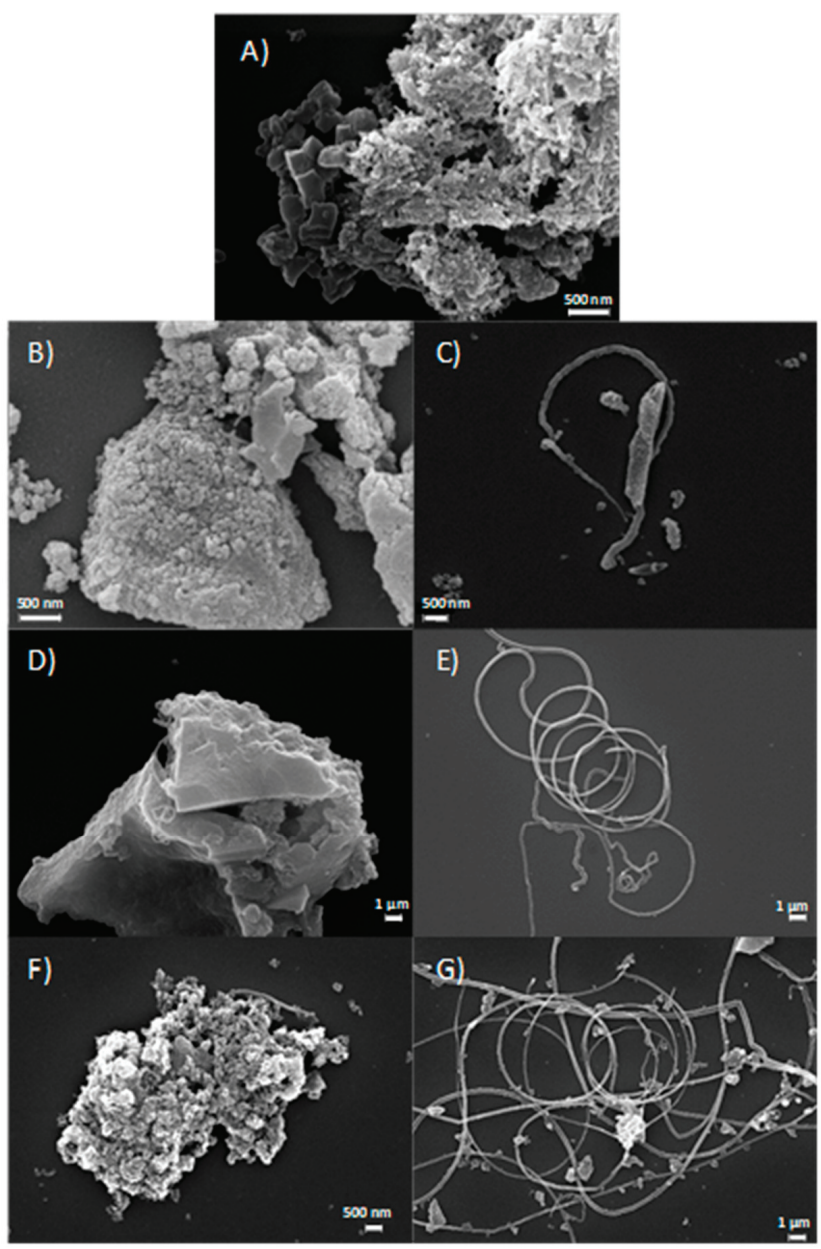

Figure 5. SEM images: (A) S_GA; (B,C): S_GA_Cu; (D,E): S_GA_Fe; (F,G): S_GA_FeCu. 


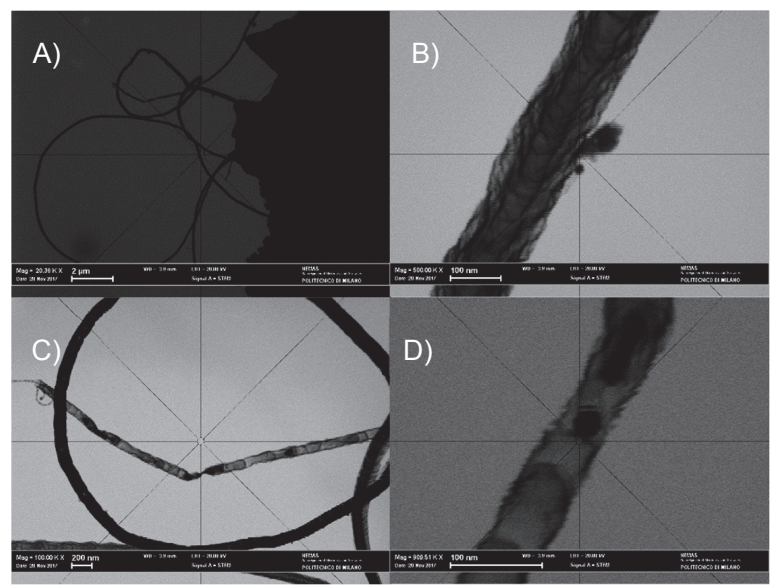

Figure 6. STEM images of S_GA_Fe. (A) Overview; (B-D) Details of (A).

Polarization curves in $0.1 \mathrm{~mol} \mathrm{dm}{ }^{-3} \mathrm{KOH}$ are reported in Figure 7 and elaborated data are displayed in Table 4. A polarization curve for a commercial catalyst based on $\mathrm{Pt}(\mathrm{EC} 20,20 \% \mathrm{Pt}$ ) and relative data are also shown for comparison.

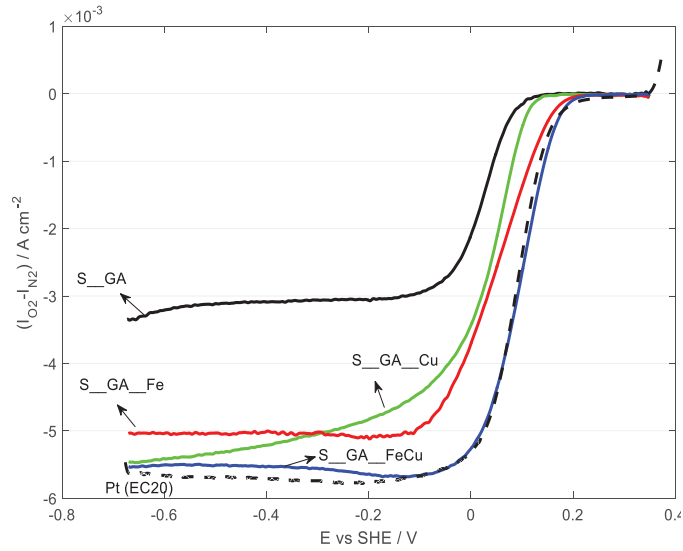

Figure 7. Oxygen reduction reaction (ORR) polarization curves recorded in oxygen-saturated $0.1 \mathrm{M} \mathrm{KOH}, \mathrm{v}=5 \mathrm{mV} \mathrm{s}^{-1}, \omega=1600 \mathrm{rpm}, \mathrm{T}=25^{\circ} \mathrm{C}$.

Table 4. ORR Onset $E_{\text {onset }}\left(\right.$ at $j=1 \mathrm{~mA} \mathrm{~cm}^{-2}$ ), Half Wave Potentials $E_{1 / 2}$, and Exchanged Electrons Number $e^{-}$.

\begin{tabular}{cccc}
\hline Sample Name & $\begin{array}{c}E_{\text {onset }} \text { versus SHE/V } \\
\text { at } \boldsymbol{j = \mathbf { 1 }} \mathbf{~ \mathbf { A ~ c m }} \mathbf{~ c m}^{-\mathbf{2}}\end{array}$ & $\boldsymbol{E}_{\mathbf{1 / 2}}$ versus SHE/V & $\mathbf{n} \boldsymbol{e}^{-}$ \\
\hline S_GA & 0.044 & 0.033 & $2.72 \pm 0.01$ \\
S_GA_Cu & 0.082 & 0.068 & $3.82 \pm 0.03$ \\
S_GA_Fe & 0.117 & 0.066 & $3.98 \pm 0.03$ \\
S_GA_FeCu & 0.145 & 0.099 & $3.48 \pm 0.02$ \\
PtEC20 & 0.135 & 0.088 & $4.0 \pm 0.1$ \\
\hline
\end{tabular}


Except for S_GA_Cu, all the samples show a well-defined limiting current. The best electrocatalytic performance pertains to S_GA_FeCu, with the most anodic onset potential ( $0.145 \mathrm{~V}$ versus SHE) and the highest $E_{1 / 2}(0.099 \mathrm{~V}$ versus SHE), also considering the Pt-based catalyst $(0.135 \mathrm{~V}$ versus SHE and $0.088 \mathrm{~V}$ versus SHE, respectively). S_GA_Fe and S_GA_Cu are more cathodic (0.117 V and $0.082 \mathrm{~V}$ versus SHE, respectively) The exchanged electron number is about 3.5-4.0 for all metal-doped materials. S_GA, with the lowest onset potential (0.044 V versus SHE) and an exchanged electron number of $\sim 2.7$ (suggesting a predominant formation of peroxides) is the worst catalyst. Similar results on iron-doped samples have been obtained in a previous work by Liang et al. [41] on Fe-N-decorated hybrids of CNTs grown on hierarchically porous carbon. However, their proposed synthetic path is more complicated and time-consuming than the one used here. As a general behavior, iron-doped carbons (S_GA_Fe and S_GA_FeCu) exhibit better electrocatalytic properties with respect to S_GA_Cu. This could be justified by the presence both of iron species [15] and of a large amount of N-CNTs characterized by a high electrocatalytic activity towards ORRs [42-46]. This peculiarity of N-CNTs derives from the presence of substitutional nitrogen in their graphene planes, which, disturbing their uniform $\pi$-cloud [47] and increasing the localized density of states at the Fermi level [48], imparts a n-type dopant activity. As a consequence, their specific electronic properties improve and their electrocatalytic activity increases [42-49]. However, the presence of both iron and N-CNTs cannot account by itself for the improved electrocatalytic activity of S_GA_FeCu with respect to S_GA_Fe.

As reported in [20], the surface hydrophilicity of active carbons plays an important role in their electroactivity toward ORRs. Therefore, the hydrophilicity of the present samples was measured in order to assess its influence on their performance. Since the contact angle measurements on rough materials are very critical [50], following [20], the time necessary to spread completely a water drop onto the sample surface was used to quantify the hydrophilicity (the shorter this time, the more hydrophilic the material). Hydrophilicity was found to increase in the order S_GA $<$ S_GA_Fe $<$ S_GA_Cu $<$ S_GA_FeCu (Table 5).

Table 5. Time Necessary to Spread a Water Drop on a Surface.

\begin{tabular}{cc}
\hline Sample Name & Time/s \\
\hline S_GA & 7.9 \\
S_GA_Fe & 5.8 \\
S_GA_Cu & 4.7 \\
S_GA_FeCu & 4.0 \\
\hline
\end{tabular}

Since $\mathrm{Fe}(0)$ is more hydrophilic than $\mathrm{Cu}(0)[49]$ and N-CNTs favorably interact with hydrophilic molecules [51], the experimental hydrophilicity scale (Table 5) suggests that the presence of a metal phase $($ as $\mathrm{Cu}(0))$ is more influential on hydrophilicity than the presence of N-CNTs. Moreover, since all the metal-doped samples exhibit similar amounts of surface oxygen and nitrogen, forming typical hydrophilic groups on the surface, the hydrophilicity of the active site, rather than the entire surface, should be responsible for the different hydrophilicities of carbons.

Coming back to the different electrocatalytic activity of S_GA_Fe and S_GA_FeCu carbons, our physico-chemical characterization shows that they have very similar structure and properties but there is a larger hydrophilicity in the S_GA_FeCu sample, which is probably related to the presence of $\mathrm{Cu}(0)$ phase. Thus, we propose that the improved performance of S_GA_FeCu has to be attributed to the different hydrophilicity of its active centers. Actually, an increase of the interactions between water and active centers could favor interactions with molecular oxygen and thus, its adsorption and, finally, its reduction. Although the influence of the active center's hydrophilicity on ORR activity of Pt-free materials should be deeply investigated, the results here presented pave the way to the comprehension of their properties. 


\section{Conclusions}

In this work, catalysts based on nitrogen-modified carbons doped with different metals (Fe, $\mathrm{Cu}$, and a mixture of them) were synthesized and characterized by BET, synchrotron radiation XRPD, micro-Raman, XPS, SEM, STEM, and hydrophilicity measurements. The N-modified carbon phases are characterized by porous structures and by the presence of N-CNTs. In the Fe-doped samples (S_GA_Fe and S_GA_FeCu), N-CNTs are more well-organized, in a larger amount, and longer than in the copper-doped ones. In Cu-doped (S_GA_Cu and S_GA_FeCu) samples, copper is present in the crystalline (ccp) phase.

In spite of the different nature of the metal-doping agent, catalysts exhibit few differences in terms of surface area, functional surface groups, and graphitization degree of the carbon phase. Electrocatalytic activity toward ORRs increases in the order S_GA_Cu < S_GA_Fe $<$ S_GA_FeCu. The presence of a larger amount of N-CNTs can account for the better performance of iron-doped catalysts with respect to S_GA_Cu. Instead, also the hydrophilicity of the active sites, which decreases in the order S_GA_FeCu > S_GA_Cu > S_GA_Fe, must be considered in order to explain the higher electrocatalytic activity of S_GA_FeCu with respect to S_GA_Fe.

The presence of iron, N-CNTs, and an improved hydrophilicity synergically boost the electrocatalytic properties of ORR catalysts.

The preliminary results here presented highlight the influence of the hydrophilicity of active sites on ORRs and pave the way to the comprehension of the electrocatalytic properties of Pt-free materials.

Supplementary Materials: The following are available online at http:/ /www.mdpi.com/2079-4991/8/9/643/s1, Figure S1: Porosity Distribution. Figure S2: Results of Raman spectra decomposition. Figure S3: XPS survey of S_GA_FeCu. Figure S4: XPS N1s region of S_GA_FeCu. Figure S5: Superimposition of XPS C1s spectra. Figure S6: XPS Fe2p spectra of S_GA_FeCu and S_GA_Fe. Table S1: Parameters inferred from Raman spectra fitting. Table S2: Lattice parameters, weight fraction (WF), average displacement parameters (Umean), and fit residuals for the refinements performed on crystalline phases.

Author Contributions: M.L. Funding Acquisition, Conceptualization, Electrochemical analysis, and BET measurements and analysis, C.C. Electrochemical Measurements, E.P. Hydrophilicity Measurements, M.C. and M.S. XRPD measurements and analysis, S.S. and S.P. Raman Measurements and analysis, N.D. and N.C. XPS measurements and analysis, A.F. STEM measurements. M.L., M.C., M.S., S.S., S.P. and N.D. contributed to the writing of the work.

Funding: This work was supported by MIUR under the Project SMARTNESS (PRIN 2015).

Acknowledgments: The authors gratefully acknowledge the European Synchrotron ESRF (Grenoble, France), beamline ID22, for providing beam time and Stefania Mazzini and Leonardo Scaglioni (UNIMI) for NMR determination of the sugar's composition.

Conflicts of Interest: The authors declare no conflict of interest.

\section{References}

1. Greeley, J.; Stephens, I.E.L.; Bondarenko, A.S.; Johansson, T.P.; Hansen, H.A.; Jaramillo, T.F.; Rossmeisl, J.; Chorkendorff, I.; Nørskov, J.K. Alloys of Platinum and Early Transition Metals as Oxygen Reduction Electrocatalysts. Nat. Chem. 2009, 1, 552-556. [CrossRef] [PubMed]

2. $\mathrm{Wu}, \mathrm{G} . ;$ Zelenay, P. Nanostructured Nonprecious Metal Catalysts for Oxygen Reduction Reaction. Acc. Chem. Res. 2013, 46, 1878-1889. [CrossRef] [PubMed]

3. Ghosh, T.; Vukmirovic, M.B.; Di Salvo, F.J.; Adzic, R.R. Intermetallics as Novel Supports for Pt Monolayer $\mathrm{O}_{2}$ Reduction Electrocatalysts: Potential for Significantly Improving Properties. J. Am. Chem. Soc. 2010, 132, 906-907. [CrossRef] [PubMed]

4. Bashyam, R.; Zelenay, P. A Class of Non-Precious Metal Composite Catalysts for Fuel Cells. Nature 2006, 443, 63-66. [CrossRef] [PubMed]

5. Lefèvre, M.; Proietti, E.; Jaouen, F.; Dodelet, J.P. Iron-Based Catalysts with Improved Oxygen Reduction Activity in Polymer Electrolyte Fuel Cells. Science 2009, 324, 71-74. [CrossRef] [PubMed] 
6. Jaouen, F.; Herranz, J.; Lefèvre, M.; Dodelet, J.-P.; Kramm, U.I.; Herrmann, I.; Bogdanoff, P.; Maruyama, J.; Nagaoka, T.; Garsuch, A.; et al. Cross-Laboratory Experimental Study of Non-Noble-Metal Electrocatalysts for the Oxygen Reduction Reaction. ACS Appl. Mater. Interfaces 2009, 1, 1623-1639. [CrossRef] [PubMed]

7. Wu, G.; More, K.L.; Johnston, C.M.; Zelenay, P. High-Performance Electrocatalysts for Oxygen Reduction Derived from Polyaniline, Iron, and Cobalt. Science 2011, 332, 443-447. [CrossRef] [PubMed]

8. Cheon, J.Y.; Kim, T.; Choi, Y.; Jeong, H.Y.; Kim, M.G.; Sa, Y.J.; Kim, J.; Lee, Z.; Yang, T.H.; Kwon, K.; et al. Ordered Mesoporous Porphyrinic Carbons with Very High Electrocatalytic Activity for the Oxygen Reduction Reaction. Sci. Rep. 2013, 3, 2715. [CrossRef] [PubMed]

9. Guan, B.Y.; Yu, L.; Lou, X.W. A Dual-Metal-Organic-Framework Derived Electrocatalyst for Oxygen Reduction. Energy Environ. Sci. 2016, 9, 3092-3096. [CrossRef]

10. Xia, B.Y.; Yan, Y.; Li, N.; Wu, H.B.; Lou, X.W.; Wang, X. A Metal-Organic Framework-Derived Bifunctional Oxygen Electrocatalyst. Nat. Energy 2016, 1, 15006. [CrossRef]

11. Liu, T.; Zhao, P.; Hua, X.; Luo, W.; Chen, S.; Cheng, G. An Fe-N-C Hybrid Electrocatalyst Derived from a Bimetal-Organic Framework for Efficient Oxygen Reduction. J. Mater. Chem. A 2016, 4, 11357-11364. [CrossRef]

12. Masa, J.; Xia, W.; Muhler, M.; Schuhmann, W. On the Role of Metals in Nitrogen-Doped Carbon Electrocatalysts for Oxygen Reduction. Angew. Chem. Int. Ed. 2015, 54, 10102-10120. [CrossRef] [PubMed]

13. Tylus, U.; Jia, Q.; Strickland, K.; Ramaswamy, N.; Serov, A.; Atanassov, P.; Mukerjee, S. Elucidating Oxygen Reduction Active Sites in Pyrolyzed Metal-Nitrogen Coordinated Non-Precious-Metal Electrocatalyst Systems. J. Phys. Chem. C 2014, 118, 8999-9008. [CrossRef] [PubMed]

14. Choi, C.H.; Choi, W.S.; Kasian, O.; Mechler, A.K.; Sougrati, M.T.; Brüller, S.; Strickland, K.; Jia, Q.; Mukerjee, S.; Mayrhofer, K.J.J.; et al. Unraveling the Nature of Sites Active toward Hydrogen Peroxide Reduction in Fe-N-C Catalysts. Angew. Chem. Int. Ed. 2017, 56, 8809-8812. [CrossRef] [PubMed]

15. Workman, M.J.; Dzara, M.; Ngo, C.; Pylypenko, S.; Serov, A.; McKinney, S.; Gordon, J.; Atanassov, P.; Artyushkova, K. Platinum Group Metal-Free Electrocatalysts: Effects of Synthesis on Structure and Performance in Proton-Exchange Membrane Fuel Cell Cathodes. J. Power Sources 2017, 348, 30-39. [CrossRef]

16. Longhi, M.; Marzorati, S.; Checchia, S.; Sacchi, B.; Santo, N.; Zaffino, C.; Scavini, M. Sugar-Based Catalysts for Oxygen Reduction Reaction. Effects of the Functionalization of the Nitrogen Precursors on the Electrocatalytic Activity. Electrochim. Acta 2016, 222, 781-792. [CrossRef]

17. Su, C.-Y.; Cheng, H.; Li, W.; Liu, Z.-Q.; Li, N.; Hou, Z.; Bai, F.-Q.; Zhang, H.-X.; Ma, T.-Y. Atomic Modulation of FeCo-Nitrogen-Carbon Bifunctional Oxygen Electrodes for Rechargeable and Flexible All-Solid-State Zinc-Air Battery. Adv. Energy Mater. 2017, 7, 1602420. [CrossRef]

18. Witkowska, A.; Giuli, G.; Renzi, M.; Marzorati, S.; Yiming, W.; Nobili, F.; Longhi, M. Fe Local Structure in Pt-Free Nitrogen-Modified Carbon Based Electrocatalysts: XAFS Study. J. Phys. Conf. Ser. 2015, 012131/1-012131/4. [CrossRef]

19. Artyushkova, K.; Serov, A.; Rojas-Carbonell, S.; Atanassov, P. Chemistry of Multidinous Active Sites for Oxygen Reduction Reaction in Transition Metal-Nitrogen-Carbon Electrocatalysts. J. Phys. Chem. C 2015, 119, 25917-25928. [CrossRef]

20. Hao, G.-P.; Sahraie, N.R.; Zhang, Q.; Krause, S.; Oschatz, M.; Bachmatiuk, A.; Strasser, P.; Kaskel, S. Hydrophilic Non-Precious Metal Nitrogen-Doped Carbon Electrocatalysts for Enhanced Efficiency in Oxygen Reduction Reaction. Chem. Commun. 2015, 51, 17285-17288. [CrossRef] [PubMed]

21. Kumar, K.V.; Preuss, K.; Guo, Z.X.; Titirici, M.M. Understanding the Hydrophilicity and Water Adsorption Behavior of Nanoporous Nitrogen-Doped Carbons. J. Phys. Chem. C 2016, 120, 18167-18179. [CrossRef]

22. Bogdanov, K.; Fedorov, A.; Osipov, V.; Enoki, T.; Takai, K.; Hayashi, T.; Ermakov, V.; Moshkalev, S.; Baranov, A. Annealing-Induced Structural Changes of Carbon Onions: High-Resolution Transmission Electron, Microscopy and Raman Studies. Carbon 2014, 73, 78-86. [CrossRef]

23. Larson, A.C.; Von Dreele, R.B. General Structural Analysis System (GSAS); Los Alamos National Laboratory, Report LAUR: Los Alamos, NM, USA, 2004.

24. Sing, K.S.W.; Everett, D.H.; Haul, R.A.W.; Moscou, L.; Pierotti, R.A.; Rouquerol, J.; Siemieniewska, T. Reporting Physisorption Data for Gas/Solid Systems with Special Reference to the Determination of Surface Area and Porosity. Pure Appl. Chem. 1985, 57, 603-619. [CrossRef]

25. Thommes, M. Physical Adsorption Characterization of Nanoporous Materials. Chem. Ing. Tech. 2010, 82, 1059-1073. [CrossRef] 
26. Leonard, N.D.; Nallathambi, V.; Calabrese Burton, S. Carbon Supports for Non-Precious Metal Proton Exchange Membrane Fuel Cells. ECS Trans. 2011, 41, 1175-1181. [CrossRef]

27. Xy, J.B.; Zhao, T.S. Mesoporous Carbon with Uniquely Combined Electrochemical and Mass Transport Characteristics for Polymer Electrolyte Membrane Fuel Cells. RSC Adv. 2013, 3, 16-24.

28. Marzorati, S.; Longhi, M. Templating Induced Behavior of Platinum-free Carbons for Oxygen Reduction Reaction. J. Electroanal. Chem. 2016, 775, 350-355. [CrossRef]

29. Ferrari, A.C.; Robertson, J. Interpretation of Raman Spectra of Disordered and Amorphous Carbon. Phys. Rev. B 2001, 61, 14095-14107. [CrossRef]

30. Santangelo, S. Controlled Surface Functionalisation of Carbon Nanotubes by Nitric Acid Vapors Generated from Sub-Azeotropic Solution. Surf. Interface Anal. 2016, 48, 17-25. [CrossRef]

31. Cançado, L.G.; Takai, K.; Enoki, T.; Endo, M.; Kim, Y.A.; Mizusaki, H.; Jorio, A.; Coelho, L.N.; Magalhães-Paniago, R.; Pimenta, M.A. General Equation for the Determination of the Crystallite Size $\mathrm{L}_{\mathrm{a}}$ of Nanographite by Raman Spectroscopy. Appl. Phys. Lett. 2006, 8, 163106-163108. [CrossRef]

32. Klement, W., Jr. Technical Report 401844; WM Keck Laboratory for Engineering Materials, California Institute of Technology: Pasadina, CA, USA, 1963. Available online: http://www.dtic.mil/dtic/tr/fulltext/u2/ 401844.pdf (accessed on 18 July 2018).

33. Chen, Q.; Jin, Z. The Fe-Cu System: A Thermodynamic Evaluation. Metal. Mater. Trans. A 1995, 26, 417-426. [CrossRef]

34. Peng, H.; Liu, F.; Liu, X.; Liao, S.; You, C.; Tian, X.; Nan, H.; Luo, F.; Song, H.; Fu, Z.; et al. Effect of Transition Metals on the Structure and Performance of the Doped Carbon Catalysts Derived from Polyaniline and Melamine for ORR Application. ACS Catal. 2014, 4, 3797-3805. [CrossRef]

35. Lahaye, J.; Nanse, G.; Bagreev, A.; Strelko, V. Porous Structure and Surface Chemistry of Nitrogen Containing Carbons from Polymers. Carbon 1999, 37, 585-590. [CrossRef]

36. Díaz, J.; Paolicelli, G.; Ferrer, S.; Comin, F. Separation of the $\mathrm{sp}^{3}$ and $\mathrm{sp}^{2}$ Components in the C1s Photoemission Spectra of Amorphous Carbon Films. Phys. Rev. B 1996, 54, 8064-8069. [CrossRef]

37. Biesinger, M.C.; Lau, L.W.M.; Gerson, A.R.; Smart, R.S.C. Resolving Surface Chemical States in XPS Analysis of First Row Transition Metals, Oxides and Hydroxides: Sc, Ti, V, Cu, and Zn. Appl. Surf. Sci. 2010, 257, 887-898. [CrossRef]

38. Galbiati, I.; Bianchi, C.L.; Longhi, M.; Carra, A.; Formaro, L. Iron and Copper Containing Oxygen Reduction Catalysts from Templated Glucose-Histidine. Fuel Cells 2010, 10, 251-258. [CrossRef]

39. Formaro, L.; Longhi, M.; Messina, P.; Galbiati, I. Catalysts Free from Noble Metals Suitable for the Electrochemical Reduction of Oxygen. U.S. Patent US 20140162869 A1, 12 June 2014.

40. Andrews, R.; Jacques, D.; Qian, D.; Rantell, T. Multiwall Carbon Nanotubes: Synthesis and Application. Acc. Chem. Res. 2002, 35, 1008-1017. [CrossRef] [PubMed]

41. Liang, J.; Zhou, R.F.; Chen, X.M.; Tang, Y.H.; Qiao, S.Z. Fe-N Decorated Hybrids of CNTs Grown on Hierarchically Porous Carbon for High-Performance Oxygen Reduction. Adv. Mater. 2014, 26, 6074-6079. [CrossRef] [PubMed]

42. Maldonado, S.; Stevenson, K.J. Influence of Nitrogen Doping on Oxygen Reduction Electrocatalysis at Carbon Nanofiber Electrodes. J. Phys. Chem. B 2005, 109, 4707-4716. [CrossRef] [PubMed]

43. Van Dommele, S.; de Jong, K.P.; Bitter, J.H. Nitrogen-Containing Carbon Nanotubes as Solid Base Catalysts. Chem. Commun. 2006, 4859-4861. [CrossRef]

44. Shao, Y.; Sui, J.; Yin, G.; Gao, Y. Nitrogen-Doped Carbon Nanostructures and their Composites as Catalytic Materials for Proton Exchange Membrane Fuel Cell. Appl. Catal. B 2008, 79, 89-99. [CrossRef]

45. Sidik, R.A.; Anderson, A.B.; Subramanian, N.P.; Kumaraguru, S.P.; Popov, B.N. $\mathrm{O}_{2}$ Reduction on Graphite and Nitrogen-Doped Graphite: Experiment and Theory. J. Phys. Chem. B 2006, 110, 1787-1793. [CrossRef] [PubMed]

46. Liu, R.; Wu, D.; Feng, X.; Müllen, K. Nitrogen-Doped Ordered Mesoporous Graphitic Arrays with High Electrocatalytic Activity for Oxygen Reduction. Angew. Chem. 2010, 122, 2619-2623. [CrossRef]

47. Chizari, K.; Janowska, I.; Houllé, M.; Florea, I.; Ersen, O.; Romero, T.; Bernhardt, P.; Ledoux, M.J.; Pham-Huu, C. Tuning of Nitrogen-Doped Carbon Nanotubes as Catalyst Support for Liquid-Phase Reaction. Appl. Catal. A Gen. 2010, 380, 72-80. [CrossRef] 
48. Terrones, M.; Ajayan, P.M.; Banhart, F.; Blase, X.; Carroll, D.L.; Charlier, J.C.; Czerw, R.; Foley, B.; Grobert, N.; Kamalakaran, R.; et al. N-Doping and Coalescence of Carbon Nanotubes: Synthesis and Electronic Properties. Appl. Phys. A Mater. Sci. Process. 2002, 74, 355-361. [CrossRef]

49. Ismagilov, Z.R.; Shalagina, A.E.; Podyacheva, O.Y.; Ischenko, A.V.; Kibis, L.S.; Boronin, A.I.; Chesalov, Y.A.; Kochubey, D.I.; Romanenko, A.I.; Anikeeva, O.B.; et al. Structure and Electrical Conductivity of Nitrogen-Doped Carbon Nanofibers. Carbon 2009, 47, 1922-1929. [CrossRef]

50. Afanasev, B.N.; Akulova, Y.P. A Correlation Between the Hydrophilicity of a Metal and its Surface Tension. Calculation of the Bond Energy of Water Molecules Adsorbed on an Uncharged Metal Surface. Prot. Met. 2000, 36, 25-30. [CrossRef]

51. Lee, W.J.; Maiti, U.N.; Lee, J.M.; Lim, J.; Han, T.H.; Sang, O.K. Nitrogen-Doped Carbon Nanotubes and Graphene Composite Structures for Energy and Catalytic Applications. Chem. Commun. 2014, 50, 6818-6830. [CrossRef] [PubMed]

(c) 2018 by the authors. Licensee MDPI, Basel, Switzerland. This article is an open access article distributed under the terms and conditions of the Creative Commons Attribution (CC BY) license (http:/ / creativecommons.org/licenses/by/4.0/). 
Article

\title{
Nano- $\mathrm{MnO}_{2}$ Decoration of $\mathrm{TiO}_{2}$ Microparticles to Promote Gaseous Ethanol Visible Photoremoval
}

\author{
Marta Stucchi ${ }^{1, *}$, Daria C. Boffito ${ }^{2}$, Eleonora Pargoletti ${ }^{1,3}$, Giuseppina Cerrato ${ }^{4}$, \\ Claudia L. Bianchi ${ }^{1,3}$ and Giuseppe Cappelletti ${ }^{1,3}$ \\ 1 Chemistry Department, University of Milan, via Golgi 19, 20133 Milano, Italy; \\ eleonora.pargoletti@unimi.it (E.P.); claudia.bianchi@unimi.it (C.L.B.); giuseppe.cappelletti@unimi.it (G.C.) \\ 2 Chemical Engineering Department, Ècole Polytechnique Montréal, Pavillon Principal, Centre-Ville, \\ Montréal, QC H3C 3A4, Canada; daria-camilla.boffito@polymtl.ca \\ 3 National Consortium for Materials Science and Technology (INSTM), via Giusti 9, 50121 Florence, Italy \\ 4 Chemistry Department \& NIS Centre, University of Turin, via Pietro Giuria 7, 10125 Turin, Italy; \\ giuseppina.cerrato@unito.it \\ * Correspondence: marta.stucchi@polymtl.ca; Tel.: +39-347-600-0699
}

Received: 11 August 2018; Accepted: 31 August 2018; Published: 3 September 2018

\begin{abstract}
TiO}_{2}$-based photocatalysis under visible light is an attractive way to abate air pollutants. Moreover, developing photocatalytic materials on a large-scale requires safe and low-cost precursors. Both high-performance $\mathrm{TiO}_{2}$ nanopowders and visible-light active noble metals do not match these requirements. Here, we report the design of novel Mn-decorated micrometric $\mathrm{TiO}_{2}$ particles. Pigmentary $\mathrm{TiO}_{2}$ replaced unsafe nano- $\mathrm{TiO}_{2}$ and firmly supported $\mathrm{MnO}_{\mathbf{x}}$ particles. $\mathrm{Mn}$ replaced noble metals such as $\mathrm{Au}$ or $\mathrm{Ag}$, opening the way for the development of lower cost catalysts. Varying Mn loading or $\mathrm{pH}$ during the impregnation affected the final activity, thus giving important information to optimize the synthesis. Photocatalytic activity screening occurred on the gas-phase degradation of ethanol as a reference molecule, both under ultraviolet (UV) $(6 \mathrm{~h})$ and Light Emitting Diode (LED) $(24 \mathrm{~h})$ irradiation. Mn-doped $\mathrm{TiO}_{2}$ reached a maximum ethanol degradation of $35 \%$ under visible light after $24 \mathrm{~h}$ for the sample containing $20 \%$ of $\mathrm{Mn}$. Also, we found that an acidic $\mathrm{pH}$ increased both ethanol degradation and mineralization to $\mathrm{CO}_{2}$, while an alkaline $\mathrm{pH}$ drastically slowed down the reaction. A strict correlation between photocatalytic results and physico-chemical characterizations of the synthesized powders were drawn.
\end{abstract}

Keywords: micrometric $\mathrm{TiO}_{2}$; $\mathrm{Mn}$ decoration; visible light photocatalysis; impregnation $\mathrm{pH}$; surface hydroxyl groups

\section{Introduction}

Environmental photocatalysis based on $\mathrm{TiO}_{2}$ and its applications for pollution abatement relies on some key aspects: (i) The availability of inexpensive and stable $\mathrm{TiO}_{2}$ [1]; (ii) the photoelectric effect, for which photocatalysis depends upon the energy of the incident photons, but not on their intensity (thus, even a small amount of photons of the required energy induces photocatalysis) [2]; (iii) the effectiveness of photocatalysis in abating pollution as it accumulates, as opposed to treating large volumes [3,4].

In 2001, Wolkoff and Nielsen [5] estimated indoor concentrations for twelve Volatile Organic Compounds (VOCs). Concentrations of organics such as benzene, ethylbenzene, and $o$-xylene were less than $5 \mu \mathrm{g} \mathrm{m}^{-3}$; toluene and xylene isomers, instead, exceeded $5 \mu \mathrm{g} \mathrm{m}^{-3}$, with concentrations greater than $15 \mu \mathrm{g} \mathrm{m}^{-3}$ in most cases. Recently, Höllbacher et al. [6] studied indoor air quality considering specific human activities, and they monitored VOCs, particulate matter (PM), carbonyl compounds and $\mathrm{CO}_{2}$. The highest VOC concentration recorded was around $3500 \mu \mathrm{g} \mathrm{m}^{-3}$; they detected a maximum formaldehyde concentration of $76 \mu \mathrm{g} \mathrm{m}^{-3}$, and the PM concentration was $378 \mu \mathrm{g} \mathrm{m}^{-3}$. 
The concentration level of many pollutants changes the incidence of diseases among people who spend time inside buildings [7].

The conventional air-purification systems are usually provided with filters. However, in such filters, pollutants can be accumulated. Moreover, treatment of old filters could cause the risk of secondary pollution. Although $\mathrm{TiO}_{2}$ is excellent to photocatalytically cleave organic compounds, photocatalysis appears as hardly applicable indoors, because visible light is not sufficient to activate $\mathrm{TiO}_{2}$. Indeed, anatase $\mathrm{TiO}_{2}$ absorbs ultraviolet light with wavelengths shorter than $380 \mathrm{~nm}$ [8]. Considering the sunlight, the Ultraviolet (UV) content barely covers $5 \%$ of the total irradiation spectrum, whereas the ultraviolet light in indoor illumination is significantly smaller because the fluorescent lamps mainly emit visible light [9]. Moreover, considering the growing concerns about energy consumption utilization, Light Emitting Diode lamps (LEDs) are increasingly replacing all other kinds of classical lighting system. LED emits in the range of 400-700 nm wavelengths only, without any UV component (IUPAC Gold Book, Light-emitting diode, LED). The number of papers regarding the modification of $\mathrm{TiO}_{2}$ to improve its photocatalytic properties is countless. Noble metal nanoparticles are actually the only promising way for the enhancement of $\mathrm{TiO}_{2}$ properties in the visible spectrum. For example, Pan and $\mathrm{Xu}$ [10] deposited noble-metal nanoparticles $(\mathrm{Ag}, \mathrm{Pt}$, and $\mathrm{Pd})$ on a $\mathrm{TiO}_{2}$ surface. The resulting $\mathrm{M}-\mathrm{TiO}_{2}(\mathrm{M}=\mathrm{Ag}, \mathrm{Pt}$, and $\mathrm{Pd})$ nanocomposites were visible-light active for the selective oxidation of benzyl alcohol. Elahifard et al. [11] synthesized $\mathrm{Ag} / \mathrm{AgBr} / \mathrm{TiO}_{2}$ covered apatite and proved their high photocatalytic activity as anti-bactericidal under visible light. Also, $\mathrm{Au} / \mathrm{TiO}_{2}$ catalysts degraded formaldehyde under visible light in a single pass continuous flow reactor, with conversions above $80 \%$ [12].

However, the high cost of metals such as $\mathrm{Au}, \mathrm{Ag}$, and $\mathrm{Pt}$, limits the large-scale production of photoactive $\mathrm{TiO}_{2}$-based building materials for pollution abatement in indoor environments. The use of some transition metal oxides could increase the photocatalytic activity. Among them, manganese oxides $\left(\mathrm{MnO}_{\mathrm{x}}\right)$ recently emerged as quite active in the degradation of organic (VOCs) or inorganic $\left(\mathrm{NO}_{x}\right)$ pollutants, as reported in the recent literature [13]. Since $\mathrm{MnO}_{2}$ is rich in non-stoichiometric oxygen vacancies, it could be exploited to increase the carrier density and electrical conductivity of semiconductors [14-16]. $\mathrm{Mn}$ can form different oxides, such as $\mathrm{Mn}_{3} \mathrm{O}_{4}, \mathrm{Mn}_{2} \mathrm{O}_{3}$, and $\mathrm{MnO}_{2}$ that show different behavior in relation to the catalytic reaction in which they are involved [17-19].

Papers report several synthetic procedures to obtain $\mathrm{Mn}-\mathrm{TiO}_{2}$ nanoparticles from Ti-based precursors [20-22]. Binas et al. [20] reported a sol-gel method for the synthesis of Mn-doped $\mathrm{TiO}_{2}$ photocatalysts with a grain size ranging between 20 and $30 \mathrm{~nm}$, active for degradation of Methylene Blue under visible light. Xue et al. [21] synthesized mesoporous structured $\mathrm{MnO}_{2} / \mathrm{TiO}_{2}$ by a modified sol-gel method, showing excellent adsorption properties over the entire visible light range. Another recent paper reported the sol-gel synthesis of $20 \mathrm{wt} . \% \mathrm{Mn} / \mathrm{TiO}_{2}$ nanocomposites at different $\mathrm{pH}$. The nanocomposite synthesized at $\mathrm{pH}=7$, which was smaller in crystal size and had a larger pore volume, was the most active in methylene blue degradation. This study showed that $\mathrm{pH}$ influenced the amount of dopants on $\mathrm{TiO}_{2}$, the amount of $\mathrm{OH}$ functional groups on its surfaces, crystal sizes, and pore volume [22].

On the basis of this preliminary research and with the aim of replacing nanopowders with safer micro- $\mathrm{TiO}_{2}$, here we report for the first time Mn-decorated samples by impregnation of micropigmentary $\mathrm{TiO}_{2}$ particles at different $\mathrm{pH}$. We studied the photocatalytic activity both under UV and LED irradiation, selecting ethanol as a model VOC molecule. All the powders were finely characterized and a strict correlation between their physicochemical properties and photoactivity was drawn.

\section{Materials and Methods}

All chemicals were of reagent grade purity and were used without further purification; doubly distilled water passed through a Milli-Q apparatus that was used to prepare solutions and suspensions. Manganese (II) nitrate tetrahydrate $\left(\mathrm{Mn}\left(\mathrm{NO}_{3}\right)_{2} \cdot 4 \mathrm{H}_{2} \mathrm{O}, 99 \%\right.$, Sigma-Aldrich, Sigma-Aldrich SRL, Milan, Italy) was the salt precursor; the impregnation procedure required acetone $\left(\mathrm{CH}_{3} \mathrm{COCH}_{3}\right)(\geq 99.9 \%$, Sigma-Aldrich, Sigma-Aldrich SRL, Milan, Italy), potassium hydroxide $(\mathrm{KOH})$, and hydrochloric acid 
( $\mathrm{HCl}$ (reagent grade, 37\%, Sigma-Aldrich, Sigma-Aldrich SRL, Milan, Italy) to set the acidic or alkaline pH. Micrometric $\mathrm{TiO}_{2}$ (by Kronos, identified with the acronym 1077) consists of $100 \%$ anatase spherical primary particles of $130 \mathrm{~nm}$, with a surface area of $11 \mathrm{~m}^{2} \mathrm{~g}^{-1}$, as reported by Bianchi et al. [23].

\subsection{Synthesis of Mn-Impregnated Titania Samples}

The Mn-modified samples were obtained through an impregnation method: (i) A fixed amount $(1 \mathrm{~g})$ of 1077 was suspended in an aqueous solution (to cover completely the 1077 powder layer at the bottom of the glass flask) with a few drops of acetone in order to increase the wettability of the titania particles; (ii) then, a $\mathrm{Mn}\left(\mathrm{NO}_{3}\right)_{2} \cdot 4 \mathrm{H}_{2} \mathrm{O}$ solution was added with a different $\mathrm{Mn}$ weight amount (in the range $5-30 \%$ ). The natural $\mathrm{pH}$ of the initial suspension was 4 . The dried $\mathrm{Mn}$-doped $\mathrm{TiO}_{2}$ particles were obtained by means of a Rotavapor for $26 \mathrm{~h}\left(\right.$ at $40{ }^{\circ} \mathrm{C}$ for $24 \mathrm{~h}$ and $80^{\circ} \mathrm{C}$ for the final $2 \mathrm{~h}$ ), followed by a thermal treatment in an oven at $100{ }^{\circ} \mathrm{C}$ overnight. Every sample was calcined at $400{ }^{\circ} \mathrm{C}$ for $2 \mathrm{~h}$ in air.

Further, fixing the $\mathrm{Mn}$ amount to $20 \%$, the $\mathrm{pH}$ of the suspension changed from the spontaneous value (around $\mathrm{pH} 4)$ to both acidic $(\mathrm{pH} 3)$ and alkaline $(\mathrm{pH} 9,12)$ by addition of $\mathrm{HCl}$ and $\mathrm{KOH}$, respectively. The solvent evaporation procedure and the heating treatment were the same as previously reported [24].

The samples were labeled as to $\mathrm{Mn}_{\mathrm{x}} 1077 \_\mathrm{y}$, where $\mathrm{x}$ is the Mn weight percentage and $\mathrm{y}$ is the $\mathrm{pH}$ value.

\subsection{Physico-Chemical Characterizations}

X-ray powder diffraction (XRPD) (Malvern Panalytical Srl, Milan, Italy) analysis was performed on a Philips PW 3710 Bragg-Brentano goniometer equipped with a scintillation counter and $1^{\circ}$ divergence slit, $0.2 \mathrm{~mm}$ receiving slit, and $0.04^{\circ}$ soller slit systems. We employed graphite-monochromated $\mathrm{Cu}$ $\mathrm{K} \alpha$ radiation $(\mathrm{Cu} \mathrm{K} \alpha 1 \lambda=1.54056 \AA, \mathrm{K} \alpha 2 \lambda=1.54433 \AA)$ at $40 \mathrm{kV} \times 40 \mathrm{~mA}$ nominal X-rays power. Diffraction patterns were collected between $20^{\circ}$ and $80^{\circ}$ with a step size of $0.1^{\circ}$.

A JEOL 3010-UHR Instrument (acceleration potential 300 kV, LaB6 filament) (JEOL Ltd., Milan, Italy) was utilized to acquire the High Resolution-Transmission Electron Microscopy (HR-TEM) images to evaluate the morphology of all the adopted catalysts.

The BET surface area $\left(\mathrm{S}_{\mathrm{BET}}\right)$ (Beckan Coulter, Indianapolis, IN, USA) was determined from nitrogen adsorption-desorption isotherms at $77 \mathrm{~K}$, by using Coulter SA 3100 apparatus.

Diffuse Reflectance spectra (DRS) (Shimadzu Europe, Duisburg, Germany) of the nanopowders were measured on a UV-Vis spectrophotometer Shimadzu UV-2600 equipped with an integrating sphere; $\mathrm{BaSO}_{4}$ was used as a "total white" reference.

X-ray Photoelectron Spectroscopy (XPS) (Thermo Scientific, Massachusetts, USA) analysis was carried out by means of an M-probe apparatus (Surface Science Instrument), using a monochromatic $\mathrm{Al} \mathrm{K} \alpha$ radiation source $(1486.6 \mathrm{eV})$. The XPS binding energy scale was charge corrected using the standard calibration, fixing the $\mathrm{C}-1 \mathrm{~s}$ peak at $284.6 \mathrm{eV}$.

\subsection{Photocatalytic Tests}

Ethanol $\left(\mathrm{CH}_{3} \mathrm{CH}_{2} \mathrm{OH}\right)$ was selected to evaluate the photocatalytic properties of the Mn-modified $\mathrm{TiO}_{2}$ samples in the gaseous phase. The starting pollutant concentration was $400 \mathrm{ppm}$. The photodegradation reaction was performed in a four openings PIREX glass reactor of $5 \mathrm{~L}$. A gas chromatograph (Agilent 3000 A Micro-GC, Santa Clara, CA, USA), directly connected to the reactor, monitored the internal concentration of the organic molecule, as well as of any by-products and $\mathrm{CO}_{2}$, as reported in our previous work [24]. Two different irradiation sources, a UV lamp (HG 500 Jelosil SRL, 315-400 nm and irradiation intensity of $30 \mathrm{~W} \mathrm{~m}^{-2}$, Milan, Italy) and an LED one (MW Mean Well, $400-700 \mathrm{~nm}, 350 \mathrm{~mA}, 16.8 \mathrm{~W}$ and irradiation intensity of 15,000 lx, to simulate the visible light, Taiwan, China) were used. According to the adopted source, photocatalytic tests lasted $6 \mathrm{~h}$ and $24 \mathrm{~h}$, respectively. A hygrometer was placed inside the reactor to continuously monitor the relative humidity (RH around $40 \%$ for the whole reaction). 
All the $\mathrm{Mn}-\mathrm{TiO}_{2}$ powders, suspended in 2-propanol, were deposited on a $100 \mathrm{~cm}^{2}$ glass slab to obtain a homogeneous thin film. The covered glass support was placed at the bottom of the reactor. A cleaning procedure through the exploitation of an inert gas was performed to remove $\mathrm{CO}_{2}$ traces. The desired amount of the organic pollutant was introduced through a microliter syringe.

Dark tests together with photolysis experiments (both under UV and visible light) were carried out to evaluate the molecules adsorption and their direct degradation, respectively. For both the irradiation sources, ethanol adsorption and photolysis were always negligible $(<2 \%)$.

\section{Results and Discussion}

\subsection{Ethanol Photodegradation Under UV and LED Sources}

Firstly, $\mathrm{Mn}_{\mathrm{x}} 1077 \_4$ (X refers to the $\mathrm{Mn} \%$, while number 4 refers to $\mathrm{pH}$, with $\mathrm{x}$ in the range $5-30 \%$ ) powders were tested on the photodegradation of gaseous ethanol molecules both under UV and visible light. Star $\mathrm{Mn}_{\mathrm{x}}$ 1077_4 ting from the ultraviolet-assisted experiments, as already stated in our previous work [23], the abatement of the pollutant and its complete conversion to CO $\mathrm{Mn}_{\mathrm{x}} 1077 \_42$ within $\mathrm{Mn}_{\mathrm{x}} 1077 \_4 \mathrm{n} 6 \mathrm{~h}$, see Table 1, were reached by bare $\mathrm{TiO}_{2}$ (1077), notwithstanding the micrometric distribution of primary particles and aggregates (see Section 3.2). On the contrary, by impregnating the pristine $\mathrm{TiO}_{2}$ with $\mathrm{Mn}$, the photocatalytic performance drastically decreased, upon increasing dopant loading, see Table 1, 2nd and 3rd columns. As reported in the literature, the $\mathrm{OH}$ species distributed onto the $\mathrm{TiO}_{2}$ surface mostly affect the photocatalytic activity $[22,25]$. Thus, the partial covering of the active sites, which can be activated by UV light, is much more adverse compared to the increment given by $\mathrm{Mn}$ in terms of electron capture.

Table 1. Gaseous ethanol photodegradation and mineralization degrees by both pure and Mn-doped 1077 samples, under ultraviolet (UV) (after 6 h) and Light Emitting Diode (LED) (after 24 h) irradiation sources.

\begin{tabular}{ccccc}
\hline \multirow{2}{*}{ Sample } & \multicolumn{2}{c}{ UV (After 6 h) } & \multicolumn{2}{c}{ LED (After 24 h) } \\
\cline { 2 - 5 } & \% Degradation & \% Mineralization & \% Degradation & \% Mineralization \\
\hline 1077 & 100 & 100 & $<2$ & $<2$ \\
Mn $1077 \_4$ & 51 & 14 & 6 & $<2$ \\
Mn $_{10} 1077 \_4$ & 50 & 13 & 12 & $<2$ \\
Mn $_{20}$ 1077_4 & 39 & 8 & 35 & 7 \\
Mn $_{30}$ 1077_4 & 10 & $<2$ & 10 & $<2$ \\
\hline
\end{tabular}

Further, the aim of the present work was the exploitation of the prepared photocatalysts under LED light. As expected, pure 1077 sample showed a scarce amount of activity under visible light (negligible ethanol molecules degradation and mineralization after prolonged irradiation; Table 1, 4th and 5th columns). Instead, by either comparing both the disappearance and mineralization of Mn-doped $\mathrm{TiO}_{2}$ or considering the different Mn loadings, $\mathrm{Mn}_{20}$ 1077_4 powder exhibited the best photocatalytic performance (Table 1, 4th and 5th columns). Moreover, EtOH degradation was lower for Mn loadings higher than $20 \%$ (Table 1, $\mathrm{Mn}_{30} 1077 \_4$ sample). Again, as widely reported, the decoration of the $\mathrm{TiO}_{2}$ surface by Mn-based nanoparticles (NPs) increased the visible light absorption but partially covered the active surface sites [22]. Indeed, Mn NPs and active sites have a synergistic effect on the final photocatalytic activity. Thus, when both contributions are balanced, the maximum efficiency is achieved, as reported in the recent literature [26]. Metal and metal oxides species can positively act on the photoactivity of $\mathrm{TiO}_{2}$, as demonstrated in the case of $\mathrm{Cu}$ by Chiang and Doong [27], because they are able to capture more photons from visible light, leading to the formation of more electron-hole couples, as we also showed in our previous work [26]. Therefore, in a similar way, $\mathrm{Mn}$ and $\mathrm{MnO}_{2}$ species deposited on the micrometric anatase particles could act as electron traps [28], limiting the $\mathrm{e}^{-} / \mathrm{h}^{+}$recombination. Moreover, whatever species modifies the bare $\mathrm{TiO}_{2}$ support strongly affects the 
material properties, especially in relation to its amount. Indeed, the dopant content in each $\mathrm{TiO}_{2}$-matrix sample is related to the efficiency of the electron-hole recombination process, as well as to the formation of the hydroxyl radicals under an irradiation source [29].

The photocatalytic oxidation pathway was demonstrated to be a two-step process, where acetaldehyde is the main intermediate molecule, and $\mathrm{CO}_{2}$ and $\mathrm{H}_{2} \mathrm{O}$ the final products [30-32]:

$$
\mathrm{CH}_{3} \mathrm{CH}_{2} \mathrm{OH} \rightarrow \mathrm{CH}_{3} \mathrm{CHO} \rightarrow 2 \mathrm{CO}_{2}
$$

Figure 1 corroborates the previous mechanism showing how the progressive UV-assisted photodegradation of ethanol (in the case of $\mathrm{Mn}_{20} 1077$ 4, as a representative sample) led to the formation of an acetaldehyde by-product and then to the complete conversion to $\mathrm{CO}_{2}$. Instead, by means of LED irradiation a drastic decrease of the starting molecule degradation occurred accompanied by a slow acetaldehyde production and partial mineralization, see Table 1, 5th column.

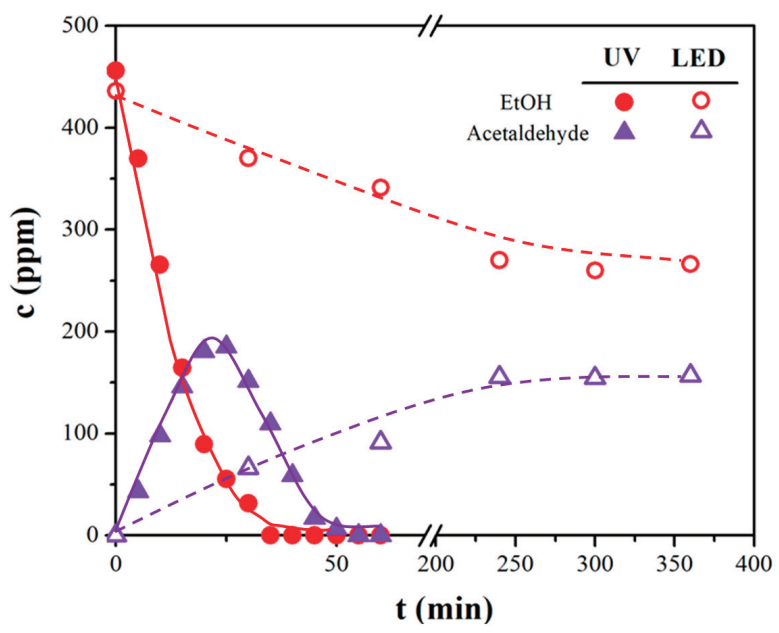

Figure 1. Ethanol disappearance and acetaldehyde formation in the case of $\mathrm{Mn}_{20} 1077 \_4$ under both UV and LED sources.

The second part of the research work was devoted to evaluating the role of the impregnation $\mathrm{pH}$ on the photocatalytic activity. Based on the promising results obtained with manganese-doped powders under LED light, the 20\% Mn loading ( $\mathrm{Mn}_{20} 1077$ y series) was selected. A different pH impregnation environment seemed to influence the final ethanol photodegradation, see Figure 2.

Particularly, an acidic pH (samples $\mathrm{Mn}_{20} 1077 \_3$ and $\mathrm{Mn}_{20} 1077 \_4$ ) led to an increase of both EtOH disappearance and the degree of mineralization (up to $35 \%$ and $10 \%$, respectively for $\mathrm{Mn}_{20} 1077$; Figure 2 and Table 1 in inset). On the contrary, moving towards alkaline values, the overall photocatalytic performances seemed to be drastically inhibited (down to $7 \%$ and $<3 \%$ for disappearance and mineralization by $\mathrm{Mn}_{20} 1077 \_12$, respectively). To explain this phenomenon, we believe that the adsorption of ethanol molecules is mostly dependent on the concentration of hydroxyls groups on the surface of the catalyst. Thus, in order to evaluate the role played by either Mn amount or the $\mathrm{pH}$ of impregnation on the structural, morphological, and optical properties, several physicochemical analyses were performed. 


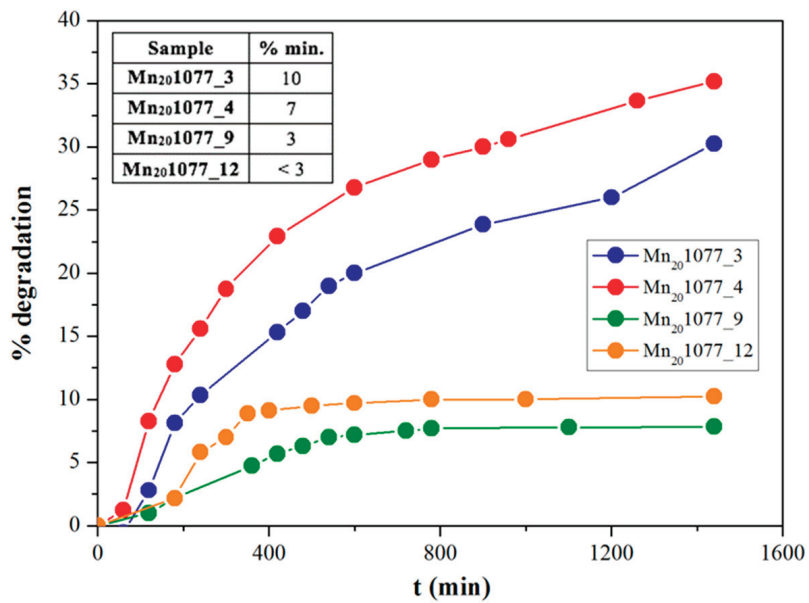

Figure 2. Ethanol degradation percentages after $24 \mathrm{~h}$ of Light Emitting Diode(LED) photocatalysis, by different $\mathrm{pH}$ Mn-impregnated $\mathrm{TiO}_{2}$ samples. Table in inset: Relative mineralization degrees.

\section{2. $\mathrm{Mn}$-TiO $\mathrm{O}_{2}$ Physico-Chemical Properties}

As a key parameter to explain the photoactivity of a catalyst, especially in the visible region, band gap evaluation by diffuse reflectance spectra (DRS) analysis was performed and is shown in Figure 3.

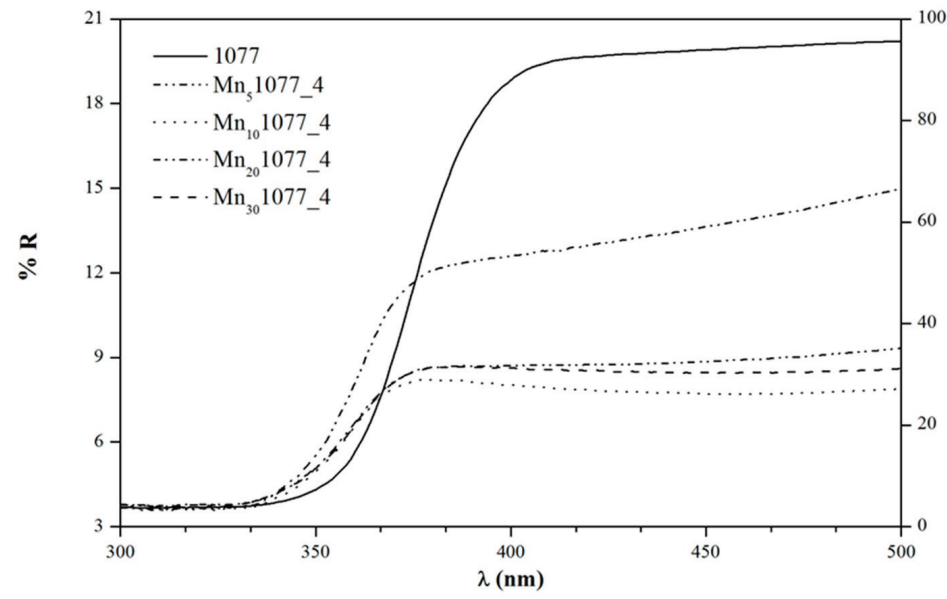

Figure 3. Diffuse reflectance spectra of impregnated $\mathrm{TiO}_{2}$ powders with different Mn-dopant concentrations.

As expected, considering the ethanol degradation results under LED light, an increasing amount of manganese led to a decrease of the band gap values, see Table 2, 2nd column and Figure 3. This reduction should improve the photocatalytic performance of doped $\mathrm{TiO}_{2}$ particles. On the contrary, varying $\mathrm{pH}$ did not seem to influence the optical properties, as shown in Table 2. Hence, the sole DRS measurements were not enough to explain the photocatalytic performances under LED light by varying either the Mn content or the impregnation $\mathrm{pH}$, see Figure 2. 
Table 2. Band gap values (by diffuse reflectance spectra (DRS)), specific surface area values $\left(\mathrm{S}_{\mathrm{BET}}\right)$ and manganese-to-titanium (Mn/Ti) atomic ratios (by EDS and XPS) for all the adopted samples.

\begin{tabular}{|c|c|c|c|c|}
\hline \multirow{2}{*}{ Sample } & \multirow{2}{*}{ Band Gap (eV) } & \multirow{2}{*}{$S_{B E T}\left(\mathrm{~m}^{2} \mathrm{~g}^{-1}\right)$} & \multicolumn{2}{|c|}{$\mathrm{Mn} / \mathrm{Ti}$} \\
\hline & & & EDX & XPS \\
\hline 1077 & 3.28 & 10 & - & - \\
\hline $\mathrm{Mn}_{5} 1077 \_4$ & 3.05 & 15 & 0.04 & 0.06 \\
\hline $\mathrm{Mn}_{10} 1077 \_4$ & 2.96 & 14 & 0.09 & 0.12 \\
\hline $\mathrm{Mn}_{20}$ 1077_4 & 2.91 & 16 & 0.18 & 0.22 \\
\hline $\mathrm{Mn}_{30} 1077 \_4$ & 2.83 & 11 & 0.30 & 0.37 \\
\hline $\mathrm{Mn}_{20} 1077 \_3$ & 3.19 & 10 & 0.18 & 0.21 \\
\hline $\mathrm{Mn}_{20} 1077 \_9$ & 3.08 & 9 & 0.06 & 0.29 \\
\hline $\mathrm{Mn}_{20} 1077 \_12$ & 2.94 & 7 & 0.05 & 0.50 \\
\hline
\end{tabular}

From a structural point of view, X-ray diffraction patterns, shown in Figure 4, revealed that the Mn content did not affect the $\mathrm{TiO}_{2}$ phase composition. Indeed, all patterns show the peak at around $25^{\circ}$ ascribable to the anatase phase (ICDD Anatase file No. 21-1272). Interestingly, for Mn amounts higher than $10 \%$, peaks at $2 \theta$ around $43^{\circ}$ and $56^{\circ}$ appeared, as shown in Figure 4, which could be assigned to pyrolusite $\mathrm{MnO}_{2}$ species. Instead, $\mathrm{pH}$ did not significantly induce structural modifications.

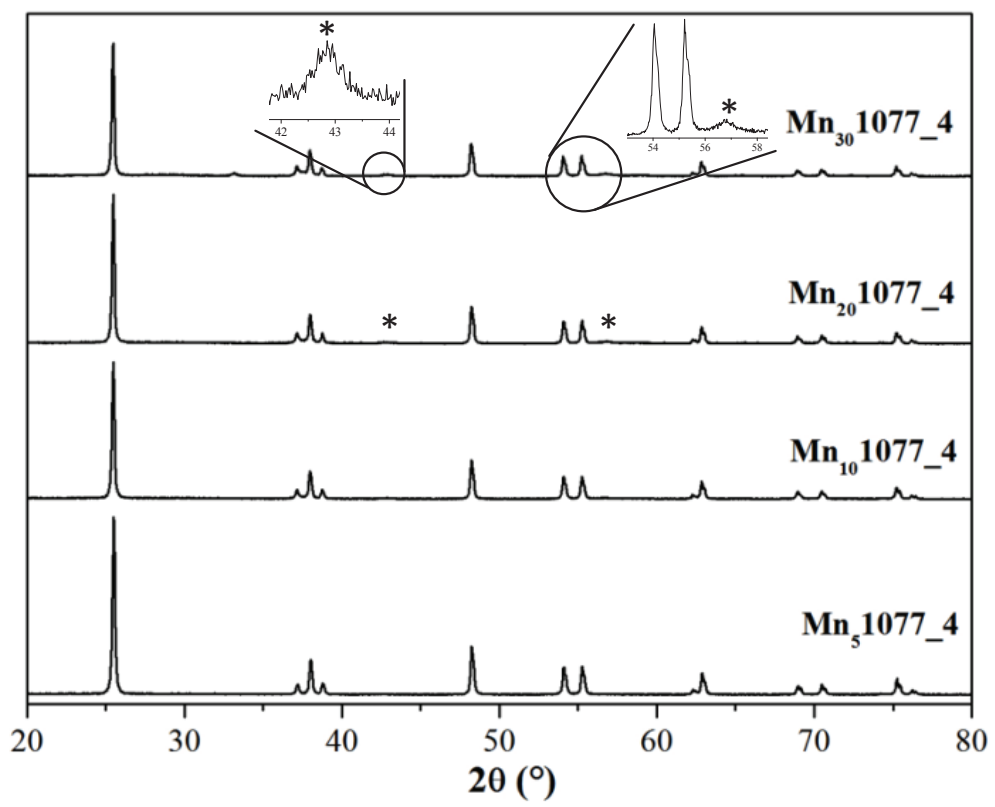

Figure 4. X-ray diffraction lines of $\mathrm{Mn}_{\mathrm{x}} 1077 \_4$ samples ( ${ }^{*}=\mathrm{MnO}_{2}$ pyrolusite polymorph).

Then, HR-TEM analyses were performed to evaluate the morphological features of the photocatalysts, see Figure 5. All samples showed the peculiar characteristics of the bare $\mathrm{TiO}_{2}$ material, which is made up of ordered particles with large average size, namely in the micrometric range (50-100 nm or more in diameter) and smoothed roundish contours: The (101) family of anatase crystal planes $(0.352 \mathrm{~nm}$; ICDD anatase file No. 21-1272) [33,34] was observed, see the electron diffraction pattern reported in Figure $5 b$, which is relevant for all the ordered $\mathrm{TiO}_{2}$ microcrystals present in Figure 5. The $\mathrm{TiO}_{2}$ morphology remains apparently unmodified for $\mathrm{Mn}$ amounts below $10 \%$, see Figure 5a, even though in some regions extra morphological features start to appear, as indicated 
by the arrows. For higher concentrations $\left(\mathrm{Mn}_{20} 1077 \_4\right.$, Figure $\left.5 \mathrm{~b}\right)$, the lattice fringes relative to the (101) family of crystal planes belonging to the pyrolusite $\mathrm{MnO}_{2}$ polymorph $(0.240 \mathrm{~nm}$; ICDD 24-0735) could be observed (as also confirmed by the electron diffraction pattern reported on the left-hand side of the image), thus corroborating the previous XRPD results. Hence, we could hypothesize that a small presence of this secondary oxide may enhance the photodegradation performances, as previously discussed.
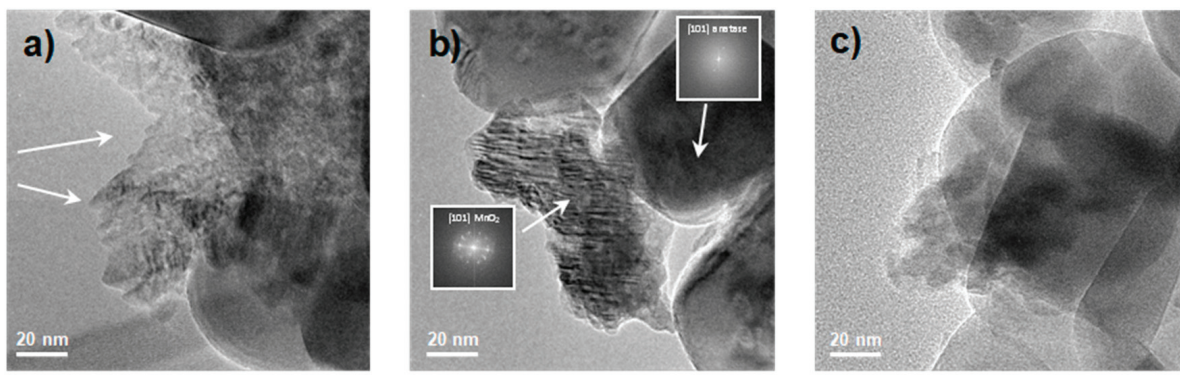

Figure 5. Transmission Electron Microscopy (TEM) images of (a) $\mathrm{Mn}_{10} 1077 \_4$; (b) $\mathrm{Mn}_{20} 1077 \_4$; and (c) $\mathrm{Mn}_{20} 1077 \_12$.

Moreover, in acidic experimental conditions $\left(\mathrm{Mn}_{20} 1077 \_4\right.$ as a representative sample in Figure $\left.5 b\right)$, $\mathrm{TiO}_{2}$ particles did not exhibit any morphological changes, whereas the Mn species were very evident as small envelopes of thin, closely packed particles (average dimensions 3-6 nm) with clear fringe patterns of pyrolusite $\mathrm{MnO}_{2}$. In addition, with alkaline impregnation $\mathrm{pH}$, see Figure $5 c$, a second family plane (111) of manganese dioxide polymorph was also observable.

Furthermore, BET analyses showed relatively low values of surface area for all the adopted samples, confirming the micrometric texture of the aggregates; a slight increase was appreciable for Mn-impregnated $\mathrm{TiO}_{2}$ (from 10 to $16 \mathrm{~m}^{2} \mathrm{~g}^{-1}$; Table 2, 3rd column). However, at alkaline $\mathrm{pH}$, this parameter decreased down to $7 \mathrm{~m}^{2} \mathrm{~g}^{-1}$ for the $\mathrm{Mn}_{20} 1077 \_12$ sample, see Table 2. These results could be explained by taking into account the actual Mn content obtained by both EDS and XPS analyses, see Table 2, 4th column. The bulk amount of manganese species was consistent with the one expected from the synthetic procedure for all the Mn concentrations. Regarding the impregnated samples at different $\mathrm{pH}$, the interactions between the $\mathrm{TiO}_{2}$ micrometric particles and the adopted $\mathrm{Mn}\left(\mathrm{NO}_{2}\right)_{3}$ salt precursor were deeply influenced by the $\mathrm{pH}$ value. Indeed, the final $\mathrm{Mn}$ bulk amount is similar to the starting concentration at an acidic $\mathrm{pH}$, while it decreases at alkaline $\mathrm{pH}$ values, see Table 2 , 4 th column.

On the contrary, the surface $\mathrm{Mn} / \mathrm{Ti}$ ratios were always higher than those obtained by the EDS analyses in accordance with the experimental method (impregnation) to decorate the micrometric titania powders. Then, notwithstanding the low amount of $\mathrm{Mn}$ at alkaline $\mathrm{pH}$, all the guest metal was segregated to the surface forming a dense coverage of $\mathrm{MnO}_{2}$ nanopowders. According to Li et al. [35], when manganese content increases, it becomes the recombination center for electron-hole pairs decreasing the separation efficiency of photo-generated charges, therefore invariably reducing/preventing the formation of hydroxyl radicals.

Hence, to corroborate the previous data and for a complete comprehension of the photocatalytic results, high-resolution O 1s spectra, shown in Figure 6, were fitted using four or five Gaussian/Lorentzian functions superimposed to a Shirley background. On the basis of the recent literature, the peaks could be assigned to; (i) oxygen bound to the metal ions (Ti [36,37] or Mn [38]) in the lattice (peak I at $528.5 \mathrm{eV}$ ); (ii) a high binding energy component (HBEC) developed with the increasing loss of oxygen or creation of oxygen vacancies (peak II at $530.0 \mathrm{eV}$ ) [39,40]; (iii) a low binding energy component (LBEC) due to adsorption of $\mathrm{OH}^{-}$on the surface (peak III at 531.1 eV) [37,39]; and (iv) water adsorption (peaks IV and V at binding energy (B.E.) higher than $532.0 \mathrm{eV}$ ) [37,41]. It is worth noting that the sequence of the ratios between the 
oxygen of surface $\mathrm{OH}$ groups (peak III, pink area), and the sum of the previous one and the oxygen of the chemisorbed water molecules (peak IV and $\mathrm{V}$, violet areas) at increasing $\mathrm{pH}$ was fully in accordance with the photocatalytic activities $\left(\mathrm{Mn}_{20} 1077 \_9<\mathrm{Mn}_{20} 1077 \_12<\mathrm{Mn}_{20} 1077 \_3<\mathrm{Mn}_{20} 1077 \_4\right.$, see Figure 2). Hydroxyl groups on the surface of a photocatalyst play an important role in the photocatalytic reaction since they can capture the photo-induced holes from the surface of the material, inhibiting electron-hole recombination as well as forming hydroxyl radicals with high oxidation potentials [42,43]. Thus, at alkaline $\mathrm{pH}$, the high surface $\mathrm{Mn}$ loading and the paucity of $\mathrm{OH}$ groups inhibit the photocatalytic activity.
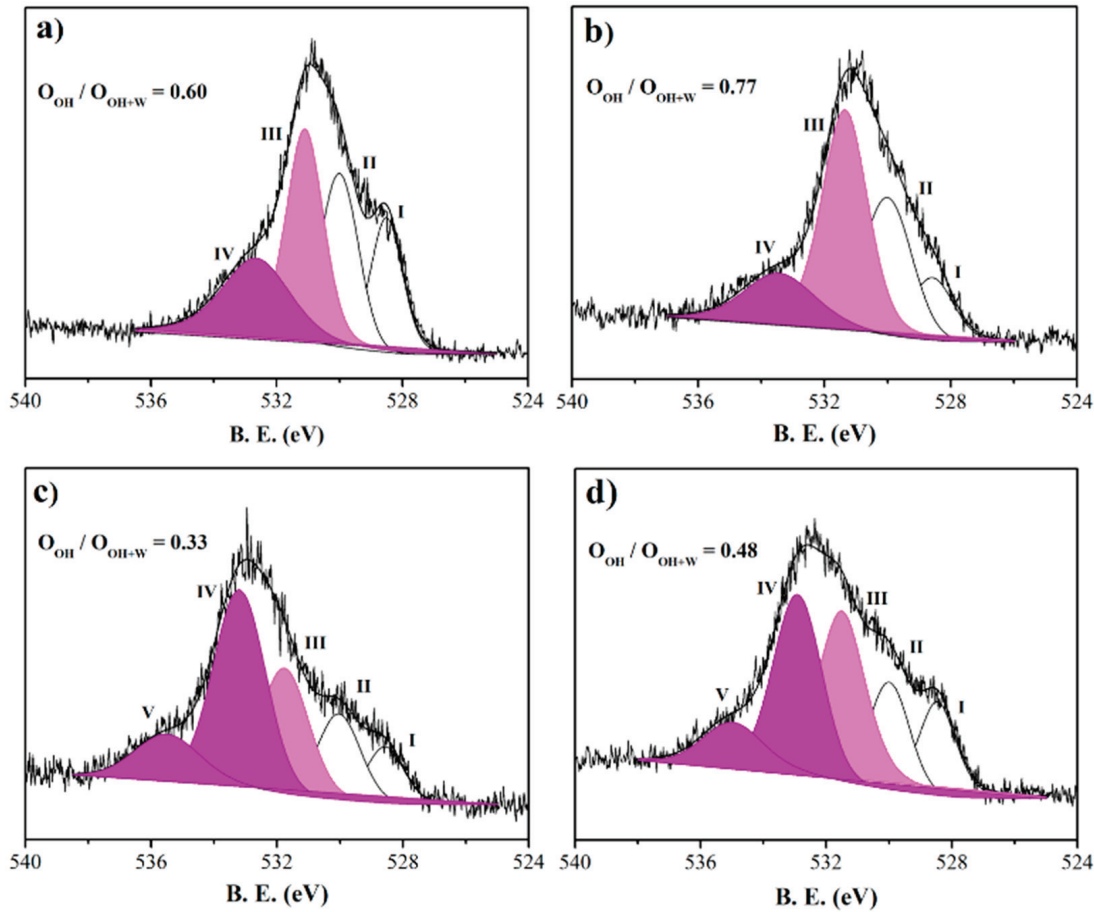

Figure 6. XPS high-resolution spectra of oxygen (O1s) relative to (a) $\mathrm{Mn}_{20} 1077 \_3$; (b) $\mathrm{Mn}_{20} 1077 \_4$; (c) $\mathrm{Mn}_{20}$ 1077_9; and (d) $\mathrm{Mn}_{20}$ 1077_12. Inset: Atomic ratio between the oxygen of surface OH groups $\left(\mathrm{O}_{\mathrm{OH}}\right.$, pink area), and the sum of the previous one and the oxygen of the chemisorbed water molecules $\left(\mathrm{O}_{\mathrm{W}}\right.$, violet areas).

\section{Conclusions}

$\mathrm{Mn}$ species activates anatase micro- $\mathrm{TiO}_{2}$ for the visible light photodegradation of organic pollutants. Particularly, the final photocatalytic performance strongly depends on the Mn amount. Indeed, we surveyed Mn loadings between 5\% and 30\% under both UV and LED irradiation. Nevertheless, bare 1077 powder was the best performing photocatalyst, and the increasing Mn content led to a drastic decrease of the ethanol photoremoval under UV light. Mn $201077 \_4$ showed the highest $\mathrm{EtOH}$ degradation under visible wavelengths. In fact, the presence of $\mathrm{Mn}$ species provoked a reduction of the band gap value, thus leading to higher efficiency under LED light.

A further phase of the present work was the investigation of the impregnation $\mathrm{pH}$ on the final photocatalysts performance. Only a fixed concentration of $\mathrm{Mn}$ (i.e., 20\%) at an acidic $\mathrm{pH}$ (3 and 4) resulted in more active samples, whereas alkaline $\mathrm{pH}$ (up to 12) reduced the photocatalytic performance. 
Indeed, we believe that the powders prepared at a higher $\mathrm{pH}$ of impregnation are less active because of the segregation of a high amount of Mn species and concomitantly a low amount of surface hydroxyl groups.

The novel results reported herein are a step forward in the photodegradation of the indoor gaseous pollutants by a micrometric $\mathrm{Mn}$-decorated $\mathrm{TiO}_{2}$ catalyst under visible light. Moreover, the positive effect obtained at an acidic $\mathrm{pH}$ could be further investigated, to assess whether lower values improve the final catalytic performance.

Author Contributions: Conceptualization, M.S.; Methodology, G.C. (Giuseppina Cerrato) and E.P.; Validation, E.P.; Investigation, M.S., G.C. (Giuseppina Cerrato) and E.P.; Writing-Original Draft Preparation, M.S., G.C. (Giuseppe Cappelletti) and G.C. (Giuseppina Cerrato); Writing-Review \& Editing, M.S., C.L.B.; Supervision, G.C. (Giuseppe Cappelletti); Project Administration, C.L.B.; Funding Acquisition, D.C.B. and C.L.B.

Funding: This research was funded by the Coopération Québec-Italie 2017-2019, within the project QU17MO09 and it was undertaken, in part, thanks to funding from the Canada Research Chairs program.

Acknowledgments: The authors gratefully acknowledge the support of the Natural Sciences and Engineering Research Council of Canada (NSERC).

Conflicts of Interest: The authors declare no conflict of interest.

\section{References}

1. Wold, A. Photocatalytic properties of titanium dioxide $\left(\mathrm{TiO}_{2}\right)$. Chem. Mater. 1993, 5, 280-283. [CrossRef]

2. Fujishima, A.; Rao, T.N.; Tryk, D.A. Titanium dioxide photocatalysis. J. Photochem. Photobiol. C Photochem. Rev. 2000, 1, 1-21. [CrossRef]

3. Fujishima, A.; Zhang, X. Titanium dioxide photocatalysis: present situation and future approaches. C. R. Chim. 2006, 9, 750-760. [CrossRef]

4. Nakata, K.; Fujishima, A. $\mathrm{TiO}_{2}$ photocatalysis: Design and applications. J. Photochem. Photobiol. C Photochem. Rev. 2012, 13, 169-189. [CrossRef]

5. Wolkoff, P.; Nielsen, G.D. Organic compounds in indoor air-Their relevance for perceived indoor air quality? Atmos. Environ. 2001, 35, 4407-4417. [CrossRef]

6. Höllbacher, E.; Ters, T.; Rieder-Gradinger, C.; Srebotnik, E. Emissions of indoor air pollutants from six user scenarios in a model room. Atmos. Environ. 2017, 150, 389-394. [CrossRef]

7. Śmiełowska, M.; Marć, M.; Zabiegała, B. Indoor air quality in public utility environments-A review. Environ. Sci. Pollut. Res. 2017, 24, 11166-11176. [CrossRef] [PubMed]

8. Sanjinés, R.; Tang, H.; Berger, H.; Gozzo, F.; Margaritondo, G.; Lévy, F. Electronic structure of anatase $\mathrm{TiO}_{2}$ oxide. J. Appl. Phys. 1994, 75, 2945-2951. [CrossRef]

9. Nakata, K.; Ochiai, T.; Murakami, T.; Fujishima, A. Photoenergy conversion with $\mathrm{TiO}_{2}$ photocatalysis: New materials and recent applications. Electrochim. Acta 2012, 84, 103-111. [CrossRef]

10. Pan, X.; Xu, Y.-J. Defect-Mediated Growth of Noble-Metal (Ag, Pt, and Pd) Nanoparticles on $\mathrm{TiO}_{2}$ with Oxygen Vacancies for Photocatalytic Redox Reactions under Visible Light. J. Phys. Chem. C 2013, 117, 17996-18005. [CrossRef]

11. Elahifard, M.R.; Rahimnejad, S.; Haghighi, S.; Gholami, M.R. Apatite-Coated Ag/AgBr/TiO 2 Visible-Light Photocatalyst for Destruction of Bacteria. J. Am. Chem. Soc. 2007, 129, 9552-9553. [CrossRef] [PubMed]

12. Zhu, X.; Jin, C.; Li, X.S.; Liu, J.L.; Sun, Z.G.; Shi, C.; Li, X.; Zhu, A.M. Photocatalytic formaldehyde oxidation over plasmonic $\mathrm{Au} / \mathrm{TiO}_{2}$ under visible light: Moisture indispensability and light enhancement. ACS Catal. 2017, 7, 6514-6524. [CrossRef]

13. Bastos, S.S.T.; Órfão, J.J.M.; Freitas, M.M.A.; Pereira, M.F.R.; Figueiredo, J.L. Manganese oxide catalysts synthesized by exotemplating for the total oxidation of ethanol. Appl. Catal. B Environ. 2009, 93, 30-37. [CrossRef]

14. Wang, G.; Ling, Y.; Li, Y. Oxygen-deficient metal oxide nanostructures for photoelectrochemical water oxidation and other applications. Nanoscale 2012, 4, 6682-6691. [CrossRef] [PubMed]

15. Pargoletti, E.; Cappelletti, G.; Minguzzi, A.; Rondinini, S.; Leoni, M.; Marelli, M.; Vertova, A. High-performance of bare and Ti-doped $\alpha-\mathrm{MnO}_{2}$ nanoparticles in catalyzing the Oxygen Reduction Reaction. J. Power. Sources 2016, 325, 116-128. [CrossRef] 
16. Orsini, S.; Pargoletti, E.; Vertova, A.; Minguzzi, A.; Locatelli, C.; Rondinini, S.; Cappelletti, G. Ad hoc tailored electrocatalytic $\mathrm{MnO}_{2}$ nanorods for the oxygen reduction in aqueous and organic media. J. Electroanal. Chem. 2018, 808, 439-445. [CrossRef]

17. Liao, Y.; Zhang, X.; Peng, R.; Zhao, M.; Ye, D. Catalytic properties of manganese oxide polyhedra with hollow and solid morphologies in toluene removal. Appl. Surf. Sci. 2017, 405, 20-28. [CrossRef]

18. Kim, S.C.; Shim, W.G. Catalytic combustion of VOCs over a series of manganese oxide catalysts. Appl. Catal. B Environ. 2010, 98, 180-185. [CrossRef]

19. Pargoletti, E.; Pifferi, V.; Falciola, L.; Facchinetti, G.; Re Depaolini, A.; Davoli, E.; Marelli, M.; Cappelletti, G. A detailed investigation of $\mathrm{MnO}_{2}$ nanorods to be grown onto activated carbon. High efficiency towards aqueous methyl orange adsorption/degradation. Appl. Surf. Sci. 2018. [CrossRef]

20. Binas, V.D.; Sambani, K.; Maggos, T.; Katsanaki, A.; Kiriakidis, G. Synthesis and photocatalytic activity of Mn-doped $\mathrm{TiO}_{2}$ nanostructured powders under UV and visible light. Appl. Catal. B Environ. 2012, 113-114, 79-86. [CrossRef]

21. Xue, M.; Huang, L.; Wang, J.-Q.; Wang, Y.; Gao, L.; Zhu, J.; Zou, Z.-G. The direct synthesis of mesoporous structured $\mathrm{MnO}_{2} / \mathrm{TiO}_{2}$ nanocomposite: a novel visible-light active photocatalyst with large pore size. Nanotechnology 2008, 19. [CrossRef] [PubMed]

22. Oseghe, E.O.; Ndungu, P.G.; Jonnalagadda, S.B. Synthesis of mesoporous $\mathrm{Mn} / \mathrm{TiO}_{2}$ nanocomposites and investigating the photocatalytic properties in aqueous systems. Environ. Sci. Pollut. Res. 2015, 22, 211-222. [CrossRef] [PubMed]

23. Bianchi, C.L.; Pirola, C.; Galli, F.; Stucchi, M.; Morandi, S. Nano and micro-TiO ${ }_{2}$ for the photodegradation of ethanol: experimental data and kinetic modelling. RSC Adv. 2015, 5, 53419-53425. [CrossRef]

24. Stucchi, M.; Bianchi, C.L.; Pirola, C.; Vitali, S.; Cerrato, G.; Morandi, S.; Argirusis, C.; Sourkouni, G.; Sakkas, P.M.; Capucci, V. Surface decoration of commercial micro-sized $\mathrm{TiO}_{2}$ by means of high energy ultrasound: A way to enhance its photocatalytic activity under visible light. Appl. Catal. B Environ. 2015, 178, 124-132. [CrossRef]

25. Turchi, C.S.; Ollis, D.F. Photocatalytic degradation of organic water contaminants: Mechanisms involving hydroxyl radical attack. J. Catal. 1990, 122, 178-192. [CrossRef]

26. Stucchi, M.; Bianchi, C.L.; Pirola, C.; Cerrato, G.; Morandi, S.; Argirusis, C.; Sourkouni, G.; Naldoni, A.; Capucci, V. Copper NPs decorated titania: A novel synthesis by high energy US with a study of the photocatalytic activity under visible light. Ultrason. Sonochem. 2016, 31, 295-301. [CrossRef] [PubMed]

27. Chiang, L.; Doong, R. Cu-TiO ${ }_{2}$ nanorods with enhanced ultraviolet- and visible-light photoactivity for bisphenol A degradation. J. Hazard. Mater. 2014, 277, 84-92. [CrossRef] [PubMed]

28. Zhang, W.; Liu, Y.; Yu, B.; Zhang, J.; Liang, W. Effects of silver substrates on the visible light photocatalytic activities of copper-doped titanium dioxide thin films. Mater. Sci. Semicond. Process. 2015, 30, 527-534. [CrossRef]

29. Mazierski, P.; Nischk, M.; Gołkowska, M.; Lisowski, W.; Gazda, M.; Winiarski, M.J.; Klimczuk, T.; Zaleska-Medynska, A. Photocatalytic activity of nitrogen doped $\mathrm{TiO}_{2}$ nanotubes prepared by anodic oxidation: The effect of applied voltage, anodization time and amount of nitrogen dopant. Appl. Catal. B Environ. 2016, 196, 77-88. [CrossRef]

30. Vorontsov, A. Selectivity of photocatalytic oxidation of gaseous ethanol over pure and modified $\mathrm{TiO}_{2}$. J. Catal. 2004, 221, 102-109. [CrossRef]

31. Adjimi, S.; Roux, J.-C.; Sergent, N.; Delpech, F.; Thivel, P.-X.; Pera-Titus, M. Photocatalytic oxidation of ethanol using paper-based nano- $\mathrm{TiO}_{2}$ immobilized on porous silica: A modelling study. Chem. Eng. J. 2014, 251, 381-391. [CrossRef]

32. Katsiev, K.; Harrison, G.; Alghamdi, H.; Alsalik, Y.; Wilson, A.; Thornton, G.; Idriss, H. Mechanism of Ethanol Photooxidation on Single-Crystal Anatase $\mathrm{TiO}_{2}$ (101). J. Phys. Chem. C 2017, 121, 2940-2950. [CrossRef]

33. Bianchi, C.L.; Gatto, S.; Pirola, C.; Naldoni, A.; Di Michele, A.; Cerrato, G.; Crocellà, V.; Capucci, V. Photocatalytic degradation of acetone, acetaldehyde and toluene in gas-phase: Comparison between nano and micro-sized $\mathrm{TiO}_{2}$. Appl. Catal. B Environ. 2014, 146, 123-130. [CrossRef]

34. Cappelletti, G.; Ricci, C.; Ardizzone, S.; Parola, C.; Anedda, A. Aged titania nanoparticles: The simultaneous control of local and long-range properties. J. Phys. Chem. B 2005, 109, 4448-4454. [CrossRef] [PubMed]

35. Li, H.; Wang, D.; Fan, H.; Jiang, T.; Li, X.; Xie, T. Synthesis of ordered multivalent Mn- $\mathrm{TiO}_{2}$ nanospheres with tunable size: A high performance visible-light photocatalyst. Nano Res. 2011, 4, 460-469. [CrossRef] 
36. Cappelletti, G.; Bianchi, C.L.; Ardizzone, S. XPS study of the surfactant film adsorbed onto growing titania nanoparticles. Appl. Surf. Sci. 2006, 253, 519-524. [CrossRef]

37. Cappelletti, G.; Ardizzone, S.; Bianchi, C.L.; Gialanella, S.; Naldoni, A.; Pirola, C.; Ragaini, V. Photodegradation of pollutants in air: Enhanced properties of nano- $\mathrm{TiO}_{2}$ prepared by ultrasound. Nanoscale Res. Lett. 2009, 4, 97-105. [CrossRef] [PubMed]

38. Wang, H.; Chen, J.; Hu, S.; Zhang, X.; Fan, X.; Du, J.; Huang, Y.-G.; Li, Q.-Y. Direct growth of flower-like 3D $\mathrm{MnO}_{2}$ ultrathin nanosheets on carbon paper as efficient cathode catalyst for rechargeable $\mathrm{Li}-\mathrm{O}_{2}$ batteries. RSC Adv. 2015, 5, 72495-72499. [CrossRef]

39. Ishfaq, M.; Rizwan Khan, M.; Bhopal, M.F.; Nasim, F.; Ali, A.; Bhatti, A.S.; Ahmed, I.; Bhardwaj, S.; Cepek, C. $1.5 \mathrm{MeV}$ proton irradiation effects on electrical and structural properties of $\mathrm{TiO}_{2} / \mathrm{n}$-Si interface. J. Appl. Phys. 2014, 115, 174506. [CrossRef]

40. Naeem, M.; Hasanain, S.K.; Kobayashi, M.; Ishida, Y.; Fujimori, A.; Buzby, S.; Shah, S.I. Effect of reducing atmosphere on the magnetism of $\mathrm{Zn}_{1-x} \mathrm{Co}_{x} \mathrm{O}(0 \leq x \leq 0.10)$ nanoparticles. Nanotechnology 2006, 17, 2675-2680. [CrossRef] [PubMed]

41. Kang, S.; Pawar, R.C.; Pyo, Y.; Khare, V.; Lee, C.S. Size-controlled BiOCl-RGO composites having enhanced photodegradative properties. J. Exp. Nanosci. 2016, 11, 259-275. [CrossRef]

42. Hou, Y.D.; Wang, X.C.; Wu, L.; Chen, X.F.; Ding, Z.X.; Wang, X.X.; Fu, X.Z. N-Doped $\mathrm{SiO}_{2} / \mathrm{TiO}_{2}$ mesoporous nanoparticles with enhanced photocatalytic activity under visible-light irradiation. Chemosphere 2008, 72 , 414-421. [CrossRef] [PubMed]

43. Xu, Y.; Lei, B.; Guo, L.; Zhou, W.; Liu, Y. Preparation, characterization and photocatalytic activity of manganese doped $\mathrm{TiO}_{2}$ immobilized on silica gel. J. Hazard. Mater. 2008, 160, 78-82. [CrossRef] [PubMed]

(c) 2018 by the authors. Licensee MDPI, Basel, Switzerland. This article is an open access article distributed under the terms and conditions of the Creative Commons Attribution (CC BY) license (http:/ / creativecommons.org/licenses/by/4.0/). 
MDPI

St. Alban-Anlage 66

4052 Basel

Switzerland

Tel. +41616837734

Fax +41 613028918

www.mdpi.com

Nanomaterials Editorial Office

E-mail: nanomaterials@mdpi.com www.mdpi.com/journal/nanomaterials

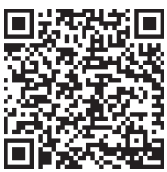



MDPI

St. Alban-Anlage 66

4052 Basel

Switzerland

Tel: +4161 6837734

Fax: +41 613028918 